FOR THE PEOPLE FOR EDVCATION FOR SCIENCE

LIBRARY

OF

THE AMERICAN MUSEUM

OF

NATURAL HISTORY 




THE EVOLUTION

AND DISTRIBUTION OF FISHES 


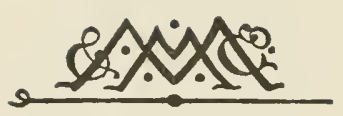




\section{THE EVOLUTION}

\section{AND DISTRIBUTION OF}

\section{FISHES}

By

JOHN MUIRHEAD MACFARLANE, D. Sc., L.L. D.

Emeritus Professor of Botany;

University Carnegie Foundationer;

Late Director of the Botanic Garden;

University of Pennsylvania.

New York

THE MACMILLAN COMPANY 


$$
\begin{aligned}
& 24-9 \operatorname{sis} 7 \text { jue } 4 \\
& \text { Copyright, } 1923 \\
& \text { by }
\end{aligned}
$$

J. M. Macfarlane

All Rights Reserved

Printed by

Enterprise Publishing Company

Burlington, N. J., U. S. A. 


\section{With Pleasure}

The Author dedicates this volume

to

Mrs. William West Frazier, Jr.

as a sincere token of appreciation

for her sympathetic interest

in his aims and studies.

$\mathbb{4}$ 



\section{PREFACE}

In I 9 I $S$ the writer published a volume that was entitled "The Causes and Course of Organic Evolution." A section of it was devoted to an inquiry into the environal relation of plants and animals, as determining largely their distribution in time and space. The conclusion was then reached, that organisms evolved first in freshwater areas, and only by degrees spread into marine surroundings.

During his inquiries the author gradually concluded that fishes might form the most important biological group by which to test the value of such a conclusion. For in the volume named he presented short details of their past and present history, which seemed to indicate that they at first evolved amid freshwater surroundings. Field studies also made by the writer during his earlier scientific career and subsequently, strongly pointed in like direction. But some details that either weakened the position, or that claimed further investigation, accumulated amid the abundant evidence that proved to be favorable. The writer therefore resolved to make as thorough a comparison as possible of the groups of fishes, and even of specific genera amongst these.

The outcome is seen in part in the present volume, which represents the almost continuous labors of the past six years. As the author pursued his detailed researches, some originally puzzling conditions gradually began to have a definite meaning attached to them. Thus the presence of abundant fossilized fish remains in zones of cannel coal, and their absence from ordinary coal strata; the like occurrence of freshwater fishes and of related organisms ecologically in the oil shales of the Edinburgh Coal Field that the writer studied for years in his earlier career; the peculiar character, the chemical composition, and the fossilized fish remains, of the marls that he studied in mature years from New Jersey to Florida, all had welcome light thrown on them, at the same time that the evolutionary history of fishes unfolded in its manifold ramifications. 
So as the results of observation and of study accumulated, it became evident that two related but distinct volumes were needed, in order that the conclusions reached might be placed properly before the scientific world. That now presented was written in $1920-2 \mathrm{I}$, and finished in August of the latter year. The other, which bears title: "Fishes the Source of Petroleum," was largely written from the early part of 192 I onward, and was finished in December of I922. Any discriminating reader of the two volumes will readily perceive that some such history attaches to them.

In preparing both volumes the writer has endeavored to quote the exact words of authors whose observations he has referred to. The reader therefore can now share with the writer the pleasure of examining original, and so ever-fresh, statements that bear on questions at issue.

While the writer has spent years in study of rock formations and their included organic remains, it is of necessity true that many of his statements have been derived from examination of the published investigations of others. Such also is true of the abundant zoölogical results here presented. But for any defects that may be shown in this presentation, the writer desires to be alone responsible. If therefore conclusions are here reached that will advance scientific truth, such deserve to be conserved; should some prove to be incorrect, they can readily be discarded. For all scientific advance has shown that Truth alone will endure, error and misstatement will fade away.

Special and grateful acknowledgment is now made of the invaluable aid furnished by the writings, and in some cases by the illustrations, of A. S. Woodward; of his early teachers and friendly helpers Sir A. Geikie and Dr. R. H. Traquair; of his university predecessor or colleague, Professors Leidy and Cope. In dedication of this volume to a lady who has ever striven to aid and advance scientific progress, the author pays a small but deserved tribute. The printers and publishers of it have shown that consideration and regard, which ensure that it can worthily see the light.

Philadelphia, April, r923. 


\section{CONTENTS}

Chapter I.

PAGE

Introduction $\ldots \ldots \ldots \ldots \ldots \ldots \ldots \ldots \ldots$ I

Chapter II.

Geological Conditions in relation to the Evolution of Fishes ................... 23

Chapter III.

The Evolution of Fishes from Invertebrates...... . 60

Chapter IV.

The Physical and Biological Environment of Fishes in Silurian and Devonian Times........... 96

Chapter V.

The Physical and Biological Environment of Fishes in Carboniferous and Permian Times........ 137

Chapter VI.

The Physical and Biological Environment of Fishes during the Triassic-Jurassic Period......... 172

Chapter VII.

The Physical and Biological Environment of Fishes during the Cretaceous Period............ 208

Chapter VIII.

The Physical and Biological Environment of Fishes from Eocene to Recent Times............ 23 I 


\section{Chapter IX.}

Primitive Fishes in Time and Space.......... 256

\section{Chapter $\mathrm{X}$.}

The Dipneusti and Crossopterygii in Time and Space 293

\section{Chapter XI.}

The Chondrostei and Holostei in Time and Space... 316

\section{Chapter XII.}

The Soft-finned Teleostei in Time and Space..... 346

\section{Chapter Xili.}

The Spine-finned Teleostei in Time and Space..... 372

\section{Chapter XIV.}

Past Geographic and Geologic Conditions in Relation to the Distribution of Fishes........... 402

\section{Chapter XV.}

Fishes in Relation to a South Atlantic Continent.... 43 I

Chapter XVI.

A Review of the Tanganyika Problem......... 463

Chapter XViI.

The Geographic and Geologic Relations of the More Primitive Fishes ................ $48_{3}$

\section{Chapter XViII.}

Synoptic Review of Previous Chapters......... . 503 References to Literature............... 534 Index ............................ $54^{2}$ 


\section{THE EVOLUTION \\ AND DISTRIBUTION OF FISHES}

\section{CHAPTER I \\ INTRODUCTION}

It has been a generally accepted dictum with zoologists during the past hundred years, and has been even more emphasized during the past twenty, that animal life in general and not least the great group of fishes originated amid marine surroundings, and only gradually spread toward a freshwater environment. Were one to adduce evidence for this it might be said to include the views set forth in every important manual and textbook on zoology and palaeozoology, as well as in the well-known special treatises and research volumes that deal with recent as well as fossil fishes. And yet against such a conclusion there existed many weighty observations and field studies, brought forward by the very authors of the marine idea.

The writer spent much available time during several years of his student and earlier teaching days in investigating the fossil flora and fauna of the Edinburgh region, and also the stratigraphic relation of these. The area covered included extensive developments of Lower Carboniferous or Calciferous sandstone rocks that extend for miles westward from Edinburgh as well as across the Firth of Forth into a large part of Fifeshire. It also included the higher group of rocks known as the Carboniferous Limestone that stretches in extensive beds and as a great trough, from some miles east of Edinburgh across into Fifeshire. Above this were the Millstone Grit and the True Coal Measures, both widely developed on either side of the Firth. Dura Den, of classic Old Red Sandstone fame, adjoined the writer's ancestral territory, while the Silurian beds of the Pentland hills came in for a share of attention. 
Throughout all of these strata, with the exception only of the Carboniferous Limestone series, abundant fossil plant remains often occurred side by side with entire fossil fishes, or with their jaws, teeth, scales and spines. Such remains again were at times associated with a stippled and shining body that on reference to the skilled palaeontologist Traquair was identified as part of a carboniferous eurypterid. Occasional thin beds of what were identified as freshwater carboniferous molluscs at times interrupted the plant and fish bearing strata, while the now celebrated freshwater limestones of Burdie House, and of Camps near Mid Calder, revealed remains of ferns, lepidodendra, calamites, and fishes, surrounded by myriads of freshwater entomostracans, mainly Leperditia scotoburdiegalensis.

Here then seemed to be an enormous accumulation of non-marine strata, that at times was constituted in places by beds of coal from one or two inches to five feet in thickness. In striking contrast to all of this were the rocks and enclosed fossils that made up the main masses of the Carboniferous Limestone system, on top of which the writer was born and lived through his preuniversity years. These often literally teemed with a complex of fossils that proclaimed a very different and a typically marine life. Broken remains of Productus, Spirifer, Encrinus, Euomphalus, and other equally characteristic marine organisms at times almost made up the limestone basis in which the more entire calcareous tests were imbedded. But amongst all of these marine beds, over wide miles of country studied, the writer only rarely found a genuine fish remain.

More arresting and puzzling still, according to the then accepted views, was the occasional interbedding amongst the Carboniferous Limestone rocks of an ironstone stratum that enclosed just such plants, fishes and eurypterids as characterized the Calciferous rocks below. Their fossilized remains usually occurred in ironstone or in ferruginous shale, that indicated chemical interaction between organisms and dissolved iron salts, the latter of which had precipitated from the surrounding waters. With glee Traquair at times welcomed such fish specimens when brought 
to him for identification, or displayed others that he had gathered and on which he was then (I876-I882) publishing.

The impression was, therefore, almost unwillingly forced in on the writer's mind, now fully forty years ago, that during the great Carboniferous epoch a practically continuous deposit of freshwater strata with typical plant and fish enclosures gave rise to the foundation beds or Calciferous Sandstone series of that system; that then an extensive though not deep submergence of land occurred under the sea, during which the Carboniferous Limestone was formed as a great marine deposit. Even then however occasional elevation for a longer or shorter time permitted the development of a nearby land flora and invasion again of teeming freshwater fishes in lakes or swamps of that period. These however showed no trace of existence in marine strata. Finally, during deposit of the Coal Measures, freshwater fishes that were very different in type from those of the lower rocks, were met with in ironstone in shale, or in sandstone strata that alternated with and often shaded into coal beds.

The mental picture thus gradually formed through a period of fully five years-namely from is 876 to i 88 Iseemed antagonistic to the tacit or openly expressed views of many palaeontologists and zoologists. Very slowly through succeeding decades a correct explanation began to dawn, and this was outlined recently in the volume that the present writer has entitled "The Causes and Course of Organic Evolution." Shortly stated, and founding on facts presented in Chapters I I, I2, I 4, and I 8 of that work, he would claim that all organic life evolved in freshwater and even most primitively in thermal or subthermal areas akin to those of the Yellowstone, the New Zealand, the Austrian, the Icelandic and like regions of to-day. This also took place, he considers, in early proterozoic, protobiotic or archean time. Gradually new and ever more complex forms evolved which continued to inhabit freshwaters. But from such freshwater environment successive organismal invasions of the sea first, and of the land at a later period, started the main groups of marine plants and ani- 
mals as well as the land types. The marine environment once reached, there were presented wide and continuous fields of activity in migration, in feeding, in escape from foes, in reproduction, and in rearing of the young. Varied and changing environal stimuli steadily produced new and varied forms that became increasingly adapted to marine life, but seldom indeed showed capacity for readaptation to freshwater, not to say land existence.

In an address before the Academy of Natural Sciences of Philadelphia in I9I2, the writer explained the application of these principles to the leading groups of animals, and an abstract of this address was published later by Dr. A. W. Miller in his "Report on the Progress of Botany" in "Proceedings of the 36 th Annual Meeting, Pennsylvania Pharmaceutical Association" (I9I3). Such were his first published statements regarding the origin of the important groups of animals. In applying these principles to fishes in the volume already quoted (p.403) the writer expressed himself as follows: "We would shortly sum up our conclusions by saying that the Cyclostomata were probably, as they still are in part, of freshwater origin; that the Selachii are and have been through long epochs nearly all evolved as marine forms; that the Polypteridae are and probably have been freshwater in habitat and history; that the Dipneustei are similar to the last; that the Chondrostei or spoonbill and sturgeon series agree with the two last except that some of the sturgeons pass into the sea to feed and return inland to spawn; that the Holostei are now wholly freshwater; that of the thirteen suborders of the Teleostei given by Boulenger, the first or Malacopterygii are almost wholly freshwater, the third or Symbranchii are mainly fresh-more rarely brackish water inhabitants, the fourth or Apodes - that includes the eels-are rarely freshwater, usually marine and breeding there at considerable depths, the fifth or Haplomi-that includes the common pike-are largely freshwater though a fair number live and even breed in the sea, and the remaining nine (Heteromi, Catosteomi, etc.) are almost wholly marine with rarely freshwater inclusive genera. 
"But a comparative review of the number of freshwater and marine genera of the present day, in the light of their known first appearance in geologic time, brings out some rather remarkable results. Thus, of the entire group of the Gnathostomata or toothed fishes, 453 living genera are purely freshwater in their life history, and 902 genera are marine, with occasional freshwater representatives. But when such statistics are compared with the geological record, another and different relation is revealed. The oldest known groups of the true fishes are the Crossopterygii, the Dipneustei, and the Chondrostei, representatives of all of which have been found in the lower Devonian. All of these are freshwater forms at the present day, and many if not all of the fossil forms likewise were. But as these attained to the greatest climax of their development in inland seas, in lacustrine and in fluviatile situations, the group of the Selachii probably evolved from the primitive acanthodeans, took to a marine life, and soon became an increasingly powerful type of fish up to the period of the carboniferous epoch or even later. Their aggressive and voracious tendencies, their often lithe movements, and their inclination to feed on dead as well as living animal matter, seem to have enabled them to contend successfully with the giant representatives of the cephalopod molluscs that at that time largely held the seas. But the highest or teleostome fishes gradually evolved from the Permian period onward in ever increasing numbers. It is a striking fact however that, if we compare the number of living genera of fishes whose ancestry dates from the period of the Cretaceous or further back, 320 living genera are freshwater, and I 55 are marine. Only during the period from the Cretaceous and especially from the beginning of the Eocene onward do the teleostean fishes attain that enormous marine development which now characterizes them; so that, while I 33 genera of recently evolved living teleosteans are freshwater, 747 genera are marine. This remarkable development seems to have been correlated with a gradual dying out alike of the dominant groups of cephalopod molluscs and of selachean fishes. So, when we sum up all of the living genera of gnathostome fishes, and find that 453 are freshwater 
and 902 are marine, this by no means represents the primitive distributional relation.

"We would therefore consider that all palaeontological, structural, and geographical evidence strongly favors the view that the primitive fishes have had a freshwater origin, and that derivative marine forms have evolved from these, which in the case of the anciently derived selacheans, and of the recent teleosteans, reached each to a high climax of species diversity, the former during the Cretaceous period, the latter in our own day."

If such conclusions are in harmony with the phylogeny and gradual distribution of fishes over freshwater and saltwater areas it should be highly probable that its correctness can be demonstrated by an appeal to the palaeontological record. Further, if that record is sufficiently complete, it should enable us to determine with fair accuracy the approximate period when the main groups and even the smaller families of fishes migrated from a freshwater to a marine environment or vice versa. As a result an evolutionary sequence and exactness could thereby be obtained that would be in helpful contrast to the vague and uncertain record of the past.

In now selecting the group of fishes for detailed treatment the writer has been guided by several considerations. First, it has been generally accepted as the group that connects the invertebrates with the more evolved vertebrates. Second, it shows several very distinct living divisions that can nevertheless be traced back through the greater extent of the palaeontological record to forms that strongly suggest community of origin and structure; Third, from its environal relations, and so from causes that will be fully discussed later, the group is one that is surprisingly well represented from later Silurian times up to the present day. Fourth, in spite of the great amount relatively of soft tissue that makes up each individual, the early formation, from at least Silurian times onward, of external scales and later of a resisting bony framework, ensured preservation of the remains in an exceptionally favorable manner. Fifth, owing to rare but remarkable combinations of geological conditions, that are fully discussed later 
on, the above parts are at times encountered in enormous quantity and in a beautiful state of preservation. Sixth, the group has furnished so large a share of human food that it has received much careful and detailed attention.

Such combined conditions are possessed by few if any other divisions of animals. But the writer might add that he hopes soon to publish data that will serve equally well to elucidate the past and present history of the Crustacea. Still later it may be possible to treat the Mollusca in a similar manner, though the effort promises to be a more extended one. But should some student of this last great and diverse assemblage be inclined to undertake the work alike from the embryological, the morphological, the ecological, the taxonomic and palaeontological side, the results will unquestionably be of highest value.

In undertaking such a study as the present, the writer is fully conscious of his own limitations and shortcomings, but would plead in fullest extenuation that having reached certain published conclusions it is incumbent on him to verify or to disprove the statements already made. The field is a wide one, the evidences must be drawn from many and diverse sources of human knowledge, the conclusions reached must be fortified by abundant and exact observations, such conclusions also must fit in with like observations made for other groups of animals than the fishes, as well as for plants. Finally the facts obtained from study of fossil forms must be correlated with, and must lead up to, a correct interpretation of the data already gathered as to living fishes.

So in the immediately succeeding chapters consideration is given to such general questions as the changes of the earth before and during the period of the evolution of fishes; the possible relation of recent to fossil fishes; the environal conditions by which evolving fishes were surrounded; the invertebrate predecessors and ancestors of fishes; also the succession of forms observed during successive epochs. Only thus is it possible to obtain a fairly concrete and accurate picture of the group as a whole. Such treatment also forms a fitting introduction to still later chapters, which deal with the great subdivisions of 
the group, alike in their morphological aspects and as yielding confirmatory and detailed verification of the principles already laid down in the earlier volume by the author.

In the remainder of this chapter we may now consider the fundamental evolutionary causes which effected the development of fishes from simpler types; the mode of operation of these causes; and the relative importance of each causal agent alongside others that operated.

As more fully set forth in the work already referred to, the writer would regard it as a great and fundamental law that all organisms have evolved-not through the agency of matter or chemical atoms as ordinarily understood-but from the continuous activity and increasing condensation of energy. This universally present energy, activating and building up atoms into organic molecules, shows successive condensation phases that we designate, according to their wave-length and other physical properties, the thermic, lumic, chemic and electric states of energymotion. These in the order named, and when acting on simple chemical atoms, gradually build up or link together those inorganic compounds that pass from bivalent to trivalent and thence to quartivalent compounds. The matter or chemical atoms thus acted on are in themselves inert, passive, dead; but according to the condensation quality and phase of the energy applied they assume those conditions of atomic linkage and those physical characters that determine the different types of molecules.

But in passing from the inorganic to the organic, the writer has suggested $(I: 73-96) *$ the further condensation of electric energy into that state of energy-action which he has named the duplo-electric, and which he considers to be specially concerned in elaboration of those colloid molecules that form the necessary basis of all organic existence. The colloid states of many inorganic bodies are now well known, since the first description of them by Graham, now little more than a half century since. The colloid states of silicon, sulphur, iron, platinum, silver, gold and others, are now well recognized. In all of these, as in

*In all references to literature, the first and italicized number indicates the author and work in question as given in "References to Literature" on pp. 534.542, the second number indicates the page. 
all organic tissues, water is an essential constituent of each molecule, and gives to combined molecular masses a degree of plasticity, adaptability, and gradual response to environal changes that at once suggest and foreshadow organic molecular linkages.

But for the upbuilding of complex organic molecules the writer considers that gradually, by action and reaction between increasingly complex colloid molecules, a more condensed form of energy than the duplo-electric developed, which he has named the biotic. This arose as environal terrestrial factors became appropriate to, and stimulating for its development.

Definite heat of, and heat-radiations from, the earth; definite chemic actions and reactions, that resulted in linkages into complex mineralogic molecules; definite currents of electric energy through definite bodies of varied but varying conductivity or resistance; definite formations of mixed and complex colloid bodies from dissolved minerals; these and many like conditions that must have evolved as the earth itself evolved as a steadily cooling mass, might and probably did favor biotic energy-condensation.

This energy, conducted only through complex colloid molecular masses, stimulated the formation of many of the simpler and ultimately highly complex bodies like protoplasm of the organic realm, which then became its special vehicle or conductor. In relation to environment such highly organized energy-matter complexes showed exactly those responses that were more or less characteristic of all bodies, but specially of colloid ones, as Le Bon and S. Le Duc have indicated (3;4;passim), and as the present author has presented in his work $(I: 3 \mathrm{I})$. So the five great physiological activities of irritability or capacity for molecular response to environment, mutrition or the absorption and disposing of new particles to replace those removed, respiration or the removal of superfluous effete particles-a phenomenon feebly shown by some inorganic colloid bodies, growth or increase in molecular complexity or size or in both, and reproduction or the throwing off of a portion of the whole that would serve to multiply and perpetuate the type; all became stamped on primitive organic bodies as an evolved 
and more perfect heritage from simpler inorganic colloid substances or bodies.

Each of these functions also might vary in activity, in exhibition, in relation the one to the other, or to agencies around, according to the kind and strength of environal stimuli that the organism might be exposed to. This will be seen to be strikingly true in the history of many groups of fishes at various stages in their existence.

But an examination of the simplest plant and animal organisms now living tends to show that the latter branched off from the former as a group that gradually became adapted to active motion, or in other words which showed increasingly active and delicate response to environal stimuli; also that they came to depend more and more on the catching and absorption of other living organic bodies, that is they became epibiotic in their nutritive relations. Soon however the common stock of simpler plants and of the most primitive animals, that had branched off from them in their higher members, became increasingly responsive to environal stimuli, and so a still higher and more perfect quality of energy condensed from the biotic, and such the writer has termed the cognitic. This became associated with a correspondingly complex exhibition of, and linkage of, matter to form chromatin substance. And the aggregation of this chromatin into a definite mass gave rise to that highly energized body of each cell or protoplasmic mass that we call the nucleus. So the biotic energy of each cell protoplasm, and the more condensed cognitic energy of each cell nucleus conferred first the vegetative (or living) and later the actively irrito-responsive qualities on each organism that was made up of an aggregation of many such cells.

Thus each organism, by activity of the protoplasm, became slowly adapted to or modified for the appropriate chemical substances that might act as food or as promoters of respiratory change. But in virtue of the highly sensitive and responsive chromatin substance of the nucleus, increasingly active response was made to heat, light, moisture conditions, gravity and other environal exhibitions of energy. 
A stage however was evidently reached in the history of actively motile animals when even more rapid, correlated and condensed perception not of one but of several simultaneously acting environal stimuli, and equally rapid combination of these into a single direct response, became necessary in the struggle for existence. Accordingly the writer has suggested the slow evolution of that still more condensed exhibition of energy, the cogitic, that became correlated with and conducted by a correspondingly condensed linkage of molecules to constitute the neuratin or granular network substance of nerve cells.

This stage having been reached, further evolutionary progress up to the nemerteans and thence to fishes, consisted in increasing aggregation of nerve cells to form ganglionic masses, and ultimately in formation of the centralized brain system with its nerve fibres and its peripheral sensory, motor and inhibitory nerve cells. But as is strikingly demonstrated both by nemerteans and fishes, though led up to by similar and simpler groups, a variety of peripheral sense-centers was developed to a highly perfect degree for reception of varied environal stimuli. These became more and more perfected as the eyes, ears, tactile skin organs, taste organs, and nostrils of fishes. But, on the other hand, certain sense organs, or sense centers, that were originally present, may have undergone partial or complete degeneration, in transition from a lower group like the nemerteans to a higher one like the fishes. Thus can be explained the rudimentary parietal eyes, the pituitary body, and other structures of fishes.

But in the evolution of every structural detail five factors of prime importance are more or less actively concerned, and the combined action of these five, in relation to the energies already noted which give potency to them, we term Pentamorphogeny, or the five form-evolving factors. These are Heredity, Environment, Proenvironment, Selection, and Reproduction. Each is discussed in the author's work already cited ( $I: 174: 242)$, but brief consideration of these here with special reference to the groups of organisms treated in the present volume, may not be inappropriate. For they form the basic evolutionary fac- 
tors, which in varying strength, direction, time and point of application, affect each and every organism, so as to bring about one of three possible results. These results may be: (a) steady and progressive, or at times rather sudden and marked (mutational) evolution, into types that depart more and more from the parent forms; (b) an evenly balanced or equilibrated organic relation to surrounding factors, so that through a more or less prolonged period of time, an organism or group of hereditarily derived organisms may remain apparently unchanged in structure and function; (c) a steady or rapid maladjustment to environal agents, so that devolution and degeneration, may ensue, succeeded it may be by death of the organism or group of organisms involved.

It follows from the above statements that the factors of Pentamorphogeny which affect every organism, and the results which ensue, either in evolution, equilibration, or devolution of such organism, owe their inception to environal agents. So it is appropriate here to mention at least some of the agents that have operated in the past either to evolve, to continue, or to destroy the organisms specially treated of in this volume. These environal agents are now being more and more minutely studied under the term ecology. And for extended consideration the reader is referred to special books in this biological field. It is however important to note that all of these agents represent the action of some form of energy, whether of inorganic or of organic origin.

Such universal environal agents as heat (thermic energy), light (lumic energy), chemic compounds (chemic energy), electricity (electric energy), geotropism (gravic energy), in their varied exhibitions, all act either together or more or less apart, so as to affect higher invertebrates and fishes. Thus it has been observed that widespread destruction of great shoals of fishes may result, if in the case of tropical species, the temperature rather suddenly drops, and conversely the same result may ensue if, through rise in temperature owing to submarine volcanic action, oceanic waters become heated above a definite optimum for fishes of temperate seas. 
Sudden or slow denudation changes, alterations in the relation and elevation or depression of land alongside rivers and seas, the setting free into waters, of beneficial or of deleterious food compounds, the presence or absence of particles so large or so fine as to interfere with respiratory change, the existence of barriers that might prevent or of passages that might promote, distribution of individuals or species, all need consideration.

But those much more complex exhibitions of organic energy that we group as bacterial and fungoid diseases, or as animal parasites, may likewise operate as environal factors of prime importance.

In the separate or joint action of the above stimuli or energized factors, as being environal exhibitions of energy, each organism is affected to varying extent and responds accordingly. So by slow degree the five above named cooperating agencies of Pentamorphogeny, viz. Heredity, Environment, Proenvironment, Selection, and Reproduction have become impressed on each organism as a result of the conjoint actions of all external agents, and the conjoint reactions that each organism has shown to such actions. The sum total of these actions and reactions causes evolution, equilibrium or devolution in each organism, either temporarily or permanently, up to the period of death. Each of these factors can now be briefly reviewed.

\section{HEREDITY.}

Since, in the gradual evolution of the earth, the simpler inorganic compounds were formed step by step as cooling and crystallization proceeded, so in the varied and long continued actions and reactions between organisms and the sum total of their environment, definite structures have been built up that show definite structural details so long as the environment remains fairly constant. For it is undoubtedly true, in the past history of the world, that there was a time when such inorganic bodies as carbonate of lime, sulphate of soda, or potassium phosphate did not and could not exist, owing to unsuitable environal conditions. But given the needed environal states, the simpler constituents of these bodies united into stable union and 
through subsequent periods up to the present have been preserved. In exactly similar, though in greatly more complex manner, definite simpler organic constituents have united into highly complex unions that remain morphologically identical with each other, so long as like environal agencies operate on them and cause like response by the organism.

In the case of fishes and of the more primitive types that lead up to them, long eons of slow evolutionary action and reaction had to elapse, after the simplest organisms were evolved, before sufficiently complex bodies were built up that could act as the complex progenitors of nemerteans and later of fishes. But at each step in the process definite organisms, characterized by definite structural details, became equilibrated to an average environment and thus constituted a species-type that reproduced its kind. Thus myriads of individuals might show through long ages a heredity or similarity of detail.

Alike for nemerteans, for primitive and even degraded fishes like Amphioxus, for cyclostomes, for dipnoans, and for some ganoids, a surprising similarity in hereditary details has evidently persisted through long ages, so that individuals belonging to each of these groups all retain at the present day close resemblances of hereditary structure, even though scattered widely apart over the world. Therefore, though no traces of the first three groups named are surely met with in the fossil state owing to the soft nature of their body-substance, their structure, embryology and distribution clearly proclaim them to be very ancient forms that still exhibit a surprising constancy of heredity for each group. They thus become of high importance, as indicating the pathway of evolution pursued by related forms that have been entirely blotted out, owing to adverse and destructive environal surroundings.

\section{ENVIRONMENT.}

But some of the above individuals, by environal change, might be so altered in their complex organic constituents, that new details of bodily organization would appear. Thus freshwater fishes that live in and are exposed to 
strong currents of cold water in high alpine regions develop details of structure that greatly resemble each other, even in groups that otherwise are systematically apart. Again marine teleosts that have in recent ages become environally adapted to life amid the brilliant colorations of coral cliffs, coves and recesses, now rival in tint and not unfrequently in grotesque structural modifications, the seascape that surrounds them. The past forty years also have revealed to science those remarkable groups of deep-sea fishes, which while differing in important details of taxonomic heredity, agree in the huge eyes and other structural features (p.458) that environally have formed in response to the dim light conditions of the deep sea. Though biologists have often disputed over these and many like acquired structural details, till their wordy disputations have almost rivalled those of the medieval "philosophers," these modifications all proclaim exact actions of varied environal agents that affect and slowly modify the organisms involved. The manner in which such modifications are effected will concern us under the next or third heading.

\section{PROENVIRONMENT.}

The writer has shown in another work ( $I$ :ISS, I94, 205-242,629-65I) that in all organisms a correlating and synthesizing action proceeds which he has designated the Law of Proenviromment. Least evident and simplest in action amongst the lowest plants, it becomes increasingly important as one passes to the simpler animals or the higher plants, and thence onward to those more evolved. For in the numerous actions or environal stimuli to which every organism is exposed, it becomes increasingly necessary that these stimuli be more and more quickly linked together into a single correlated reaction-response that the organism can make to such stimuli. This correlation and combination-capacity exists in feeble and sluggish manner in the protoplasmic network of simplest plants; becomes largely concentrated in the chromatin-nuclear substance of nucleate plants and lower animals; is still more condensed in the nerve cells of the simpler animals; and reaches its climax in the complex groupings of nerve-cells that make 
up the brain-masses of higher invertebrates and of vertebrates.

As will be traced in a succeeding chapter, and as the writer has already shown in the above-cited work, the highly complex brain-masses that characterize the nemerteans, and above them as well as derived from them, the fishes, give to all of these the capacity to receive numerous diverse stimuli, to pass these quickly to the correlating and combining brain centres, and therefrom to proenviron or project a path of action for the time that is most satisfying to each organism involved. So if the sum-total of environal stimuli conduces to progressive advance and improvement in the adaptability of an organism to its environment, evolution results; if the environal stimuli and the hereditary details are in balanced relation organic equilibrium results; if the summated stimuli tend to cause disintegration, simplification, and inadaptability to an advancing environment, degeneration ensues.

Amongst Nemerteans, and every group of fishes, abundant exhibitions of the above law are seen. Thus the lithe, active and quickly adaptable movements that we associate with most Teleosts represent the action of many environal agents - not least of predatory enemies - through many millions of years, which have acted on every hand as environal stimuli. These stimuli, almost instantly conveyed to the great correlating centre or brain, have there been combined into a single resultant response that may cause each animal so to move as to escape from three or more dangerous enemies on different sides; to glide rapidly from noxious gases, hot waters and falling dust passed into surrounding waters, toward a body of water free from such injurious agents; to dart suddenly from a dark position to a lighted place where some food-animals are disporting, and to seize accurately one or more of them. In short, on slight reflection, it will be patent to every one that most of the acts of fishes as well as of other animals up to man himself, are truly complex or summated proenvironal responses, due to a relinkage and recombination of energized molecules, in definite nerve centres, where such summating relinkage occurs. So while every stimulus applied to a 
nemertean or fish constitutes a physical or physico-chemical (including it may be a complex physico-chemical or organic) action, the ultimate behavior of each animal to such constitutes a proenvironal reaction or response.

\section{SELECTION or selective survival.}

This contributory factor to the great Law of Pentamorphogeny has been so fully dwelt upon by Darwin, Wallace and subsequent students, that only a few notes need be added here. In its actual and exact working as a phase of Pentamorphogeny, it has not unfrequently been brought in to explain facts that pertain to the other four phases, and in its strict application it is largely a secondary or derived factor that depends on the earlier action of some one of the four other factors. Thus the plates and spicules of some nemertean and of some primitive fish species are primarily chitinous or calcareous deposits within cell cavities, that represent superfluous products of metabolism. But disliked by opposing animals, and offering a certain resistance in attack, those forms have slowly become dominant in which the deposits have increased in amount and in exactness of deposition. Then the process of natural selection steadily proceeded, till now only the cyclostomes, and a few simplified scaleless derivatives from originally scaled types of fish, represent groups that survive by sheltering in mud, in sand, in holes, or as for the Hag Fishes by exudation of abundant mucilage and adoption of a parasitic habit.

The abundant secretion of mucus, the evolution of electric organs, the production of defensive or of-as in the chimaeroid sharks-offensive spines, are in part proenvironal adaptations, but secondarily become of prime importance in the life-struggle, as being conditions that favor perpetuation of the species which develops these to the most appropriate degree. Similarly the protective coloration, alike as an offense and as a defense arrangement, seems to represent primarily a proenvironal response to the action of certain surrounding light rays, but secondarily may determine, by action of natural selection, either the continued life or the death of a species. 
In some cases even it seems to be undoubtedly true that what at one time aided powerfully in defense might become by degrees a burden, and ultimately an impediment to life-activity and survival. Thus the heavily armored and unwieldy Cephalaspids, Pterichthyids, Dinichthids, and Titanichthids of Devonian age (pp. 129) largely survived up to a certain stage, owing to steadily increased armament. But the very weight of this caused them to become bottom feeders, which gradually were blotted out alongside more active and predaceous elasmobranchs and ganoids.

Natural selection then, or selective survival, is largely a secondary and passive agency in the great pentamorphogenic act that organisms are molded by, during their entire life period.

\section{REPRODUCTION.}

Our knowledge of this phase of pentamorphogenyso far as it concerns animals-is still largely in the making. The writer has given a few reasons for regarding it as an important factor for plants. In his "Descent of Man," Darwin advanced arguments in favor of "Sexual Selection," but the potency of this lias been very variously viewed by later authors. The fact has long been known that amongst fishes a sexual dimorphism of marked kind may exist. This also becomes associated with structural differences that must tend to upset the specific equilibrium of the bisexual individuals. Thus the claspers and dorsal spines on the males of various Rays, the bright coloration of the males of some Teleosts during breeding season, the at times smaller size of the males as compared with the females as in the Bowfin (Amia calva), the enlargement of the oval fin in the male of Polypterus, and not least the nest-building habits of the Stickleback and of various African fishes, give rise to structural differences that must more or less tend to variation in the type. But until wider studies are forthcoming it would be impossible to estimate the potency of these details as evolutionary factors.

The capacity for artificial hybridization between species of a genus has been definitely established for Salmo by Day 
and others, while repeated descriptions have been made of supposed natural hybrids between distinct species, as for example with the snappers (Lutianus) of Cuba. So far as at present known however, these are rare and exceptional conditions.

But it should be borne in mind that we are still largely ignorant as to the possible effect of changed environment on the eggs and young of nemerteans and fishes. Graham Kerr has pointed out $(5: 8)$ that this embryonic stage may also be the most susceptible in the history of individuals and species. An extensive field for experimental study is here open.

Having briefly reviewed the above important biologic conditions it can now be stated that the four fundamental theses of the present volume are: (a) that the Nemertinea are the progenitors of all the chordate groups, including the Hemichordata, the Urochordata, the Cephalochordata and Euchordata, (b) that the freshwater and land Metanemerteans of the present day represent direct descendants of related forms that evolved from simpler though environally similar freshwater types, but which also gave off outliers that passed into marine surroundings and there evolved numerous new genera and species; (c) that from the higher freshwater Metanemerteans the Euchordata developed, and long remained wholly or almost wholly in like freshwater environment as their metanemertean ancestors, (d) that in process of this development the Euchordata early separated-probably in late Cambrian or early Ordovician times-into two divergent groups, the Cyclostomata and the Gnathostomata, and that representatives of both still exist. Though outside the field of the present work, but already dealt with by the author ( $I$ : 454-474) it might be added that he regards freshwater cyclostomes allied to Petromyzon or some nearly related and diverging series, as the progenitors of the Amphibia and still later of the Mammalia. A few words can now be added regarding the four above positions, preliminary to their detailed consideration in subsequent chapters.

(a) Under the first heading it can be said that the Metanemertinea is the only group of invertebrates which 
shows a fundamental structural basis, in nearly every detail, on which could continuously and gradually be evolved or built up those characters which we associate with euchordate or vertebrate organisms. For whether one compares the ectodermal or skin derivatives, the brain and nervous systems, the alimentary canal with associated gland tissue, the proboscis sheath-or rhynchocoelom-as forerunner of the notochord of vertebrates, the proboscis as subsequently modified in part into oral structures and in part into the pituitary body of vertebrates, the blood vascular system, the excretory system, the origin and fate of the reproductive elements, and finally the development of the embryo, all exhibit homological details and continuity that are approached by no other group of organisms.

(b) Under the second heading, the writer would draw attention to the facts and arguments already adduced by him which showed that a freshwater environment was the primeval ecological arena in which evolved all of the important animal groups. But on first sight it might seem vain to advocate a freshwater origin for Nemerteans in light of Bürger's synopsizing statement $(6: 48 \mathrm{I})$ thus: "The Nemerteans are almost exclusively inhabitants of the sea. We ought so to express it, because out of 406 assured species, which are at present known, only 7 live in freshwater, 8 on land, and I as a parasite in a freshwater snail." But it should be said that the Rhabdocoela, which are evidently progenitors of the Nemertinea, include to-day a majority of freshwater species, and may well have included a preponderating majority in former ages, when all the circumstances of the case are considered. Further, the writer has shown that alike amongst sponges, coelenterates, polyzoans, worms, crustaceans and other groups, the simplest known types are still freshwater inhabitants, even though they may now be few in numbers there. So though the freshwater and land nemerteans are now poor in genera and species, compared with marine ones, this need not cause us to consider that such has always been true in past geologic times. It rather seems to be true that from a more primitive freshwater rhabdocoel ancestry two main evolutionary lines of nemertean specialization started. One which in part 
remained freshwater or became lymnicolous evolved ultimately as the Metanemertinea not a few of which gradually became marine, another seems early to have migrated seaward and evolved as the Protonemertinea. This in time gave off two evolving but diverging lines that gave rise to the Mesonemertinea and later to the Heteronemertinea.

(c) Under the third heading it must be acknowledged and accepted that between the simplest living Euchordate type and the highest metanemertean there is a wide gap, even if we include fossil forms like Palaeospondylus, Lanarkia, and others described on later pages (p. II2, I2I). But when we include the Ammocoetes larva of Petromyzon, that of the marine Ascidians, also the larva and adult state of Amphioxus the gap becomes much narrower. If further one considers how long-continued and enormous have been the denudation, destruction, and rearrangement of land areas; equally the organic stresses, denudations, and obliterations; also the many millions of years during which these processes have continued, the wonder should be rather that the record is so complete for such soft-bodied animals. It has likewise been accepted, almost without question, that Palaeospondylus and Lanarkia as well as other primitive fossil fish genera were marine. The writer adduces evidence later on which proves that all of them remained for long ages as freshwater organisms, and only slowly evolved sidelines that passed into the sea, and were able to survive there alongside varied competitors.

(d) Under the last heading we need only at present reiterate the view which has been generally accepted by zoologists, viz. that the primitive line of fish evolution early split up into at least two steadily diverging branches. One of these probably continued long and wholly in freshwater surroundings, and unquestionably must once have included numerous genera which made up the group now known as the Cyclostomata. For only on this hypothesis can we account for the structural details of the various genera that now make up the group. While some living species, according to Gage, are free-swimming and in no sense parasitic, the gradual perfecting of a suctorial disc, 
such as occurs more or less from rhabdocoel Turbellarians up to larval amphibian tadpoles, inclined some to a semiectoparasitic and later to a purely ectoparasitic freshwater life. That this change took place somewhat recently is suggested by the fact that parasitism is made on teleost fishes, which began to evolve in Jurassic and early Cretaceous time. As these Teleosts-descended from more ancient freshwater ganoid ancestors-gradually migrated seaward, the ecto-parasitic fishes evidently kept attachment, and in time became modified into the endoparasitic and highly predatory myxinoid group, which now appears to breed in the deep seas.

From ancient representatives of the above Cyclostomata we would trace the evolution of primitive and later of evolved amphibians, which from present knowledge evidently developed from Mid-Devonian to early Permian time.

A second group, that must early have diverged from common ancestors with the Cyclostomata, gave rise to the main stock of gnathostome or jaw-bearing and toothed fishes. These, as traced in succeeding chapters, had already attained to a fair degree of piscine organization by late Silurian time; and purely amid a freshwater environment. Subsequently this main stock split up into classes of gnathostome fishes, from some of which all of our living representatives have arisen. 


\section{CHAPTER II \\ Geological Conditions in Relation to the Evolution of Fishes}

The first clear evidence we have of fossil fish remains is in rocks of upper Silurian age. The celebrated fishbeds or bone-beds of the Downton series in England, of the Kincardine series in Scotland, of the Waterlime in North America, and of the Oesel beds in Russia, suddenly reveal a varied and bizarre variety of fishes, of which we now have no direct living representatives. Such occurrences prove that long anterior to the time of deposition of these beds, still more ancient and ancestral forms of fish had evolved from some phylum or phyla of the invertebrates. This must have occurred during Ordovician, or even during Cambrian time.

So in chapter 3 the writer extends his previously published proof that the Nemertinea is the invertebrate group from which all of the chordate or notochordal divisions have started. As existing at the present day the number of nemertean genera is forty-two and of species fully four hundred. But since all of those now existing have soft and readily decomposable bodies, they would leave no fossilized traces in the rocks, or might at most and under rare conditions have their firmer tissues indicated. For the occasional preservation of medusoid, of trilobite, and even of soft fish tissues has already been demonstrated. Similar nemertean remains, however, are still unknown, unless indeed some of the "conodont" genera are the teeth of nemerteans or of primitive cyclostome fishes.

A few amongst other reasons for regarding the Nemerteans as being an ancient group geologically are:-(a) representative living species occur in practically every part of the world, and this suggests a slow but extensive distribution, and gradual adaptation to environal surroundings, of existing genera; (b) two genera and fifteen species are either freshwater or terrestrial in habitat, though the majority are now marine littoral dwellers, while two genera, Pelagonemertes and Malacobdella are pelagic; (c) even 
if we confine attention to the freshwater genus Stichostemma, the seven known species occur in Pennsylvania, Britain, France, Germany, Austria, Switzerland, Russia, Turkestan and East Africa. The terrestrial genus Geonemertes includes seven species distributed over the Bermudas, Rodriguez, the Palau Isles, New Zealand, Australia, New Guinea, and Samarai Isle. The littoral marine species are world-wide, and even such genera as Prostoma (Tetrastemma) with 63 species, Cerebratulus with sixtythree species, and Amphiporus with sixty-three species are all represented by some species over every littoral region. The marine genus Tubulanus is represented by species from the frozen seas of Greenland southward along the Pacific and Atlantic coasts to the tip of South America.

Such considerations at once cause us to inquire whether the earth has undergone fundamental changes-alike of elevation and depression-in the past; whether the main landmasses have-as claimed by the earlier geologistsremained largely as they now are throughout geologic time; or rather have undergone extensive alterations, elevations and depressions, denudations and rearrangements, as claimed by Frech, de Lapparent, Arldt and other recent writers; whether the same geologic agencies as we now observe were equally or more or less active in earlier times? The remainder of this chapter will be devoted to these and to related themes, while later chapters will elucidate the subject further.

I. The primitive plastic crust.

No matter what view may be accepted as to the origin and condition of the earth prior to the appearance of plant and animal life on it, all present physical, geological and palaeontological facts indicate that the surface crust, from Archean to Permian time, was more plastic, uniformly extended, and subject to variations in marine, freshwater, and terrestrial conditions than during recent epochs. This plastic nature of the crust prevented the formation of deep depressions and equally of lofty mountain ranges that are both inimical to rapid organic evolution and activity. So, even if it be granted that denudation has worn away the 
higher palaeozoic hill-ranges, and has filled up the depressions of ocean beds, the practical absence of a high alpine and of an abyssmal flora and fauna in palaeozoic and even more recent rocks is partial proof of plastic crustal conditions.

But more striking still is the frequent alternation, within a few feet or even inches in rock thickness, of numerous layers that may differ markedly in mineralogic composition, or that may yield a typically lacustrine fauna from one bed, a marine fauna from another immediately above or below, and then a series of beds that differ from these as well as from each other, but which may be largely or wholly devoid of organic remains. Such conditions are eminently typical from the Silurian to the Permian or Triassic epoch, but seem to reach a climax from the Upper Devonian to the close of the Carboniferous, and again become marked during the Jurassic epoch. The truth of this is attested in all of the detailed accounts of rocksections given by geological surveys, in the articles of geological magazines, in technical reports on commercial mineral strata, and has often impressed the writer-as doubtless it has impressed all field workers- when travelling over and examining successive rock sections for their organic contents.

This relatively plastic and changeable condition was clearly due in part to the thinness, and highly faulted nature, of the early sedimentary crust; in part to the very extensive exhibition of volcanic activity that then prevailed, as compared with its localized and reduced exhibition at the present time. Thus geologists are agreed (Geikie, 7 : 86 I-907; Chamberlin-Salisbury, 8:II:I 75-I 94, etc.) that the Archaean rocks often represent a thickness of about $2 \mathrm{I}, 000$ yards or I 2 miles, as compared with 15,000 to 20,000 yards as the thickness of the formations that make up more recent strata. These foundational Archaean rocks are, however, extensively altered, faulted, contorted, and often even overturned on each other. During the Ordovician and Silurian periods extensive volcanic change also proceeded, and the same is true over wide areas of Devonian strata in some continents. 
One effect of this would be the frequent formation of fissures for the passage outward of chemically active gases, and for the percolation inward of chemically active liquids from the surface. These would hasten the decomposition and denudation of exposed rocks, at the same time that other masses were being deposited in freshwater or in littoral marine areas. Furthermore, the writer has already emphasized $(9: 249 ; I: 53)$ that such restricted areas of the present day as the Yellowstone region, the geysers of Iceland, the terraced hot-springs of New Zealand, and the thermal springs of Japan, may have been of wide and frequent occurrence during early geologic times. Though, owing to subsequent denudation-change, the deposits formed by them may have left small trace behind, it seems to be amid such chemically and physically active centers that we should expect to encounter the first dawnings of life.

\section{Geological and early biological relations.}

Now from the standpoint of organic evolution, it seems necessary to accept that primitive plant organisms began to form during the early part of the Mid-Archaean epoch*; that these gradually gave rise to higher plants, and later to the simpler unicellular animals; while throughout the Ordovician and early Cambrian periods types had appeared that were, on the animal side, the ancestral originators of the graptolites, corals, brachiopods, trilobites, and molluscs of later Cambrian rocks.

Now alike from the standpoints of morphological detail as of neurological complexity, we may regard the fishes of Silurian age as fairly intermediate between simple nonnucleate unicellular animals on the one hand, and anthropoid apes on the other. The average thickness of beds, from the base of the semistratified or stratified rocks that are classified as mid-Archaean to the base of the upper Silurian may be taken as 70,000 feet, from estimates for the different formations made by Prestwich, Geikie, Haug, de Lapparent, Chamberlin, Grabau, and others. The

* The writer throughout will use the term Archaean rather than Proterozoic, as it is a noncommittal term, and all available evidence indicates that simple cellular plants appeased first, while primitive animal types branched off from these at a considerably later time. 
thickness of beds from the base of the Devonian to those of recent date may be given approximately as 85,000 feet. This would indicate that the beginnings of life date well back into mid-archean or even older rocks. Such is the conclusion that Patten $(I O: 338)$ has already reached. All such records, however, are confessedly imperfect and approximate. The want of record of organic remains in Archean and even in some Cambrian rocks seems to be wholly due to the soft perishable nature of the primitive organisms. Only when sponges, hydroids, or actinioids began to secrete calcareous or siliceous or chitinous spicules or tests, when previously protoplasmic echinoderms began to form increasingly heavy tests as in the cystoids, or when brachiopods and molluscs started, while in the "phylembryo" or in the "veliger" stage of their phylogeny to secrete a chitinous and later a calcareous shell, did the likelihood occur of their being preserved as fossils.

This circumstance greatly complicates the question as to whether primitive organisms originated in a freshwater or in a marine environment. The writer has already shortly set forth his views $(I: 410)$ that certainly most and probably all of the great animal groups as well as plant groups started as inhabitants of lakes and swamps. Only secondarily and still later did they migrate into marine areas, or on to the land. In regard to fishes he hopes in the subsequent context to prove clearly that such is eminently true for them. With abundant and ever-increasing material for study of the Crustacea, Arachnida, Mollusca, and other groups, he hopes also to prove its correctness in detail for them, as he already has in general outline.

If, then, a decidedly more plastic state of the evolving crust existed up to Silurian or even Carboniferous times, such would give rise to several important conditions that would all be highly favorable to organic development and change. Thus, as compared with present distribution of land and sea, a much more extensive expanse of land and of freshwater areas must have existed above the sea-level, while the ocean itself-existing as a highly plastic but heavy and continuous mass-would tend to form sags or depressions around or between the land areas. These de- 
pressions must have been much shallower however than the often deep and at times ravine-like inequalities of the ocean bed now, that is confined within and between hard and thick sub-oceanic rock-floors. Instead, therefore, of the exposed land and water surfaces being as now, in the proportion of $\mathrm{I}$ to 3 , it seems almost assured that a ratio of 2 in land to 5 in sea would be a conservative estimate. Such a configuration is set forth to some extent by Frech in "Lethaea geognostica."

The land masses, however, in virtue of the plastic character of the earth's crust, must seldom have been elevated above sea level to more than 3000 or $3,500 \mathrm{ft}$., and even over more extensive areas must have been comparatively level, like the eastern part of Central Brazil and the Congo basin of West Africa now.

Owing also to frequent inequalities and localizations in deposition of material, with resulting surface stresses, or from shifting of bodies of freshwater owing to volcanic strains and upheavals wide expanses of freshwater must often have extended in the form of lakes, swamps and sluggish rivers. These-as will be explained later-seem to have formed often as wide expanses only a few feet above the sea level. So when crustal disturbances took place, an invasion by the sea of such freshwater expanses must often have caused a sudden and marked change in floral or faunal characters, that we can frequently read the record of, alike from the altered nature of the rock-forming deposits, and the remains of fossilized organisms. The converse result would naturally happen when slight elevations of shallow sea-bottoms caused sudden destruction of marine life, and the ushering in of a lacustrine, or swamp, or terrestrial vegetation.

The above do not represent vague or hypothetical environal changes, but are exactly required by, and exactly conform to, all the evidences before us, when we investigate the early fossiliferous rocks, and not least the fish and other organisms enclosed in these. In line also with the studies of Joly $(I I ; 23)$ on the solution and transfer of salt from decomposing rocks, and its gradual accumulation in the sea under constant evaporation action, it should be 
borne in mind that freshwater must once have been more abundant proportionately than now. To what degree this held true, however, is as yet undetermined.

\section{Primitive freshwater and marine areas contrasted.}

But equally in geological, paleontological and biological writings of the past and present century, the preponderating extent of the ocean; the highly dynamic action of it in effecting crustal changes; the supposition that in it all life originated, and from it all freshwater and land animals emerged; also that the present ocean beds are fairly continuous with those of palaeozoic times; have been so insisted on and elaborated, that the possibility of a different interpretation has seemed superfluous. But reared and educated as the writer was amid Carboniferous and Old Red formations, the extensive deposits of these in which no traces of marine life occurred, but in which abundant and continuous beds of evident freshwater origin were followed of ten through hundreds of feet in thickness, caused him to query the correctness of the current interpretations.

These impressions however of more than forty years ago had been somewhat anticipated, and were succeeded by like queries of other investigators. Thus, in the careful and elaborate monograph by Rupert Jones on the Estherieae (I2) constant emphasis is laid on the freshwater habitats of all existing species, and apparently also of all species described from Old Red rocks upward. But the usual presence and admixture with these of abundant fish, eurypterid, and plant remains, some of which, and particularly the fishes, had been directly or tacitly claimed as marine, constantly inclined him to hesitate in his final decisions. And a like attitude was assumed by him in a more recent article.

A. Geikie, with wide experience as a field geologist as well as a writer, in viewing the fish remains and associated organisms of Old Red age, fully accepted a lacustrine habitat for these, and so he designated their Scottish areas of occurrence as Lake Orcadie, Lake Caledonia etc. (7; 1008$)$. 
The most emphatic query however-likewise from the geological side-is that of Chamberlin in his paper "On the habitat of the early vertebrates" ( $13 ; 400)$ as well as in many sections of the textbook of which he is joint author ( 8 ; II). In the former, his opening paragraphs were evidently influenced by earlier descriptions of Newberry and Orton for "Corniferous" beds, and their supposed marine origin. Detailed reference is made to this in subsequent pages of the present work (p.p. I26, I 29). Later, in his "Geology" he says $(\mathcal{8} ; \mathrm{II} ; 482)$ regarding the Devonian, "The general faunal conception is, that in the Appalachian tract and in the Canadian provinces lying to the north-east of it, as well as in Great Britain and Russia, there were many lodgment basins that were progressively filled by land-wash and freshwater sediments, and that these basins were the home of a freshwater or brakishwater fauna, in which ostracoderms and fishes were the leading elements, and crustaceans their chief colleagues." And again he remarks under "the Mississippi period" (p. 535): "Fish appear to have first effectually invaded the open sea in the Devonian period, but during that period true marine fishes seem to have been inferior in number and variety, to those of the inland waters."

Elsewhere, and in another work, the writer hopes also to quote the modified or limited view expressed by J. M. Clarke as to the origin and distribution of the eurypterids, and which advocates the existence of wide freshwater areas in which these giant arachnids disported.

In succeeding chapters of this work, the question is fully discussed by the writer, on the ground of evidence there adduced. But for a proper understanding of the evolution of fishes in relation to their environment, the following seem to be requisite conditions:-(a) the earth's crust was then in a relatively plastic state; (b) as a consequence, the land and sea were more uniformly distributed than now; (c) high land elevation and deep ocean beds were as yet alike absent; (d) extensive and connected freshwater areas existed, and permitted wide migration and resulting dispersion of freshwater organisms, not least of nemerteans and fishes; (e) the extended and fairly uniform distribution 
of land devoid of cold mountain areas, and of seas devoid of dark ocean depths, formed the most wide-spread and favorable environal conditions for active organic evolution.

Geologically then the writer would consider that great masses of rock strata of Upper Silurian, of Devonian, and of Carboniferous age are of freshwater origin, and that these in many cases equal or excel rocks that are clearly of marine origin. Thus the Scottish deposits described by Campbell in Kincardineshire $(17 ; 923)$, the corresponding Downtonian beds of Central England, the Niagara and Waterlime strata of North America, those of Oesel in Russia, also some Swedish beds are largely or wholly freshwater. The extensive deposits of Old Red or Devonian rocks over the Northern United States and Southern Canada, over North and Central Scotland, Ireland and some parts of England, those of Russia and Germany also are of similar origin. Some of the Lower Carboniferous or Mississippian of North America, the Calciferous of Central Scotland the Culm of Austria and parts of Germany, as well as the greater extent of the enormous deposits that make up the True Coal Measures of North America, of Europe, of parts of Asia and of Australia should be similarly classified.

The truth of the above is in part proved by the habitual absence of marine organisms; by the uniform presence of a biological assemblage that is treated of in detail in some succeeding chapters; by the frequent direct continuity in structure, in mode of life, and in habitat of such groups as the Coelacanthidae, the Palaeoniscidae and representatives of the Dipnoi (Dipneustei), from Devonian or Carboniferous days on to Cretaceous or even recent time. Abundant proof of such will be adduced later.

It might well be objected now, that if such conditions existed during palaeozoic or even more recent epochs, examples possibly should be left still, that would more or less parallel or reproduce the above. Such seem largely to be fulfilled in the group of fishes that has come down from early Old Red times to our own day as the Dipneustei. The three living genera and all the species of these, inhabit wide areas of South America, of West and Central Africa, 
and of Australia, that are either semi--lacustrine expanses, or are subject to periodic floods annually or for short periods, during which time considerable transfer of detritus and rock-forming materials occur. The observations of Baldwin Spencer, of Graham Kerr and others, along such lines will be referred to later.

But as depicting the possible geological changes effected where the Australian dipnustean Neoceratodus occurs, Spencer's description $(I 5 ; 8 I$ ) deserves quotation. He says, regarding the wide flood--plain of the Burnett river: "In the rainy season, the creeks, dry in summer, become converted into roaring torrents; the river rises suddenly, as much sometimes as 50 feet in a very few days, and down from the hills and the country round an enormous amount of sand is swept suddenly into the water. When once the big sandbanks of the river have been seen in dry weather, it is easy to realize what a vast amount of sand must be swept down into the stream at flood-time every year."

While many of the larger rivers of the present day show an equally marked rise and fall of the waters, some develop flood plains of much greater extent than the above. Thus the Amazon may spread in places to a width of $300-400$ miles during the wet season, while it as well as the Congo, Niger, Zambezi and many smaller rivers, may form extensive lakes that vary from shallow marshy areas to sheets of several feet in depth. These, as now existing, give us some faint idea of the enormous geologic changes that must have gone on at a greatly more rapid rate during the palaeozoic period.

As will appear later when the physical and biological environment of fishes is traced out, it is highly probable that the remains of many of these were stranded over such flood-plains as the above. They may then have been covered by a deposit of mud, or muddy sand, or of fine sand, and on retreat of the waters to their regular bed, the deposit might have been exposed to hot suns which would cake together the whole of the enclosed fishes. Later on, and within a few days at most, the entire mass would become dried and preserved in comparatively natural positions. 
So it may well be inferred that, over wide continental areas both of the northern and southern hemispheres, extensive river systems drained wide regions of comparatively low land, and that in their course they may have formed huge marshy lakes of varying depth but temporary duration. When these flood-plains or swollen lakes dried up masses of fish may have become stranded, buried under the finer mud deposits and then dried under hot suns, thereafter to undergo fossilization in at least some cases.

\section{The geologic age of continents.}

Another widely discussed and greatly disputed problem in geology has been the relative permanence of existing continental masses, as compared with the possible former distribution of land and sea in a totally different manner. From the biological standpoint, and not least from that of the history and dispersal of fishes, a fundamentally different disposal of the great land areas from that of the present or of recent time, is a prime necessity that will become evident as we proceed. So the outline charts suggested by Neumayr, Schuchert, de Lapparent, Frech and others, as being explanatory of past land and sea areas, have much in their favor, and especially so in connection with the gradual evolution and distribution of fishes. Though only approximate in exactness probably, they are of extreme value, and will be reproduced in unaltered or in modified form, as occasion requires in the succeeding text.

The hitherto prevalent view that fishes as a group originated in the sea, could most easily be supported in a superficial manner on the hypothesis that the existing oceans are fundamental and are ancient reservoirs of salt water, from which successive races of fish could pass inward to the rivers and lakes of encircling land masses. But geologists and zoologists have alike failed to realize, that those genera which show at present the most marked tendency to pass from a saline to a fresh-water environment, belong to larger aggregates which are mainly fresh-water inhabitants. Thus the lampreys, the sturgeons, the salmon, the shad and many other anadromous fishes have had-as we shall later show - a freshwater origin and history up till now. 
Furthermore, the passage inland of such fishes is for the performance of that most important and primary lifefunction-the reproduction of the species. All known evidence indicates, that the inland situation sought out for the spawning act represents a habit of ancient and hereditary character, which antedates the period when such animals tended to pass from a freshwater to a marine life.

\section{Terrestrial oscillations and stratigraphic successions.}

In the development of geology as a science during the past century of effort, thick rock sections have of ten been hurriedly examined and charted; fossils found in some stratum of the section have been mixed with others from higher or lower strata; inaccurate statements have often subsequently been made as to the exact zone where the fossils were found; while not unfrequently a single and at times even thin stratum with its organic contents, has been described as typical of the entire section. But during the past thirty years, as more exact methods of observation and recording have been introduced, every changing type of rock is duly described and measured even though only a half inch to inch in thickness. In studying these on their charts then, one is often surprised or at times even puzzled, by the apparent suddenness and sharpness of the transition from one palaeontological facies to another, and not unfrequently also from one to another and different type of rock. These are indications of the frequent oscillations that have occurred in the earth's crust, and of the suddenness with which one congeries of organisms may have been blotted out, and another ushered in, that may have differed markedly in ecologic and taxonomic affinities from the former. Neglect to correlate, in exact stratigraphic succession, the organisms that are typical for each stratum passed through, has been the main and a fertile source of erroneous opinions in the past.

On the other hand, the continuous persistence over wide areas of Europe and North America of thin strata, that possess a uniform lithological character, and that enclose fossils of highly typical nature, often furnishes valuable means for determination of the successional relations of 
thicker strata above and below. No better example of such can be adduced than the so-called "bone beds" of Silurian, Devonian and succeeding epochs. These are often crowded with entire teeth, scales or bones of well-recognized groups of fishes, or with the crushed fragments of these. Extending of ten in stratigraphic continuity over hundreds of square miles of territory; at times repeated in character, with a few inches or even feet of strata intervening between them till four or five bone beds may be recorded in a section 50 feet to roo feet in thickness; they furnish evidence of the teeming abundance of fishes to a degree that almost staggers conception. Numerous cases of their occurrence will concern us later, while it is with some of them that the palaeontological record of fishes first opens.

Remarkable features of practically all of these, "Bonebeds" are that the rock-matrix is of an extremely fine and often fissile texture; that it is often so hard and closegrained as to give out a metallic ring when struck; and that while in some cases the matrix is jammed with teeth scales or bones, in others the matrix is finely laminated, and carries between the laminae perfectly preserved and flattened fish or other remains.

Murchison, in describing the English Downton beds of the Ludlow series says: "The highest member of the Ludlow rocks is the most interesting inasmuch as until recently it was described by myself as being the oldest rock in which fossil fishes had been found. The only exception is that already alluded to-the occurrence of a fragment of Pteraspis in the central part of the same formation. The uppermost Ludlow rocks also contain the earliest remains of land plants. The lower layers of this zone, as seen at Ludlow, are finely laminated, earthy, greenish-gray sandstones, containing a few ichthyolites with several shelly remains characteristic of the formation. It was the middle part only of this band, or a gingerbread-colored layer of a thickness of three or four inches, and dwindling away to a quarter of an inch, which exhibited, when my attention was first directed to it, a mottled mass of bony fragments, for the most part of small size, and of very peculiar character. These, with a few remains of shells and crustaceans, includ- 
ing Pterygotus problematicus, occur in a cement in which varying proportions of carbonate of lime, phosphate of lime, iron-oxide, and bitumen are disseminazed." The writer has cited the above as being one of the earliest descriptions of some of the most ancient fish beds, and also as referring to peculiarities that will be treated of later.

Rohon says $(6 I: 4)$ in his paper entitled: "Die obersilurischen Fische von Oesel" that the beds are divisible into two zones, a lower or Wenlock, and an upper or Ludlow. The former shows no fish remains. The latterwhich is again subdivided into two zones-shows in one of these abundant animal remains. Alike at Rotziküll near Kielkond, in strata known as "Wita-steinbruch," also at Wesiko and Hoheneichen, some strata are charged with fossilized animals that include Ceratiocaris nöttingi, Eurypterus fischeri, Pterygotus osiliensis, Bunodes lunula and rugosus, also in one or other of the above localities, and in association with the above or related types, a rich variety and quantity of such primitive fish-genera as Thyestes, (Auchenaspis), Tremataspis, Coelolepis, Thelodus (Pachylepis), Oniscolepis, etc. The delicate details of sculpturing on the exoskeletal plates of these, prove that they must have been quickly and perfectly preserved after death. The "Wita-steinbruch" of Rotziküll he describes as a very uniformly stratified, fine-grained, yellowwhite dolomite, which readily absorbs water, but when dry is very hard and breaks under hammer-blows into irregular pieces of different size and form. One naturally asks then as to the nature and mode of origin of such rock-strata.

Beds described by Traquair, and which the writer has examined near Loanhead, Edinburgh; also the celebrated Solenhofen and Eichstadt slate deposits, with others in Russia, Australia and elsewhere all closely agree in texture, and in their abundant fish fauna. The usually exquisite state of preservation of the fossils, not least of the fishes, has often been commented on.

While in some cases, as with the Downton bone beds, the fish remains are piled together in confused masses, in many instances the animals are preserved entire, and are of all sizes from two or three inches up to as many feet. 
Now the writer has watched through successive days, the changes effected in fishes that have been thrown up, and have become high and dry along the shore-lines of marine areas. He has also noted along estuarine banks, over lake margins, and to a less extent though with sufficiently informing outcome, over the floodplains of rivers and streams where fishes had been stranded, likewise in two notable instances along streams where thousands of fishes had been poisoned by chemical products thrown out from mills along the banks. In all cases within eight to ten days nearly every trace of these had been destroyed, by the joint softening, disintegraing and mechanical action of rain, dew, bacteria, small crustaceans, insect larvae and higher animals. Rarely one can note a gradual but yet sufficient deposit of mud, sand or lime that can cover and conserve the firmer parts while the softer decay.

\section{Volcanic dust and the preservation of organisms.}

Even if we accept the action of the above agencies, some more rapid, widespread, and perfect mode of destruction, enclosure and permanent preservation of fishes, as well as other organisms, seems to be called for, as an important geologic and palaeontologic factor. Mention has already been made of wide-spread volcanic action during palaeozoic times. And though less violent and extensive, according to present knowledge in its surface manifestations, this action was continued into mesozoic and more recent periods with at times cataclysmic results.

Now nearly all of the historic and cataclysmic volcanic outbreaks of the past two hundred years have been accompanied by copious discharges of poisonous gases, by upheavals or explosions amid terrestrial, lacustrine, and marine strata that mechanically have caused widespread death of organisms over thousands of square miles. In nearly every case also there have been shot into the air enormous quantities of fine volcanic dust of varying composition, that became redeposited as beds which have varied from seldom less than an inch to one hundred feet or more in thickness. 
In geological treatises such deposits have been referred to and in some cases described at considerable length. But their importance as possible conserving agents from the palaeontological standpoint seems almost wholly to have been overlooked. A somewhat detailed consideration of them seems therefore to be appropriate here.

As to the nature of the volcanic dust, this varies greatly according to locality, and the composition of the crustal rock that has undergone pulverizing. But as granitic masses constitute a large portion of the foundational crust of the earth these must most commonly have been reduced to powder and exploded from vents. The following table, therefore, is arranged to show the chemical composition of a series of granitic rocks.

\begin{tabular}{|c|c|c|c|c|c|c|c|c|c|c|c|}
\hline $\mathrm{SiO}_{2}$ & . & & 70.60 & 72.24 & 74.82 & $73 \cdot 3^{8}$ & 71.90 & 73.27 & 66.83 & 71.62 & 71.83 \\
\hline $\mathrm{Al}_{2} \mathrm{O}_{3}$ & . & . & 16.40 & 14.92 & 16.14 & 14.86 & 14.12 & $15.5 \mathrm{I}$ & 15.24 & 14.99 & 15.27 \\
\hline $\mathrm{Fe}_{2} \mathrm{O}_{3}$ & . & . & 1.52 & 1.63 & & 0.10 & 1.20 & 0.33 & 2.73 & 1.27 & 1.25 \\
\hline $\mathrm{FeO}$ & - & . & 0.36 & 0.23 & I. 52 & 1.64 & 0.86 & I.I 4 & I. 66 & I.OI & 1.05 \\
\hline $\mathrm{MnO}$ & . & . & 0.48 & 0.32 & & & 0.05 & trace & 0.10 & 0.17 & 0.22 \\
\hline $\mathrm{MgO}$ & . & . & 1.00 & 0.36 & 0.47 & 0.23 & 0.33 & 0.15 & 1.63 & 0.74 & 0.73 \\
\hline $\mathrm{CaO}$ & . & . & 2.47 & 1.68 & 1.68 & 0.89 & 1.13 & 2.74 & 3.59 & 1.33 & 2.06 \\
\hline $\mathrm{Na}_{2} \mathrm{O}$ & . & . & 4.I4 & 3.51 & 6.12 & 3.94 & 4.52 & 4.70 & 3.10 & 3.62 & $4.2 \mathrm{I}$ \\
\hline $\mathrm{H}_{2} \mathrm{O}$ & . & . & 4.29 & 5.10 & 3.55 & 3.89 & $4.8 \mathrm{I}$ & 1.66 & $4 \cdot 4^{6}$ & 4.81 & 4.07 \\
\hline
\end{tabular}

The above shows that silica, alumina, and iron oxide make up about 90 p.c. of the total granitic mass. It is

\section{Constituents}

No. I

Silica $\left(\mathrm{SiO}_{2}\right.$

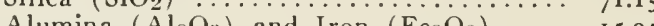

Alumina $\left(\mathrm{Al}_{2} \mathrm{O}_{3}\right)$ and Iron $\left(\mathrm{Fe}_{2} \mathrm{O}_{3}\right) \ldots . .15 .95$

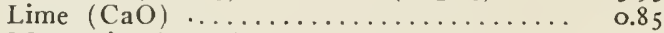

Magnesia $(\mathrm{MgO}) \quad \ldots \ldots \ldots \ldots \ldots \ldots \ldots$ o.tI

Manganese $\left(\mathrm{MnO}^{\prime}\right) \ldots \ldots \ldots \ldots \ldots \ldots \ldots$ trace

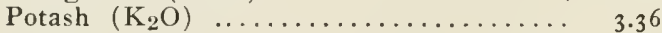

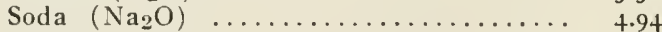

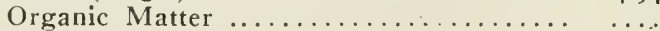

Sulphuric Acid $\left(\mathrm{SO}_{3}\right) \ldots \ldots \ldots \ldots \ldots \ldots \ldots$
No. 2

68.91

6.12

$3 \cdot 44$

...

0.36

3.09

8.75

8.88

of interest therefore to compare with this the analysis of two samples of volcanic dust as given by I. C. Russell in his valuable and original work $(I 7: 292)$, No. I being from Truckee Canyon, Nevada, and No. 2 from Nebraska. 
The close agreement of Table I with that given for granite is suggestive. The high percentage of organic matter (8.75) and of sulphuric acid (8.88) in Table 2 over granite is readily explained when one considers that the volcanic dust was ejected during Eocene times, and might readily have been mixed with organic remains of that period. Proof of this is given below. Again the amount of lime or of iron may vary, and either may give a distinct character or color to the rock formed, or cause it the more readily to recombine with other rocks. Russell says (p. 286) that in Nebraska volcanic dust covers twenty counties, sometimes to 50 feet in depth in the southwestern part of the state, but becomes gradually thinner and finer when traced eastward. So the volcano must have been to the south-west.

Geikie again in quoting an earlier and graphic writer says :-_."A vast column of exceedingly fine dust rises out of the crater, sometimes to a height of several miles, and then spreads outwards like a sheet of cloud. The remarkable fineness of the dust may be understood from the fact that during great volcanic explosions no boxes, watches, or closefitting joints have been found to be able to exclude it."

As regards the distance to which the dust may be carried Bonney ( $I 8:$ I 89 ) in describing an eruption at Mt. Hecla says: "one, which began in September I 845 lasted for more than a year, and the ejected dust fell abundantly in the Orkneys, quite 500 miles away. Copious discharges of this material seem indeed to be rather characteristic of Icelandic eruptions." Writing again of the volcanic peaks of South America he says (p. 24I): "But the most noted of all is Consequina, for it was the scene of a frightful eruption in 1835 . . . It began on the morning of January 2oth, when several loud detonations were heard, followed by the ejection of a cloud of inky smoke . . . The cloud spread gradually outwards, obscuring the sun, while fine dust fell from it like rain. This went on for two days, the sand falling more and more thickly, and the explosions becoming louder and louder. On the third day they reached a maximum, and the darkness became intense. The quantity of material that fell was so great that for 
leagues around people actually deserted their homes, fearing lest their roofs might be crushed in. At Leon, more than a hundred miles away, the dust lay several inches deep, and it was carried to Jamaica, Vera Cruz, and Santa Fe de Bogota, over an area of 1500 miles in diameter."

When such fine dust falls on the surface of a swamp, a lake, or the sea, it might be supposed that the whole would be swept away, and mixed with materials of erosion. But Judd $(19 ; 72)$ has well observed: "Everyone is familiar with the fact that pumice floats upon water; this it does not because it is a material specifically lighter than water, but because cavities filled with air make up a great part of its bulk. If we pulverize pumice, we find the powder sinks readily in water." And later (p. 74) after speaking of oceanic volcanic debris-pumice, dust, etc.,-he says: "these particles of volcanic dust and fragments of pumice, by their disintegration give rise to a clayey material, and the oxidation of the magnetite, which all lavas contain, communicates to the mass a reddish tint. This appears to be the true origin of those masses of "red clay" which, according to recent researches, are found to cover all the deeper parts of the ocean."

But it may well be suggested that equally abundant dust deposits have taken place on land and in lacustrine or in swamp areas, where they could rapidly entomb and preserve even delicate organisms. Many evident examples of this will be referred to later.

The quantity of dust carried and the extent of area covered have both been fairly accurately estimated. In addition to statements made above, the following are helpful. "In I 882 at Vesuvius the ashes not only fell thickly on the villages round the base of the mountain, but travelled as far as Ascoli, fifty-six miles distant on one side, and Casano, one hundred and five miles on the other." (Geikie 3 rd edit. p. 2 I3). In the eruption of Cotopaxi on the 26 th of June 1877 the same author says (p. 213): "At Guayaquil on the coast, one hundred and fifty miles distant, the shower of ashes continued till the first of July (i.e. five days). Dr. Wolff collected the ashes daily, and estimated that at that place there fell three hundred and fifteen kilogrammes on 
every square kilometre, during the first thirty hours, and on the 3 oth of June two hundred and nine kilogrammes in twelve hours. During a much less important eruption of the same mountain on the $3 \mathrm{~d}$ of July, I 880 , the amount of volcanic dust ejected, according to $\mathrm{Mr}$. Whymper, could not have been less, and was probably vastly more, than two millions of tons.'

But Russell's observations (op. cit. p. 285) specially emphasize the great geological importance of such deposits. "In the Sierra Nevada, and over large portions of the Great Basin, deposits of volcanic dust many feet in thickness are frequently met with," and these, in part of Pleistocene, in part of more recent age, become finer and finer, with increasing distance from their source. Again ( p. 288) he says: "In Alaska and adjacent portions of Canada, still other extensive deposits of volcanic dust of recent date are known. The writer, while journeying up the Yukon River in I889, observed above the mouth of Pelly River a conspicuous white band from eight to twelve inches thick, in the upper portions of the river terraces, which was traced for fully two hundred miles. This deposit of remarkably pure volcanic dust had previously been noted in the adjacent regions, and was more fully examined by Hayes in I88I. The various observations show that it occupies an area of fully fifty-two thousand two-hundred and eighty square miles, and varies in thickness from a few inches on its northeast border, to between seventy-five and one hundred feet near its southwest margin. Its volume has been computed by Hayes to be in the neighborhood of one-hundred and sixty-five cubic miles. The volcano from which this vast eruption of fine dust was derived, is as yet unknown, but from its distribution, and its increase both in thickness, and in coarseness toward the southwest, the point of eruption is judged to be some seventy-five miles northwest of Mt. St. Elias.

This Alaskan deposit is pure white, except when impurities are present, and indistinguishable, at least in its physical properties, from the similar material found so abundantly in California, Oregon, and Washington." 
Russell's volume gives a most graphic picture of volcanic activity as proceeding in Coenozoic time. But the activity was undoubtedly much greater and more widespread during the palaeozoic epoch.

As to the nature of the rocks formed by such dusts, Judd says $(19 ; 89)$ : "Some volcanic materials, when mixed with water, have the property of rapidly "setting" like concrete. The ancient Romans and modern Italians, well acquainted with this property of certain kinds of volcanic dust and lapilli, have in all ages employed this "puzzolana" as it is called, as mortar for building . . . The cause of the "setting" of "puzzolana" and tufa is that rain water, containing a small proportion of carbonic acid acts on the lime in the volcanic fragments, and these become cemented together by the carbonate of lime and the free silica which are thus produced in the mass." Here Judd refers specially to a variety of lime dust produced by pulverization in volcanic cavities of limestone and siliceous rocks and extrusion of this in almost pure lime-silica combination as an impalpable dust. Such then would fundamentally differ from rock produced by hardening of granitic dust or of a quite pure lime rock.

That considerable subsequent chemical activity and rearrangement may occur in volcanic dust is also noted by Judd (p. I 55) as follows: "Scoria and pumice-stones are frequently found to be acted upon by acid vapors to such an extent that the whole of the material is reduced to a white pulverulent mass. In these cases the oxides of iron and the alkalis have united with the sulphuric or hydrochloric or carbonic acids, the compounds being carried away in solution by the rain water falling on the mass; the materials left are silica, the hydrated silicate of alumina, and hydrated sulphate of lime (gypsum), all of which are of a white color."

It is well known, and has often been commented on, that such subaerial deposits, with their preceding or accompanying earth shocks, and emission of noxious gases, rapidly kill organisms over wide areas, and these may then be found as preserved enclosures. Thus Russell (op. cit. p. 286) after referring to dust-like deposits of volcanic 
origin in Utah, often $30-50 \mathrm{ft}$. thick, says that "some of these deposits are interbedded with lacustrine sediments of Tertiary age," while those of Washington and Oregon "contain the leaves of Tertiary plants, or are associated with lacustral sediments and lava flows in such a manner as to show that they are of Tertiary age." And again he says: "The volcanic dust of the Pacific States sometimes contains the bones of mammals, and is frequently charged with quantities of leaves, showing that some of the tempests generated by volcanic agencies were disastrous to animal and plant life. These and related disturbances in environment probably had much to do with the modification and extinction, especially of the higher mammalian species."

An equally interesting phase of the subject is given by the same geologist, who describes Lake Mono, "a body of intensely alkaline water" at the base of the eastern slope of the Sierra Nevada. In rowing over to two islands that rise in it he says: "The water over which we pass gives the fingers a slippery feeling; if we taste it we find that it is intensely alkaline and bitter. As we look down into the water we see that it is clear and limpid, but the view is usually obstructed by countless numbers of brine shrimps (Artemia) and larvae of flies. The larvae are thrown ashore by the waves in windrows that are frequently a foot or more deep." We might add to the above that were such to be suddenly covered by a volcanic layer of dust, this on hardening would present exactly the type of rock, and the group of organisms, that Rupert Jones repeatedly refers to in his monograph on the Phyllopoda.

The celebrated eruption of Krakatoa in I 883 was so carefully noted by many observers, and the results were so accurately correlated and recorded by Verbeek (20); and by the special committee of the Royal Society (2I; passim), that many lessons of great value in the present inquiry can be gathered.

As to the origin of the enormous amount of dust ejected, and which in varying grades of fineness spread over the atmosphere of nearly the whole world, Judd gives a graphic description thus: "the great bulk of the volcanic dust of Krakatoa was undoubtedly formed by the striking together 
of fragments of pumice, as they were violently ejected from the crater and fell back again into it. The noise made by this hurtling of fragments in the air was remarked upon by several observers, and as I have myself noticed at Stromboli, is often more striking than the sound of the explosions. The action of this "dust making" mill, as an active volcano undoubtedly is, was well illustrated by the Vesuvian eruption of I 822 . Mr. Scrope, who was an eye witness of that eruption, describes how day after day, as the eruption proceeded, the dust particles became finer and finer, till at last they were able to penetrate the finest cracks, finding their way into and filling all locked boxes, drawers and similar receptacles."

As to its composition Verbeek secured samples, the chemical composition of three of which are subjoined. Says he: "I have in each case rejected the volatile matters and calculated the total to i oo."

\begin{tabular}{|c|c|c|c|}
\hline & $\begin{array}{l}\text { A. Dust which fell } \\
\text { at Krakatoa. } \\
\text { Collected by Captain } \\
\text { Fergenaar Buitenzorg }\end{array}$ & $\begin{array}{l}\text { B. Dust which fell } \\
\text { at points within } 100 \\
\text { miles from the } \\
\text { volcano. } \\
\text { Buitenzorg. }\end{array}$ & $\begin{array}{l}\text { C. Dust which fell } \\
\text { nearly } 900 \text { miles } \\
\text { from the } \\
\text { volcano. } \\
\text { S. Barbarossa. }\end{array}$ \\
\hline & $\begin{array}{c}\text { Anal. } \\
\text { Prof. Winkler }\end{array}$ & Prof. Anal. Winkler & A. Schwager \\
\hline 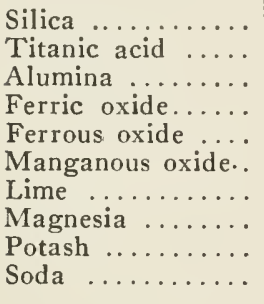 & $\begin{array}{r}6 \mathrm{~J} .36 \\
\mathrm{r} .12 \\
\mathrm{r} \cdot 77 \\
4.39 \\
\mathrm{I} .71 \\
.41 \\
3.45 \\
2.32 \\
2.51 \\
4.98\end{array}$ & $\begin{array}{r}66.77 \\
0.67 \\
\mathrm{x} .44 \\
3.41 \\
1.37 \\
.38 \\
2.90 \\
1.67 \\
2.25 \\
4.14\end{array}$ & $\begin{array}{r}68.99 \\
0.39 \\
\text { r } 5.24 \\
0.28 \\
3.72 \\
\text { trace } \\
2.76 \\
0.83 \\
3.47 \\
4.32\end{array}$ \\
\hline
\end{tabular}

The amount of dust discharged must have been enormous. Thus at the climax period on August 27 th "on board three vessels the pumice dust fell on deck" in such quantities as to employ the crews for hours in shovelling it from the decks, and in beating it from the sails and rigging. On board the "G. G. Loudon," anchored in Lampong Bay, it 
is recorded that after the rain of pumice stone in the early morning, only dust and water fell in the form of mud, which accumulated on deck at the rate of six inches in ten minutes.

But it is observed that the discharge was probably much less than that from other volcanoes in historic times, for that "of $\mathrm{I}_{7} 8_{3}$, and of Tomboro, in Sumbawa in I 8 I 5 , were all accompanied by the extrusion of much larger quantities of material than that thrown out of Krakatoa in I 883."

As to the total quantity of dust ejected, and the distance to which this was carried, the results unfortunately from the geological standpoint are meagre and conflicting. From the reports of persons on board vessels in various parts of the ocean, and from those of persons at various points of land Verbeek has reached conclusions of approximate value. But Archibald $(2 I ; 448)$ comments thus on these: "If we suppose that the area represented by these ships alone" (dealt with in the report) "was I, I00,000 sq. miles, and was covered uniformly to a depth of only 5 millimeters or 0.02 inch with dust, we should find for the total amount which thus fell I 4.4 cubic kilometres ( $3 \mathrm{I} / 2$ cubic miles) an amount not much less than that calculated by Mr. Verbeek for the total amount of materials of all kinds ejected. It appears then that the finer dust, which was transported to more than 2000 English miles from the volcano toward the west alone, might have equalled in amount what fell in its immediate vicinity; and it seems quite possible that as large or even larger a quantity was blown into such minute particles as to be capable of remaining in the highest regions of the atmosphere, and being carried right around the world in the tropical zone within a few days after the eruption."

From the mineralogical, the geological, and not least for our present purpose from the palaeontological standpoints, some comparative analyses made by Retgers at the Buitenzorg station are highly suggestive, as are the comments by Judd on these. He separated the glassy or vitreous particles from the crystalline, and also the several mineralogical varieties of the latter-the felspar, the enstatite, the augite and the magnetite-from each other, with the following results: 


\begin{tabular}{|c|c|c|c|c|c|}
\hline & 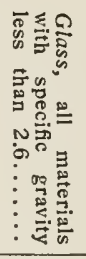 & 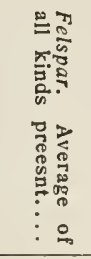 & 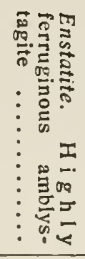 & 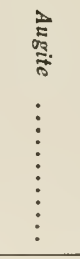 & 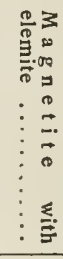 \\
\hline 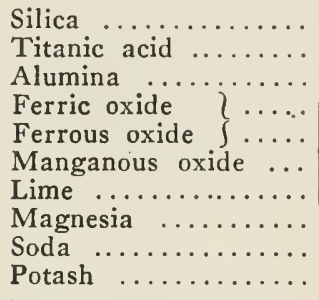 & $\begin{array}{r}68.12 \\
0.18 \\
15.81 \\
5.01\end{array}$ & $\begin{array}{l}58.29 \\
27.19\end{array}$ & $\begin{array}{r}52.3 \\
6.1 \\
27.7 \\
\text { trace } \\
2.2 \\
13.6\end{array}$ & $\begin{array}{r}48.6 \\
8.2 \\
\mathrm{r} 4.0 \\
18.9 \\
11.6\end{array}$ & $\begin{array}{r}6.7 \\
56.0\end{array}$ \\
\hline Potash $\ldots \ldots \ldots \ldots$ & 99.23 & 100.79 & ror.9 & IOI.3 & - \\
\hline
\end{tabular}

In connection with such results Judd refers to the varying composition of the dust at different distances from the centre of ejection and says that samples were taken "from many points, ranging from 40 to I, IOO English miles away from the volcano." Those nearest the volcano showed "greater abundance in them of fragments of crystals, especially those of magnetite and other dark colored minerals. Those dusts which were collected at the greatest distance from the volcano were excessively fine and almost perfectly white in color."

The above exactly explains the varying aspect, composition, and consistency of many rock-strata occurring in all formations from the Silurian upward, and which are usually rich in the most finely preserved fossil remains. Judd's conclusions are as follows: "Of the immense mass of comminuted matter thrown into the air 9/ro of this material consisted of glass having a specific gravity of less than 2.3, drawn out into fine threads and thin plates, often hollow and containing bubbles of air, and sometimes in all probability reduced to particles of ultra-microscopic dimensions. These particles of glass would tend to float by the adhesion between them and air, and in the higher and rarer portion of the atmosphere their suspension may not improbably 
have been aided by their mutual repulsion resulting from a highly electrified condition."

"The crystalline particles in the mass would consist of fragments of felspar, with a specific gravity ranging from 2.54 to 2.75 , of fragments of pyroxene with densities of 3.3 to 3.5 , and of magnetite, with a density of 5.0 . The crystals of felspar, hypersthene, and augite were, in the original pumice, of much greater size than the magnetite. But the easy double cleavage in the felspar, and to a smaller extent in the pyroxenes, would facilitate the reduction of these minerals to finer particles than the magnetite."

As the particles travelled outwards from the centre, they would tend to fall, therefore, in the following order:(I) magnetite (the heaviest and least friable material); (2) pyroxenes (next in weight and only moderately cleavable); (3) felspar (lighter and very cleavable); and (4) and last, the very light and friable glass."

"At all points therefore the dust which fell would have a tendency to differ in composition from the pumice out of which it was formed. Near the volcano the abundance of the crystalline materials falling, and especially of the magnetite and the pyroxenes, would render the dust darker in color and more basic in composition; while farther away the glass and felspar particles which fell, would have a smaller admixture of the more basic materials. A certain proportion of the glass, including the ultramicroscopical, the elongated and the very thin particles would float almost indefinitely and would not find any place in the masses of dust collected around the volcano."

The number of active or recently extinct volcanoes throughout the world has been estimated by Judd as approximately I000. But the relative thinness and plasticity of the crust during palaeozoic times, must have favored a much larger number, and such is consonant with the rock record. Even in Mesozoic and Coenozoic times pronounced activity is indicated, though the volcano-rents themselves have of ten been obliterated. Furthermore, while the activity has mainly been exhibited from the cones or higher points of land areas, it must frequently have been submarine, and productive of destructive tidal waves. 
It scems possible, therefore, that by invoking the aid of such agencies, the origin, structure, and richly fossiliferous nature of many bone beds, fish beds, and related strata can be explained, for where multitudes of entire fishes are preserved as perfectly as in a museum, the volcanic dust probably fell as these were being destroyed by mechanical concussion, by poisonous gases, or by super-heated waters, possibly even through clogging with dust of the gills. If such destruction occurred-as we hope to show actually did happen in fresh-water lakes or swamps, or in shallow seas whose bottoms became elevated either during death of the fishes or soon after, the continued fall of dust would immediately cover and seal them up. As the oily constituents of the fishes exuded, and as increased pressure of the ashy material took place, simultaneously with drying of the dust deposits in the sun, the oil would aid in preservation if sufficiently rich, while the deposits of ash, gradually hardening by chemical action and reaction as above described, would render permanent the preservation process.

Where, as in the Downton deposits of England and the Corniferous deposits of America, an intermingled mass of teeth, scales, spines or jaws mainly make up the "bonebed," the soft dead bodies of great shoals of fishes killed in some sudden manner as above described, had undergone considerable decay in some shallow, freshwater lagoon. While decay of the flesh took place an abundant discharge of oily constitutents occurred, the harder parts became separated and dropped into the volcanic ash, where they were, by pressure and chemical action, condensed into a solid mass. The discharged oily materials receive consideration below.

Such an explanation seems to afford a complete key to many hard fissile beds of Old Red Sandstone. Thus those described by Flett $\left(22 ; 3 \delta_{3}\right)$ in the Orkney Isles and by a A. Geikie $(23 ; 399)$ for Dunnet Head, are cases in point. Though we would not press the matter unduly at this stage, it even affords a likely reason for the origin of many beds of ironstone, that in the States, in Canada, and in various parts of Europe, are so often encountered in sections of Old Red and of Carboniferous age, not to say in later deposits. The of ten abundant embedded or interlaminated 
remains of fishes, eurypterids, and molluscs of freshwater habitat in such ironstones are a noteworthy feature.

\section{Petroleum and its probable relation to fishes.}

Another highly important geological phenomenon, that we hope to show is intimately connected with the life, death and fossilization of fishes, can now be taken up. Throughout many parts of the world, and at times on gigantic scale, reservoirs of natural oil, of petroleum, of gas and of asphalt have been discovered, and today constitute highly important commercial products.

From the upper Silurian rocks, upward to comparatively recent Tertiary formations, rich deposits of these have been tapped and extensively utilized. But the question of the possible source and mode of formation of such bituminous deposits, has called forth a wide variety of views. These views have been synopsized by Engler and Höfer (24: II, passim), also by Redwood (25; I, 268-283). An inorganic and an organic source have alike been claimed. The former we will not further discuss, since we regard the extremely varied products of petroleum as without an approach or parallel, in any synthetic action effected through expenditure of inorganic energies, but as being exactly such as might be called "end-products" of destructive analysis amongst plants and animals. But some advocates of the "organic" theory of origin have suggested that petroleum and its products represent decomposed plant substances, produced either from accumulation of resin and allied hydro-carbons formed by trees, or from decomposition-possibly under heat and pressure-of vegetable fats and fixed oils developed in the tissues.

Now at the present day the tissues of many Hepaticae or scale-mosses and of the true mosses, also the spores of club mosses are rich in fixed oils. But though we would not deny origin of a very limited amount thus, the total possible accumulations of these or of resinous hydrocarbons, seem wholly insufficient to explain the huge-almost inexhaustible-supplies of petroleum throughout the world.

If we turn now to the animal world, most groups of animals contain supplies of a fatty nature. But to explain 
requisite conditions from an animal source one must almost of necessity postulate: (a) the existence throughout the entire geological record from the Silurian upward of a most prolific type of organism; (b) the production in such of a substance or substances that would directly, or by decomposition-change, give rise to petroleum and its products; (c) the comparatively sudden destruction on an extensive scale of great masses of the organism, and the accumulation of these masses in special pockets or layers of strata; (d) the comparatively rapid decay of the accumulated organic masses in freshwater or possibly in salt water, and the setting free of the more stable oil from the rapidly decomposing albumen products; (e) the gradual absorption of this oil into some stratum of highly pervious nature; (f) the nearby presence of lower and upper impervious beds that would bottle up and conserve the oil; ( $g$ ) the subsequent anticlinal-more rarely synclinal-uptilting of the entire rock mass, and its exposure to frictional, volcanic or other source of heat; $(h)$ the resulting splitting up of the accumulated oils, under pressure and fairly high temperature into petroleum products.

While we would not deny that in some cases and only to a very small extent other groups of animals than fishes have contributed, and probably did contribute, to this outcome, the writer would strongly affirm-from all the evidence to hand-that fishes formed the source of supply to a preponderating extent. Further, all of the above requirements are fulfilled when we follow out the geological records of fishes. Thus many palaeontologists have often commented on the oily aspect of the matrix in which fish remains occurred from the time of the Devonian onward. And this applied, not to one or a few species, but to many, distributed over the successive periods.

Murchison early drew attention to the possible origin of bituminous rocks in the following words $(26: 542)$ : "The Flagstones of Caithness, which were first described by me in the year 1827 under the name of 'Bituminous Schists' ('Trans.Geol.Soc.s 2, v. 2 ( I 827 ) 2 I 3 ) are in many places impregnated with bitumen, chiefly resulting from the vast quantity of fishes embedded in them. Their most dur- 
able and best qualities as flagstones, are derived from an admixture of this bitumen with finely laminated siliceous, calcareous and argillaceous particles, the whole forming a natural cement more impervious to moisture than any stone with which I am acquainted." He then subjoins analyses and valuable observations on the nature of the rocks.

Again in I 829 Murchison, in noting the abundance of fossil fishes in the oil shales of Seefeld in the Tyrol (28: I39) suggested "the probability of so many fishes having materially cooperated in bituminization of the schist." This view has been repeatedly seconded since.

But at the present day many fishes like the salmon and barramunda of freshwaters, also the sardine, anchovy and specially the menhaden (pogie or mossbunker) of saltwaters are rich in oils. Our knowledge of the last fish is probably most detailed and exact, thanks to the studies of Brown Goode (29:180). He has shown that a gallon of oil is yielded by 100 to 250 animals, according to the lean or fat state of these at different periods of the year. Each animal is on the average I 2 inches long, weighs I I ozs. and attains full size in about four years. As many as I 5,000,000 of them have been taken in a limited area by one company in a season. So were one gallon of oil yielded by 50 fish, the above season's catch would represent I00,000 gallons of oil.

But more striking is an estimate by Goode, who reckons "the total number destroyed annually on our coast by predaceous animals at a million of millions," and again he gives (29: I09) "three thousand.millions of millions (3,000000,000,000,000,000)." Now it seems a conservative estimate if we consider that the closely jumbled together teeth, bones, and fin-spines of many Silurian, Devonian, and more recent bone-beds, that cover thousands of square miles of area in many cases, represent an even greater and more widespread destruction of fish-life than that wrought within a year by predaceous animals for the menhaden. If then we accept that a gallon of oil was yielded by 200 fish, the yield would represent five quadrillions of gallons of oil. 
If we compare this with the total production of oil from the oil fields of Pennsylvania and New York up to January, I $8 S_{5}$, this amounted only to $26,000,000$ barrels of forty-two gallons, or one billion, ninety-two million gallons in all. Sterry Hunt in calculating the oil contents of the petroliferous dolomite of Chicago estimated "its petroleum content at one-tenth of one per cent, and the thickness of the stratum at 500 feet, both of which figures are probably within the limits." He accordingly estimated "the petroleum contained in it to be more than $2,500,000$ barrels to the square mile." Both of the above figuresenormous though they may seem-fall far short of the probable destruction of menhaden during any one year. Now the total production of crude petroleum from all of the oil fields of the world, up to I9I 4, was $5,593,262,936$ barrels of 42 gallons, or a total of 234,9 I 7, 043,3 I 2 gallons (The American Petrol. Indust. (I916) 258-59). If we again accept it that 200 fishes are required to yield one gallon of oil this would involve the sudden destruction of only 47 trillions of fish, or the one twenty-thousandth part of the number of menhaden estimated to be preyed on and destroyed in a year. But, as will be frequently noted in later pages, some of the fossil fishes that are surrounded by zones of bituminous material in the different formations, are only one-half to one-third the size of average menhaden. On the other hand a considerable number of species, notably those of the freshwater Pennsylvanian-New York shales (pp.I34-35), of the freshwater SolenhofenBugey shales (p.I95), and of the marine Kansas-Texas shales (p.223-24) are equal to or larger than the menhaden. So the above calculations can well stand as at least an approximately fair estimate of the average fish-yield.

The world's production of petroleum, however, is at present drawn from nearly every one of the geologic formations, from the Silurian upward. Now in any one of the many bituminous horizons listed, the wholesale destruction of fish-life must have been truly cataclysmic and widespread. Furthermore, and contrary to past reasonings of most geologists if we except those of Russell and one or two others, the most celebrated fish-strata have their enclosed 
organisms so perfectly preserved in the death attitude, (Fig. I) that sealing up and preservation of the organisms must

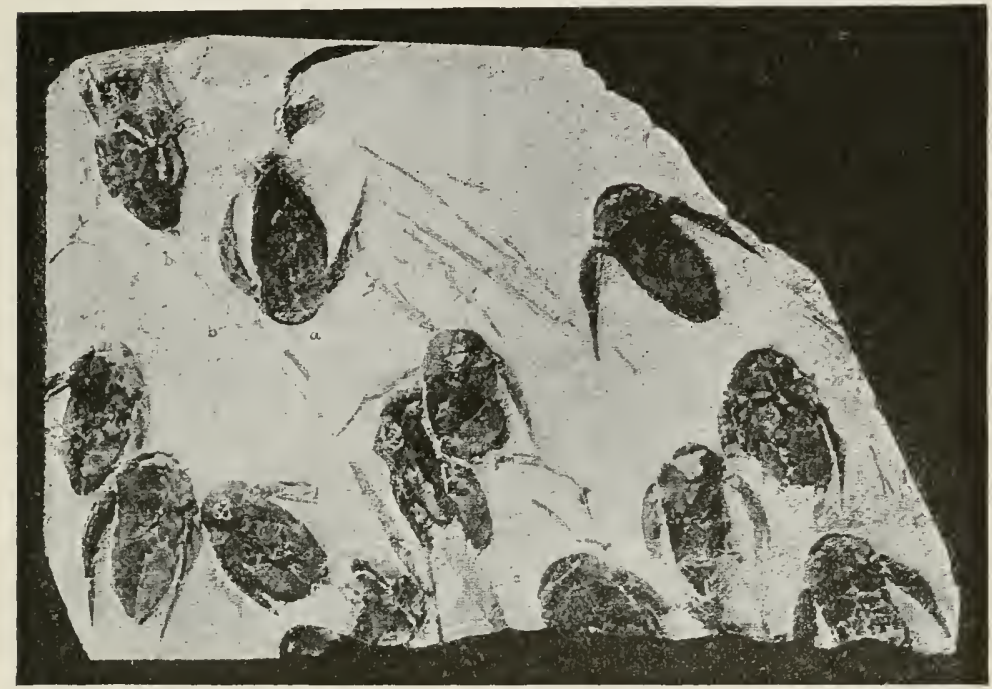

FIG. I. Slab of rock with specimens of Bothriolepis from Miguasha, New Brunswick, laid bare with many others by Prof. Patten. Note headed direction of the animals. (After Patten).

have been effected wholesale, and often to a depth of several inches or even feet within a few days at most. Otherwise, and had the period been more extended, disintegration of the fish, escape of the oily products, and the breaking up of the skeleton would inevitably have resulted. Such actually seems to have been the case where "bone-beds" were formed.

As to the actual quantity of fish that had perished, and of oil obtainable from rock strata, many "bone-beds" can be continuously traced over hundreds of miles in America, in Britain, and over the European continent. This also in rocks belonging to nearly every one of the great formations. From many indications even, suggested by the stratigraphic, the lithologic, the palaeontologic, and geochemic standpoints, the writer would not be surprised to learn in time that some of these bone-beds have a lineal continuity for a thousand to fifteen hundred miles. 
As not a few geologists have already suggested, the contents of each of these bone-beds must have represented the sudden death and decomposition of as great an accumulation of fishes as Goode has indicated above for destruction of the menhaden by its enemies in a year. But since the rock, in which such enormous numbers are mainly found, is often of a hard fissile metallic character, and probably indicates a sudden volcanic dust deposit formed during active volcanic changes in the earth's crust, these hosts of fishes may not only have been killed and entombed, they, enclosed in the dust stratum may have been upheaved above the water, exposed to sun-heat and sun-drying, as well as to volcanic crustal heat, till abundant oils had exuded.

Now when one geologically examines the areas over the world that are already known to be rich in petroleum, it appears that the great majority of these are in close contact with, or have an indirect connection with, strata that abound in fossil fishes. Thus that hitherto richest and most extensively exploited area that extends from West Virginia through Western Pennsylvania and eastern Ohio northward through Ontario and Erie to the Great Slave Lake and Hudson Bay, is the region that has yielded a more abundant and varied fish-fauna enclosed in rocks of the Old Red Sandstone or of the Carboniferous age, than any other part of the world. As described also by J. P. Lesley for the Old Red and the Carboniferous systems of Pennsylvania ( $30: \mathrm{II}:$ I 453; III: I 759:2565) the numerous extensive and prolific fish "bone-beds" that are intercalated between other strata, form a remarkable feature of these formations as of others described later in this work.

Redwood again points out (25:I:I64) that the Upper and perhaps the Lower Silurian strata of north eastern North America may yet yield abundant supplies of mineral gas, if not of petroleum. While such might represent decomposition products from decay of primitive Silurian cyclostomatous fishes, it is just possible that the primary source of this might result from superincumbent strata of Old Red or Devonian age. Redwood, Engler, and others have shown that petroleum-yielding strata of every age, from the Silurian up to the Tertiary period, occur over prac- 
tically the whole world. While the detailed search for these has gone forward rapidly, we still desiderate accurate details as to the rocks that contain, or are near to, the sources of the petroleum. But in many instances we know now that these are usually adjacent to beds that are rich in fossil fish remains.

But the writer now takes exception-as he will repeatedly do later-to a statement in Redwood's work (25: I:280) and by implication to that of the other two authors cited, which says regarding the possible origin of petroleum: "The Engler-Höfer theory, as developed by its authors up to the present time, states that petroleum is derived from the natural decomposition in situ of the fatty remains of marine organisms, both animal and vegetable." Up to at least the Liassic period, we would distinctly affirm that nearly all of the petroleum is the decomposition product of freshwater fishes, and only from late Jurassic or early Cretaceous times onward do marine fishes seem to have contributed largely - in some cases perhaps entirely-to its formation.

That at least some species or even genera of fossil fish were rich in products of an oily nature, throughout all of the geologic formations, will be frequently emphasized in later pages of this work. One of the many exact proofs is, that often isolated fossilized fishes are surrounded by abundant oily products, that give a characteristic aspect and odor to the enclosing block of rock. Again where masses of ten to twenty are heaped together in a rock that otherwise is sparcely fossiliferous, the area around the mass specially shows an oily horizon.

As to the exact manner in which the fat, oil, or other more complex constituents of fishes may have contributed to formation of petroleum, it might first be noted that in the case of the living Protopterus "the nutrition of the dormant fish is effected by the absorption of the fat stored up about the kidnevs and gonads" (2:5 I3). In contrast to this, of its ally Lepidosiren, it has been said: "during the rainy season the Lepidosiren eats voraciously, and a reserve of fat is stored up in the tissues. The great amount present in the muscular tissues of fresh- and salt-water fishes 
already named, is familiar to everyone who has dissected them.'

In view of the prodigious quantities of fishes that must often have been destroyed wholesale through volcanic activity (pp. I 20, I 48) during the Old Red to Triassic periods, it might be expected that more abundant remains of these would have been preserved in the different rockstrata of freshwater origin. Thus we have manifold proofs that Selachians existed in freshwater areas from Devonian on tc Permian days at least, and in the sea also for a relatively short period during Carboniferous times, but abundantly from Upper Jurassic and Lower Cretaceous times onward. But rather scant traces of them are met with in the fossil state, unless they developed some resisting parts such as teeth, spines, scales or jaws. Except for these, and for the very rare and sudden preservation of them in entire state in the Solenhofen, the Wyoming, and other hard fine fissile rocks, we would have been unaware of their existence. The soft and oily tissues as such have nearly always disappeared.

The above data all point strongly to the conclusion that petroleum products are mainly due to destructive decomposition of fish-oils, resulting from wholesale death of fishes during different geologic periods of the earth's history. Such widespread destruction seems in nearly every case to be explainable by direct or indirect volcanic action, such as poisonous gases, volcanic ashes or scoriae, lava flows, earth and water concussions, or supramaximal heating of areas in which fishes lived. But the accumulating petroleum products may have been slightly added to by simultaneous or later destructive decomposition of vegetable products. Thus Redwood $(25: I: 47)$ says while describing the Assam oil-fields: "Mr. F. R. Mallet has enumerated the districts where oil has been noticed in the districts mentioned. Thick soft sandstone is the principal rock traversed by the drill, but here clay also occurs. The oil always rises on or near the outcrop of the coal-bearing group, usually near the outcrop of a seam or seams of coal. Mr. Mallet records an instance in which the oil oozes from the coal itself, though as he points out, this 
may have been merely due to the fact that the coal is the last rock through which the oil passed to the surface."

The writer also, when making field studies of the oilshales of Midlothian in Scotland, was often impressed by the presence of flattened impressions of the stems and branches of Lepidodendron, Lepidophloios and Ulodendron, side-by-side with those of various species of Calciferous Sandstone fishes, the shale itself being completely permeated by the bituminous products, that at once began to "sweat out" when a piece of the shale was heated. Redwood gives a valuable and condensed epitome of the arguments for a vegetable and animal origin of the petroleum on pp. $272-283$ of his first volume, and to it the reader is referred who desires added information.

If it be now asked: What became of the oil, fatty tissue, or muscles of ancient fishes when these were entombed wholesale, the first suggestive answer was given in 1867 by the exact chemical investigations of Warren and Storer (3I:I2I-I 76$)$. Experimenting with menhaden oil they converted this into a soap, by blowing steam into a mixture of lime and the oil. The soap was then strongly heated, and the distillate obtained was a crude petroleum oil. By redistillation many of the characteristic hydrocarbons that are now manufactured from petroleum oil were obtained, such as amylene, caproylene, benzole, toluol, xylol, isocumole, etc. But a matter of considerable interest, in relation to the pitch or bituminous strata of Seefeld, Caithness, and many other places mentioned in later pages, was "the separation of a sort of tar" (p.I 85) from one of the liquors obtained during the investigation.

It was stated above that a mixture of lime with the fish oil was treated with steam. Now in the great majority of cases, bituminous fish beds contain a moderate to large amount of calcareous material; while volcanic action seems unquestionably to be associated with the formation of such beds. This again would suggest a possible superheating of the strata and their enclosed organisms, some time subsequent to their deposition. Still later, earth movements and upliftings or foldings, to produce that usual anticlinal relation of rocks which so often is characteristic 
of oil-strata, would also explain the subsequent formation of secondary products of petroleum decomposition.

Recently Engler has stated from experimental evidence, that decomposition of animal oil is effected by two stages. First, owing to bacterial action-and this we claim would proceed much more rapidly and perfectly in freshwater than in the sea-nitrogenous matters are eliminated, "the action being automatically stopped almost as soon as the fats are attacked." The second stage, clearly demonstrated by Warren and Storer as well as confirmed by Engler's more recent results, consists in the combined and continued action of heat and pressure on the oils, though, according to Engler, even this may be initiated by oil-splitting bacteria.

The entire subject opens up many avenues for future observation and experiment, especially in view of the writer's claim that a freshwater and not a marine habitat was through long ages typical for fishes.

From all that has been adduced above then the writer would conclude: (a) that many isolated fishes, or groups of them in the fossilized state, show rich petroleum products around or within the specimens; (b) that petroleum oils are usually found only where abundant fish remains occur; (c) that sudden destruction of fish-life by direct volcanic agency, and over wide expanses of water has been recorded, and evidently also took place widely and violently from late Silurian to Miocene age; (d) that contrary to past opinion, and as is demonstrated in succeeding chapters, this took place wholly or almost wholly in freshwater areas, and only in later Jurassic and succeeding times did such occur in saltwater; (e) that the amount of destruction and the widespread nature of it, as evidenced by "bone-beds" of fishes, by bituminous schists, etc., would amply account for all of the petroleum oil or gas, hitherto removed by man from any strata; (f) that frequent sudden entombment and preservation of fossil fishes were effected by volcanic dust showers which accompanied or succeeded such destructive agents as poisonous gases, earth and water concussions, superheating of waters and other means; (g) that the oils and fats, possibly even degenerate muscular tissue, set free abundant products from which petroleum 
supplies could be obtained; $(h)$ that the varied and exact experiments of Warren and Storer prove that nearly all of the crude petroleum, as well as the more typical products of destructive distillation obtained from it, can be accounted for as due to decomposition of fish-oils, through heating of these under pressure, or by some simlar expenditure of energy. 


\section{CHAPTER III.}

\section{THE EVOLUTION OF FISHES FROM INVERTEBRATES}

Numerous views have been advanced to account for the origin of vertebrate or chordate animals from some invertebrate stock. These are synopsized in various zoological textbooks, and need not now concern us. The writer in his "Causes and Course of Organic Evolution" has already adduced abundant reasons for accepting the group Nemertinea as that which most exactly and most continuously satisfies requirements. Such a view had previously been strongly advocated by Harting and especially by Hubrecht, to some extent also by Balfour and Lankester. But all of these authors dealt only with a few of the organs. In this chapter the writer will review, and still further advance, arguments and evidences in favor of this contention.

The group Nemertinea as now existing, is made up of genera and species, the simpler of which show surprisingly graded connections with the Turbellaria, as pointed out by several authors, and synopsized by Bürger. In the most evolved or metanemertean members of the Nemertinea also these exhibit remarkable fundamental agreement with the simpler chordate animals. All however are softbodied, if we except the styliform teeth, and so far as yet known have left no fossil remains. But as pointed out in last chapter, their present geographical distribution compels us to accept that they are a very ancient group. Their distribution also, might on first thought cause us to conclude that the group originated along littoral sea areas. For nearly 450 of the 465 species now known, occur there. But the wide extension of the nine freshwater and the eight land species, also their continued persistence in spite of denundation and geologic changes generally, strongly incline us to favor a freshwater origin for the entire group.

A very strong argument for this is, that in the rhabdocoel turbellarians-the majority of which are freshwater-that important organ the proboscis develops as 
an outgrowth and backward growth from the dorsal region of the gullet, so that the mouth and the protrusible proboscis open by a common aperture. This condition is retained in most species of the nemertean sub-group that Bürger has designated the Metanemertini (op. cit. p. 404), and which includes all of the freshwater and land species, as well as related marine ones. But since all of the Nemertinea exhibit a common fundamental structure, and as every fact of evolutionary history warrants the possession by them of interconnected details, we will not hesitate to compare details of any species, though laying special emphasis on the Metanemertini.

In connection with these, and generally treated now as groups of the Chordata, are the Hemichordata or siphon worms, the Urochordata or ascidians, and the Cephalochordata or lancelets. These will at times be referred to, though the writer would regard all as derivative phyla that have branched off from some advanced nemertean line, or from types intermediate between the nemerteans and the true fishes.

I. Size and shape.

Metanemerteans may vary from 3 to $500 \mathrm{~mm}$. in length by $1 / 2$ to $20 \mathrm{~mm}$. in width. Some species of Drepanophorus are $400 \mathrm{~mm}$. x $20 \mathrm{~mm}$. Dendy says regarding the land form Geonemertes australis: "as it lies at rest with the proboscis retracted it has very much the appearance of a slug or of a small planarian worm, and is very soft and slimy. When it begins to crawl, which it readily does on being disturbed, the body elongates, until in large specimens it measures about $40 \mathrm{~mm}$. in length by $2.5 \mathrm{~mm}$. in greatest breadth. The anterior extremity is then seen to be rounded and perhaps slightly swollen into a head, the posterior extremity tapering gradually to a blunt point where the anus is situated." The above two types then are about twenty times longer than broad.

In size and shape Amphioxus, Myxine, Petromyzon, and many of the higher fishes show progressive advance on the above, but frequently retain the same relative length to breadth, as well as outline. 
II. Color, While some metanemerteans are gray, silvery or brownish in color, like many fishes, they often tend to assume gaudy hues of blue, green, pink, and crimson, that seem to be protective in value (Bürger p. 533). Similar tints and degrees of coloration characterize some fishes, and in both groups the tints are due to pigment-cells embedded in the skin, and which may change in tint with change of environment.

III. Skin. In metanemerteans this consists of an epidermis that is richly ciliated; in Amphioxus the embryo only is ciliated, while fishes, so far as known, have lost the external cilia, but retain these over some internal surfaces.

Glands, embedded in the epidermis, and resulting from modification of its cells, are very abundant amongst nemerteans. They may be single or arranged in packets, and vary from elongate-tubular to ovate in shape. These mainly secrete the abundant mucus that surrounds the skin, but may also exude a somewhat granular substance, and even pigment materials. In Cyclostomata many goblet-shaped cells excrete a very abundant mucus, that may even more completely envelop each animal than in the last group. In other fishes mucous excretions from epidermal gland-ceils, are usual, the amount of excretion reaching its climax in the dipnoans, where as in some land nemerteans, a special overflow may at times be changed into a cocoon (32:20I), as shown by Parker for Protopterus.

Thread cells or stinging cells occur in the epidermis of some Nemerteans (e.g. Lineus, Bürger, p. 50), but these are often restricted to the epidermal cells of the proboscis as in Macrura and Cerebratulus (Bürger p. 2 I 2 ). In cyclostomes the myxinoids are provided with urticating cells that in structure and mode of action resemble those of nemerteans. Some epidermal cells of young lampreys secrete a digestive ferment, and such may represent modified urticating glands. Poison glands are found in not a few fishes, but usually associated with surface spines through which the poison is excreted. The group of Weever fishes (Trachinus) is an example. 
Dermal plates or scales. Such structural details call for special emphasis, since they suggest a parting of the way amongst ancient nemerteans, that led on the one hand to the soft-bodied cyclostomes, and on the other to the tubercled and later to the plated or scaled fishes. While most nemerteans remain soft in their surface tissues, others-e.g., species of Eunemertes, Cephalothrix, Tetrastemma and Geonemertes-may secrete glistening oval, angular, or hooklike masses of a crystalline nature, and which are mainly composed of carbonate of lime $(33: 67 ; 34: 430 ; 35: 104$; $36: 56)$. These cells are often in direct contact with others which are glandular, and so the entire morphological foundation exists here for further evolution of such isolated placoid granules or spines as characterize the primitive genera of fishes, Thelodus and Lanarkia, of Silurian and Devonian strata. From these again to the placoid or ganoid scales of fishes the gradation is easy.

Closely related to such secretions amongst the metanemerteans, and originating from the middle part of the invaginated epidermis that forms the substance of the proboscis, are the horny stylets that project as offensive organs when the proboscis is extruded (Fig. 5). These arise in succession from cells or groups of cells present in the mid-region of the proboscis when seen at rest. Structurally they suggest a very appropriate starting point for formation of horny vertebrate teeth, and this in a way that will be more fully explained in a later section. As described by Montgomery and by Bürger (op.cit. 227-29) they originate as a secretion of the modified epidermal cells of the mid-proboscis, and consist of two to five distinct and concentric layers of tooth substance, the outermost of which has a shining structureless aspect.

In various genera then of the Metanemerteans two epidermal formations arise: (I) calcareous epidermal secretions that form alongside glandular epidermal cells; and (2) the horny proboscis teeth or stylets that undergo steady wear and renewal. The former, by increasing complexity in structure and by increased activity of the related epidermal cells, would start formation of the tubercies, spines, and ultimately the elaborate plates and scales that 
are so typical of the main groups of fishes. The latter, by increasing specialization in development, and condensing modification of the front part of the proboscis, would form the horny to calcareous teeth of the buccal region in cyclostomes and higher fishes.

So from some primitively related genera of metanemerteans, that had all early developed proboscidial stylet teeth, which later became buccal or pharyngeal teeth, we would trace two divergent lines of evolution. One of these, remaining soft-bodied in its epidermis, pursued one pathway of progress that led to the cyclostomes and later to primitive ancestors of the caecilian amphibians. The other, by secretion of horny and calcareous tubercles, led up to Thelodus, Cladoselache and still higher types that made up the main line of piscine development. But that the calcified tubercles, the stylet teeth, and the buccal teeth represent practically identical formations has been already emphasized by Bridge $(36: 247-48)$ and others.

\section{Sense-organs of the Head.}

These are (a) the frontal sense-organ of nemerteans which we have correlated $(I: 428)$ with the olfactory sense organ of fishes; (b) the eyes or optic sense-organs; and (c) the auditory sense-organs.

(a) The frontal or olfactory sense-organ. In metanemerteans, at the front end of the head, a small orifice opens into a saccular depression that is lined with ciliated cells, and is surrounded internally by an investment of muscular tissue. The organ is innervated by a branch from the anterior part of the dorsal ganglion. Above this frontal organ lie clusters of glandular cells-the so-called "headglands"- -and often the orifices of these open into the organ. Bürger has named this the taste organ. - In Cerebratulus three such organs-one median and two lateral paired ones-occur and show similar structure. From their position, structure, early embryonic origin $(6: 373)$, nerve supply, and relation to the head-glands above, the writer views such as an unpaired or paired (Cerebratulus) olfactory organ. In Amphioxus the olfactory organ is likewise a single saccular depression lined with ciliated cells, 
and is further innervated by "an antero-dorsal hollow outgrowth from the brain." In Cyclostomes the olfactory organ is similarly unpaired in the embryonic state and remains so in the hag-fishes; but in the lampreys as adult life is reached a vertical median septum divides the organ into halves, and these are supplied by two olfactory nerves from the brain. In gnathostome fishes two distinct and paired olfactory organs, that are innervated by two olfactory nerves, are present. In many teleosts an evident homologue to the head glands of metanemerteans is seen in the glandular "nasal sacs," which similarly are backward and dorsal prolongations from each nasal organ.

(b) The eyes or optic organs. In metanemerteans these show great variation, alike as to number, paired or median position, complexity of structure, and function. Even in one genus, like Geonemertes, they may vary from the most common number four, to as many as thirty or forty (35: I IO). At times the anterior of the four usually present are paired with each other and are well developed, while the posterior pair may be smaller, more or less approximated, and even placed in submedian position with each other. This anticipates and resembles the parietal and pineal eyes of the cyclostomes and higher fishes. In structure they show all of the fundamental parts that characterize fishes and higher vertebrates. In position they lie above and in front of the brain.

(c) The auditory organs. In the great majority of metanemerteans paired structures open along the posterolateral part of the head and have been termed the cerebral organs. In I9I 4 the writer drew attention to their structural similarity to the embryonic ear of vertebrates $(I: 429)$. They attain their highest development in meta- and hetero-nemerteans, where they appear as swellings behind or beside the front part of the dorsal brainlobes. They open by small external pores along the sides of the head, and at the bottom of the head-grooves. In cyclostomes and elasmobranchs the orifice of the ear in the embryo is in line with the first inpouching of the branchial system, and so occupies the same position as in nemerteans, since the writer regards the head-grooves and the first 
branchial pouches as homologues. The external ear-orifices remain open in both of the above groups, and so this condition forms another point of contact with nemerteans. But the positions of the orifices become gradually shifted till ultimately they open on the latero-dorsal or dorsal surface.

(d) Epidermal hairs. The only other external character that deserves notice here is the hair. 'This seems to be one of the most primitive, as it is the most persistent epidermal sense modification of animals. For the "borsten," "geiselhaare," "haftpapillen," and "hacken" of the rhabdocoels (37:20 I 2-2030) are all varieties of tactile epidermal cells. Such persist among the nemerteans as sensory hairs, that Montgomery as well as other authors frequently refer to. In the metanemerteans he describes them on the posterior part of the body, on anterior and posterior parts alike, or in somewhat diffuse manner $(38: 1)$. Regarding fishes Bridge says $\left(36: 3^{8} 3\right)$ "the most remarkable and certainly the most characteristic of the sense-organs of Cyclostomes and Fishes are bud-like groups of epidermic cells in relation with the ends of sensory nerve fibres. Each consists of a central core of sensory cells, provided with terminal cuticular sensory hairs, and surrounded by a zone of supporting and mucus-secreting cells which leave the hairs exposed at the apex of the bud." He then describes the two varieties known as "end-buds" and "nerve-eminences.".

\section{The mouth.}

In all freshwater and land nemerteans the mouth is a small subterminal orifice that opens into a pharynx or buccal cavity of varying size. This is a common cavity that shows on its inner ventral aspect the small opening of the gullet, and behind this a more or less circular ridge that is the attaching edge of the proboscis to the proboscissheath. This ridge we will call, for a reason that will appear presently, the velum. It bounds the anterior part or orifice of the proboscis, and so demarcates also the front edge of the proboscis-sheath (Fig. 2m.p.) from the buccal cavity. Glandular cells are embedded in its surrounding tissue, and evidently pour their secretion into its cavity. 


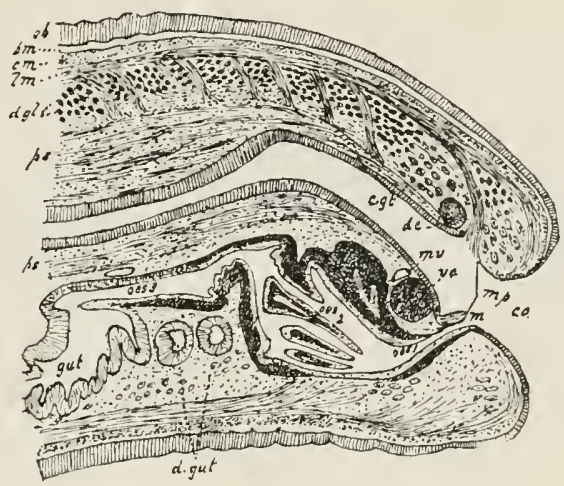

FIG. 2. Long. sect. head region of Geonemertes australis, $m$, mouth; co, common opening of mouth and proboscis tube; m.p. velum; d.c, v.c, dorsal and ventral brain masses; c.gl, cephalic gland; oes, $1,2,3$ anterior, mid, and posterior oesophageal areas, the dark area of the mid-oesophagus is highly glandular, and seems at least in part to be the primitive rudiment of the thyroid gland; d. gut, intestinal diverticulum or probable hepatic process; ep. epidermis; c.m, l.m, circular and longit. muscle masses; d.gl, dorsal glands; ps. muscular proboscis tissue. (Reduced from Dendy).

A like description would apply to the mouth and buccal region of Cyclostomata and other fishes. But the velum or membrane deserves more detailed consideration. This has been accepted above as the bounding edge of the united proboscis and proboscis sheath of higher nemerteans. Now if, as traced below, the proboscis becomes greatly shortened, and at least in its hinder part converted into the pituitary body or hypophysis of cvclostomes and other fishes, at the same time that the proboscis-sheath becomes the notochord, the velum would be a ridge or expanse in front of the point where the notochord ends and the upcurved pituitary body joins the infundibulum. Such is exactly the relation as indicated by the subjoined figure (Fig. 3) when supplemented by others, given by Dohrn (Camb. Zool. 391). Alike in Amphioxus, in Cyclostomes, and in higher fishes, it can be traced, at times prolonged into lobes or at times becoming richly vascular lateral thickenings, as in the Dipnoi. Morphologically, as well as phylogenetical$l y$, therefore, the velum is a very persistent and important demarcating ridge. 


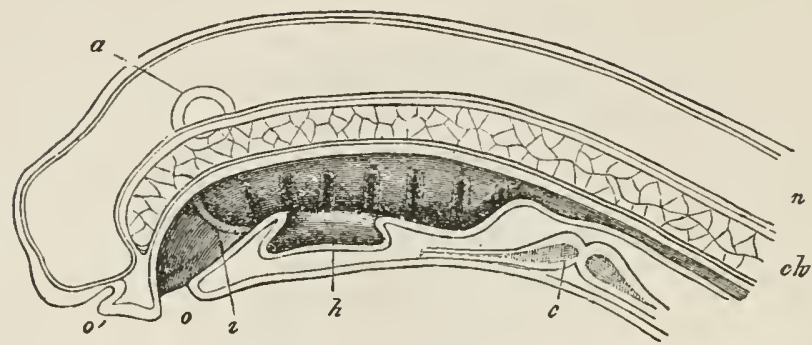

FIG. 3. Vertical section of young larva of Lamprey (Petromyzon) showing notochord, ch, mouth, 0 , velum, $v$, developing thyroid gland, $h$, that is the probable homologue of the glandular mid-oesophagus of Metanemerteans, and of the endostyle in primitive vertebrates.

Oesophagus. The small orifice of the gullet in higher nemerteans leads into the oseophagus, which in some land nemerteans shows division into three parts, an anterior narrow tube, an enlarged highly glandular mid-area, and a more constricted slightly glandular posterior part. But the mid-area is not merely glandular, some if not all of its cells are "very richly ciliated." It would thus exactly correspond in requirements to a primitive and diffuse condition of the endostyle in ascidians, to the hypopharyngeal groove of Amphioxus, and to the thyroid gland of fishes, as well as of higher vertebrates. In the description by von Graff $(34: 430)$ and Dendy $(35: 93)$ it is not determined whether the cells are in part glandular in part ciliate, or as possibly may be the case are both conjoined. Bürger's descriptions (6: 198-99) and figures indicate that there are distinct ciliate and glandular cells but either condition would furnish the basis for gradual differentiation and restriction of the cells to the ventral surface of the oesophagus, to in part a glandular in part a ciliate state, to the condensing of these into four longitudinal tracts, and thus to formation of the endostyle or hypopharyngeal groove (Fig. 4.gl) of the primitive chordate types Ascidia and Amphioxus.

Now while in the larva of Petromyzon it remains an open groove, it later becomes closed, "highly complicated, with paired anterior and posterior horns and a median spiral portion," eventually in the adult "the organ is partly 


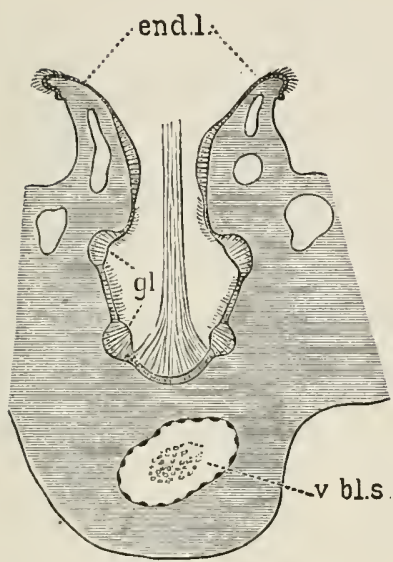

FIg. 4a.

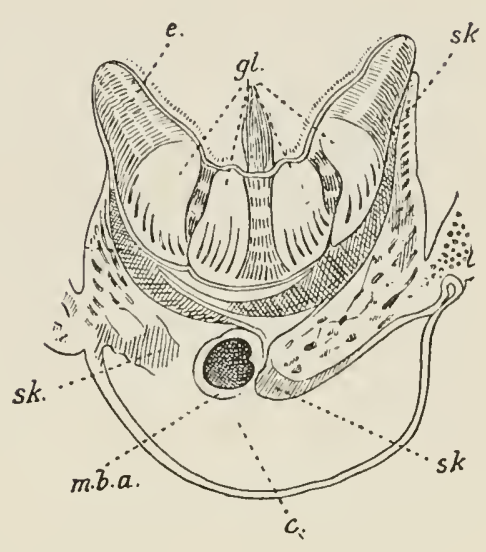

FIg. 4 b.

FIg. 4a. Transverse section of anterior ventral part of alimentary canal-or branchial sac-of Ascidia mentula, showing ciliated depression or endostyle (end . I) with four longitudinal patches of glandular mucus secreting cells $(\mathrm{gl})$. Below is a blood sinus (v. bl. s). (After Herdman).

FIg. 4b. Like section of Amphioxus showing endostyle (e) with four glandular tracts (gl) that secret mucus; m.b.a, blood vessel; sk, skeletal plates. (After Lankester).

absorbed and partly divided up into a series of glandular follicles, and eventually forms the thyroid body." As described by Newton Parker (32: 1 73) in Protopterus there is a close resemblance, between the thyroid in it, and the meso-oesophagus in Metanemerteans; and this gives added value to Kerr's contention that the Dipnoi are an ancient and likewise a primitive group, which retains many simple ancestral conditions. The descriptions and figures of Dendy suggest four paired glandular ciliated and columnarcelled lobes that occupy the mid-ventral head region in Geonemertes australis. A more detailed study of the mesooesophagus in freshwater and in land nemerteans is however highly desirable, as thus presenting the probable diffuse beginnings of the vertebrate thyroid organ.

VI. Respiratory system.

At this juncture it may be appropriate to study the primitive beginnings of the respiratory system. The writer 
has already drawn attention $(I: 445)$ to the probable origin of the first gill-cleft, spiracular cleft, or hyomandibular cleft, as it has been variously called. He showed that from the two ciliated depressions of some turbellarians, to the two ciliated furrows of nemerteans, and thence to the ciliated branchial cavities of a cyclostome, the series is a progressive one. But in nemerteans the ciliated furrows externally are continued into two depressions-one on either side of the head-that are placed behind the velum, and come into close contact with the oesophagus, while anteriorly they give rise to the sacs above treated of and which the writer regards as the rudiments of the chordate auditory organs.

Neglecting the latter meanwhile, the two former regions are in position alongside alike the anterior oesophageal wall and dilatations or even plexuses of blood-vessels formed at the anterior end of the three main blood-vessels. Here then are all the connections and structures for formation of the first pair of branchial orifices and pouches in cyclostomes. For by fusion of the adjacent tissues of the oesophageal wall, of blood vessels, and of the furrows, currents of water could be established through the mouth, gullet, preoesophagus, and furrows to the exterior. In serial succession a formation of additional canals and internal dilatations could arise, seeing that abundant vascular loops occur in some nemerteans, close behind the anterior system already described. Such a development is foreshadowed in Stichostemma eilhardi $(38: \mathrm{I})$, that is referred to later. A series of respiratory orifices then, along either side of the preoesophagus and mesooesophagus, and in communication with such a rich set of vascular loops as is shown by the above-named animal, would form a basis for origin of the respiratory system in fishes.

Two distinct types also seem to have originated. In one of these fifteen to possibly twenty pairs of external and internal orifices were formed, with pouch-like respiratory enlargements between, that were embedded in the mesoblastic substance of the perioesophageal region. This type must have characterized the primitive ancestors of the Cyclostomata, for in species of Bdellostoma fourteen to 
ten, to seven, and even to six pairs are now traced, evidently in a steadily condensing and reducing series. In the second type a series of seven (possibly more), to six, to four cleftfissures seem to have originated in the perioesophageal region, from the oesophagus outward. This became the forerunner of the plan shown in the gnathostome series of fishes with their gill arches and gill filaments.

The gut or post-oesophageal tract may either be a simple straight tube, or frequently in metanemerteans it may be expanded into irregular swellings or even into paired lobes $(35: 93)$. In this manner the digestive and especially the absorptive surface is increased. The same result is secured in many fishes by formation of the spiral valve.

\section{The liver.}

The progressive continuity in evolution of the liver from nemerteans to fishes is we believe admirably illustrated. In simpler metanemerteans there seems to be no special appendage to the gut. But in Geonemertes Dendy says: "just where it joins the oesophagus the gut gives off as usual, a characteristic diverticulum which runs forward beneath the last portion of the oesophagus and ends blindly." Sections of this structure are seen in figure 2. But while Dendy states as above, his figure might suggest that it originated from and emptied into any part of the "gut" region. A more minute study of it is desirable. In Amphioxus a like position, relation and development occur. "In Petromyzon, Lepidostens, and a few teleosts the liver remains unilobed" also. But even in myxinoids and in higher fishes it becomes a bilobed or trilobed structure that of ten attains large size, and may develop an accessory gallbladder.

We are still ignorant of the nature of the secretion in nemerteans and Amphioxus, but the early origin of this gland as a primitively simple anterior outgrowth of the foregut from nemerteans to teleosts is fairly diagnostic.

The termination of the alimentary canal in the anus agrees in all of the above. 
Our knowledge of the embryology of freshwater and land nemerteans is still too imperfect to permit definite statements as to the formation of mesenteric folds for hanging of the alimentary canal in place, after the manner seen in vertebrates. But the formation of paired "imaginal discs;" and the ingrowth in bilateral fashion of the posterior pair of these in the embryo, recalls the closely similar mode of formation of the mesoblastic mesenteries in vertebrates. Bürger's statement however, as quoted below (p. 93), seems to indicate an exact homology.

\section{The proboscis and proboscis sheath.}

From their mode of origin, and their close relation to the anterior part of the alimentary canal, the proboscis and the proboscis-sheath or rhynchocoel can next be studied. This double structure is undoubtedly anticipated and led up to in the corresponding though simpler structure of the rhabdocoel turbellarians. The great importance of the sheath phylogentically consists in its being evidently the evolving predecessor of the notochord, while the proboscis evidently becomes modified into the pituitary body, as well as various buccal structures; a very brilliant generalization this, for which we are mainly indebted to Hubrecht.

Zoologists are agreed that the proboscis represents an ectodermal invagination or introvert near the anterior head region. But two different modes of origin might be claimed for it. Either it is an in-pitting from the buccal region within and behind the mouth-and this conforms to its relation in turbellarians, as well as in freshwater, in land, and in not a few marine nemerteans-; or it is an invagination of the anterior cephalic region outside of and above the mouth, as in many marine nemerteans. The writer has advocated the former as the true interpretation, for all transition stages from an intraoral to an extraoral position can be traced in living marine types, which for many reasons the writer regards as derivative from freshwater forms. Figure 2 then would represent the primitive condition.

But with progressive elaboration, elongation, and sensitivity to environal agents, the inverted structure gradually evolved an inner highly glandular half that could 
be rapidly protruded, within a more external, eversible and muscular half (Fig. 5), that functions as a sensitive, tactile and offensive organ. The specially thick and mus-

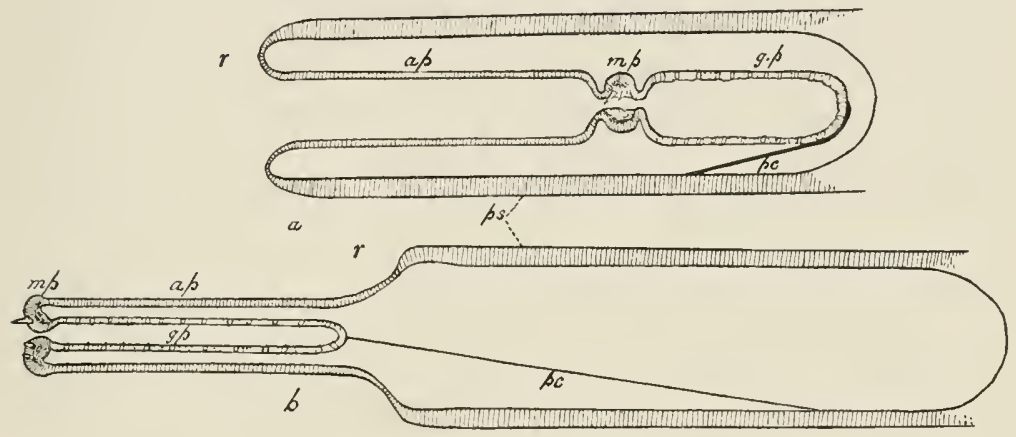

FIG. 5. Diagram of metanemertean proboscis as retracted within (a) or extruded from (b) the proboscis sheath, p.s. The rim of attachment, $r$, of the proboscis to its sheath seems to correspond with the velum of vertebrates. ap. anterior protrusible and muscular part of proboscis; m.p, median muscular stylet area; $s$, stylet; g.p, inner glandular part; p.c, proboscis muscle.

cular area, that unites the inner and outer parts of the tube in metanemerteans, develops the characteristic stylets already treated of, and that can be steadily renewed as old ones are worn away. The surface of the external coat is often abundantly beset with fine glandular papillae. The entire organ is innervated by an abundant set of circularly disposed nerve-fibres, that have been minutely described and figured by von Graff (3+:430) and his successors.

In contrast to the eversible, muscular, and often papillose outer tube, the inner is thin-walled, and its surfacelayer consists of richly glandular cells that stain deeply. So it may shortly be said that the proboscis in metanemerteans consists of three portions, (I) an outer eversible tube portion, that in Geonemertes and others has highly muscular walls and papillose surface; (2) a median somewhat swollen and highly fibro-muscular zone in which develop and are embedded the semicalcareous semicorneous stylets; (3) the internal thin-walled tube that in the retracted proboscis is in line with the outer, and is con- 
nected with it by the stylet zone. Its inner surface epithelium is highly glandular.

Hubrecht considered that in transition from nemerteans to fishes, the entire proboscis became greatly shortened and condensed, and during embryological development separated from the front rim of the enclosing sheath or rhynchocoel, then became bent upward posteriorly, and uniting with a downgrowth of the brain-the infundibulum-became the important glandular tube that is known as the hypophysis cerebri or pituitary body $(4 I: 350-355)$. But the writer has suggested what seems a more complete explanation of the evolutionary changes involved $(I: 420)$. For since the proboscis in freshwater and land nemerteans is an ingrowth of the posterior buccal cavity, the anterior muscular eversible part, as it underwent steady condensation and shortening in the evolution of primitive fishes, might gradually fuse with and spread over the buccal cavity, or stomodoeum. Thus would arise the muscular buccal area of vertebrates, and specially the powerful suctorial disc that is typical of cyclostomes, sturgeons, larval gar-pike, of some teleosts, also of larval urodele amphibians and even of mammals. A tendency to the formation of stylets, and ultimately from them of buccal teeth, might spread over the entire area. This would account for their abundance in Petromyzon, as well as in some of the true fishes.

The highly muscular mid-proboscis may, on its ventrolateral sides have condensed and grown forward in simple or in bilobed form as the tongue of cyclostomes, elasmobranchs, dipnoans and crossopterygian fishes; while the stylets may have been replaced by the strong buccal teeth of Petromyzon or the ventral plates of teeth in higher fishes. Such a view is decidedly favored also by Dean's statement $(42: 57)$ that in the cyclostome Bdellostoma the tongue, which is bilobed and "studded with rows of rasplike teeth, may be greatly everted, and then drawn in by stout tongue muscles." The nerve threads that passed to and innervated this anterior portion seem gradually to have separated from their posterior roots, and 
these roots then in growing downward would become the vertebrate infundibulum.

In vertebrate morphology the peculiar character and relation of the downgrowth from the thalamencephalon, known as the infundibulum, has often excited discussion. Its history seems to be satisfactorily explained in phylogenetic continuity from the nemerteans. For Hubrecht and others have shown that from the cerebral ganglia two strong nerves run down to, enter, and innervate the proboscis. In the anterior muscular portion of it, the two nerves break up into a complex circular and longitudinal system, that give extreme sensitivity to the entire proboscis, specially to the anterior portion. Now, as this anterior part separated, as suggested above, from the innermost or glandular part, the main nerve threads would become more or less weakened, sundered, and reduced in function, though they evidently remained in contact with the glandular portion. So we would suggest that the infundibulum represents the largely abortive remnant pair of proboscis nerves that still remain in contact with and innervate the pituitary body. Balfour says regarding it: "in Mammalia the posterior part of the primitive infundibulum becomes the corpus albicans, which is double in man and the higher apes."

Though it must at once be acknowledged that no living animal presents transition conditions that fit in with all the requirements of the case, the explanations above given are so well correlated with the morphological requirements that such suggestions are at least permissible, specially seeing that no equally helpful ones have been forthcoming.

The proboscis-sheath or rhynchocoel, as studied by different observers, is a strong muscular tube, which in simpler groups of nemerteans extends only one-third backward from the head. But in most of the nemerteans it stretches from behind the dorsal ganglion to the anal region of the tail. Anteriorly it unites with the rim of the proboscis by a circular zone named the rhynchodoeum by Bürger. It is at this zone that sudden rupture of the sheath from the proboscis may occur, when an animal is strongly irritated. A gradual but permanent separation of 
the two evidently took place embryologically, when the sheath became-as suggested by Hubrecht and fully accepted by the author-by degrees modified into the notochord. We have already pointed out that this circular zone corresponds to the velar rim in vertebrates.

Structurally the proboscis-sheath consists of an external circular and an internal longitudinal zone of thick muscular fibres, which posteriorly tend to intermix. Filling the cavity of it and surrounding the proboscis, is a corpusculated fluid, except in the marine metanemertean genus Cerebratulus, where the corpuscles or loose cells seem by multiplication largely to fill up the posterior part of the cavity with a loose nucleated cellular mass. So, as $\mathrm{Hu}$ brecht remarks, the cavity may become "sometimes even entirely obliterated." He adds (4I:36I-63) : "we might picture to ourselves the eventual conversion of a hollow proboscidian sheath into a solid notochord, the more so as functionally the proboscidian sheath in nemerteans may already be looked upon as an axis, around which the other organs symmetrically arrange themselves as they do around the notochord in vertebrates. It must at the same time be borne in mind that the muscular coating in this posterior portion is found to be considerably reduced and replaced by a more or less homogenous and comparatively thin sheath." But the writer would emphasize that in the last detail the resemblance becomes the more marked to the vertebrate notochord.

Now, if in a remote geologic past, namely in Ordovician or in lower Silurian time, organisms like metanemerteans existed rather abundantly, a stage may well have been reached when the proboscis-sheath became, from environal action and proenvironal response, more and more a mechanical and strengthening cylinder, rather than as at first a protective sheath for the highly sensitive proboscis. The latter then might have its structure and function more and more condensed into the head region, while the muscular substance of the sheath might by degrees become changed into "a more or less homogenous sheath of fibrous tissue." As condensation and morphological conversion of the proboscis took place, separation of the proboscis sheath 
anteriorly from it along the rim region (rhynchodoeum) would be effected. Thus the way would be clear for the ventral brain ganglia, and for the ventral commissure that united these to rise closely upward and in front of the blunt anterior end of the evolving notochord, till placing of the ventral ganglia, somewhat behind, but close against the dorsal ganglia would be effected.

The writer then, in view of this and the many other details of structural similarity that he now shows to exist, would emphatically advance on Hubrecht's decidedly cautious position when he says: "I need hardly insist upon the fact that I do not advocate any direct relation between existing nemerteans and existing vertebrates; my argument goes no further than the attempt to show that the general plan of structure of a nemertean is more in accordance with that of a vertebrate animal than is, for example, that of the Archiannelida." So many exact structures correspond in both groups, or are carried forward from a more primitive nemertean to a more evolved chordate state, that the writer would claim a continuous evolutionary sequence, even though some desiderated and highly important intermediate stages are still wanting.

IX. The Nervous System.

This eminently confirms the above conclusions. The writer has already dealt at considerable length with it ( $I$ :433-44 I ), but some details deserve emphasis here.

The brain in most metanemerteans consists of two relatively large dorsal or anterior brain-lobes, that are united by a dorsal commissure. The latter, from its apparent homology with vertebrate details, we can call the anterior commissure. In nemerteans and in fishes the writer has pointed out that a median nerve starts from the middle of the anterior commissure. In nemerteans and in the simpler turbellarians, zoologists have for years called this the dorsal nerve. But in fishes and higher vertebrates it has been called from its discoverer Reissner's fibre. It is again referred to below.

While the anterior or dorsal brain-lobes remain simple in most of the metanemerteans, in the genus Eupolia at 
least these are deeply divided crosswise into an upper anterior and a lower posterior pair. Such a condition may well have been common to many extinct nemerteans, and it suggests the probable primitive origin of the ancestral fore and mid brain of vertebrates. The ventral brain-lobes that, on separation of the sheath-notochord from the proboscispituitary body, seem to have risen upward so as to be behind the dorsal masses, could then become the hind brain, while the strong commissure joining them suggests origin of the pons varolii of the vertebrate brain.

The above then suggests that the brain masses in higher nemerteans consist of an anterior and superior pair of lobes, and of a posterior and inferior pair of lobes, all united by commissures. Further, the superior pair may-as in Eupolia-undergo subdivision into what would then become an anterior and a median pair. Now in relation to the evolving vertebrate brain Graham Kerr (43) has made some highly important observations. For on the basis of his study of the dipnoan brain he concludes that the vertebrate brain primitively consists of two brain masses, an anterior and a posterior. And in relation to the paired lobes of nemerteans his study of the three genera of living Dipnoi causes him to conclude "that the hemisphere region is primitively paired," and so is "against the more generally accepted view that the hemispheres are to be looked on as the terminal region of the brain, as a 'telencephalon' in the sense of His." The above views he has further elaborated in his recent volume on "Vertebrata" (4t:85).

The brain substance of metanemerteans and of fishes consists of zones of gray and of white matter, the gray substance being specially rich in large ganglionic cells.

The primitive beginnings of the spinal cord in fishes have been variously outlined and interpreted by different workers. Hubrecht first clearly set forth a possible explanation, and connection evolutionarily, with nemerteans. In the latter two main cords run continuously backward from the ventral brain-lobes as the lateral nerves. These may vary in position from lateral to slightly latero-ventral or latero-dorsal. In the marine genus Langia however they are markedly dorso-lateral. But in metanemerteans toward 
the posterior end of the body, the two nerves gradually rise upward and form a posterior commissure above the intestine. Now were such a close connection to be gradually carried forward toward the brain region, the result would be that an apposition and ultimate more or less complete dorsal fusion would be effected between the two lateral nerves.

But in rhabdocoel turbellarians and in metanemerteans two dorsal nerve threads gradually come together and fuse lengthwise as the median dorsal nerve of the latter group. This nerve, according to most authors, springs from the dorsal brain commissure, and there arises by two distinct roots. Now in the vertebrate brain a fine nerve arises in median line from the anterior commissure but by two roots. This, first observed about sixty years ago by Reissner, has been traced to occur in the entire vertebrate series by a number of workers. Its main investigator Sargent (45: I29) states that it tends to suffer degeneration only in animals like the blind cave fishes, where the eyes have more or less become functionless or absorbed. In its backward passage from the brain this nerve fibre becomes embedded between the substance of the lateral thickenings of the spinal cord, and tapers out near the anus.*

Further, in rhabdocoels and in worms as a great group, two ventral nerve threads start from the ventral ganglia of the head and run backward, either widely apart, or somewhat near each other, or closely apposed. These, in the more evolved "worms" and in "arthropods," become the dominant nerve tracts, while the lateral and the dorsal pairs of nerves become feeble or are absorbed. In metanemerteans these ventral threads are moderately represented as median nerves of the lower surface. So in these latter account has to be taken of three pairs of longitudinal nerves, as a whole: (I) the ventral median nerves that are only moderately developed but have become the main ones in worms and in arthropods; (2) the lateral or latero-dorsal nerves that are the specially strong ones in metanemer-

*The writer is unable to accept the views of Nicholls on this subject $(46: 1)$. His conclusion that the median dorsal thread is a muscle, is entirely uncorrelated with any like structure in other animals. His paper throughout is characterized by a malignant and unscientific spirit that is wholly regrettable. 
teans, and that run backward on each side of the body to form a union above the intestine; (3) the two dorsal nerve threads which-more or less separate and important in rhabdocoels-have fused lengthwise except at their roots and are only moderately strong.

In transition to the vertebrates the following seems to have taken place: (a) the strong lateral nerves, that in metanemerteans have already formed a commissure above the intestine, have gradually risen upward dorsally, from behind forward, till apposition and lateral union of the two nerves have been effected forward to their root origin from the ganglia; (b) during this process the dorsal paired nerve has by degrees become surrounded by the uprising lateral nerves, and its important optico-motor functions have by degrees been usurped by the laterals, so that it suffers marked reduction and degeneration; (c) the ventral pair of nerves or "mundschlund" system of Bürger "from its origin along the lower posterior edges of the ventral brain-masses, and its abundant distribution round the mouth, the pharynx, the alimentary canal, and the skin, would correspond with the ventral nerve threads of Turbellarians. This seems gradually to have evolved into what might be termed the ventro-sympathetic in protochordates, and later into the sympathetic system of cyclostomes and higher vertebrates." ( $I: 440)$.

As indicative of such gradual evolutionary changes it is noteworthy that in Amphioxus (Branchiostoma) and in true fishes, the first rudiment embryologically. of the spinal cord appears as an epiblastic groove, that spreads forward from the anal region, and on either side of which arises a plate or thickening of tissue lengthwise that we would interpret as the lateral nerves of metanemerteans. By gradual uprising, thickening, and fusing of the upper edges of these plates the neural canal is formed. As the two lateral plates or nerves continue to thicken they so press on the canal as to convert this into a median slit. But in Amphioxus the complete dorsal fusion of the plates or nerves anteriorly is not effected, so that a dorsal "longitudinal cleft" is left. It should further be noted that in metanemerteans a copious anastomosis of nerve-fibres takes 
place between the lateral nerves, and so such fibres establish a commencing condensation and correlation-relation between these lateral nerves, that must aid in their subsequent approximation and union. This correlation and anastomosis is further advanced in chordate animals.

\section{$\mathrm{X}$. Structure of the sense-organs.}

The external aspect and relation of the sense-organs have already been dealt with. As to their minute structure and mode of origin, highly interesting and connecting stages of evolving complexity can be traced, some points of which have been dealt with above. (a) The nasal organ as accepted by the writer for nemerteans, is supplied abundantly by nerves which pass off from the anterior region of the dorsal brain-lobes. "As described and figured by Bürger the epithelial cells of each nasal depression consist of ciliated sensory or olfactory cells, that alternate with interstitial or supporting cells, an arrangement exactly similar to that seen in the vertebrate olfactory organ."

(b) The eyes in higher nemerteans show a minute structure and sensory complexity that closely allies them in ascending series with the eyes of vertebrates. Nerves pass to them from a lateral part of the dorsal brain-lobes, that seem exactly to correspond to the optic brain centres in the mid-brain of fishes. Each eye shows a cup-shaped depression composed of columnar retinal cells, a pigment zone, a finely granular cup-substance, an optic capsule, and delicate ganglion cells that pass to and end below the columnar cells. In the young of Petromyzon and in Myxine the eyes are now reduced to two functional on either side of the head, and in the former to two vestigial eyes that are in sub-median or median dorsal position on the head, these being the pineal and parapineal or parietal eyes of authors. The functional ones then are scarcely more complex than in higher nemerteans, being still devoid of lens, cornea, and sclerotic constituents, as well as eye-muscles. But in the adult Petromyzon these have all been formed, and are continued in higher fishes, where such additional complexities as a choroid gland, a cartilaginous or osseous sclerotic layer, a retinal tapetum lucidum, etc., arise 
As already noted, two of the typical four eyes present in most species of Geonemertes and other related genera, seem to have an exceptionally suggestive history, as transition is made from these to cyclostomes and higher vertebrates, not least also, if accepted interpretations are correct, to some of the most ancient fishes. For from detailed study of the past quarter century it is now generally accepted that the parietal eyes, or pineal and parapineal organs, seen in lampreys and other vertebrates, represent two more or less degenerate eyes. Studnicka's detailed work on the European freshwater lamprey (47) and that of Dendy on the New Zealand freshwater lamprey (48: I) as well as studies by the latter and by Cameron on higher groups all fortify such a conclusion. In position these arise behind the olfactory swelling, and in the lamprey a larger upper and a smaller lower one are in line with each other. In the New Zealand lamprey-Geotria -Dendy says "the larger and better developed of the two does not lie above but behind the smaller and less welldeveloped organ, so that both are distinctly visible when the brain is viewed from above." He considers however that they probably were paired organs primitively.

As in the eyes of the higher nemerteans and of larval lampreys, the pineal organ is circular and shows a retina, a pigment layer, a pellucida, a capsule, and a ganglionic cell-system, the last being prolonged from near the posterior commissure. Dendy considered that the pineal organ at least can still function as a light-perceptor. It is of interest also to observe that in some large though primitive and long extinct fishes to be described later, a distinct opening or openings occur in the cephalic buckler, that is probably indicative of the presence in these of parietal eyes.

(c) The auditory organs. These have already been generally referred to. Their internal structure has been described by the writer $(I: 429-43 I)$ as follows:

"The 'cerebral organs' of nemerteans have been much discussed, though unanimity of opinion as to their function has not yet been reached. These however seem, like most other parts of nemerteans, to be the simple rudiments of more evolved structures in vertebrates. They are 
paired organs developed along the postero-lateral sides of the head. Each in its simplest state is 'a mere groove in the epidermis not extending deeper than the basement membrane; it is lined by ciliated cells, and at the bottom are large gland cells; while the organ is supplied by nerves from the dorsal ganglion of the brain. In Carinella rubicund $a$ and others the groove becomes an oblique canal, the blind end of which is surrounded by a mass of ganglion cells, lying outside the cutis. In the higher forms the canal penetrates deeper into the body as far as the brain. The gland cells and the associated nerve tissue increase in amount, and the canal becomes differentiated into two regions-an extra-ganglionic 'lateral canal' and an intraganglionic 'cerebral canal' (c) which frequently terminates in an enlarged sac. In Drepanophorus the cerebral canal is quite exceptional, in that it bifurcates, one branch terminating in a sac with sensory epithelium, the other being glandular; this in $D$. crassus extends backwards beyond the brain as a free tube. In several genera of this order the cerebral organ lies in front of the brain (Tetrastemma, sp. of Eunemertes, and of Amphiporus) ; in others it lies at the side, and in still others behind the brainin which case it attains a great size. In all cases the organ is separate from the dorsal brain mass, from which it receives nerves.' (Benham in Lank. Zool. IV, p. I 85 ).

"A comparison with the embryology and structure of the vertebrate ear leads us to believe that here one has to deal with evolving stages leading toward that organ. The accompanying diagram, copied from Bürger's beautiful work, is suggestive, and can be compared with a figure of the embryonic ear in a mammal.

"It is now well recognized that the ear is innervated by two distinct branches of the auditory nerve, and that it performs a double function. The cochlear branch, distributed to the cochlea and ampullae of the ear, enables the latter to perceive sounds; the vestibular branch that passes to the semicircular canals has for function the maintaining of equilibrium, or, as we would suggest is geoperceptive or geotactic. 


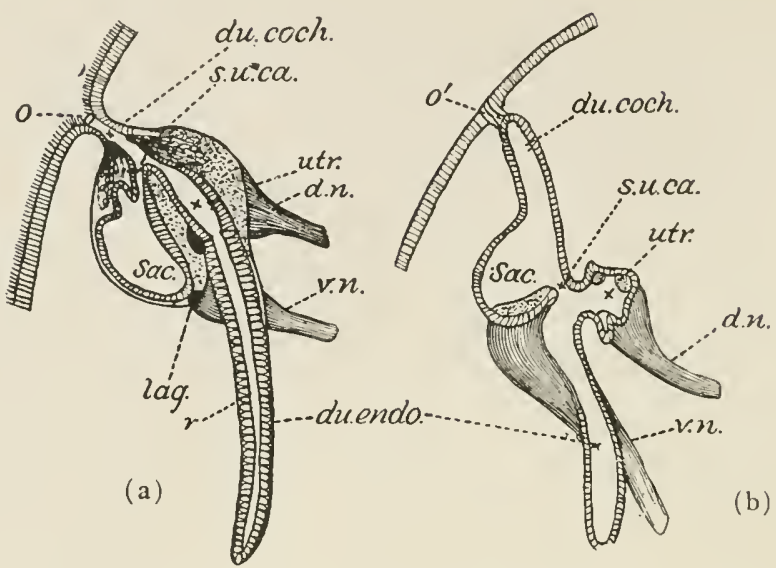

Fig. 6.- $a$ (to left) cerebral organ of Drepanophorus compared as an auditory organ with $b$ (to right), the young auditory organ of mammal, $o$, $o$ open or closed external orifice; $d u$. coch. ductus cochlearis; s. $u$. ca. sacculoutricular canal; utr. utriculus; sac. sacculus; $d . n ., v . n$. dorsal and ventral auditory nerves; $d u$. endo. ductus endolymphaticus.

"In Cerebratulus, as described and figured by Bürger, the external orifice, the ciliated canal, the two diverticula, and the distinct nerve branches seem well to correspond to the ear orifice, the ciliated lymph duct, the sacculus and utriculus, and the cochleo-vestibular nerves of the ear. That of Drepanophorus is even more exact. Two to three auditory nerves here are inserted between the two organs, the sacculus and the utriculus, as in vertebrates (Fig. 6a), the maculae extend along their base, while the elongated process seems from position, relation, and shape to represent the ductus endolymphaticus.

"If the comparison made above be correct it follows that the ductus cochlearis of vertebrates and not the ductus endolymphaticus, represents the primitive invagination tube of the auditory organ. Further, the elongated process shown for Drepanophorus in Fig. 6a suggests exact homology with the ductus endolymphaticus of vertebrates; while Bürger's statement, that it passes backward and becomes embedded in the cellular tissue of the body, recalls the often extensive ramifications of it in many freshwater 
teleosts. The opening of its upper end on the dorsal surface of the head in elasmobranchs would then represent a special new formation. The histological description of the organ given by Devoletzky suggests that ciliated sensory epithelium and supporting cells are here often surrounded by a mass of nerves as in the vertebrate ear; while the secretion of mucus from surrounding gland cells and the presence of ten of refractive 'körnchen'-that are possible rudiments of otoliths-is most instructive."

"A minute comparative study of living nemerteans may yet reveal more exact relationship, while the group seems to present us with suggestive stages from a comparatively simple type like Carinella up to a high degree of organization. It will be noted, however, that the auditory function seems largely to predominate over the equilibrating one, since no distinct semicircular canals are traceable. But when we remember that only one exists in Myxine, and that two are alone formed in Petromyzon, we need not wonder if the equilibrating function here is diffused along the sides or bases of the sac attachments."

\section{The blood-vascular system.}

Some authors have held that the primitive vascular system in vertebrates consisted primarily of a dorsal and a ventral vessel. Thus Bridge (36:3 I 4) says: "There is little doubt that, primarily, the vascular system of vertebrate animals consisted of a dorsal artery (dorsal aorta), running along the median dorsal line of the alimentary canal, and a ventral or subintestinal vein similarly related to the ventral surface of the digestive tube. The two vessels were connected by a series of pairs of lateral branches, which had their origins from the dorsal vessel, and, by their subdivision, formed a capillary network in the walls of the alimentary canal. From these networks paired veins issued and opened into the subintestinal vein." We can now compare the above with the system in meta- and hetero-nemerteans. In these the main vascular system consists of a longitudinal dorsal vessel that runs in line between the proboscis sheath and the alimentary canal, also of two lateral paired trunks 
that nearly always keep a course in close proximity to the lateral nerves, and so are widely apart from each other.

The position and course of the dorsal vessel exactly agree with what we find in the dorsal aorta of vertebrates. In both also numerous lateral metameric vessels are given off to the body tissues, from near the head on to the tail region. The lateral vessels are of more doubtful value, but seem to have a direct homology with one of two vertebrate systems, namely either the lateral veins or the posterior cardinals. But since they are in line with two cephalic veins, and fall into a common "venous sinus" cavity with these, they probably together behave as anterior and posterior cardinals. Now if the three main nerves-the dorsal and the two laterals-stand in intimate relation to these vessels for metabolic purposes, we might expect that when the lateral nerves gradually rose upward to unite dorsally, these cardinals would follow a similar course as transition took place from nemerteans to primitive fishes. Their position in vertebrates suggests that this is what happened, while a transition condition of blood vessels and nerves is seen in Langia, one of the marine heteronemerteans. Such a migration dorsad of the lateral veins, from an originally lateral position, alongside the lateral nerves, is strong proof that the two plates or lateral thickenings of the spinal cord, represent the dorsal uprising and fusion of two originally lateral nerves.

Again in several metanemerteans, and for Amphiporus pulcher in particular $(6: 243)$ an anterior pair of vessels forms abundant anastomosing ramifications behind the brain and cerebral organs, also in near position to where an anterior as well as succeeding pairs of gill-clefts might be formed in later evolution, for aeration of the blood. These make up the parastomodeal network and the vessels constituting it gradually reunite into what seems to be the homologue of the vertebrate ventral aorta. This, as in vertebrates, joins what may well be called the sinus venosus.

As to the structure of the blood vessels Dendy has made some valuable observations on the Australian land nemertean already referred to. He shows microscopically that 
each vessel has an internal nucleated zone, which suggests a bounding epithelial layer, but of this he is doubtful. "Outside this nucleated layer there comes a thin layer of very delicate fibres, doubtless muscular, arranged in a circular direction around the vessel. Outside the muscular layer comes a single layer of large vesicular-looking irregularly ovoid cells, with small nuclei and slightly granular contents. The wall of the vessel then, in its narrow portions, is made up of three distinct layers." If the innermost layer should prove to be a continuous endothelium, the structural agreement with average vertebrate bloodvessels is perfect.

The writer has already $(I: 444)$ summed up the morpho-physiological conditions, as to the methods and direction of blood-circulation thus:

"The distribution of the blood-vascular system in the Nemertinea has been carefully studied during the past sixty years, though we still desiderate fuller physiological details. While the simplest system (e. g., Cephalothrix) shows only two longitudinal vessels in close proximity to the lateral nerves, in higher forms there are two lateral and a dorsal vessel, which with accessory vessels to the proboscis sheath, and transverse ones connecting all, show a marked anticipation of the vertebrate vascular system.

"In considering this system further, alike in its own distribution and in its aerating and excreting connections, we believe it is correct to consider that proximity to the nervous system for metabolic renewal of the nervous substance, and the periodic transfer of its blood to some aerating region or regions, are of prime importance. The former is effected by the frequent formation of expansions of the blood-vascular system into two longitudinal sinuses near the brain, and the passage of blood-vessels parallel to the nerve trunks. The latter is effected by those expansions that run parallel to the proboscis sheath, or near to the cephalic groove, whose vessels seem to correspond to the posterior cardinals of Cyclostomata and higher forms, since in all extensive connections are made by these vessels with the renal or excretory, and with the reproductive systems. In the forward course of these vessels to the 
heart, in the nemerteans as in the cyclostomes, the posterior cardinals run directly beneath the sheath or notochord.

"In many genera these two vessels unite anteriorly into a common cavity that seems to correspond to the venous sinus in lower vertebrates, while two anterior veins that often form a loop system in the front part of the head and that also unite with the sinus, would equally correspond to the anterior cardinals. A single vessel in the higher nemerteans, starting posteriorly from the anal commissure, corresponds in origin, course, and position to the dorsal aorta of most vertebrates, and it, along with the anterior cardinals, gives rise to the above mentioned vascular loopsystem round the front part of the head, that agrees with the circulus cephalicus of vertebrates.

"But further, in many Heteronemertinea, an oralcervical pair of vessels (Schlundgefäss-system of Bürger) starts from a median ventral vein given off from the cardiac ring or commissure, and which agrees in relation with the ventral aorta of vertebrate types. These oralcervical vessels branch repeatedly after the manner of afferent branchial arteries, are in direct connection with the - as we shall term them tentatively-anterior cardinals, and ramifying round the cardiac organ and cephalic groove agree well with the internal jugulars. The anterior ending of the median ventral vein, from which these spring, and the side vessels given off from it in front of the mouth (Bürger, p. 254), agree well with the hyoidean sinus and mandibular veins of lower vertebrates. The posterior. fusion again of the oral-cervical vessels with the sinus venosus-like enlargements of the lateral vessels constitutes another agreement.

"Vessels which Bürger has called the proboscis-tube vessels arise at their anterior end in vascular swellings, and posteriorly join the lateral (cardinal?) veins. These might therefore be the beginnings of the lateral veins of cyclostomes.

"As regards the transverse vessels the description that has been given by authors for the cyclostomes could accurately apply for the nemertean segmental somatic arteries that are regularly supplied to the myotomes from the dor- 
sal aorta. A corresponding series of somatic veins also empty into the cardinals (laterals).

"As to the methods and direction of blood circulation our knowledge is still vague. Bürger considers that the blood flows along the dorsal aorta which is the most powerful pulsating one. It then flows into the transverse vessels, thence into the lateral vessels, from which it is propelled forward. This, if fully proved to be correct, would agree fairly well with the cyclostome circulation. Interesting also is Böhmig's discovery in nemerteans of unicellular valvular swellings that occur at irregular intervals along the interior of the vessels, and there act as valves for the course of the blood flow.

"The nucleated and often pigmented blood corpuscles contain true haemoglobin in not a few cases, both of which are characters that lead up to the vertebrates."

XII. The excretory or nephridial system.

In passing from the blood-vascular to the excretory system, a highly important question presents itself. For amongst the simpler types of invertebrate, no recognisable blood-system is observable, though an excretory one exists from infusors upward. The first beginnings then of the former deserve to be traced. The writer, in regarding the rhabdocoel turbellarians as ancestral to nemerteans, suggested the following for them: "in view of the extreme and varied ramifications of the excretory system in 'rhabdocoels' as described and figured by von Graff, in view also of what is noted below regarding the joint bloodvascular and excretory systems of nemerteans, it seems not unfair to suggest that, in transition from the rhabdocoels to the nemerteans, a portion and specially certain of the main trunks of the excretory system in the former, may gradually have been set aside for the double function of tissue aeration and waste-removal, while the finer branches and capillaries may have remained as excretory vessels purely." He then went into details that favored such.

The writer was not then aware that Dendy and Spencer had both suggested, some years before, a possible transition relation between excretory tubes and circulatory 
vessels (35: IOI). It should also be observed that $\mathrm{Hu}$ brecht and Oudemans, almost simultaneously with each other, (49:5 I;50:suppl. I), showed that direct connection may exist between the two systems.

Shortly stated then, the evolutionary history of the excretory system, from nemerteans to higher fishes, might be tentatively sketched as follows: In metanemerteans and heteronemerteans a set of fine paired tubules became gradually separated off from the main longitudinal vessels that hitherto functioned in common with the tubules, as circulatory and excretory tubes. While the main vessels then became more and more modified into a blood-vascular system, formed migrant corpuscles, and inside these gradually elaborated hæmoglobin, the finer metamerically-arranged tubes became purely excretory structures. These at first seem to have been simple coiled tubules that closely surrounded the blood vessels, in a few anterior ones, but later in twenty to possibly forty or fifty longitudinal pairs. Each tubule-coil opened externally by a minute lateral pore, as still seen in species of the above groups; internally they became increasingly elongated, closely coiled on themselves, and by their blind ends maintained intimate contact with the blood-vessels, by slightly enlarged swellings provided with ciliate or "flame" cells. Such a system then, might be called an archinephros. In transition to cyclostomes and higher fishes the paired tubules of each side probably fused during embryonic life-stages to form a longitudinal "archinephric or segmental duct" that drew off the excretory products and that opened up by paired pores into a urinary sinus. As a result, closure of the two rows of external pores seems to have occurred, except for two posterior terminal ones that we would correlate with the pair of abdominal pores present in most fishes. In embryos of cyclostomes the two ducts, along with twenty, condensing to six, and even in adults to two, anterior pairs of coiled tubules can be traced, and these together form the pronephros or head kidney that is centred around the head-region. This pronephros is more or less retained in some teleosts also.

A set of later-formed and more posterior tubules, that similarly opened into the segmental ducts, and that may be 
from ten reducing to six pairs in number, formed the mesonephros, that strongly suggests the middle set of nemertean tubules. The two longitudinal ducts of these now end behind in a common urinary sinus which opens into the common cloacal area. But while the mesonephric tubules were at first strictly symmetrical, "in myxinoids only do they remain so. In other craniates, at all events throughout the greater length of the mesonephros, a varying number of new tubules arise from masses of cells nipped off from the first rudiment. All of the mesonephric tubules are therefore derived from the same original series of rudiments by a sort of budding. These secondary tubules acquire the typical structure and relations," but since the tubules then became crowded "their metameric order is lost." $(5 I: 87)$.

Until more minute comparative study has been made it would be impossible to say whether the most posterior tubules of some metanemerteans are the forerunners of the supposed metanephros of male elasmobranchs, and the metanephros of higher vertebrates. Such seems a likely explanation. The abdominal pores of most fishes would appear, as noted above, to be surviving remnants of one pair of tubule-pores seen in metanemerteans. Their paired persistence in the most ancient classes (Dipnoi, Crossopterygii, Holostei, Chondrostei, and most Elasmobranchii), their occasional persistence only in a few Teleostei (Mormyridae, Salmonidae), and their disappearance in most Teleostei and in some specialized Elasmobranchii, favor such a conclusion.

The higher nemerteans are dioecious as a rule, though a few species of Tetrastemma seem to be truly hermaphrodite. The former condition is practically constant for vertebrates, but a tendency to primitive hermaphroditism is shown by Myxine, where sperms may be produced in a younger, and eggs in an older stage of the animal.

\section{The reproductive organs.}

In Nemerteans the reproductive sacs are arranged in numerous metameric pairs along the sides of the animal, and alternate with the often paired lobes of the digestive tract. 
Each sac, as described and figured by Dendy, is a swollen expanse of mesoblastic tissue lined by epithelial cells, and that opens by a duct externally along the dorso-lateral aspect. In cyclostomes the paired relation has been lost, though it is retained in other fishes. But the sacs are also mesoblastic and similarly constructed. The discharge of the sperms or eggs, however, is effected in one of three different ways, that are doubtless graded derivations from the primitive nemertean type. The simplest is shown by cyclostome fishes, where, instead of the sacs opening individually by external pores as in nemerteans, the ducts of the former now open into the body-cavity, and from here the products are set free through two (Petromyzon) or one pore, that opens into a cloacal cavity, and thence to the exterior. In other fishes more complicated conditions have developed, that fall under one of two heads. Thus, in elasmobranchs, holocephalans, and possibly also in Dipnoi, a split-off branch of the segmental or archinephric duct becomes the Mullerian duct that opens into the body-cavity, receives the reproductive products, and conveys these through the cloaca to the exterior. The most complicated advance on nemerteans is seen in teleosteans, where the lining layer of tissue round the ovary or testes becomes elongated into a tube that conveys the products into the bodycavity, and from the latter they pass through genital pores to the exterior. Minor modifications on both types may again take place.

\section{Development of the egg.}

Two types of embryonic development are known in nemerteans, called respectively the direct and the indirect. The former is typical of freshwater or land forms amongst invertebrates, the latter develops amongst marine types. The former occurs amongst protonemerteans, some mesonemerteans, and in all metanemerteans hitherto studied. The latter is shown by some mesonemerteans and all heteronemerteans. Our knowledge regarding both modes is still very fragmentary, but as holding the key to the primitive development of vertebrates, should be most exact and copious. It may be hoped then that fullest details 
will soon be forthcoming. We will here trace mainly the "direct" mode, as being typical of all freshwater, land, and some marine forms.

The egg undergoes holoblastic and nearly equal segmentation inside the egg-case. The cells, pushing apart, leave a large blastocoel cavity and soon all of these cells form cilia. Next by invagination of half of these cells, a two-layered gastrula is formed. In Amphioxus the egg also shows holoblastic and nearly equal segmentation inside the egg-case, a similar blastocoel cavity is formed, and invagination occurs. Only the outer or epiblast cells here however become ciliate, though areas or patches of internal ciliate cells may later be formed by the embryo. Amongst cyclostome fishes Petromyzon shows holoblastic though decidedly unequal segmentation; and this leads up to the condition in Myxine which in this, as in so many other modified and derivative details, shows a meroblastic type. In the former a restricted kind of invagination takes place, giving rise to a small-celled epiblast and a larger-celled hypoblast, as is true also of Amphioxus. Cilia, however, are absent and only later form on restricted areas of epiblast or hypoblast. In higher fishes either holoblastic or meroblastic segmentation is seen, according to the group studied, and variations also are seen in formation of epiand hypo-blast.

The embryo, when freed from the egg-case in all of the above, soon assumes a somewhat elongate shape, and in succession the neural ridges that unite to form the neural canal, also the various anterior sense organs, appear in all in fundamentally similar and successive manner. Meanwhile a few cells, set free into the area between epiand hypo-blast, give rise to five patches or plates of cells in nemerteans and in Amphioxus; or two rather irregular plates in Petromyzon and other fishes, which apparently represent a condensation and fusion into pairs between four of the above five. These are the first mesoblastic rudiments of the coelomic plates. Alike in nemerteans and in Amphioxus one plate is anterior, two are antero-lateral and two are medio-posterior. In nemerteans by hollowing out and continued growth of the posterior pair, the alimen- 
tary canal becomes surrounded by and hung in mesoblastic folds, while the muscles and other mesoblastic tissues originate from the anterior three. So Bürger says: "in einem Embryo, der einige Tage alt ist, verwachsen endlich der nunmehr unpare ventrale und dorsale Mesodermsack, so dass nunmehr . . . zwei Zell-blätter existiren, von denen das eine den Darm umgiebt, das andere der Körperwand angepresst ist. Der Spalt zwischen ihnen ist grössentheils aus Mangel an Raum unterdrückt, kommt indess im hinteren Drittel des Embryos in Gestalt einer ziemlich geräumigen Höhle zur Ausbildung. Wir haben in den beiden Zellblättern Splanchnopleura und Somatopleura, in der Höhle ein Cöelom vor uns."

The five plates in Amphioxus behave much as in nemerteans, but their gradual growth and changes have been more carefully studied by several observers, to whose results the reader is referred.

Reviewing all of the above comparative details, the writer would strongly emphasize that the metanemerteans show so many structural, functional, and embryological characters which are either common from them to Amphioxus and to Petromyzon or even to the higher fishes, or they present so many characters which gradually lead up from them to the three groups named, that they stand out preeminently alongside all other invertebrates as the forerunners and phylogenetic ancestors of Amphioxus, the cyclostomes, and the true fishes.

But now it must be at once and freely acknowledged that remains of nemerteans and even of cyclostomes are unknown palaeontologically. The only doubtful representatives are the "conodonts" of Silurian and other rocks, which are discussed in another chapter (pp. I07-09). But this fact need in no way excite surprise, nor should it cause one to reject the view that both groups may have existed abundantly in Silurian, in Ordovician, or even-for nemerteans at least-in Cambrian times. For we should scarcely have known of the abundant existence of many elasmobranch genera from the Devonian period onward till now, had they not evolved the teeth, scales, and plates that occur in isolated fragments and abundant quantity in not a few 
rocks. But it can be asserted with entire confidence that the primitive Silurian fishes undoubtedly sprang from some ancestral invertebrate types of more archaic build. And the metanemerteans are the only organisms which, not merely in superficial aspect, but in minute structural detail, fulfill the requirements of the case. Vigorous and continued investigation therefore of all available material, at all stages in their life-history, will yield results of highest evolutionary importance. 


\section{CHAPTER IV.}

The Physical and Biological Environment of Fishes.

(a) During the Silurian and Devonian Epochs.

It may be accepted as an almost invariable principle that a study of the environal relations of any group of organisms will prove a highly helpful guide in determining the exact lines of evolutionary progression pursued by such organisms. We desire now to apply such a principle to fishes. If, as already emphasized in the previous chapter, they developed from freshwater Nemerteans, we might expect to find that so soon as any method of fossilization, or any organismal parts capable of being fossilized, had developed, traces might be got of the organisms of the period in question. If, moreover, several distinct groups of plants and of animals are found to be preserved side by side in the same strata, such would pretty surely indicate that these were more or less closely associated during life, if not in the same environal medium, at least in one removed at no great distance.

A study of the mass of stratified rocks that makes up the Laurentian and Huronian systems of America has failed to reveal recognizable organic remains, except possibly in the upper strata of the Huronian. We are compelled to accept it, however, that a varied invertebrate fauna had already appeared, though most or all of the existing organiisms must have been soft-bodied. But when the Cambrian rocks are reached an abundant marine invertebrate fauna is encountered, the literature on which is synopsized in the textbooks of Chamberlin-Salisbury (8:276-303), of Prestwich, of Geikie ( $7:$ II: 933-94 I ) and others. Thus graptolites, corals, trilobites, brachiopods, cephalopods and other molluscs are often abundant. These form a biological congeries that at once stamps the rocks in which they occur as of marine origin. So far as yet revealed no traces of lacustrine, fluviatile or land organisms have been noted But land undoubtedly existed; for cliffs of erosion, strata composed of fine shales or limestones, of coarser mudstone or sandstone, and even rough conglomerates, are all encountered often in continuous series. The writer has 
already advanced weighty evidence for the view that all the marine organisms were secondarily derived from freshwater types that had previously evolved and lived amid freshwaters. These, he claims, sent derivative offshoots into littoral marine regions, which there fed and multiplied abundantly. Partial proof of this is that nearly all of the main invertebrate groups retain their most primitive types in freshwater environment up to the present day, ( $I: 378-410)$.

But as we pass through the series of Silurian rocks a striking change can be traced. By the earlier students of these rocks their uniformly marine deposition was accepted without question. And so far as the Lower Silurian or the Llandovery and Wenlock beds of the Upper Silurian reveal their secrets, their fauna is probably wholly marine. The succeeding or Ludlow Rocks, however, indicate a marked change over wide areas, alike of Northern Europe and North America, and such can now be treated under the succeeding caption.

A. The physical and biological environment of Silurian Fishes.

We may begin with the now well known central English rocks that are classed collectively as the Ludlow group, since increasing study has been given to them and their enclosed organisms in that region from about i 860 onward. First described by Murchison in I826 (28: I 2), and more fully in "Siluria." (26: I37) two decades later, they were examined in detail by Symonds (52:193), then by Symonds and Lambert (53: 1 52) who described the exact succession and thickness of the beds, as determined during construction of the Malvern and Ledbury Tunnels. This succession beginning from below, deserves quotation-

"I. Aymestry rock with Pentamerus Knightii, etc. (Io ft.)

2. Upper Ludlow rock with Chonetes lata, etc. (I $40 \mathrm{ft}$.) The Ludlow bone-bed seems to be wanting here.

3. Downton bed, thin ( $9 \mathrm{ft}$.) with Lingula.

4-8. Red and mottled marls and thin sandstone (2 ro ft.) with Lingula and Pteraspis.

9. Gray shale and thin grit (8 ft.) with Cephalaspis and Pterygotus.

10-1r. Purple shales and thin sandstones ( $34 \mathrm{ft}$.).

12. Gray marl passing into red and grey marl and bluish gray rock (2o ft.), with Auchenaspis, Plectrodus, Cephalaspis, Onchus, Pterygotus ludensis, Lingula and a Lituite (?). 
These pass upwards conformably into a series of red marls, with yellowish gray and pink sandstone, containing Pteraspis and Cephalaspis, and undoubtedly forming the base of the Cornstone series of the Old Red Sandstone.

J. W. Salter in commenting on the fossils (p. 162) gives Pachytheca sphaerica as a probable plant found with the animals. Now the presence of marine fossils in the Aymestry and in Upper Ludlow groups, and even the continued occurrence of species of Lingula in at least some strata of the Downton and other higher beds, would incline anyone who had even a slight "marine" bias to view all of the beds and their organisms as marine. And in the subsequent papers of Roberts-Randall (54:229) and of Randall $(55: 494)$ this is more or less accepted though with a query. For in the latter paper Randall favored the idea of a gradual change from marine surroundings in the lower rocks to freshwater conditions above. The careful record from Linley Brook of rock successions, given in the earlier of these two papers is subjoined, as being of value from the palaeontological standpoint.

\section{VERTICAL SECTION OF THE BEDS EXPOSED AT LINLEY BROOK.}

(a) Northern drift with boulders

Feet. Inches.

(b) Upper Coal Measures

(c) Red Clays, unfossiliferous.............. 6 o

(d) Light colored grits with plant remains........... $20 \quad 0$

(e) Hard micaceous grits, charged with fish-remains. 7 o

UPPER BONE BED.

(f) Flagstones with current markings........... I 9

(g) Micaceous sandy grits with Lingulae......... o II

(h) Greenish irregularly laminated rock with con-

(i) Hard calcareous grit with broken Lingula......... I

(k) Laminated micaceous and sandy shale........ $20 \quad 0$

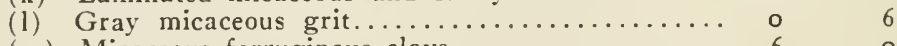

(m) Micaceous ferruginous clays............... 6 (n) Yellowish sandstones (Downton Series) with
Beyrichiae and Lingulae, also two or more ferruginous bands with large quantities of dermal studs of Thelodus, fragments of

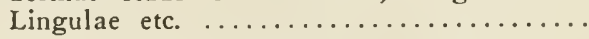

LOWER OR LUdLOW BONE BED.

(o) Hard calcareous shales with fish-remains, Lingu-

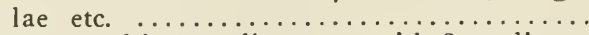

(p) Flaggy bed of impure limestone with Serpulites..

(q) Hard impure limestone (Aymestry Series)

\begin{tabular}{l}
0 \\
0 \\
9 \\
1 \\
0 \\
0 \\
0 \\
6 \\
0 \\
0 \\
0 \\
0 \\
\hline
\end{tabular}


Now in all of the above descriptions the Lingulae are said to be either broken or the shells are heaped together with the fish and eurypterid remains. Such may quite well, therefore, have been derived as washouts and redeposits from older rocks, or may have been washed up during high seas and mixed with the fishes in coastal lacustrine marshes. Further light is shed on this later.

If comparison be made of the organisms mentioned in the two tables of the papers referred to above it will be observed that, except for Lingula, the enclosed organisms of the lower or Aymestry series are marine and are quite different from those above, also that in the latter or Ludlow and Temeside beds there are grouped mainly eurypterid and fish remains, while Salter adds that "the plant which Dr. Hooker described (Q. J. Geol. Soc. 9 (I853) I 2) and for which he now proposes the characteristic name Pachytheca sphaerica is the common fossil in the sandstone, and accompanied as at Ludlow by plant remains and fragments of Pterygotus."

Before offering any interpretation we may take up the views of more recent observers. A. S. Woodward, $(56: 429)$ in a valuable review of the relation between the Lower Old Red and Upper Silurian as illustrated in the Ludlow region, strongly inclined to view the latter as passage beds from Old Red lacustrine conditions above to increasingly marine ones below. But he was at times puzzled by the biological relationships. Thus, he says (p. 435):

"The passage beds in question vary in different places in constitution and thickness, but they all show the mingling of truly marine fossils such as Lingula with the fishes and eurypterids, which must have been able to live either in the open sea or in lakes." Now in most of the above descriptions the Lingulae are said to be either broken or the shells lie on the surfaces of the shales, or as layers of triturated remains. Thus in the paper of Roberts and Randall (p. 23I) they specially note: (a) the abundance of Lingulae that occur in two relations; either as well-preserved shells upon the surfaces of the shales, or as layers of triturated shells: (b) the importance of the fish-fauna of the 
upper bone bed. W. S. Symonds again (57: I 86) writes: "Near Kington the bone-bed of the Upper Ludlow rock is there over-laid by brown-colored strata containing a typical Upper Ludlow shell, Chonetes lata. These beds are again overlaid by strata containing the remains of fishes, especially the Cyathaspis Banksii and portions of the crustacean Pterygotus and also two species of Eurypteri." So we would again reiterate that such remains of Lingula may quite well have been derived as washouts and redeposits from older rocks, or may have been washed up from a marine habitat during high seas and mixed with remains of the fishes in coastal lacustrine marshes. Further light is shed on this later.

As to the areal extent of this Upper Silurian Fauna Woodward says:- "Its beginning is curiously marked over an area of at least a thousand square miles by the Ludlow Bone Bed, which is a layer of small and even minute fishfragments mingled with comminuted remains of other animals which have been washed together. Notwithstanding its great extent, this bone bed is rarely more than three or four inches in thickness." Comparison with similar beds of other lands strongly suggests that it may have been many thousands of square miles in extent, and this is in line with Woodward's suggestion of a possible correlation of these beds with similar ones in Scotland and in the Baltic area, a subject that is treated below.

A paper on "The Highest Silurian Rocks of the Ludlow District" ( $58:$ I 95$)$ by Misses Elles and Slater is specially detailed and suggestive. They say:- "In the LudlowDownton district there exists an interesting series of rocks, limited by the Aymestry Limestone at their base and the Old Red Sandstone at their summit, and it is with these that the present paper deals. Lithologically they present a varied series of sediments ranging from limestones on the one hand, through calcareous flagstones and shales to shallow-water sandstones on the other; and these lithological changes are associated with certain changes in the fauna.

"Palaeontologically, these rocks are characterized by the presence of Eurypteridae, which, although rare in the lower 
beds, gradually increase in importance until they attain their maximum development in the beds immediately underlying the Old Red Sandstone. The rich brachiopod-fauna characteristic of the lower beds dwindles and almost dies out with the approach of shallow water conditions, although the molluscs are somewhat more persistent."

"The recurrence throughout of conditions tending to the formation of "Bone Beds" is also worthy of note, such conditions having prevailed at four distinct times at least during the deposition of the rocks."

As it is of importance here to compare the different classifications of strata, and the views held regarding the relation of the enclosed organișms of these strata, we append the tables of Elles and Slater.

\section{PURPLE-RED SANDSTONES AND MARLS OF THE OLD RED SANDSTONES.}

\begin{tabular}{|c|c|c|}
\hline III. & $\begin{array}{c}\text { F. Temeside } \\
\text { or } \\
\text { Eurypterus } \\
\text { Shales. }\end{array}$ & $\left\{\begin{array}{l}f . \text { Gray carbonaceous grit-Fragment- } \\
\text { Bed. } \\
e . \text { Olive shales with Eurypteridae. } \\
d . \text { Temeside Bone-Bed. } \\
c . \text { Olive shales with Eurypteridae. } \\
b . \text { Gray micaceous grit. } \\
a . \text { Variegated shales and marls, } \\
\text { greenish sandstones at base. }\end{array}\right.$ \\
\hline $\begin{array}{l}\text { Temeside } \\
\text { Group. }\end{array}$ & $\begin{array}{c}E \text {. Downton-Castle } \\
\text { or } \\
\text { Yellow } \\
\text { Sandstones. }\end{array}$ & $\left\{\begin{array}{l}\text { e. Micaceous sandstones with fish- } \\
\text { band and a few Lingulae. } \\
\text { d. Carbonaceous sandstones. } \\
\text { c. Massive yellow sandstones, with } \\
\text { Lingula minima. } \\
\text { b. Platychisma Bed, passing laterally } \\
\quad \text { into a Bone-Bed - (Dow n to } n \\
\text { Bone-Bed). } \\
\text { a. Unfossiliferous sandy shales. }\end{array}\right.$ \\
\hline $\begin{array}{l}\text { II. } \\
\text { per Ludlow }\end{array}$ & $\begin{array}{l}\text { D. Upper Whitcliffe } \\
\text { Chr } \\
\text { Chonetes Flags. }\end{array}$ & $\left\{\begin{array}{l}\text { c. Ludlow Bone-Bed. } \\
\text { b. Calcareous shales and flags with } \\
\quad \text { Spirifera elevata. } \\
\text { a. Calcareous olive flags with Cho- } \\
\text { netes elevata. }\end{array}\right.$ \\
\hline Group. & $\begin{array}{c}\text { C. Lower Whitcliffe } \\
\text { or Rhynchonella } \\
\text { Flags. }\end{array}$ & $\left\{\begin{array}{l}\text { b. Concretion-Band. } \\
\text { a. Calcareous blue flags with Rhyn- } \\
\text { chonella nucula. }\end{array}\right.$ \\
\hline I. & $\begin{array}{c}\text { Mocktree or } \\
\text { Dayia Shales. }\end{array}$ & $\left\{\begin{array}{l}\text { Shales and limestones full of Dayia } \\
\text { navicula. }\end{array}\right.$ \\
\hline $\begin{array}{l}\text { Aymestry } \\
\text { Group. }\end{array}$ & $\begin{array}{l}A \text {. Aymestry } \\
\text { chidium Lir }\end{array}$ & $\left\{\begin{array}{c}\text { Massive limestones with Conchidium } \\
\text { knightii. }\end{array}\right.$ \\
\hline
\end{tabular}


After describing the lower and evidently marine beds up to "calcareous shales and flags with Spirifera elevata" they make the following remarks (p. 203): "They are immediately succeeded by the famous Ludlow Bone Bed which is too well known to require description. It is best developed at the lower end of the section, on the south side of the road, where it is $21 / 2$ feet above road-level, and reaches a maximum thickness of nearly six inches. It is, however, very commonly separated into two thin bands of 'bony' material, divided by a few inches of soft mud-stone. In addition to the numerous fish remains which the Bone Bed contains, we have identified Chonetes striatella, Orbiculoidea rugata and Orthis sp.; a similar fauna, with Beyrichia in addition, being found in the softer mudstone separating the "bony layers." And as to the higher or Temeside group they write (p. 203):-“Temeside group. The succeeding sandstones ( $\mathrm{Ea}$ ) differ somewhat in lithology from beds" below. So the writers remark "They seem to usher in new conditions; for, above the Ludlow bonebeds, the articulate brachiopoda, so characteristic of the lower beds, have almost disappeared, Lingulae and the molluscan fauna alone remaining; and we therefore consider that the dividing line between the Upper Ludlow and Temeside Groups is best drawn at this horizon." Next (p. 205): "The overlying grit-bed which is conspicuously 'bony' at its lower and upper limits, is here seen at its maximum development (2 feet), but, like the other BoneBeds of this Series, it thins away rapidly to west and east." The bone bed (Fd) "which we designate the Temeside Bone Bed may be regarded as a grey micaceous grit, in which large fragments of bone and fish spines are disseminated. There is, in addition, a considerable amount of carbonaceous matter, but whether of vegetable or animal origin is not clear. As a whole, this Temeside Bone Bed is coarser and more diffuse than the Ludlow Bone Bed, and very different from the latter in general appearance."

The succeeding olive shales $(F, e)$ are 2 to 4 feet thick. "Eurypterid remains are abundant," but hard to identify. "These are succeeded by another grey micaceous grit, I foot, $(F, f)$ at the top of which occurs a well marked layer crowd- 
ed with carbonaceous fragments, but in which bones are rare. Purple-red sandstones with shaly partings come on immediately above this 'Fragment-bed;' these differ in general lithology from anything that we have seen at a lower horizon; and since the 'Fragment-bed' at their base appears fairly constant over wide areas and is easily recognizable, we suggest its adoption as the upper limit of the Silurian system in this district."

To complete the evidence required, their tables giving the palaeontological distribution of all known species are appended to the paper.

Now an inspection of this extensive table (pp. 2 I 9-2O) brings out very clearly that exactly the difference in fauna of the freshwater Old Red rocks and the marine Devonian rocks, observed in the next formation to be studied, applies also here. For on p. 2 I 9 and the upper half of p. 220 , the organisms are all typical marine invertebrates which occur below the Ludlow Bone-bed, if we except rare occurrences of some brachiopod shells, which evidently represent a temporary sea invasion or inwash, when the "soft-mudstone" was deposited (p. 203) between the Lower and Upper of the two Ludlow beds. The organisms listed however on the lower half of p. 220 under "Crustacea" and "Pisces" are freshwater, and attain their climax of abundance alike in species and individuals in the Upper or Temeside Bone-bed and associated Olive shale. Here Pachytheca, Eurypterids, Leperditia, Physocaris, and abundant fishes form a characteristic freshwater companionship, such as is carried forward in facies into the Old Red rocks. The intrusion here of a few Lingula shells can be quite readily explained in one of at least four ways. But at present we reserve discussion of this.

Observations made by King and Lewis $(59: 437)$ in the South Staffordshire region closely parallel those just given

On the east side of Scotland in the Pentland Hill region, and on the west in the Leshmahagow region, members of the Geological Survey have mapped Silurian areas that seem exactly to correspond with the beds already described, and 
so these have been named by them "Ludlow" and "Downtonian" beds or by Goodchild $(60: 599)$ the Lanarkian.

In addition to a varied assemblage of eurypterid and fish forms, phyllopods belonging to the genus Ceratiocaris are abundant, and as decidedly indicating nearby land life a fossil scorpion, Palaeophonus, and carbonized remains of what seem to be lycopodineous plants are met with. It is from the strata of these areas also that Traquair secured the rich material on which his fish genera Lanarkia, Ateleaspis etc. are founded.

In more recent years Campbell has published an important paper $(14: 923)$ on an extensive series of Downtonian rocks in South-eastern Kincardineshire, Scotland. These he catalogues as follows:

Feet

7. Tuffs and tuffaceous sandstones............... 800

6. Grey sandstone and fossiliferous sandy shales and mudstones (with fish band) ................... 600

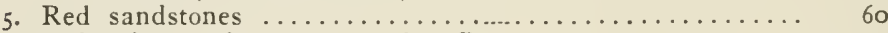

4. Volcanic conglomerates and tuffs................ to

3. Grey and brown sandstones with thin red mudstones.... rooo

2. Purple sandstones ........................... 60

I. Basement breccias with intercalated sandy mudstones.... 200

Regarding the above he states that No. 6 "alike in its lithological characters and in its fossil contents, shows the Silurian rather than the Old Red Sandstone affinity of its succession." In these beds he "found not only Dictyocaris, but also Eurypterus sp. and fragmentary plant remains." Of fish remains found by him there Traquair identified ( I) Cephalaspidian scutes belonging to a species as yet unnamed and undescribed; (2) fragments of the median plates of a beautiful new Cyathaspis named by Traquair C. Campbelli. He has also found with these Ceratiocaris, Archidesmus sp., and a new genus of Myriapod,-a probable larval form of insect, a new species of Eurypterus, and fragments of a scorpion.

In reviewing all of these therefore he concludes (p. 934): "In Kincardineshire no evidence has been obtained so far which would point to marine sedimentation. No undoubtedly marine organism has been found, and the association of the eurypterids with plant remains, scorpion fragments, galley worms, and a larval form of insect, ap- 
pears to show that the green and grey mudstones were laid down in close proximity to a land area, and at the most can imply only estuarine conditions."

Campbell further draws attention to the striking similarity of beds described by Kiaer $\left(6_{I}\right)$ for the Christiania region, since the contained organisms seem at least generically identical, and include several types of fish.

Kiaer entitles his paper "A new Downtonian Fauna in the Sandstone Series of the Kristiania area." This series is fully 500 meters thick, and consists of a lower part rich in shales, and an upper part poor in shales. Fossils and clear trail marks only occur in the lower part, while the richest horizon is a "gray-green calcareous and argillaceous sandstone, which can be easily split into somewhat thin and irregular slabs." He describes the subjoined group of wholly freshwater organisms:

(I) Dictyocaris, very common.

(2) Ceratiocaris, not often in good specimens.

(3) Eurypterus norvegicus, very common.

(4) Eurypterus minutus, rare.

(5) Eurypterus sp. rare.

(6) Pterygotus sp. rare, in fragments.

(7) Aceraspis robustus, very common.

(8) Micraspis gracilis, not common.

(9) Pterolepis nitidus, very common.

(Io) Pharyngolepis oblongus, not common.

(I I) Rhyncholepis parvulus, common.

The five last were all new anaspid or hyperplacodous fishes (p. 257) that show near affinity with Scottish and later evolved Canadian types. He regards the entire series "of Phyllocarids, Eurypterids, and Ostracoderm fishes" as freshwater, but records a set of marine types in what he calls an "uppermost marine Ludlow zone." An almost identical association of organisms also was recorded by $\mathrm{J}$. $\mathrm{V}$. Rohon ( $I 6)$ in rocks of the island of Oesel in the Baltic.

During the past 30 years an examination of the Upper Silurian rocks of the Eastern States and Canada has revealed a surprising similarity-almost close identity-with those of the Old World. Thus the lower strata of the former region that have been called the Niagara and Guelph seem to represent the Aymestry and related marine strata of England. The succeeding and higher beds again, 
agree closely with the top beds of the Upper Ludlow and with the Temeside groups of England. In I 884 Claypole described the primitive fish Palaeaspis from Silurian rocks of Pennsylvania (62: I 224) and a few years later Matthew $(63: 49)$ described another primitive type-Diplaspis acadica-from Lower New Brunswick in Canada. He correlates the rocks as Niagaran, but they may correspond more nearly with the upper Salina and Waterlime beds of the United States. Associated with the fish-much as in the European beds-Ceratiocaris pusillus "occurs in myriads in the black fissile shales" (p. 55), and also a crustacean Bunodella horrida. Matthew emphasizes three distinct and rather widely separate localities for these Silurian rocks, all of which are devoid of marine organisms, but show freshwater types similar to those of W. Russia, S. Norway (Kiaer), and Scotland. These are the island of Anticosti in the Gaspe or eastern Quebec area of Canada; Arisaig in eastern Nova Scotia; and along Passamaquoddy Bay in southern New Brunswick. Of these he says: "Thus in three districts of Acadia, the lower measures of the Silurian series are represented by bituminous shales and limestones to the north, and dark carbonaceous shales to the south, which presumably are contemporaneous." And in accepting that these belong to the Clinton groups he adds that the fish remains "occur in the mass of strata included in the 670 feet mentioned in the section at p. 165 of the Report of the Geological Survey of Canada for I 870-71."

In "The Ancestry of the Upper Devonian Placoderms of Ohio" Claypole (64:349) traces the relation of fish life downward from the Devonian to the Silurian beds, and speaking of the Salina beds says: "In these were found the shields of Palaeaspis in great numbers. They are consequently of equal age, to say the least, with the Pteraspis of the Ludlow, all of the yet known specimens of which except one solitary shield of Cyathaspis (Scaphaspis) ludensis have come from the upper division."

But a marked feature of the American area is the extensive deposits or infiltrations of salt that have given the name Salina to the group. Such deposits, however, are restricted to certain beds, and suggest that wide but still 
shallow expanses were invaded at periods by the sea. The waters were then isolated and their salt precipitated.

Before reviewing the above evidence, it should be stated that supposed fish remains have been reported from the base of the Upper, or even from beds of the lower Silurian, but the records are so scant, or the material is so doubtful that we prefer not to found any views upon such. There is no reason, however, why such records need not be verified and even greatly extended in the future, for the most primitive fishes almost certainly existed when the oldest Silurian rocks were deposited.

Mention should here be made of an extremely abundant type of organic remain that is scattered over many layers of strata from Lower Silurian up to at least Carboniferous days. For the small or almost minute brown to nearly black shining bodies that have been named "conodonts" or cone teeth, have attracted the attention of observers in Russia, Britain, and not least in N. America. These in some cases are simple cone-like teeth, which, when attached to the animal forming them, were probably composed in part at least of carbonate of lime, but may also have been in part horny. But most show a compound structure, and consist then of a tooth-plate that bears from two to many teeth of varying size, number, and disposition.

Newberry, Hinde, and others have well compared these with the teeth and tooth-plates of living Cyclostome fishes, which however are wholly or largely of a horny nature. The writer also has suggested that they may all represent evolved and complex derivatives from the horny teeth formed in the mid part of the proboscis in Metanemerteans. For if we accept that freshwater Metanemerteans may have swarmed in Cambrian lakes and swamps, these by progressive change may have given rise to Cyclostomes, some of which retained horny teeth as in existing types, while others may have advanced to a more complex calcareous type.

The writer has arranged in Fig. 7, a set of illustrations from $a$ to $r$, some of which are the horny teeth of existing Cyclostome fishes, and others are conodonts copied from the works of Newberry and Hinde. The close resemblance in many cases is at least suggestive. The writer also has 


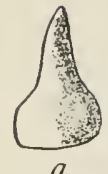

a
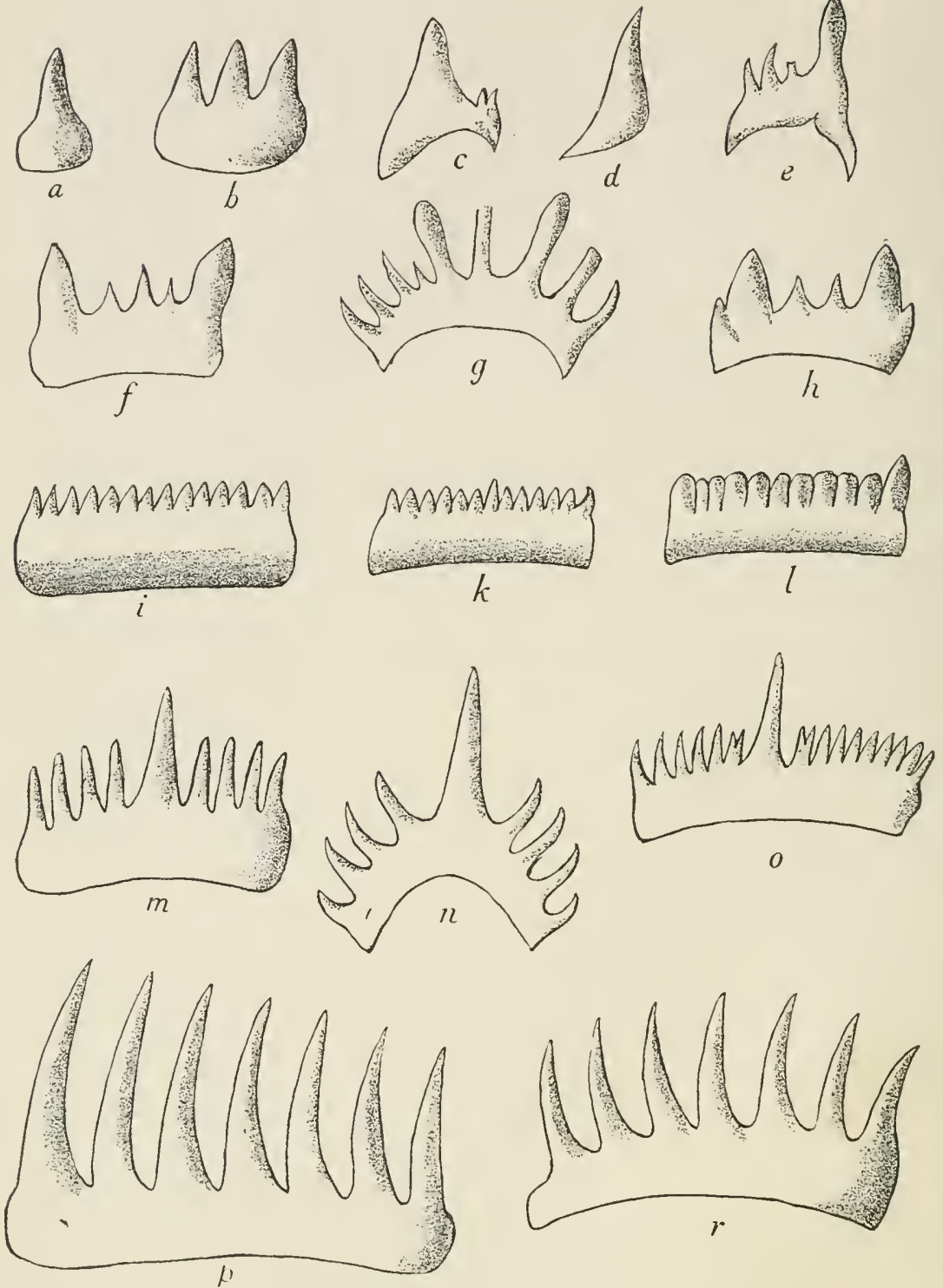

FIG. 7. Conodonts and cyclostomatous teeth. $a . b$. external and internal labial teeth, Petromyzon fluviatile; $c, d, e$, conodonts (from Newberry and Hinde); $f$, maxillary tooth-plate, Geotria australis; h, do. G. chilensis; g, tooth-plate of Conodont (from Newberry); $i$, mandibular tooth-plate, $G$. chilensis; $k, l$, conodont tooth-plates (from Newberry and Hinde); $m$, toothplate, Petromyzon marinus; $n, o$, conodont tooth-plates (from Newberry and Hinde); $p$, lateral tooth-plate, Myxine glutinosa; $r$, do. of conodont, Polygnathus (from Hinde). All enlarged. 
pointed out, in the above quoted work, the curious facts that living Cyclostomes are rich in oil, and also that supplies of petroleum or rock oil, as well as abundant remains of conodonts, first appear synchronously in Cambrian and Silurian rocks. It may be hoped that added evidence will soon be obtained as to the possible affinity or not of the two kinds of structure.

In trying to condense and interpret the knowledge now presented the writer would infer that most, if not all, of the Lower Silurian rocks and even of the LlandoveryWenlock in England, or the Niagaran-lower Salina in America, were deposited as marine accumulations, and so include typical assemblages of littoral marine fossils, such as are catalogued by many palaeontologists. But no undoubted fish remains occur with these. Such deposits were adjacent to extensive though low-lying land-masses, which, in the Upper Silurian period, were of ten extensively flooded by invasions of the sea, so that the freshwater and the marine life at times became mixed. The types at that time ablest to survive such oscillatory changes, were mainly species of Lingula or Chonetes, which may be found along with a varied littoral marine life, or at times occurring in depauperate state, or in the Upper or freshwater beds their remains occur as washed out and redeposited shells, along with what evidently was a widespread freshwater fauna.

Such oscillatory changes were due to widespread volcanic action, as recorded by various geologists, and as summed up for East Scotland by Campbell as follows (op. cit. 935): "One must conclude that early in Downtonian times (or perhaps in pre-Downtonian but subsequent to the movements which folded the eastern schists) volcanic activity had already begun in the schist country to the north of the Highland Fault.'

But in pre-Downtonian and Mid-Salina times the sea gradually retreated and left extensive N. European-and evidently N. E. American-continental areas of no great elevation, that were traversed by far-reaching river systems. These rivers must have often expanded into marshes or shallow lakes, that in their periodic change of level during dry and wet seasons, simulated the drainage areas of the 
Amazon, the Congo, or the Nile. Abundant deposits were thus made annually in some places, continuously in others where they would give rise to fine shales or lime precipitates, to coarse cherts or sandstones where they were laid down nearer the main river-beds, or to coarse conglomerates where adjacent to the main river-channel. For the statement made by Campbell (p. 935) when speaking of these very rocks: "the coarse volcanic conglomerate, like those of the Old Red Sandstone, is in all likelihood a torrential flood gravel" is exactly duplicated by Baldwin Spencer, in his description of the "Neoceratodus" region of Australia, that is cited on p. 32 of this work.

The bone-beds, varying in number from one to as many as five in some areas, that so sharply appear amongst the other strata, and which may be from a half-inch to as much as nine inches in thickness, can be exactly explained as sudden deposits of volcanic dust that, in a few hours or days, had entombed and preserved myriads of plant and animal remains.

The biological assemblage of these Upper Silurian deposits can now be considered. Except for the presence of some species of Lingula in intercalated beds, or the occasional intrusion of stunted forms amongst others to be now named, the entire group of organisms is totally different from that found in the typical marine strata of the lower Silurian, the Ordovician, or the Cambrian. Myriads of the phyllopod genus Ceratiocaris; such genera of the Eurypteridae as Pterygotus and Eurypterus; entire examples or more or less broken fragments of the scorpioid Palaeophonus; a new genus of myriapod; tubercles plates or entire examples of primitive fishes belonging to such genera as Thelodus, Lanarkia, Lasanius, Cyathaspis, Cephalaspis, Auchenaspis and Tremataspis; abundant remains of the problematic plant Parka decipiens; and not unfrequent lycopodineous specimens; make up the whole.

Now the writer hopes to show elsewhere that species of Ceratiocaris like many other of the simpler Crustacea, are and have been freshwater in habitat. The history of the Eurypteridae evidently is that from some primitive precambrian freshwater ancestor of the Arachnida, one line 
advanced to ultimate gigantic size and amid freshwater environment, as the true Eurypterida. Another early evolved amid increasingly estuarine and later littoral surroundings as the Trilobita, while a third passed on to land and gave origin amongst others to the Scorpionida. Now largely on account of the intermixture or abundance in intercalated strata of the entire or broken shells of depauperate examples of Lingula, more rarely' of Chonetes, Clarke and Ruedemann in their elaborate memoir (65) on the Eurypterida have concluded that these began as marine organisms, and in late Silurian or Devonian time became freshwater. The suggested evidence for a marine life at any period is so scant or wholly wanting, and the many facts in favor of a freshwater origin are so impressive, that we accept the latter as true, and trust later to demonstrate this fully.

As regards the abundance in individuals of the genera of fishes already cited, this must have been prodigious over wide areas. For the widespread continuity and similarity of the Silurian bone-beds of America, of Britain, of Russia, and of Sweden indicate that innumerable myriads must have died within a few hours, and been sealed up entire and preserved from subsequent destructive action; or after a greater or less degree of disintegration, lasting possibly over two or three weeks, the hard calcareous teeth or plates or bones became piled together in layered masses.

The three groups of animals then, given in the above study, whose remains are specially abundant are the ceratiocarid crustaceans, the eurypterids, and the fishes. The possible origin of the oil or petroleum yielded by the Silurian and later rock-strata has already been discussed. By far the most likely source of such seems to be the animals just named, and especially the fishes.

Finally as to the affinities of the Silurian fishes, all so far as known belong to very primitive and now wholly extinct groups that are treated of later. The internal tissues were undoubtedly soft and easily perishable; and even if cartilage was present it also must have been of soft consistence. So our knowledge of them is wholly confined to the exo-skeleton, which in very primitive types like The- 
odus, or Lanarkia (Fig. Sa, Sb) consisted of scattered tubercles embedded in a firm skin. More extensive deposition of calcium carbonate gave rise to such armored types as Cyathaspis, Auchenaspis and Cephalaspis. Isolated defensive spines, referred to the genera Onchus and Climatius suggest that primitive forerunners of the Shark alliance or Selachii were already evolving in Silurian freshwaters.

Owing to an environal combination of conditions that is still often highly destructive to fish-life, but was then undoubtedly greatly more active and widespread, such as subaqueous earthquakes, explosions of poisonous gases, widespread deposition of volcanic dust and ashes, severe storms over land and lake areas, sudden torrential rise and fall of the lakes, rivers, or swamps in which the fishes

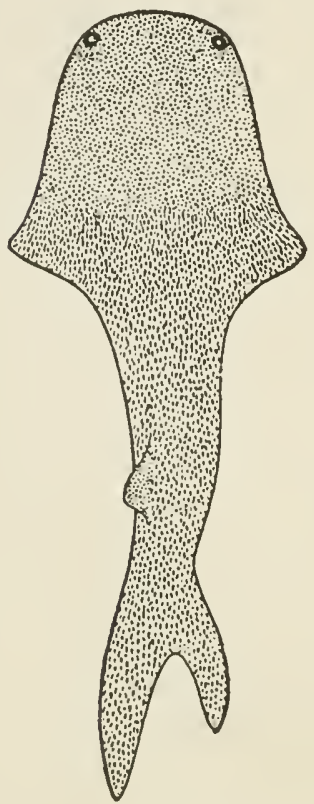

FIG. $8, a$

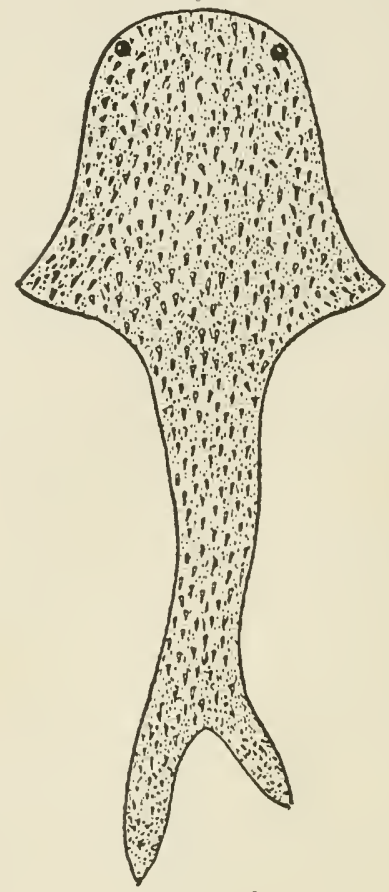

Fig. $8, b$

FIG, 8, $-a$, Restoration of Thelodus scoticus, a primitive fish probably derived from a metanemertean ancestry. $b$, Restoration of Lanarkia spinosa. (After Traquair.) 
lived, rapid destructive transfer of sand, gravel, and even small stones, all must have combined to produce a biological wear and tear that would cause extensive migrations, exposure to new environal surroundings and factors, rapid specific variations, and evolution of increasingly divergent types of organisms, often also sudden as well as widespread death.

But in line with such results the question may well be asked: Why did not rapid and wide migrations occur from freshwater to littoral or suboceanic habitats? The answer is evidently got when we remember that these fishes were wholly or largely devoid of hard teeth, that they were mainly of heavy flattened build, and were suited for shuffling or grubbing after their food over muddy or sandy surfaces. Above all, there is strong likelihood that the seas and littoral regions were abundantly stocked with medusoid and cephalopod organisms. For though we are still unacquainted with the offensive or defensive parts of these, it seems fairly probable that some of these were formidable antagonists, which could drive back into freshwater such of the clumsy fishes as ventured into the sea. So while related types to some of these primitive fishes survived into the Lower and even into the Upper Devonian, their place was gradually taken by more lithe, flexible and resisting descendants.

We are therefore compelled to conclude that the most primitive fishes known to us, originated wholly in freshwater areas, and are there known to us in countless myriads as fossilized forms. The associated animals and plants constitute with these a biological assemblage that are totally different from marine organisms of the same period.

\section{B. The Physical and biological environment of Devon- ian fishes.}

It is now generally conceded that at least throughout Europe and North America a complete or almost complete continuity in succession of the rocks can be traced from Upper Silurian beds such as the Temeside, to others whose organisms indicate transition to Devonian or Old Red times. But the rocks of Central Russia show marked 
discontinuity, and so suggest volcanic action and displacement. As for the Upper Silurian, so also for the Devonian, we hope to show that two very distinct assemblages of organisms characterize freshwater and marine deposits respectively.

Over wide areas of the North Eastern United States, of South England, of Northern France, Central Germany and Russia, South-west China and New South Wales thick deposits of marine strata, that enclose typical marine fossils, have been followed out. To these the term Devonian was restricted by some geologists. But distinct from such beds, and often forming enormous stratified masses, occur other deposits with a very different biological assemblage, and which have had a very different physical history from the former. To these the older geologists gave the name Old Red Sandstone. In endeavoring to unravel gradually the history of the relation and succession of these two groups, the writer was at first completely bewildered, then puzzled, still later in hopeful mood, and finally satisfied as to exact explanations. Such mental phases were due to the frequent description by the earlier geologists, of blocks of fossils which had been collected in some one, or in a few neighboring regions, but which had not been exactly labeled as to stratigraphic occurrence and succession. Or again geologists in the field had accumulated collections which were described by colleagues, who had never or seldom visited the rocks. Not unfrequently also one could trace a distinct prepossession or mental bias, on the part of some writer for an already-formed theory or opinion.

In study of these we may again start with European strata, as they have been longer and more fully compared, than those of North America or other continents. As now synopsized by Geikie ( $7: 9 \$ 2-999)$, by Prestwich (66:II : $74-82)$, by de Lapparent $(67: I 1: 836)$, and by RoemerFrech $(68: 1: 34-55$; II : I I 7-256) the rocks of central Europe from south England eastward, and to which the term Devonian was first applied by Murchison and Sedgwick, are clearly marine, but largely littoral-marine in origin. The nature of the rocks, the abundant lists of marine fos- 
sils, the absence of plants and animals that would suggest freshwater conditions, all conspire to stamp them.

But probably contemporaneous with these, or at times intercalated between them, as seems particularly to be true of those in North America to be noted below, are extensive and thick masses of rock, which from their predominantly red color and high ferruginous content, were early named "the Old Red Sandstone." These are largely confined-in their known exposure-to Wales, to North and East Ireland, are very extensively developed in Scotland and Russia, and they appear also in Norway. Their great development in North America will be referred to later. Studied throughout Europe in succession by Murchison, Fleming, Godwin-Austen, Ramsay, Hugh Miller, Mitchell, Agassiz, Powrie, Geikie, Peach, Flett and many others, the strata seemed to be divided into at least two or even three divisions that were mainly characterized by their diverse fish remains.

Geikie says regarding them (7:1007): "The Old Red Sandstone of Britain, according to the author's researches, consists of two subdivisions, the lower of which passes down conformably into the Upper Silurian deposits, the upper shading off in the same manner into the base of the Carboniferous system, while they are separated from each other by an unconformability." This author made a very detailed study of the entire system throughout the British Isles, and alike in special papers $(69: 3$ I $2 ; 23: 345)$ as well as in his exhaustive work "Ancient Volcanoes of Great Britain" ( 70$)$ has developed the view that the rocks of both lower and upper divisions were enormous lacustrine deposits, that occasionally reached a maximum thickness of 30,000 feet. These were laid down in a group of freshwaters which he named Lakes Caledonia, Orcadie, Cheviot, and Lorne, and of them he says: "There is sufficient diversity of lithological and palaeontological characters to show that these several areas were on the whole distinct basins, separated from each other and from the sea. The interval between the Lower and Upper Old Red Sandstones was so protracted, and the geographical changes accomplished during it were so extensive, that the 
basins in which the late parts of the system were deposited, only partially correspond with those of the older lakes."

In a later study by Goodchild $(7 I: 59 \mathrm{I})$ he says: "as regards its mode of origin there appears to be evidence of a satisfactory nature that the whole of this vast formation was accumulated under continental conditions, partly in large inland lakes, partly as torrential deposits of various kinds, partly as old desert sands, and partly as the results of extensive volcanic action." He estimates the thickness of the lower series as reaching in places to 20,000 feet, while the upper, that he divides into an Orcadian, a Nairn, and an Elgin set, may reach 17,000 feet.

As might be expected, the rocks that compose the Lower Old Red Sandstone, while largely of a reddish ferruginous tint, include red shales, grey and yellow sandstones, occasionally-usually thin-limestone, or "cornstone" beds, and in Forfarshire hard close-grained grey flagstones. Powrie has described these in detail $(72: 413)$, and specially refers to "one very extensive and highly fossiliferous Fishbed, holding an intermediate position among the flaggy beds, continuous and apparently equally extensive with them." He "found this fish-bed in Carterland Den in Kincardineshire, near Farnell, at Turin Hill, in some quarries south of Forfar, in many places on the Sidlaws, in Balruddery Den in Forfarshire, and in Rossie Den in Perthshire. It thus extends over a range of more than twenty miles." As to its contents he says: "wherever this deposit has been discovered it abounds in ichthyic and crustacean remains, the former being far the more abundant."

Hull $(73: 225)$ has fairly well synopsized the condition of affairs in the relation of the marine Devonian to the freshwater Old Red Sandstone thus (p. 274): "At the close of the Upper Silurian period, represented in Ireland by the Glengariff beds, in Wales by the Upper Ludlow and Passage beds, and in Scotland by the Lower Old Red Sandstone, there was a general elevation of all the northern and western portions of the British Isles, accompanied by flexuring of the strata, and followed by extensive denudation. In the area of the south of England, however, and adjoining continental districts it was otherwise. Here 
there was, on the contrary, continuous depression, and the sea overspread this area, in which were deposited the Lower and Middle Devonian beds. With the Upper Devonian stages or Old Red Sandstone proper, the submersion of the western and northern portions of the British Isles began. Lacustrine conditions were established in the south of Ireland, portions of Scotland, and the north of Ireland. In the waters of these lakes the Old Red conglomerates and succeeding beds with Anodonta were laid down."

Speaking of the Ludlow area $(56: 434)$ A. S. Woodward says: "The red sandstones, marls, and included nodular limestones (locally known as cornstones), which are definitely determined at many points to constitute the lower part of the Old Red series formed in the "Welsh Lake," contain numerous fish-remains of the genera Pteraspis, Cephalaspis, and Phlyctaenaspis. This is the typical Lower Devonian Fish-Fauna, and occurs with slight variations in regions as remote from each other as Cornwall, Southern Scotland (especially Forfarshire), Galicia, Spitzbergen, New Brunswick and Newfoundland. The rocks containing the fish remains, indeed, are almost identical in the Welsh area, Spitzbergen, and Newfoundland; and if specimens from these different localities were mixed it would be difficult to separate them correctly. . . F Fragments of Stylonurus and other Eurypterids are occasionally discovered with the fish remains."

In contrast to the above observers Macnair and Reid (74:106) have attempted a destructive criticism, and have advocated a marine origin for the Old Red Sandstone beds, but they entirely fail to show why a typical marine invertebrate fauna is not associated with the enclosed organisms; they fail to note the great abundance of Estheria membranacea, which like the entire group of Phyllopoda-past and present-have only freshwater associations; they do not note that the plants found side by side with the eurypterids, fishes, and Estheria, are absent from the marine strata. Other grave objections can be taken to their conclusions, even on lithological grounds. It should be said, however, that occasional inroads of the sea, specially in 
the Welsh region, caused restricted deposits of typical marine fossils between the freshwater beds.

The biological assemblage of the European Lower Old Red rocks in part slightly resembles that of the Upper Silurian, but on the whole is markedly different. Mitchell (75: I 45) and Powrie (72:4I3) early noted abundant though poorly preserved plant remains. Parka decipiens, spores of Pachytheca, the myriapod Kampecaris forfarensis, species of Eurypterus and Pterygotus anglicus as well as a very rich fish fauna were recorded. More recent workers have greatly extended their lists, and particularly have encountered abundant remains of such land plants as the fern Archaeopteris, also Psilophyton, Sigillaria, and Calamites.

Goodchild ( 7 I:59I), Flett, and Campbell have given detailed descriptions and lists from the north of Scotland, while from the western part the Scottish Geological Survey has contributed much.

So abundant and typical in some of these Caledonian beds are definite organisms that Goodchild (p. 6oo) classifies some of them thus:

Myriapod Beds

Volcanic Rocks

Acanthodian Beds of Turin Hill

Cephalaspis Beds of Auchtertyre

Volcanic rocks

Pterygotus beds of Carmylie, etc.

All of these, from our present knowledge, are freshwater beds.

The remarkable and unwieldy buckler-shaped Silurian genera Cephalaspis (Fig. 9a) and Pteraspis are continued into the lowermost or Caledonian rocks, that are exposed in Forfarshire, in the Lorne region, in Herefordshire, and in East Wales $(76: 463)$, though the species as determined by Traquair are different, Cephalaspis lyelli being the most widely extended. The Acanthodians (Fig. 9e) or primitive elasmobranchs of the Upper Silurian are represented by Climatius ornatus and Parexus recurrus, while with these in Forfarshire occur two types of Myriapod, Kampecaris forfarensis and Archidesmus sp. 
In beds higher than these apparently, that Goodchild calls the Orcadian, he and Flett have made known a rich series of fishes that suggest a gradual splitting up, and evolution of older types, into the two great elasmobranch and ganoid groups of succeeding formations. Also while some genera, like Coccosteus (Fig. 9d), extend through the entire series, others are typical of, or even extremely abundant in, definite strata. The following is a partial
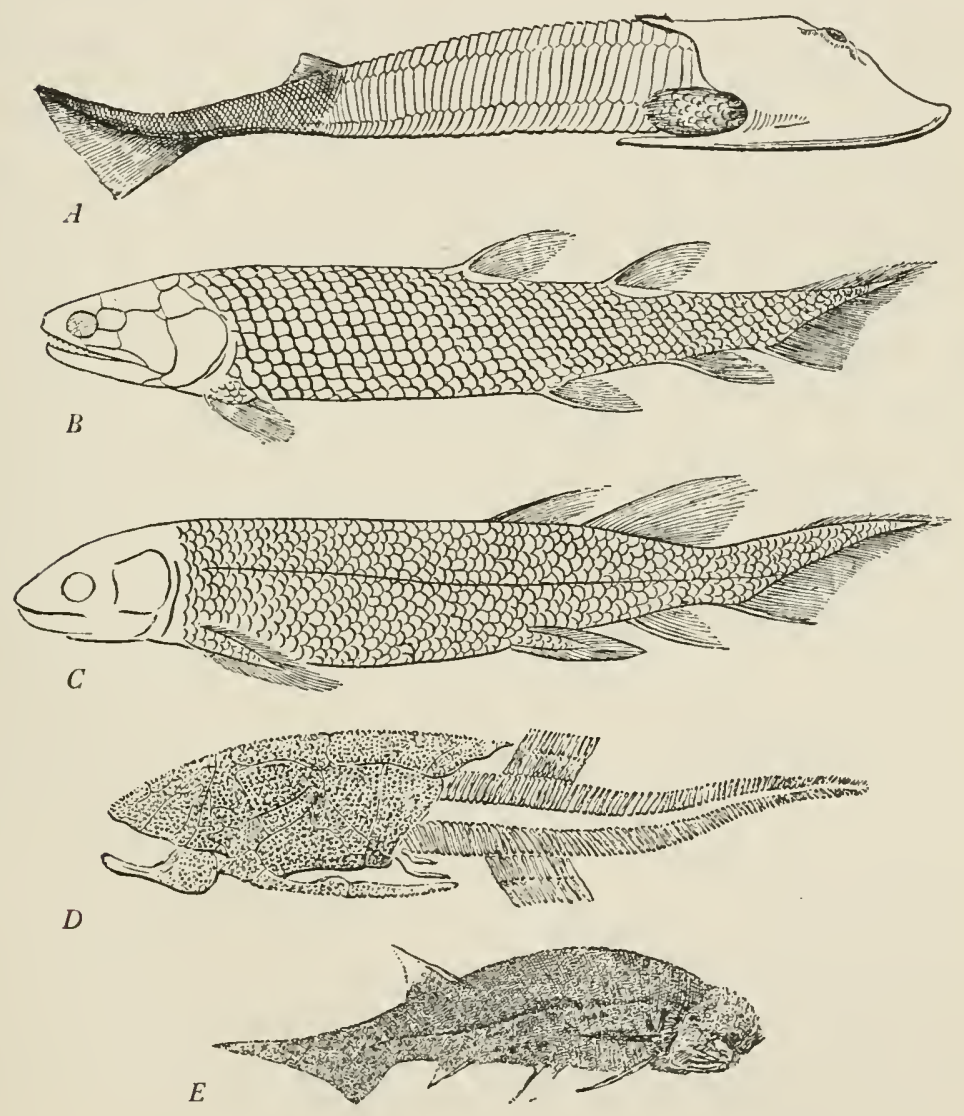

Fig. 9. Fishes of the Old Red Sandstone (Devonian) period. a Cephalaspis lyelli (after Lankester); b, Osteolepis microlepidotus; c, Dipterus valenciennesii (both after Traquair); $d$, Coccosteus decipiens; $e$, Acanthodes mitchelli (after B. N. Peach). All reduced from A. Geikie. 
list of those recorded: Tristicopterus alatus, Dipterus macropterus and D. valenciennesii (Fig. 9c), Microbrachius dicki, Homosteus milleri, Coccosteus decipiens and $C$. minor, Diplacanthus striatus, and D. tenuistriatus, Mesacanthus peachi, Cheiracanthus murchisonii and C. latus, Glyptolepis pancidens, Gyroptychins microlepidotus, Osteolepis microlepidotus (Fig. 9b), and macrolepidotus, Thursius macrolepidotus and T. pholidotus, Diplopterus agassizii, Mesacanthus pusillus, Pterichthys milleri, $P$. productus, and P. oblongus, Cheirolepis trailli, Glyptoptychius angustus and Parexus sp. These deposits therefore are rich alike in individuals and species.

While the remains of these fishes are often scant or absent from the coarser sandstones or shales, they may be crowded in countless numbers in the harder shales and flagstones. Flett says $(22: 383)$ that these "calcareous and bituminous flags are the chief receptacles of the fossil remains enclosed in these rocks. The fossil collector very soon learns that the best specimens are obtained in a brittle hard, usually slaty and thin-bedded rock, which rings to the hammer like a piece of metal. This is in some measure due to the compactness and impermeability which is conferred on these rocks by their abundant calcareous matter." Though this type of rock might quite be a fine argillaceous lacustrine or fluviatile deposit, that afterwards became baked, the writer cannot but suggest that such may rather have been due to deposit of volcanic dust that suddenly killed, covered up, and permeated the armor of each individual. Favoring this is Flett's observation: "it would seem as if these species had been unsuited to the new environment in some manner or other, and their extinction had been rapid and complete. The flags so crowded with fossil remains of Dipterus valenciennesii-only a few of which have attained their full size-irresistibly impress on the mind the idea of a sudden extermination." Other writers express a like opinion.

The unconformability noted by Geikie and his successors, between deposits of the Lower and Upper Old Red rocks, must represent a considerable lapse in time. But before treating of this it may be opportune to observe, 
that the evolution of fishes up to this stage doubtless consisted in the appearance of groups of soft-bodied scaleless animals with cyclostome affinities, of which the remarkable Palaeospondylus gunni (Fig. Io) from the Old Red rocks

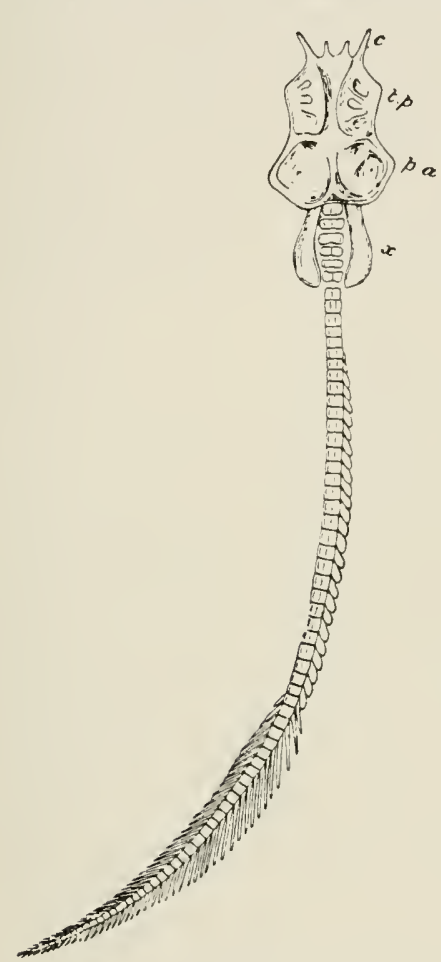

FIG. 10. Restored figure of skeleton, Palaeospondylus gunni. $c$, calcified cephalic cirri; $p a$, auditory capsule; $t p$, supposed nasal capsule; $x$, postoccipital plate. (After Traquair.) of Caithness is the only known illustration. Alongside $\mathrm{s} \mathrm{u} \mathrm{ch}$ there evolved-probably from a Thelodus-like ancestry-the sluggish, toothless, and heavilyarmored bottom-feeders, that have been included in the great group Ostracodermi. Thes e reached their climax-alike as to structure and abundance of individuals-in the late Silurian times, and were becoming rare or extinct in early Old Red age.

But meanwhile, evolving from a Birkenia-Lasanius ancestry of Silurian age, the more lithe forms that were ancestral, in the writer's estimate, to the ganoids and elasmobranchs, were increasingly asserting themselves, and became dominant in freshwaters of the Lower Old Red period. So it should be specially emphasized that the forerunners of all the later Selachians were of freshwater origin. On the European continent, however, an apparent exception to the above has greatly puzzled the writer. For Schlüter and Traquair (77:723) have described the heterostracous genera Drepanapis and Phlyctaenaspis from the Hunsrücken slates of Gemünden. These genera are asserted to be in direct association with crinoids, starfishes, trilobites, bivalve and cephalopod molluscs. This causes Traquair to declare: "It is perfectly clear from the contained invertebrate fossils that the Hunsrück slates are 
of marine origin, and consequently that their "mailed" fishes were inhabitants of the sea. This is however not strange when we remember that mailed fishes (Pterichthys, etc.) also occur in the Middle Devonian Limestone of the Eifel, in company with such purely marine fossils as crinoids and brachiopods." The writer might advance possible explanations regarding the above undoubtedly exceptional relations, but would preferably desiderate a more critical study of the rock-successions in connection with their contained fossils. That the organisms thus grouped together, lived in distinct freshwater and marine environment, seems to the present author assured.

The Upper Old Red rocks of Europe are represented over a wide range of country from South-east Ireland across Central Scotland to Norway, Russia, and probably even Spitzbergen. So this range would include a considerable part of Frech's Arctic-Atlantic continent. The strata are on the whole of a lighter color than the lower Old Red rocks, though ferruginous red predominates. The richest fossiliferous rocks are also here of a hard fissile argillaceous or argillo-calcareous type, that might again suggest rapid deposition of volcanic dust. This is eminently true of the celebrated "cyclopteris" or Kiltorcan rocks of South-east Ireland and of northern Scotland. From these areas large and beautifully preserved leaves of Palaeopteris (Archaeopteris), stems of Knorria, Calamites, Lepidodendron and other drifted land plants have been abundantly secured. In Ireland the freshwater lamellibranch Anodonta jukesii is associated with these. The freshwater phyllopod Estheria membranacea is still abundant, and in this connection no palaeontologist has been a more consistent and yet unconscious advocate for the freshwater habitat of primitive fishes than Rupert-Jones. Thus, in recording the finding of Estheria by C. W. Peach in three quarries in the parish of Wick $(78: 22)$ he observes that "Dipterus, Diplopterus, Osteolepis, Glyptolepis, and Coccosteus with land plants are also found in these quarries," and he accompanies this with such statements as: "In the Estherian flagstones of Caithness we have no evidence of any marine 
characters, nor does their being associated with some thousand feet of sandstones and conglomerates render it impossible that they themselves should have been formed in freshwater or brakish water." But his subsequent remarks indicate that his mind was in a somewhat uncertain state.

On page 16 he makes the very significant observation that the Estheria tests "are found in a thin bed, and lie in great quantities on the surface planes, never to any depth, but just as it were interleaved. Here, as well as at all the other localities, they are accompanied by scales of fishes and pieces of bone." Now, from direct observation by the writer on the deposits of mud and sand over the wide flood-plains of Southern States rivers, from our knowledge of the greatly more extended periodic riverfloods of the Orinoco, Congo, and other continental rivers, the above observation suggests that each "thin bed" of Old Red rock, represented a periodic flood deposit, and on retreat of the waters shallow marshy areas were left in which, as with present-day Estherieae, the tiny organisms multiplied prodigiously. When the next succeeding periodic inundation took place, fish scales and bones, plant remains and other organic debris would be deposited, succeeded by a new "thin bed" of mud or fine sand that sealed up the Estherieae "in great quantities on the surface planes." This is in line also with Barrell's contention (79: 335 ).

Here it may appropriately be added that Jones obtained specimens of Estheria membranacea from Livonia in Russia, and says (p. I 8 ) "these are identical with the Estheriae from Caithness." Also (p. 20) "on the river Torgel in Livland Dr. Pander found that the hard white sandstones used for grindstones, contain fine remains of Asterolepis (Pander) and that the overlying bluish marls and clays contain scales and teeth of Osteolepis, Dipterus and Glyptolepis in company with Estheria membranacea."

The fish fauna of the Upper Old Red rocks is a varied but steadily evolving one. In addition to clumsy heavily- 
i 24 Evolution and Distribution of Fishes

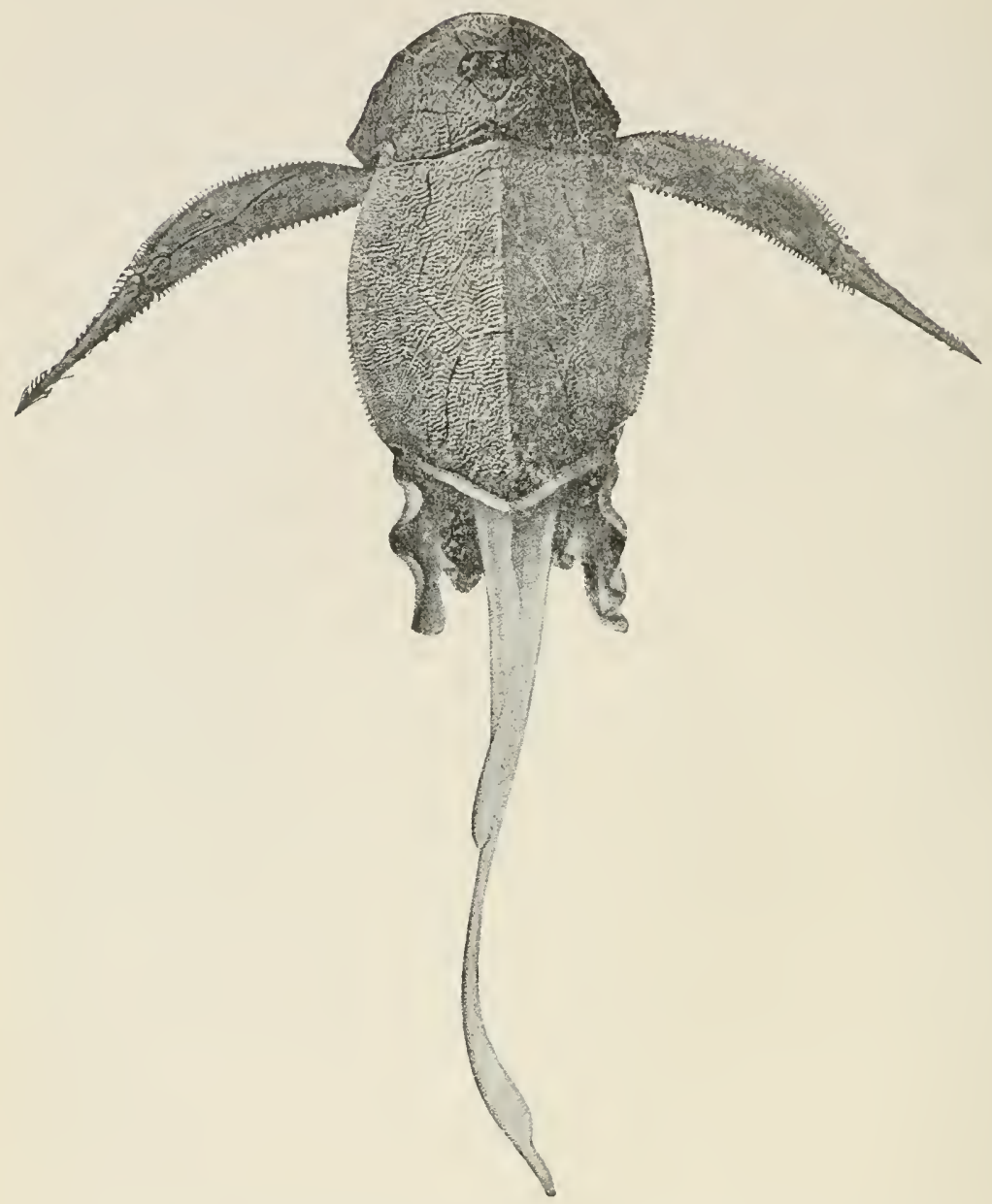

FIG. II. Bothriolepis canadensis, dorsal surface, about threeeighth natural size. (After Patten).

armored members of the Antiarchi like Bothriolepis (Fig. I I) and Asterolepis, or of the Arthrodira-like Coccosteus and allies, that persist from lower Old Red strata, though altered in the representative species, the rather more agile and still existing Dipneusti are now represented by Phaneropleuron (Fig. I 2.) and Palaedaphus, as compared with Dipterus of the lower rocks. But the crossopterygian group is now a prominent one, and in such genera as Holoptychius, 
Dendrodus, Glyptopomus, and Glyptolepis the formation can be widely recognized over the entire "Arctic-Atlantic" area. The numerous species described by Traquair (LankTraq. in Palaeon. Soc. I868-19I4) indicate a still greater wealth for the future. The suggestive couple of papers by Barrell $(79: 345,387)$ emphasize somewhat strongly a fluviatile rather than a lacustrine origin for many of the Old Red beds. And unquestionably if one considers floodplain possibilities, the areas of fluviatile deposition may have been extensive. A combination, however, of fluviatile, of lacustrine, and of Huvio-lacustrine flood-plain sedimentation seems better to explain the requirements of the case. The valuable observations also of Rogers ( $8 I: 100)$ for North Devon, and of J. W. Evans (82:547) for North and South Devon, as for South Wales and Southall, suggest that the area once covered in Britain by Upper Old Red deposits may have been considerable.

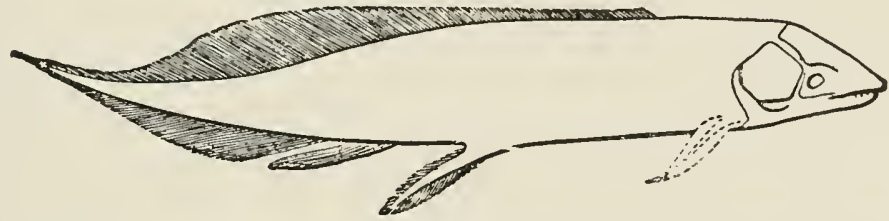

FIG. I2. Phaneropleuron andersoni, a primitive dipnoan fish from Upper Old Red rocks of Scotland, about one-third natural size. (From Traquair.)

As to the wide range of the fishes, A. S. Woodward writes thus (Proc. Geol. Assoc. I 8 (I904) 433): "It may be said that Holoptychius and Sauripterus (or Crossopterygian genera of equal rank) with Bothriolepis and Asterolepis characterize the Upper Old Red Sandstone or Upper Devonian wherever it occurs-in Britain, Belgium, Germany, Russia, Spitzbergen, Greenland, Canada and the Catskills of New York. All assertions to the contrary are based on a wrong interpretation of the fragments, by which alone the fishes are so frequently represented."

Turning now to the Devonian, Erian, or Old Red system of North America we seem here to encounter a fairly even continuity, but likewise alternation, in the Devonian 
or marine and the Old Red or freshwater rocks. This seems also to be confirmed by the close identity of the fauna, though, as might be expected across so wide an extent of country and stretch of time, some very different and even remarkable types are here met with.

Reference might now be made to the excellent condensed description of the formation given by ChamberlinSalisbury (8:4I8). There a division into palaeo- mesoand neo-devonic is accepted from Clarke and Schuchert. An examination of these subdivisions, and of their contained fossils, demonstrates that steady alternation, of freshwater or land surfaces with littoral or deep-littoral marine areas, took place.

Further in the exhaustive studies that have been made of the latter by Newberry, Orton, Clarke, Hayes, Prosser, Meek, Worthen, Williams, Gregory, Weller, Fuller, Ulrich, Schuchert and many others, the fauna recorded is uniformly and consistently marine, while it stands out in sharp contrast with the results to be recorded below. But in saying this, exception must be taken to some of the pioneer work of such distinguished palaeontologists as the earlier leaders of the Ohio survey. Thus in the graphic - though as we would interpret conditions the entirely mistaken-word pictures given in Vols. I and 3 of the Ohio survey, $\left(8_{3}: 264 ; 84: 603\right)$ extensive ocean-stretches are put before the minds eye, as being peopled by an abundant marine fish fauna.

But when we correlate carefully all the information since gained regarding the Old Red rocks of Ohio, and compare such with the descriptions in the above-cited volumes, as well as the rock section given in V.3 (Geology) p. 604, instead of regarding all of the rocks as having been deposited in "an ancient sea," or as being "an open-sea deposit," the writer would accept that the lowermost rocks in the Corbin's Mill section which contain flinty nodules, or which are fossiliferous and abound in brachiopods, marine gasterpods etc. are truly marine. But he would emphatically claim that the "shaly limestone," which not unfrequently contained wood of a species of ancient pine (Dadoxylon newberryi Dawson), tells of lacustrine or flood-plain con- 
ditions. When further a bone-bed occurs just above, that is "a six-inch layer" and is crowded with fish remains, we would again claim that this represents a sudden volcanic dust deposit, that killed and in a few days entombed the surrounding fishes over hundreds of miles. This again was succeeded by a blue limestone that closely resembles freshwater limestones of Europe. Orton says of this: "the fossils of the Delaware beds are at this point chiefly fishremains. Teeth, plates, jaws and other bones are not unfrequently met with throughout $25 \mathrm{ft}$. of this series." But he does not account for the great abundance of these, nor for the total absence of undoubted marine organisms, if the deposit was laid down in "an ancient sea."

It would be a premature task as yet to attempt any correlation of the deposits as treated by Orton and others. The palaeontological researches however of Hall, Newberry, Dawson, Claypole, Clarke, Whiteaves, Matthew, Traquair and Eastman, indicate three fairly sharply-marked groups of freshwater strata, intercalated between others that are marine.

The lowermost beds of the formation in the central Eastern States, consist of the Helderbergian and Oriskanian. These are wholly of the marine type, and yield an abundant invertebrate marine fauna, though no marine fish remains, where accurate record of beds has been made. But probably deposited synchronously with them, though in freshwater areas, are the Canadian beds, that are often called the Gaspé and Campbellton. The included fishes are, in their affinities, a curious blending of the European Upper Silurian and Lower Old Red. Thus there are abundant examples of Thelodus (Fig. 8a), several species of Cephalaspis (Fig. 9a), and from the lower-most beds Asterolepis clarkei, all of these being of Silurian-Devonian age and of agnathous structure.

But with them are Acanthodes semistriatus and Climatius latispinosus representing primitive selachians; spines of the probably allied selachians Homacanthus and Machaeracanthus, the arthrodire Phlyctaenaspis acadica-a close ally of Coccosteus - and isolated teeth of Dendrodus. 
Flourishing with the above, but as land dwellers Dawson $\left(8_{5}: 523\right)$ has described various eurypterids, species of insects, and an abundant flora that included Calamites, Lepidodendra, numerous species of fern, the specialized genus Cordaites and other less certain types.

Succeeding to the above, and during mesodevonic times, an extensive tract of palaeodevonic sea-bottom became elevated over a wide extent of New York and Pennsylvania, westward to Illinois and Iowa. This became peopled with a flora and fauna that approximated to the lower part of the European Old Red Sandstone, but which includes some striking intrinsic types. This is the Onondaga, Ulsterian, or Corniferous limestone area above referred to. In addition to three species of Coccosteus, remarkable allies of it are Dinichthy's with jawbones (Fig. I3) about two feet in length, Protitanichthys, Macropetalichthys, and Asterosteus.

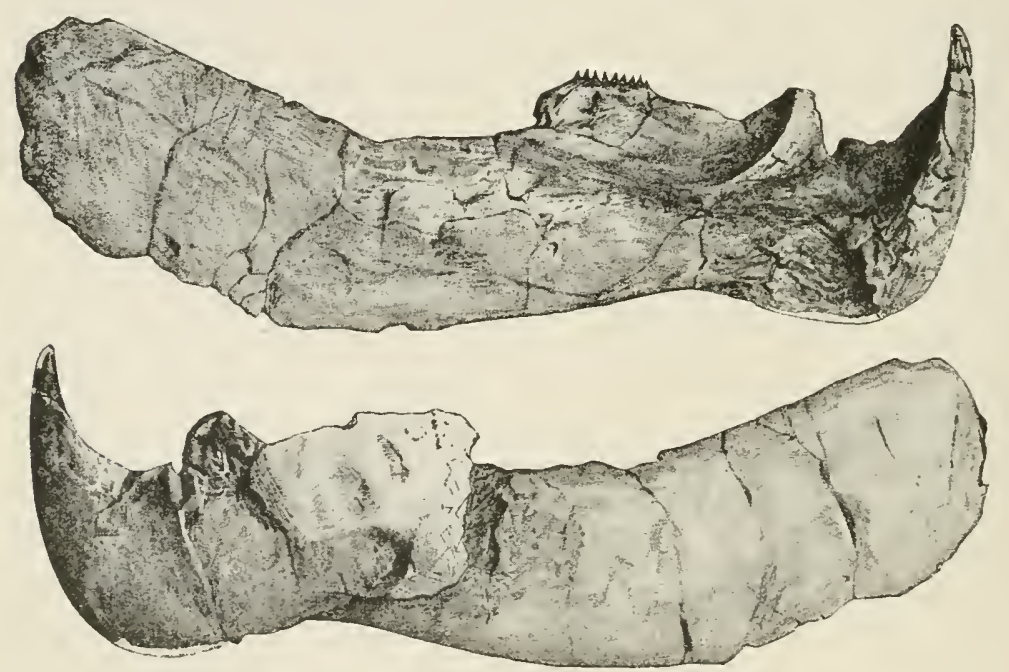

FIG. 13. Dinichthys hertzeri.. Upper figure shows view of jawbone from inner side, lower figure from outer side. (Reduced from Newberry.)

Now Newberry, in his elaborate palaeontological reports, takes it for granted throughout that these were marine fishes and of marine origin. Thus, to quote only 


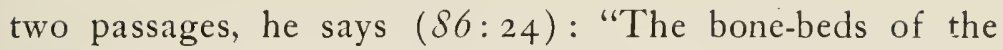
Corniferous Limestone, in which the remains of millions of marine fishes (ital. author) of Middle Devonian age are strewed over the old sea-bottom, contain numerous studlike, often highly ornamented dermal tubercles, and occasionally fragments of the pectoral spines of Machaeracunthus, but almost no teeth of cartilaginous fishes." And on the succeeding page he says: "The derivation of this fish-fauna is not known to us. The Devonian Cephalaspidians, Cephalaspis, Acanthaspis and Acantholepis have affinities with Pteraspis and Scaphaspis of the Upper Silurian and are perhaps their descendants, but the origin of the most striking and characteristic elements in this fauna-the gigantic Dinichthidae and the scaled and plated Ganoids, Onychodus, Macropetalichthys and Asterosteus, as also the great pterichthid Aspidichthys and the Elasmobranchs Rhynchodus and Machaeracanthus, among the largest and most highly specialized of all fishes-will perhaps always remain a mystery. Most of these were inhabitants of the Corniferous sea, and came in from the great oceanic basins with the flood which, at a certain time, inundated parts of the North American continent and deposited upon them the sediments which we call the Lower and Middle Devonian rocks."

Then on page 30 he suggests that the entire bone-bed "accumulated in some nook or bay, perhaps bordering a coral reef where large and small fishes congregated age after age, until their Kjokkenmöddings formed a sheet some inches in thickness over all the sea-bottom." Now the remarkable feature is that neither Newberry nor subsequently Orton in "Palaeontology of Ohio" describe a single coral or other marine organism from the bed. Claypole again ( $87: 313)$ in his paper on "The Devonian Era in the Ohio Basin" says: "Apparently the fishes of the Corniferous were tenants of the open sea and the clear water, where dwelt the coral polyps, and where the deposits were limestone." In the entire absence of traces of the corals, in the presence toward its base (p. 3 I6) of "masses of silicified wood (Dadoxylon newberryi Dawson)," and in the occurrence of similar fishes in Europe alongside remains 
of a land vegetation, we are forced to conclude that the Upper Corniferous of the Middle Devonian was of freshwater origin, unless weighty arguments to the contrary can be adduced.

But undoubtedly a mixing of lists of fossils, from closely placed beds or laminae, some of which were of marine, some of freshwater origin, has frequently taken place for Ohio. Thus the recording of Lingula and Discina with fish remains, while perhaps rarely indicating rapid changes in the relation of sea and land, is accurately and readily explained by the more recent studies of C. S. Prosser (88:297) on "The Sunbury Shale of Ohio," where he shows that only fish remains occur throughout one bed, while the above-named brachiopods are found abundantly at the base of the bed where change was proceeding. They are not mixed together.

As Whiteaves and Eastman have pointed out, a wide extension of this series of beds, with similar fish-remains, was continued into Hudson's Bay (89: I9 I), and on p. I93 he shows the close resemblances of the strata there to the Eifelian deposits of Bohemian and Russian Central Europe.

During deposit of the Huron and Hamilton shales and limestones, the sea again encroached at least in some areas, and this period marks the transition from a Mid to an Upper Devonian fish fauna. So when land elevation again took place, and freshwater conditions were reestablished, deposits over extensive areas of rocks with contained fishremains, were laid down, that extend westward from New York and Pennsylvania through Ohio to Iowa and Colorado. These form the Catskill and Cleveland series. The abundance and rich variety of this Upper Devonian Fish Fauna is demonstrated in the lists given by Claypole for Ohio (87:3 I 8) and by Eastman generally (op. cit. pp. 24I 72 ). Thus the former lists fully a hundred species from the Ohio shales. For the New World as for the Old therefore, this period was evidently the one when fish-life was dominant and prodigiously abundant in freshwaters, though - so far as exact evidence goes-was wholly or almost wholly absent from the sea. 
A somewhat related fish-fauna is that from Scaumenac Bay and other parts of Canada, but so far as it is now known, it did not include such gigantic forms as Dinichthys and Titanichthys. Eastman's condensed list (89: I6, I7) is as varied as it is suggestive.

In North America, as in Europe, the fossilized fishfauna of the Upper Devonian is nearly always associated with beds that are rich in eurypterids, in phyllopods, in highly evolved scorpions and myriapods, in a characteristic mollusc, and in finely preserved specimens of ferns and lepidodendroid plants. These have been described or referred to by Dawson, Newberry, Claypole (op. cit. p. 342), Patten (10:377) and others. More than passing mention however should be made of "a freshwater mollusc." Originally named Anodon jukesii by Edward Forbes, its history and biological environment have been ably traced by R. B. Newton $(90: 245)$ who named it Archanodon jukesii. He points out that Forbes found with it, at Knocktopher in Ireland, remains of the eurypterid Pterygotus, of the fish Holoptychius, also the Upper Old Red plants Cyclopteris, Archaeopteris (or Palaeopteris) libernicus, Lepidodendron, and Stigmaria. Subsequently commented on by Baily, Jukes, Hull, and Boyd Dawkins, it was by the last compared with Cypricardites catskillensis a closely allied form from Chenango County, New York State. In Ireland as in America similar environal conditions evidently prevailed, for he writes: "In Ireland the mollusc occurs with Palaeopteris hibernica etc., Coccosteus etc., and Eurypterus scouleri? etc; in Northumberland with Ulodendron ornatissimum and Calamites; and in America $A$. catskillensis, the close ally of the British species, is found in company with plant and fish remains (Holonema rugosum)." Here then we have a glimpse of a freshwater biological grouping that must have been more or less continuous from England to America.

So he concludes: "All these facts demonstrate that the genus Archanodon was of lacustrine or fluviatile origin, and that the deposition of the beds containing it, whether in England, Ireland or America must have been regulated 
by similar physical conditions, and in close proximity to land."

The most recent and remarkable additions to our knowledge regarding the distribution of Devonian fishes are due to material secured by the Arctic "Fram" expedition of Nansen, and by the "Terra Nova" expedition to the Antarctic. The fossils from the former region were secured by Dr. Schei at four localities round the upper end of Goose Fiord in Ellesmere Land, and on his death were described by Kiaer (gI $a: \mathrm{I})$. The rocks evidently belong to the "uppermost member of the Devonian," and consist of red and gray sandstones, sandy and micaceous schists, "anthracite in strips and thin layers," also at three of the four localities of "bituminous layers in the light gray sandstone." The richest locality yielded "a quantity of mussels, numerous fish remains, and indeterminable fragments of plants."

Two species of Psammosteus, one of Bothriolepis, Holoptychius scheii, a Glyptolepis that is possibly identical with G. paucidens, and a species of Osteolepis, together indicate Old Red freshwater deposits that had been laid down in waters which must have been more or less continuous from Russia, Scandinavia, and Scotland westward to the central and arctic parts of the North American continent.

Still more recently A. S. Woodward has published in the records of the British Terra Nova Expedition ( $9 \mathrm{I} b$ : 5 I) a paper that opens up new and striking suggestions as to the distribution and environment of some Old Red fishes. For in "Fish Remains from the Upper Old Red Sandstone of Granite Harbor, Antarctica" he has been able to identify the following:

Antiarchi

Bissacanthoides debenhami

Bothriolepis antarctica

Elasmobranchii

Cheiracanthus sp.

Dipnoi

Fragments of Coccosteus
Crossopterygii

Holoptychius antarcticus

Osteolepid

Actinopterygii

Palaeoniscid.

The existence of the above fishes in palaeozoic rocks near the South Pole, opens up many puzzling problems. But Granite Harbor is south from Australia, though nearly 
3000 miles removed, and it is from Australia that primitive Carboniferous fishes have been obtained. The genera however of these are the same as those recorded from India, Russia, Scotland and N. E. America, and all are of freshwater habitat. Six also of the above-named genera were first found in North Europe, so that a possible generic distribution, almost from pole to pole, during Old Red and Carboniferous times, seems to be indicated, and this by way of Eastern Australia. With the above two papers before us the conclusion then seems sound, that from near the North Pole to near the South Pole an extensive area of land once existed, the lakes, rivers, and flood-plains of which harbored related genera and even allied species of fish. These were so numerous that abundant remains of them are now being laid bare from widely apart centres. The map that forms Fig. I 5 (p. I 36) suggests possible land areas during Upper Old Red and Carboniferous times. The land areas however may have been greater.

As to the food and mode of feeding of the Silurian and Old Red fishes, all evidence indicates that the Agnatha were devoid of teeth, and were "bottom-feeders." Again the primitive dipneustians like Coccosteus, Macropetalichthys, and Dipterus were wholly devoid of ordinary cutting teeth, and only had broad tubercled crushing plates in the lower palate. So these resembled, but were more primitive than, the similar plates of such a living dipnoan as Neoceratodus of Australia. Now we know that the three living dipnoan genera (Neoceratodus, Lepidosiren, Protopterus) feed largely on aquatic vegetation, but also in part on small freshwater animals. The frequent accumulation of crushed vegetable remains, or of teeming masses of phyllopod crustaceans, alongside these primitive fishes, would indicate that they, like their existing dipnoan descendants, were largely herbivorous, possibly to a less degree dependent on small and soft animal prey.

The appearance of chondrostean types like Cheirolepis, and of crossopterygian types like Osteolepis and Megalichthy's with dentarian teeth of small to moderate size, suggest the catching of small prey, as is true of their nearest descendants of to-day. 
But the gradual evolution of Onchus and Cladoselache, of monacanthid and diplacanthid forms, that seem all to be primitive selachians, from the late Silurian to the close of the Old Red period, introduces a new and more voracious type of fish. For while in Cladoselache and Acanthodes, the teeth are of variable size, form, and adaptability for grasping or tearing, in genera like Ischnacanthus and Acanthodopsis they are strong and adapted for grasping prey. Their further striking evolution along increasingly carnivorous lines will be traced, when we reach the next great geologic period.

In shortly reviewing now the Old Red Sandstone period, we would regard this as the contemporaneous and freshwater geologic representative of the Devonian or marine set of rocks, though in recent years the term "Devonian" has been often applied to both. During deposition of these, varying oscillations took place in the relation of the land, of freshwater, and of marine areas. But throughout the period a huge and practically continuous northern continent -the North Atlantis of Frech-was developing a rapidly advancing plant and animal life. For to find Holoptychius giganteus in Upper Old Red rocks of New York, Pennsylvania, Iowa, and Colorado, in the north of Scotland, in Belgium and in West Russia; to find H. nobilissimus and H. flemingi (Fig. I 4) with a like Old World distribution; to find closely related species like $H$. halli, and $H$. americamus along with $H$. giganteus in rocks ranging from New York to Colorado, indicate a community of environal conditions that must have been extensive and intercommunicating.

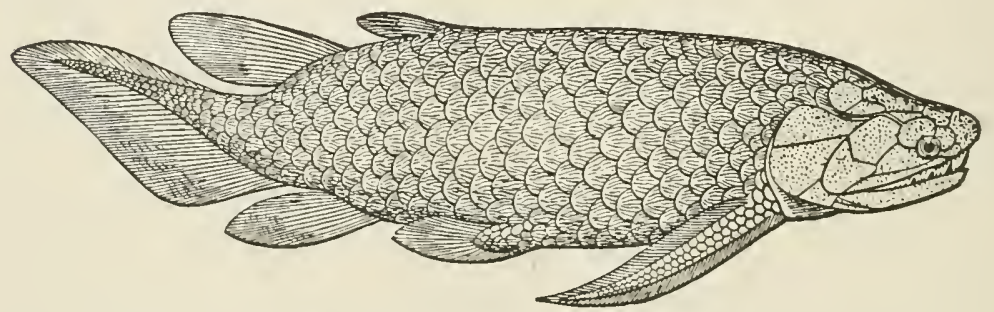

Fig. I4. Holoptychius flemingi. A crossopterygean fish from Upper Old Red rocks of Scotland. About one-eighth natural size. (From Traquair). 
So while in the seas and along the shores of that northern region, a teeming invertebrate fauna existed, that was rich in corals, echinoderms, brachiopods, and molluscs, extensive freshwater lakes, rivers and swamps developed and sheltered myriads of phyllopod crustaceans, of eurypterids, of bivalve molluscs, and specially of fishes, that attained at times to huge size and formidable defensive armature. While some of these like Cephalaspis, Bothriolepis and Euphanerops have left no living descendants or representatives, others belonged to elasmobranch, dipnoan, or ganoid groups that are still alive in derivative types.

Contemporaneous with these on land areas and often washed into the freshwater deposits to be preserved there, were scorpions, myriapods, and insects, as well as a varied vegetation, many members of which had reached to a high stage of lepidodendroid, equisetoid, or pteridoid organization. This freshwater or land flora and fauna have been made known to us, in part by preservation in or between successive deposits of mud, lime, or sand that were laid down during periodic freshets which affected lake, river and flood-plain areas, in part by rapid deposit of volcanic dust or other debris laid down during or soon after widespread volcanic activity. This destroyed countless myriads of organisms, not least of fishes, whose hard parts occur often in "bone-beds."

The question of mineral-oil or petroleum production has already been treated (pp. 49-59), but we would here emphasize that as the climax of fish-evolution in number of individuals and wide community of species had now been reached, so it is from these strata that the richest and most valuable supplies of mineral oil have been secured in the latter half of the past century. Such we would attribute almost wholly to the volcanic destruction and rapid entombment of myriads of fishes.

Finally before passing to the next great formation, we would direct attention to the diagram of possible continental relations that existed during the late Devonian and Carboniferous periods (Fig. I 5). This sets forth details that seem to be needed in explanation of the evolution and distribution of ancient fishes of that time. Wide continuity 


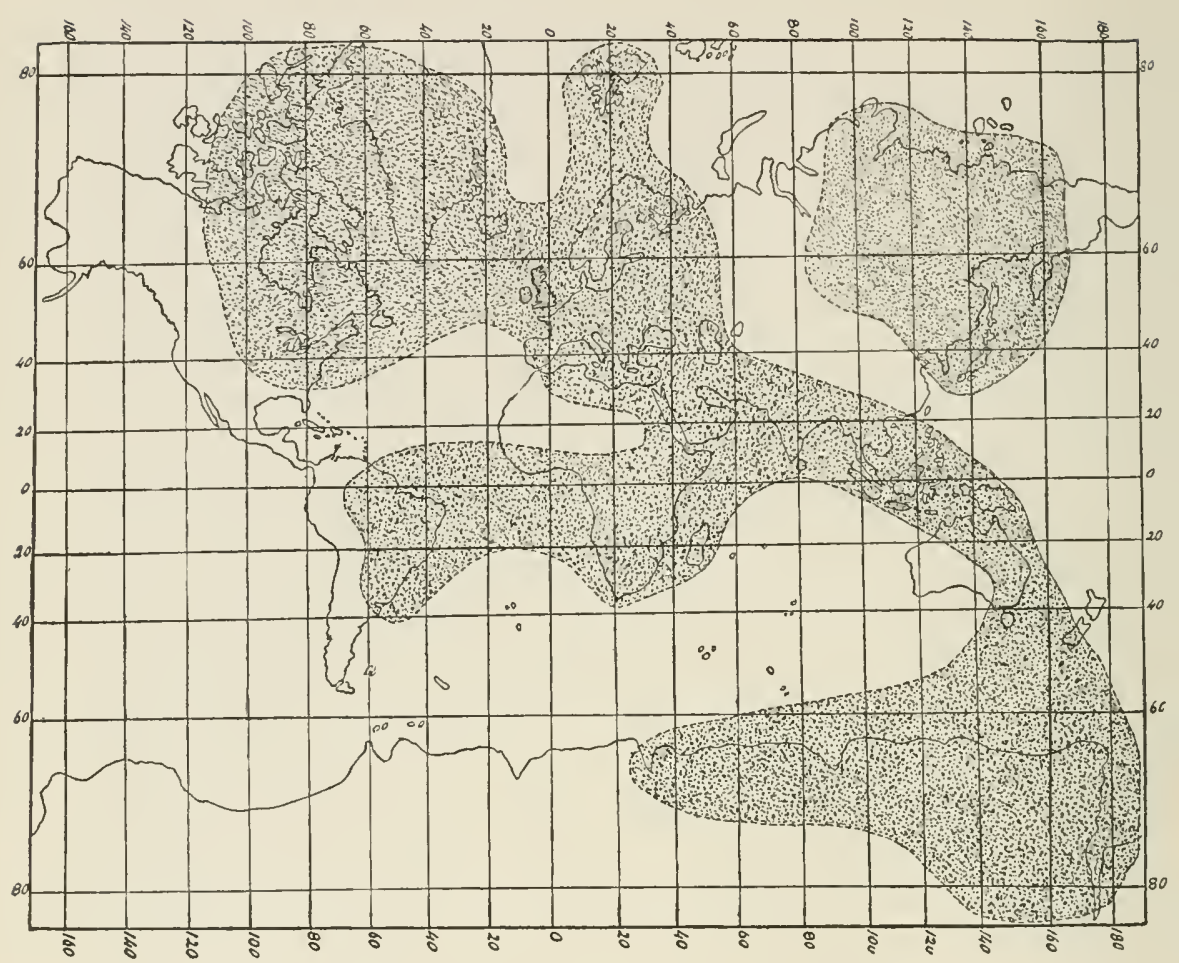

FIG. I5. Chart showing possible outlines of land, by shaded area, as existing in late Old Red or Devonian, and in Carboniferous times. Such is indicated by the distribution of plants, also of freshwater fishes and other animals.

and extension of the continental masses of the earth are indicated alike over the northern and the southern hemispheres. Only thus can one properly explain the continuous range of dipnoan and crossopterygian types in the fossil state; the early and continued residence in America and Australia of types of these or of their descendants; also the lingering existence of the three genera Neoceratodus, Protopterus, and Lepidosiren in Australia, Africa and South America respectively. If we accept compactness in the land-masses of the globe at this time, it aids in solution of many problems. 


\section{CHAPTER V.}

The Physical and Biological Environment of Fishes.

(b) During the Carboniferous and Permian Epochs.

In the Carboniferous and Permian as in the SiluroDevcnian systems freshwater and marine strata, both often of great thickness, have to be distinguished, though it is difficult as yet to correlate these exactly over the world. But in the Northern Hemisphere, over a great part of Europe and North America, probably also of Russian Siberia, a fairly continuous land-area must have persisted from "Old Red" times. For only thus can we interpret the plant and animal organisms encountered in the rocks. Here also it may at once be emphasized, that during the Mid-Carboniferous-possibly somewhat earlier-we first trace the invasion of marine areas by evolving lithe freshwater fishes belonging to the great elasmobranch series. But a truly remarkable feature is that these become practically exterminated again over such areas, in late Carboniferous or in early Permian days.

In the Carboniferous formation as a whole, two important groups of rocks are largely-often wholly-of freshwater or land origin. The lowermost of these has been variously called the Culm, Calciferous Sandstone, Mississippian (in N. America) or Lower Carboniferous, and its beds evidently extended continuously from Central North America, eastward through north Britain and France, to Mid Germany and Mid Russia. Chronologically this series seems to have been formed over the North Atlantic and Nearctic continents of Frech-both of which must have been more or less continuous as indicated by him-at a time when further south in Europe, and also in North America, the marine beds of the Lower Carboniferous or Mississippian, were in process of deposition. So while the latter contain a great wealth of typical marine 
invertebrate-rarely fish-organisms, the former indicates largely or wholly freshwater conditions.

But while in some localities or regions there seems to be direct conformability and therefore continuity, from the top of the Old Red to the base of the Calciferous or Mississippian, in other cases a considerable period must have elapsed, when terrestrial denudation and environal changes were proceeding. That profound changes in the relation of land and sea were also in progress is evident, and is almost certainly to be explained by the frequent volcanic outbursts, accompanied by extensive deformation and faulting of strata through earth shrinkage. Regarding such Geikie says: "One of the most singular features of the Lower Carboniferous rocks of Scotland is the prodigious abundance of the intercalated volcanic rocks," and he distinguishes two great types of these, (I) the plateaux "where the volcanic materials were discharged so copiously that they now form broad tablelands or ranges of hills, sometimes many hundreds of square miles in extent, and I 500 feet or more in thickness;" and (2) puys or vent-cones where small and local amounts of lavas, and more copious showers of ash were thrown out. Such must undoubtedly have caused widespread destruction to animal and even to plant life, while it gave occasion later for evolving and commencing new types to multiply and spread abroad.

The writer spent the leisure time, during years of his earlier scientific career, in tracing these Calciferous rocks over extensive tracts of the Forth basin, and as already noted he was constantly impressed by their predominant freshwater character, as well as the great thickness of the strata involved. Composed of varying beds of sandstone that were of a reddish-yellow or white color, of hard black fissile shale, of softer argillaceous layers, of extensive freshwater limestone beds, or of brown-black bituminous oil shales, these all yielded a greater or less abundance of associated plant and animal remains. But as the writer has already shown, in unravelling the history of Lepidophloios (92: I 8I), it often happened that the bulkier portions of some plant might be found in one set of beds, 
usually the finer sandstones; the smaller and lighter plant parts or the larger fishes in another, of ten the bituminous shales; while delicate twigs, expanded "fern" fronds, and small fishes might be spread out over the thin laminae of black fissile shale.

As Stur, B. Peach, Traquair, Kidston and other palaeontologists have shown, the biological assemblage of organisms is typical. Thus the writer has often laid bare from adjacent parts of the hard yellow-white limestone of Burdiehouse, a jaw with huge glistening brown-black teeth of Rhizodus hibbertii, myriads of the minute phyllopod Leperditia okeni rar. scotoburdiegalensis, delicately expanded leaves of Sphenopteris affinis, S. hoeninghausii, or $S$. bifida, the sporangiferous cones of Lepidodendron and Lepidophloios, fragments of Eurypterus scouleri, and not infrequently somewhat crushed but entire specimens of such freshwater fishes as Elonichthy's robisoni, E. bucklandi,

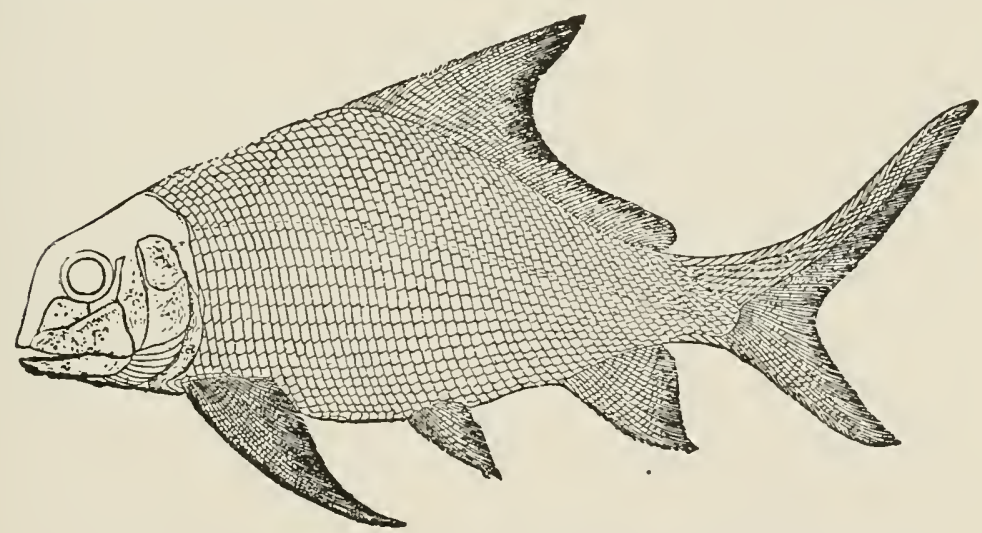

Fig. I6. Eurynotus crenatus, a common actinopterygian ganoid fish from the Calciferous or Lower Carboniferous beds of MidScotland. About one-fourth natural size. (Restored by Traquair.)

Rhadinichthys ornatissimus or Eurynotus crenatus, (Fig. I6). And for exact identification the latter usually passed under the master eye of Traquair.

The marked agreement between the flora-and such also we know to be true of the fauna-of the Calciferous 
series in the Forth basin and that of the "Culm" in east central Europe as elucidated by Stur, was first indicated to the writer by the veteran naturalist C. W. Peach, fully forty years ago. This demonstrated an organic continuity, as there doubtless was a geographic. But Heer has described (93: I6I) an interesting set of beds in Bear Island, that seem equally in their plant and animal organisms to extend the Calciferous formation into far northern regions, and also to relate it with the Upper Old Red of Europe and Canada.

Here it might be said that mixed or truly estuarine conditions are of minor account and of doubtful identification, though their supposed widespread existence in the past has been extensively used by palaeontologists to explain puzzling combinations. It is the difficulty of reconciling such an abundant fish-fauna as that of the Carboniferous system, with life in wide freshwater areas, that often caused so painstaking an observer as Traquair to postulate or tacitly accept a marine or at least an estuarine environment, when most or all of the facts in view favored a freshwater existence. It is, we believe, this restricted attitude of mind that caused him to think of localized estuaries, rather than of connected continental masses, and so caused him to overlook the great value biologically of what he so often and wisely pointed out, viz. the wide distribution of some species or genus over different lands, and the invariable association of such with certain phyllopods, eurypterids, scorpions, freshwater molluscs, and-not least-of like genera or even species of plants.

It is this failure also to realize that fishes were largely at this time, and previously had been wholly, land-locked animals of freshwater habitat, and that were undergoing wide intercontinental evolution, which caused him to pen the following (77:707): "We have in the estuarine beds of the Lower Carboniferous series of the central valley of Scotland, a fish-fauna of which many of the species persist through thousands of feet of strata, and must therefore have lived for a very long time without change in their specific characteristics. Then, after the Millstone Grit, 
poor in fish remains, is passed, we come to a new fauna, from which nearly all of the Lower Carboniferous species and with them also a number of genera have disappeared, their place being taken by an Upper Carboniferous assemblage, which in its main features is characteristic not only of the Coal Measures of Scotland, but of the Lower and Middle Coal measures of England, extending also into the transition series of the latter country."

Long-continued and increasing environal changes in the wide continental areas inhabited by the two groups of fishes he here compared, could only result in a changed facies of the species he refers to. In this connection Rupert-Jones very neatly remarks: "All animals may have been marine, subsequently brakish or freshwater, and this may have been the case with Estheria, but except for the progressive aspect of the argument, the converse might just as well hold good for the Lingula, the Spirorbis, Avicula, Anthracosia, Anthracomya, and Pleurophorus, mentioned as being found in the older rocks in company with Estheria."

What actually happened for fishes is fully set forth in a succeeding chapter. Here it may shortly be said that while the ganoids, crossopterygians, and not a few elasmobranchs remained in their former freshwater habitats, a gradual migration of some lithe, predaceous and powerful elasmobranchs into the sea took place during late Upper Old Red or more likely during Lower Carboniferous time. Then, and then only, their remains begin to appear alongside typical invertebrate marine forms, and this condition persists into the Upper Carboniferous or even Lower Permian.

As to the nature and successional relation of the chief fossiliferous beds of the Calciferous series round Edinburgh, the accompanying table (Fig. I 7 ) from one of Traquair's extensive papers (77:plate I) will illustrate, while it also sets forth the thickness of the beds. From a fairly intimate acquaintance with them the writer would regard the Craigleith sandstones and Wardie shales, the Burdiehouse limestone, the uppermost "Oil shales" and all of the connecting beds between these as purely freshwater, 


\section{i 42 Evolution And Distribution of Fishes}

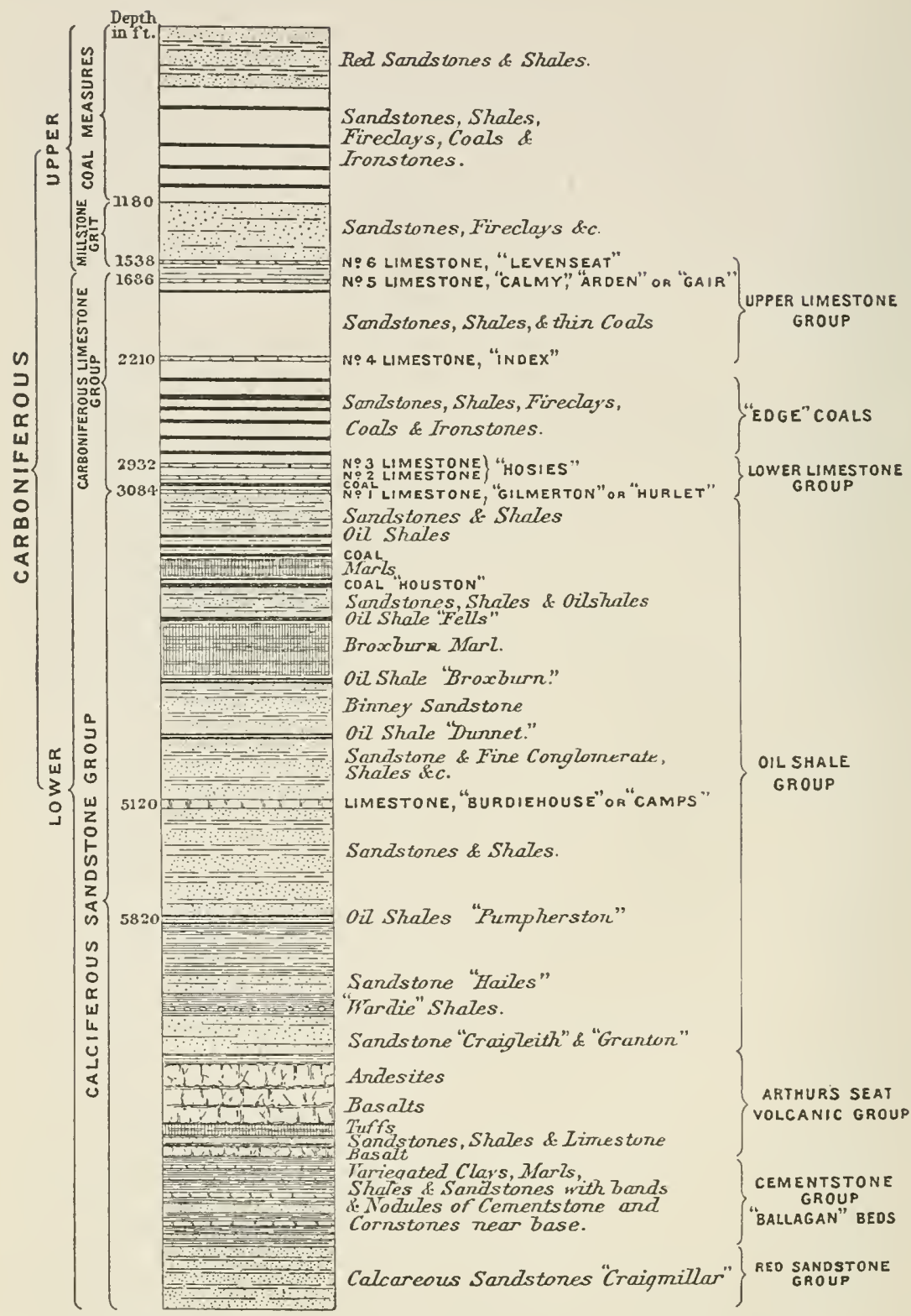

FIG. 17. Diagram showing relation of strata and their probable thickness in the Carboniferous Formation round Edinburgh. Detailed prominence is given to the lower or freshwater Calciferous beds with their oil shales and related strata. These are often rich in fish remains. (From Traquair). 
the Lower Limestone as in considerable part marine, the Edge coal as freshwater, the Upper Limestone as in part freshwater, in part marine, the Coal Measures as almost wholly freshwater. But in order to discuss this question more intelligently, there is appended the list given by Traquair of the entire fish-fauna of the Edinburgh rocks.

From the subjoined list (p.p. I 44-45) it will be seen that while elasmobranchs are most largely confined to the "Lower" or "Upper" Limestone, that are accepted as marine, Acanthodes sulcatus is common to the freshwater Burdiehouse and Dunnet shale; Tristychius arcuatus is reported from the Burdiehouse and $\mathrm{W}$ ardie shales, but also from the Upper Limestone; several occur in the Edge Coal and Upper Limestone; Sphenacanthus sermlatus and Cynopodius cremulatus in the freshwater Burdiehouse, Dunnet, and Edge Coal deposits, but also in the marine Upper Limestone.

But more remarkable is the list of crossopterygian and accipenseroid forms, for Rhizodus hibberti-a most typical freshwater species is also recorded from the Lower and Upper Limestone. The same is true of Elonichthys robisoni, Nematoptychius greenocki and Eurynotus crenatus, all common and typical freshwater fishes of the Edinburgh Calciferous rocks, But it should most importantly be observed here that all of the above species come either from the "Gilmerton Ironstone" beds of the Lower Limestone Series, or from the "South Parrot Coal shale" of the Upper Limestone Series, both of which are freshwater beds intercalcated amid what are mainly true marine limestones. Traquair however gives a list of what had now become either anadromous or wholly marine fishes (op. cit. p. 693) as follows:

Cladodus mirabilis

Cladodus striatus

Pelalodus acuminatus

Ctenoptychius lobatus

Ctenoptychius serratus

Petalorhynchus psittacinus

Polyrhizodus magnus

Pristodus falcatus
Copodus planus

Psammodus rugosus

Cochliodus conlorlus

Xystrodus striatus

Poecilodus jonesii

Psephodus magnus

Acondylacanthus jenkinsoni

Harpacanthus fimbriatus. 


\section{LIST OF FISHES, EDINBURGH DISTRICT}

\begin{tabular}{|c|c|c|c|c|c|c|c|}
\hline & 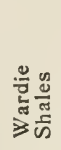 & 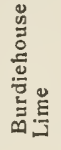 & 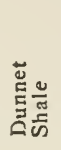 & 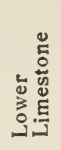 & 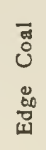 & 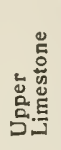 & 厄ू \\
\hline \multicolumn{8}{|l|}{ Elasmobranchii } \\
\hline Pleuracanthus laevissimus ...... & & & & & & & * \\
\hline Pleuracanthus elegans $\ldots . . . \ldots$. & & & & & * & * & \\
\hline Pleuracanthus gracillimus ...... & & & & & * & & \\
\hline Pleuracanthus horridulus ....... & & & & & * & * & \\
\hline Pleuracanthus fastigiatus $\ldots \ldots \ldots$ & & & & & * & * & \\
\hline Diplodus gibbosus $\ldots \ldots \ldots \ldots \ldots$ & & & & & * & & * \\
\hline Diplodus parvulus $\ldots \ldots \ldots \ldots \ldots$ & & & * & & * & * & \\
\hline Cladodus mirabilis $\ldots \ldots \ldots \ldots \ldots$ & & & & * & & & \\
\hline $\begin{array}{l}\text { Cladodus striatus } \ldots \ldots \ldots \ldots \ldots \\
\text { Dicentrodus bicuspidatus } \ldots \ldots \ldots\end{array}$ & & & & & * & * & \\
\hline Janassa linguaeformis ......... & & & & & & & $*$ \\
\hline Petalorhynchus psittacinus ...... & & & & * & & & \\
\hline Petalodus acuminatus $\ldots \ldots \ldots$ & & & & * & & & \\
\hline Ctenoptychius serratus ......... & & & & * & & & \\
\hline Ctenoptychius lobatus ......... & & & & * & & & \\
\hline Ctenoptychius apicalis $\ldots . \ldots \ldots$ & & & & & & & * \\
\hline Polyrhizodus magnus $\ldots . \ldots \ldots \ldots$ & & & & * & & & \\
\hline Callopristodus pectinatus $\ldots . \ldots \ldots$ & & * & & & * & * & \\
\hline Pristodus falcatus ............. & & & & * & & & \\
\hline Copodus planus $\ldots \ldots \ldots \ldots \ldots \ldots$ & & & & * & & & \\
\hline Psammodus rugosus $\ldots \ldots \ldots \ldots$ & & & & * & & & \\
\hline Helodus simplex ............. & & & & & & & $*$ \\
\hline Pleuroplax Rankinei ........... & & & & & & & * \\
\hline Pleuroplax falcatus .......... & & & & & * & & \\
\hline Xystrodus striatus $\ldots \ldots \ldots \ldots \ldots$ & & & & * & & & \\
\hline Cochliodus contortus $\ldots \ldots \ldots \ldots$ & & & & * & & & \\
\hline Poecilodus Jonesii ............ & & & & * & & & \\
\hline Psephodus magnus ............ & & & & * & & & \\
\hline Acondylacanthus Jenkinsoni ...... & & & & * & & & \\
\hline Lepracanthus Colei ............ & & & & & & & * \\
\hline Tristychius arcuatus $\ldots \ldots \ldots \ldots \ldots$ & * & * & & & & * & \\
\hline Tristychius minor $: \ldots \ldots \ldots \ldots \ldots$ & & * & & & & & \\
\hline Euphyacanthus semistriatus ..... & & & * & & & * & \\
\hline Sphenacanthus serrulatus ....... & & * & * & & * & * & * \\
\hline Sphenacanthus hybodoides ....... & & & & & & & * \\
\hline Gyracanthus rectus $\ldots \ldots \ldots \ldots$ & & * & * & & & & \\
\hline Gyracanthus nobilis $\ldots \ldots \ldots \ldots$ & & & & & * & & \\
\hline Gyracanthus youngi $\ldots \ldots \ldots \ldots \ldots$ & & & & & 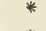 & & \\
\hline Gyracanthus formosus ......... & & & * & & * & * & \\
\hline Aganacanthus striatulus $\ldots . \ldots \ldots$ & & & & & & & \\
\hline Cynopodius crenulatus $\ldots \ldots \ldots \ldots$ & & * & * & & * & * & \\
\hline Euctenius elegans $\ldots \ldots \ldots \ldots \ldots$ & & & & & * & * & \\
\hline Harpacanthus fimbriatus ........ & & & & * & & & \\
\hline Harpacanthus major $\ldots \ldots \ldots \ldots \ldots$ & & & & & * & & \\
\hline Acanthodes Wardii ....... & & & & & & & * \\
\hline Acanthodes sulcatus $\ldots \ldots \ldots \ldots \ldots$ & * & * & ** & & ? & ? & \\
\hline Acanthodopsis Wardii .......... & & & & & & & * \\
\hline
\end{tabular}




\section{LIST OF FISHES, EDINBURGH DISTRICT-Continued}

\begin{tabular}{|c|c|c|c|c|c|c|c|c|}
\hline & 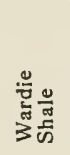 & 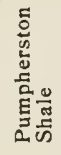 & 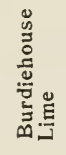 & 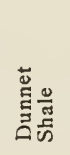 & 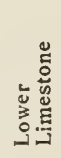 & 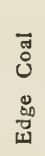 & 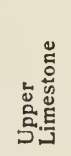 & 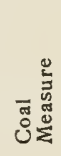 \\
\hline \begin{tabular}{l}
\multicolumn{4}{c}{ Crossopterygii } \\
Megalichthys Hibberti $\ldots \ldots$ \\
Megalichthys laticeps $\ldots \ldots$ \\
Megalichthys laevis $\ldots \ldots$ \\
Megalichthys pygmaeus $\ldots$ \\
Megalichthys sp. $\ldots \ldots$ \\
Rhizodopsis sauroides $\ldots \ldots$ \\
Rhizodus Hibberti $\ldots \ldots$ \\
Rhizodus ornatus $\ldots \ldots$ \\
Strepsodus sauroides $\ldots \ldots$ \\
Strepsodus sulcatus $\ldots \ldots$ \\
Strepsodus striatulus $\ldots \ldots$ \\
Coelacanthus elegans $\ldots \ldots$ \\
Coelacanthus abdenensis $\ldots$
\end{tabular} & $*$ & & $\begin{array}{l}* \\
*\end{array}$ & * & * & $\begin{array}{l}* \\
* \\
*\end{array}$ & * & $\begin{array}{l}* \\
* \\
* \\
* \\
* \\
*\end{array}$ \\
\hline $\begin{array}{l}\text { Dipnoi } \\
\text { Uronemus splendens } \ldots \ldots \ldots \\
\text { Unonemus lobatus } \ldots \ldots \ldots \\
\text { Ctenodus interruptus } \ldots \ldots \ldots \\
\text { Ctenodus cristatus } \ldots \ldots \ldots \\
\text { Ctenodus angustulus } \ldots \ldots \ldots \\
\text { Sagenodus quinquecostatus .. }\end{array}$ & & * & $\begin{array}{l}* \\
?\end{array}$ & * & * & $\begin{array}{l}* \\
* \\
*\end{array}$ & $*$ & * \\
\hline 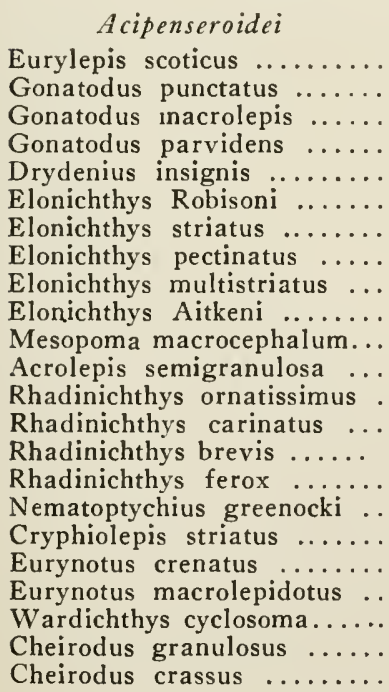 & $\begin{array}{l}* \\
* \\
* \\
* \\
* \\
* \\
* \\
*\end{array}$ & * & $\begin{array}{l}* \\
*\end{array}$ & $\begin{array}{l}* \\
* \\
*\end{array}$ & $\begin{array}{l}* \\
*\end{array}$ & $\begin{array}{l}* \\
* \\
* \\
* \\
*\end{array}$ & $\begin{array}{l}* \\
*\end{array}$ & * \\
\hline
\end{tabular}


As the author then well remarks: "not one of the abovequoted species occurs in any of the lists which I have given from the Calciferous Sandstone Series of the district, while all of them except Harpacanthus fimbriatus are well known from the Mountain Limestone of England, and except Pristodus falcatus, of Ireland likewise." It will be noted also that the above list consists wholly of elasmobranchs. From abundant evidence advanced by several of the British palaeontologists however, it is evident that a few of the hitherto inland fishes, and also these elasmobranchs were becoming anadromous, or even had become wholly littoral marine species. Previous papers by Traquair (97: I :34; $94: 2: 540)$ as well as subsequent ones support a like conclusion.

A richly fossiliferous set of Scottish Calciferous rocks is met with in the Eskdale-Liddesdale region. Peach, Kidston, and Traquair have jointly studied its organisms. Freshwater crustaceans, eurypterids, and scorpions, as well as 28 species of fish were listed. Kidston, in discussing the fossil plants, joins hands with Peach in emphasizing the striking similarity of the organisms they studied, to a set from Illinois studied by Meek and Worthen.

But that fishes were by no means the most highly evolved animals of the Calciferous age is proved by Huxley's description of the Amphibian Pholiderpeton from the Forth basin, while the other genera described by him from Ireland, give proof that during the Old Red period, certain derivative descendants from some group of the fishes, had already become by degrees evolved and modified up to the amphibian stage. The writer has already claimed that the direct line of ascent is to be sought for in types allied to the cyclostomes; from these intermediate organisms probably led to primitive representatives of the Amphibia apoda, thence to simpler, and later to more evolved, Urodela. The writer fully realized, when the claim was made, that very slight palaeontological evidence existed in favor of such a view. But the serious gap has been considerably bridged over since, and this most perfectly by recent publications of the Carnegie Institution. Most suggestive is 
Moodie's memoir on "The Coal-Measure Amphibia of North America" (95). The genera Molgophis, Cocytinus, Ptyonius, Aestocephalus and Lysorophus, seem to be at least some of the desired types. But further investigation of Old Red and of Calciferous as well as more recent rocks, for the discovery of advancing organisms between cyclostomes and aistopod batrachians, is greatly needed.

In eastern North America, the Calciferous or Culm of Europe seems synchronous with the extensive-though often marine-beds that make up the Mississippian series. The marine beds yield a varied and very typical marine fauna, the invertebrate fossils of which have been copiously listed, though fish remains are rare or conspicuously absent. But the Mauch Chunk of Pennsylvania and West Virginia; the Waverley and Cuyahoga shales of Ohio; the Mauch Chunk and Pennington of Virginia; the Burlington of North Missouri and Illinois; also the Horton of East Canada, give ample evidence of a combined freshwater and land flora and fauna. These also are even more varied and extensive than those of the Old World. They have been described mainly by Hall, Dawson, Newberry, Worthen, Whiteaves, Eastman, Lambe, and Condit amongst others.

The earlier and succeeding editions of Dawson's "Acadia" opened up wide palaeontological vistas. In describing the Horton series of Nova Scotia (85:25I) and the Lower Carboniferous or Albert shales of New Brunswick, Dawson (96:337) and Lambe (97: I) refer to an exactly similar biological aggregate as that of Europe. Swarms of phyllopod and other entomostracans such as Leaia leidyi, Estheria sp. Leperditia suberecta, eurypterids, scorpions, millipedes and insects-mainly orthopterous,freshwater molluscs, great shoals of fossilized fishes, "and footprints of batrachians" occur, but no strictly marine remains.

Speaking of a thin bed (No. 6 of Division 4) "full of remains of small fishes" Dawson says: "It has a true stigmarian underclay. I suppose it to have been a swamp or forest submerged and occupied by fishes, while its vegetation was still standing. It contains remains of fishes of the 
genera Ctenoptychius, Diplodus, Rhizodus and Palaeoniscus. It also contains Cythere, Naiadites (Anthracomya) and Spirorbis. In the other beds which contain fish remains, most of these consist of small lepidoganoids, but there are occasional teeth and scales of large species of Rhizodus," and also teeth of elasmobranch fishes of considerable size, some of which he describes and figures. Later he adds: "the larger ganoids, and the shark-like Diplodonts no doubt preyed upon the smaller fishes, as the abundant scales seen in their coprolites prove. The flat-toothed sharks like Psammodus and Conchodus may have ground up the shells of Naiadites."

Both authors, in describing the freshwater Albert shales, were equally arrested by the conditions that surrounded and in part caused wholesale destruction of, the fishes. Thus in describing the five species of Rhadinichthys (Palaeoniscus of Dawson) Dawson says (96:340): "The whole of these fishes have been preserved entire, the body being perfectly flattened, and thrown into attitudes which imply that they were embedded when living, or immediately after death. The material in which they are contained is shown by its microscopical and chemical characters to have been a vegetable muck or mud, and the fish were entirely overwhelmed by it, in the manner of a bursting bog, or were stiffled by the non-oxygenated water mixed with this mud, and suddenly killed and embedded in the accumulating sediment." Here, as in the frequent preservation of fish and other organisms in the fossil state, sudden flood-plain freshets might explain the results, though the sudden throwing into the water of deleterious products seems more likely

Lambe draws an exact parallel between the Albert beds and those of the Scottish Calciferous system. But regarding the fishes he says: "they belong to the same genera, but differ as to species." This, however clearly indicates that some important and continuous land-connection united both areas, as the chart of Frech sets forth.

A noteworthy feature of these Albert shales is their apparent identity in color, consistence, and oil-content with the oil-shales of the Scottish Calciferous system. Thus they 
are of a dark grey to brown color, are of a fine close grain, they split into layers or sheets, and the strata are 5 to 6 feet thick. But the bands form only a thin part of the shales and sandstones in which they lie. These have been grouped as follows by Lambe (p. i I) :

Calcareo-bituminous shales, from grey to dark brown in color, including the so-called Albert shales................ 850 feet

Grey bituminous and micaceous oil-bearing sandstone, and lower conglomerates, in massive beds, usually of reddist tint, and unconformable to the preceding.................. 700 feet

Following R. D. Stewart he inclined to view the bituminous material largely as a product of plant decomposition. $\mathrm{He}$ also regarded the fishes as being marine, for he observes: "It is probable that the waters in which lived the fishes about to be described, were cut off to a great extent from the sea, and formed the lagoons in which the material that produced the shales was deposited." And as to the quantity of these fishes he adds: "the numberless remains of fishes in some of the beds can be attributed only to the occasional wholesale destruction of the fishes." But the associated plants, the correlated resemblance in details to the Scottish beds, the complete absence of true marine remains, and the undoubted freshwater habitat in other regions of the genera he treats of, clearly prove the beds to be freshwater deposits. In this, as in many other cases now cited, we would trace the origin of the bituminous supplies to chemical or biochemical decomposition of the oils contained in the fishes.

Of the fishes that he describes he remarks regarding Rhadinichthy's alberti that it " evidently swarmed in countless numbers in the waters of its time." Scarcely less abundant was Elonichthys browni, the general aspect of which, as well as the structure of the ganoid scales from different parts of the body are shown in Fig. I 8.

In the eastern and central States, conditions closely simulating those already given, prevailed during deposition of the middle and upper Mississippian. But such often alternated with invasions of the sea, and so of a marine fauna. This is well set forth in the elaborate reports of 


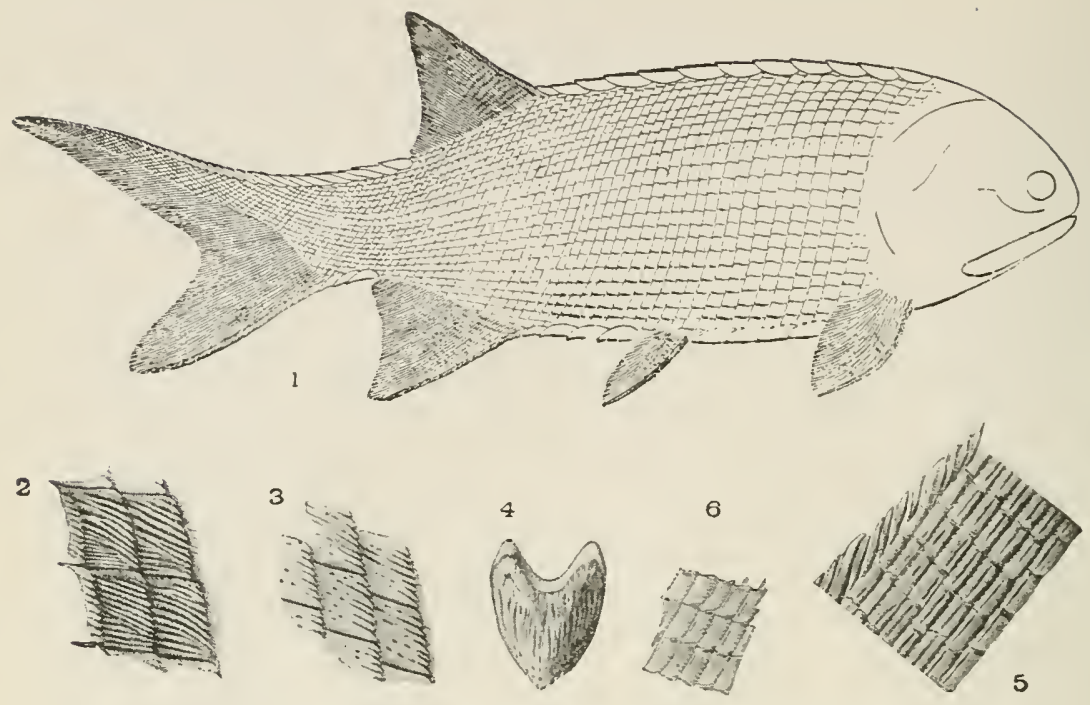

FIG. 18. Elonichthys browni.-1; outline restoration of fish, one-half natural size; 2,3 , two types of flank scales; 4, ridge scale; all enlarged: 5, portion of dorsal fin-rays and marginal fulcra; 6 , portion of rays from base of dorsal fin. (All reduced from Lambe).

the Pennsylvania, New York, Ohio, Illinois, Iowa and other State Surveys. In several of these also, bone or "fish-beds," that vary from one to several inches in thickness occur. Lesley frequently refers to these in Pennsylvania. But the most noteworthy probably are four thin and apparently marine beds that have been studied by Newberry and Worthen in the Burlington zone of Illinois ( $98: 12$ ). One of these, in which the teeth and spines of fishes are embedded in great numbers "stretches at least from Quincy, Illinois . . . to Augusta in Iowa," points nearly a hundred miles apart. This indicates that the cause which produced such general destruction amongst the vertebrated animals of this period was not local, but operated simultaneously over a wide geographical area.

To the writer it seems that such an area, at least io,ooo square miles in extent, and continuously covered with the remains of fishes that were however of freshwater ancestry, supplies the best possible explanation for origin of the Illinois oil beds. The soft perishable oily parts 
seem to have supplied the oil, the hard parts to have supplied the contents of the probably true marine elasmobranch "bone-beds."

A detailed study of the numerous published lists of rock sections given in the State surveys, or in some of the geological magazines, reveals how very unstable was the earth's crust up to this time, and how frequently alternation of freshwater and of marine conditions prevailed. The natural outcome is that the geologist, who accurately takes note of each horizon and of its fossil contents, constantly records from adjoining and often thin beds, a freshwater and then a marine list of organisms. An excellent example of this is furnished by Condits "Conemaugh Formation in Ohio" (99), which though dealing with the Higher Carboniferous beds, is typical for those now treated of.

As demonstrating also the widespread destruction to fish-life that proceeded now, contemporaneously with the evolution of new types, we may note in passing that the unwieldy and giant fishes, like Coccosteus, Phlyctaenaspis, Dinichthys, Titanichthys and Macropetalichthys, typical of the North American Upper Old Red period, had wholly died out by the close of the Mississippian, and had been replaced by a higher, more lithe, and more voracious type of fish, belonging to freshwater elasmobranch, and, to a lesser extent, to crossopterygian affinities.

The Mountain Limestone and Millstone Grit. Between the Iower and Uppermost Carboniferous formations of Europe, there are often intercalated two extensive sets of rocks that in Britain have received the above designation. The former is very largely of marine origin, though at times showing intercalated freshwater beds. It may be as much as 4,000 feet in thickness. The latter is singularly devoid of organic remains, but varies from 1200 to 5500 feet in thickness. As the writer abundantly verified about forty years ago, and as the published results of Kidston for plants, and of Peach and Traquair for animals has equally demonstrated since, the "Grit" beds separate two totally distinct biological groups of organisms, that are specifically and often even generically or ordinally distinct. These are the Lower Carboniferous, Culm or Mississippian, and 
the Upper Carboniferous, True Coal Measures, or Pennsylvanian.

Probably no other formation has been so fully and readily accepted as of freshwater or terrestrial formation than the latter, for it and the important coal-beds of the world have been inseparably linked in human thought for the past fifteen decades. So while we would view the petroleum oils of the Old Red and the Lower Carboniferous formations as being fish derivatives, it is equally true that the pure carbon or coal of the present group is of vegetable origin. But from its intimate relation to an abundant fish-life, it is not at all improbable that some types of coal, like the cannel or parrot, largely owe their bituminous properties to intrinsic permeations of fish oil.*

But before treating of the biological assemblage that characterizes the Coal Measures, it should be observed that the invasion of marine regions by elasmobranch fishes mainly, which started in the Calciferous period or possibly earlier, became a most pronounced event during deposition of the Mountain Limestone, and was continued into the Coal Measures. This migrational change is fully discussed in Chapter 9 (pp. 275-79) and so consideration of the fishgroups involved can be deferred meanwhile.

The Coal Measures (or Pennsylvania beds.) The high economic value of the rocks composing this division has caused detailed study of its physical and biological features alike. But it should be borne in mind that though the great mass of strata composing it suggests a freshwater and land origin, continued though less prolonged oscillation of the earth's crust than in preceding epochs, often caused temporary marine invasion, over large areas that fundamentally remained as land masses. Probably the most careful and extensive demonstrations of this are brought forward by Kirkby in his paper "On the Occurrence of marine fossils in the Coal Measures of Fife" (I00:378); also by J. Ward $(I O I: 42)$, and by J. T. Stobbs $(I O 2: 495)$. The last named points out how easy it is to confound fossils

* This subject is fully considered in the writer's volume entitled "Fishes the Source of Petroleum" (1923). 
of different strata, unless the observer has himself dug out the fossils and noted the exact locations and relations. He tabulates eleven distinct marine bands. And in regard to these, as compared with the greatly more extensive and thick terrestrial bands, Hind in a palaeontological Supplement says that there are two distinct molluscan faunas, which recur with irregular alternations. The freshwater fauna is characterized by the Unio-like genera Carbonicola and Anthracomya, and the Dreissensia-like Naiadites; the other by Pterinopecten papyraceus, Possidonella, with many species of cephalopods, and the two never mix.

But on the succeeding page he states, for "the marine band associated with the Gin-mine Coal" that the two elasmobranch genera Listracanthus and Edestus occur in it. Quoting other localities for Listracanthus he reaches the conclusion that "Listracanthus is associated with a marine fauna. We may therefore consider that Listracanthus always had a marine habitat. Many of the fishes associated with it in the bed below the Gin-mine are also found with a non-marine fauna," and he appends a list setting this forth. Bolton $(103: 424)$ and Woodward $(104: 486)$ also record Listracanthus in nodules of shale strata, and conclude that these are all marine beds. So it evidently is an elasmobranch which had largely left a freshwater habitat and mainly lived in marine surroundings. This is discussed later (p. 275). But here it may be said that all of the other fishes listed by Hind (p. 529), and including Edestus, were freshwater.

The environal relations of Coal-measure organisms have been so often described, and more or less correctly figured, that a general word-picture is unnecessary. Nor, in view of the surprising similarity of the rocks, of the factors which gave rise to these, and of the organisms enclosed, need we deal with localized areas, in their physical or biological relation to fishes. Rather it might at once be stated-in view of the knowledge we now have of Coal Measure strata and their fossils-that some such compact and yet extensive connecting land areas, as are traced by Frech $(105: 83)$ are a necessity for the understanding of the facts and problems involved. 
Extensive lists of the plants have been given in the past half-century by Lesquereux, Dawson, Lester Ward and Fontaine in this country; by Lindley and Hutton, Williamson, Kidston, Seward and others in Britain; by Zeiller, Renault and Grand d.Eury in France; and by Weiss, Feistmantel, Stur, Barrois and others for Germany-Austria. All agree that wide land areas of low flat swampy character; of warm but moist humid atmosphere, during some seasons of the year, alternating with hot, bright-almost xerophytic-conditions at other seasons; were typical. The farreaching but comparatively shallow waters of lakes, sluggish rivers and lagoons teemed with such phyllopods as Estheria tenella, Leaia leidyi and a variety of freshwater ostracods. These seem to have formed the food for great shoals of freshwater fishes of rather sluggish habit, as did also the gasteropods and the abundant pelecypods like Carbonicola, Anthracomya, and Naiadites (ro6), all or most of which hung by byssus threads from the trunks of the swamp-loving trees, as Dawson and Hind have shown. Alongside these were great eurypterids, whose specific details have been elucidated by $\mathrm{H}$. Woodward ( 107 ), Laurie ( I08: I 5 I, 509) and Clarke-Ruedemann (65). The last however were fast disappearing, compared with their more giant predecessors of the Lower Carboniferous, Old Red, and Silurian ages. Scorpions, spiders, and insects were abundant, while in the swamps, flood-plain pools, rivers and lakes, a new and diversified fish fauna existed. Before dealing with this in some detail, it might be stated that a rich amphibian evolution had resulted in the appearance of types varying from 2 or 3 inches long to others that were 6 to 8 feet. Many of the latter, like their coccostean and other piscine predecessors were heavily armored and clumsy animals. So, if the abundant vegetation of the period caused it to be called "the age of plants," equally truly might it be called "the age of amphibians." The older records by Dawson, Huxley, and Miall as well as the recent publications of the Carnegie Institution ( IOg) by Case and Moodie fully demonstrate this.

Viewed as a whole the fish fauna of the period was surprisingly uniform in general types, but differed in the 
distinctness of the species or at times of the genera. So whether we compare lists gathered across the world from the Eastern States to Australia, or from Canada to Cape Colony the general resemblance is striking. Further this fauna was to a large degree freshwater, the elasmobranchs alone being the group that still sent voracious and predatory outliers into the seas of the period. The number and affinities of these are set forth in Chapter 9 (pp. 279-80).

Even the primitive sharks like Cladodus, Chomatodus, Diplodus, Pleurodus, and Ctenoptychius were still lakedwellers, or were anadromous in some species, or freshwater in some and anadromous in other species of a genus. The remains of many of these therefore belonged to the groups Ichthyotomi, Petalodontidae, and Psammodontidae, which were loosely cartilaginous, but can be recognized in their hard teeth and plates, which are often intermingled beside freshwater chondrosteans, dipnoans, and crossopterygians.

J. W. Davis gives $(I I O: 56)$ a graphic picture, derived from study of the Cannel Coal of Yorkshire. This formation, as he states, was due to decay of abundant vegetation that became "aggregated in a small inland lake, very shallow and liable to be dried up. The plants forming the coal were washed into this lake by streams, and becoming decomposed, and settling to the bottom, accumulated in a homogeneous mass, prior to its being changed by pressure and chemical causes into coal. The interlamination of shales, more frequent and thicker near the sides of the lake, would naturally result from the mud, also brought down by the streams, settling to the bottom more quickly than the leaves of the plants, but at the same time carrying down with it a large percentage of carbonaceous substance. In some parts the lake appears to have become filled up or elevated above the water-level; and seat-earth filled with Stigmaria rootlets was the result. From the seat-earth grew plants whose remains have formed thin bands of ordinary coal.

"After the accumulation of the decaying vegetable matter, sometimes deposited in water and forming cannel 
or gas coal, at others on land, and resulting in thin beds of ordinary coal, the whole was submerged beneath the water, and an average of from $\mathrm{I}-2$ feet of black bituminous mud, containing few traces of animal exuviae, except an occasional layer of Entomostraca, was deposited. Above the black shale there is a light-grey colored stratum, about Io in. to I ft. thick, which is almost, or entirely composed of the shells of Anthracosiae. Countless numbers of the shells of these molluscs occur; they are always found crushed. They were the shells of animals such as would be found at the present time inhabiting and luxuriating in semistagnant pools. . . Above the shell-bed are about twenty feet of bluish-white shales, containing several layers of ironstone nodules. Shells of Anthracosia are common in the ironstone, but do not occur in the shale. All of these facts point to one issue-that we have in these beds an example of an inland lake of freshwater origin. This is a most important conclusion when we come to consider the variety of fish-remains which have been obtained from these strata.

"The fossil fish are found in greatest abundance at Tingley; where the coal has been worked, elsewhere fish remains are either quite absent or occur with great rarity. At Tingley they are found in largest numbers between the cannel coal and "Hubb," many beautiful examples however have been obtained from all parts of the cannel coal, and they not unfrequently occur in the 'Hubb.' The following is a list of the fishes which I have been able to identify:

Coelacanthus lepturus

Ctenodus elegans

Megalichthys Hibberti

Rhizodopsis sp.

Palaeoniscus sp.

Gyracanthus formosus

Ctenacanthus hybodoides

Diplodus gibbosus

Ctenoptychius pectinatus

Helodus simplex

Ostracanthus dilatatus

Compsacanthus triangularis

Compsacanthus major

Cladodus teeth

Petalodus
Rhizodus-scales

Ctenodus sp. ribs and bones

Pleuracanthus laevissimus

Pleuracanthus erectus

Pleuracanthus pulchellus

Pleuracanthus alternidentatus

Pleuracanthus alatus

Pleuracanthus robustus

Pleuracanthus (Orthacanthus)

Spirorbis carbonarius

cylindricus

Entomostraca

Julus?

Anthracosia (Unio)

Labyrinthodont (?) ribs, teeth, etc. 
He then adds "Most of the fishes composed in this list belong to the Elasmobranchii and Ganoidei; but whereas the Elasmobranchii are generally considered to be of marine origin, and the ganoids rather to pertain to freshwater, we have them both in this case, fossil together, and evidently deposited in the immediate neighborhood of the spot where they lived. The sharks were of large size." He then refers to the relative abundance of each lot of the above, and later compares his own results with those of Newberry $\left(8_{3}: 284\right)$ and proceeds "after careful study of the deposit Dr. Newberry considers that there was in this locality at the time when the coal was forming, an open lagoon, densely populated with fishes and salamanders, and that after a time this lagoon was choked up with growing vegetation, and peat (which afterwards changed to cubical coal) succeeded to the carbonaceous mud (now Cannel) that had previously accumulated at the bottom of the water." He then states that Newberry found nine species of Eurylepis, a small tile-scaled ganoid, two or three species of Coelacanthus (closely allied to C. lepturus of the English Coal Measures), scales and teeth of Rhizodus, spines of Orthacanthus and Compsacanthus, and teeth of Diplodus. The striking parallelism as above revealed is arresting.

Two extensive and specially suggestive British papers, alike from the physical and biological standpoints are: (I) "List of Fossil Fishes" in the "Catalogue of Western Scottish Fossils" by Professor J. Young, and (2) "The geological Features of the North Staffordshire Coal Field" by John Ward. In the former a most extensive list is given of all known western fossil fishes found in the Carboniferous Lime or in the Coal Measures. Reference to p. 279 will show that of Elasmobranchii thirty species are either freshwater or are anadromous, and thirty-three species are now marine, these too are almost wholly from the Limestone series. But of "Ganoids" and dipnoans, thirty-two species, or all recorded, are from freshwater beds. Many of the last also, as well as of the freshwater ganoids, occurred in beds that yielded remains of six species of Laby- 
rinthodont belonging to as many genera. These, like other amphibians, were intolerant of saltwater.

Ward's paper confirms and even extends the results of Young.

Papers that treat of the Northern and North-east French coal-fields, of the Belgian and of the east German fields, largely duplicate the conditions above revealed.

The total thickness of the Coal Measures in Britain has, by Hull, Geikie, Ward and others been estimated at 2,000 to as much as I 2, 000 feet, though 3,000-5,000 includes average variations.

Over the eastern half of the North American continent the Coal Measures cover several widely extended regions in all of which rich coal beds occur. That a nearly or quite synchronous connection existed between these and the above Measures of the Old World is assured from many considerations, and not least from the generic or even specific identity of the organic remains. The occasional variability in species or genera probably favors the view of Chamberlin, that definite and isolated centres of physical as well as organismal formation existed. Thus while the Michigan and Rhode Island areas may each have remained distinct for a protracted period, continuity probably was kept up in the Pennsylvania, Ohio, Kentucky and Tennessee regions. Again the Illinois-Indiana region may have had at least slight connection with the Missouri-Iowa area, and so on. But until very exact stratigraphic and palaeontological evidence is at hand, we can only approximately surmise.

Equally as suggesting the possible mode of origin of coal, the great stretches that must long have remained as swampy lakes, and the types of associated organisms in these lakes, Newberry's account of the locality above referred to may be quoted from a later publication (86). "The Linton (Ohio) locality is especially interesting and instructive. It has already yielded more than twenty species of fishes and nearly forty species of aquatic amphibians, all inhabitants of the same body of water. These are found in a thin stratum of cannel, which, over a limited area, underlies 
a thick bed of cubical coal, of which the place is near the top of the Lower Coal Measures. This is a bed of coal which extends over some thousands of square miles, and it is usually a soft coking coal, not unlike that of the Pittsburg seam, which lies about 500 feet higher. At Linton, however, we have evidence that the great marsh in which the peat accumulated that formed Coal No. 6 was for a time a lake or lagoon, inhabited by the fishes or amphibians to which I have referred. While this remained an open body of water carbonaceous mud accumulated at its bottom, derived from the drainage of the neighboring marsh, which carried with it fine particles of completely macerated vegetable tissue. In this carbonaceous mud that is now cannel coal, were buried the scales, bones, spines, and often entire individuals of the inhabitants of the waters above. Sometimes nearly the whole mass is made up of animal debris. Many of the fishes and amphibians were highly carnivorous and powerful, as we learn from their teeth and coprolites.'

Chamberlin describes life in the North American coal areas $\left(8: I 1: 6 I_{3}\right)$ as follows: "Aside from the developments of the freshwater fish and of the amphibians, which have already been sufficiently emphasized, perhaps the most suggestive feature was the association of the arthropods with other forms of life. Eurypterids were still in existence, and their relics are so intimately associated with beautifully preserved ferns, calamites, insects, spiders and scorpions, as to leave no reasonable doubt that they were freshwater forms. In the more notable localities, as at Mazon Creek, Illinois, and Cannelton, Pennsylvania, the fern fronds were preserved with almost perfect fidelity and without the coiling, crumpling and shredding that would have inevitably attended transportation for any notable distance. At the famous locality on Mazon Creek, uncrumpled fronds form the centers of thousands of concretions, and insects, spiders, scorpions and eurpyterids form the centers of others associated with them. All must have been fossilized with a minimum of transportation, and under the most quiet conditions. Almost equally in- 
structive is the association at Cannelton, though the vegetation is more fragmentary."

The rich eastern Australian oil shales that have been described by Carne (IIL) and others, also the associated beds of calcareous and arenaceous shale, have yielded as yet few traces of fishes. Suessmilch, however, notes (II3: I38) that: "a fossil fish (Urosthenes australis) has been obtained from the Upper Coal Measures, both in the Lithgow and Newcastle districts, while from the latter locality the wings of some undescribed insects, belonging probably to the Neuroptera, have been obtained." A labyrinthodont and abundant fossilized plants alongside caused him to regard all as of freshwater origin.

The remarkable set of fish remains that has been described by A. S. Woodward (II4:I) from calcareous, arenaceous, and shale beds of Mansfield in Victoria, probably belong to the same rock series as that which furnished Urosthenes further north. They indicate a Carboniferous age, and are preserved alongside abundant plant remains in some strata, though without trace of marine organisms. The most striking and probably most abundant type of fish is that named Gyracanthides murrayi by Woodward (Fig. I9). Belonging to the primitive elasmobranchs, it first clearly revealed the exact disposition of the formidable fin-spines that have been named Gyracanthus, and which occur at times in considerable amount in Carboniferous and Carbo-Permian beds from central North America to Britain. In addition to remains of acanthodian elasmobranchs, the other fishes belong to Ctenodus, a genus of ancient Dipnoans; and to Elonichthys and Strepsodus among ganoids. All of this is added proof that from northern Europe and America to Southern Australia, freshwater passageways existed that permitted steady migration and variation amongst related groups of fishes.

We may shortly sum up now, for the fishes of the Coal Measures, by saying that the once prevalent and primitive Ostracoderms and Arthrodires had wholly disappeared; the primitive and rapidly evolving Elasmobranchs were the most predaceous and lithe. So some of the latter gradually 


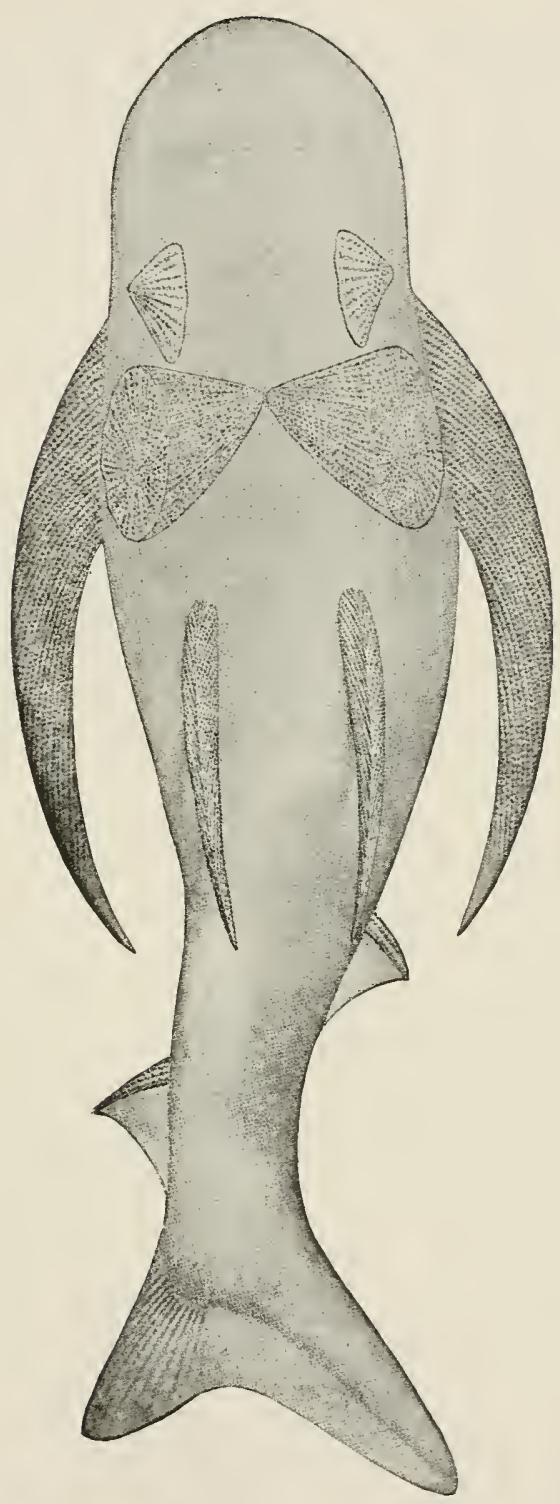

FIG. 19. Gyracanthides murrayi. An ancient but highly modified Elasmobranch, one-third nat. size. Ventral view of head and abdomen, but tail twisted to give side view. (Reduced from A. S. Woodward). 
invaded the sea from early or Mid-Calciferous time onward, while many still kept to inland waters. Of Crossopterygians, Rhizodus-in spite of formidable teeth-had almost died out, but its allies Strepsodus and Rhizodopsis were abundant in Europe, though rare or largely absent in America. Coelacanthus, on the other hand, was abundant in both countries. But the Actinopterygii, or "ganoids" in the older sense, were, as to number of individuals and of species, the most abundant. The genus Rhadinichthys, that attained its climax in the Calciferous of Britain and New Brunswick, persisted in several known species, into the Coal Measures alike of Britain and of the United States. But the genera Elonichthys, Platysomus and Acrolepis are preeminent in distribution, as they occur from the Calciferous up to the Permian, and from Bohemia on the east to Illinois on the west. The last named genus also seems to have extended from Russia to Cape Colony.

\section{The Physical and Biological Environment of THE PERMIAN.}

In Europe this formation is at times conformable to and continuous with the Coal Measures, or may be more or less unconformable. In North America it usually grades upward so insensibly from the Coal Formation that the term Permo-Carboniferous (or more accurately CarboPermian as here used) has been widely applied. By general consent palaeontologists have viewed it as bringing to a close the oldest and most primitive of the three great organic evolutionary stages of stratigraphic history, the Palaeozoic. But all indications are that during deposition of its strata, profound changes were proceeding in climatic conditions; in the relative distribution of land and sea; in biological stress and strain, or action and reaction amongst organisms; in destruction of many previously existing types; and in evolution of new and fast varying types; in alternation of dry hot xerophytic with cool and even glacial atmospheric states, over regions of the earth whose 
flora and fauna we have already been studying. A suggestive discussion of some of these problems may be found in Chamberlin-Salisbury's "Geology" ( $8:$ II : 640-677).

With increasing firming, but also faulting of the earth's crust, active volcanic and seismic disturbances gave rise to huge masses of volcanic rock, that not only added to, hardened, and deformed the older strata, but in known instances aided powerfully in elevating mountain masses, as has been shown for the Appalachian and Ouachita ranges in the United States. But in this process much of the former relatively flat marshy ground of the Carboniferous seems to have been elevated and converted into wide plateaux, much resembling those of Thibet, and the "bad lands" of the West. These then became subject to periods of desiccation, and alternately of rapid denudation, by action of rains descending from the mountains.

As gradually elucidated in Europe during the past seventy-five years by King ( 115 ), by H. B. Geinitz ( 116 ), by Weiss, ( $I I 7)$, by Goeppert ( $I I 8)$, and specially by Fritsch ( $I I 9)$, as traced in India by Medlicott and Blanford, also by Oldham (I20:19r), and in North America by Fontaine-White (I2I); by Prosser (I22), by Hussakof and Case (I23), the formation exhibits considerable diversity of character, "that seems largely dependent on whether the strata were: (a) deposited in a marine habitat; (b) deposited in rather deep lacustrine areas as shaly, sandy, or gravelly strata; or (c) formed in estuaries, swamps, lagoons, alluvial plains, and open or covered woodlands" (I23:207:101). These by no means follow definite and successive relations, but except for the lastwhich is best developed near the top of the system-the marine and lacustrine are often interbedded. The marine rocks, usually limestone in nature, attain their greatest development from the Alps eastward to North India, and in the western and south western United States. These contain a rather poor assemblage of typical invertebrate marine forms, but mixed amongst these are no vertebrate remains. 
The second stratigraphic type is greatly the thickest and most typical, being made up very largely of red sandstones and conglomerates, at times interbedded with marls, shales, and coal beds, more rarely with marine beds like (a) above. In the fine sandstones, shales, and shaly coals, plant-remains occur that are mostly a curious combination of palaeozoic and mesozoic types. Thus species of Asterophyllites, Calamites, Sigillaria, Lepidodendron, and sphenopterid-neuropterid forms, all surviving from the luxuriant Carboniferous flora, are mixed with Walchia, Baiera, Voltzia, Glossopteris and Callipteris, that foreshadow mesozoic vegetation.

Mixed often with these-as at Autun in France-may be crowded layers of phyllopod and other entomostracans, various higher crustaceans, also, according to Fritsch, a macrostomid predecessor of the King Crab, which he named Praelimulus, and which like the eurypterids was thoroughly freshwater; masses of univalve and of bivalve shells; scorpions and insects. These undoubtedly must have been only a few that were more resisting in their outer tissues, compared with many others of softer structure that quickly decayed.

But vertebrate life was steadily evolving, for while the fishes became impoverished in individuals and species, amphibians and even reptiles, became increasingly abundant and specialized. Details regarding all of these for Europe are given by Fritsch (119) and Gaudry (124), and in America in the Carnegie Publications already cited.

The sumptuous volumes of Fritsch furnish the most recent and fullest accounts of European Permian conditions, but these pertain to the upper part of the system that has been termed the Zechstein in Germany. The lower beds of the system in that region are treated in detail in Geinitz's work "Die Dyas." But this Lower Permian is characterized, much as in eastern Pennsylvania, by extensive masses of purple-red rock, and so in Germany is often known as the "Rothliegende."

Two important physical factors seem both to have cooperated in reducing and often obliterating freshwater and land life, during deposit of the Rothliegende or Lower Per- 
mian, as compared with their luxuriance during the Coal Measure period, throughout Europe. One was the widespread extrusion of igneous rocks as beds of lava, tuff and dust, or the injection of volcanic material into the older stratified rocks as extensive dykes. Such must of ten have caused a wholesale destruction of plant and animal life over many thousands of square miles of country.

Another and remarkable change that seems to have become more and more pronounced during deposition of the Lower Permian was the initiation of a well-marked glacial period. In Europe conglomerate beds occur that seem only explicable as glacial clay and boulder formations. But it is in the Southern Hemisphere, from South East Africa to India and Australia, that the most pronounced examples of glacial phenomena are testified to by the rocks. It is not surprising, therefore, that while the lower part of the Lower Permian (Rothliegende) shows marked resemblances to the Upper part of the Carboniferous, the Upper Permian shows transition toward the later or Triassic system.

The uppermost zone of the Permian is the Kupferschiefer (copper-slate) which, equally in Europe and in Texas, shows one or more clay-beds, that are rich in copper ore. This is the zone also that is usually richest in freshwater or land fossils, and whose contents have been most fully examined.

The accounts alike of Geinitz and of Fritsch testify to the presence of an abundant freshwater-land flora and fauna, while the numerous wide stretches of rocks that show mud layers with rain-pits or sun-cracks, or of shaly sandstones with tracks of amphibians and shore rippleridges, suggest that dry hot conditions at one time, no less than glacial climatic states at another, were typical. But that the flora was often abundant and varied is proved by the thick coal beds found in the Lower Permian of France, East Germany, and West Russia, as well as in India, Australia and South Africa.

The freshwater and land fauna preserved to us consist of numerous insects, myriapods, estheriae, and specially 
fishes and amphibians, some of the last being of large size ancl unwieldy build.

If now we compare the statements made as to the nonmarine Permian organisms, the lists of fossil fishes given, the relation of these physically and biologically, the practical absence of fish records from the marine rocks, and the affinities of these fishes with preceding and succeeding fish-faunas, the observations of Geinitz and Fritsch for Bohemia, and of Case for the Western States and specially Texas, are fairly typical for other areas. Amongst the fishes, representatives of the selachian or elasmobranch, dipnoan, crossopterygian and chondrostean groups are all known. And of these Case says: "There are no forms which can be called distinctly marine."

But Fritsch, in speaking of the life-conditions of the elasmobranchs says: "At the time of the Permian formation, the Xenacanthidae in Bohemia probably lived in brakish water at the mouths of rivers, and utilized as food the palaeoniscids, the acanthodians, and many other animals, which the rivers brought from the dry-lands to the sea during floods." But as if largely or wholly to contradict or minimize the "brakish water" statement he then adds: "in company with the Xenacanthidae, we encounter beside the Palaeoniscidae and Xenacanthidae likewise stegocephalids, myriapods, estheriae, and insects, which were brought down from the dry land." Now in giving "stegocephalids" it should be observed that all amphibians are intolerant of even brakish water, and further the entire assemblage suggests only lacustrine or fluviatile surroundings.

By what catastrophe the elasmobranch fish-life of the Carboniferous seas was virtually wiped out, we can as yet only surmise. But that such actually happened will be fully set forth in another section (p. 2S6).

The Carbo-Permian beds of America cover a large area included in North-West Texas, Oklahoma, New Mexico, and Kansas. Cummins ( $125: 186$ ) and Gordon ( $I 26: 2 \mathrm{I}$ ) recognize three zones; (a) a lowest or Wichita, the deepest beds of which are in part marine, in part freshwater, and decidedly suggest their being top-beds of the Carboni- 
ferous system; (2) a Middle or Clear Fork Formation, in which, as in the Wichita, fossils are abundant; (3) an uppermost or Double Mountain Formation. The organisms in these have been studied by Cope, White, Case, and Hussakof.

The second of the above named authors also has recorded a varied list of plants such as Cordaites, Neuropteris, Odontopteris, Pecopteris and Sphenophyllum, that are therefore of Carboniferous affinities. But with them are Gigantopteris, Callipteris, Gomphostrobus, Taeniopteris and $W$ alchia, that as strikingly suggest a Triassic plant-facies.

Case has built up an admirable mental "Restoration of the Region and Environment in which the Animals lived" ( $123: 207: 147)$, that deserves quotation in full. He says: "Considering only the region in Texas and Oklahoma, which is typical of all the Red beds, we may restore in imagination a great flat land stretching away from the Wichita Mountains and the Arbuckle Hills to the east and south where it joined the ocean waters. The western border of the flat we do not know. The normally semiarid condition of the land was interrupted by incursions of the sea, and fluctuations of the climate to more humid conditions. The aridity never attained a degree which prevented the growth of some vegetation, or the presence of pools of water and running streams, but was sufficiently intense at times to prevent the accumulation of much vegetable debris in swamps or stagnant lagoons. In the times of increased humidity, the vegetation increased in quantity, the waters accumulated in large areas, and were overshadowed by a heavy growth, and the streams expanded and spread over their flood-plains, leaving masses of irregularly bedded sandstone and clay. . . Upon this flat, largely around the pools and streams, lived the wonderfully complex amphibian and reptilian life. The waters swarmed with fish and amphibians, and were constantly invaded by predaceous reptiles in search of food. And he sums up by saying: "The fauna was one of estuaries, swamps, lagoons, alluvial plains and open or covered woodlands." 
Directly connected with our special theme is his statement: "in certain places, such as the patches of light blue clay, where the remains of small amphibians, sharks, etc., are generally abundant, plant remains are also common," indicating that the animals were entombed in or near their natural habitat. A striking feature, that physically connects these beds with corresponding ones of Europe is brought out in his observation that: "The bluish clay is copper bearing in many places." The term "Kupferschiefer" would apply equally therefore to Texan as to central European beds.

The subjoined tabular list that he gives at once indicates the variety of the fish-life, and their relation to the "Illinois" beds of the "Upper Pennsylvania" or top of the Carboniferous system.

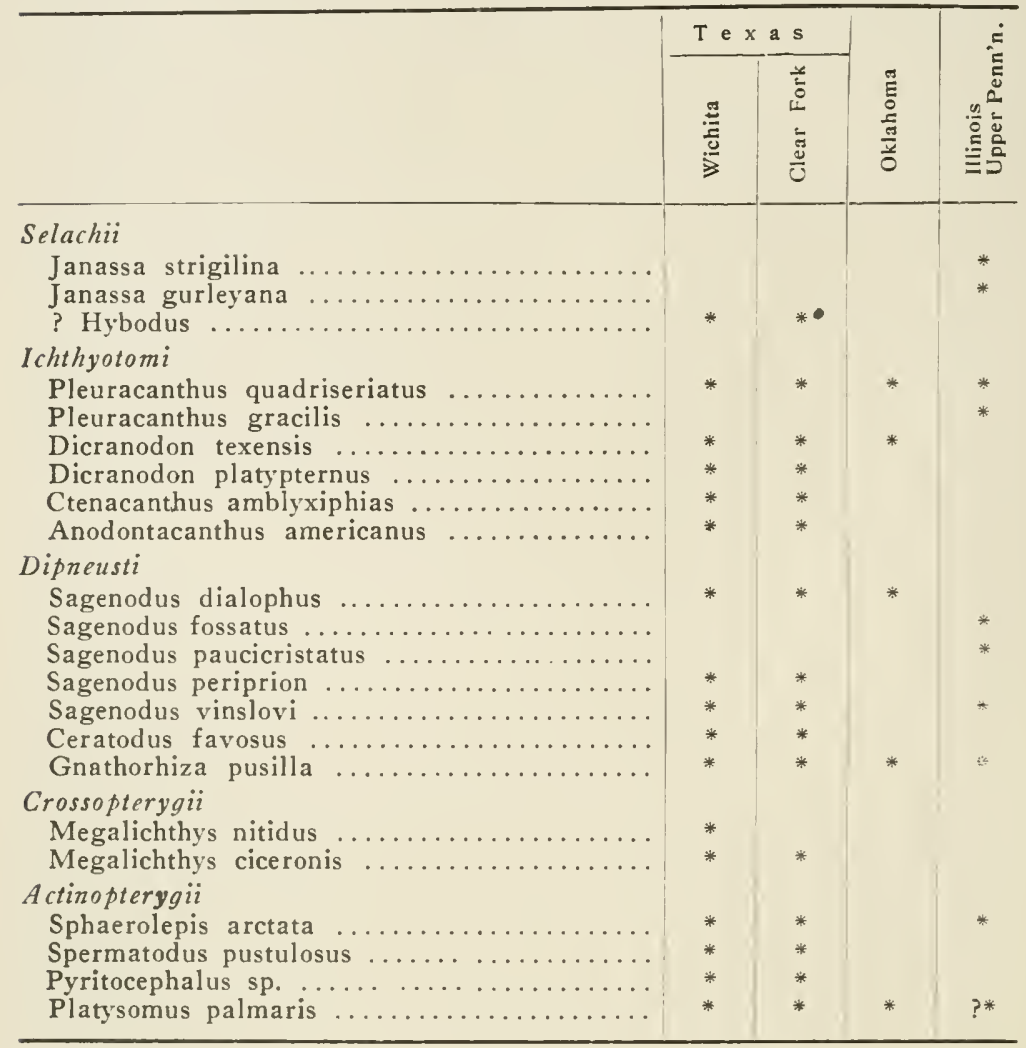


In a paper by Hussakof-likewise published in the series of the Carnegie Institution (I23)- "On the Permian Fishes of North America," but further by statement and table, that author makes a helpful comparison with the fish-fauna of Bohemia.

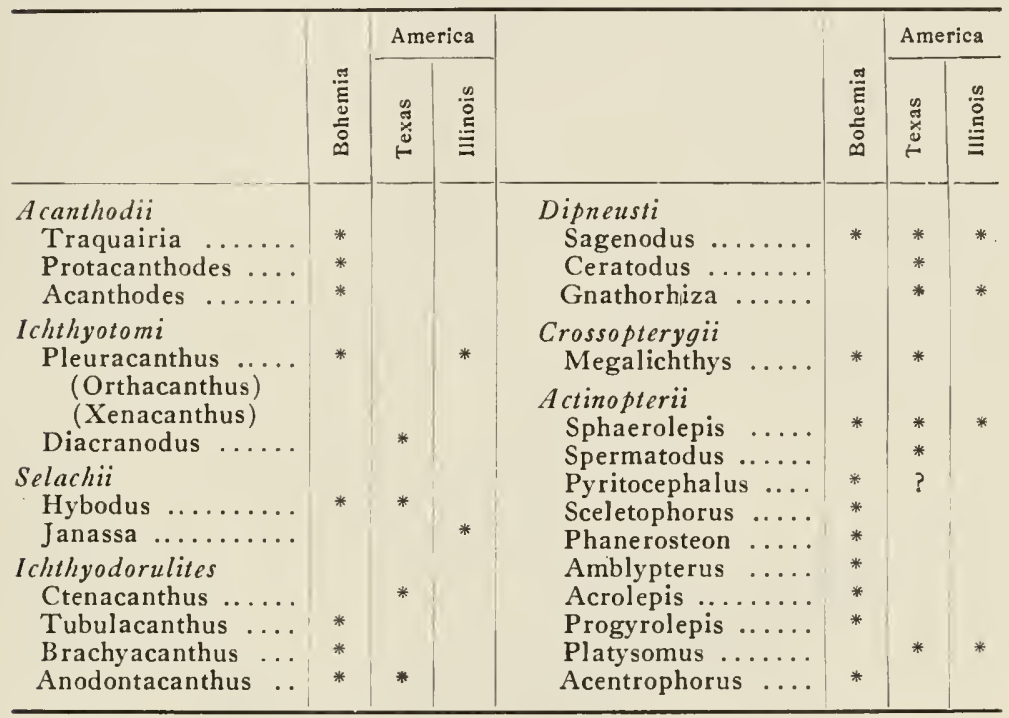

Hussakof then says: "while the groups represented in the two are, with the exception of the Acanthodii, the same, there is a marked difference in the genera respectively represented, proving the long segregation of the two stocks from which the Permian faunas of the two localities are descended. The most remarkable difference between the faunas is the presence of Acanthodii (three genera) in Bohemia, and their absence in Texas." So the closing remark of Case is well illustrated by such distributional details: "The presence of a great North Atlantic continent in Carboniferous and earlier times is accepted as a proved fact by all the writers on the subject, and need not be defended here." He might quite appropriately have added further: "Connection of it also with a great North-East European, Indian, and Australian landmass is strongly suggested." 
Reviewing shortly the groups of Permian fishes, it may be said that the elasmobranchs are represented by six species of Pleuracanthus, three of Acanthodes, two of Diplodus, and one of Janassa and Wodnika.

In distribution they extend more or less from Bohemia to England, Illinois, and southward to Texas. Acanthodes is the most persistent, for species are traced from the Lower Old Red up to the Lower Permian; while Pleuracanthus, Janassa and Diplodus extend up from the Lower Carboniferous. The Dipnoans are known by the genera Conchopoma and Sagenodus, the latter, which occurred in the Coal Measures, being scarce in Europe, but showing a rich development of species, from Illinois to Texas. According also to Fritsch our present-day Neoceratodus of Australia was anticipated already by a species of Ceratodus.

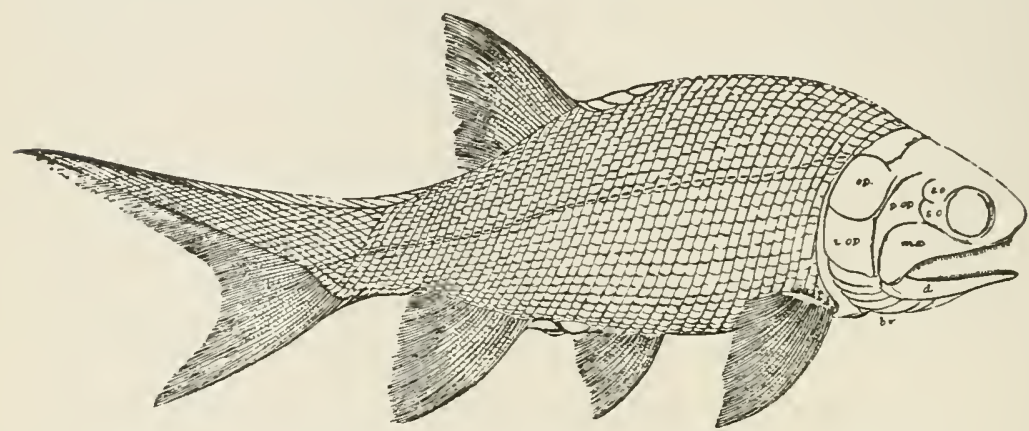

FIG. 20. Amblypterus latus, from Lower Permian beds of Lebach, Saarbrücken, Rhenish Prussia. About one-half natural size. (After Traquair.)

The Crossopterygians were represented by two species of Megalichthys and one of Coelacanthus, both genera continued from the Carboniferous. The Chondrosteans were probably the most abundant in individuals, and consisted of Amblypterus (Fig. 20) and Palaeoniscus (Fig. $2 \mathrm{I}$ ), each with five or six species that extended more or less across Europe, while Acrolepis, Elonichthys, Platysomus (Fig. 45, p. 28I ), Pygopterus and Thrissolepis are less abundant.

With the close of the Permian, and therefore of the great Palaeozoic era, it can correctly be said that primitive fishes first appeared in freshwaters and very largely per- 


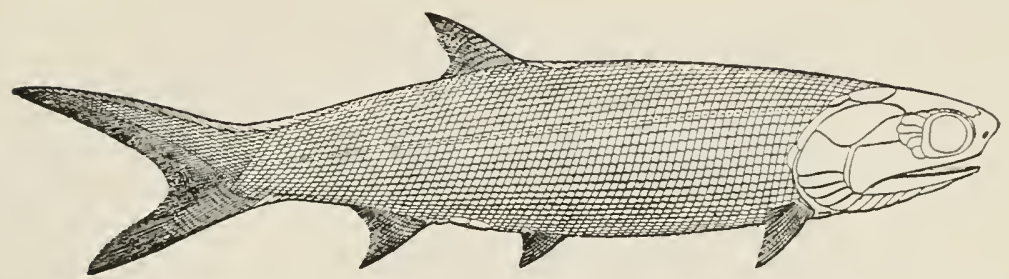

Fig. 21. Palaeoniscus macropomus. From Kupferschiefer beds in Upper Permian of Ilmenau, Thuringia. One-third natural size. (From restoration by Traquair.)

sisted there, only some genera of elasmobranchs having migrated into sea waters and became rather abundant along coastal regions during Carboniferous time. The latter seem largely or wholly to have died out in the sea during Permian days. In habit and habitat the earlier fishes were mainly clumsy ground-feeders, but during deposition of Old Red strata, they became more active, aggressive, and strongly carnivorous. This was most true of the elasmobranchs with taper body, lithe movements, and well-developed teeth. So temporarily they were able to migrate into the sea and live for a time there against competitive organisms. The other groups, the Dipneustei, the Crossopterygii, and Chondrostei remained wholly freshwater, or a very few may rarely have become anadromous in habit. The type of fish thus evolved was largely adapted therefore to shallow, and often decidedly putrid water, as Baldwin Spencer has shown to be true for the existing Neoceratodus (op. cit. p. 3 ). As an aid, therefore, to gill action most of the groups evolved an air-bladder, which, though now absent as an evident structure in the marine Elasmobranchii of today, seems feebly indicated, according to Miklucho-Maclay in some sharks ( $I 27: 448$ ) as a small open dorsal diverticulum of the oesophagus. While still retained in the Dipnoi, Chondrostei, and Crossopterygii, as well as in most freshwater Teleostei of more recent origin, it has largely or wholly been absorbed in the existing Elasmobranchii and marine Teleostei, since it must have become a hindrance rather than a help when the latter groups passed into the restless highly oxygenated waters of the ocean. 


\section{CHAPTER VI}

The Physical and Biological Environment of Fishes. (c) During the Triassic-Jurassic Period.

I. The Triassic Formation, like others already studied, can be fairly sharply divided into freshwater and marine beds. In Europe, the formation has been grouped under four divisions: the lowest or Bunter, a higher or Muschelkalk, a third the Keuper, and a highest or Rhaetic. Broadly it may be said that over the above region the lower part of the Bunter, the lower Keuper or Lettenköhle, the upper Keuper, and the Rhaetic were of freshwater origin. The upper Bunter, the Muschelkalk, and occasional beds of the Keuper were marine. But even in the often thick deposits of Muschelkalk rocks, strata are met with, that alike by their plants and their freshwater animal remains, as by their entire want of marine organisms, proclaim a temporary elevation of land, and sub-aerial or freshwater deposits.

The most exhaustive general treatment is that of Frech and collaborators (128). But their somewhat mixed and diffuse treatment is only slightly helpful in an inquiry like the present. For an accurate estimate of the varying lifeconditions of the period can only be reached from detailed study of books or papers of individual authors.

If one peruse the extensive lists of fossils given in "Lethaea" for strata of the typical Upper Bunter, for the Muschelkalk generally, and for various beds of the Keuper, one at once notes that the lists are wholly made up of invertebrate and typically marine organisms, while vertebrates are wholly absent. But to this are some exceptions. Thus Wysogorski (I28:II pt. I : 55-57) gives from the Lower Muschelkalk of Upper Silesia, a typical marine lot in the Dadocrinus zone, but also a list of what suggest land or freshwater animals including eight saurian reptiles, one labyrinthodont (Capitosaurus), also teeth, plates and scraps of such fishes as Saurichthys latifrons, S. lepidosteus, Colobodus chorzowensis, and C. gogolinensis. These 
again are stated to be mixed up with Myophoria, Lima, and Terebratula. But on p. 62 under Upper Silesian Keuper he notes that: "The few organic remains belong to a freshwater fauna, which consists unitedly of amphibians (Mastodonsaurus), saurians (Termatosaurus) dipnoans (Ceratodus), ganoids (Colobodus and Saurichthys), freshwater mussels and snails (Anoplophora, Paludina)." So the former probably was recorded from a thin band of rock of freshwater origin deposited during some land oscillation, between marine beds. This view is entirely in accord then with the finding of Colobodus and Saurichthys in both lists.

Another, and at first sight puzzling, development is that of the bone-beds of England, of Mid and North Germany, of North Italy and elsewhere. These occur at the junction of the Rhaetic with the Keuper below, or in the Rhaetic, or as in the Wurtemburg bone-beds, at the junction of the Rhaetic and the Lias. It is not unlikely that one of these bone-beds at least may represent one continuous stratum, for in England and over a large part of the European continent, the Rhaetic bone-bed seems always to adjoin an extensive marine deposit, whose most abundant fossil is Avicula contorta. So it is known as the "Avicula contorta" zone. In the bone-beds proper occur Ceratodus latissimus (altus), C. parvus, $C$. silesiacus, the teeth or spines of Acrodus minimus, Hybodus minor and $H$. laeviusculus, as well as bones of reptiles. Either above, or in close proximity, are beds with abundant plant-remains.

Now all of the above genera of fishes, as well as the associated organisms, belong to groups that in the palaeozoic rocks are clearly freshwater. The probable explanation is that though marine beds may be near to or adjoining each bone-bed above or below, the latter was formed on a land surface owing to some sudden and comparatively short-lived upheaval of what had been a marine bed. Soon thereafter and as a nearly concomitant event, terrible and widespread destruction of freshwater fishes caused stranding of these on top of the upheaved marine beds. These fishes then underwent decay during deposition of the mud or micaceous clay that now surrounded them. So their 
teeth, bony plates, scales and dental spines were alone left in countless numbers as main constituents of each bone-bed.

The above view is eminently favored by such a section as that given in Arthaber's article on the Raibl fishdeposits. It is here seen that $(128: 298)$ the fish-strata lie between an upper and a lower marine band, the latter with corals and echinoids, the former with marine molluscs. The freshwater zone includes typical land plants, also the fishes Pholidopleurus typus, Belonorhynchus striolatus and Ptycholepis raiblensis.

But another and equally noteworthy feature of the Trias, that is connected also with the above bone-beds as we believe, is the occurrence, in midst of marine dolomitic strata, of deposits rich in fish and reptilian remains, but characterized further by their highly bituminous and even asphaltic quality. The bituminous beds at Besano near Lake Lugano, the Perledo beds near Lake Como, the Lumezzane beds in Lombardy, the Giffoni beds of Salerno, the Tyrolese beds of Seefeld, and the Raibl beds in Carinthia, are all highly bituminous. As noted below also the Upper Triassic beds of Eastern America are of ten of like nature. Deeke, Basano, Kner, Newberry and others have described the rich fish-fauna that characterizes these beds. Such genera as Heterolepidotus, Lepidotus, Semionotus (Fig. 22), Pholidophorus, Coelacanthus, Catopterus, Dictyopyge and Belonorhynchus are typical. All of these genera were of freshwater habitat.

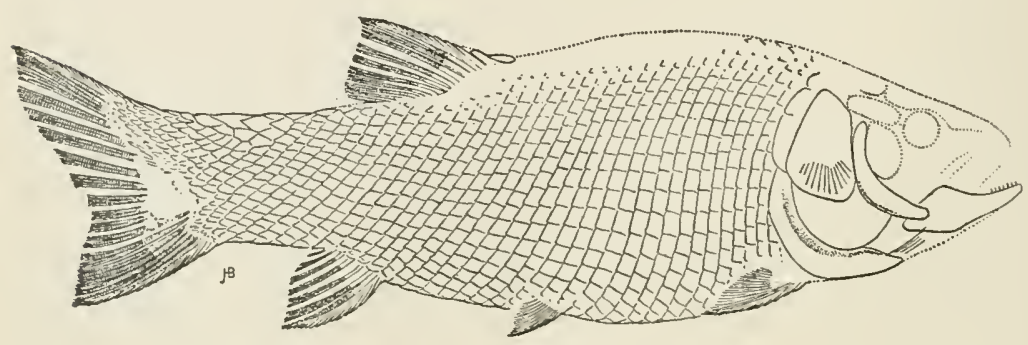

Fig. 22. Semionotus (Ischypterus) agassizii. A Triassic fish common to the rocks of New Jersey and New England. About one-third natural size. (Reduced from Eastman). 
Now we would not only claim a freshwater origin for these fishes, we would further suggest that the bituminous material is a direct product of decomposition of oily constituents set free from the decaying fish. The statements quoted below from Newberry leave little doubt regarding this, while the statistics already presented furnish proof that wholesale destruction of a teeming freshwater fishlife was the source for, and furnished the supplies of, the Triassic bituminous material.

In spite therefore of the apparent mixing of marine invertebrate remains and of selachian bones or plates, or the not infrequent intercalation of a bed of varying width amongst typical marine dolomitic, chalk, or limestone deposits of great thickness, a careful study of the nature of their deposits, of their included organisms, and of the biological relation of these to each other, reveals that Triassic vertebrate life was still wholly freshwater, or that a very few only of the predatory elasmobranchs and specially the cestracionts were advancing seaward.

When comparison is made of the fish-fauna of the above four divisions, throughout Europe, it becomes evident that the older selachian groups which lingered on into the Permian have entirely disappeared, the Elasmobranchii even as a great class seem to have temporarily suffered an eclipse alike in numbers and in species. And when introduced to us again later on in the Lias, they are found to be freshwater forms which are increasingly developing a marine environment. The Dipneustei are no longer represented by Dipterus, Uronemus or Sagenodus of the Palaeozoic epoch, but have evolved the genus Ceratodus that closely resembled the Barramunda of Australia. The Chondrosteans are wonderfully rich in types that are intermediate between palaeozoic and upper mesozoic genera. The older types of crossopterygians have entirely disappeared, and in their places are Graphiurus, Diplurus and Undina, all freshwater in habitat.

Of the chondrostean "ganoids" that come into marked prominence, such genera as Dictyopyge, Belonorhynchus, Saurichthys, Semionotus, Colobodus, Heterolepidotus, Allolepidotus, Pholidophorus, Thoracopterus, Pholidopleu- 
rus and Peltopleurus were abundant, while the last four were destined to become increasingly rich in species, specially from the Rhaetic to the Liassic beds above. They all swarmed in, and were confined to, the lakes and swamps of the continental areas of the time.

The freshwater phyllopod Estheria minuta, along with allied Entomostraca, teemed in quiet waters of ponds or pools, a fairly rich insect-life is indicated, though the absence as yet of colored flowers and of succulent fruits, gave little occasion for the evolution of other than orthopterous, neuropterous and hemipterous genera. Limulus, as representing a condensed and modified derivative genus from the once abundant eurypterids, was led up to by the curiously intermediate Permian genus Prestwichia, but is still like them of freshwater habitat.

In examining first the set of British rocks, it can be said that a recognition of the freshwater character of such strata as above mentioned has been repeatedly voiced by not a few geologists. Thus in a joint paper by Newton and Brodie ( $129: 537$ ), after referring to "the unique specimen of Dipteronotus cyphus from the Bunter of Bromsgrove," the former author describes a new species as Semionotus brodiei, and Brodie notes that his son obtained Palaeoniscus (Dictyopyge as now viewed) superstes and a Semionotus. On the slate on which the first specimens were found were two impressions of footsteps of a large labyrinthodont. He then adds, "a similar stratum, with similar fossils, occurs at several localities in Worcestershire. Footprints of labyrinthodonts, generally of small size, are occasionally found on the surface of the sandstones, and at Rowington remains of plants in a very imperfect condition, among which is Voltzia in fructification, and some small fruits resembling the Jurassic Carpolithus so-called."

Further on he notes the abundance of Estheriae in beds of the Waterstones, and adds: "The Waterstones are famous for the number (comprising nine genera) of salamandroid batrachians, a large number and variety of which have been found at Warwick, Leamington, and Coventry; and a unique collection is preserved in Warwick museum." 
Succeeding to the above is a paper $(130: 542)$ by E. Wilson "On the Triassic Beds at Colwick Woods," in which he refers to abundant fish-remains from the transition beds of the Waterstones of the Upper Keuper which at this point rest on the basement beds of the Lower Keuper. He speaks of "quite a shoal of the fishes, these often lying over each other," and then adds "these deposits I believe to have probably had a fluviatile origin. The waterstones on the other hand, (at the base of which the fishes occurred, and to which series they belong) are regularly bedded finegrained sandstones and marls, showing ripple marks and sun-cracks." In a footnote he says: "in these lowest beds of the Waterstones at Colwick I found the stem of a land plant, having the appearance of Equisetites columnaris and probably allied thereto." He considered that the strata "were evidently formed in waters which were tranquil, but extremely shallow, and liable to entire or perhaps partial desiccation. These waters were in all probability those of saline lakes or lagoons" (but why saline? writer). "Possibly the fishes found at Colwick may have become entrapped in the shallows of such a lake, and killed in numbers by the drying up or the increasing salinity of the water."

L. J. Wills $(I 3 I: 28)$ confirms and in some respects extends the above sets of results, while he gives a list of organisms found by him in the sandstone and the shale layers respectively thus:

I. THE SANDSTONE.

Plantae

Equisetites arenaceus

Zamites vogesiacus

Voltzia sp. also Coniferous wood

Pisces

Acrodus, spine of

Coprolite

AMPHIBIA

Labyrinthodont, tooth of

REPTILIA

Hyperodapedon

\section{THE SHALE.}

Plantae

Equisetites arenaceus

$Z$ amites vogesiacus

Voltzia

Chiropteris digitata

ARTHROPODA

Estheria minuta

PISCES

Dipteronotus cyphus

Scales.

Again a series of papers by L. Richardson ( $132: 374$, $385,425 ; 133: 385)$ deal mainly with the uppermost or Rhaetic rocks. In the latter publication he gives a very detailed sectional table, which shows that the Sully beds 
of the Lower Rhaetic were deposited as alternating freshwater and marine deposits with typical and quite distinct fossils for each. Then follow some alternating layers of black shale and of bone beds rich in fish remains but all devoid of marine organisms. Along with the fish, or in adjacent beds, abundant remains of Estheria minuta and a plant Lycopodites are recorded. The fish remains include Acrodus minimus, Hybodus minor, H. cloacinus, Gyrolepis alberti, Saurichthys alberti, and Sargodon tomicus, the labyrinthodont Mastodonsaurus-that at once indicates freshwater conditions, - small teeth of Sphaerodus and "a mandible believed to belong to Palaeosaurus, as well as other saurian remains."

The beds of the Upper Rhaetic seem to suggest a marine invasion, but unless the above-named author has mixed up contents of freshwater beds with these, the presence with Pecten, Avicula, Pteria and Aviculoidea, of Gyrolepis scales suggests either that some hitherto freshwater species were slowly invading seashores, or as is much more likely that the last were washed out from older strata and redeposited in marine beds.

So apart from fishes, large amphibians and reptiles allied to those of the Permian, like Mastodonsaurus, Trematosaurus and Hyperodapedon, waded in the swamps, or basked in the freshwaters, or progressed over the muds deposited from recent freshets of the lakes or rivers. Thus they left "footprints on the sands of time" that to-day have enabled palaeontologists to distinguish many species, even in absence of the animal remains. Such equally applies to the reptiles, that now are represented by the three great divisions of the crocodiles, the lizards, and the turtles.

First evidence of mammals is seen in the small form Microlestes, which once was regarded as a primitive marsupial, but as only fragmentary remains of the skull are known, it may equally well have been a primitive monotreme.

In passing now to other regions where the Triassic was represented by freshwater beds, it may first be well to inquire as to the possible extent geographically of the system. 


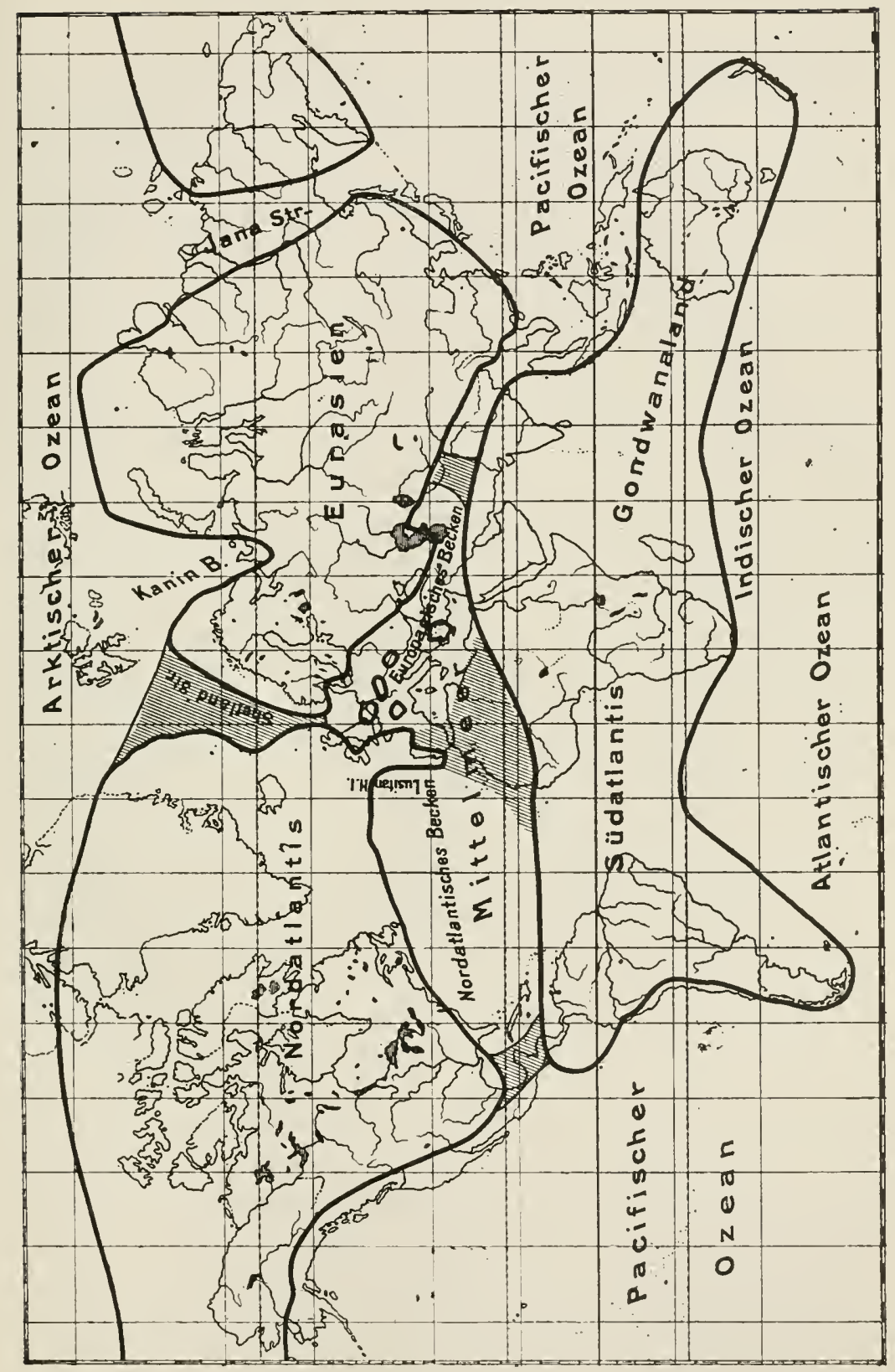

FIG. 23 
The preceding chart (Fig. 23) sets forth the views of de Lapparent and successors. It shows that two compact expanses of dry land existed, such as might give opportunity for migration and evolving adaptation of plant and animal types over the greater part of what are now more or less sharply separated continents. So, as during previous epochs, one might expect to find a certain correlated similarity in structural advance, in taxonomic affinity, and in adaptation to environment of varying character. Such also is largely true.

On the American continent, it is now agreed by geologists and palaeontologists that the Triassic drylands, freshwater lakes, and river systems with their flood-plains, covered an extensive territory, that can still be fairly accurately traced east of the Alleghanies from Canada to the Gulf, also southward through Brazil to Chile and the Falkland Isles. But so far as one can judge from fossil remains, the geologic period represented, seems to be that of the Upper Keuper and the Rhaetic of Europe. It may therefore be that in the period between the Permian and the Rhaetic extensive land denudation may have proceeded, while marine strata were being enormously accumulated in the west, from Alaska and British Columbia southward to California and Idaho.

In contrast to his views on Devonian fish life Newberry consistently advocated a freshwater or even more an estuarine environment, in his study of "Fossil Fishes and Fossil Plants of the Triassic rocks of New Jersey and the Connecticut Valley" (I34). These rocks, now usually known as the Newark series, he regarded as having been laid down during the latter half of the Triassic age, and so in the Upper Keuper or in the Rhaetic period. They extend in a north-east and south-west direction, parallel to the Alleghanies, and may represent the deposits laid down in some great lake that extended from Nova Scotia to the Carolinas, or even to the present Gulf of Mexico. The deposit varies from 2000 to 5000 feet in thickness, and is largely composed of red sandstones, shales and micaceous deposits. Most of these are barren in fossils, or show only scanty remains. We accept it that they were wholly fresh- 
water, for while Newberry speaks of "estuaries," no trace of a marine organism, nor of a mixture of freshwater and marine organisms has been demonstrated.

But Newberry says "the Connecticut area includes layers of nearly black shale charged with carbonaceous matter, containing many remains of fishes and plants, and even some thin films of coal. Also a small part of the series in $\mathrm{New}$ Jersey consists of dark or dove-colored shales charged with organic matter, sometimes crowded with the remains of fishes and exhaling a marked bituminous odor when struck with a hammer" (p. 4). In connection with the possible origin of petroleum and natural gas the last statement is most suggestive, as is also the following (p. 2r): "The layers of the shale which contain the largest number of fishes are impregnated with bituminous matter, burning for a time when thrown into the fire, and when struck with a hammer giving off a peculiar odor. Similar fish-beds are known to exist at Pompton, Plainfield, and beneath the trap of the Palisades above Hoboken, and it seems probable that the great mortality which strewed the bottom of the basin at times with dead fishes was the result of some phase of the volcanic action which poured out the trap-masses of the Palisades and Newark mountains."

Lull (I35:397) in treating of "The Life of the Connecticut Trias" points out that the fishes all occur in two bands of black bituminous shale, the lower of which rests on a sheet of volcanic rock about 250 feet thick. The shale is 50 feet to 100 . feet thick and includes both plants and fishes. Above it is a zone of shale rooo feet thick with dinosaur foot-prints. This is covered by a second sheet of volcanic trap about 500 feet thick, and it again is covered by a shale about 200 feet thick with dinosaur footprints. Above it is the second black bituminous shale about Ioo feet thick and enclosing plant also fish remains. Over this is another trap sheet about I 50 feet thick. Here, as in other similar cases, we would suggest that the bituminous shales represent volcanic dust deposits laid down in a shallow, but extensive lake; that this ensured the fine preservation of the fishes as shown by Eastman's illustrations, and that the abundant petroleum oil resulted from destructive trans- 
formation of the natural fish oil when heated by the volcanic flows.

Chamberlin considered $(8:$ III $: 9)$ that the deposits were of "shallow water or subaerial origin," the latter being indicated by the numerous "ripple marks, sun-cracks, tracks of land animals, etc."

Eastman, in "Triassic Fishes of Connecticut" ( $130:$ ), says: "While there is nothing in the character of the fossil fishes which would prove conclusively whether the deposits were formed in salt or brakish or fresh water, the physical character of the deposits, and the fossils other than fishes found in them, make it substantially certain that the deposits are not marine. No corals, echinoderms, or brachiopods have been found in the Triassic in Connecticut or in any other of the Triassic basins of eastern North America. Molluscs are very few, and most of those found are undoubtedly fresh-water forms. A very few marine molluscs, it is claimed, have been found in the Triassic of Pennsyl. vania. A few crustacea, probably freshwater or brakishwater forms, have been found in some of the southern Triassic basins, though not in Connecticut. A few insect larvae have been found. For the rest the fossils of the formation consist of land plants and tracks of reptiles and amphibians, with a few skeletons of reptiles. Such an assemblage of fossils makes it clear that the formation is not marine, though the presence of a few marine shells (if those shells are rightly identified) indicate conditions in part estuarine."

The organic remains from this Newark series consist of plants with affinity to Carbo-Permian genera, but in the cycadeous and coniferous forms approach much more nearly to a later Mesozoic age. The animals are fishes, amphibians, reptiles, and-at Turner's Falls-apparently birds. While fishes are abundant in various beds, amphibioreptilian animals are scant in their osseous remains, but are often richly indicated by their footprints. These alone proclaim that an abundant amphibian life-possibly derived by evolution from the varied Carbo-Permian amphibian organisms of the Texan area-occupied the margins of the lakes or river-plains, and this entirely agrees with the 
evidence noted below, that has been gathered from the Western Triassic region.

The fishes recorded belong to the genera Semionotus (Ischypterus of Egerton and Newberry), Catopterus, Acentrophorus, Dictyopyge, Ptycholepis and Diplurus; mainly members of the Chondrosteidae or sturgeon series. While the genus Catopterus is, so far as known, peculiar to Eastern American strata, Semionotus and Dictyopyge are common to Britain, Germany, Switzerland, South Africa and Australia. Ptycholepis again includes seven species, of which five occur in the Lias of England, one in the Upper Trias of South East Europe, and one in the Connecticut beds. Diplurus is a crossopterygian allied to the more ancient Coelacanthus.

Over western North America, as in Europe, an extensive marine and a nearly as extensive freshwater, series of deposits took place during Triassic time. The former now covers a wide area from Alaska southward through British Columbia, California and Nevada on through Mexico and southward to Chile. Over all of this the Triassic sea laid down typical marine strata with equally typical marine organisms, that included foraminifera, corals, echinoids and crinoids, univalve and bivalve molluscs, an exceptionally rich variety of ammonites and other cephalopods, but no recorded vertebrate life.

The freshwater strata, as at present exposed, or left after subsequent denudation, may have been developed more or less continuously with the eastern deposits, over the greater part of North America. Such a view is that incorporated in the chart of de Lapparent; and when we think of the masses of freshwater strata now known to occur in central and Northern Mexico, in North West Texas, in Eastern California, and West Oklohoma there is much evidence in its favor. Not only so, a bridge in the region of Honduras and eastward, may have connected this northern expanse with a wide extension over eastern South America. For in Brazil, the Argentine, and southward to the Falkland Islands, wide areas exist where a typical Triassic flora and freshwater or land fauna have been traced. 
Further the striking similarity in genera, but distinctness in species, of plant and animal-not least fish-remains, shown between South America and South Africa strongly indicate such an Americo-African connection as DeLapparent figures. We need not here refer in detail to the lists of plants from all of these localities, that indicate a marked continuity in the Glossopteris flora, from South America across Africa to Australia and even New Zealand. It will suffice to state that the fauna fundamentally shows a like continuity.

In South Africa the great mass of beds that collectively has been called the Karoo formation was laid down according to G. S. Corstorphine in a great inland lake ( $137: 123$ ) and seems to represent Upper Permian and Triassic beds. According to Hatch and Corstorphine ( $138: 195$ ) there are three distinctly marked zones: (I) the uppermost or Stormberg beds, that from their fossils suggest a corresponding age with the Eastern American beds; (2) the Upper Karoo beds that may be of Bunter; and (3) the Lower Karoo or Ecca beds of probable Permian age. These authors give from the Stormberg a varied plant list of "Glossopteris" type, such fishes as Ceratodus capensis, C. kannemeyeri, Semionotus capensis and Cleithrolepis extoni. Bain and Woodward (139:239) add to these Palaeoniscus bainii, P. sculptus, and Dictyopyge draperi. An abundant amphibio-reptilian life accompanies all of the above, while Broom ( $140: 30)$ has instituted an interesting comparison between the Karoo genera of these beds and those recorded from the Elgin sandstones of Scotland.

The affinities of the above-named African fishes-that are all by descent and environment freshwater-are close with species from the Upper Permian and the Triassic of Europe and America. Thus Dictyopyge draperi links North American, British and Swiss species, with others - given below-from the Upper Trias, of New South Wales. Semionotus includes world-wide species of the Trias; Cleithrolepis, so far as known, is common only to South Africa and New South Wales. The teeth of Ceratodus recall those of allied species found only in freshwater 
strata from America through Europe to Africa, India, and Australia:

As being of great importance from the physico-biological standpoint, Hatch and Corstorphine point out that on top of the Stormberg beds, though doubtfully at what particular time, great deposits of volcanic material were thrown out, which in some places have a thickness of 4500 feet. Such enormous volcanic deposits must have caused and accompanied tremendous alterations in land-areas, wide-spread destruction to plant and animal life, constant oscillations in land and water surfaces, as well as other environal changes that would all aid in the evolution of new species and genera, as well as the obliteration of others.

Neglecting Indian strata, that promise greatly more for the future than the secured results indicate, attention may now be given to Australian Triassic developments. As set forth by Frech these extend through Queensland, Victoria and New South Wales, on even to the Island of Tasmania, and are mainly if not wholly of freshwater origin. Thanks to the efforts of A. S. Woodward, the fishfauna has received considerable attention $(14 I: 10)$. The general nature of the flora and fauna has been treated by Etheridge and Feistmantel, who observe that plants and fish are plentiful. Estheria coglani, as a native phyllopod, persists through hundreds of feet of strata, while the two labyrinthodonts Mastodonsaurus and Platyceps are associated. Feistmantel has given $(142: 40)$ a classified list of the organisms found up to about 1890 .

In Woodward's earlier communication on fishes from Gosford rocks, Edgeworth David makes a preliminary statement, in part as follows: "Although the shales associated with the fish-beds are probably partly tufaceous, it is very improbable, to judge from the remarkable evenness and regularity of these strata, that the fish perished through an inflow of volcanic mud, or the falling of a shower of volcanic dust. The evidence quoted seems rather to favor the supposition that the fish, which evidently lived in some land-locked lake or sheltered estuary, where there was not sufficient current to efface the ripple marks, and 
where delicate plants could be preserved in the fine muds, were killed by the sudden silting up of the lake or estuary with beds of coarse sand or gravel, swept down by powerful floods of freshwater."

But Woodward in his later memoir ( $141: 10$ (1908) when speaking of collections from the same formation, but at St. Peters locality says: "The fish-remains obtained by Mr. Dunstan from the Hawkesbury formation at St. Peters belong to two distinct series, which are described separately in the following memoir. The first and much the largest series was discovered in a dark indurated shale, which splits with a more or less irregular fracture; while the second series was found in a grey mudstone closely resembling that in which numerous fishes occur at Gosford. The skeletal parts of the fishes in the first series are actually preserved, though considerably stained and partly obscured by the oxide of iron and manganese, with some pyrites."

"The fishes of the second series occur chiefly as impressions on the rock, which are stained black with a thin film of bituminous material, resulting from the decomposition of the original organic tissues. In both cases the fishes appear to have been complete when buried, and show no signs of having been disturbed by currents or by predaceous animals. Like most well-preserved fossil fishes, they probably denote some local accident, which suddenly destroyed and entombed them."

The writer would again suggest here that as such fish would become putrid, softened, and disintegrated within a week in freshwater, and as the fine mudstones indicate no violent mode of detrital deposit in relation to the organisms, death by volcanic shock or gaseous discharge took place, with immediately succeeding entombment amid volcanic dust, either under water, or in shallow water that in a day or two became dried up and sun-exposed. The whole then probably firmed, and gradual exudation of oily material sealed the organisms, as well as furnished the chemical basis for transformation of their oils into bituminous products. Woodward has the following list from the Gosford beds : 
SELACHII. Sphenacanthus or ?.

DipNor. Gosfordia, a genus allied to but distinct from Conchopoma of Permian rocks, from Ctenodus of Palaeozoic rocks, and Ceratodus of Mesozoic age.

GANOIDEI. Myriolepis clarkei; M. latus, allied to the South African Athersionia.

Apateolepis australis, related to the Carboniferous genera Phanerosteon and Actinophorus.

Dictyopyge illustrans, $D$. robusta, and $D$. symmetrica.

Belonorhynchus gigas and $B$. gracilis.

Semionotus australis and $S$. tenuis.

Pristisomus gracilis, $P$. latus, and $P$. crassus.

Cleithrolepis granulatus and $C$.? latus.

Pholidophorus? gregarius.

Peltopleurus? dubius.

After an elaborate analysis and comparison with other fish faunas he concludes: "So far as can be determined from the fishes therefore, the Hawkesbury beds may be regarded as homotaxial with the Keuper of Europe, or at least with the Rhaetic, and on the whole the writer is inclined to adopt the first of these interpretations." The above list however suggests a curious admixture, of genera peculiar to the strata such as Gosfordia, Myriolepis, Apateolepis; of others like Cleithrolepis that are common to South Africa and Australia; and still others like Diclyopyge, Semionotus and Pholidophorus that stretch across the continents.

But that over the present area, a degree of separation in time or space, may give rise to a very different fauna, is proved by the St. Peters list. This includes amongst selachians Pleuracanthus paridens; amongst Dipnoi, Sagenodus laticeps; amongst Actinopterygii Palaeoniscus crassus and $P$. antipodeus, Elonichthys armatus, E. semilineatus, Myriolepis pectinata, Elipsopholis dunstanii, Semionolus formosus and Pholidophorus australis. Commenting on the above Woodward inclines to regard the group as of Carbo-Permian affinity. But the presence of such typically upper Triassic or Liassic genera as Semionolus and Pholidophorus along with Palaeoniscus, would suggest rather that this Australian area was a combining centre or mixing place for older and newer elements derived from other regions.

But in connection with our present fundamental contention, Woodward's observations on the Dipnoi are most 
important. He says: "The fragmentary skeleton of Sagenodus is of great interest when considered in connection with other recent discoveries of extinct dipnoan fishes in Australia. There is now evidence of fore-runners of the surviving Ceratodus in the Devonian of New South Wales (Ganorhynchus sussmilchi), the Carboniferous of Victoria (Ctenodus breviceps), the Permo-Carboniferous and Triassic of New South Wales (Gosfordia truncata), and the Jurassic of Victoria (Ceratodus avus). It is thus clear that Dipnoi have always lived in the Australian region, and there is no reason why Ceratodus may not have evolved there." It must be remembered however that Ceratodus was once practically world-wide, and that the richest and oldest known centre for dipnoans was the British-Russian area of the Lower Old Red. But the remarkable distribution of the perennially freshwater group Dipnoi is one of the outstanding proofs that some fishes have tenaceously clung to their primitive environment.

\section{The Jurassic Formation.}

The Jurassic Formation is of surpassing interest from the standpoint of fish-life. For it is in this that we again have clear evidence of migration from a freshwater to a marine life. Several factors seem to have cooperated toward such a result. First. geologists are agreed that a considerable-in some places great encroachment of the sea on the Triassic and Permian land-areas took place, which may be said to have reached an apparent climax in our own day. During this shifting process great masses of fishes became exterminated, while others became modified and adapted to changed environment. Second: this evidently inclined many hitherto freshwater or anadromous animals to adopt a semi-marine and eventually marine life, through struggle for existence in the former areas alongside evolving and formidable reptiles. Third: From being rather unwieldy animals with-in many cases-a dentition that was poorly adapted for combat and offensive destruction, one group of fishes-the Elasmobranchii-evolved highly specialized catching, tearing and often in addition 
crushing teeth, that made them formidable antagonists. Fourth: the body-covering of scales, the body-muscles, and also the fins became of a highly perfected type in these. Fifth: from having had few antagonists equal to or more powerful than themselves in freshwater, as the increasingly huge carnivorous reptiles evolved, these evidently pressed on the freshwater fishes, drove them to sea, and even then many species and genera of reptiles-following the fishshoals-became modified as sea-dwellers. Sixth: the abundant invertebrate life in the sea, that would serve as suitable food, aided the persistence, multiplication and dissemination there of elasmobranchs. Seventh: considerable parts of subaerial areas, during the Permian and the Triassic, became of a dry xerophytic and semi-desertic nature, while simultaneously subject to considerable denudation, and to formation of wide lacustrine expanses that of ten became shallow and saline. So not a few previously freshwater organisms, - including fishes, must have become accustomed to a fairly saline environment. Preparation was thus made for passage toward the sea of those types which best survived in the saline environment. Eighth: the climax of cephalopod development was reached during lower jurassic time and then decreased. Possibly also medusoids, related to those so beautifully preserved in the Solenhofen slates may up to this time have been abundant and troublesome marine dwellers, but now may have begun to dwindle in importance. Opportunity was thus at length given for passage of the most predaceous or otherwise adapted, of the freshwater fishes into the sea. The Selachians first, and later lateral derivatives from the "ganoids" seized the opportunity.

As emphasized by Sauvage (I43: I) and other geologists and palaeontologists, the Rhaetic or Upper Triassic beds pass almost insensibly into those of the Liassic, while we have already incidentally indicated that not a few plant and animal genera are continuous through both formations. But while extensive changes in the relation of land and sea seem to have proceeded slowly during Triassic times, oscillations between land and sea seem to have been frequent and variable during the Jurassic. So marine or 
freshwater deposits on land surfaces often alternate in close succession with each other. Biologically one result of this was that-as in the case of Solenhofen slates-an admixture of organisms may be entombed in what appears to be a continuous rock mass of 40 to 80 feet in thickness.

Broadly it may be said that the first-deposited or Liassic beds are in some areas wholly or largely freshwater- as is true of the Lower Lias, - in others marine as is true often of Mid-Liassic beds. The lower and middle Oolites are largely marine, though in Europe the "Stonesfield Slates" seem to be largely freshwater deposits. The upper or "Portland Oolite," and the Purbeck that corresponds to the Upper Jurassic of America, are of mixed character below but largely freshwater above, while the lowest or Wealden beds of the Cretaceous formation are essentially of fresh water or land origin.

But before proceeding further it should now be stated that a palaeontological classification of Jurassic and Cretaceous strata has come into vogue, which while undoubtedly of great service in distinguishing marine strata, has tended to throw into the background a true biological estimate of the land and freshwater deposits of both formations. Or even through the reporting loosely of two or more groups of fossils from strata that are adjacent but quite distinct in origin, correspondingly loose views have originated as to the true interpretation biologically of the fossils. So while definite species of pelecypodous, gasteropodous, or cephalopodous molluscs may be helpful stratigraphic guides in determining marine horizons, if these organisms are mixed, in tabulations, with organisms from other and it may be adjacent freshwater beds, an obscure or entirely incorrect view may be got as a whole. One of the early and also careful observers in this respect is P. B. Brodie, whose "History of Fossil Insects in the secondary rocks of England ( 1845 )" abounds in detailed classifications of strata with their typical fossils.

In trying therefore to obtain a correct picture of the physico-biological aspects of the Jurassic, the writer proposes first to refer to or directly quote, descriptions of previous observers. 
In papers by Wright $(I+f: 24)$ and Roberts (It5:229) extensive lists are given of marine invertebrate organisms in appropriate strata, but no mention is made of fishes, reptiles or mammals, all of which were then abundant over land or lacustrine areas. In contrast to this Judd in "The Secondary Rocks of Scotland" (146:97) not only lists abundant and typical marine fossils from lower Jurassic rocks of the Moray Firth region, he further emphasizes the freshwater nature of many strata, which he correlates with the Portland, Purbeck and Wealden of Anglo-French areas. They agree also in showing, not unfrequently, alternations of freshwater and marine beds with their appropriate fossils. But for the former beds he habitually uses the expression "estuarine," to which the writer would take exception, and replace by the name lacustrine. For wherever a careful discrimination is made, the so-called "estuarine" beds contain only freshwater fossils, or these rarely mixed with what evidently were washed-out and redeposited oyster shells. For in referring (p. IO3) to an "argillaceous type of estuarine strata" that is made up largely of finely laminated clays, he states that these clays "contain also thin bands of limestone, sometimes crowded with shells of Cyrena, Unio, and other freshwater bivalves, sometimes with Paludina and other freshwater univalves, and at others made up of dwarfed Ostreae and other marine shells, crowded together in masses, and forming beds exactly resembling the well-known "Cinder-beds" of the Purbeck. In these clays, beds crowded with the valves of Cyprides and Estheriae also occur, with veritable bonebands, made up of scales and teeth of fishes and bones of reptiles. Not unfrequently these clays are crowded with plant-remains; and interstratified with them occur beds of lignite or coal, sometimes several feet in thickness, some of which have been worked with success.'

"No one can examine these strata of the argillaceous type without being at once struck with their resemblance to those of the Purbeck formation, and also to those of similar character which occur at the top of the Wealden in the Isle of Wight and elsewhere, which I have described in detail under the name of the Punfield Formation." 
But a small mass of strata along the Moray Firth shore known as the Linksfield Slates, and that is of doubtful Wealden, Purbeck or Rhaetic age, deserves attention from its fossils. These he lists (p. I 48) as follows:

* Femur of Trionyx sp.

* Vertebrae of Plesiosaurus sp.

* Scales of Semionotus punctatus

* Scales of Lepidotus minor

* Scales of Pholidophorus sp.

* Scales of Eugnathus sp.

* Teeth of Hybodus lazusoni

* Teeth of Hybodus dubius

+ Teeth of Sphenonchus martini

* Acrodus sp.

* Spines of Hybodus

†Ostrea sp.

+Pteroperna $s p$.

$\dagger$ Mytilus sp.

\section{+ Modiola hilliana}

+ Modiola sp.

$\dagger$ Astarte sp.

* Unio sp.

* Cyrena

* Cyclas (several species)

* Melanopsis $s p$.

* Paludina sp.

* Planorbis sp.

* Candona? globosa

* Estheria minuta var brodieana

+ Spine of Echinoderm

* Neuropteris and other ferns

* Fragments of wood.

Now as in the former case, so here, there is a sharply marked set of lacustrine organisms, which we have indicated by an *, as well as a set of marine remains indicated thus $t$. And we venture to affirm that the two sets occur in quite distinct, though it may be closely adjacent beds. For all of the above fish remains had been up to this point, and most of them remained, freshwater inhabitants. Acrodus and Hybodus alone were now wavering between a lake and sea environment.

Partial proof of the above is got on p. I62, where he gives the exact succession and thickness of beds at Strathsteven, and here steady alternation of marine and lacustrine beds, with their appropriate fossils, is evident. But on p. I 82 an evident mixing up of the two sets of organisms is set forth in his list.

But in many lists of fossils from typically marine Jurassic strata, several genera of Cestracionts become increasingly prominent alongside marine vertebrate organisms. These are Hybodus, Acrodus, Asteracanthus, and Strophodus. The same is true, amongst chimaeroid selachians, of the genera Myriacanthus, Squaloraja, Ischyodus, and Ganodus. Unfortunately not a few of the species of these genera are only known to us by their teeth, or by their teeth 
and spines. Hybodus (Figs. 24, 25) and Acrodus however - which may be evolved representatives of the palaeozoic Orodus and Campodus, extend from the Trias to the Upper
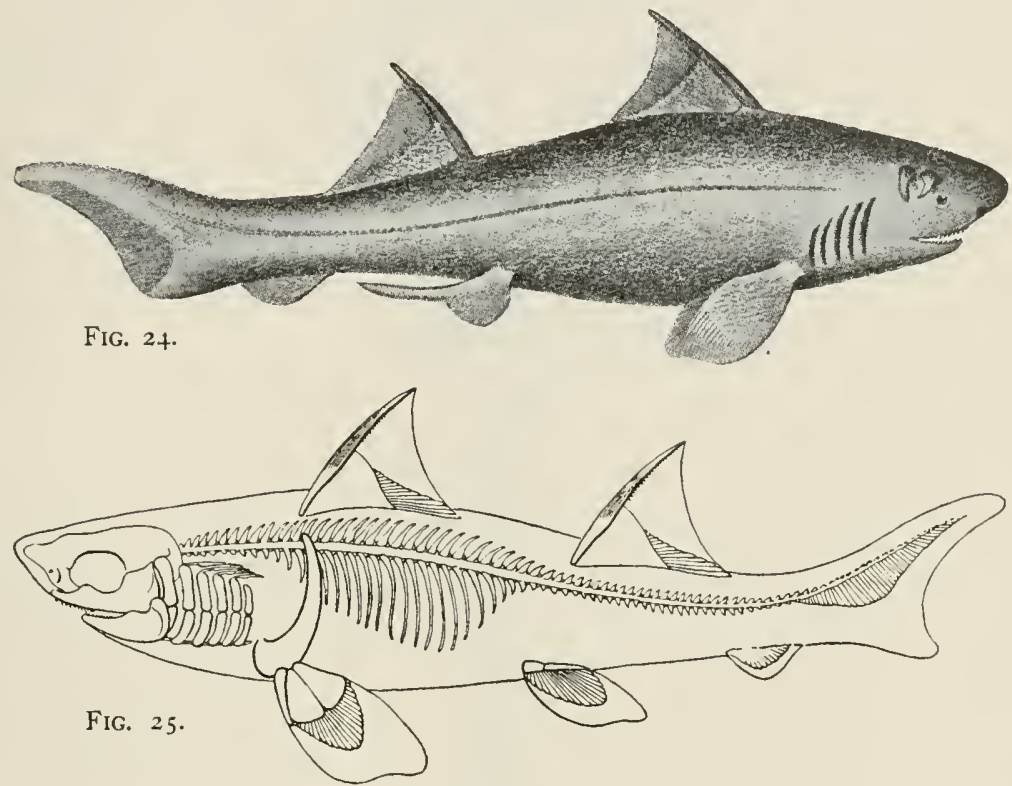

FIG. 24. Hybodus hauffianus, restored view of fish, from Upper Liassic bituminous shales of Wurtemburg. Fig. 25. Skeleton of H. fraasi from Solenhofen slates. (After Campbell Brown).

Cretaceous, and were during Triassic times at least, partially if not wholly freshwater. But from the Lower Lias upward to the close of the Jurassic, they evidently became largely and at length wholly marine, and continued so till their extinction in the late Cretaceous. The other genera above named, that appeared first in Liassic or in Oolitic strata, either died out during the Jurassic, or persisted in marine surroundings to the close of the Cretaceous, as with Ischyodus. Further a few Jurassic genera, like Squatina (Fig. 26), Rhinobatus, and Cestracion, that had taken to marine surroundings, continued alive in one or more species up even to the present day.

So while it is possible to speak only with a fair degree of accuracy, the evidence seems sufficient to warrant the 


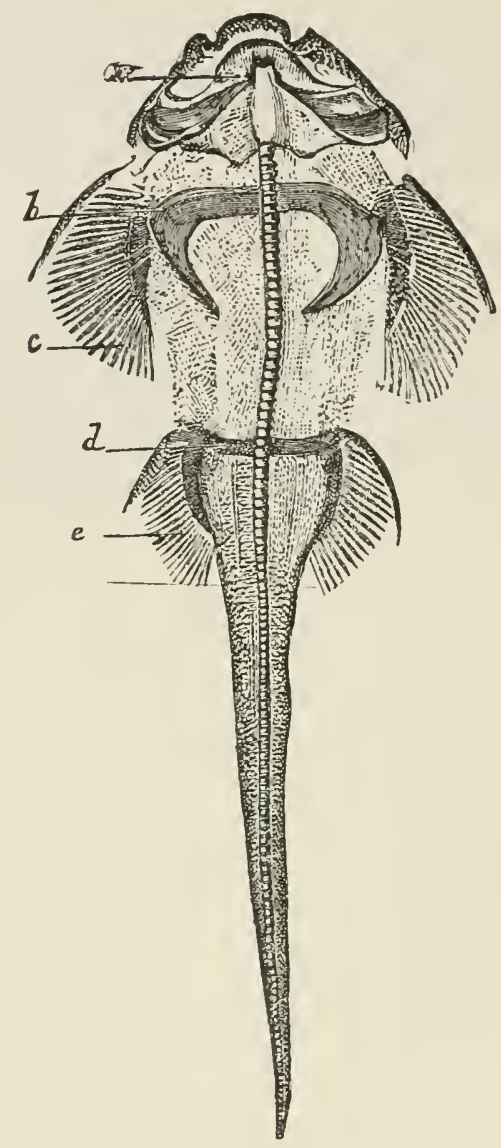

FIG. 26. Squatina speciosa, an ancient type of ray-fish from the lithographic stone of Solenhofen, Bavaria. a, mandible; b, pectoral arch; c, pectoral fin; d, pelvic arch; e, pelvic fin. Two-thirds natural size. (From A. S. Woodward).

statement that after complete, or almost complete, obliteration of marine fishes in early Permian time, during the Triassic or early Liassic days derivatives of the older elasmobranchs that inhabited lakes, river beds and swamps, again began to descend to the sea, where their descendants are still a powerful and aggressive, though not very abundant, group.

An equally abundant land flora, and land to freshwater fauna, have been described and listed for central European 
beds. But the prominent feature is the varied lot of amphibious to marine reptiles that invaded or often swam on the waters. A like condition is revealed by a considerable thickness of the Stonesfield Slates and the Kimmeridge clay. It is in this latter zone also that the remarkable Solenhofen and Cerin slates occur that are dealt with in considerable detail below, and the organisms of which give us a fuller and more graphic idea of the life of this period, than do any other known rocks of the entire geologic scale.

In some upper Portland beds, and in Purbeck sections of central England, Brodie and others obtained rich organic remains from a set of slaty limestones. In addition to land plants, cyprids, a great variety of insects, several genera of freshwater molluscs, and an important series of fish remains were assembled. While a considerable number of elasmobranch fishes like Hybodus and Acrodus still lived in the lakes, the dipnoan and ganoid genera were greatly more numerous, and in some localities their remains are piled on each other. So in many places over the European continent from England eastward, bituminous rocks that contain decomposed products of these fishes are known.

Over the European continent extensive masses of Jurassic freshwater beds have been treated of by Oppel $(I+7)$, by Quenstedt ( $148:$ I ), also by Credner, Meyer, Pictet, and others. But attention may now be given to the remarkable Solenhofen-Eichstadt slates. The fishfauna of these was studied in succession by Agassiz, A. Wagner, V. Meyer, Winckler, and V. Reis. But the most complete and recent study is that of I. Walther entitled "Die Fauna der Solenhofener Plattenkalke" (I 49: I35). The material composing these slates is an extremely fine-grained and hard limestone that has attained international repute as yielding the finest grade of lithographic stone. The deposit occurs in somewhat discontinuous masses along the Wiesenthal of Bavaria, and varies from $20 \mathrm{ft}$. to nearly $80 \mathrm{ft}$. in thickness. It is readily divisible into a series of layers (Flinze of Walther) that vary from thin plates to blocks which average IO-I 5 c.m. in thickness. These split apart readily from each other, owing to delicate films of deposit that are usually of darker and more earthy 
aspect than the hard lime rock. The enclosed organisms are of most diverse character, but whether plants, medusae, brittle-stars, echinoids, leeches, worms, crustaceans, molluscs, fishes, reptiles or birds the finer structural details are revealed often in marvellous manner. Further as grouped by Walther they may roughly be divided into water and land forms.

It becomes therefore a matter of special interest to learn how such a deposit originated. Walther evidently very correctly pictures, as a background setting and starting point, the presence of a Kimmeridgean land-mass, into which extends a lagoon or shallow arm of the Jurassic sea that then covered large areas in Western Germany, France, and East England. Coral reefs and islands dotted over this sea, while through activity of the associated marine organisms, those deep deposits of organic lime-carbonate origin had formed which we know as the marine Liassic and lower Oolitic strata.

But Walther then pictures a constant tendency to elevation and depression of the lagoon that now is the Wiesenthal, with resulting death and stranding of the organisms near the surface of each deposit, when such by elevation became dried in the sun. The wafting of dark-colored land debris-inorganic and organic-gave rise to the separating films that now cause parting of the layers (or flinze). Renewed depression of the lagoon area started another limey deposit over its surface, that lasted till renewed elevation took place. Sudden death of the organisms was effected, owing to and simultaneously with, volcanic changes that caused the elevation.

This view is an ingenious and attractive one, and further seems well to fit the case, since Walther shows that the landderived animals were evidently mostly dead before being embalmed in the strata, while the marine organisms-the medusae, brittlestars, antedons, crustaceans, and some fishes -were entombed in the living state. But for many reasons the writer would suggest a different and much more efficient explanation, one however which would doubtless have been ruled out of court before publication of Russell's work. 
First. It should be observed from his grouping of beds on p. I 45 that different combinations or sets of organisms are found at different localities; also that there may be several zones for medusae, several for the fish Leptolepis, several for reptiles, etc. In other words there is often a successional repetition. Second: the land forms were mainly dead when entombed, the marine ones were alive. Third: all were quickly and perfectly covered over and encased. And here we might note specially regarding the remains of the various genera of Medusae. The writer has often watched myriads of these cast up on many shores from Scotland to New Jersey and Florida. If left exposed to drying sun and wind even for three hours practically no trace is left of their organization. Again the brittlestars were killed and covered before they attempted auto-disorganization. As Walther himself well puts it also (p.206) "no putrifactive bacteria destroyed the muscle of the fish, no scavengering crabs had devoured the dead corpse." Fourth: the entombing substance was quickly and evenly deposited; was an extremely fine crystalline dust or a watery crystalline deposit; and it quickly hardened into an extremely close uniform fissile rock. Fifth: some rapidly destructive substance, agency, or set of phenomena caused far-reaching death in the air ( as for the pterodactyls and insects), in freshwater (as for the leeches and ganoid fishes), and later in the sea (as for the medusae, brittlestars, etc). Sixth. These fine deposits of crystalline lime substance were at irregular intervals covered by thin deposits of darker and apparently aerial debris. Seventh. As Walther accepts and explains, both kinds of deposits were not solution-precipitates, they seem to be made up of extremely comminuted crystalline or isolated particles.

We would consider then that the entire Altmühl-Solenhofen deposit represents a huge mass of coral rock-deposit that was caught up by a volcano or volcanoes, ground up in its vent during days, or even weeks of eruptions, crystallized and then shot out over hundreds of miles of country. Violent winds, earthquakes, and poisonous gaseous discharges meanwhile brought wholesale death to land or freshwater animals; while the crystalline volcanic dust percolating 
downwards into the shallow waters of the now elevated lagoon along with discharges of gases at each climax of oscillation caused asphixiation of the marine organisms.

So, if we make use of the exact statistics gathered by Bonney, Judd, and specially by I. C. Russell ( $I 7: 284-296)$, the entire deposit may have been made within a few days. Or at most three or four main periods of activity, such as Walther's photographs of the strata suggest, may have occurred, each within a few weeks or possibly longer periods of time apart, and each depositing four to twenty feet of volcanic lime-dust produced from pulverized coral-rock. The mention by Walther of four successive medusoid zones (p. 2 ro of his work), and of several zones with abundant Leptolepis fish remains favors such a view.

The revelation given by these Solenhofen beds of a rich fish-life is probably unequalled by any other single rock formation, if we except the even richer Monte Bolca deposits. Whole shoals of individuals belonging to the genus Leptolepis must have perished in some freshwater area, and been swept rapidly on as dead bodies where they became spread out and entombed in sidewise manner. Some fishes -probably by action of poisonous gases-had time to disgorge their food before death; while others show small fishes still in the alimentary canal, as with Caturus and Thrissops, whose food seems largely to have been the small fry of Leptolepis.

As indicating the extreme richness of the fish-fauna thus brought together we subjoin Walther's list in its entirety. And as his combined results were gathered from various localities along the Wiesenthal, each locality is indicated by a capital letter that is the initial for the locality name. These are Kelheim (K), Eichstadt (E), Solenhofen (S), Mörnsheim (M), Langenaltheim (L), Daiting (D) and Nusplingen $(\mathrm{N})$.

ELASMOBRANCHII.

Order Squalidae.

Fam. Notidanidae

m Notidanus eximius.

E. D. N.

$\mathrm{m}$ Notidanus intermedius $\mathrm{M}$.

$m$ Notidanus serratus $\mathrm{N}$.

$\mathrm{m}$ Notidanus atagneri S.
Fam. Cestraciontidae.

f-m Acrodus falcifer, E. S. L. Fam. Scyllidae.

$\mathrm{m}$ Palaeoscyllium formosum E. S.

m Pristiurus eximius E.

Fam. Lamnidae.

$\mathrm{m}$ Sphenodus nitidus S. 
Fam. Squatinidae.

m Squatina alifera, E. S.

Fam. Rhinobatidae

$\mathrm{m}$ Spathobatis mirabilis E.

$\mathrm{m}$ Asterodermus platypterus K. E. S.

$\mathrm{m}$ Asterodermus titanius $\mathrm{K}$.

Order Holocephali.

$\mathrm{m}$ Ischyodus avitus, $\mathrm{K}$.

$\mathrm{m}$ Ischyodus quenstedti, K. L. S.

$\mathrm{m}$ Ischyodus schuebleri, $\mathrm{K}$.

$\mathrm{m}$ Ischyodus suevicus N.

m Chimaeropsis paradoxa, E. S.

DipNor. Wanting.

GANOIDEI.

Order Crossopterygii.

$f$ Undina acutidens. $Z$.

f Undina minuta.

f Undina penicillata. K.E.Z.

$\mathrm{f}$ Libys polypterus, $\mathrm{K}$.

f Libys superbus, K. Z.

f Coccoderma bavaricum.

f Coccoderma gigas.

f Coccoderma nudum.

f Coccoderma substriolatum.

f Coccoderma suevicum.

Order Heterocerci.

f Coccolepis bucklandi, E. S.

Order Lepidosteidae.

Fam. Stylodontidae.

f Heterostrophus latus, S.

f Heterostrophus lepidotus, $\mathrm{K}$.

Fam. Sphaerodontidae.

$\mathrm{f}$ Lepidotus armatus, S.

$\mathrm{f}$ Lepidotus decoratus, S.

$\mathrm{f}$ Lepidotus gigas, $\mathrm{S}$.

$\mathrm{f}$ Lepidotus intermedius, $\mathrm{K}$.

$\mathrm{f}$ Lepidotus maximus, K.E.S.

$f \quad L e p i d o t u s$ notopterus, K.E.S.

$\mathrm{f}$ Lepidotus oblongus, E. S.

f Lepidotus pustulosus, S. D.

$f$ Lepidotus subovatus.

$\mathrm{f}$ Lepidotus unguiculatus, D.

Fam. Saurodontidae.

f Eugnathus macrodon

f Eugnathus microlepidotus, E. D. N.

f Pleuropholis laevissima, E.

f Pholidophorus dentatus, N.

f Pholidophorus intermedius.

f Pholidophorus macrocephalus, K. E.

f Pholidophorus latus, N.

f Pholidophorus micronyx, $\mathrm{K}$.

f Pholidophorus microps, S.

f Pholidophorus ovatus, E. f Pholidophorus tenuistriatus, N.

f Isopholis brevivelis, E.

f Isopholis latimanus, K. E.

f Isopholis muensteri, $\mathrm{K}$.

f Ophiopsis attenuata, E.

f Ophiopsis intermedia.

$\mathrm{f}$ Ophiopsis muensteri $\mathrm{K}$.

f Ophiopsis procera, S.

f Ophiopsis serrata.

f Eusemius beatae E.

f Propterus denticulatus.

f Propterus elongatus, E.

f Propterus gracilis, E. S.

f Propterus microstomus, E.

f Propterus speciosus, E.

f Propterus zieteni.

f Notagogus denticulatus.

f Histionotus oberndorferi, $\mathrm{K}$.

f Macrosemins insignis, S.

f Macrosemius latiusculus.

f Macrosemius rostratus, E. S.

Fam. Rhynchodontidae.

$\mathrm{f}$ Aspidorhynchus acutirostris (frequent).

f Aspidorhynchus mandibularis, K. E.

f Aspidorhynchus obtusirostris, E.

f Belonostomus kochi, K.

f Belonostomus muensteri, D (frequent).

f Belonostomus pygmaeus, $\mathrm{E}$.

f Belonostomus sphyraenoides, E. S. ( $Z$ ?)

$\mathrm{f}-\mathrm{m}$ Belonostomus tenuirostris, E. S. (frequent).

Order Amiadae.

Fam. Pachycormidae.

f Hypsocormus insignis, K. E. S.

f Hypsocormus macrodon, K. E.

f Sauropsis longimanus, E.

f Diplolepis sp, E.

f Agassizia titania, E.

Fam. Eugnathidae.

f Caturus contractus. S.

f Caturus cyprinoides, E.

f Caturus elongatus, E. S.

f Caturus furcatus,

K. E. S. L. D. N. C.

f Caturus granulauts, K.

f Caturus macrurus, E. S.

$f$ Caturus microchirus, E. S.

f Caturus pachyurus,

K. E. S.

f Caturus subovatus. 
f Strobilodus giganteus,

E. S. N. K.

f Strobilodus suevicus, N.

f Liodesmus gracilis,

K. Z. E.

f Liodesmus sprattiformis, S.

f Eurycormus speciosus, K. E. N.

f Callopterus agassizi, K. S.

f Oligopleurus cyprinoides, K. C.

f Oenoscopus esocinus, $\mathrm{K}$.

f Macrorlipis muensteri, $\mathrm{K}$.

f Macrorhipis striatissima, $\mathrm{K}$.

f Aethalion blainvillei, E.

$f$ Aethalion crassus, E.

$f$ Aethalion tenuis.

Fam. Amiadae.

f Megalurus altivelis.

f Megalurus brevicostatus, $\mathrm{K}$.

f Megalurus elegantissimus.

f Megalurus elongatus.

$f$ Megalurus grandis, $\mathrm{E}$.

f Megalurus grandis, E.

f Megalurus lepidotus.

f Megalurus polyspondylus, E. f Lophiurus minutus, E. Order Pycnodontidae.

$\mathrm{f}$ Gyrodus hexagonus, S. (frequent.)

f Gyrodus macropthalmus, K. E.

f Gyrodus platurus, S.

f Gyrodus rugosus, K. S. N.

$f$ Gyrodus titanius,

K. S. D. N.

Microdon elegans, K. S.

$\mathrm{f}-\mathrm{m}$ Mesodon heckeli, $\mathrm{S}$.

$\mathrm{f}-\mathrm{m}$ Mesodon macropterus, E. C.

$\mathrm{f}-\mathrm{m}$ Mesodon pulchellus, E.

$\mathrm{m}$ Mesturus verrucosus, $\mathrm{K}$. E. Tfinestei

$\mathrm{f}$ Leptolepis knorri, E. S. (frequent.)

f Leptolepis macrolepidotus, $\mathrm{S}$.

f Leptolepis polyspondylus, E. S. C.

f Leptolepis sprattiformis, E. S. N.

f Thrissops formosus, K. E.

f Thrissops propterus, E.

f Thrissops salmoneus, K. E. S. D. C.

f Thrissops subovatus, $\mathrm{K}$.

The above includes a larger number of species than is known from all of the other beds of the Jurassic system. But as directly bearing on our present study, we may now inquire as to which of these were probably freshwater and which marine. In the above list the former are prefixed, according to the present writer's views, by (f) before each species or before each genus or larger group, if these are all considered to be such; and by $(\mathrm{m})$ before the latter. This determination is based most largely on statistics and evidence set forth in later chapters of this work, where the groups and genera are specially treated. In part also it is based on evidence furnished by the mass of associated organisms that uniformly occur together.

On such a basis, and viewing the Jurassic as a whole, we would regard as freshwater beds considerable strata of the Lower and Upper Lias, of the Stonesfield slates, of the Kimmeridgean, of the Portlandian to a less degree, and of the Purbeck. With Woodward's "Museum" volumes as an aid then, it seems that of freshwater species sixty 
are recorded from the Lower Lias, forty-three from the Upper Lias, twenty-three from the Stonesfield Slate, one hundred and forty-two from the Kimmeridge beds, of which one hundred and thirty are included in the Solenhofen list, fifteen occur mainly in the upper lacustrine Portlandian strata, and forty-two in the Purbeck. In contrast, of marine species the Mid Lias is practically destitute of records, as are the Inferior Oolite and Fullers Earth. The Great Oolite and Corn Brash contain species of Hybodus, Acrodus, Asteracanthus and Strophodus. The typically marine Oxfordian and Corallian beds include Notidamus along with the four just named, as also Orthacanthus, Mesodon, Mesturus and Microdon, the last three as derivatives from freshwater types (p. 33I), Hypsocormus and Aspidorhynchus (p.34I). Each of these is represented by one to three species, rarely as with Notidanus in the Corallian by four species.

But from the perfect state of preservation shown by species of Squatina (Fig. 26, p. 194), Rhinobatus and Belemnobatis in the lithographic slates of Bavaria, as compared with many of the ganoids, these had probably also become to a greater or less degree marine. Their increasing abundance also in marine beds of the Cretaceous system likewise favors such a conclusion.

In stating the above then the writer considers that all of the great groups of fishes continued as inhabitants of the lakes, rivers and swamps, throughout the Jurassic and into the Cretaceous, except for genera of the rays, the dogfishes, probably some of the pycnodonts like Mesodon and Microdon, also more doubtfully a few "ganoid" genera like Hypsocormus and Aspidorhynchus. But even the earlier species of Hybodus and Acrodus that occur in the Lias and Stonesfield Slate, were still largely lake-dwellers, Thus Judd in treating of the Jurassic rocks of N. E. Scotland (Q. J. Geol. Soc. 29 (I 873) 97) gives the thoroughly freshwater list already quoted (p. 192).

The occurrence here of small specimens of Ostraea and of Mytilus would indicate that occasional invasions of seawater may have happened, or even that they had been washed out and redeposited. 
But the apparent mixing of records for two adjacent sets of beds, and the accurate placing of them for another in adjoining sentences, is evidently set forth in de Lapparent's work (67: I I4I-42). For on page I I 4 I he gives from Mazenay in "calcaires fissiles" of the Jurassic, Leptolepis constrictus and L. affinis-both of which we regard as freshwater-along with Lioceras serpentinum and Inoceramus cinctus, both typically marine. But at top of the adjoining page he gives from Souabe in "schistes-bitumineuse ou schistes-carton" five strata in descending order thus :

(5) schistes a Belemnites tripartitus et Inocerames.

(4) schiste et calcaire a Lioceras serpentinum et Belemnites gracilis.

(3) Calcaire a poissons (Ptychodus, Leptolepis, Lepidotus).

(2) feuillet a Posidonia Bronni.

(I) couche de passage a Monotis substriata.

The two upper and the lowest at least are typically marine beds. (3) and (2) however are freshwater. Ptychodus moreover is a Cretaceous not Jurassic genus. One of those oscillations between land and sea evidently occurred here, such as were frequent through the entire Jurassic.

A very similar state of affairs is that set down by Brodie (pp. 57-58), where he described a "bone-bed" with associated Pullastra arenicola, but when in an exact tabulated list he states that this bone-bed is "a hard thin stratum full of pyrites, and composed of bones, scales, and teeth of fish," and that "connected with this is a white and yellow sandstone full of casts of Pullastra arenicola," we recognize that the two were totally distinct. The latter was a marine bed, then above it and doubtless after sudden elevation of the region and probably by volcanic dust-deposit, a mass of freshwater fish-remains became entombed, these fishes agreeing with species that de Lapparent often refers to amid typical freshwater setting.

A suggestive paper by Roberts "On the Correlation of the Upper Jurassic rocks of the Swiss Jura with those of England" contains extensive lists for Mid and Upper Jura. These include varied and abundant marine invertebrates, but not a single plant remain, Estheria or fish. But passing to the Purbeck strata on top of the series he gives 
Chara, Cypris, Bithynia, Planorbis, Corbula, and Hydrobia, along with teeth scales and bones of fishes, all of which he regards as freshwater.

$\mathrm{J}$. V. Rohon ( $I 6: \mathrm{I}$ ) gives a valuable glimpse into freshwater beds that he and Heer regard as of Upper Liassic age, and which are exposed on the Angara river north of Irkutsk in Siberia. In contrast to the extensive
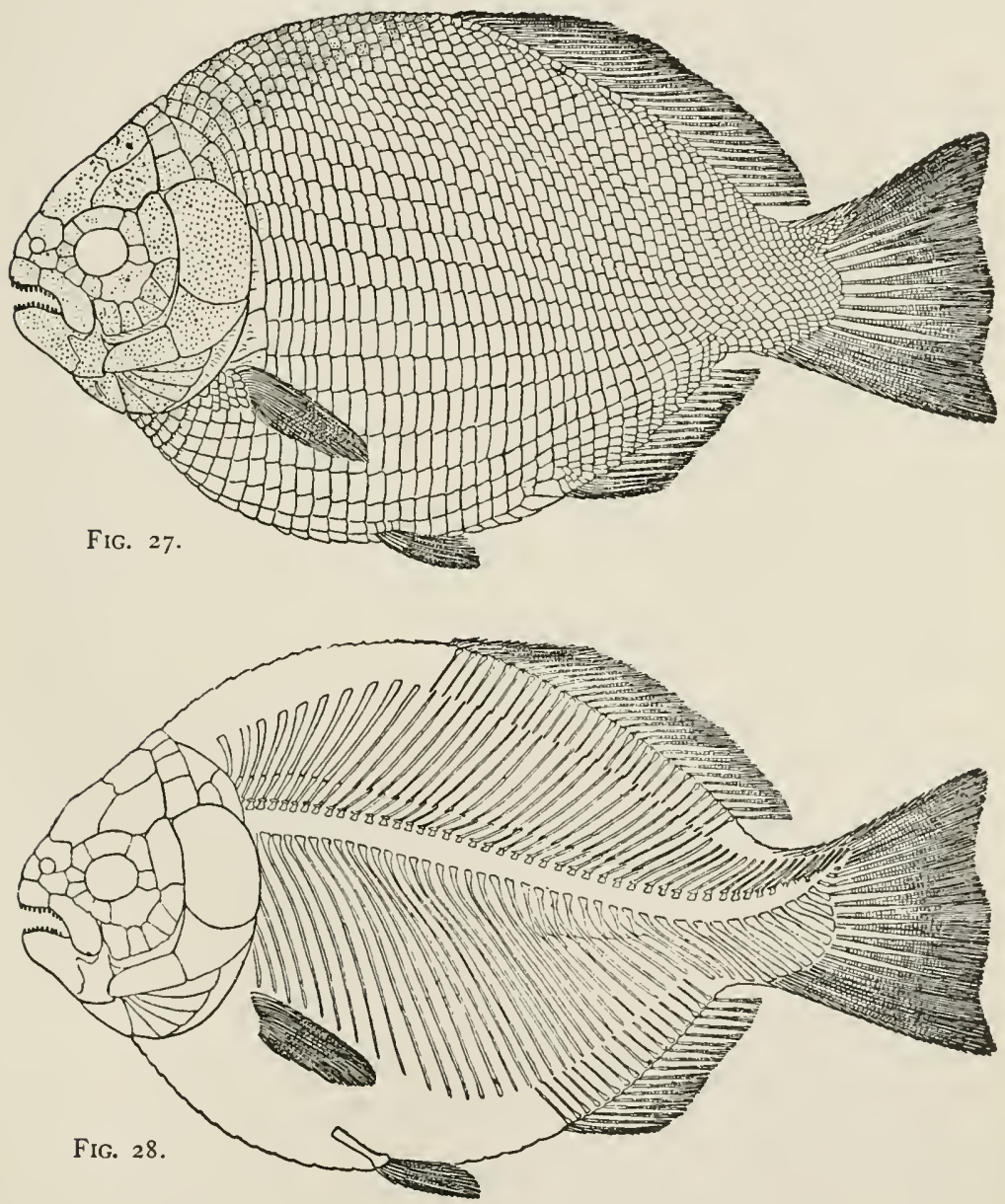

FIG. 27. Dapedius politus, a freshwater Lower Liassic ganoid fish from Dorset, England. FIG. 28, restoration of the skeleton; both one-fourth natural size. (After A. S. Woodward). 
lists that Neumayr, Nikitin and Pavlow give for higher and typical marine beds of the Jurassic in which fish remains are unmentioned, Rohon gives sixty-three species of plants, twenty-three of insects, various remains of crustaceans, and a few species of fish, probably belonging to the genus Pholidophorus, as determined by A. S. Woodward.

In the "Kota" beds of the Deccan, India, Sykes $(150: 272),(15 I: 8: 23 ; 9: 35$ I $;$ IO $: 37$ I $)$ and Egerton have described a succession of strata that appear to be transition beds from the Upper Triassic to the Lower Jurassic and which are largely or wholly freshwater in origin. In a rock section about forty feet thick Bell records the alternation of five layers of bituminous shale with limestones or dark shales. From the shale Bell and Egerton ( $I 5 I$ : I $0: 37$ I) have described Dapedius egertoni, that is allied to the South English Liassic species D. politus (Figs. 27, 28 ), Lepidotus longiceps, L. breviceps and $L$. deccanensis, while the latter further observes that "the specimens of bituminous shales contain besides the fish remains, some coprolites and some traces of plants." In the later paper it is noted that the fish remains are associated with abundance of Estheria mangaliensis, the dipnoan Ceratodus, also with Brachyops laticeps and Hyperodapedon. All of these were contemporaneous with a rich Gondwana flora, and are clearly freshwater.

But as showing how readily incorrect views may be developed, when Sykes recorded L. deccanensis, he at once concluded that this must be a marine form, and so suggested that it was "indicative of the former submerged state of the Peninsula of India." Taken in conjunction with Egerton's later observation on the geographical distribution of Lepidotus (15I: 10:373), and the other associated organisms, it indicates that a lake-bed, or extensive river floodplain, existed then amid the dry land of the Indian massif.

As in all preceding formations so for the Jurassic it will be observed that bituminous shales or bituminous rocks of some kind are usually recorded wherever a rich fish fauna exists; and it is undoubtedly still in connection with accumulations of freshwater-not marine-fishes that these bituminous products are associated. In the preceding context 
mention of such has been made in the strata of the "Kota" beds of India, while others might further have been included. Further Mansell-Pleydell in speaking on "The Geology of Dorset" ( I 53:408) says : "The Kimmeridge Clay of the vale of Blackmore is less bituminous than that of the Kimmeridge district; where it is upwards of sixty feet thick, and strongly impregnated with bitumen, giving off a disagreeable smell. It burns vividly with a bright and clear flame, but is unfit for ordinary use as fuel. . . It has an unpleasant odor when burning, resembling petroleum, and yields a reddish ash. The volatile matter of the richer beds is upwards of $73 \%$; the solid mineral matter being only $27 \%$."

Finally a noteworthy study on the Australian Jurassic is A. S. Woodward's "Fossil Fishes of the Talbragar Beds of Australia," that may be of Kimmeridgean age. In a preliminary notice by T. W. E. David and E. F. Pitmann it is said: "the fish-beds proper form the lowest of the three members into which, on lithological grounds, the deposit to which they belong may be divided. They consist of laminated hard siliceous shales, cherty in places, rendered ochreous by ferruginous infiltrations and traversed by joints" "Fish and plants are so abundant that it is difficult to find even a small fragment of the shales devoid of them. The plants are preserved in the form of siliceous impressions, their pure white color contrasting strongly with the ochreous tint of the enclosing shale." The plants included are Thinnfeldia odontopteroides, Podozamites lanceolatus, Neuropteridium australe, and Taeniopteris daintreei. Associated with them and with the fishes was a cicadeous insect. The perfect condition of the plants, the insects, and the fishes, suggests one of two possible modes of origin for the rocks and the state of the organisms. Either they became suddenly entombed and cased up by siliceous volcanic dust, or some siliceous thermal lake area, by sudden bursting and discharge of its contents, killed and enclosed the organisms intact. Future detailed study may yet settle the question.

The fishes as determined by Woodward are of exceptional interest in the present inquiry. They include a species 
of Coelacanthus, Coccolepis australis, Aetheolepis mirabilis, Archaeomaene tenuis, and A. robustus, Leptolepis talbragarensis, $L$. lowii, and $L$. gregarius. The association of insects and plants, as well as the complete absence of any marine organisms, stamp the deposit and the fishes as freshwater. But the occurrence of fossilized shoals of the firstnamed Leptolepis, at once recalls Walther's description of L. sprattiformis in the Solenhofen Slates. Again in speaking of Coccolepis Woodward says: "The genus thus defined is represented by small species in the lithographic stone (Lower Kimmeridgean) of Bavaria (Coccolepis bucklandii), and in the Purbeck beds and Lower Lias of England. It is therefore of much interest to find a large fish in the Hawkesbury-Wianamatta series of Talbragar, exhibiting characters so similar as not to be more than specifically distinguishable."

Aphnelepis, in its near relation to Semionotus and Aetheolepis, and as a specialized ally of the Liassic Dapedius, serves with the above to link the Australian and European fish-fauna in close manner. As to the preservation of these, and as shedding some light on the Solenhofen shales, the author says: "The fishes are crowded together as if suddenly destroyed and very few of them have become disintegrated before fossilization. A glance at the accompanying plates will show how beautifully even the most delicate bones and fin-rays are usually preserved." In describing and figuring the scales alike of Actheolepis and Archaeomaene he also demonstrates the graded continuity shown (Fig. 54, p. 330) from a ganoid to a perfect cycloid type. If to this we add the close anatomical structure of these and of related genera to primitive and derived teleosteans, that were, like these, dwellers in freshwater, a clear way is opened for understanding how and where primitive teleosteans first evolved, and why it is that a large proportion of these are still freshwater. It explains also how derivative types, during subsequent Cretaceous and Tertiary times, gradually passed into and stocked the seas and oceans with what are now the dominant fishes, both as regards genera and individuals. 


\section{During Triassic and Jurassic Periods}

So in the evolution of the great families Pholidophoridae, Oligopleuridae and Leptolepidae, a definite and easy transition is made, during the period from the upper Triassic to the close of the Jurassic, from the ancient Protospondylii or scaled ganoids to the great group of the Teleostei that was destined gradually to displace all of the other groups in individuals, in genera, in geographic distribution, and in adaptive contrivances. 


\section{CHAPTER VII.}

The Physical and Biological Environment of Fishes. (d) During the Cretaceous Period

The fundamental changes in distribution of land and sea, that were effected toward the close of the Liassic period and that became even more pronounced as subsequent Jurassic deposits were laid down, proceeded with equally striking results during Cretaceous time. The diagram on p. 240 shows this for the later Cretaceous. The period is an important one in our present inquiry. For all accumulated evidence combines to show that a great and varied extension of elasmobranchs into the sea now took place. It also emphasizes the view that the Dipnoans, most of the Holosteans, the Chondrosteans, and lingering Crossopterygians, as well as many of the derivative Teleosteans remained as freshwater dwellers.

Here also it may be observed that the only genera of the fishes which occur in Jurassic strata and have come down through the Cretaceous to our own day in living representatives are Rhina (Squatina), Rhinobatus, Notidamus, Cestracion, Pristiurus, and Ceratodis, all of which except the last are finely preserved in the Solenhofen slates, and all had apparently become thoroughly marine by the beginning of the Cretaceous, except Ceratodus, which persisted throughout in freshwater.

The Cretaceous vegetation was in many places luxuriant and even sufficed to furnish workable coal. Such coal beds also are practically always associated with strata that indicate inland lacustrine conditions. Thus the Wealden coal of North West Germany, and to a less extent of England; the Deister coal beds of North West Germany, the Pflanzen-quäder of Bohemia; the enormous beds of the Laramie formation, that are estimated to include "more than I00,000 square miles of coal-bearing land" ( $8:$ IIl : I 59), are a few examples.

The marine strata, as now known, have bulked more largely in geological literature, than the freshwater or 
terrestrial, and the fossils have correspondingly been emphasized. Broadly speaking the lowest or Wealden and the Neocomian beds of Central Europe, that seem exactly to correspond with the Comanchean and Dakota beds of North America, are largely freshwater, and often show direct continuity with the Purbeck or Upper Jurassic below. The Greensand-Gaults of England, the Aptian-Cenomanian of France, the Flammenmergel and Lower Pläner of Germany, and the Benton-Niobrara-Pierre-Foxhill groups of North America are wholly or largely marine. The Chalk strata of England, the Turonian-Senonian of France, and the Middle-Upper Pläner of Germany are probably inferior in position to the Laramie of North America, though in saying this the writer does not forget the controversies over the age of the last. These strata are either balanced between freshwater and marine beds, or somewhat preponderate toward the latter. The chart on "p. 2 I I sets forth the supposed correlation relation.

Two important and fundamental changes were largely consummated during this period, and undoubtedly affected organisms powerfully. First: during the Lower Cretaceous period in South Africa and in western America great volcanic activity proceeded, but this was, so to speak, the prelude to greatly more catastrophic action during the Later Cretaceous in India, in South Africa, and in Western America. Thus the enormous deposits of volcanic rock in the Deccan, that are 4,000 feet to 6,000 feet thick, cover an area of at least 200,000 square miles. The "Laramide" rocks of Dana cover a large part of Western America and indicate tremendous volcanic action.

Regarding this entire area Geikie (7: II: 1374) says: "At the close of the Jurassic period, the first great upheavals took place. Two lofty ranges of mountains-the Sierra Nevada (now with summits more than I 4,000 feet high) and the Wasatch-400 miles apart, were pushed up from the great subsiding area. These movements were followed by a prolonged subsidence, during which Cretaceous sediments accumulated over the Rocky Mountain region to a depth of 9000 feet or more. Then came another vast uplift, whereby the Cretaceous sediments were elevated 
into the crests of the Mountains, and a parallel coast-range was formed fronting the Pacific. Intense metamorphism of the Cretaceous rocks is stated to have taken place. The Rocky Mountains, with the elevated tableland from which they rise, now permanently raised above the sea, were gradually elevated to their present height. Vast lakes filled depressions among them, in which, and on the plains in front of the mountains, as in the Tertiary basins of the Alps, and the Gondwana series of the Himalaya, enormous masses of sediment accumulated. The slopes of the land were clothcd with an abundant vegetation, in which we may trace the ancestors of many of the living trees of North America. One of the most striking features in the later phases of this history was the outpouring of great floods of trachyte, basalt, and other lavas from many points and fissures over a vast space of the Rocky Mountains and the tracts lying to the West. In the Snake River region alone the basalts have a depth of 700 to I 000 feet, over an area of 300 miles in breadth."

Such profound changes in the surface-crust of the earth not only originated some of the loftiest mountain chains of the world, they must also have served by cosmic stress and strain to deepen the ocean areas, and give to these greater fixity of position. During the process a gradual breaking up and rearrangement of two great continental masses Arctogaea and Notogaea evidently proceeded from this time on to the Miocene period, when the present main outlines of land and sea were effected.

Second, With increased ridging up or elevation into mountain chains-really high land-waves or crumplings before denudation became conspicuous - of the land, the waters of the earth would become increasingly restricted to oceanic areas. So the extensive marshes, freshwater lakes, and wide lagoon-rivers, would correspondingly become reduced in extent. These two conditions however would be eminently favorable for, and would emphasize, progressive evolutionary changes in organisms. For they would bring into sharp prominence the effects of isolation of organisms; of new or changed environal states; of increased littoral, sea, and ocean areas, in which originally 
freshwater and later anadromous types of animal might increasingly multiply after they became marine dwellers, as well as other important biological and ecological factors. And one of the prominent results was the continued and increasingly abundant migration of elasmobranch fishes, and now even more of evolving teleost fishes, from a previous freshwater to an acquired marine environment.

Already we have seen that during the Jurassic period various selachian, cestraciont, pycnodont, and pachycormid fishes had branched off from freshwater ancestry into marine life. But during the Cretaceous period, derivative types from the freshwater "ganoids" gradually became modified, in a manner that is traced in subsequent chapters, along two lines of environal adaptation. One very large and important series remained amid freshwaters, but rapidly evolved into teleosteans of varied affinities and increasingly perfected structure. Another, and at first less numerous series, evolving also into teleostean types, passed into seashores, later into the deep sea, and ultimately into oceans and ocean depths. Exposed there to diverse environal conditions they evolved, through proenvironal and selective reaction, modifications that, at the present day, have culminated in forms often of grotesque, weird or defensive aspect and structure. These are considered in detail in chapters XII and XIII.

\begin{tabular}{|c|c|c|c|c|c|}
\hline Formation & N. America & England & France & Germany & Lebanon \\
\hline $\begin{array}{c}\text { Upper } \\
\text { Cretaceous }\end{array}$ & $\begin{array}{l}\text { Laramie } \\
\text { Fox Hills } \\
\text { Fort Pierre } \\
\text { Niobrara- } \\
\text { Benton } \\
\text { Graneros } \\
\text { Dakota }\end{array}$ & $\begin{array}{l}\text { Norwich } \\
\text { Chalk } \\
\ldots \ldots \ldots \\
\text { Upper Chalk } \\
\text { Middle Chalk } \\
\text { Lower Chalk }\end{array}$ & $\begin{array}{l}\text { Danian } \\
\ldots \ldots . . . \\
\text { Senonian } \\
\text { Turonian } \\
\text { Cenomanian }\end{array}$ & $\begin{array}{l}\text { Chapelle Marl } \\
\ldots . . . \\
\text { Quader } \\
\text { Upper Planer } \\
\text { Middle Planer } \\
\text { Lower Planer }\end{array}$ & $\begin{array}{l}\ldots \ldots \\
\text { Senonian } \\
\text { Turonian } \\
\text { (a) Sahel } \\
\text { (b) Hakel } \\
\text { Lower Chalk }\end{array}$ \\
\hline $\begin{array}{c}\text { Lower } \\
\text { Cretaceous } \\
\text { or } \\
\text { Comanchean }\end{array}$ & $\begin{array}{l}\ldots \ldots \\
\text { Horsetown } \\
\text { Kootenay- } \\
\text { Knoxville } \\
\text { Potomac }\end{array}$ & $\begin{array}{l}\text { Gault } \\
\text { Greensand } \\
\text { Up. Wealden } \\
\text { Lo. Wealden }\end{array}$ & $\begin{array}{l}\text { Albian } \\
\text { Aptian } \\
\text { Neocomian }\end{array}$ & $\begin{array}{l}\text { Flammen- } \\
\text { mergel } \\
\text { Gargasmergel } \\
\text { Urgonian } \\
\text { Weald Clay } \\
\text { Deister }\end{array}$ & $\begin{array}{l}\text { Nubian } \\
\text { sandstone } \\
\text { Neocomian }\end{array}$ \\
\hline
\end{tabular}


As we now have to deal biologically with the two great sets of freshwater and marine fishes, as well as some that seem to have been more or less anadromous in habit, the preceding chart may aid in correlation of the beds dealt with in the countries where the Cretaceous is most carefully studied. But it must be understood that the correlation is an attempted effort toward scientific exactness, but may be in time considerably modified.

Beginning with the lowest beds that make up the IVealden formation, this has generally been conceded as of freshwater origin But Geikie (7: I I :940), Chamberlin (8: III : I 28 ), and others have regarded the entire English deposit as having been laid down in a large "delta 20,000 or 30,000 square miles in extent." Many considerations however militate against this. Thus delta deposits are typically irregular, interbedded, and devoid of uniform organic strata, those of the Wealden are largely clays that indicate steady precipitation in still waters, and which have definite organismal zones; delta deposits are restricted to narrow and irregular channels which are interrupted by land masses between, those of the Wealden are extended and agree surprisingly well with those of the American Potomac, as well as of the Weald of North Germany.

The writer would therefore favor the explanation given by C. J. A. Meyer in his paper "On the Wealden as a fluvio-lacustrine formation" ( $155: 243)$. He adduces good evidence for the view that the freshwater Purbeck beds are uniformly continuous with the base of the Wealden; that the Wealden strata were mainly laid down in shallow lakes that seem at times to have dried up over considerable areas so as to cause sun-cracks; that such remains as fruits of Chara, in addition to the abundant fern, equisetum, cycad, coniferous fossils previously recorded, also the varied invertebrate organisms like Cypris, Unio, Physa, Paludina, and Planorbis, likewise the freshwater fishes and amphibians already known all indicate a fluvio-lacustrine environment. He therefore concludes:

(I) That the Wealden strata are a fluvio-lacustrine rather than a purely fluviatile or fluvio-estuarine deposit. 
(2) That the Wealden rivers continued in existence, although probably in much diminished volume, during the accumulation of most of the succeeding Neocomian strata.

Meyer however considers that occasional marine intrusions took place, and so gave rise to the deposits with Ostraea, Mytilus and similar marine organisms. He further states that "the higher beds of the Wealden are not only extremely uniform in character, proving to some extent their deep-water origin, but also contain freshwater fossils up to their very junction with the Neocomian strata. Speaking also of the passage beds and of the Lower Neocomian, he says, quoting Fitton, that these include "a large quantity of a kind of gravel, containing numerous fragments of fish bones. It is just such an accumulation of sediment as would result from the dispersion of shore deposits over the floor of a moderately deep lake." He also regards the "Punfield" formation of the Isle of Wight as Upper Wealden, and adds: "The occurrence of a Spanish fauna at Punfield proves, if it proves anything, that the Neocomian (Lower Greensand) series of the southeast of England and of Eastern Spain are, in point of age, equivalent deposits."

The writer is compelled also to take an exactly opposite view from A. S. Woodward $(156: 69)$ when he writes: "The Wealden estuary seems to have been the last refuge of the Jurassic marine fish fauna in this part of the world." All exact evidence shows that such Wealden fishes as Hybodus, Acrodus, Asteracanthus, Neorhombolepis, Coelodus, and Belonostomus, were either once freshwater or derivative marine descendants therefrom, that reached the sea during Jurassic times. For previous to that time no sure commingling of marine invertebrate remains, with fishes that lived alongside them, is known since early Permian time onward, while up to this time Hybodus and Acrodus occur occasionally still in freshwater relation.

Resembling the Wealden of England, and probably continuous in time, as they are in facies and organic remains, beds occur over a considerable part of North Germany that Geikie ( $7:$ II : 1203 ) summarizes as follows: "Below the Hils-thon in Westphalia, the Harz, and Hanover, the lower parts of the true marine Neocomian series are replaced by 
a massive fluviatile formation corresponding to the English Wealden, and divisible into two groups: First, Deister Sandstone ( 50 feet), like the Hastings sand of England, consisting of fine light-yellow or grey sandstone (forming a good building material), dark shales, and seams of coal varying from mere partings up to workable seams of three, and even more than six feet in thickness. These strata are full of remains of terrestrial vegetation (Equisetum, Baiera, Oleandridium, Laccopteris, Sagenopteris, Anomozamites, Pterophyllum, Podozamites and a few Conifers) also shells of freshwater genera (Cyrena, Viviparus, Cyprids), and remains of Lepidotus and other fishes; Second, Weald Clay (65-1oo feet), with thin layers of limy sandstone (Cyrena, Unio, Viviparus, Melania, Cypris, etc.)." It will be observed that there is no indication of estuarine or semimarine organisms in this list, and so we would regard all, as in the case of the English Wealden, as of lacustrine origin.

But with the close of the Wealden period, or in some places during Neocomian times, wide areas that are now dry land, became submerged to a greater or less degree below sea level, and over these areas the Upper Greensands and zones of chalk were deposited. The invertebrate life at that time must have been extremely rich, as every list of marine fossils testifies. But mixed amongst these in increasing quantity and variety are the remains of fishes. These consist chiefly of teeth, jaws, scales, or spines-more rarely of the partial or entire body-of selachian, cestraciont, chimaeroid, or more rarely of teleostean types. These, descending from the lakes or rivers, during Triassic and still more during Jurassic times, became now the prevailing groups of marine fishes, and likewise from their offensive and defensive armature, must have proved formidable antagonists to the medusae, the cephalopods, and the evolving higher marine crustaceans of that time.

But from such primitive Jurassic freshwater genera of pycnodonts as Mesodon, Athrodon, and Microdon derivative marine genera like Pycnodus, Anomoeodus, and Coelodus, arose in later Jurassic times, and reached a climax in the mid or upper Cretaceous period. Then they 
began rapidly to dwindle toward extinction in the Upper Eocene.

Alongside both of these, moreover, various derivative offshoots of freshwater teleosts, which-as traced in chapter VI-had themselves originated from more ancient and primitive "ganoids," were now adapted to a marine environment. These included some large powerful and voracious fishes like Portheus (Fig. 29, p. 227), Ichthyodectes, and Enchodus, as well as others listed in later tables (p. 226).

The abundant primitive freshwater elasmobranchs of late Old Red or Carboniferous age, like Acanthodes and Pleuracanthus, were all elongate fusiform in shape, and were much better provided with defensive spines, as well as offensive teeth, than their congeners of other groups. But after reaching a high specialization as fusiform types, or after evolving into flattened types like Ctenacanthus and Janassa respectively, amid marine environment, these, as well as great groups of their freshwater ancestors were obliterated wholesale during the Permian period and only slowly recovered in freshwater, still more slowly sent out derivatives into the sea in Jurassic time. The last again evolved into two similar main lines as before-the fusiform series or Squalidae, and the flattened series or Raiadae. The former of these two retained on the whole the fusiform body, the lithe movements, and the predaceous habits of their preexisting freshwater ancestors; the latter becamethrough intermediate types like Rhina or Squatina (Fig. $26, p .194)$ and Rhinobatus of probable Jurassic origin, modified into flattened ground-feeders of highly specialized body-structure, like Raja-the skates-and Cyclobatis both first known to us from Upper Cretaceous rocks.

In England the earlier works of Agassiz, Mantell, Dixon and E. T. Newton on the Sussex and related beds, but specially the elaborate work of A. S. Woodward on "Fossil Fishes of the English Chalk" ( 57 ) illustrate how richly the sea had become populated with elasmobranch and chimaeroid species, also that chondrosteans allied to the sturgeon as well as teleosteans of several families, were abundant over a sea that covered the south-east part of the 
country. The corresponding memoirs of W. von der Marck (158:v: II, 22,3I) for the Upper Cretaceous of Westphalia; of Reuss (I59:98), Geinitz ( 160$)$ and Fritsch $(I 6 I)$ for Bohemia demonstrated like conditions for central Europe. Those of Bassani (I62:I5), Davis ( $163: 457)$ and Pictet $\left(I 6_{4}\right)$ for Italy and Mt. Lebanon; of Leidy, Cope, Williston, Stewart $(165: 385)$, Loomis $(166)$ and others for the extensive Benton-Niobrara and related beds in central North America, all prove widespread invasion of the sea that was started almost wholly in late Jurassic times, but became highly accentuated in the Lpper Cretaceous epoch.

Such comparative distributional tables also as those of A. S. Woodward for the strata of Lebanon and England ( $167: 47 \mathrm{I}$ ), and of A. S. Stewart (Op. supra) for the Niobrara strata of Kansas, as compared with those of European, West Asiatic, and other localities are most instructive. Thus Dercetis is shown to be common to Mt. Lebanon, to Wurtemberg, to England, and to the United States. Sardinius is common to all of the above except England; Spaniodon occurs in Mt. Lebanon and the United States; while other equally striking distributional facts appear. Some of these are discussed, and a possible natural explanation is given, in future chapters. So the presence of marine invertebrate fossils, side by side with the skeletons, teeth, scales, or spines of teleost, pycnodont, cestraciont, or selachian fishes, is now a common happening of marine Cretaceous strata.

But that even over the above areas, where heavy chalk deposits had formed, an elevation of land might again give rise to freshwater lakes, with their typical fossilized organisms, has been shown clearly to have taken place. Thus over extensive parts of central Europe marine deposits of Cenomanian age were succeeded by beds that locally are known as "Pflanzen-Quäder." These not only contain abundant remains of elm, ash, laurel and other dicotyledonous trees, but the fora has been so abundant as to give rise to carbonaceous shales, or to thin beds, or even thick beds of coal. The absence of marine organisms among these remains is sufficient proof that the sea had for the time retreated. 
A significant feature of the marine beds with their invertebrate organisms, and evolving marine fishes, is the total absence of amphibians which have always and wholly frequented freshwater or the land. Thus if one overhaul the classified list prepared by the Committee of the British Association ( I68: 149) or similar more recent lists, one notices that while various amphibian genera are listed from Carboniferous, Permian, Triassic, Keuper, Bunter and other rocks of freshwater origin, none are found mixed with marine types.

In marked contrast to this was the formidable invasion of the sea by saurians, that were undoubtedly land dwellers in their earlier origin and history, but which from Jurassic and onward to early Cretaceous days passed seaward, and underwent striking modifications there. Most of the Plesiosauria and Pterosauria, so far as evidence shows, remained from Triassic to Cretaceous time as land, air or lake dwellers, and then died out. But many had a formidable organization for preying on other animals. These and succeeding derivative marine reptiles preyed heavily on fishes, as their coprolites demonstrate. So not a few of the fishes per force took to a marine life. And this biological relation it is, which we would with all caution advance, as the main explanation for the migration seaward of many groups of fishes, during late Jurassic and early Cretaceous times. Then such a genus as Elasmosaurus amongst Plesiosaurians, which in some of its species largely remained on land or in freshwater, also the entire group of the Ichthyosauria, and of the Pythonomorpha in their later history, followed the fishes seaward, and became remarkably modified accordingly. The formidable rows of teeth that they developed, the of ten elongated snout along which these were disposed, the spiral valve of the intestine, the crushed remains of cephalopods and of fishes often found fossilized in their digestive tract, and the complete modification as well as condensation of the limbs after the pattern of a cetacean, all demonstrate that they were formidable sea animals and could pass to a great distance from land in search of prey. 
It seems not unlikely, therefore, that the comparatively sudden reduction in variety, in genera, and in individuals of the hitherto dominant group of the Cephalopoda, was largely brought about by the passage into the sea of carnivorous selachians, cestracionts, and teleost fishes, which had themselves been driven from lakes, rivers and deep marshes by evolving carnivorous reptiles, and in time became the agents for destruction of the cephalopods. Still later, in the battles that often took place-as fossil evidence shows-between individuals of the evolving freshwater reptiles, whole groups migrated to the seashore and into the sea. There they devoured alike the cephalopods and the fishes. Thus Cope says of the giant snakelike Elasmosaurus that it "probably often swam many feet below the surface, raising the head to the distant air for a breath, then withdrawing it and exploring the depths 40 feet below without altering the position of its body. It must have wandered far from land, and that many kinds of fishes formed its food is shown by the teeth and scales found in the position of its stomach."

A new environal factor deserves further to be emphasized, as it probably contributed more or less to migration seaward both of fishes and some reptiles. We refer to the evolution of winged reptiles, and still later of birds. From present evidence, both of these must have been evolving in late Triassic and early Jurassic days. For already abundant remains of the winged reptiles are met with in Liassic freshwater rocks, and of birds from the Solenhofen Slates onward. The former reached their climax of development in the early or mid Cretaceous and had disappeared by the end of that epoch. Provided with great stretch of wing in relation to body-size, with powerful jaws holding equally powerful teeth, they would be able to attack fish from a new centre of action. Like the Ichthyosaurians also they gradually carried their attack to sea-shores during MidCretaceous time. Their constant presence then as a hovering foe, at first over inland waters, and later over seashores, must have contributed to the seaward passage of fishes.

The wading, and even more importantly the large diving, birds of this epoch such as Hesperornis, must have been 
as formidable and destructive for fish-life as were the pterodactyls, and like the latter they became proficient seahunters.

Though the subject is more fully discussed in a later chapter, reference might here be made to the evolutionary derivation of the earliest teleostean fishes. As has been generally accepted by leading ichthyologists of the past quarter century or even longer, these were all derived from holostean freshwater ancestry. In some cases, for example as with the highly specialized pycnodont fishes-primitively freshwater genera like Mesodon and Athrodon of the Lias, Stonesfield Slate, Kimmeridge Clay and Purbeck strata. passed seaward as bottom feeders, and without originating more dominant forms, became purely marine dwellers, like Anomoeodus, Palaeobalistum and Pycnodus of marine Cretaceous and Eocene age. Unadapted in body, in fins, in teeth, and in general build for successful defense, not to say offense, they died out in Upper Eocene times.

In contrast to the last, derivative forms of the Eugnathidae, Pachycormidae, Aspidorhynchidae, Semionotidae, and Leptolepidae passed seaward during late Jurassic or early Cretaceous times, and started the first teleostean invasion there. Still other and even more abundant representatives of the Semionotidae, Pholidophoridae, and Leptolepidae varied by slow degree and multiplied abundantly in lakes, as the progenitors of our existing freshwater teleostean groups.

As illustrating the trend of events during the Jurassic and Cretaceous periods, the following sketch might here be given of what seems to be a progressive and continuous evolutionary line of fish-modification, from Triassic to late Cretaceous age. The ganoid genus Semionotus became widely spread over the world from the early to late Triassic, and this wholly in freshwaters. By gradual reduction of the fin-fulcra, of the bones in the mandible, of the basal plates in the pectoral fins, of the intestinal spiral valve, and by decussation of the optic nerves, transition is made to the Pholidophoridae.

The species of Pholidophorus were also freshwater, and extended from the Keuper and Rhaetic or upper beds 
of the Triassic, upward to the Purbeck or mid-upper beds of the Jurassic. These again led to the Leptolepidae, and in regard to the last Woodward ( 169 : Introd. p. XIX) says: "as already observed by Agassiz, the genus Pholidophorus exhibits a very close resemblance to Leptolepis in general aspect, the osteology of the head being remarkably similar, vertebral rings being tolerably well ossified, the finfulcra very small and usually lost, while the scales are often extremely thin and deeply overlapping though for the most part united by a peg-and-socket articulation; and it is noteworthy that no identifications of splenial and coronoid elements have hitherto been discovered in the jaw."

In the Leptolepidae the fin-fulca have been absorbed, the bones of the mandible have condensed to two elements, the spiral intestinal valve has nearly or wholly been absorbed, intermuscular bones-absent in the last-gradually developed in Oligopleurus and are large in Leptolepis, while a faint trace of ganoine often persists on the exposed part of each scale. The genus Leptolepis extends from the Lias upward through the Stonesfield Slates of England and the Wianamatta of Australia, on through the Kimmeridge and Purbeck periods to the Cretaceous. The division then seems gradually to have broken up into several groups, the Diplomystidae, Clupeidae, Elopidae, and Albulidae, most of which passed seaward during late Cretaceous or early Eocene time, though some persisted in their old environment. Even now however, most of them are shore dwellers, while the shad and allied types still return to brakish or freshwater in the spawning season. A further study of these is given on p. 348 .

The flora of the Cretaceous period is as suggestive in character as are the fish, the amphibian and the reptilian faunas. For it is from the base of the system upward, that an increasingly extensive array of angiospermic flowering plants appears. By a set of combined characters, that it would be out of place to discuss here, these in time became dominant over the gymnosperms and fern allies, until by the Eocene period they were highly conspicuous. Coeval with them appeared those types of insect, like the bees, 
wasps, butterflies, and moths that aid in cross pollination of flowers which bear colored floral parts.

The extensive and intercontinental volcanic disturbances already referred to as occurring toward the close of the Lower Cretaceous, not only started marked invasions of the sea in some places, they seem also to have so created barriers against the ocean, and to have so diverted long rivercourses, that great inland lakes were created, in which an abundant fish-life might flourish. One of the most extensive and earliest of these in the Cretaceous was the centre for deposition of the freshwater strata of the Dakota formation in western North America. Regarding this Chamberlin-Salisbury ( $8:$ III: I 44) say: "The Dakota formation is present over the great plains generally, though buried over the greater part of the area. It extends westward beyond the eastern ranges of the western mountains, though in the mountain region, the area of deposition was greatly interrupted by elevations which rose above the lakes, marshes, or river flats where the sedimentation took place. In Northern Montana, it is not known west of the Rocky Mountains. The original eastern boundary of the formation is not known, for erosion has removed it from considerable areas. which it once occupied. Remnants of the formation are now exposed, as far east as eastern Iowa and Minnesota. It must have originally covered an area I,000 miles wide and 2,000 miles long, within the United States."

"The Dakota formation has commonly been regarded as a lacustrine formation, deposited during an epoch of crustal oscillation, during which the depth of the basin increased. The necessity for postulating numerous oscillations and nice adjustments, is largely removed, if the formation be regarded as the joint product of subaerial and fluviatile deposition, for deposits of this class furnish their own adjustments. The presence of bird-tracks in the Dakota of Kansas, and the preservation of some 500 species of plant fossils, mostly the leaves of angiosperms, at various points and in conditions which forbid much transportation, imply the prevalence of subaerial conditions to a notable extent at least. 
"The thickness of the formation is, on the whole, rather uniform, averaging perhaps 200 or 300 feet, though greater thicknesses are known. To the South (Texas) the Dakota formation rests on the Comanchean system unconformably. Farther north it is often in apparent conformity with the Comanchean, though it often, as in the Wasatch and Uinta Mountains, rests on older formations." (op.cit.pp. I45-46).

While the sea seems to have made great inroads on the land, during most of the Upper Cretaceous, and furnished wide opportunity for migration into it, and evolution in it, of races of elasmobranch and teleost fishes, a gradual readjustment took place, with corresponding reformation in late Cretaceous of lakes that rivalled those of the earlier or Lower Cretaceous. One of the most extensive of these again was that over the bed of which the Laramie strata were laid down in Western America. These strata vary in thickness from 1000 to 5000 feet, and from the conjoint researches of L. F. Ward, of White, of Cope, of Dawson and of Tyrrell, the lake or lakes became the centre for preservation of a varied flora, of a mammalian fauna that was mainly marsupial, of a remarkable avian and reptilian fauna, of a fish fauna described mainly by Cope, and of a rich freshwater molluscan fauna.

In India and elsewhere, deposits of like extent and history can be traced.

When such facts as the above are correlated, it will be seen that the Cretaceous formation is by no means the predominating marine one that geologists and palaeontologists have often supposed. One great reason for the latter view has been that multitudes of the marine organisms found as fossils readily lent themselves to fossilization amid the deposits in which they are embedded. Thus the foraminifera, the corals, the crinoids, echinoids and starfishes, the crustaceans, and the molluscs, were-as is usually true of marine invertebrate life-prodigiously abundant, and became quickly preserved in calcareous rocks. Readily lending themselves also to the work of the systematist, they have been elaborately described and figured, often at the expense of higher types that require more discrimination in study. 
The Cretaceous however, like the other formations already studied, is often characterized by bituminous material around fish remains, and in some parts of the world by rich reservoirs of gas, oil, bitumen or asphalt. Probably the richest bituminous centres are in central and north-central North America. The deposits however of this material have a new significance and importance in our present study. For while we would consider that all of the supplies from older formations-the Silurian, Old Red, Carboniferous, Permian and Triassic, probably also largely the Jurassic-were derived from analyzed fatty oils of freshwater fishes, it seems now to be as clearly and largely derived from marine fishes of Cretaceous age. Thus Fenneman in describing the Cretaceous oil-field of Boulder, Colo. $(170: 322)$ says: "practically the entire mesozoic group is represented in this district, and most of it is of interest in the study of the oil." Again Eldridge, Prosser, Logan, Williston and Adams amongst other investigators have examined the oil fields of Kansas, Oklahoma, N. E. Texas and Arkansas.*

Reference to the table of correlation on p. 2 I I will show that over the above region the Potomac formation forms the base of the system, and that above it are the Knoxville, Kootenay, and Horsetown. Together these form the Comanchean system and have a varying thickness of 2000 to 6000 feet. They are made up of beds in part of freshwater, in part of marine origin. The basal part of the Potomac is the Trinity group of beds, rich in fish and invertebrate marine fossils. These beds also contain rich bituminous supplies.

But the Upper Cretaceous is specially noteworthy. For the Benton and Niobrara series are both of marine origin; the former at least is extremely rich in bituminous products; and the strata, in particular the lower beds known as the Mowry shales, are in places crowded with fish-remains of marine habitat. Often the fishes are surrounded by oily products, as if the latter were still in contact with the

The writer treats in detail regarding the above question in his volume, "Fishes the Source of Petroleum," (1923). 
primary source of its supply. At times it is difficult to determine whether the petroleum has originated in a fishbearing stratum and still remains there, or whether it has not risen from such stratum, through porous ones overlying, to become eventually scaled up in some porous sandstone or sandy shale that covers the whole. Thus Adams ( $I 7 I: 3 S)$, in treating of the eastern Texan region, records bituminous clay-shale of Benton age. But from the Niobrara beds above (that he calls Austin chalk) he separates off the "Taylor Marls" that are largely made up of oil and gas bearing sandstones. It seems not unlikely that the products however came from Benton strata below.

Prosser, Logan, and Williston (I72) have given detailed study to the corresponding Kansan beds. Here also the Benton and Niobrara series are specially important. Logan in describing the Benton series divides it into seven minor systems, and in most of these abundant fish remains, oysters, Inoceramus and other marine organisms occur amongst bituminous strata. Some of the Kansan BentonNiobrara beds are very richly bituminous, and Williston (p. 243 ) after taking note of the "abundant marine invertebrates" says: "The Niobrara deposits have been famous for the past twenty-five years for the abundance, variety and perfection of its vertebrate remains." Of fishes there is an extraordinary abundance of their remains, while six genera of Mosasaurus were frequent. In the upper beds, that possibly correspond to the "Taylor marls," of Adams, he further indicates that Turtles, abundant Plesiosaurs, and toothed birds occurred, since the seas then had evidently become shallower, while Logan and Williston alike emphasize squalodont and cestraciont elasmobranchs as being profusely represented by their remains. The wealth and variety of teleosts in the Kansan cretaceous rocks is well set forth in Stewart's (op.cit. p. 386) and Loomis' (op. cit pp. 2 I 3-2 $\delta_{2}$ ) lists. Stewart's comparative tables also of American and Europeo-Asiatic genera (pp. 387-389) are highly instructive.

But in Canada the Cretaceous is likewise known to be associated with petroleum products. For, speaking of the 
Dakota sandstones of Alberta, Canada, Redwood (25: I25) says: "The Dakota sandstones at the base of the Cretaceous series is saturated, over an area of at least I,000 sq. miles, with inspissated petroleum, and is often mentioned as the Tar Sand. It rests unconformably on the Devonian limestones and shales, which are also petroliferous to a slight extent within the province, and abundantly so both northwards in Mackenzie, and southward in Ontario and the United States, so that the idea has found favor in some minds that the Tar of the Dakota sandstone is derivative from the Devonian series. But the latter, where seen along the Athabaska and its tributary valleys, cut down through the soft Cretaceous rocks, is devoid of any trace of bitumen. It may be added that the Dakota beds are petroliferous in other regions, where no such derivation is conceivably possible." The above Canadian beds, in geologic position and petroleum yield, may correspond to the Trinity beds of Eldridge and other authors. But the writer would regard the Mowry shales, that lie toward the base of the Benton series, as the more likely source of supplies. This he has discussed in another work (I73).

In face of the above evidence, the writer would consider that with passage of numerous elasmobranchs,- - perhaps more importantly of ganoids, and of teleost descendants from freshwater ganoids-into a marine environment, myriads of these were at times destroyed by some sudden and widespread cataclysmic action, were covered over within at most a week to a few weeks, and in time gave rise to marine supplies of fish oil, which in turn by destructive analysis produced those petroleum supplies that man is now utilizing. A like result is dealt with in next chapter for Tertiary strata and Tertiary fishes.

In a succeeding chapter detailed comparison will be made of the genera and families of fishes that characterized respectively the freshwater and the marine strata of Cretaceous age. But as furnishing a vivid picture of the varied marine genera of teleosts, the writer subjoins a table of these, prepared by A. Stewart (op.cit. 386) and this also sets forth their stratigraphic relations. 


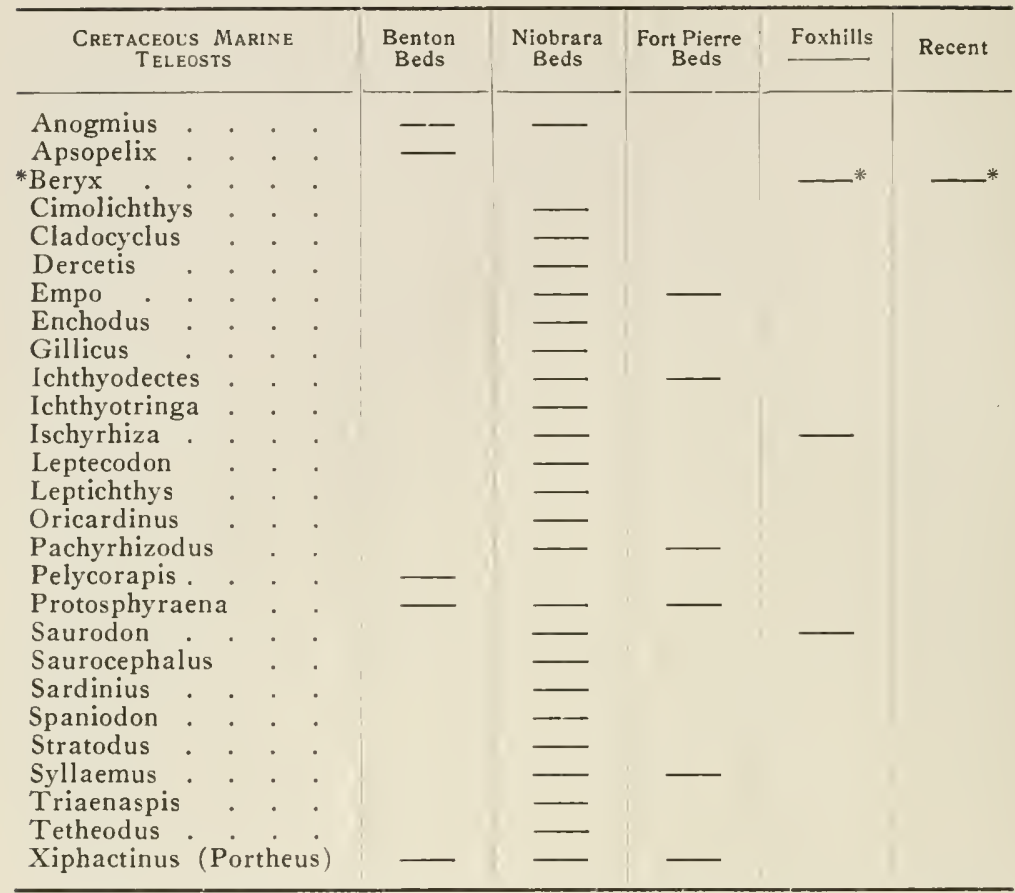

* The determination of the above is probably incorrect. (See Woodward, Brit. Mus. Cata. IV (1901) 386).

Of the Saurodontidae alone in the above list Stewart says: "This family embraced some of the largest physostomous fishes of the Cretaceous period of North America, and from the size of the jaws and the powerful dentition, we may suppose that they rivalled the Mosasaurs, the smaller ones at least, in strength and ferocity." The skull of Portheus (Xiphactinus) shown in Fig. 29, after Stewart. illustrates well the above observations.

But about twice as many other genera have been described from beds in England, Germany and from the Hakel-Sahel beds of Lebanon. So between So and 90 marine teleostean genera are thus known. Some of these deposits have long been celebrated for the beauty and delicacy in detail of the enclosed organisms. This is specially true of those from the Benton-Niobrara of Kansas, the Sussex beds of England, those of Westphalia, and the celebrated Turonian or Sahel-Hakel beds of Lebanon. Even tender 
and small fishes cover slabs in teeming numbers and show finest bones of the skeleton in position as during life. Thus J. W. Davis in describing the chalk rocks of Mount Lebanon $(163: 45 \mathrm{I})$ observes that there is a hard and soft chalk. In the former the details even of ordinarily quickly-rotting selachians are brought out with great distinctness; while he further states that: "The hard chalk of Hakel is principally remarkable for the immense number of fishes found between some of the layers composing it. Hundreds of the small Leptosomus macrurus are preserved on slates occupying a few square feet and some other species are proportionately numerous." As to the location of these beds he considers that "the upper beds of the Turonian group contain the fish-remains which have made the locality famous in ichthyological annals." The increasingly specialized structure that some of the marine teleosts of those beds

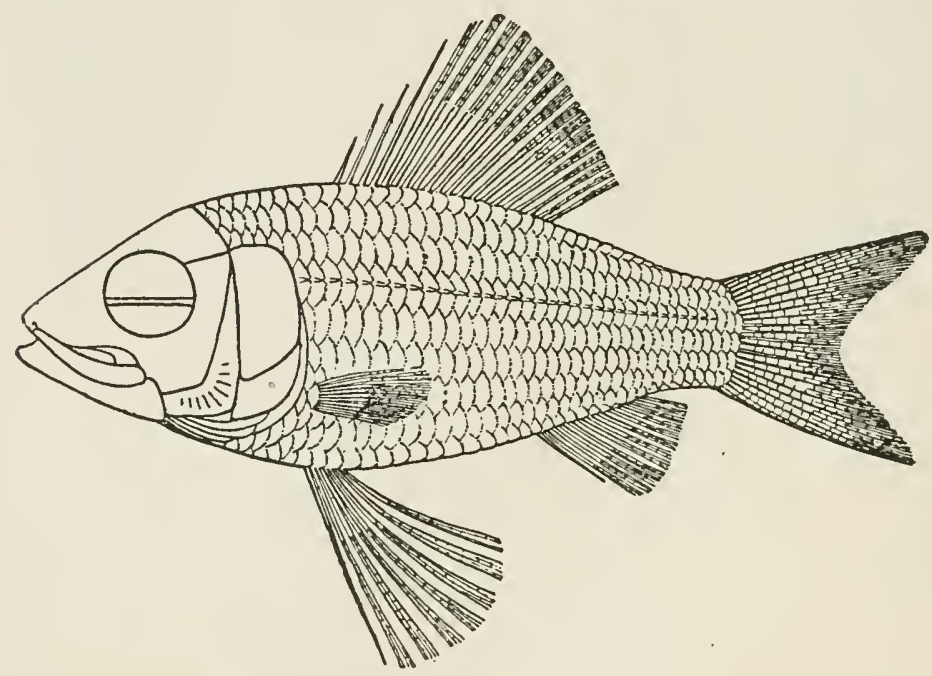

FIG. 30. Ctenothrissa vexillifer. From the marine Upper Cretaceous beds of Hakel, Mount Lebanon. Slightly enlarged. (After Woodward).

show-not least in fin formation-is well illustrated in Figure 30 of Ctenothrissa from the Hakel bed of Mount Lebanon, and in Figure 3 I of Chirothrix from the Sahel bed of the same region. 


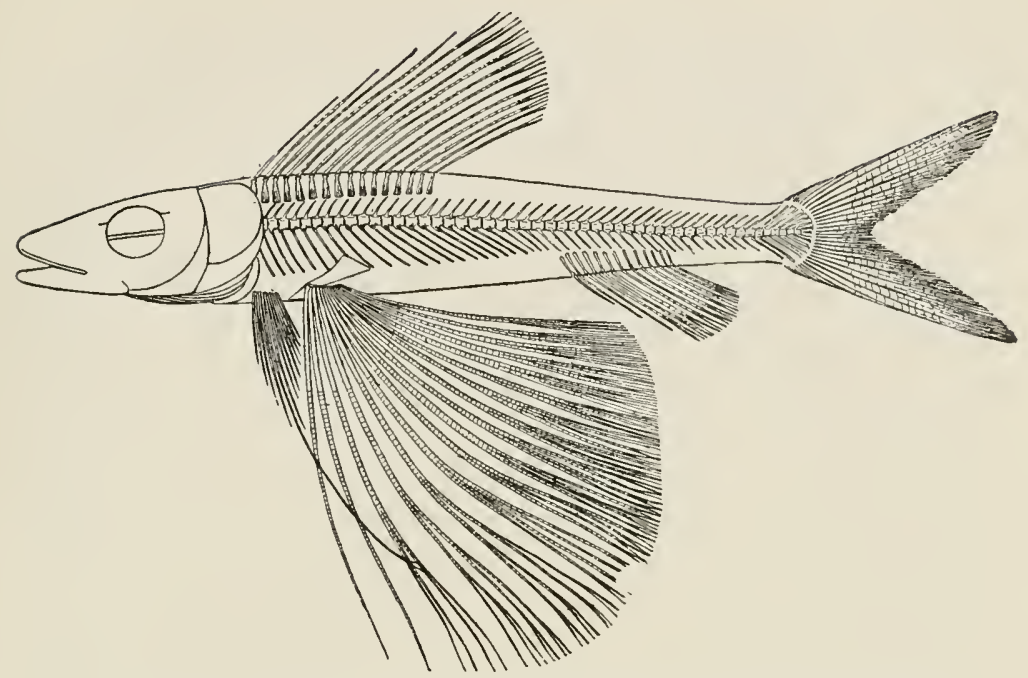

FIG. 31. Chirothrix libanicus, a soft-finned or actinopterygian marine fish from Upper Cretaceous rocks of Sahel Alma, Mount Lebanon. About two-thirds natural size. (After Woodward).

Now it deserves to be pointed out that the above very rich and also finely preserved remains of Cretaceous fishes occur in what seems to be nearly the same horizon, viz. in the beds of the Benton-Niobrara in Central America, in the upper or Terebratulina-Holaster-Micraster beds of the Middle Chalk of England ( 57 ), the top of the Mittel pläner (Mittel-quäder) or base of the Ober-pläner (Plattenkalk) of Germany, and in the upper Turonian beds of Mount Lebanon. All of these represent the Upper Turonian zone with the characteristic Inoceramus labiatus, and while it would be premature as yet to suggest that they form a continuous and coeval sheet of deposit, it can at least be said that similar or even identical genera of fishes extended over the above area, and were so similarly destroyed in preservative material that delicate fishes, as well as soft tissues of large fishes, stand out in clear detail. Such also would suggest that some common environal factors were at work to produce like results.

Attention might here be drawn to the valuable correlation-papers by Marck ( $158: 55)$, Woodward ( $167: 47$ I) 
and Stewart $(165: 385)$, in which a comparison of the various fish genera from two or more localities is made.

But though the above details are impressive, they must by no means prevent us from realizing that this entire marine association of fishes represents derivative offshoots from more primitive freshwater elasmobranchs, ganoids, or teleosts. Further a very abundant freshwater fish fauna co-existed with them. For we have ample evidence that a few elasmobranchs, all of the Dipneustei, most of the "ganoids," and a very large series of the more primitive teleosts remained in freshwater habitats. These will be studied in detail later, but here it need only be observed that over a large part of North America, not to mention other continental areas, after deposition of the marine Fox Hills group, there succeeded the Montana, Laramie and Livingstone that represent several thousand feet of strata laid down mainly in great inland lakes. The land surrounding these was in large measure covered by a very rich flora in part of gymnospermic, in part of angiospermic character. An equally abundant insect, molluscan, and vertebrate fauna occurred on the land or teemed in the lakes. Amongst the vertebrates were many ganoid and teleostean fishes, turtles, crocodiles and other giant reptiles.

Widespread volcanic activity, with corresponding destruction of plant and animal life, took place over widely apart regions of the earth during later Cretaceous time. This along with the steady evolution of predaceous and ferocious vertebrates, also the steady spread of plant and animal parasites that must often, as now, have caused havoc to higher forms explains the great blotting out of life, as passage is made from upper Cretaceous to lower Eocene beds. Striking verification of this is given later ( $p .23 \mathrm{I}$ ). But the uniformity and continuity of bedding seen in some regions indicate that similar biological continuity was possible, though doubtless this was accompanied by steady variation and new environal adaptations. 


\section{CHAPTER VIII.}

The Physical and Biological Environment of Fishes. EOCEne to Recent.

In beginning our study of the relation of fishes to environal conditions during deposition of the Tertiary rocks, a fundamental fact to be again remembered is the steady or rapid alteration in land and water areas that resulted in new geographical configurations. These culminated during late Pliocene and Pleistocene time in the main continental masses and outlines that we now see. Such changes were due to an increased soldification and thickening of the earth's crust; to the extrusion of those enormous igneous beds in India, Africa, America and to a less degree in other regions, that were referred to in last chapter; and to the resulting upheaval during Eocene to late Miocene time of the most elevated mountain chains that now exist. As a coeval result and in large measure also as a result of extensive earth shrinkage or diastrophism, great cracks, faults, downthrows and upthrusts, as well as foldings, caused a breaking up of previous continuous land-masses over the South Atlantis, the North Atlantis, "Lemuria" and other regions, which in turn started profound organic change and destruction as well as evolution.

While it is true that over wide areas in North America, in south-east Europe and elsewhere, there is a gradual merging and conformability of upper Cretaceous strata, as they pass into the lowermost Eocene beds above, it is more usual to find that marked alterations and unconformabilities occur. And this is in line with the fact that a tremendous and rapid obliteration of organisms-not least of fishes-took place during transition from Senonian and Danian, in other words from Upper Cretaceous, to lower Eocene beds. So, as Woodward's descriptions show, very few genera of freshwater Cretaceous fishes are continued directly into Eocene. The number of marine genera however is somewhat greater. By some writers it has been claimed that the fundamental change seen in organic life indicated 
the lapse of "a vast period" during which slow variation as well as obliteration were effected. While we would by no means minimize the need for extended geologic time the evidences rather are that enormous and rapid movements of the earth's crust at once extinguished great cohorts of organisms, and also caused the relatively few that were left to vary rapidly and strikingly, as they passed into new environal territory; or as they often became cut off from continuity-association with other individuals of their species; and as they then became adapted by proenvironal response to their new surroundings.

When it is fully recognized that such changes did occur, and that the ocean was gradually stocked with its groups of marine fishes, by steady migration of these out of freshwater areas into the sea, and from late Jurassic time till now, problems that otherwise seem confused and even inexplicable, become relatively simple, as later pages will explain.

With the progressive upheaval of mountain masses, from late Cretaceous to the close of Miocene times, that greatly excelled in height and bulk any that had previously been formed over the earth's crust, greatly accelerated denudation changes must have progressed over dry lands, especially over those in proximity to, and sloping rather abruptly from, the mountain ranges. This also would favor the expanse and damming up of river courses, the consequent formation of extensive lakes, the origin of changed environal states, and resulting modification of the denizens of the lakes and rivers. The great tracts that were covered by lakewaters in N. W. America, in East Brazil, in central Africa, in central and west Europe, in Tasmania and other lands are proofs that such took place.

I. Eocene Formation. Restricting attention first to the Eocene formation, extensive freshwater and marine deposits are now known that enable us to form a fair idea of general environal relations. The at times gradual, at times sudden, change from the one type of deposit to the other, tells that slow or rapid elevation or depression of the land was proceeding in many regions, some of which are touched on below. Whether such was due to volcanic 
agency, to earth shrinkage and crustal flexures, or to localized weighting of the crust by sedimentary deposits, need not now concern us.

The lowest stage of the freshwater Eocene strata has variously been called the Wasatch in western North America, the London Clay in England, the Suessonian in France, the Liburnian in Germany, the Hypsiprimnus beds in Tasmania.

But the frequent intercalation of marine beds in most of these shows that terrestrial oscillations were proceeding. The Wasatch beds of north-west America were evidently formed in a great inland lake, called by Cope the Wasatch Lake, having a length at least of about 500 miles, and a maximum width of 300 . These beds may be as much as 4000 feet thick, and have yielded a varied vertebrate fauna. The corresponding London Clay was in part freshwater, in part marine, and the same is true of deposits over mid and east continental Europe.

Above the Lower Eocene in central North America are the extensive Mid-Eocene Green River and Bridger beds of about 2000 feet average thickness, and that are probably wholly lacustrine in origin. These are extremely rich in vertebrate remains, especially mammalian.

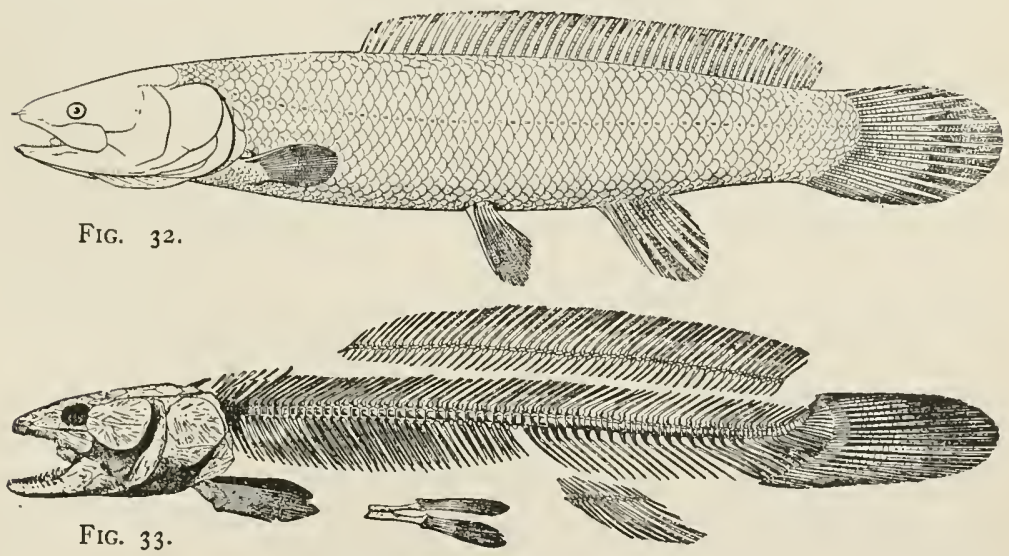

FIg. 32. Amia calva. A surviving North American fish of the group Holostei, the earliest known ancestors of which occur in freshwater Eocene beds of Wyoming and adjacent states.

Fig. 33. Skeleton of the same fish, that shows close structural relation to some Telcosts. (After Brown Goode and Franque). 
But Leidy (I74:184) and Cope (175:633) have described species of Amia (Figs. 32,33) and of the somewhat related genus Lepidosteus, as well as teleosts like Osteoglossum, Pimelodus, Asineops, Erismatopterus, and Diplomystus that is allied to Clupea and as such was described by some authors. The English Mid-Eocene or Lower Bagshot series is variable in character and organic contents, but, in its lower strata it includes the Alum Bay beds that have yielded about 250 species of plants, largely dicotyledonous; also the Bracklesham beds with marine molluscs, elasmobranchs, and higher marine vertebrates. Similar conditions are shown on the European continent, except that there was a greater persistence of marine deposits. The most noteworthy of these marine beds are the great nummulitic strata, which form the dominant mass over central-east Europe.

The upper Eocene or Uinta formation, that may be 500-80o feet thick, is a direct continuation upward of the Bridger and Wasatch below, and mainly differs in the new species and genera that have evolved. In Europe the formation again proclaims changing deposits of freshwater and marine beds with their characteristic fossils.

The flora in all of these indicates a warm temperate to a sub-tropical climate, though there may have been a mixing of temperate region plants, washed down from higher elevations, that commingled with others that grew in warmer and lower ground. Thus species of Pinus, Sequoia, Ginkgo, Quercus, Ny'ssa, Magnolia and Liquidambar, occur along with palms, Eugenia, Eucalyptus, Laurus and Ficus. Such a grouping is a sure indication that the prevailing Triassic-Jurassic gymnospermic type of vegetation was being more and more replaced by an angiospermic and mainly dicotyledonous type.

The invertebrates included a very rich and large series of insects, numerous molluscs, also freshwater and marine crustaceans. The freshwater fishes were now very largely teleostean, but the ancient Jurassic group of the Amiidae is represented by Amia and Pappichthys, the former of which still survives in the North American species $A$. calva (Figures 32,33 ). Similarly the lepidosteans were abund- 
ant, and have left remains from Wyoming eastward to France and Germany; but they are represented only by a few species in North America.

The teleostean fishes belonged to families that evolved from more primitive "ganoid" freshwater groups like the Semionotidae, the Pholidophoridae, and the Leptolepidae, and which have all remained in a freshwater habitat till now. Thus the Cyprinidae, the Siluridae, the Chromidae and the Aphredoderidae are examples. Others like the Clupeidae, Percidae, Atherinidae, and Serranidae are still in part freshwater, but have largely migrated into the sea, while still others of early Eocene origin branched off rapidly and wholly into marine surroundings as did the Carangidae, the Scombridae, and the Sparidae, that are treated of from the standpoint of descent in a later chapter.

In addition to the above and other teleostean groups like the Elopidae, the Albulidae, and the Chirocentridae, that had already passed into the sea during Cretaceous times, the sharks, dogfishes, and rays, as well as a few cestracionts must have been extremely abundant in individuals, though dying out in species, when compared with Cretaceous days.

Here we might again emphasize the evident relation of fishes to bituminous production. Thus Leidy in speaking of the Green River Shales, from which Cope described several freshwater fishes, remarks that at "Petrified Fish Cut" are thousands of beautiful fish remains, sometimes a dozen or more appearing over a square foot.of rock. Remains of insects and aquatic plants are also found in these shales, and in one instance a feather of a bird. In darker brown bands that are intercalated amongst others of a greyish-buff color, the former "are saturated with a bituminous matter which renders them combustible." The source here then evidently was from death and decay of enormous shoals of freshwater fishes. Similarly A. S. Woodward and von Ihering have described a series of Tertiary bituminous schists at Taubate in the province of S. Paulo, Brazil $(176: 63)$. These contain a great wealth of fossilized freshwater teleostean fishes, belonging to the Siluridae, Characinidae, Serranidae, and Chromidae, 
all of which are allied to genera still found in the freshwaters of South America. Von Ihering observes that these schists crop out and are worked at several localities for the crude petroleum oil. From the oil, supplies of gas, paraffin, petroleum and sulphuric acid are obtained.

But in recent years, since many of the Eocene beds have been examined from the economic standpoint, richly bituminous rocks that seemingly owe their oils to decomposition of marine fishes are now known. Thus in Texas and adjacent states the rich oil beds that have been actively exploited during the past fifteen years, are also those which contain an abundant and varied marine fish fauna that is described in detail in another work. These belong to the Cretaceous system, and seem in their faunal and stratigraphic character to resemble other bituminous beds in several parts of the world. Again the extensive Oligocene and Miocene oil strata of western California owe their oil-content, according to the present writers views, to the marine fish fauna that has been only imperfectly described as yet, but which includes genera that belong to elasmobranch and teleostean families.*

The giant amphibians and reptiles of the two previous epochs, had now almost disappeared, though smaller salamandroid forms were left. Turtles, crocodiles, and snakes were fairly common, as their entire skeletons or smaller remains, testify. But the most noteworthy feature was the appearance of representatives of all the great divisions of the mammals, with the exception of the two highest. The writer has elsewhere suggested $(I: 496)$ that these all originated by modification and increase in size of various more primitive marsupial ancestors. As with the giant amphibians of the Permian, the giant reptiles of the Jurassic and Cretaceous, so with the giant mammals of the present epoch; all of these furnish a rough and approximate measure of the great amount of evolutionary advance that some organisms may undergo, alongside others that vary slowly.

*For detailed description of these see the author's volume, "Fishes the Source of Petroleum." 
But as Cope and Lesquereux emphasized, there seems to have been a remarkable community both in organisms and in physical phenomena, between Western Europe and Western America during long periods of the Eocene, and even on into early Miocene time. Thus the latter, in comparing his results ( $177:$ I27) with those of Saporta for the gypses of Aix says: "Besides the general characters of the Flora, the peculiar compounds of the formation, the laminated shales mostly formed of ashes, the immense number of insects and freshwater fishes preserved in a succession of thin layers of greyish shale, are repeated in the upper part of the gypses of Aix precisely as they are found at Florissant." Says Saporta: "Entire shoals of fishes were surprised and buried in the muddy clay of the bottom. Even insects, suffocated in large numbers, from the smallest kind of mosquitos to ants, bees, butterflies, are preserved in the thin shales with the minutest of their organs and even the color of their wings." Later he adds: "The evidence of synchronism of the flora of Florissant with that of the Oligocene of France appears confirmed by the characters of the fauna. At least Professor Cope $(I 7 S: 67)$ identifies the White River Group" in which are the Florissant beds, "with the Aquitanian and Tongrian of Europe,-formations which close the Eocene, or are partly referable to the Eocene partly to the Miocene, and considers the Green River and the Wasatch as Suessonian or Palaeocene. This agrees with the observations of Saporta, who considers the gypses of Aix as a long series of formations continuous through the different periods intervening between the Palaeocene and the Miocene, the upper part even partaking of the character of this last epoch." Cope's observations are equally apropos ( I79:95).

A great part of the deposits thus referred to compose the formation that is now known as Oligocene, and which connects upper Eocene with typical Miocene strata. But the special interest is that a very close connection, and even a direct continuity, in physical and biological phenomena, is thus set forth between Europe and Western America. It confirms also the observations made above 
by the writer as to Amia, Pappichthys, Lepidosteus, and other fishes having been common to the lakes of the two areas.

Accepting such wide general biological relations, certain distributional features of Eocene fishes deserve attention here. Thus according to all present knowledge the great majority of the Cretaceous teleost genera had been obliterated by the close of that period. Thus of 75 Cretaceous genera recorded by Woodward (I80) only one, namely Diplomy'stus (Histiurus of Costa, Fig 34) passes from Cre-

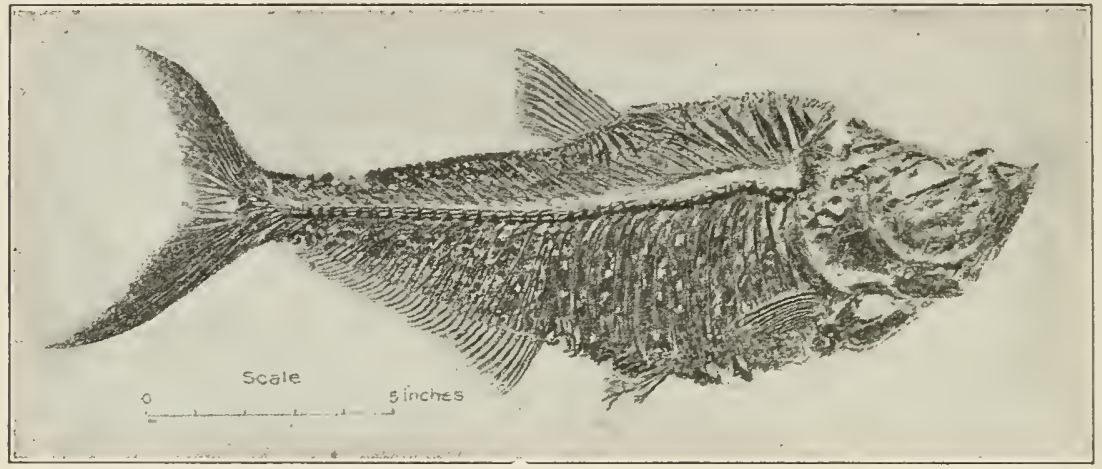

FIG. 34. Diplomystus dentatus, a freshwater clupeoid fish from Green River Eocene shales of Fossil, Wyoming. About one-fifth nat. size. (After Veatch).

taceous to Eocene beds, 29 genera first appeared in the Lower Eocene, 44 genera first appear in the Upper Eocene, and almost wholly in the remarkable Monte Bolca deposits. Now nearly all of the teleosts thus destroyed at the close of the Cretaceous were marine types, derived from freshwater "ganoids" during Jurassic and earlier Cretaceous times. These belonged to the families Elopidae, Albulidae, Saurodontidae, Chirocentridae, Ctenothrissidae, Clupeidae, Halo' sauridae, Notacanthidae, Dercetidae, Enchodontidae, Scopelidae, Gonorhynchidae, Chirothricidae, Muraenidae, Crossognathidae, Berycidae, Stromateidae, Carangidae, Scombridae, Percidae and Sparidae. Even a few only of the great Cretaceous teleostean families were continued into Eocene and later periods, not, so far as our knowledge 
goes, in their ancient genera but only in evolved and derivative genera from these that managed to persist. Thus the Scopelidae are known to us by eight genera in the Cretaceous, and they seem thereafter to have become largely decimated or modified, to reappear only in the Oligocene and Miocene strata of Switzerland and Northern Italy as the genera Scopeloides, Parascopelus and Anapterus. The Berycidae show six Cretaceous genera-for Beryx seems to be wrongly credited to the Cretaceous-which then become largely blotted out, to reappear as Myripristis and Holocentrum of the Upper Eocene.

In contrast to the above, the elasmobranch fishes that passed from freshwaters into the sea during Jurassic and Cretaceous times, are represented by fifteen genera, which have persisted at least from the latter period on through the Eocene to the present day. These are Acanthias, Centrophorus, Squatina, Rhinobatus, Raja, Cyclobatis, Notidanus, Cestracion, Scyllium, Pristiurus, Scapanorhynchus, Odontaspis, Oxyrhina, Ginglymostoma, and Lamna. Various reasons might be given for such differences in relative persistence.

In addition to marked deformations by volcanic agency at the beginning of the Eocene period, ample proof exists of continued volcanic action during deposition of these beds in many countries.

But toward the close of the Eocene and in early Oligocene time, some phenomenal displays of earth-movement and volcanic activity took place, which would largely explain the profound changes witnessed in the animal life, and not least in the fish life of those days, as compared with the late Oligocene and Miocene periods. Thus a large part of South Europe, North Africa, South Central Asia on to Japan, the Philippines and Sumatra at least, formed a great and continuous sea during Eocene time, and which is approximately outlined in the chart (Fig. 35).

In this sea the huge foraminifer Nummulites became the prevailing marine organism, while in part by accumulation of calcareous nummulitic tests, in part by activity of calcareous bacteria, deposits were formed that range from I 00 to 3,000 feet in thickness. At this time the Pyrenees, 


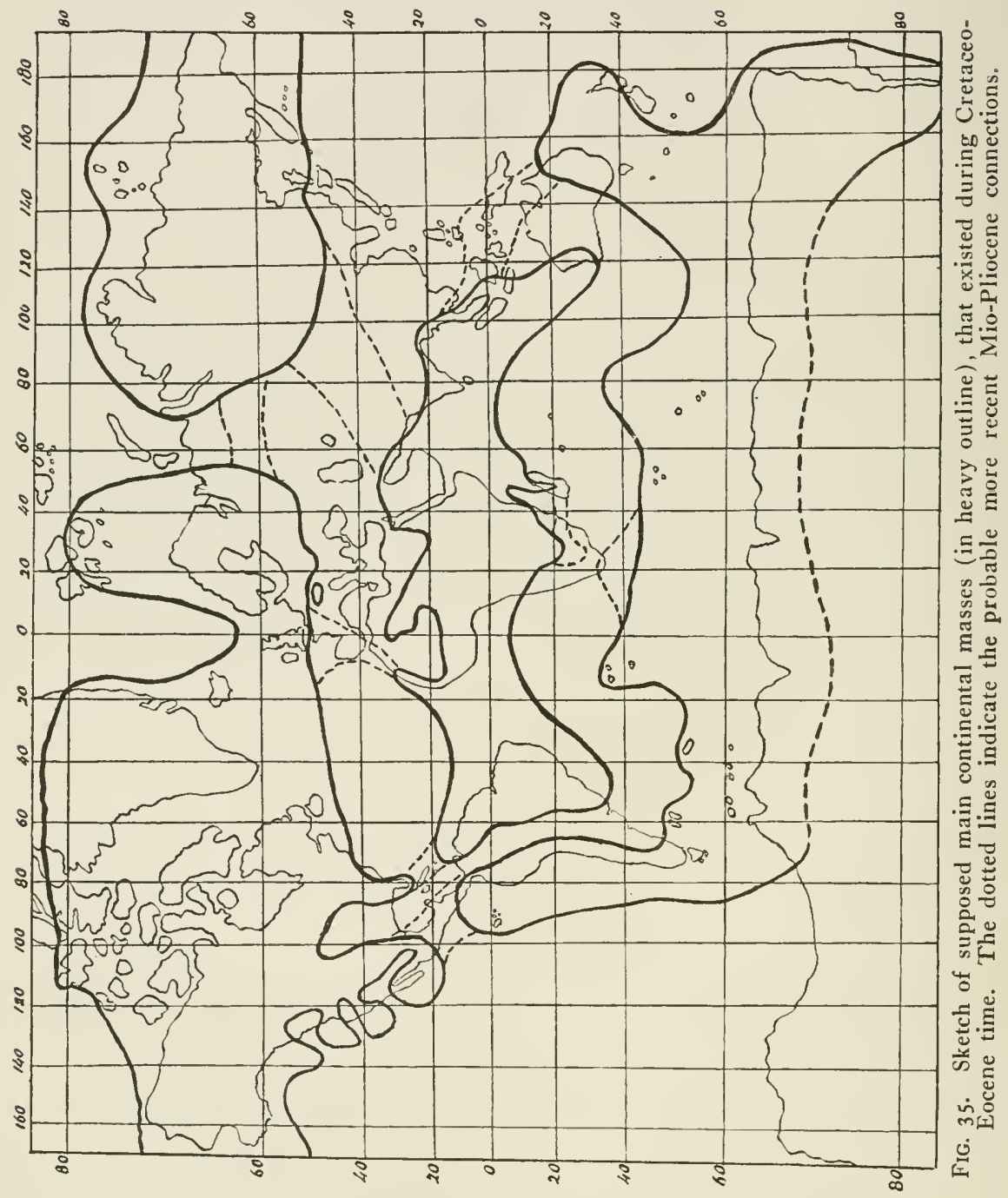


Apennines, Alps, Carpathians, Himalayas, and minor mountain ranges between, were as yet incompletely elevated or were still submerged areas.

But from late Eocene to early Oligocene time diastrophic activity caused increasingly enormous elevation of this area in some centres, and corresponding depression in others to form the Mediterranean, Red Sea, or Persian Gulf. These changes gave rise to great faults, and caused pronounced volcanic activity, largely probably from frictional heating and melting of subterranean or submarine strata, over the areas affected. Such culminated in at least four important results: (I) The above-named mountain-masses became elevated high above sea-level as huge ridges of land from 8,000 feet to I 6,000 feet at least high, over the sides, or even as in the Alps over the tops, of which the nummulitic beds were upraised. (2) Extensive outflows in part of subaerial, in part of submarine volcanic tuffs, diabases, and related rocks took place from Italy eastward to Tasmania, also over at least Western America. This must have caused sudden and widespread death of both marine and fresh water fishes, as well as great deposits of volcanic dust beds, such as Russell has traced. (3) The nummulitic organisms suffered so severely that they soon dwindled in importance, and largely disappeared toward the close of the Oligocene. (4) Many species and even genera of fishes suffered extinction, and when heaped in masses over many hundreds of miles, gave rise in time to those rich accumulations of petroleum shales and sandstones, whose existence and wealth are only now being made known in all their fullness.

As compared with statistics already given for Cretaceous and early Eocene days, it might be added that of known Eocene genera still living there are 60 , of which nearly all of the most primitive are and have been freshwater, or have only in part passed into the sea. Of these latter there are 25 . The remaining 35 genera include freshwater forms and a greater or less number of more specialized marine types in nearly every case. Not a few of them frequent the coast lines at the present day; only the larger, more powerful, or most highly modified genera like the tunny, cod, conger eels, etc., being oceanic or deep-sea. 
If we think only however of the recorded telecst fishes of the Eocene period about 52 are freshwater genera in whole or in part, while 47 are purely marine. It follows from what has been said that there is clear evidence of two successive teleostean developments and progressions from a primitive freshwater to a marine environment. First, from freshwater ganoid ancestors belonging to the groups Pachycormidae, Aspidorhynchidae, Pholidophoridae and Leptolepidae originated the late Jurassic or Cretaceous families Saurodontidae, Holosauridae, Enchodontidae, and others already cited. These were suddenly and very extensively obliterated by the close of the Cretaceous, largely owing, as we would consider, to the world-wide effects of a tremendous volcanic activity in most of the continental centres. Second, in part from evolving genera of the above groups that escaped destruction, in large part however by a later and new migration from freshwaters by members of the Clupeidae, Aphredoderidae, Berycidae, Percidae and others during Eocene days, the progenitors of our existing and abundant marine teleost fauna were established. Details of all of the above are elaborated later on (p.p. 357, 373).

II. Oligocene-Miocene Formation. As already accepted by Saporta, Cope, Lesquereux and more recent authors, complete conformability of strata, and continuity of organismal types can be traced from the Upper Eocene to the lower Oligocene and up into Miocene strata in some areas alike of the Old and New World. But a distinct break and unconformability is observed in other regions. Further, frequent elevations and depressions of land-levels took place, so that freshwater, marine, and even eolian land deposits were laid down. Steady evolution of new genera and families of plants and animals, as well as elimination of older types proceeded rapidly. All of the important groups of animals had now appeared except the genus Homo, so far as we know.

Separation of the land-masses into such as now exist had almost completely been effected by end of the period. Explain it as we may also, the flora in wide regions of the Northern Hemisphere took on a semi-tropical aspect, and 
a warm-temperate climate existed even in Greenland. Such, succeeded by colder conditions, would stimulate to organismal modification and evolution. Extensive rivers and lakes existed in north, in central, and in south Europe, in Africa, where Tanganyika was a persistent feature from late Cretaceous times probably (p. 482 ); in North America where thick lacustrine and eolian deposits-interspersed at times by heavy deposits of volcanic dust and ash-gave rise to the White River Formation.

One of the most extensive and informing deposits of Lower Oligocene age in Europe, is the Tongrian or Upper Flysch series of marine rocks, that can be traced from East France, the Voges, Glarus, N. Italy, and Vienna northward through Bavarian, Swabian and Danubian territory to Moravia and Galicia on the east. Much if not all of this region was a marine expanse, over which deposits were made to a depth of from 1000 to 6000 feet, and while as yet the greater part of the Alps was not in existence. But simultaneous with these deposits, according to the writings of Heer, extensive lakes and swamps in central and north Germany were accumulating freshwater deposits which closely resembled those described below for Switzerland.

The above marine rocks, as studied by Hauer ( $I 8 I$ : 104), Suess ( $182: 87$ ), Paul, and Fuchs amongst others, are divisible into a lower and upper zone. The former is known as the "amphisyle" zone, for the most conspicuous

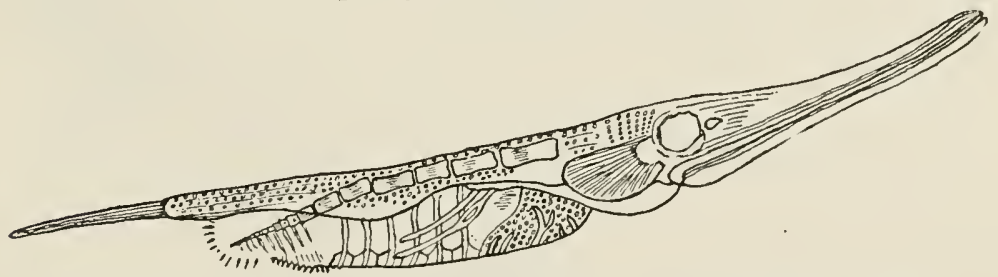

FIG. 36. Amphisyle heinrichi. A specially abundant and highly modified fish of the marine Oligocene rocks from Alsace to Baku. Enlarged nearly twice nat. size. (After Heckel).

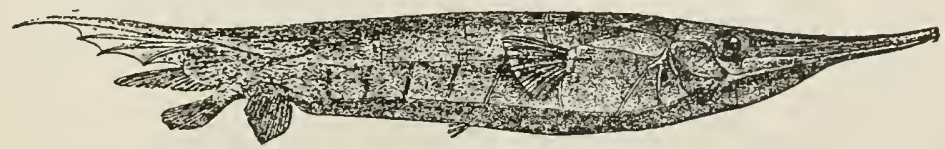

Fig. 37. Amphisyle scutata, an East Indian marine fish of near affinity with the above, but somewhat larger. (After Day). 
organism is a centriscid teleost Amphisyle heinrichi (Fig. $36)$, the remains of which are "crowded beside and over each other." It is nearly related to the living $A$. scutata of East Indian waters, that is shown in Figure 37. Close on 20 other teleosts have also been recognized. This enormous abundance of teleostean fishes, according to the writer's view, would explain the dark color and rich bituminous material of extensive strata that can be traced for hundreds of miles along the Alps and Carpathians into West Asia. Several species of the above genus still exist in the tropical seas of the Old World. Alongside these were Meletta crenata and several species of the scombrid Lepidopus, a genus whose species are still met with in many seas, also other and less abundant teleosts.

The upper zone or "Menilite" shales proper are chiefly characterized by the abundance of the clupeoid genus Meletta, the crowded remains of which as well as other teleosts, give a highly bituminous character to the rocks. It is worth noting that Meletta (Clupea) sardinites (Figs. 38,39 ) of these rocks is a near ally of the common herring, sardine, anchovy and sprat, the oil content of which is well known. Suess strongly suspected (op. cit. p. I46) that the rich fish remains and the bituminous constitutents of these rocks were related to each other.
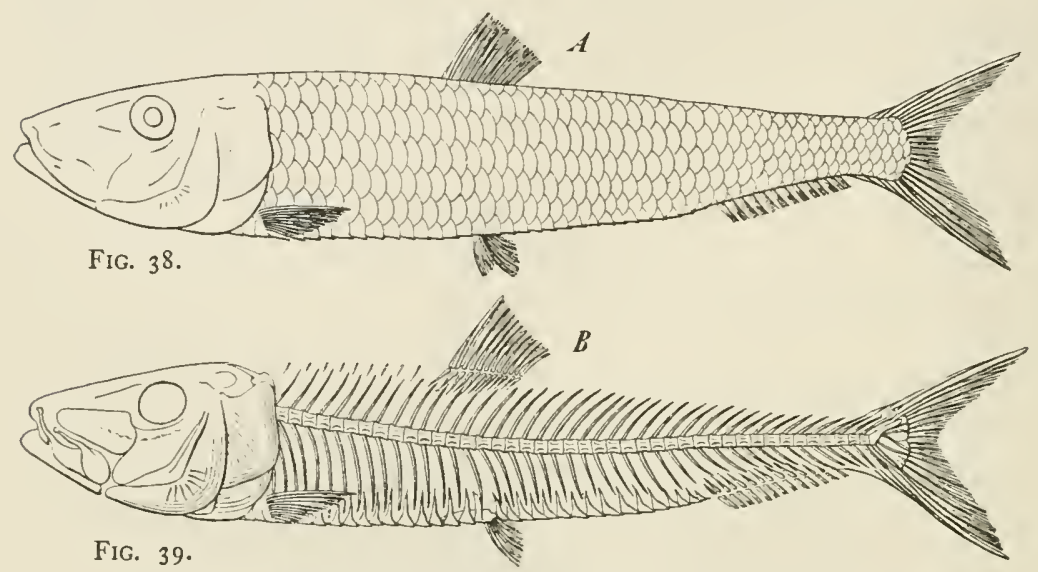

FIG. 39.

FIG. 38. Meletta (Clupea) sardinites. An abundant and typical marine teleost from the menilite shales of Mid Europe.

FIG. 39. Skeletal restoration of the same fish. (After Heckel). 
That active land denudation and resedimentation were frequent is shown by some lacustrine deposits of the period that vary from 2000 to 12,000 feet in thickness. These lacustrine deposits evidently originated in many cases from temporary elevation of marine areas, and conversion of these into lakes which received the waters of rivers, and became quickly stocked with a freshwater fauna. Varied glimpses are furnished from several of the continents, of the biological conditions that then existed around such lacustrine areas. Thus in O. Heer's striking work, as translated by Heywood ( 183 ), the following classification of the rocks that are known as "the Molasse" is given, along with their leading organic contents. This applies to the so-called Oeningen flora and fauna that are amongst the richest known:

Miocene. ( I) Oeningian or Tortonian. Upper freshwater Molasse and brown coal.

(2) Helvetian or St. Gallen Molasse. Marine beds with animals in part of Mediterranean, in part of tropical facies.

(3) Lhangian or Mayencian. Lower freshwater or grey molasse but with intercalated marine beds.

Oligocene (1) Aquitanian. Red Molasse or lower brown coal, with lignite seams and abundant terrestrial vegetation. I000 $\mathrm{m}$. thick in Italy.

(2) Stampian. In Italy $600 \mathrm{~m}$. thick.

(3) Tongrian or Lower marine Molasse. Shells, nummulites etc. $2000 \mathrm{~m}$. thick.

(4) Sestian, a marine Italian series, about 20 metres thick.

Regarding the freshwater molluscs Heer remarks: "All the univalve Mollusca which inhabited the Swiss Miocene forests, and the bivalves which peopled the brooks and lakes, belong to living genera. The species however are almost entirely extinct; and their nearest allies are no longer inhabitants of Switzerland." Snails were very numerous, and include Pupa, Planorbis, Limnaea, Paludina and Melania. As to the species Melania escheri he notes that its nearest living allies are in the rivers of tropical Asia. Numerous arachnids, also 844 species of insects that 
included 543 beetles, 20 Orthoptera, 29 Neuroptera, 8 I Hymenoptera, 3 Lepidoptera, 64 Diptera and 136 Hemiptera are all recorded.

At Oeningen, which is situated on the north or Baden side of a narrow arm of Lake Constance, occur two limestone quarries at a height of 550 feet and 700 feet above the level of the lake. Of one Heer says: "In the lower quarry, immediately upon the yellow marl, there is an extremely fine-grained limestone, which is only one inch in thickness, and splits into yellowish or grey layers as thin as paper. In these layers the plants and insects are embedded, and often are so wonderfully well preserved that they look as if they had been painted."

The fossil fishes "occur both in the upper and the lower quarry, but are restricted to particular beds. Up to the present 32 species have been described, belonging to I 5 genera. Of these genera only one (Cyclurus) allied to the carps, but distinguished by its rounded caudal fin is extinct; all the others are still met with living in freshwaters." As to their distribution, then and now, he makes the following suggestive observations: of the genera "which Oeningen has in common with the existing fauna, only one, the Cottus, belongs exclusively to the temperate and cold regions; all the rest occurring also in Mediterranean countries, or even in tropical and sub-tropical zones. The genera Perca, Acanthopsis, Cobites, Gobio, Leuciscus and Aspius are also represented in Indian rivers, and eels are found in Madeira and Teneriffe. To this must be added that the fish-fauna of Oeningen contains a number of species usually belonging to genera of warmer lands. The genus Lebias, represented by four small species, now inhabits Italy, the East, and America. Poecilia occurs only in the swamps of Carolina and South America, and Cyclurus is extinct. Thus side by side with those genera which still occur in Switzerland, but the greater part of which extend their range into warm and even torrid zones, other fishes are found which now exclusively belong to hot countries."

Further on he says: "The fishes of Oeningen belong to six families. The richest in species is that of the Carps (Cyprinoidei) which includes $2 \mathrm{I}$ species. Five of these 
belong to the genus Leuciscus...... This genus was already widely diffused in Miocene times, and it is at present to be met with in the rivers and lakes of all parts of the world."

A highly suggestive feature in some of the strata is the apparently seasonal succession of the deposited material, alike inorganic and organic. Thus it is said: "The insectbed consists of about 250 lamellae or layers, the formation of which probably occupied a long series of years, during which plants and animals were deposited at all seasons of the year in this book of nature. The layers that contain the flowers of the camphor trees and poplars were probably produced in the spring time, those which furnish winged ants and the fruits of elms, poplars, and willows in the summer, and those containing the fruits of the Camphor trees, the Diospyros, the Clematis, and the Synantheriae in the autumn. The deposits must have been formed in quiet water, and at a distance from the mouth of any river. Probably poisonous gases or vapors rose from this spot into the air, and killed the insects flying over the water. The prodigious number of species of insects here met with shows us that not only the animals of the neighboring shores, but those of a large area, must in the lapse of time have here found their graves."

Of the rocks and their contents belonging to the upper quarry he says: "The compact indigo-blue marl which covered the bottom of the lake, is overlaid by a hard bituminous limestone, which has received the name of Kettlestone. It is the chief source of the fossil plants of Oeningen." This Kettlestone also contained land and freshwater insects and crustaceans, while higher up he says it is covered by a thick white bed with large pike, a gigantic frog, a tortoise, and a large salamander. He considers that the ground then became dry, and later was submerged, when a deposit of four feet of a hard limestone ("mocken,") was formed in which were tench, other fishes, and aquatic plants. Next "a period of perfectly still water succeeded, in which a great quantity of larvae of dragon flies swam about." From the fact also "that dragon fly larvae of all ages lie intertwined in certain slabs, it would appear that these insects 
had been suddenly killed, and that they were subsequently enveloped by snow-white limestone. Had there been no violent action it would be difficult to explain how such quantities of these larvae could have been buried in the rock, some in a running, others in a resting position, with the mask extended or retracted." In the next higher bed the dragonflies disappear, but numerous remains of the white-fish Leuciscus are now found.

Heer then considers that "a rising and sinking of the ground," which might be due to volcanic agency, probably took place, since a volcanic rock occurs "that resembles the phonolitic and basaltic tuffs of the neighboring Höhgau. Further "it is manifest that the volcanoes of the Höhgau were in activity at the same time with those of Oeningen."

While agreeing with much of the valuable and original information contained in these volumes, not least that quoted above, the writer nevertheless would give a different interpretation to some of the phenomena presented. As to the origin of much of the richly fossiliferous rocksubstance, and specially the numerous thin lamellae noted, he would regard such as intermittently successive deposits of volcanic lime-dust laid down in the course at most of a few years. The source of this dust Heer sufficiently accounts for in his mention of the not far-distant volcanoes. In conjunction with this we must bear in mind that huge thicknesses of limestone strata were on every side and had to be broken through, caught up periodically in the volcanic vents, and ground to powder there before being extruded (p. 44) as a fine almost impalpable powder, which alike in air, when rain-exposed, or under water, would speedily set into the hard thin lime lamellae described.

Heer's suggestion that the land rose and fell in intermittent manner, and so caused alternate drying and flooding of the region, is in line with much that has been described as an accompaniment of volcanic disturbances and would undoubtedly aid in perfect preservation of the enclosed organisms. All of these did not decay, and break up loosely in freshwater that was slowing depositing sediment. After being spread out in water, or after being suddenly killed 
over land surfaces, they were covered and quickly dried as in ordinary herbarium process.

Three very similar deposits to the above are those described by Dunker ( $I S_{4}$ : I 55 ) from Günzburg, and by Meyer $\left(18_{5}: 8_{5}\right)$ from Unterkirchberg near Ulm, and from Aix in France. The fauna in all of these bears a strong resemblance to that described above, while the fishes

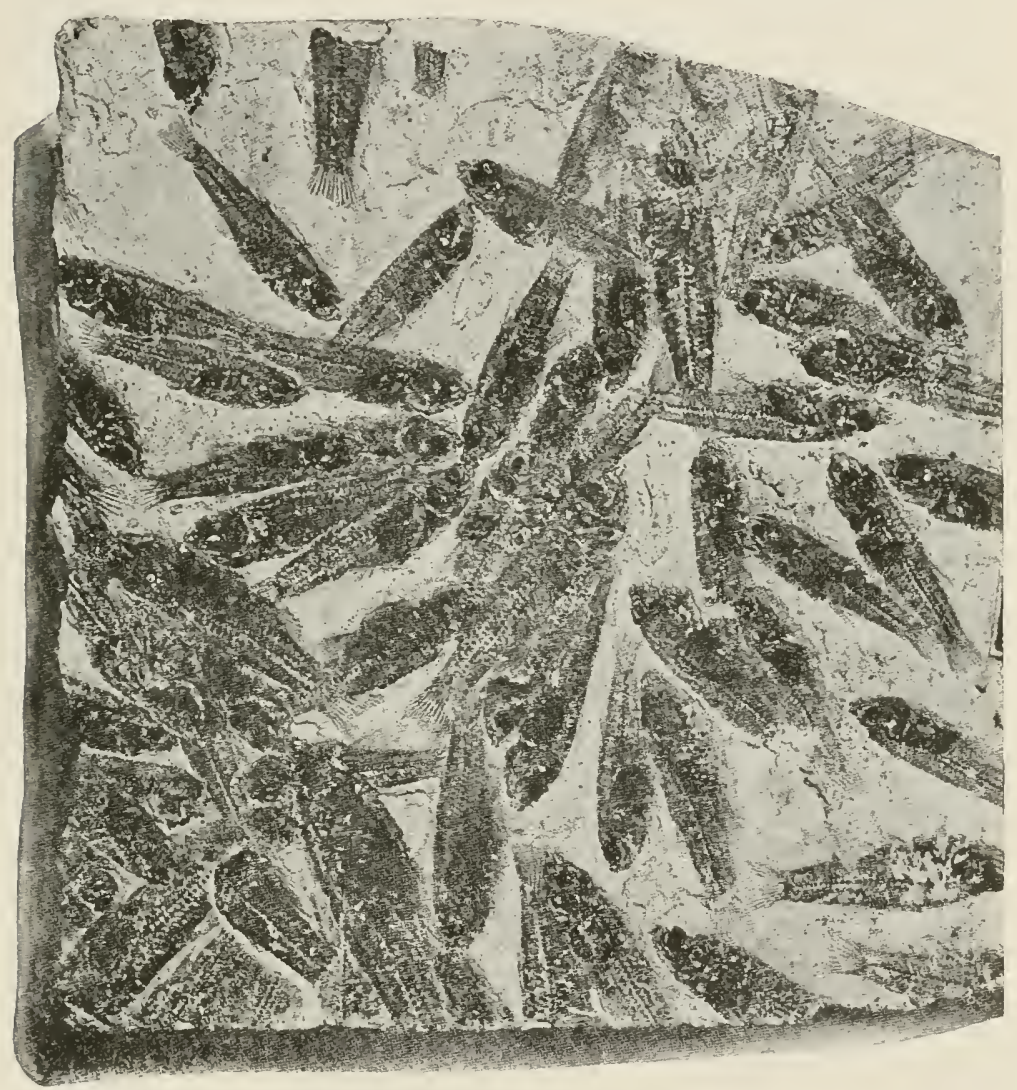

FIG. +o. Prolebias cephalotes, a freshwater Oligocene fish, shoals of which cover rock-slabs at Aix-en-Provence. Natural size. (From Haug).

were equally abundant. Figure 40 is reproduced from a rock slab studied by Haug, and it strikingly illustrates great and sudden destruction of fish-life. Meyer clearly states that these were wholly inhabitants of freshwater. And he adds: 
Es ist wenigstens auffallend, das auch in andern Tertiärbecken, wie, $z, b$, in dem Mittelrheinischen, dass die Gegenden von Frankfurt, Mainz und Wiesbaden umfasst, der reine Thon meist nur Fische, dagegen der Mergel und die derberen Kalksteine Saugethiere umschliessen. In Böhmer wo die schieferigen Thone theilweise durch den Polierschiefer und Halbopal vertreten werden, ist aehnliches der Fall."

But Meyer groups together and compares in bewildering manner, sets of teleost fishes that undoubtedly were then freshwater, such as cyprinoid and percoid types, with others like Clupea, Smerdis and Solea that were now fully established as marine fishes. Explanation we believe is got when comparison is made of Meyer's statements and results with those given in an earlier paper by Eser of Ulm $(186: 258)$. He carefully classifies, toward the end of his paper, the entire series of rocks exposed, and one then clearly sees that those numbered I- 6 a,b,c, are freshwater, and correspond to those numbered I- 8 by Meyer. But the stratum $6 \mathrm{~d}$ of Eser, or 9 of Meyer is as clearly a temporary marine intrusion. For alongside Clupea, Smerdis and other marine fish remains the molluscan genus Cardium is quoted. Below this a freshwater fauna and flora again appears as Eser's stratum 7 or as Meyer's 10. The writer suspects that a similar explanation may attach to the beds of Aix and of Margarethen.

In Sauvage's paper ( $187:$ I 7 I ) on the freshwater fishes of Menat in Auvergne, that belong possibly to the same, or to a nearly coeval date as those of Oeningen and Ronzon, he remarks as follows regarding the environment, and probable mode of preservation: These lignitic beds "accumulated in the hollow depressions of the mica schists, and there formed a little pool, around which there developed a luxuriant vegetation. Little by little the clay torn from the surrounding rocks by torrential rains, and the debris furnished by the plants which grew on the margins, had raised the depth of the basin, and owing to the foreign material and to the evaporation which is effected in the dry season, the pool was at length reduced to dryness. It was then that the leaves and the insects fell from the surrounding trees, likewise that the fishes which lived in 
the pool, had left their impression on the still soft mud. But, with another season, the rains gave to the basin its former aspect, and permitted the same set of phenomena to be reproduced." Further in describing the relation of the amioid fish Cyclurus he again accepts alternating periods of dryness and flooding in connection with the preservation of them. A closely similar set of beds to those of Menat in Auvergne is described by Reuss and Mayer in North Bohemia ( $188: \mathrm{I}$ ). The strata, as exposed in three localities, are purely of freshwater origin, and consist of brown coal, freshwater chalk, grey and reddish sandstones etc. As at Oeningen and other more western localities, the strata are rich in coniferous twigs and cones, in palm leaves and those of dicotyledons. The fauna reveals wings of Coleoptera, millions of Cypris, such freshwater shells as Helix, Bulimus, Achatina, Planorbis. The fish and reptilian remains closely resemble those of Oeningen, Steinheim, Aix-en-Provence, and Menat. They then point out that while, during Miocene time, a large part of Hungary, Galicia, Austria, and eastern Bohemian was covered by sea, the northern part of Bohemia was covered by a large lake in which was deposited the brown coal and other strata.

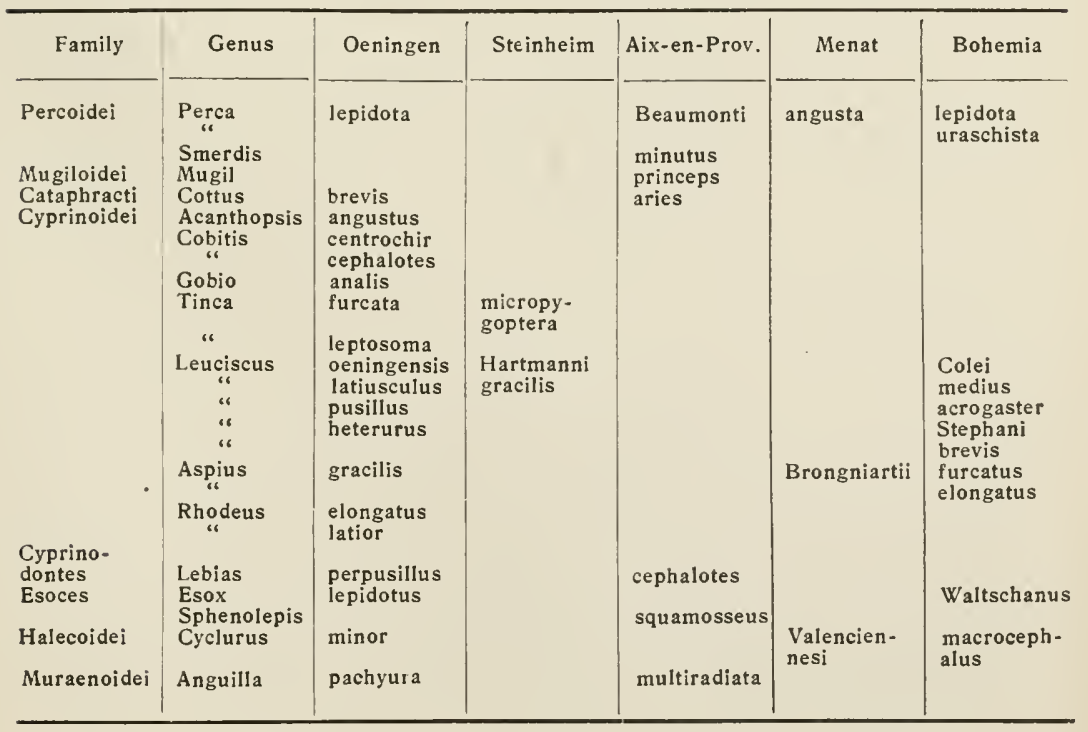


They present also the comparative table on the preceding page, which sets forth the relation of the species found in each of the localities already mentioned.

The relative abundance in some of the above deposits, and rarity in others, of species and genera is due, we take it, to the imperfection of the geological record, and imperfect modes of preservation, not to actual poverty of fish life in the freshwaters of Miocene time. For in addition to the above, and from other localities, a rich variety of species is known.

In contrast to the above list, and as being recorded from a Swiss locality not far from some of the above, to which the sea had access, we now append a list as given by A. Wettstein ( $I S q$ ) from the Oligocene "Glarnerschiefer." It will be observed that these include fishes from very different genera and even families, as compared with the above. Some of them also likeAcanthopleurus and Acanthoderma are highly modified types as compared with any forms found in freshwaters.

MARINE FISHES FROM OLIGOCENE, GLARUS, SWITZERLAND.

Sclerodermi. Acanthopleurus serratus.

Acanthoderma spinosum.

Clupeidae. Clupea brevis.

Clupea dubia.

Clupea megaptera.

Meletta (Clupea) Scheuchzeri

Scopelidae. Scopeloides glaronensis.

Gadidae. Nemopteryx trorcheli.

Berycidae. Acanus longispina.

Acanus regleysianus.

Acanus gracilis.

Percidae. Podocys minutus.

Teuthididae. Archaeoteuthis glaronensis.

Scombridae. Lepidopus glaronensis.

Lepidopus brevicauda.

Thyrsitocephalus alpinus.

Palimphyes glaronensis.

Palaeorhynchus glaronensis.

Hemirhynchus colei.

Echeneis glaronensis.

Archaeus.

Archaeoides longus.

Archaeoides longicostatus.

Archaeoides macrurus.

Isurus macrurus.

Cyttidae. Cyttoides glaronensis.

Fistularidae. Fistularia Koenigi. 
We would decidedly question the correctness in determination of the genus Podocys, regarding which Woodward ( $180: 519)$ observes "too imperfectly known for discussion."

All of the above lists emphasize the fact that alike in freshwaters as in the sea, the families of European fishes were the same as those that still are found in like environment. Also, the families as well as the genera that inhabit the two media, are largely different from each other, while the freshwater types are of more primitive character and are least modified, those of marine habitat are often highly modified in structure.

The earliest Miocene (Oligocene) deposits of North America are poorly developed in the eastern as compared with the western part, and in the east they are largely marine. But the White River and the John Day beds that spread over a wide extent of South Dakota, Utah, Colorado, Wyoming, Idaho, and westward to Northern California and Oregon at least, seem to have been very largely deposited in extensive lakes, that were a continuation of one-the Wasatch Lake-or possibly of several lakes of Eocene age. Cope says: "great lakes or seas occupied the centre of the continent during Miocene time, when the ranges were still higher. Vast forests of vegetation and a rich population of animal life, point to a humid climate during the entire period that has elapsed, since the great elevation of the Rocky Mountains in the beginning of the Eocene epoch to within comparatively recent times." When the fossil fish fauna of these lakes, that Cope in part elucidated, has been properly studied, the results will aid in many problems of distribution. As yet comparatively little has been done.

But some deposits-and notably those of Florissantare of exceptional interest. For they suggest striking correlation in physical and biological features with the Oeningian or Tortonian beds of Switzerland, though the former are of lower Oligocene, the latter of uppermost Miocene age. Thus Scudder has described about 800 species of insects, the fishes also were very abundant and are beautifully preserved, as are the insects, in a pale fissile limestone 
rock that splits into layers $(I 90)$. Everything indicates that here we have again to deal with a combination of physico-biological factors connected with volcanic activity, volcanic dust-showers, wide-spread death of animals, and rapid entombment of them in the hardening volcanic dust, such as we have frequently emphasized already.

In view of such conditions it is not surprising that some of the Oligocene-Miocene strata are becoming increasingly celebrated in the commercial world as sources of bituminous supplies. But as in the case of Eocene and Cretaceous oil beds already treated of, the richest oil reservoirs are connected with marine rocks. Thus the Monterey coastal beds of California consist largely of shales that may vary from 2000 to 4000 feet in thickness, and which yield abundant supplies of oil. According to Eldridge rich masses of foraminifera, borings of Pholas, and fish scales are the most prominent features, while in some beds enormous quantities of diatoms occur. So it has been suggested by some writers that the petroleum is derived from the soft substance of the foraminifers and diatoms. But no proof exists that such organisms can produce even approximately, sufficient fixed oils, and therefrom yield by analysis bituminous products, that would account for even a tithe of the oils now being abundantly set free. The universal occurrence of fish remains gives, we believe, the key to the situation.

The enormous deposits that were laid down along the Eocene to Pliocene coastal areas of California are outlined by Eldridge in some of his conclusions (op. cit. p. $32 \mathrm{I}$ ). Thus "there are at least Io or I 2 horizons in the 20,000 feet or more of strata from Eocene to Pliocene that carry oil in quantities of economic value. The reservoirs are either conglomerates, sandstones, or the arenaceous members of the great shale groups in the Miocene. The stratigraphical and structural conditions under which oil occurs in the known fields, are many times repeated elsewhere in the Coast Range and the territory contiguous. In several instances faults, or intense disturbances of the strata, have accompanied the folding of the entire system, causing along their lines, interstitial spaces in which petroleum could 
accumulate, and thus resulting in an increased supply and yield."

The last statement is important, and as in nearly all cases cited in previous chapters of this work, the heat evolved in the stratigraphic disturbances, would amply explain the destructive changes undergone by the fish-oils set free.

The writer is compelled to add here that it seems to him a matter for great regret, that while so voluminous a literature has appeared bearing on the relation and possible economic value of the rock strata, there is a sad dearth of information as to the organisms, the exact determination of these, the precise beds in which they occur, and their comparative abundance in these beds. Were such information forthcoming it would undoubtedly greatly aid in determination of the origin, the distribution, and the localization of the oil supplies.

III. Pliocene-Pleistocene Formation. The general resemblance of this alike in physical and biological details, to present-day conditions is such, that only a few features need to be touched on here.

Over at least wide areas of what is now land heavy freshwater or eolian deposits took place. Thus during Pliocene time the Norwich $\mathrm{Crag}$ and Cromer group in England, the lower and upper Pliocene in Central France, the Mainz beds of Germany, the Congerian and Thracian of Austria, the enormous Siwalik mass of north India, the Marsupial beds of Australia, the Lafayette and pre-Lahontan areas of North America, all reveal a land or freshwater flora and fauna often of extreme richness and which approaches in general facies to existing conditions. 


\section{CHAPTER IX.}

Fishes in Time and Space. (i ) The Primitive Fishes.

In this and several succeeding chapters, the writer proposes to trace, as perfectly as possible, the gradual evolution of the groups of fishes, the probable relation of these to each other, and the distributional areas that each group spread over, or is known to have occupied.

In previous chapters we have endeavored to show that the entire group of fishes-and so of the vertebrates as a necessary corollary-originated as direct and progressive derivatives from higher types of metanemerteans, which flourished during Cambro-Ordovician times. And as is demonstrated by a few of these, that still linger on as surviving remnants from primitive epochs, they early showed a tendency toward evolution along at least two lines which when pursued further gave rise to at least two diverging groups. These both inherited common and fundamental characters derived from the Nemerteans, but they also showed steadily acquired and progressively evolved details in diverging lines, that were superadded to the nemertean structure. These divergent details represented slowly acquired characters, that more and more distinguished the two diverging groups.

Putting aside the Urochordata and the Cephalochordata that we have shortly discussed elsewhere $(I: 539)$, and reference to which is constantly made in sections of this work, the following questions naturally arise: (a) what are the most primitive fishes as yet recognized; (b) in what region may they first have been evolved; (c) how widely did they become distributed; (d) how long did they persist? In any attempted answer the extreme incompleteness of the geological record, and also the comparatively soft nature of these primitive types, except where a calcareous skeletal system evolved, must ever be kept in view. The graphic table opposite, which will be analyzed and explained later from the structural standpoint, indicates the successive evolutionary lines that the writer proposes to follow. 
Three main lines for the true fishes are there indicated; the most primitive being the Malacodermata; a more evolved and diverging one from it being the Placodermata; and derived in common with the last but now including the highest fishes, are the Lepidodermata.

\section{PISCES.}

Malacodermata.

Order r. Conodontes (Polygnathus, Prioniodus).

Order 2. Petromyzontes (Petromyzon, Geotria).

Order 3. Myxinoides (Myxine, Bdellostoma).

Order 4. Palaeospondylides (Palaeospondylus).

Placodermata.

Order I. Protoplacoda (Heterostraci in part, Coelolepidae).

(Thelodus, Lanarkia.)

Order 2. Heteroplacoda (Heterostraci in part).

(Drepanaspis, Psammosteus.)

Order 3. Symplacoda (Heterostraci in part, Pteraspidae).

Order 4. Cephaloplacoda (Osteostraci).

Order 5. Polyplacoda (Antiarchi)

(Cephalaspis, Tremataspis).

Order 6. Hyperplacoda (Anaspidae). (Pterichthys, Bothriolepis.)

(Birkenia, Lasanius.)

Order 7. Microplacoda (Elasmobranchii).

(Pleuracanthus, Lamna.)

LEPIDODERMATA.

Order I. Dipneustei.

Sub-Order r. Arthrodira (Coccosteus, Dinichthys).

Sub-Order 2. Dipnoi (Neoceratodus, Protopterus).

Order 2. Crossopterygii (Rhizodus, Polypterus).

Order 3. Chondrostei (Palaeoniscus, Acipenser).

Order 4. Holostei (Semionotus, Amia).

Order 5. Teleostei.

Sub-Order x. Malacopterygii (Portheus, Salmo).

Sub-Order 2. Acanthopterygii (Asineops, Perca).

Of the first no fossil remains are certainly known. The simple or compound tooth or comb-like bodies, however, that have been named "conodonts," bear a striking resemblance in form to the variously shaped and placed teeth of genera of the Cyclostomata. They were reported by Pander (I90a) from Cambrian and Silurian strata of Russia. He inclined to regard them as the teeth of cyclostomes or of sharks. Later they were discovered in the Upper Silurian beds of England, in the Lower Silurian and in Devonian beds of Canada and New York, in Carboniferous 
strata of England, Scotland and Ohio, also in Permian rocks of England. The figures and descriptions given by Pander and by Newberry (19I:4I:Pl.57) suggest the appropriateness of such varied generic names as those that Pander employed, no matter what the animals were that carried them. As to abundance, Newberry (p. 4I) says that they are "found in great numbers in the Cleveland Shale of the Waverly group at Bedford, Cayuga Co." and that the surfaces of the layers of the shale are sometimes so covered that thousands occur on a square foot, and again, "the number of these objects is immense, and the variety of form which they exhibit is but imperfectly shown in the figures."

A comparison is made in Figure 7 (p. Io8) of some conodont and existing cyclostomatous teeth. And as to the distribution of the former it may be said that the Hamilton, Genesee, and other rocks in which they occur are in part or largely of freshwater origin, but their occurrence much later in the Mountain Limestone, as recorded by Moore, would indicate that they in time spread seaward, as is later traced for elasmobranch fishes.

Now if one compare the varied shapes of Conodonts as given by Newberry and Hinde ( $192: 35$ I) with the varied descriptions given in condensed manner by Lönnberg (193:282-288) as well as the descriptions and figures by authors that he cites, it scarcely seems possible that two sets of structures should vary so exactly in parallel manner in different genera and yet belong to totally different groups of animals. Zittel considers that the histological structure differs; but, if one compares Fig. I that accompanies Beard's paper on "The Nature of the Teeth of the Marsipobranch Fishes" (197:727) with Zittel's figure the resemblance is worth noting. It has also been said that Conodonts are calcareous, and cyclostome teeth purely chitinous, but this need not be a fundamental objection when changes undergone during fossilization or progressive evolution are considered. The writer then would decidedly favor the view that conodonts are the buccal teeth of primitive cyclostomes, but he would welcome more extensive information and details before final decision. 
All are agreed that the cyclostomes are the most primitive of the true fishes. Some zoologists have held that they are degenerate derivatives from some of the higher fishes, but such is absolutely contrary to all structural, physiological, taxonomic and developmental evidence. Through commencing epizoism and-as in Myxine-through ultimate endoparasitism, a few degenerate characters are shown, but these are by no means profound. From the progressive evolutionary standpoint they should have been evolving in early or mid Cambrian time; and from action of the great biological law of "preclimax, climax, and anticlimax" that the writer considers to appear all along the line of organic development, they should have reached a biological climax in size, structure, abundance, and wide distribution from early Silurian to late Old Red time. The anticlimax would progress slowly through Carboniferous to Permian, possibly even to Triassic time, and thereafter only lingering remnants might be left.

Such an evolutionary history runs exactly parallel to the knowledge we have of conodonts. Now it may be said that traces of conodonts should appear in strata from Triassic to recent times, if they truly are cyclostome teeth. But the comparative rarity and localized distribution of the species and genera of cyclostomes now, indicates that a restricting and destructive action has gone on for at least considerable geologic time amongst the group.

Shortly then we would sum up by saying: (I) that the probability of conodonts being crustacean gastric or mandibular teeth is most unlikely, or even impossible, alike from variety, structure, and the absence of crustacean remains then, to which such would belong. (2) They are, for much the same reasons not likely to be annelidan teeth, as alongside them might be expected the typical setae that do not appear. (3) Annelidan teeth are simple pointed tearing structures, conodonts show great diversity of shape and structure. (4) The shapes of conodonts and of cyclostome teeth very closely agree, and differ from the teeth in the other groups to which they have been assigned. (5) The abundant occurrence of conodonts in Siluro-Devonian strata, is evolutionarily in keeping with their being of cyclo- 
stome affinity, since that period fits in well as the climax period for cyclostomes. (6) The tissue relation of metanemertean proboscis teeth, of conodonts, and of cyclostome teeth, suggest a likely evolutionary continuity. Till much stronger evidence has been adduced therefore, than any hitherto advanced for their annelidan or crustacean origin the writer would decidedly favor the view that conodonts indicate the former existence of cyclostome fishes in prodigious numbers, which reached a climax in Mid or late Silurian and early Devonian time. It may be hoped however, either that more definite light will be shed by further study of conodonts, or that some layer of subaquatic volcanic ash may yet be discovered, in which as with the medusae, the annelids, and the skates of the Solenhofen slates, fossilized cyclostomes may be discovered. Though we need not press the point too far, it is worthy of note that the area over which conodonts have been found, namely from W. Russia across Britain to eastern North America, is that which includes the habitat for nearly all of the primitive fishes next to be studied.

In the above scheme of classification, we next include that ancient and remarkable type from the Lower Old Red rocks of Northern Scotland, which Traquair named Palaeospondylus (Fig. Io, p. I2 I). It exhibits many of the primitive characters of the Cyclostomata, along with decidedly more advanced structural details. The absence of scales of true or even of horny teeth, of limbs and calcified parts, except for the vertebral and neural elements, causes the writer to regard it as a small but advanced sideline of evolution, from a cyclostome ancestry.

We next reach a large series which the writer would consider to be derivative from that line of metanemertean descent in which secretion of isolated calcareous granules (p. 63), knobs, and ultimately complex surface plates became a hereditary peculiarity. In process of evolution also these slowly split apart into two fairly distinct types, the placoid or isolated, and the lepidoid or overlapping. These accordingly are termed the Placodermata and the Lepidodermata in the foregoing scheme of classification. The former of these on many grounds is generally regarded 
as the more primitive, and reasons for accepting such a view are advanced later. We have divided it into six subgroups that are of diverse morphological value.

From the slight and rather superficial knowledge as yet obtained of the animals, the Protoplacoda (Coelolepidae) deserve to be placed lowest in the scale. Of the recognised genera Thelodus includes one species that is known only by its isolated placoid scales from the Upper Silurian of W. England, of N. E. Germany and of W. Russia. A second, known in the entire fish, occurs in Lower Old Red rocks of central Scotland (Fig. Sa, p. II 2 ), while a third is from the Upper Devonian of Russia. Lanarkia is found in the "Downtonian" beds of Lanarkshire in Scotland (Fig. 8b, p. I I2). Both were provided with scattered tubercles (Thelodus) or hollow spines (Lanarkia), but were probably of soft cartilaginous tissue within. Mouth and sense-organs are as yet unknown.

The Heteroplacoda include Drepanaspis and Psammosteus that occur from Britain eastward to Russia. In contrast to the first group these are covered by flat tubercles or plates of variable size, those covering the head being at times large flat shields with intervening smaller plates. The simple transverse slit-like mouth, the paired lateral sense-organs, and probable soft body substance, suggest sluggish primitive animals derived from evolutionary advance on the Protoplacoda.

The Symplacoda consist of three genera Cyathaspis, Palaeaspis, and Pteraspis, that are distributed from the Upper Silurian of England and Galicia, to the Lower Old Red Rocks of England, Scotland, Galicia, Eifel, East Prussia, Spitzbergen, and New Brunswick in Canada.

Regarding the above three genera Bridge (36:530) following Traquair says "that they constitute a natural sequence of forms, beginning with organisms whose Elasmobranch ancestry is extremely probable." The writer would incline to view the first of the three as a very primitive placoid type, which by progressive specialization gave rise, in very direct line, to the elasmobranch series, and to derivative side-lines that constituted the two latter genera. These had a heavy defensive armature and clumsy habit. 
The Cephaloplacoda (Cephalaspidae) include five genera, Cephalaspis (Fig. 9a, p. I I9) Eukeraspis, Auchenaspis, Didymaspis, and Tremataspis, that extended from the Silurian upward to Lower Old Red rocks, and that cover a territory nearly coterminous with the Symplacoda.

The Polyplacoda (Antiarchi) includes the four genera Pterichthy's, Bothriolepis (Fig. I I, p. I 24), Asterolepis, and Microbrachius that form a remarkable assemblage with evident affinities to each other, but that are highly aberrant in relation to the main lines of fish evolution. Beginning with Pterichthy's, that is abundant in the Lower Old Red rocks of $\mathrm{N}$. Scotland and has often been figured in textbooks and memoirs, species pass into the Upper Old Red or Devonian of W. Russia, of Germany, of Britain, of Scaumenac Bay in Canada, and of Pennsylvania. It is suggestive also to observe that the eight species of Bothri-
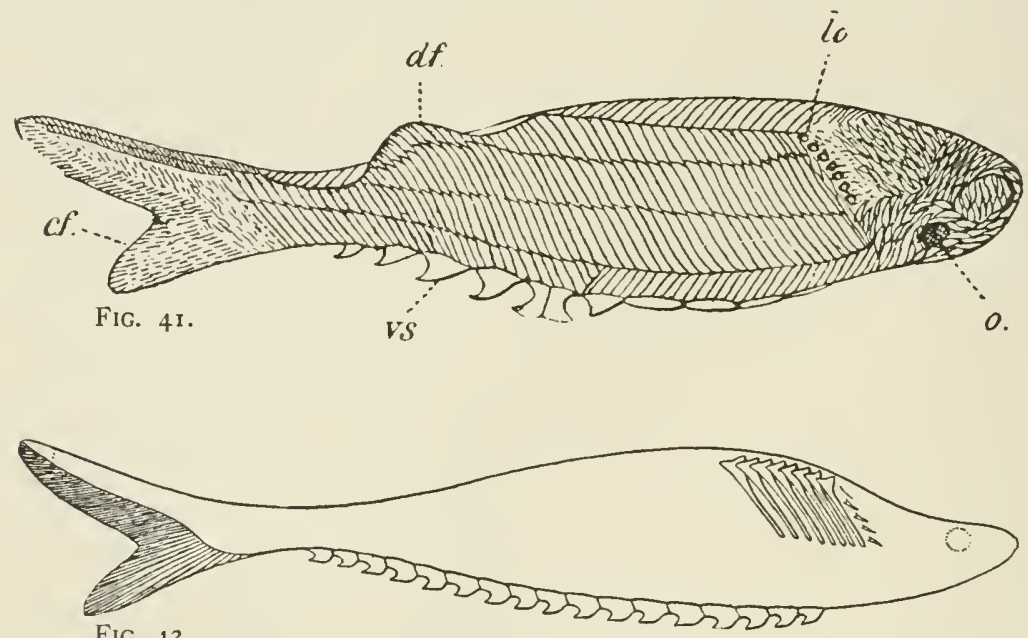

Fig. 42.

Fic. 4r. Birkenia elegans, a primitive Silurian fish, found abundantly in Downtonian beds of Lanarkshire, Scotland; slightly enlarged. $c f$, caudal fin; $d f$, dorsal fin; lo, lateral and probably branchial pores; 0 , eye centre; vs, ventral scutes.

FIG. 42. Lasanius problematicus, found with above, and probably closely allied; slightly enlarged. (Both after Traquair). 
olepis are distributed from W. Russia, across Scotland and England into N. E. America.

The Hyperplacoda (Anaspida) seem to be a greatly less aberrant and less heavily armored group than all of those already reviewed, except the first. The three genera Birkenia (Fig. 4I), Lasanius (Fig. 42), and Euphanerops, occur from the Upper Silurian rocks of Scotland to the Upper Devonian rocks of Canada. In not a few characters they suggest a rather continuous advance from the Protoplacoda to primitive members of the Microplacoda or Elasmobranchii, that are referred to below. As is true also of the Protoplacoda, the Microplacoda, and other of the above great primitive groups, the Hyperplacoda developed no true bone-forming cells in any of their tissues.

But at this stage we would now stop to inquire as to the environal medium in which all of the above fishes lived, and the possible means, as well as extent, of their geographical distribution. As already claimed (p. I Io) none of the rocks in which they are found, contain marine organisms. In many cases land plants are spread out alongside the fishes or in the same stratum of rock, while not unfrequently phyllopod crustaceans, eurypterids, and scorpions that are invariably of land or freshwater environment, are preserved alongside the fishes. Such conjointly proclaim a freshwater life for all. No authentic case of a marine environment has been observed or verified by the writer, though from loosely recorded lists of organisms taken from adjoining but quite distinct beds of the same stratigraphic section, mistakes might be, and have been, easily made.

Regarding their distribution, lack of sufficiently extensive evidence from the world's continents would suggest caution as to conclusions. But to judge from present knowledge we would accept it that fish-life probably evolved, in early Silurian times, over some continental mass that stretched from Russia westward to eastern North America. Also that by late Silurian time several divergent, and in not a few cases remarkably modified and cuirassed, lines of fish-evolution with nearest affinity to very primitive elasmobranchs (or Microplacoda) had appeared. Many 
of these were continued into Lower Old Red or Devonian times, while other and more highly modified but ungainly types reached a climax of cuirassed perfection, to become extinct toward the close of the Upper Devonian period. Meanwhile types like Birkenia and Lasanius, of late Silurian and Devonian times, most nearly led up to incipient elasmobranchs, and all of these inhabited a set of lakes and rivers that were at times connected or at times separate. So the same species, or at least the same genera, are often continuous over much of the above area.

As already noted (p. I I 2 ), widespread volcanic activity during late Silurian, and specially during late Devonian times, probably accounts in great part, for the obliteration of most of these forms, which had largely evolved into awkward heavily mailed mud-bottom feeders.

In passing now to the Microplacoda or Elasmobranchii, we would accept it that from some type allied to Birkenia and Lasanius, a series of organisms arose in late Silurian or early Old Red times, some of which gradually evolved and then culminated in the Cladoselachii, the Acanthodii, and the Pleuracanthidae. For the heterocercal tail, the apparently distinct branchial slits, the rounded snout, the subcephalic mouth, the varied nature and position of the scales or scutes, and the fusiform body in the two abovenamed genera, all strongly suggest probable evolution from them or from some early related types, of the three groups above named. Moreover, the lithe aspect of the entire animal, as contrasted with the cumbrous and heavy aspect of most of the previous groups, would favor escape and survival amid untoward conditions that caused the unwieldy to succumb.

But the three groups, Cladoselachii, Acanthodii, and Pleuracanthidae, illustrate well the extreme difficulty of dealing with these early sharks, on account of their soft structure, which seems always to have left only scattered teeth, fin-spines, or detached-rarely shagreen-connectedscales. So temporary generic names-that formerly, and even still in not a few cases, were required, till more accurate knowledge was obtained-have been multiplied to a degree that produces confusing synonymy. But it may safely 
be accepted now that the fin-spines named Cheiracanthus, Diplacanthus, Euthacanthus, Gyracanthus, and Macracanthus belonged to acanthodean forms like Acanthodes or Climatius; that Triodus, Diplodus, Didymodus, Thrinacodus, and probably Cladodus, are isolated teeth, while isolated spines like those called Compsacanthus, Orthacanthus, and Xenacanthus are defensive parts belonging to pleuracanthid types $(195: 2)$.

The genus Acanthodes (Fig. 9e, p. I I9) or Acanthoessus appears first in Lower Old Red rocks of Northern and Central Scotland, in which also the allied genera Climatius and Parexus are found. In the same or in related rocks Diplacanthus, Ischnacanthus and Cheiracanthus spines are of ten abundant, and are isolated parts of the three above named genera. According to present knowledge they were very abundant in lakes of Old Red age, that occupied areas over N. Scotland. Thence they seem to have spread, with lapse of time, westward into Canadian lakes that covered in part the Scaumenac region, as well as eastward into Russia. So their remains are encountered in the upper freshwater Devonian strata of these widely apart regions.

But the genus Acanthodes evidently persisted near or in its ancestral centre, while the others died out largely or wholly at the close of the Devonian. The result is that in freshwater Calciferous rocks of Dumfriesshire, in Scotland, and upward through the Coal Measures of Scotland and England, the genus persisted; later in Permian rocks of France, Germany and Bohemia it remained fairly abundant, but then gradually disappeared.

The above geologic distribution again suggests geographic and biologic continuity from W. Russia through Britain to Canada at least, and throughout in freshwater regions. Defence rather than offence is also suggested for the entire series. For the lithe shape of body, the welldeveloped fins, the powerful defensive fin-spines, and the small closely set placoid scales, all conform to the former, while the entire absence or small size of teeth except in Acanthodopsis and Ischnacanthus suggest weak or inoffensive relations. And wherever fossilized alongside other organisms, the latter invariably proclaim a lake, swamp, 
or river life. This is eminently true of the Scottish, the Canadian, and the Russian strata, as already described (p. I 35). The writer has collected specimens in the Calciferous rocks of Water-of-Leith that lay beside fern and lepidodendroid remains, but no suggested trace of marine organisms was found. The coal-Measure rocks of Carluke, of Midlothian, of Yorkshire, and of Staffordshire in Britain, all contain the genus alongside plants, Estheria, occasional scorpions, and eurypterids.

But according to much of past accepted opinion, the conditions and relations for Acanthodes seemed to be very different for eastern and central North American strata. For the view has been almost universally expressed that the greater part of the Old Red or Devonian, consisted of rocks of marine origin. The writer has already touched slightly on this problem (p. I 26), but he desires now to discuss it in fuller detail, and not least owing to its important bearing on the origin and distribution of the Arthrodira, that are treated of later (p. 294).

In the elaborate memoirs of the New York, Pennsylvania, Ohio, Illinois, Iowa, and other surveys, it is either tacitly or openly accepted that the Devonian strata and their fossils are of marine origin. We need scarcely linger now over reasons for this, as some are explained below. Instead also of dealing with all of the above memoirs, the writer proposes to confine attention mainly to those of the Ohio survey, supplementing with results recently secured by Eastman and others.

Newberry, in his excellent volumes of the Ohio survey, and in his monograph on the palaeozoic fishes of North America (86) has dealt with the subject most fully. As he sets forth by diagram in Vol. I, pt. I of the Ohio volumes he divided the Devonian of Ohio into the Oriskany, the Corniferous, the Hamilton, the Huron and the Erie zones. The second of these he subdivided into a lower or Columbus limestone, and an upper Delaware or Sandusky limestone, since the two differed markedly in character and fossils Superior to the Devonian he placed, as Lower Carboniferous rocks, the groups named Cleveland Shale, and Waverley beds, the latter being subdivided into Bedford 
shale, Berea grit, and Cuyahoga shale. We need not linger over the dispute as to whether these should be regarded as Lower Carboniferous or Upper Devonian. Shortly the writer would consider that they are probably contemporaneous below with the Upper Old Red, and above with the Calciferous of Europe. But their mode of origin and the enclosed organic remains deeply concern us.

Newberry and successors have viewed the Corniferous as a marine series, and it may at once be accepted that the Lower or Columbus Limestone, the Schoharie of authors, is such, for the abundant invertebrate marine fossils fully demonstrate this. It is highly noteworthy however that no fish remains are intermixed with these. But the Delaware or Sandusky limestone above, which he considers to have been deposited in some extensive sea, is unquestionably freshwater in origin. For in marked contrast to the lower: (a) it is devoid of marine organisms, and though mention is made of occasional Lingula and Discina types these are not normally intrinsic; (b) its lowermost course, the "bone-bed" is a mass of fish remains that all belonged to freshwater species of the period; (c) included in the beds above the last are several forms of tree fern trunks and a Lepidodendron. So we would consider that after deposition of the marine Columbus limestone, some sudden volcanic activity took place, that caused elevation of the land, formation of an extensive lake, destruction of great shoals of freshwater fishes whose soft parts decayed, but whose teeth, spines and plates formed much of the fish or bone bed of two to six inches in thickness. Thereafter continued deposition of freshwater limestone went on, that is largely unfossiliferous, but which encloses tree fern and "Dadoxylon" trunks, parts of Lepidodendron, and occasional freshwater fish remains, though no marine invertebrates. The Marcellus shales seem to form the top of this series.

Another change in the land and invasion by the sea took place probably gradually, to constitute the "Hamilton" series of rocks. For Newberry says that in "the extreme upper portion of the Sandusky member of the Coniferous group, several characteristic Hamilton fossils are found 
in considerable abundance, such as Spirifer mucronatus, Cyrtia hamiltonensis, etc." As its fossils proclaim, we would regard the Hamilton as a marine series.

But elevation of land again took place, freshwater lake deposits again formed, and these gave rise to rocks of the Huron shales, that Newberry has described as "a nearly homogeneous bituminous shale, attaining a maximum thickness of 350 feet" (196: 13). Later he adds (p. I 5 ): "The great fossil fishes found in the Huron shale have been frequently referred to in the preceding volumes of this report. Two species of Dinichthys, the largest and most remarkable of all known ganoids," (now by many referred to the Lung-fishes or Dipneusti) "one of Aspidichthy's, and one of Ctenacanthus are described and figured." And again he says (I97-I9I) that the Huron shale is "undoubtedly the source from which petroleum emanates in such abundance in Western Pennsylvania." In Prosser's more recent volume (p. 522 ) a calamite probably belonging to the primitive genus Pseudobormia is also described. Here in passing we would emphasize the intimate association of petroleum with the giant fishes above named.

But a new land depression caused re-invasion of the sea, with resulting formation of the Erie shale, that may be from IOO feet to 500 feet thick. This abounds in "species of Spirifer, Orthis, Leiorhynchus etc." and so is typically marine. But renewed elevation took place ( $197: 486)$ and the Cleveland shale was deposited in some freshwater expanse. It is "usually a highly bituminous shale containing Io to I 5 per cent of combustible matter." As to its organisms he says that the fossils "are not numerous or varied, yet it is not, as formerly supposed, entirely unfossiliferous" for "at Newburg scarcely a fragment of it can be found which does not contain scales of fishes" while "the surfaces of the shale are also in this locality sometimes covered with little comb-like fossils called by Pander 'conodonts.' "'

With all of the above and related data before us it is natural to find that Claypole gives the following neat table: 


"Ohic $\left\{\begin{array}{l}\text { Cleveland shale } \ldots \ldots \ldots \ldots \ldots \ldots \ldots \text { Fish fossils abundant. (F)* } \\ \text { Erie shale } \ldots \ldots \ldots \ldots \ldots \ldots \ldots \ldots \\ \text { Huron shale } \ldots \ldots \ldots \ldots \ldots \ldots \ldots \\ \text { Hamilton shale } \ldots \ldots \ldots \ldots \ldots \ldots \\ \text { Corniferous limestone } \ldots \ldots \ldots \ldots \ldots \text { " }\end{array}\right.$

To the above might here be added Claypole's "Section of Cleveland Shale in Cuyahoga County," (Fig. 43) with the leading fish types indicated from each zone $(87: 316)$ :

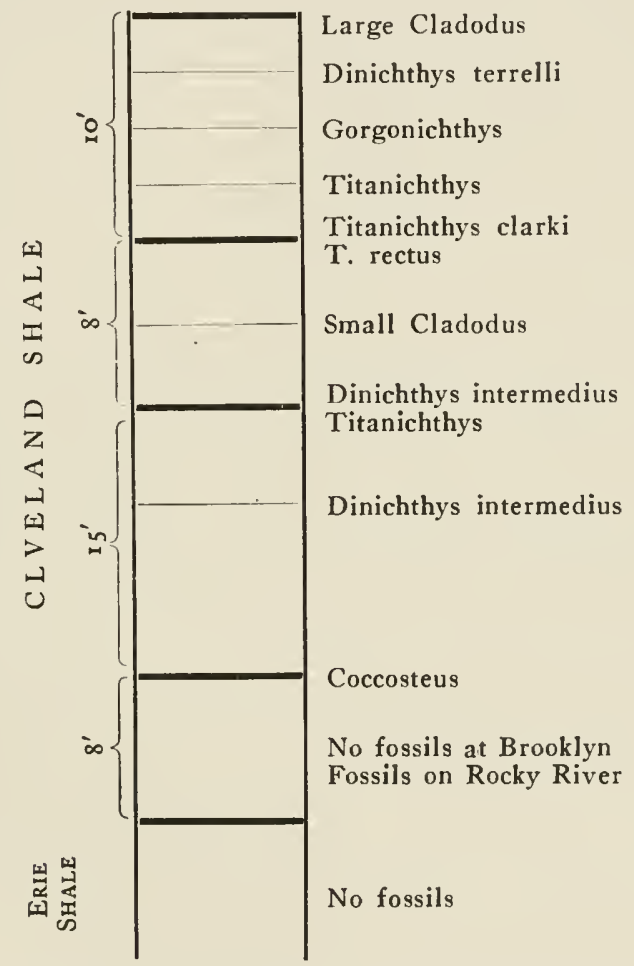

Fig. 43. Section of Cleveland Shale, showing relative positions of the beds containing abundant and large types of Arthrodira.

From the Delaware or Sandusky series of the Corniferous limestone Newberry described Machaeracanthus sulcatus, M. major and $M$. peracutus, also a species of Cladodus, Ptychodus and Rhynchodus. Such furnish ample proof that primitive elasmobranchs and chimaeroids had

* The present writer has appended in brackets the letters (F) for freshwater and (M) for marine deposits. 
then evolved in the freshwaters of Eastern America, while as yet no trace of them has been met with in marine beds.

Attention may next be drawn to the list of fishes recorded from the Lower Devonian freshwater beds of Campbellton (N.B. Canada). These, as listed by Eastman (198:275) include the following elasmobranchs and chimaeroids: Acanthodes semistriatus, Climatius latispinosus, Gyracanthus incurous, Protodus jexi, Doliodus problematicus, Cheiracanthus costellatus, Homacanthus gracilis, and Machaeracanthus sulcatus.

In comparing the above lists it is of interest to find that while the species may be different, such genera as Acanthodes, Climatius, Cladodus, and others are common to the freshwater strata of Canada, the Eastern States and Europe.

The Chemung and Catskill strata seem at least in part to have had freshwater origin, for such genera as Dipterus, Dinichthys, Onychodus, and Holoptychius were wholly freshwater in habitat. These along with the freshwater mollusc Anodonta, and with the plant genera Archaeopteris, Sigillaria, and Lepidodendron strongly suggest that while the Chemung may be regarded as Upper Devonian, the Catskill, like the Cleveland shale, possibly merges into Mississippian or Lower Carboniferous. Regarding it Chamberlin $(8: 434)$ says: "The Catskill formation is sufficiently different from the rest of the Upper Devonian to indicate that the sediments of which it is composed accumulated under conditions very different from those which obtained further west. This formation is poor in fossils, and such as occur are partly, if not wholly, of fresh- and brakish-water forms. Hence it is inferred that the Catskill region was at least so far shut off from the ocean as not to afford the conditions necessary for marine life. The formation is notable for its redness, a feature which marks many other farmations made in inclosed or partly inclosed seas, inland lakes, or basins."

The above extended, but highly necessary digression, is partial proof that species of Acanthodes, Climatius and other primitive elasmobranchs had gradually evolved over some fairly continuous northern area of land. In this area 
occurred freshwater connections, either as lakes, marshes, or rivers, which may frequently have changed their depths, configuration, and relations, during successive periods of time, but which so established a linked-up connection that species or genera of the group occupied some part of the above extensive area between the period of the Lower Old Red and that of the Permian.

The highly suggestive observations of A. S. Woodward on the evolutionary relation of the paired fins in Acanthodes (199:5) should here be noted.

The two groups of the Cladoselachii (or Pleuroptergyii) and the Ichthyotomi include elasmobranchs that show many affinities with the Acanthodii Both, however, so far as now known, appear later in the earth's history. For the best known representative of the first-Cladoselache fyleri-as well as three more recently described species, are only reported from Upper Devonian-or as Newberry viewed them Lower Carboniferous-shales of Ohio. Another and allied species has been found in the Calciferous beds of Kilbride in Scotland, while teeth like those from Ohio, have been found in North America, Europe, and even India. The exact beds, from which all of these were derived, clearly indicate a freshwater environment.

The highly interesting but imperfectly known Chondrenchelys problematica of Traquair, that as yet is known only from the Calciferous rocks of Eskdale Scotland, seems in some structural points to connect the Pleuropterygii and the Ichthyotomi.

The group Ichthyotomi is of special interest, alike from the standpoints of structure, distribution and phylogeny. For structurally of Pleuracanthus (Fig. 44) it has well been said that "it is a form of fish which might with very little modification become a selachian, dipnoan or crossopterygian." (200:32) Thus the notochord is a continuous tube with slight calcifications, the cartilaginous endoskeleton has only small granular calcifications, the paired fins consist of a median segmented axis bearing fringe-like lateral cartilages, and the exoskeleton consists of small placoid granules, in addition to a strong median dorsooccipital spine. 


\section{Evolution and Distribution of Fishes}

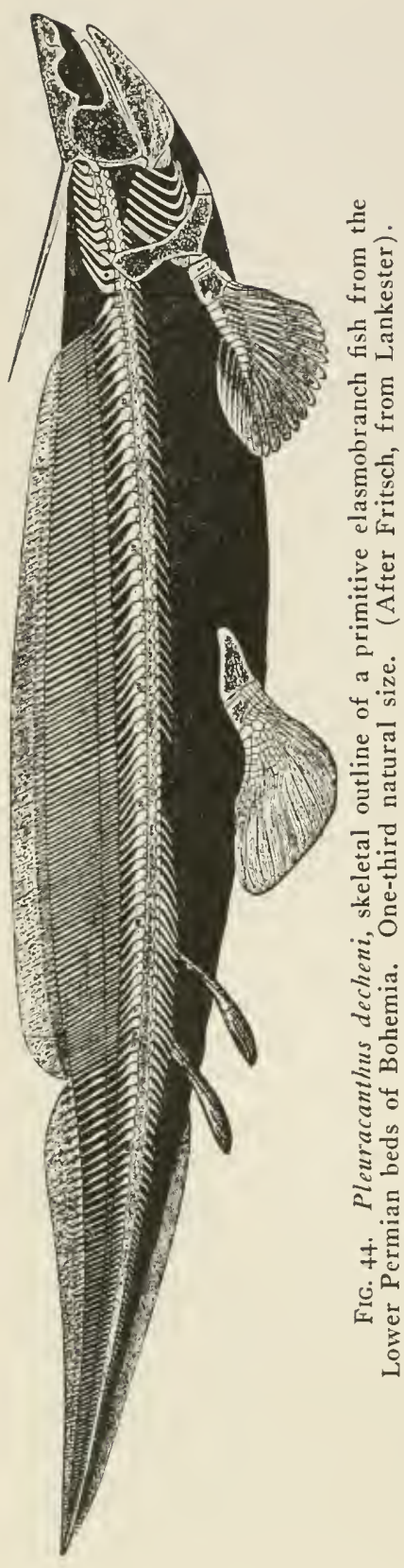

In time-extension remains of species occur from Lower Carboniferous to Lower Permian beds, and in space-extension they are found from Nova Scotia, Illinois and Ohio through Britain and France to Prussia, Silesia and Bohemia in Europe. A species even has been described from the freshwater Hawkesbury beds of New South Wales. But if-as seems likely-the isolated teeth, that have been called Clad$o d u s$, belong to pleuracanthid fishes, then the group first appears in freshwater strata of Mid-Devonian age in Eastern America.

Davis (I IO:32I), after discussing the affinities of Pleuracanthus referred to several species, and "argued that both Coelacanthus and Pleuracanthus were probably freshwater fishes, the former possessed of an air-bladder." Brongniart and Sauvage also agree (20I) that Pleuracanthus gaudryi is like the other fishes of the Commentry deposit of freshwater habitat.

So Pleuracanthus, with whichfollowing Egerton, Fritsch and others---we unite Compsacanthus, Orthacanthus, Xenacanthus and Diplo$d u s$, is everywhere a freshwater genus. For the entire assemblage of organisms in the Borough Lee rocks near Edinburgh; those from Middle or Upper Coal Measures of Lanark, Northumberland, York and Staffordshire in England; most of the fish-bearing beds of Ohio and Illinois; and the Gasköhle of Bo- 
hemia-so admirably monographed by Fritsch-all proclaim deposit in marshy areas, whose depth of water varied from time to time.

So far as present evidence then carries us, it can be said that not merely the very primitive groups of fishes in Upper Silurian and in Lower to Mid-Devonian time were wholly freshwater, this condition persisted well into Upper Old Red or Devonian times. But a marked distributional change seems then to have begun. And one may here record Chamberlin's words $(8: I I: 535)$ as to the fish life of the Devonian-Carboniferous. "Fish appear to have first effectually invaded the open sea in the Devonian period, but during that period true marine fishes seem to have been inferior in number and variety to those of the inland waters. But by the middle of the Mississippian (Calciferous or Lower Carboniferous: author) period the marine fishes had made such relative progress that they were in unquestioned supremacy, while the freshwater forms had notably declined, if we may trust the record." The first part of this statement is apparently correct; as to the second the Mississippian and Carboniferous anadromous fishes were fewer than the freshwater, and the purely marine ones were decidedly in the minority, as already in part explained. But, as will be emphasized later, the striking feature is that in late Carboniferous or in Permian times most or possibly all of these marine migrants had died out for some reason (p. 286).

As bearing on the entire question of the possible distribution in time and space of the great elasmobranch group, it may be well now to ascertain whether any exact evidence exists as to the environment of the group up till at least Triassic times. A note of caution given by Wheelton Hind deserves here to be quoted ( 106 ). "The marine or freshwater origin of much of the Coal Measures has always been a disputed point. Palaeontologists have hesitated to affirm the latter on account of the almost universal occurrence throughout the coal fields of Europe, in some few beds at the base of the Coal Measures, of Unio-like shells with typically marine forms; but it is questionable whether the presence of the two forms together is not apparent only. 
I say apparent because in collecting fossils from coal pits there is always great difficulty in accurately determining, to within a few feet or inches, the exact bed where each is obtained; very few indeed can be obtained in situ, the greater part are gathered from the spoil-heaps, where accurate reference to any horizon is next to impossible. A freshwater bed a few inches thick would pass unnoticed, and its fossils be mixed with those from marine beds above or below it. Many very thin beds containing fossils peculiar to themselves are known to occur at many geological horizons, and as I shall describe hereafter, certain narrow bands containing a typical marine fauna do occur in the Upper Carboniferous strata, only to be recognized as of marine origin by their fossil contents. So that I conceive it to be highly probable that thin freshwater bands exist among the marine beds at the base of the Coal Measures, a series universally recognized as once deposited under changing conditions.'

Quoting from Dr. John Young (202:223) we read "as far as Scotland is concerned I have never observed any commingling of true marine fossils in any of our musselband beds. The reptiles, fishes, molluscs, annelids, ostracods, and other organisms belong to genera and species that are seldom or never met with in marine limestone strata. This being the case, I believe the opinions formerly entertained, as to the marine origin of the strata of our upper and middle Coal Measures, especially of the bed characterized by Anthracomya was an opinion based on faulty observation, and which will yet be proved to be untrue when the fossils occupying each horizon of strata come to be critically examined. Oscillations of the earth's crust, may bring strata, which have been deposited under either lacustrine or estuarine conditions, into very close contact with those of true oceanic deposits, and this may be repeated again and again in the same series of beds. It becomes therefore the work of the palaeontologist to say which of the organisms found in this commingling of beds properly belong to the sea, and which to lakes and rivers." 
Hind then adds "this is most valuable evidence, as beds of coal and ironstone occur in the Carboniferous Limestone series of Scotland, where there is a frequent alternation of beds, with a typically marine fauna, with those containing Carbonicola and its congeners."

The question then arises: Is there direct evidence of the existence of elasmobranch fishes in marine Carboniferous strata? As partial evidence of the complete absence, from some records, of fish remains in certain typical marine beds, the writer might cite Vaughan's paper entitled "The Palaeontological sequence in the Carboniferous Limestone of the Bristol area" (203: I8I). Here the author gives alike the exact succession of beds, and elaborate lists of the fossils characteristic of each. $\mathrm{He}$ at the same time quotes Lloyd Morgan's series of papers on the subject. Not a fish is recorded from any of the beds examined. Abundant evidence of a like nature could be furnished.

But that frequent oscillations were proceeding in the earth's crust, is evidenced by the careful record of Stobbs on "The Marine Beds in the Coal Measures of North Staffordshire" (I02:495). He cites at least six narrow and typical marine bands intercalated between an extensive set of beds that are all of freshwater origin. And it is usually in freshwater ironstone or in shaley coal beds that fish remains, and frequently also plants, occur. He then refers to dark shale that contains large "bullions" which were flattened in shape, and were very fossiliferous. These bullions enclosed Pterinopecten papyraceus, Dimorphoceros gilbertsoni, Glyphioceras diadema, Listracanthus wardi, and Acanthodes wardi. Now the latter is a fish that invariably is reported with freshwater crustaceans, ganoids, plant remains etc. But Hind in the latter part of Stobb's paper says that "Listracanthus is associated with a marine fauna," and later (p. 529) gives a list of fourteen freshwater fish remains from these bullions of the supposed marine bed. We would suggest that the bullions are secondary inclusions from a freshwater bed deposited alongside marine organisms.

As bearing on the above questions, as well as on the group of fishes already studied, and others to be studied in 
future pages, we may next refer to Professor John Young's "Catalogue of the Western Scottish Fossils" (III). On p. 60 he says, "the remains of fishes extend from the lower beds of the Calciferous series, up through the several divisions of the Limestone strata, Middle Coal and Ironstone, Millstone Grit, and Upper Coal Measures. Two groups are represented viz. lepidoganoids and plagiostomous fishes. The former are chiefly confined to the freshwater or brakish water strata, being very rarely met with in any of the beds of purely marine origin. The remains of plagiostomous fishes, on the other hand, are found in both marine and freshwater strata, certain genera being peculiar to each of these groups."

He then gives an extensive list that includes upwards of sixty elasmobranchs, but of these nearly half are from marine limestone rocks. All of the others are from coal, from shale associated with coal, or from blackband ironstone, which, by its fossils the present writer has proved to be usually associated with plant remains, eurypterids, etc., while marine organisms are absent. Young fortunately quotes extensively ecological associations of animals, in the latter part of his paper, from which we may extract the following :

(I) From the roof shale of the Palace Craig ironstone he gives the amphibians Pholaderpeton sp. Pteroplax cornuta, Anthracosaurus russelli and Loxomma allmanni, the freshwater crustacean Anthrapalaemon grossartii, the mollusc Anthracosia, several species of Lepidostrobus cones, the elasmobranch fishes Acanthodes wardi, Gyracanthus formosus, G. tuberculatus, Ctenacanthus major, Diplodus gibbosus, and Cladodus; the dipnoans Ctenodus cristatus and C. tuberculatus; the crossopterygians Strepsodus sauroides, Megalichthys hibberti, $M$. coccolepis and $M$. rugosus. Here, therefore, a goodly list of fishes is directly associated with amphibians that cannot tolerate saltwater, as well as with many other freshwater types.

(2) In Broadstone beds S. E. of Beith he describes a lot of typically marine organisms, but gives with them the elasmobranchs Psammodus rugosus, Ctenoptychius serratus, 
Tomodus convexus, Deltoptychius acutus, Cladodus mirabilis, Helodus and Petalodus.

(3) In the roof of Splint Coal at Newmains (p. 92) occurred: of elasmobranchs Gyracanthus, Ctenacanthus, Orthacanthus cylindricus, Climaxodus (Janassa) imbricatus; the dipnoans Citenodus imbricatus and C. tuberculatus with various other fish remains; while a light colored shale just above contained Sigillaria.

(4) Near Newtown (p. 88) the roof-shale of the Splint coal has yielded Orthacanthus cylindricus, Diplodus gibbosus, Ctenacanthus brevis and C. major.

The first, third and fourth are freshwater, the second is marine. Many other equally instructive combinations are given.

We would refer next to two papers (204:32:332; $35: \mathrm{I} 8 \mathrm{I}$ ) by $\mathrm{J}$. W. Davis in which is described "a thin stratum of shale known to extend over an area of several miles, immediately above the Better-bed Coal in the neighborhood of Clifton and Low Moor, S. E. of Halifax," and which varied from a quarter to three-eighth inch in thickness. It " is almost entirely composed of the fragmentary remains of fishes and labyrinthodonts." The following selachians are enumerated in the earlier paper, and all of them we would regard as freshwater, since they occur with labyrinthodont remains, also with freshwater ganoids, while the same fishes also occur in many localities always associated with plants, freshwater molluscs, etc.:

\section{Elasmobranchs.}

Gyracanthus formosus
Gyracanthus tuberculatus
Ctenacanthus hybodoides
Ctenacanthus sp.
Lepracanthus colei
Acanthodes wardi
Pleuracanthus laevissimus
Orthacanthus cylindricus
Diplodus gibbosus
Hoplonchus sp. nov.
Pleurodus rankinii
Pleurodus affinis
Helodus stwplex
Cladodus mirabilis (anad.)
Petalodus hastingsiae
Ctenoptychius apicalis

Gyracanthus formosus

Gyracanthus tuberculatus

Ctenacanthus hybodoides

Ctenacanthus sp.

Lepracanthus colei

Acanthodes wardi

Pleuracanthus laevissimus

Orthacanthus cylindricus

Diplodus gibbosus

Plonchus sp. nov.

Pleurodus affinis

Helodus siziplex

Petalodus hastingsiae

Ctenoptychius apicalis
Ganoids.
Megalichthys hibberti
Holoptychius sauroides
Strepsodus sauroides
Acrolepis sp.
Platysomus sp. rare.
Acanthodopsis.egertoni
Gyrolepis rankinii
Palaeoniscus sp.
Coelacanthus lepturus
Ctenodus ellipticus
Ctenodus tuberculatus 
Mention might also be made of another paper by $\mathrm{J}$. W. Davis on the English Yoredale rocks (205:40:614) and of three by $T$. Atthey (206: I:77, 266;9:249) on coal seams at Newsham, as giving added detail.

But for an exhaustive and correct interpretation of details, the writer next presents statistics regarding two lists of fishes, namely that of J. W. Davis "On the Fossil Fishes of the Carboniferous Limestone Series of Great Britain" (207) and the Catalogue list of Prof. Young already cited. Davis gives about one hundred and sixty marine species of selachian and cestraciont fish, but naturally this number would be considerably reduced did we know the true relation of teeth and fin-spines to each other. He also records six species of what he calls "ganoids," but three of these have been shown to be elasmobranchs, while the other three according to Woodward are unidentifiable. The writer reckons that in Young's list are thirty species of elasmobranch and thirty species of dipnoans and ganoids from purely freshwater strata, also thirty species of the former group that are marine. But comparative study of the thirty elasmobranchs reveals that while twelve of these are always and only recorded from freshwater strata, the remaining nineteen species may come from freshwater and saltwater strata alike, or are in other words anadromous.*

The most striking difference in the two lists is the practically total absence of ganoids from Davis's catalogue. The explanation of this difference is that all of the ganoids and labyrinthodonts in Young's list are freshwater, and the ganoids have remained so throughout their entire history, except for a few derivative side-lines to be traced later, and which in the sea became a dwindling factor. The elasmobranchs of Young's list, on the other hand, include both freshwater, anadromous, and marine elasmobranch types. Thus of the first we might cite species like Pleuracanthus (Diplodus) gibbosus, P. (Orthacanthus) cylindricus, Gyracanthus formosus, Pleuroplax (Pleurodus) affinis, $P$. rankini, Tristychius arcuatus, Cladodus parvus and others. But species like Cladodus conicus, C. laevis,

* The writer here uses this word-possibly in too wide or vague a sense-to indicate any fish that can live in, and migrate from, either freshwater or marine environment. 
Chomatodts of four species, Ctenoptychius (Harpacodus) dentatus and others are, like not a few fish of the present day, anadromous in habit. Accordingly, in the writer's subjoined classification of Young's list, he has not only given the marine fishes that were derived from freshwater ancestry, and those-wholly absent from Davis' list-that remained freshwater, he has also indicated by the prefix an the types that were evidently anadromous, and so are often included in both lists.

\section{LIST OF FISHES FROM YOUNG'S "CATALOGUE OF THE WESTERN SCOTTISH FOSSILS."}

Arranged According to Natural Habitat.

The prefix an indicates that the species seems to have been anadromous in habitat.

Freshwater.

(I) ELASMOBRANCHII an Chomatodus cinctus an Chomatodus clavatus an Chomatodus linearis an Chomatodus obliquus an Cladodus conicus an Cladodus laevis Cladodus parvus an Ctenacanthus brevis Ctenacanthus hybodoides an Ctenacanthus major an Ctenacanthus tenuistriatus Ctenoptychius (Petalodus) apicalis

an Ctenoptychius dentatus Ctenoptychius pectinatus Diplodus (Pleuracanthus) gibbosus

Gyracanthus formosus

an Helodus lacvissimus Helodus simplex

an Leptacanthus jenkinsoni

an Leptacanthus junceus Orthacanthus cylindricus Pleurodus affinis Pleurodus rankinei Petalodus apicalis Tristychius arcuatus Acanthodes sulcatus Acanthodes reardi Poecilodus angustus an Poecilodus obliquus Janassa imbricata

(2) GanoldeI

Acrolepis sp.

Amphicentrum granulosum Asterolepis sp.

Coelacanthus lepturus

Cycloptychius sp.

Dendroptychius sp.

Eurynotus crenatus

Gyrolepis rankinei

Megalichthys? coccolepis

Megalichthys hibberti

Megalichthys? rugosus

Mesolepis sp.

Palaeoniscus duvernoyi

Palaeoniscus egertoni

Palaeoniscus monensis

Palaeoniscus ornatissimus

Palaeoniscus robisoni

Palaeoniscus striolatus

Palaeoniscus wardi

Platysomus declivus

Platysomus parvulus

Pygopterus sp.

Rhizodopsis granulatus

Rhizodus hibberti

Rhizodus portlocki

Strepsodus sauroides

(3) Dipnoi

Ctenodus cristatus

Ctenodus imbricatus

Ctenodus tuberculatus

Uronemus magnus 
Marine.

Carcharopsis prototypus

Cladodus milleri

Cladodus mirabilis

Cladodus striatus

Cochliodus (Deltoptychius)

Cochliodus acutus

Cochliodus compactus

Cochliodus contortus

Cochliodus magnus

Cochliodus (Xystrodus) striatus

Deltoptychius acutus

Ctenoptychius dentatus

Homacanthus microdus

Glossodus marginatus

Helodus denticulatus

Helodus didymus

Helodus mammillaris

Oracanthus milleri
Oracanthus minor

Orodus cinctus

Petrodus patelliformsi

Petalodus hastingsiae

Petalodus lobatus

Petalodus (Petalorhynchus) benniei

Petalodus (Petalorhynchus) psittacinus

Paecilodus aliformis

Paecilodus jonesii

Polyrhizodus pusillus

Polyrhizodus radicans

Psammodus porosus

Psammodus rugosus

Psephodus magnus

Physonemus sp.

In further explanation of the writer's classification of Young's list he would add that this was prepared by separating all those that were invariably reported from marine limestones, such as the North Mine, Kirkton, Peter's Hill, Broadstone, Dockra, Roughwood, Calderside, and Newfield from other deposits of freshwater origin like Rutherglen, New Mains, Carmylie, Barkip, etc., in which all of the fish remains lie side by side with carboniferous plants, Estheria, and labyrinthodont remains. The conclusion to be drawn is that during late Devonian or early Calciferous times an extensive migration of elasmobranch and chimaeroid fishes occurred from the lakes, swamps, and rivers, into the shore margins and seas of those times. In the process, and doubtless due in no small measure to changed environment of waters, food, or defence and offence, as well as other agents, many new species and in time genera evolved there, as the list of Davis in particular strongly suggests. Alike the Hybodontidae, the Orodontidae, the Cochliodontidae, the specialized Psammodontidae and the Petalodontidae seem all to have participated in the movement seaward, while so far as present information goes the Psammodontidae evolved as a purely marine derivative group, from a still more ancient stock of anadromous, and before that of freshwater ancestry.

From the Lower Carboniferous upward even to the Permian in some cases, the large group of the Petalodonti- 
dae is met with. The species of it may be said to be known only by their teeth, except in one or two rare cases, where parts of the head and the shagreen of the skin are preserved. From the usual absence of fin-spines beside the teeth, they suggest possible derivation from a soft-finned ancestry like the Cladodontidae. The richest in species of the genera are-if identifications of teeth alone are to be trusted-Janassa, Petalodus, Ctenoptychius and Polyrhizodus.

Janassa is a genus that extends from Lower Carboniferous into Permian beds, and has been specially recorded from the freshwater Permian deposit of Britain known as the Marl Slate, also from the probably contemporaneous Kupferschiefer of Germany and the "Boghead" of France. Abundant "fern" and coniferous impressions, labyrinthodont imprints, and numerous fishes belonging to Janassa, Platysomus gibbosus (Fig. 45), Palaeoniscus sp. Acanthodes, Pleuracanthus (Fig. 44) and Amblypterus, also various as yet freshwater reptiles, lived side by side or decayed together. Janassa bituminosa is a typical freshwater fish of the Upper Permian, while decomposition and destructive chemical alteration of the oils from it and others above noted, doubtless gave rise to the highly bituminous rock in which they are of ten embedded.

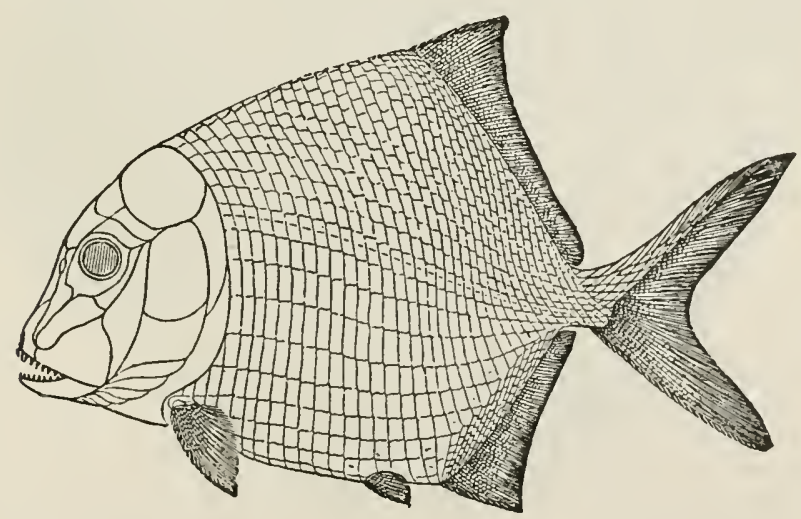

Fig. 45. Platysomus gibbosus, a freshwater chondrostean ganoid from the Kupferschiefer and Marl Slate rocks of Permian age in Central Europe. About one-fourth natural size. (Restored by Traquair). 
Another palaeozoic elasmobranch group is that of the Psammodontidae, the genera of which seem to have passed wholly into a marine habitat, and are met with throughout the Carboniferous Limestone rocks, but they became rare or died out while the Coal Measures were being deposited. In shape and dentition they seem somewhat to have resembled the Pycnodonts of much later date and of different ancestry. But there seem here to be two interesting cases of parallelism in evolution. For starting from Eurynotus (Fig. I6, p. I39) and even more primitive types that are of chondrostean descent, a gradual condensation of the body; modification of the dorsal and ventral fins; reduction in size of the paired fins, and of the mouth; rounding, shortening, and massing of the teeth till their almost complete absorption in Cheirodus, are continuous stages in a process of condensing specialization observed from Eurynotus through Mesolepis (Fig. 46) and Platysomus (Fig. 45 ) to Cheirodus. Similarly starting from Lepidotus and

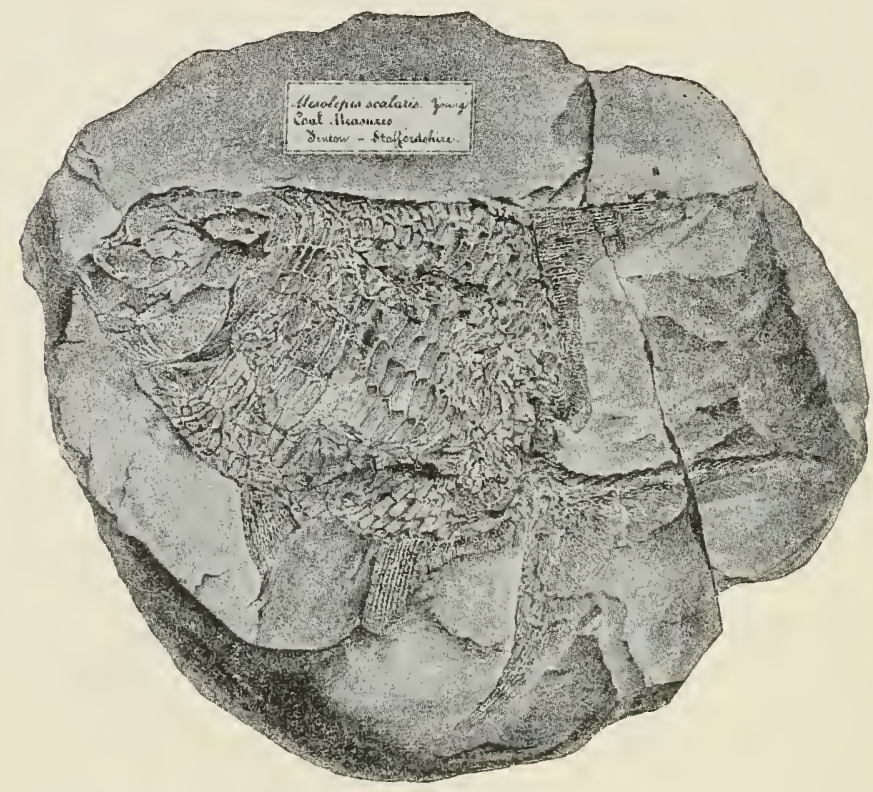

FIG 46. Mesolepis scalaris, a chondrostean fish that is intermeditate between Eurynotus and Platysomus. From the Coal Measures of central England. One-half natural size. (Reproduced from Traquair). 
more primitive forms, that are of holostean descent, gradual transition is made through Cleithrolepis and Dapedius to Microdon and Mesodon, thence to Coelodus and Palaeobalistum. A like parellelism is shown by several groups of the bony fishes.

In regard to American palaeozoic elasmobranchs, Newberry seems clearly to have reached the conclusion-in marked contrast to that formed by him about Devonian elasmobranchs and more ancient fishes-that not a few of these originated as, and remained as, freshwater inhabitants. Some of them also must have been large and striking forms. Speaking of the Ohio Coal strata ( 86 : 2 I I) he says: "The Linton locality is specially interesting and instructive. It has already yielded more than twenty species of fishes, and nearly forty species of aquatic amphibians, all inhabitants of the same body of water. These are found in a thin stratum of cannel which, over a limited area, underlies a thick bed of cubical coal (No. 6 of the Ohio Reports), of which the place is near the top of the Lower Coal Measures," and later he adds, "we have evidence that the great marsh in which the peat accumulated that formed Coal No. 6 was for a time a lake or lagoon, inhabited by the fishes and amphibians to which I have referred."

Probably the most striking genus is that named Edestus by Leidy, and which is found in the Mississippi-Illinois coal fields. It was minutely studied by Miss Hitchcock, Leidy, Newberry, Hussakof, but was properly interpreted by Eastman ( $2 O S: 2 S I$ ). The remains consist of bony jawplates that bear often large serrated teeth. These indicate the existence of a large selachian fish in the eastern American Coal-fields that must have been $8 \mathrm{ft}$. to $\mathrm{Io} \mathrm{ft}$. in length. They occur in a bituminous shale that "is apparently a freshwater sediment," while the associated fossils include a large number of fish teeth, some of which belong to carnivorous sharks, as Cladodus and Petalodus; and others with crushing teeth which probably fed on hardshelled molluscs, as Orodus, Orthopleurodus etc. "The habitat of Edestus would therefore seem to have been somewhat similar to that of Rhizodus and Megalichthys, 
of which the teeth, scales, etc. are so common in the coal shales and cannels of England and Scotland."

But as with the European fauna so here, an abundant migration seaward of freshwater species, and evolution of many marine types subsequently took place. A rich locality for these fossils is the North Central or Illinois Coal Field, from the marine Carboniferous Limestone of which Newberry, Worthen and St. John have described upwards of 300 species." ( $98: 209 ; \mathrm{v} \cdot 4, \mathrm{v} \cdot 7)$. As with the list of Davis in comparison with that of Young, so here, certain of the genera were purely freshwater, others were marine, while not a few were anadromous. If we may safely judge from those that are associated with chondrostean and ganoid fishes, also with amphibians, the number of freshwater species amounts to about thirty, while anadromous ones are still more abundant. So for the American as for the European land area, an extensive seaward migration of elasmobranchs had evidently taken place in late Devonian or early Mississippian time, and many new species as well as genera subsequently evolved as anadromous or as wholly marine forms.

In regard to the succession of strata that contain these fishes, the lowermost or Bedford Shale, that rests on the freshwater Cleveland Shale, is largely, possibly wholly, marine. The Berea Grit in its lower part is also, but it becomes, in the Chagrin Falls region freshwater, and contains abundant remains of the equisetoid Annularia, of the freshwater chondrostean fishes Palaeoniscus and Ctenacanthus. But we yet await, for American strata as a whole, lists that may as accurately determine the distribution of elasmobranchs, as do those of Davis, Young, Traquair, Atthey and others for European strata.

Reviewing now the above, and many other records which cannot here be dealt with, the writer would conclude that in late Old Red or Devonian, and specially in early Carboniferous time, primitive elasmobranchs attained to enormous development, alike in species and individuals, in freshwater lakes, rivers, and swamps. Much of the literature-we might well say nearly all of it-of the past has accepted it, without proper proof, that they were marine, 
but a critical comparison of the associated plants, animals, and strata, clearly demonstrates that the elasmobranchs originated as, and in considerable degree remained, a freshwater group throughout the above epochs. The frequent entire absence of any fish remains from typical marine strata that abound in brachiopods, pelecypods, cephalopods, and marine crustaceans, is a strong argument against the marine origin of fishes also. Their existence at first in freshwater only of Silurian, also of early and mid Devonian; their gradual spread seaward in anadromous manner during Calciferous or Mississippian time; and their rapid evolutionary expansion, in the Carboniferous Limestone and earlier Coal Measures periods, into the sea, constitute a sequence of events.

Numerous examples of Acanthodidae, Pleuracanthidae, Cladodontidae, Petalodontidae, Cochlidontidae, Cestraciontidae, and Ptychodontidae are so inextricably connected with undoubted freshwater forms, that the writer is compelled to accept the freshwater origin of the Elasmobranchii as a whole. But during late Devonian and Calciferous or Mississippian time some genera reached the sea, and as in nearly all such cases, for plants as well as animals ( $I: 324-4$ IO), they there multiplied abundantly and evolved numerous new types. The climax of evolution for the phylum, in palaeozoic time, was reached from the Carboniferous Limestone to near the close of the Coal Measures.

Combining the records of Woodward's Catalogue ( $\mathrm{V} . \mathrm{I}, 2$ ) with recent additions, and reckoning on a conservative basis, it appears that there were at least fifty-five genera that included about three hundred and sixty species. Of these about twenty genera, and close on one hundred species remained as freshwater or as anadromous species, the remainder became largely or wholly marine. The distribution of these over the world follows very closely that already cited for other groups. But in America the westward extension of the freshwater ones was carried to Illinois, Iowa, Missouri, and in a few cases even, if the records and localities are alike correct-to the coal strata of Nebraska and Kansas. 
After formation of the Coal Measure beds, some widespread agency evidently blotted out the elasmobranchs wholesale, for only five genera-and these all freshwaterAcanthodes, Pleuracanthus, Diplodus, Janassa, and Wodnika survived, though in greatly reduced number of species. But from the accounts of Fritsch, Kner, and Sauvage, the individuals of some species were occasionally very abundant. The remarkable feature however is that the destruction of fish-life was more pronounced on the sea than on land; so that of the true elasmobranchs named above the first four genera alone survived, while of the Cestracionts Wodnika is alone known to us. All five of these seem to have been wholly, or as with Diplodus in most of its species, mainly freshwater.

The question may well be asked then: Did a complete obliteration of marine, and largely also of freshwater, elasmobranch fish-life occur toward the close of the Carboniferous or in early Permian time? Such seems to have been true, so far as present exact records lead us, while as stated below, they alone persisted in inland lakes till later Jurassic times when a gradual reinvasion of the sea took place. The immigrant types then reintroduced have persisted in their more or less direct descendants, to our own day. This temporary destruction-almost to the disappearing point-of a large group like the elasmobranchs, that had not only multiplied extensively in freshwater, but had spread thence into the sea, is one of the most arresting facts in natural history. For the slow and very gradual reappearance of them, doubtless by fresh evolution from the few genera spared alive, in Jurassic and specially in Cretaceous strata, suggests that some sudden, cataclysmic, and wide physical change took place, that was most felt over the ocean, somewhat less over freshwater and land areas.

A paper directly bearing on the Permian elasmobranch fauna is that of M. E. Roche $(210: 9: 78$; not v.20 as quoted by Sauvage). In this he distinguishes three horizons at the base of the Permian bituminous schists of Autun. All are characterized by definite species of fish. In addition to typical freshwater crossopterygians and 
ganoids, the elasmobranchs Acanthodes and Pleuracanthus still persist in great abundance, and mixed with amphibian, reptilian and also plant remains.

In his "Fauna der Gaskohle" Fritsch gives many suggestive details regarding Pleuracanthus and the Acanthodii $(2 I I: 3: 48)$. To the latter group he adds the two new genera Traquairia and Protacanthodes, as well as describes small species of Acanthodes, on which, along with freshwater crustaceans like Estheria and Gampsonyx, Pleuracanthus largely fed. He consistently inclines to regard the entire assemblage of plant and animal organisms as being geologically of estuarine and brakish-water origin, but absolutely no reason exists for such a position, specially seeing that he mentions with them and describes amphibian remains.

While Pleuracanthus in several species was common over wide freshwater regions of North America in Carboniferous times, it also persisted there into the Permian, for Cope has recognized its remains, and under the names Diplodus and Didymodus he has described the teeth of it, from the Permian of East Illinois and Texas (2 I2: ( 1877 ) I92; (I884) 572). But a recent and valuable memoir is "The Permian Fishes of North America" by L. Hussakof $(2 I 3)$ in which Janassa, Pleuracanthus, Diacranodus, and Anodontacanthus are all treated of. He comments also on the absence of Acanthodes from the rich Texan beds, as compared with its presence in Europe, though he regards the fossiliferous strata as possibly correlative. The entire Permian fish series of North America is freshwater, and we shall have occasion later to refer to the dipnoan and ganoid inhabitants of it.

Of special interest geographically is Woodward's paper on the Hawkesbury fishes of Australia (2If). In this he describes Pleuracanthus parvidens from an extensive set of freshwater deposits, that also contained dipnoans, crossopterygians and chondrosteans. Says he "this typically upper palaeozoic shark has not hitherto been found in the southern hemisphere. It occurs in the Carboniferous and Lower Permian of Europe, and in the Coal Measures of North America. Identical teeth have also been discovered 
in the Upper Trias( Keuper) of England." The "finely preserved state shown by it and all of the others, indicates a sudden death and entombment in a volcanic dust-shower that gave rise to the 'dark indurated shale' in which all were found."

In continuing to trace the elasmobranchs upward through the geologic scale, an almost complete break occurs from the Mid Permian to the top of the Triassic formation. Few genera as such survived from the Permian into the Triassic, so far as we at present know. In the above quotation from Woodward it is suggested that possibly Pleuracanthus lingered on into Triassic time. The group however that persisted most directly was that of the Cestraciontidae or Port Jackson sharks. Not only so, if the view entertained by some be correct the abundant genera Orodus and Campodus of Carboniferous and Coal Measure strata -where they are known mainly by teeth-were continued upward into Mesozoic life, as the equally abundant genus Hybodus (Figs. 24, 25, p. 193). For in all three genera the teeth are practically alike, and the fin-spines closely agree. But these unfortunately are the only parts preserved. The above two Carboniferous genera are rarely freshwater in a few species, mainly they are marine. Hybodus probably was descended from one of the former, for it remained in freshwater.

Nearly allied, and often found in the same strata as Hybodus, are teeth and spines of Acrodus. Both show a wide distribution in freshwater across Central Europe up to the close of the Wealden period, though an entire absence from America, till Cretaceous times. But both occur in freshwater beds of the Bunter, Muschelkalk, Lettenkohle-where they are associated with the freshwater crustaceans Estheria mimuta, with Ceratodus and with the labyrinthodont, Mastodonsaurus-the Keuper, Rhaetic, Lower Lias, Stonesfield Slate, Lower Kimmeridgean, Purbeck and Wealden. But while Hybodus seems then to have become extinct, Acrodus seems meanwhile to have migrated, with other and recently evolved allies, into marine surroundings, and then to have expanded its range, during late Jurassic and specially Cretaceous times, into 
the seas of eastern North America, Brazil, and India at least.

Other Cestracionts, like Palaeobates, Palaeospinax, Strophodus, and Bdellodus, derived doubtless from modification and adaptation of freshwater palaeozoic forms that lived on in scant numbers, and as yet unknown to science, appear alongside or after the latter, and in the same beds. An abundant literature might be correlated and cited to prove equally the contemporaneous relation and the freshwater habitat of these, notably of Hybodus andAcrodus, the two commonest and most widely dispersed genera.

Thus L. Richardson, in describing the Rhaetic rocks of Monmouthshire $(215: 374)$ and of Glamorganshire (pp. 385,39 I) speaks of a bone bed in each, and says: "A fine piece of this fish-bed . . contained in great abundance, the teeth of Acrodus minimus, Gyrolepis alberti (?), Sargodon tomicus, and Lepidotus (?) less commonly of Hybodus minor and H. cloacinus." In subjacent beds he found Lycopodites and abundance of Estheria, as well as remains of the amphibian Mastodonsaurus. In a still later paper $\left(216: 3^{8} 5\right)$ he plots out inch by inch the strata of the Keuper, Rhaetic, and Lower Lias. In the Lower Rhaetic he describes a set of four marl deposits-the Sully beds-in which shells of the marine Ostraea, Avicula, and Pecten are mixed with Gyrolepis, Sargodon, and Acrodus. These suggest either that a constant land oscillation was proceeding, with a mixture of either living or dead marine and freshwater types, or the above shells were washed out and redeposited with the fishes. A thin layer of shale separated these from a five-inch bone bed made up of remains of Acrodus minimus, Saurichthys acuminatus, Sargodon tomicus, Hybodus minor, H. cloacinus and fragments of bone. Still higher up vertebrae of Plesiosaurus and Glyptolepis alberti were added.

In a paper by Brodie on the Upper Keuper (217:43: 540 ) he tells of finding together Palaeoniscus, Semionotus, remains of Cestraciont sharks, footprints of labyrinthodonts, plants like Voltzia and Carpolithus, also marls with Estheria. Wills and Smith, for the Upper Keuper of Central England, emphasize $(2 I 8: 461)$ a bone bed with 
290 Evolution and Distribution of Fishes FRESHWATER HABITAT

MARINE HABITAT

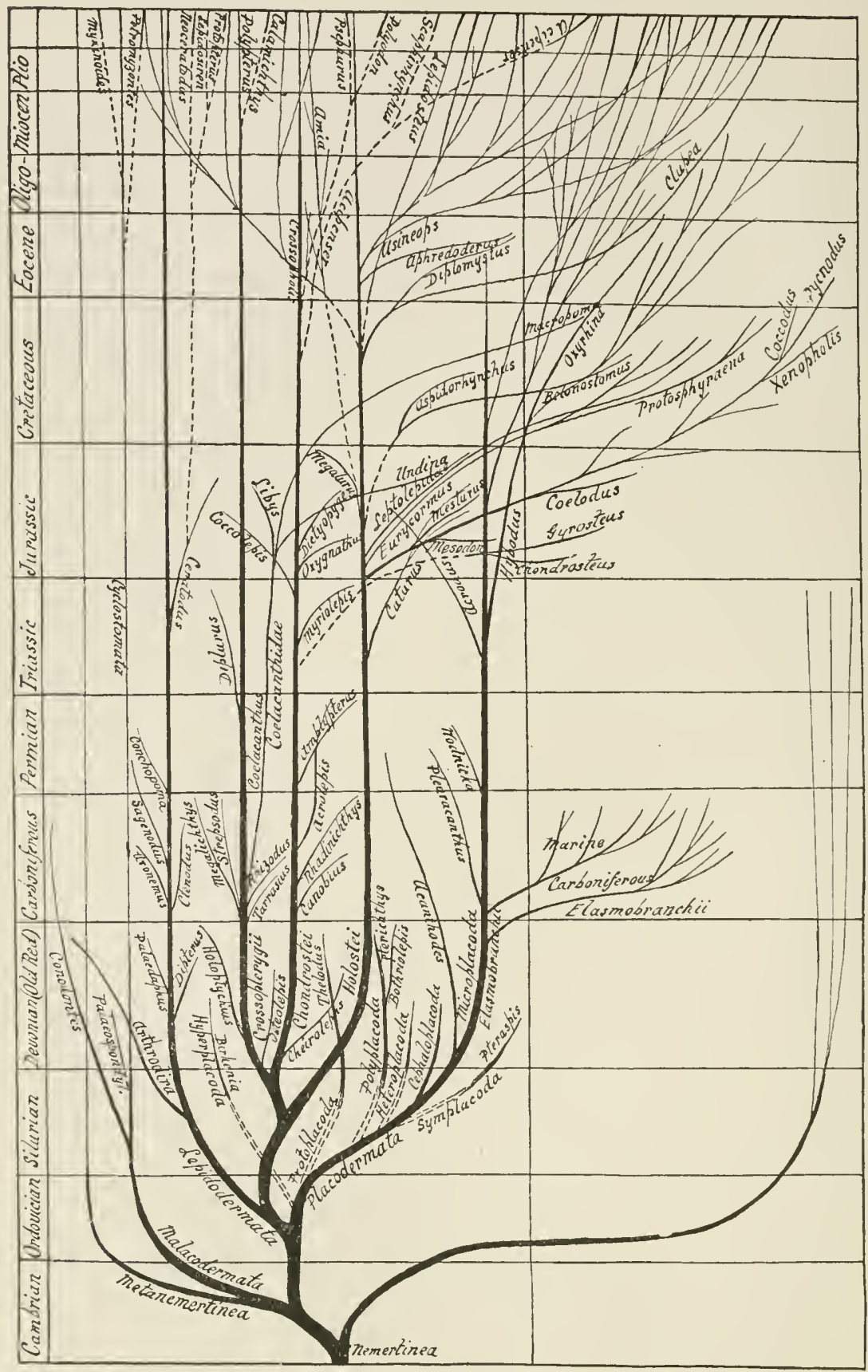

Fig. 47. Chart showing probable lines of ascent, distributional zones and relation to habitat, of important large groups or genera of fishes. 
Acrodus, Phoebodus, Ceratodus and Semionotus as well as Estheria minuta.

But increasing re-invasion of the sea by elasmobranchs took place during Rhaetic and Lower Jurassic times, till in Mid and late Jurassic marine rocks five families became prominent. These were the Notidanidae, Scyllidae or dogfishes, the Rhinidae or angel sharks, the Rhinobatidae or primitive rays, and two generic descendants of the cestracionts viz. Palaeospinax and Cestracion or Heterodontus.

A noteworthy feature of all of these groups is that they persist, in representative genera, down to our time. Furthermore all may be said to be marine. The question then arises as to the centre or region, and also the time, when the great elasmobranch phylum again became dominant and reestablished itself in the sea?

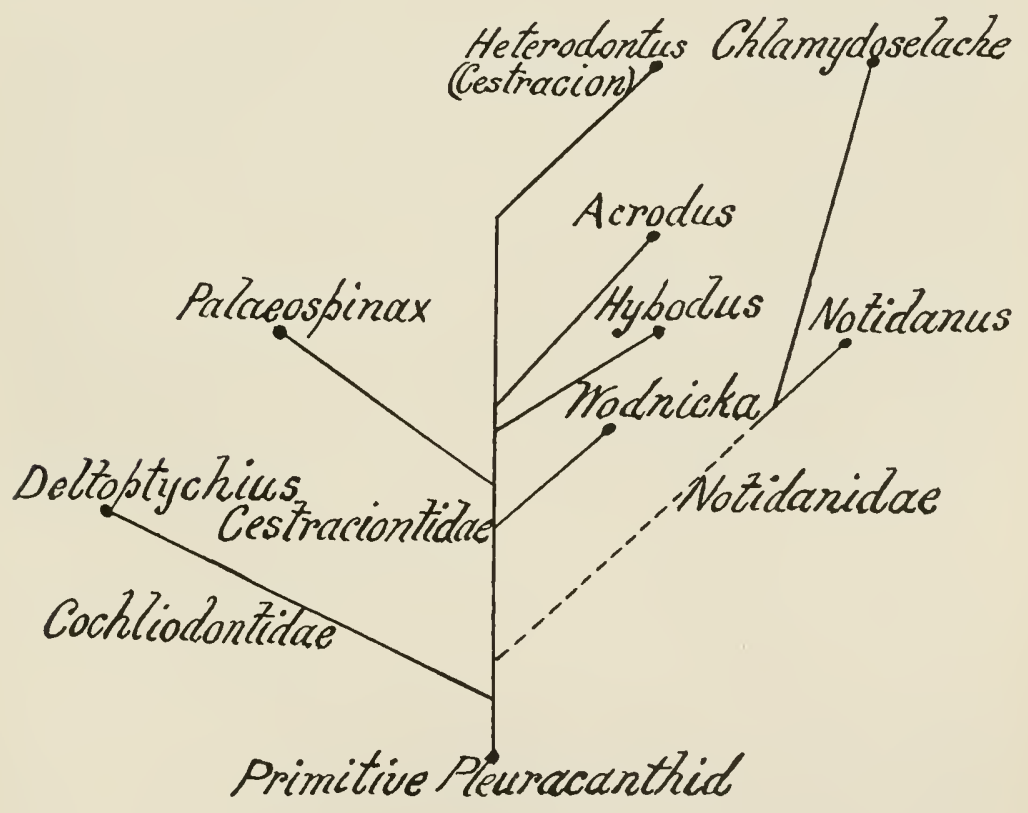

The writer believes that for the Cestracionts this can be fairly readily established. For the very frequent occurrence of Hybodus and Acrodus in freshwater strata from the Bunter and Muschelkalk, upward to the Wealden as 
already shown, is undoubted. So in review it may be said that the probable evolution of the Cestracionts was somewhat as follows.

Some primitive type of the Pleuracanthidae seems to have evolved, during early Carboniferous times, at least three divergent types, one of which the Cochliodontidae, became extinct by close of that period. Another, but of which no direct trace exists till the Jurassic period, evolved into the Notidanidae. A third, the Cestraciontidae, probably originated during Carboniferous times but is only known by characteristic teeth named Orodus and Campodus. But from the former or a near ally, and during the Permo-Triassic originated Wodnika and later Hybodus (Fig. 24, p. 193). Still later Acrodus and Synechodus, the palatal teeth of which are at times found fossil in mass, continued the group through the Cretaceous period. Descendants from some such types again originated the living though now rare species of Port Jackson sharks (Heterodontus or Cestracion). The above might be represented diagrammatically as in the chart on the preceding page, but for a different set of views and for diagram of a different mode of evolution the reader is referred to Campbell Brown's suggestive paper (2I9).

The chart that forms Figure 47 (p. 290) will be useful, as illustrating diagrammatically the probable lines of evolutionary ascent, and the habitats of fishes already dealt with, or that will be considered later. 


\section{CHAPTER $\mathrm{X}$.}

\section{The Evolution of Fishes.}

\section{The Dipneusti and Crossopterygil.}

The Dipneusti as a group is, and has been, probably the most solid, uniform, and least variable one in the entire range of fish-life. For from first appearance in Devonian rocks, up to the present day when three representative genera exist in widely apart regions of the world, leading types of the group have shown a unity of characters which is in marked contrast with what is seen in other groups. Accordingly Kerr $(43 ; 44)$ has well emphasized the numerous primitive characters observed in living genera.

But the few now surviving seem to be a lingering rem. nant of what was during Devonian or Old Red time, a large, widely distributed, and abundant group, that has left great accumulations of remains, either as entire animals, as bony cephalic or trunk plates, or as teeth with or without the dental bones. Unfortunately, of the soft parts we know practically nothing in the fossil forms, though from the standpoint of comparative morphology, such would have shed light on many important questions.

As we hope to prove in the subsequent context, all evidently developed in extensive freshwater areas, that must have been more or less in continuous relation, so as to permit gradual distribution of the evolving species from Russia and northern North America of the Atlantis continent, to Africa, India and Australia of the Gondwana continent, as well as to South America, by the time of the late Permian or early Triassic.

But in considering the evolution and gradual distribution of the entire group in widest relation, some recent leading ichthyologists, and notably Eastman, have given a much wider signficance to it, than was earlier done. For Eastman brings together weighty arguments in favor of uniting, with the more typical and long-lived group of the Dipneusti, that of the Arthrodira, which are almost wholly confined to Devonian rocks. He has developed his views 
fully in Memoirs of the geological surveys for New York (89:93) and for Iowa (198:158) respectively. These are a continuation of two still earlier papers (222: I3 I ; 223:I). He there inclines to divide the group into three main lines of descent. But so far as the writer can judge, he would incline to accept two only, a scaleless or arthrodiran, and a cycloid-scaled or dipnoan group division.

As to first origin of the groups, the view that they originated in the late Silurian period, as a type that combined characters of Birkenia and of related primitive fishes, with those of some primitive members of the Crossopterygii has much in its favor. If the calcified plates described by Barrande as Coccosteus and Homosteus are correctly diagnosed then the group has left remains in the Silurian of Northern Central Europe. But in Lower Old Red strata it had already split up into two well-marked divisions the scaleless or arthrodiran and the scaled or dipnoan lines. As representatives of the former all became extinct, so far as we know, during Old Red times, they may first claim attention.

In freshwater lakes of the Russian, German, and Scotch areas, abundant-at times teeming-remains of Coccosteus (Fig. 9d. p. I I 9), Brachydirus, Phlyctaenaspis, and Chelyophorus lived, and now cover with their remains the strata then deposited. This is specially true for Coccosteus minor of the Caithness rocks. This species varied from 3 to 18 inches in length; and in the absence of scales, in the rudimentary pectoral fins, in the persistent notochord and in other characters, a primitive condition is indicated. But the complex nature of the cranial, and the post-cranial plates, suggests cumbrous defensive specialization as in the "ostracoderms" of the same age already studied. Extension of Coccosteus and of Phlyctaenaspis westward into the Canadian and eastern United States regions, seems later to have been effected, so that the former has been described by Newberry from the freshwater Sandusky or Delaware strata, that are of Mid-Devonian age. But when he says (224:34) "if sought for in the shore and offshore deposits of the Chemung, Catskill, and Vespertine of Pennsylvania and New York, the remains of Coccosteus 
will be met with in greater abundance than anywhere in the Corniferous Limestone" he mistakes the environal relation of all of the rocks, as already indicated (p. I29).

In close succession, however, to the above appeared those increasingly gigantic but related forms which, from North Europe, have been described as Homosteus and Heterosteus. From there as well as from the Delaware limestone strata of North America evolved others that have been named Macropetalichthys. From the Delaware strata also, still others reached a climax of size, of cumbrous defensive specialization, and of relative abundance, so that they have been well named Dinichthys and Titanichthys. In some species of the last genus, the head must have been about three feet across, and the entire animal from ten to twelve ieet in length.

Speaking of Coccosteus and Dinichthys, Eastman says in the Journal of Geology (8.p.I88) "The two genera are most intimately related, and though their terminal members are sufficiently well characterized, they are connected by insensible gradations. The typical species of Dinichthys represent unquestionably a later and more advanced stage of specialization than that with which we are familiar in Coccosteus decipiens for example. But between these extremes lies a host of intermediate forms. Evidience of specialization in forms like $D$. herzeri, $D$. terrelli etc. is strikingly apparent." The subject is more fully discussed by him also in a later work (225: I I 8-I39).

As to the distribution, the European genera are all found in rocks that during the past quarter century have been accepted as freshwater in origin. The eastern American genera and species range from the Delaware up into the highest division or Cleveland shale, and were all of freshwater habitat. That considerable expanses of more or less connected freshwater-either lakes, swamps, or rivers-may have flooded large tracts of country at times, and so gave ample opportunity for growth, variations, and increasingly wide distribution of Dinichthys, is clearly proved. Thus $D$. pustulosus and $D$. tuberculatus have been recorded from western New York, southward to Kentucky, and westward to Iowa, Illinois, and Wisconsin. This need 
not cause us to presuppose a large lake of such extent, nor even a contemporaneous freshwater connection. But one must accept that over this region at the same or at successive times, wide freshwater connections existed, that were taken advantage of in the progressive migrations of these fishes.

Though no great importance need meanwhile be attached to the identification by Newberry of specimens from near Liege, Belgium, which he considered to be specifically the same as his Dinichthy's tuberculatus, such a view at least suggests much for future verification geographically.

The geologic zones in which the American arthrodires occur extend from the Delaware limestone-not from the marine Columbus proper as some have asserted-up through the Huron and Cleveland shales (Fig. 43, p. 269), or their equivalents in surrounding states, such as the Chemung and Catskills of Pennsylvania and New York. As already pointed out these are (p. 268) freshwater deposits, and if at times intercalated strata show marine organisms the arthrodires are there conspicuous by their absence. But such a record as "Arthrodire fragments, Encrinal limestone (Hamilton) ; Eighteen mile creek, New York" could readily be explained as a washout by the sea of some freshwater strata, and succeeding redeposits of the fragments in that sea alongside marine shore organisms.

The climax in size, abundance, and variety of species was reached in the top zone or Cleveland Shale of Ohio, and the Genesee-Portage shale of New York, both black bituminous shales that have yielded abundant freshwater elasmobranch fishes, true dipnoans and ganoids, but which is entirely destitute of any assemblage of marine organisms. The continuation westward of these beds into Iowa and Wisconsin greatly extends the range of the Arthrodires, but also raises important environal questions. Thus in some of the earlier volumes of the Iowa Geological Survey it is repeatedly stated that the abundant though broken and rounded teeth and bones that make up a brecciaconglomerate from three inches to three feet in thickness belongs to the Cedar Creek formation, and the statement is also reiterated that there are, mixed with the fish remains, 
such marine organisms as Stromatopora. Accordingly Eastman states that Ptyctodus, Rhynchodus, species of Dinichthys and Dipterus were found in "Cedar Valley Limestone, Iowa."

But more careful and extended study of these beds by J. A. Udden shows that the Cedar Creek limestone is a marine formation in its lithologic, its organismal, and its stratigraphic continuity. An evident break then occurred in deposit, due to elevation and succeeding denudation of land. Next a thin seam of black bituminous material was laid down neatly on the abraded irregular surface of the Cedar Valley rocks. This was succeeded by a greenish argillaceous dolomite, that formed the fish conglomerate, while this again passed up into a greenish gray shale with fish teeth and "impressions of vegetable tissue." This again was succeeded by a Lingula-limestone, and it by still higher beds of marine character. These Udden calls collectively the "Sweetland Creek Beds." Though only a suggestion, the writer would propose: that the Cedar Creek Beds represent the Erian of Ohio rocks; that after deposition of them a sudden upheaval of land took place, and denudation of it set in. By subsequent volcanic agency the land became covered by freshwater, a multitude of freshwater chimaeroids-Rhynchodus and Ptyctodus-as well as arthrodires and dipnoans, were later destroyed, and while the decaying carcases rotted for a few weeks till teeth and bones were set free, all were entombed in a volcanic dust that formed the "greenish stony argillaceous dolomite" which became the inorganic matrix.

All of the above freshwater deposits might represent a thinned-out western representative of the Cleveland shale, while, the entire series, from the lowermost beds of the Cedar Creek limestone to the marine summit series of the "Sweetland Creek Beds" constitute what some geologists have united as the "Hamilton Group." So instead of the apparent anomaly of finding arthrodires and marine organisms in mixed organic relation, the above beds, when accurately interpreted, form a welcome verification of the writer's fundamental thesis. Recent complete lists of North American devonian arthrodires and their stratigra- 
phical positions, are given by Eastman for Iowa ( 198 275-290).

The higher Dipneusti or lung fishes have shown a surprising organic continuity, and fundamental similarity of structure, from Lower Old Red to present times. Like the Arthrodira, they developed as a purely freshwater series, and they have continued to occupy this medium, in all their extensive migrations and modifications, through the many millions of years of their history. Eastman has compared his own and Dollo's views as to their phylogeny and relationship (op. cit. p. 208).

The oldest known genus, Dipterus, is represented by two species from the freshwater Lower Old Red rocks of N. Scotland. A species (Fig.9c, p. I I9)-D. Valenciennesii -is of ten extremely abundant in fairly large or even perfect specimens from the base to the top of the series. Other species have been described from the Devonian of Russia. But a striking difference is that the latter are represented only by isolated teeth or dental plates. This suggests that the Scottish specimens were suddenly killed and very quickly dried, to be later covered by mud; or they were quickly sealed up under water by some volcanic ash-deposit, while those from Russia evidently underwent prolonged maceration, and after the hard parts had separated from the decayed mass, they settled in some lake or river bottom.

Representatives of the genus must steadily have spread abroad from the northern European centre of evolution, and had reached the eastern American area in early Upper Devonian times. For from the freshwater Chemung of Pennsylvania, from the nearly or quite contemporaneous Catskill of New York, and even from the Cedar Creek and State Quarry beds of Illinois and Iowa, remains of species of Dipterus have been secured. But like specimens from Russia, they are only isolated hard parts.

Meanwhile, alike in its ancestral region as in the West, the genus was splitting up and evolving into others that departed more or less from the primitive type. So arose Phaneropleuron (Fig. x 2,p.125) in the Scottish Canadian region of the Upper Devonian, and Ctenodus of the Upper Devonian and Calciferous Sandstone of America and 
Britain respectively. But alongside the latter in the Old and New World, evolved the still very imperfectly known genus Palaedaphus, that for size seems to have rivalled some of the bulky arthrodires.

As one passes from the Upper Old Red or Devonian to the Calciferous of Scotland, the genera Uronemus and Ctenodus become prominent, while the allied but more ancient Dipterus and Phaneropleuron disappear.

But meanwhile a wide invasion of Dipnoans into the Australian section of the Gondwana continent had been effected. For while Newberry described a dipnoan jawbone from the freshwater Chemung of America as Ganorhynchus beecheri, a closely similar object from the freshwater Devonian of New South Wales, has been named G. siissmilchii. Further while Ctenodus was still persisting in the Carboniferous of the Europeo-American area, it reached Australia as $C$. brericeps, that was described by Woodward from Victoria. Still later this genus gave off an allied line, Sagenodus, that seems to have been coexistent, over a large part of the world, with the primitive elasmobranch, Pleuracanthus, not only in Carboniferous, but up even into Permian time. For species typical of both formations extend from Eastern America through $\mathrm{N}$. Europe southward into Australia.

Once established in Australian lakes and swampy river stretches, the above genera were later replaced by Gosfordia of the Permo-Triassic, and it in turn by Ceratodus during the early Jurassic, while the existing genus Neoceratodus is a fairly direct descendant of the last. Woodward, in commenting on this remarkable southern continuity of the Dipnoans (2r4:27), says: "It is thus clear that Dipnoi have always lived in the Australian region, and there is no reason why Ceratodus itself (? Neoceratodus) may not have evolved there." If one were to add after "region" in the above quotation, the phrase "since late Devonian time" the statement would be appropriate, but the existence of Dipterus in the lowest Old Red Rocks of Europe, possibly even the extension backward of dipnoans into the Upper Silurian of Bohemia as Gompholepis and Dipnoites strongly indicate that primitive evolution of Dipneusti may 
have been effected over the Russo-Scottish area, and that they spread outward, during succeeding epochs, as will be further traced below, over nearly the entire earth.

The genus Ceratodus continued the succession above hinted at. For while Sagenodus still lingered on in the Permian and Permo-Triassic, from Illinois and Texas eastward through Bohemia and Russia to Australia, species of the former genus were rapidly spreading over an even more extensive area. For the highly resistant dental plates and denticles of Ceratodus have been found in the freshwater beds of the Upper Muschelkalk and superincumbent Lettenkohle-Keuper of Central Germany and of England. Others however have been found in the South African Stormberg rocks of Triassic age; in probably contemporaneous rocks of the Kota-Maleri beds of India (226:300); and in the Hawkesbury beds of Australia. Remains of the genus in the Rhaetic of England and Germany; in the Stonesfield Slate of Central England; and in the Jurassic from Colorado on the west to Victoria in Australia on the east, demonstrate its extensive generic range.

But a suggestive theoretical proposition deserves now to be made. As is well known the only living genera beside Neoceratodus of Australia is Lepidosiren paradoxa of the Amazon and Paraguay river regions, also Protopterus whose three species extend over a great part of central Africa. The common and fundamental characters of all three existing genera, but at the same time the subdivisional differences of Neoceratodus as compared with the other two-that are strongly emphasized by Eastman (89:9399) - would seem to indicate that at an early period geologically a common lepidosirenid ancestor to Gosfordia, Lepidosiren, and Protopterus may have spread westward from Australia. This could well occur along the Gondwana continental line, during Jurassic and early Cretaceous times, when many similar migrations of plants and animals took place.

The existing distribution of the three species of Protopterus in Africa is fully 2000 miles lengthwise by 3,500 miles in greatest width, while it is quite possible that in Eocene-Miocene ages the range may have been considerably 
greater. Further of the three species now alive Boulenger has shown $(227: 37-42)$ that $P$. dolloi which extends over the lower reaches of the Congo in Africa, shows nearest affinity to Lepidosiren, which is a highly modified type of the group. Such suggests that Lepidosiren was possibly not derived from migration southward of a North American type, but is the specialized end-member of a series that migrated westward from an ancient Australian habitat.

Ceratodus seems to have lingered on in North America till the close of the Cretaceous or early Eocene epoch. For from the Laramie beds, that have been variously interpreted as Upper Cretaceous or Lower Eocene, Cope has described some rather imperfect tooth-plates under two specific names. Then from New South Wales, teeth that were found in Tertiary alluvial beds indicate that while the more modified Neoceratodus was evolving from the older genus in Queensland, Ceratodus itself was nearing extinction.

In review then it appears that the arthrodire-dipnoan phylum of fishes evolved in freshwaters of Old Red or even of late Silurian age, and that the focus of evolution was located in lakes or rivers of North-Central Europe. Thence a more or less continuous extension westward to IllinoisIowa, and southward to Texas, took place before latest Devonian time. Then there had evolved those clumsy forms the sub-group of arthrodires in which the scales became absorbed-as has often happened amongst tribes of higher fishes. These ranged from Europe to Central North America, but attained a climax of defensive specialization though ungainly awkwardness in Dinichthys and Titanichthy's of the Upper Devonian in North America. But the smaller and more active scaled dipnoans reached, probably by a Turkestan-Indian line of passage, the eastern or Australian part of Gondwana by the close of devonian days, and there permanently persisted in descendant representatives. Outliers of the latter floated westward at a later period into African Gondwana, over the larger part of which they are now spread. From the most specialized of the three African species, namely $P$. dolloi of the Lower Congo, still later outliers passed westward across the great 
land-bridge of cretaceous-eocene time (Fig. 35, p. 240) to evolve Lepidosiren in South America.

The Crossopterygii. The groups treated in this and previous chapter, include fishes whose endoskeleton was wholly cartilaginous, or such strengthened by calcareous deposits. Only the teeth and their accessory parts, or the exoskeletal structures, were histologically so elaborated as to constitute true bony material. But in now passing to the Crossopterygii, and later to the Actinopterygii, we ascend to groups that steadily assume increasing endoskeletal complexity and bony composition. Correlated therewith is a definite plan of membrane ossification for the head, that is possibly foreshadowed in previous groups; also connected mechanical union and bracing of the anterior paired and of the unpaired fins with the head and the notochordal tube; increased ossification of this tube, and a highly pliable adaptation of the osseous centres or vertebrae of it, so as to connect and correlate the muscle masses in their motor action; finally, a perfected mode of aquatic respiration that was adapted to proper aeration of the tissues and removal of waste products, from organisms whose motions became steadily more lithe, and adaptable.

The above combined characteristics became progressively more pronounced from the Mid-devonian on to Jurassic times, when the Crossopterygii reached or had passed their climax of most perfect evolutionary adaptation; the Polypteridae being now the only surviving remnants. The Actinopterygii however carried forward these details to greatest perfection, and in the process ultimately evolved the highest or teleost division.

Of the Crossopterygii the most ancient and primitive in their structural details seem to be the Osteolepidae. The family can be traced back to the Lower Old Red Sandstone in such genera as Osteolepis (Fig. 9b, p. I I9), Thursius and Diplopterus. For in the diphycercal to heterocercal tail, in the rhomboidal and slightly overlapping to cycloid and deeply overlapping scales, in the simple or only slightly infolded wall that covers the pulp cavity of the teeth, as well as other characters, the Osteolepidae and specially Diplopterus seem to be the most primitive. As these 
characteristics are all well established in Lower Old Red beds, the Osteolepids probably evolved in later Silurian time from some ancestral type intermediate between primitive dipnoan and holostean examples. But alongside these the more specialized though related genera Glyptolepis and Tristichopterus often occur, while all of them are accompanied by dipnoans like Coccosteus and Dipterus, as well as Acanthodes and other elasmobranchs.

As Geikie $(23: 345)$, Flett $\left(22: 38_{3}\right)$, Goodchild $(7 I: 59 \mathrm{I})$ and others have described, several of these inhabited that area of Lower Old Red deposit which Geikie named Lake Orcadie. But that the deposits formed in it represented a long period of time, and varying organic changes in the process, is shown by the beds being, in parts of N. Scotland, from 5000 to I 6,000 feet thick, while three of the zones-the Stromness-Cromarty beds, the overlying or Thurso-Rousay beds, and the highest or John-o-Groat flags with Eday sandstones, - vary markedly in organic relation. Thus Osteolepis macrolepidotus and Diplopterus agassizii are common to the two lower, but are absent from the top zone. Thursius pholidotus is found in the middle, but is absent in the lower and upper beds. Other illustrative cases might easily be cited.

As emphasizing the relation of primitive crossopterygians to other groups, we give a list that is taken mainly from Flett's papers. This also will bring out the environal associations.

Crossopterygians.

Osteolepis macrolepidotus, O. microlepidotus, Thursius pholidolus, T. macrolepidotus, Diplopterus agassizii, Glyptolepis paucidens, G. leptopterus, Tristichopterus alatus.

Other Associated Fishes.

Coccosteus decipiens, C. minor, Dipterus valenciennesii, D. macropterus, IIomosteus milleri, Cheirolepis trailli, Acanthodes peachii, Diplacanthus striatus, D. tenuistriatus, Cheiracanthus grandispinus, $C$. latus, $C$. murchisoni, Gyroptychius angustus and G. macrolepidotus, Mesacanthus pusillus, M. peachii, Homacanthus borealis, Palaeospondylus gunnii, Rhadinacanthus longispinus, Microbrachium dicki, Pterichthys milleri, P. productus.

On p. 405 Traill remarks: "The calcareous and bituminous flags are the chief receptacles of the fossil remains 
enclosed in these rocks. The amount of bituminous material may exceed 10\% of the entire rock material." But further Geikie and his successors specially note that in the Thurso beds "Estheria membranacea crowds the surfaces of the shales and flagstones," and this feature equally extends to strata of the Orkneys and other widely removed parts. Also "plant remains abound in many parts of the Thurso flagstone group. So far as yet known not a single true marine plant occurs there, all the traces hitherto noticed point to terrestrial vegetation." Flett then expresses his own as well as Geikie's view when he says that all were laid down in shallow tranquil water, and in landlocked freshwater areas. So the above list applies not to crossopterygians only, but to a biological congeries which collectively lived in Lake Orcadie at one time or another during the Lower Old Red period. One gets an idea of the relative abundance of Osteolepids at this time from Geikie's statement that of O. microlepidotus as many as a hundred individuals may be counted within a space of three or four square feet, mingled with remains of Acanthodes and Cheiracanthus. Though the material is usually poor, a close parallel seems to have existed between the above beds with their organisms and those of the Devonian in Russia. So far as ascertained however physical and organic connection with N. E. America had not yet or had only recently been effected. Now none of these fishes has been reported alongside a marine assemblage of organisms, or in what seems to be a marine type of rock. Therefore for the Crossopterygians as for others already studied, or to be studied, all had a freshwater origin and environment, up to the top of the Lower Old Red series and often showed a great wealth of individuals.

Of the more evolved genera Holoptychius, Sauripterus, Cricodus, Eusthenopteron ( Fig. 48), Glyptopomus, and Onychodus, these all appear in the Middle and Upper Devonian of Scotland, Russia, or N. E. America, and often abundantly. The diphycercal to usually heterocercal tail, the relatively large strongly overlapping scales, the complex tooth structure, the obtuse to acute paired fins, and the 
often large size of some species, all indicate morphological advance over those of the lower rocks.

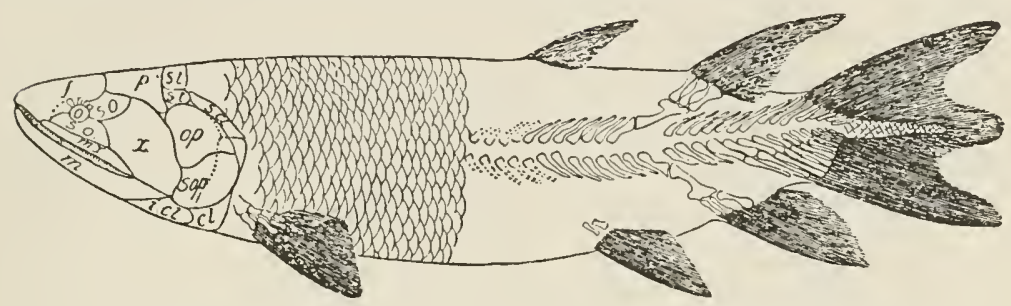

Fig. 48. Eusthenopteron foordi, a crossopterygian fish from the Upper Devonian of Scaumenac Bay, Canada. Letters indicate constituent head bones. About one-sixth natural size. (After Whiteaves.)

In the Upper Old Red-or Upper Devonian-possibly even in the Mid-Devonian of eastern North America-of Scotland, Belgium, Russia, of eastern Canada, and of the North East United States some or all of the above genera are found. The celebrated Dura Den beds of east Central Scotland, those of Nairn and Elgin in N. Scotland, and the Devonian beds of Russia, early furnished rich material for study by Miller, Agassiz, and Eichwald, while the more recent discoveries of Lohest, Newberry, and Whiteaves in Belgium, Eastern America, and Canada respectively, have materially extended our knowledge of the series.

Traquair has also pointed out that the Nairn and the Elgin beds, which are at or near the summit of the series, represent two distinct faunal areas of deposit. The former contains Holoptychines decoratus, along with Psammosteus tesellatus, Asterolepis maximus, Polyplocodus leptognathus, and Coccosteus magnus; while the latter contain Holoptychius nobilissimus, $H$. giganteus, $H$. decoratus, Glyptopomus minor, Sauripterus crassidens, along with Psammosteus taylori, $P$. pustulatus, Cosmacanthus malcolmsoni, Bothriolepis major, Phyllolepis concentrica, Conchodus ostreaeformis etc. He then states that "palaeontologically the Nairn beds may be compared with those of Wenden in Russia; the Elgin strata with those of the Sjass of the same country."

Hull has indicated $(73: 255)$ that the Kiltorcan beds of South Ireland show close affinity with the upper Scottish 
beds, alike lithologically and in their organisms. But in addition to like genera of fishes, there occur in the same strata abundant impressions of Adiantites and the freshwater mollusc Anodonta jukesii. He therefore says: "It is abundantly clear that lacustrine conditions prevailed over this area of the south of Ireland, during the deposition of these beds, and that thus by their fossils and physical relations they correspond with the deposits of those great inland lakes already referred to."

It would seem as if the Canadian and the States fishes had originated in, and had gradually spread westward from, the North European Old Red areas, for while the subgenus Glyptolepis of the genus Holoptychinus occurs in the lower Old Red of Scotland as G. leptopterus, it appears in the upper Old Red of Scaumenac Bay, as G. quebecensis. A like retarded developmental distribution has been repeatedly noted for other types. The finding by Newberry of Onychodus sigmoides, and of Holoptychinus scales, in the Ohio and Onondaga rocks, indicates that rapid migration from Europe westward was then proceeding, while from the Chemung-Catskill series eight or nine species of holoptychian remains have been described.

But as already noted for the Dipneusti, a wide extension of the freshwater basins took place in central North America, so that remains of Onychodus and Holoptychizus have been obtained from Iowa and Colorado.

In all cases examined by the writer the beds in which the above genera occur are clearly freshwater, as are those of the Lower Old Red. For the absence of marine remains, the increasing frequency of a flora mixed with the fishes that is prophetic of the Carboniferous formation, alike in its types and in its richness, also the frequent continuity in genera that are clearly freshwater in the Lower, and continue so to the Upper, are all powerful arguments.

With transition from Old Red to Carboniferous rocks, a complete change in crossopterygian genera takes place, so that while all of the above are blotted out, their place is taken by Tarrasius, Rhizodus, Rhizodopsis, Megalichthy's, and Coelacanthus. In regard to these it may at once be said that all of them are entirely absent from the varied 
lists of marine elasmobranchs of the period, as given by Davis, by Young, and by Traquair $(77: 693,696)$. But the last named author, in dealing with the problem, speaks throughout of "marine fishes" and "estuarine fishes." Not one fact however in the above and in many other papers by him, favors the idea even of "estuarine conditions," which have bulked greatly too much in geological and palaeontological literature. He gives rich lists from the Calciferous beds, which in all of their connections and indications are freshwater. These include Megalichthys, Rhizodus, Strepsodus as well as Tarrasius from Eskdale; he gives from the "Edge Coal" Megalichthys, Rhi odus, Strepsodus, Rhizodopsis and Coelacanthus; also from the Coal Measures Megalichthys, Rhizodopsis, Strepsodus, and Coelacanthus.

While the elasmobranchs then sent numerous outliers into the sea during the period at present under consideration, there seems no reliable evidence for accepting it that a single genus of crossopterygians migrated into marine surroundings.

The genera that are named together above show, so far as known, varying distributional ranges. Thus Tarrasius is peculiar to the Calciferous, Rhizodus to the Calciferous and freshwater ironstone-shale beds of the Lower Carboniferous, Strepsodus ranges from Calciferous to Coal Measure strata, Rhizodopsis occurs only in the Coal Measures from Silesia to Britain, and thence on to Nova Scotia, while Megalichthys and Coelacanthus extended from the Calciferous up to the Permian. But all disappear with the Upper Permian, to be replaced by other genera that are discussed below.

The Crossopterygians of the European Coal Measures were evidently able to spread by some freshwater line of travel to America, for two species of Rhizodus (Megalichthys of Agassiz and Hibbert) and three species of Coelacanthus, as well as scant remains of the true Megalichthys were early described by Newberry from the Ohio coal fields. In referring to them and other organisms he says that they were "from a single locality, which has already become somewhat celebrated for the number and interest of the fossil forms it has furnished. I refer to Linton on 
the Ohio river, at the mouth of yellow Creek. The fossils are found there in a thin stratum of cannel, which underlies a thick seam of bituminous coal, that we have called No. 6, because it is the sixth workable seam from the base of the productive Coal Measures. Already about twenty species of fishes have been obtained from this deposit, and at least as many amphibians."

Cope in subsequently describing these amphibians says of the deposit: "They occur in a small basin near the middle of the series, in the lower part of the 'diamond bed.' This is eight feet in thickness and the fossil batrachia and fishes are found on the slate, which is in contact with the lower three to six inches of the seam, which is cannel coal." As to its mode of origin, Newberry says: "We learn from a careful study of the deposit, that there was in this locality at the time when the coal was forming, an open lagoon, densely populated with fishes and salamanders; and that after a time this lagoon was choked up with growing vegetation; and peat (which afterwards changed to cubical coal) succeeded to the carbonaceous mud (now cannel), that had previously accumulated at the bottom of the water. The fishes of this pool were mostly small tilescaled ganoids, belonging to the genus Eurylepis. Though here extremely abundant, they have not been found elsewhere. . There were also in this lagoon two or perhaps three species of Coelacanthus (one of which is so closely allied to C. lepturus of the Coal Measures of Europe, that they should perhaps not be separated) and yet this genus has been nowhere else recognized on the American continent. There are also found here the thin scales, from one to two inches in diameter, some ornamented and some plain, and also the lance-head teeth of Rhizodus, and the teeth and spines of Diplodus." It is worthy of passing note here that C. elegans (C.lepturus) is specifically the same as that reported from England and Scotland.

In proceeding from the Carboniferous to the Permian rocks Megalichthys and Coelacanthus still persist, for Cope has described two species under the name Ectosteorhachis (Parabatrachus of Owen) from the Permian of Texas; while Coelacanthus granulatus has been found in the Upper 
Permian of Durham in England and of Riechelsdorf in Germany (199:400).

With changing environal life-conditions the above types of fish evidently changed and evolved new though nearly related genera from the Triassic on to the Mid-Jurassic periods. These are Diplurus from the Trias of New Jersey and Connecticut; Graphiurus and Heptanema from the Keuper beds, also Undina from the Lias; while Undina, Libys and Coccoderma from Lower Kimmeridgean beds carry the Crossopterygians on to mid-Jurassic times.

In commenting on Huxley's review of the Coelacanths (22I:d I O, d, I 2$)$ Newberry writes $(83: 338)$ : "Professor Huxley has called attention to the very great resemblance, and almost generic identity, of Coelacanthus, Undina, and Macropoma; and cites this succession of fishes-the inhabitants of ages, to our comprehension, infinitely removed from each other-as affording a striking example of what he terms a 'persistent type.'

We may now inquire as to the distribution and environal relation of each of the above genera. Diplurus longicaudatus was described by Newberry from specimens secured at Boonton, N. J. and Durham, Conn. As more recently discussed by Eastman, the age and position of these beds seem to be "the summital portion of the middle Trias, as developed in the Mediterranean region." (228:25). In both localities "certain layers of the shales are crowded with fishes, a slab a yard square, carrying sometimes a half dozen or more. Some of these are dismembered, consisting of a shapeless aggregate of scales and bones, but most are nearly perfect; and the number found at about the same level with their perfection of preservation, seem to show that the generation inhabiting that portion of the Triassic basin at a certain time were somewhat suddenly killed and sunk to the bottom, where they were soon covered with the accumulating sediment, and were thus preserved. The layers of shale which contained the largest number of fishes, are impregnated with bituminous matter, burning for a time when thrown into the fire, and when struck with a hammer giving off a peculiar odor. Similar fish beds are known to exist at Pompton, Plainfield, 
and beneath the trap of the Palisades above Hoboken, and it seems probable that the great mortality, which strewed the bottom of the basin at times with dead fishes, was the result of some phase of the volcanic action which poured out the trap masses of the Palisades and Newark mountains."

He considered that these shales were for ages deposited in troughs that were occupied by fresh-or brakish -water lakes or estuaries which represented the surface drainage of the adjacent country. So Eastman writes: "While there is nothing in the character of the fossil fishes which would prove conclusively whether the deposits took place in salt or brakish or freshwater, the physical character of the deposits, and the fossils other than fishes found in them, make it substantially certain that the deposits are not marine.

"No corals, echinoderms, or brachiopods have been found in the Triassic in Connecticut, or in any other of the Triassic basins of eastern North America. Molluscs are very few, and most of those found are undoubtedly freshwater forms. A very few marine molluscs, it is claimed, have been found in the Triassic of Pennsylvania. A few crustacea, probably freshwater or brakish water forms, have been found in some of the southern Triassic basins, though not in Connecticut. A few insect larvae have been found. For the rest, the fossils of the formation consist of land-plants, and tracks of reptiles and amphibians, with a few skeletons of reptiles. Such an assemblage of fossils makes it clear that the formation is not marine, though the presence of a few marine shells (if those shells are rightly identified) indicate conditions in part estuarine."

On p. 76 Newberry, in speaking of the possible feeding habits of Diplurus, adds to the above: "the only vegetable remains found in the fish-beds of New Jersey and Connecticut, are those of land-plants-fronds of cycads and twigs of conifers-and it is hardly probable these could have formed the subsistence of Diplurus. Molluscs and crustaceans are entirely absent, so unless he devoured the scaled ganoids, of which the remains are so abundant, it is difficult to imagine of what his food could have consisted." It 
will be noted that there are some differences in result between the two above observers, but as to possible vegetable food a rich soft vegetation doubtless grew that has left no trace in fossil state.

But the above collective evidence plainly demonstrates that-like all of its ancestral relatives-Diplurus was a freshwater fish that inhabited lakes and marshes.

A more complicated history however attaches to Grapliurus, Undina (Figs. 49, 50), Libys, Coccoderma, and Heptanema. In all past literature, it has been accepted openly or tacitly that these were marine fishes. Even where related genera have been regarded as freshwater, others have been view'ed as marine. Thus Eastman, while establishing a correct organic homology between the fishes of New Jersey-Connecticut, and those of the European Keuper, considers the former to be freshwater, the latter marine,

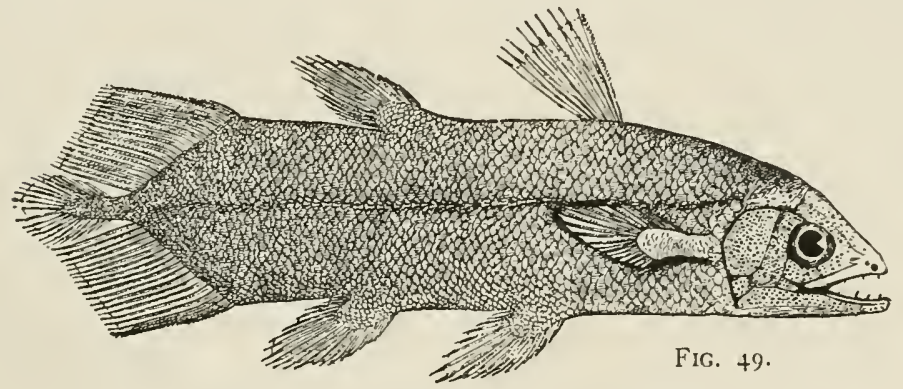

Fig. 49. Undina penicillata. Restored view of entire fish from Solenhofen slates, one-fifth natural size. (After Kayser).

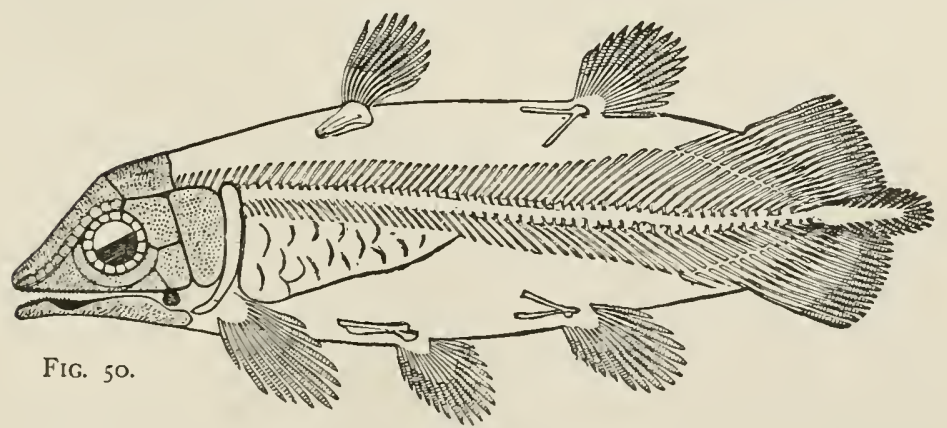

Fig. 5o. Undina gulo. Skeletal outline of fish found in Lower Liassic rocks of Dorset in England, one-tenth natural size. (After Egerton). 
largely owing to the biased statements of others (229:3 I, 32 , etc.). Now in the lists of fishes that he quotes from the works of Kner, Bassani, de Zigno, Deecke, deAlessandri and others for European beds, some rather curious anomalies crop up. Thus while the fish-faunas of Perledo, Giffoni, Hallein, Seefeld and Lumezzano include Crossopterygians like Heptanema and Undina, also numerous "ganoids" that in other extra-American strata are undoubtedly freshwater, all of the above authors directly or tacitly accept that the strata and fishes are marine.

The beds of the above-named localities are all bituminous schists, or limestone strata as in the case of Perledo, and all have been noted for their rich faunal remains. Along with the fish-remains however various authors have listed genuine marine organisms. The puzzle is in large part solved when we are able to read back into their exact stratigraphic connections. We may take the case of the Raibl beds. H. G. Bronn in describing these $(230: 2)$ says that A. Bouè $(23 I: 47)$ "fanden sich dort über graulichen der Jura-Formation zugetheilten Kalksteinen schwärzliche bituminöse Mergelschiefer und mergelige Sandsteine, welche Schichten von blauem Stink-Dolomite mit Resten von Ganoiden-Fischen und von Pflanzen einschlössen, die mit Voltzia und Cupressus vergleichbar sind. Diese Bildungen wären dann durch die von Wulfen beschriebenen Muschel-Marmore und Mergel bedeckt, deren organischen Einschlüsse Boué mit Deshayes gemeinsam noch genauer untersuchte, und als Cryptina raibliana, Isocardia carinthiaca, Cypricardia antiqua, Corbula rosthorni, Cidaris-stacheln u. s. w. bezeichnete und abbildete." He next quotes Morlot (232:255) as follows: "nach Morlot sollten auf Buntsandstein, rothe Porphyre, Alpenkalk (Muschelkalk) fast stets von dolomitischer Beschaffenheit und ohne Versteinerungen, dann oberer "alpinischer Muschelkalk" mit Myophoria whatlyae Buch, und den von Boué beschriebenen Schaalthieren folgen, der an seiner unteren Grenze jene schwartzen bituminösen Schiefer mit Voltzia und Fischen einschlosse, welche nach Heckel denen von Seefeld bei Hall in Tyrol ähnlich, aber als Arten verschieden wären. Nach oben entheilte dieser Muschelkalk Perna, Gervillia, Trigo- 
nia, und Corbula und würde von oberem Alpenkalke bedeckt."

The associated plant-remains were Noeggerathia vogesiaca, Voltzia heterophylla, Pterophyllum minus, Taeniopteris marantacea, an undetermined fern, etc.; and all indicate an upper Keuper or Lower Liassic affinity.

The history of the entire series of associated strata we would interpret as follows: In succession to a marine group of beds, and through elevation of land, a considerable area became a basin into which freshwaters discharged. This basin contained, or had swept into it, a multitude of fishes -all of freshwater habitat. From some sudden terrene - probably volcanic action, these were suddenly killed in vast quantities, were mixed with remains of land plants from surrounding lake-margins, and were rapidly covered over by a volcanic ash-deposit. The bed thus formed was next depressed below sea-level, and a marine deposit was laid down that was rich in typical marine organisms but for a clear reason not in fishes, as given above. Through subsequent deposit and pressure of added beds, as well as in all likelihood from generation of high temperatures by volcanic agency or grinding and faulting of the rock-masses, decomposition of the fish-oils that had been set free from the entombed fishes took place, with formation of abundant bituminous material.

So while-as will be fully dealt with later-the fish beds of Comen near Gorz, and their organisms are evidently marine, we accept it, from similar evidence as the above, that the bituminous beds of Raibl, Besano, Giffoni, Perledo, etc. all contained freshwater fishes, and the analyzed fixed or fatty oils of these gave the bituminous character to the rocks themselves that has in part made them famous. This completely correlates them also ecologically with the similar-probably contemporaneous-rocks of New Jersey and Connecticut. As regards the Solenhofen and similar types of stratum, these contain so heterogeneous an assembled mass of land, freshwater and marine remains, that we claim for the enclosed examples of Heptanema, Graphiurus, Undina, Libys and Coccoderma, a freshwater 
origin and ancestry, in view of what has been said regarding these genera above.

But the last and lingering remnant genus of ancient Crossopterygians, viz. Macropoma is as yet a puzzle. Occurring in Cretaceous rocks of Turonian and Senonian age, the animal as described by Mantell, Dixon, Huxley and others, seems to be associated only with marine strata, and their related organisms. Unlike many fishes that have become marine however, the tenacious retention of the ossified air-bladder is noteworthy.

In the oldest description by Mantell he states that (Amia) Macropoma lewesiensis belonged to the "Lower Chalk" of Sussex, as does also Dixon. Mantell however, indicates (pp. I39-142) a great variety of beds, and varying organisms in these, when he says that the "Lower Chalk" is regularly stratified, the lines of separation being composed of a softer chalk that in some places contains so great a proportion of argilla, as to assume the appearance of marl. The latter also occurs in transverse and vertical veins, in which the remains of fishes are more frequent than in the more solid strata." And again he says that eight or ten layers of chalk may be separated by as many seams of chalk marl.

In the elaborate account also of "The Lower and Middle Chalk of England" (233) Jukes-Browne has recorded (p. 44) Macropoma from the Lower Chalk of the Kentish coast, and there associated with a dozen other marine fishes. Again speaking of the Middle Chalk he says (p. 369): "Remains of fish are abundant in some localities, especially in the counties of Kent and Sussex. Many of the species are the same as those occurring in the Lower Chalk, such as Ptychodus decurrens, P. mammillaris, Macropoma mantelli, and Beryx (Ctenothrissa) radians."

The description and beautiful figure given by Fritsch $(I 6 I)$ also leaves one in doubt as to the environal stratigraphy. One wonders however as to the meaning of the above-recorded fishes being "in transverse and vertical veins" also as to the exact fossils found in each chalk layer, and in each alternating marl layer, as well as the chemical composition of each. So until an extremely careful and ex- 
tensive study has been made of the rocks at Southeram, Maidstone, Hamsey, Steyning, Dover, and other localities of South England, as well as similar regions on the continent, the writer would withhold opinion on this suggested lone marine derivative of the otherwise freshwater coelacanth series.

The two surviving genera of this great group, namely Polypterus and Calamichthys that occur over a large area of the river and lake systems of Central Africa, seem to be ancient and highly modified derivatives of still older genera. These must, long since, have passed southward into the Gondwana continent. It is not unlikely, however, that once the Cretaceous and Tertiary deposits of that ancient land-mass are better known, connecting links between them and more remote ancestors of Jurassic or Triassic age may be secured. 


\section{CHAPTER XI.}

The Evolution of Fishes. III. The Chondrostei And Protospondylei (Holostei).

The Chondrostei. The second great group of the Teleostomi or higher fishes ranks next in time of appearance and structure to those already examined. That the group is more advanced and highly evolved than those already studied is proved: (a) by the known presence only of one genus in Old Red rocks; (b) by the more perfect ossification of the skeleton; (c) by the condensed character of the supports for the paired fins; (d) by the tail-fin being rarely diphycercal, usually heterocercal, sometimes homocercal.

A. S. Woodward's introductory observations on the group in Volume 3 of his "Catalogue" are so exact that we quote as follows: "The origin of these fishes is still entirely obscure. Among known fossils they range downwards as far as the Crossopterygians, while there is as yet no evidence of a link between these two groups. On the other hand it is clear that the Chondrostean is later than the Crossopterygian type; for the former is represented in the Devonian solely by the rare genus Cheirolepis, while the latter is dominant throughout, and the members of the Chondrostei do not flourish vigorously until those of the Crossopterygii begin to decline in the Carboniferous and Permian. The modifications by which a Crossopterygian could be changed into a Chondrostean are also readily comprehensible. In the latter the paired fins are always polybasal, with excessively shortened lobe; and among Crossopterygii the genera with most elongated lobate fins flourish the earliest, all survivors above the Devonian having the lobe comparatively abbreviate." And after reviewing additional characters, he writes: "when the Chondrostei suddenly become dominant, as they do in the lower Carboniferous, they already exhibit a remarkable series of modifications," and some of these he then dwells on. 
It may be alike indicative and suggestive to observe here that there are four existing genera. Acipenser, the group of the sturgeons, includes about i 6 species over the northern hemisphere. Some of these are freshwater, but most are now anadromous in habit, and so pass out into the sea to feed, but return to interior river areas to spawn. Scaphirhynchus, the genus of shovel-nosed sturgeons, includes four species, one of which lives in south-western rivers of North America, while the other three that by some authors are made into a separate genus (Kessleria) occur in rivers of Central Asia. Polyodon, the spoonbill, occupies nearly the same area as the American Scaphirhynchus, and Psephyrus is found in the rivers of China. There is still much to be learned as to the last three.

The oldest known representative of the Chondrostei is Cheirolepis trailli. This is one of the fishes noted by Flett (22) and Goodchild ( $7 I: 59 \mathrm{I})$ as typical of the Achanarras-Cromarty-Stromness beds. These, as already stated (p. I 20), were all of freshwater habitat. This equally applies to the only other and more recent species $C$. canadensis from the upper Devonian of Scaumenac Bay in Canada. So far then as present facts go, the Chondrosteans are first known in freshwater areas.

The genera Canobius, Phanerosteon, Holurus, Nematoptychius, Rhadinichthys, Elonichthys, Cycloptychius, Acrolepis, and Gonatodus all appear first in strata of Calciferous Sandstone age, and the first four disappear with its close. The others persist however, up into Carboniferous Limestone age (Gonatodus), or even into the Coal Measures. They are all absent however from the marine lists given by Davis (205:614;207), Traquair (77:690), and others, but are continuously noted from freshwater beds. Thus in Traquair's lists while he frequently speaks of "estuarine fishes" the assemblages given by him from Wardie Beach, from the freshwater of Burdiehouse, also from the Straiton and Pentland oil shales, are clearly all lacustrine-not estuarine-groups. For the presence alongside them of Dipnoans, of Crossopterygians, of other Chondrosteans yet to be studied, as well as of a varied land flora, is thoroughly indicative. 
The appended list of the "Fossil Fishes collected by the Geological Survey of Scotland in Eskdale and Liddesdale" is eminently typical of the fish associations, as well as of the Lower Calciferous strata that yielded them. It permits their correlation also with fishes of other strata.

LIST OF FISHES (From Trans. Roy. Soc. Edin. 30 [1883] 15).

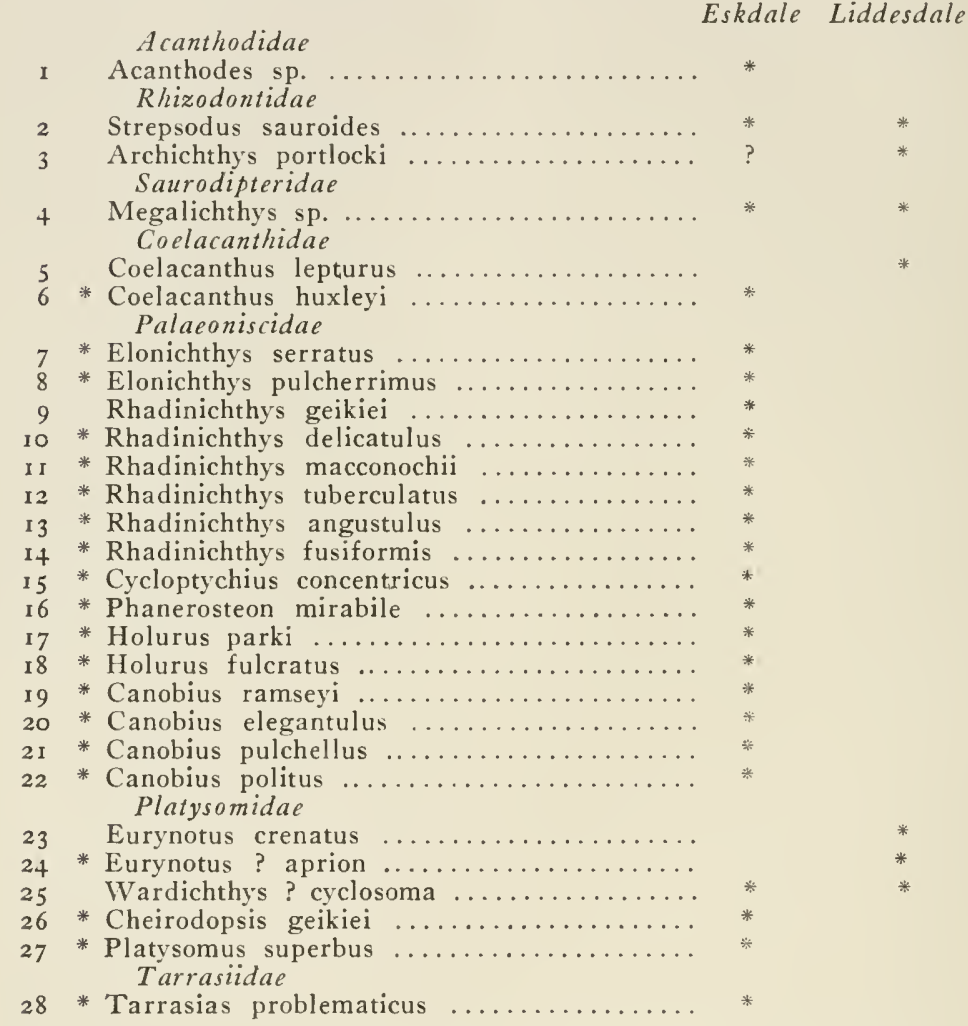

\section{Eskdale Liddesdale}

Since the great majority of the species belonging to the above genera have been found across central Scotland, and since Cheirolepis is from Scottish rocks also, such suggest that primitive Chondrosteans evolved in the area extending from N. Britain to W. Russia. But that they spread fairly rapidly westward into Canada is shown by the earlier descriptions of Dawson, $(85)$, also more recent papers by him and by Lambe $(97: \mathrm{I})$. Dawson in describing five new species of Rhadinichthys says, "The 
whole of these fishes have been preserved entire, the body being perfectly flattened and thrown into attitudes which imply that they were embedded when living or immediately after death. The material in which they are contained is shown, by its microscopical and chemical characters to have been a vegetable muck or mud, and the fish were either overwhelmed by it in the manner of a bursting bog, or were stiffled by the non-oxygenated water mixed with mud, and suddenly killed and embedded in the accumulating sediment. That they occur in this perfect state, and in a limited thickness of the deposit, may imply that at certain times they were overwhelmed by the eruption of the foetid organic mud into the water in which they lived. The bed is low down in the Lower Carboniferous series, being the equivalent of the Horton series of Nova Scotia; so that these fishes are among the oldest that we know in the Carboniferous period."

Lambe in continuing and extending Dawson's work notes also the enormous abundance of the fish remains, and says for Rhadinichthys alberti alone, that: "It evidently swarmed in countless numbers in the waters of its time." With it he also describes Canobius modulus and three indigenous species of Elonichthys, of which E. browni was probably commonest (Fig I 8, p. I 50). So in comparing the Albert shales of New Brunswick with the Calciferous of Scotland he observes that the fishes "belong to the same genera but differ as to species." Associated again with these are the freshwater entomostracans Leaia leidyi, Estheria, Beyrichia, and a rich land flora. Dawson and he both note the highly bituminous nature of the Albert rocks. Thus Lambe says that "at Albert mines and vicinity, certain layers of the shale are replete with the remains of fishes of the family Palaeoniscidae" and in "attaining a thickness sometimes of five or six feet yield abundant oil and sulphate of ammonia." He observes also that "the numberless remains of fishes in some of the beds can be attributed only to the occasional wholesale destruction of the fishes."

By the time that the anadromous and the ultimately marine elasmobranchs had fully invaded the sea (p. 28o), and were in some cases becoming fossilized in their teeth 
or spines, amid Carboniferous Limestone deposits, the freshwater Elasmobranchs, Dipneusteans, and Crossopterygians, were spreading alongside Chondrosteans. Therefore such a freshwater bed as Traquair calls $(77: 4)$ the "Gilmerton ironstone" is spoken of thus: "between the lowest marine limestones is a well-known coal seam the North Greens, and not far above is the Gilmerton Ironstone" which yielded:

Acanthodes sp.

Gonatodus macrolepis

Elonichthys robisoni

Elonichthys multistriatus

Nematoptychius greenocki

\section{Eurynotus crenatus}

Megalichthys sp.

Rhizodus hibberti

Rhizodus ornatus

Sagenodus quinquecostatus

also the labyrinthodonts Pholidogaster pisciformis, Loxomma allmani, andMacromerium scoticum. His succeeding observation then is wide of the mark: "Here it will be seen that the elasmobranch fauna of the marine limestone is utterly wanting, and the estuarine fishes have returned." The writer would incline to phrase it thus: "After deposition of the lower marine limestone bed, marked elevation of the land occurred. Over this an abundant marshy vegetation developed, that originated the "North Greens" coal, while still later part of its surface became a lake that soon was invaded by freshwater fishes and giant amphibians whose remains are left in the freshwater ferruginous rockdeposits."

From the above also it will be seen that the statement of Sauvage for the Lower Carboniferous (Calciferous) of Scotland is incorrect when he says: "Tandis que les Ganoides en general, et les Palaeoniscides en particulier, sont singularement rares dans le Carbonifere inferieur, nous devons noter leur abondance a Eskdale et a Liddesdale." The Palaeoniscidae were often extremely abundant and were widespread by the close of the period, as were also the Platysomidae treated of below.

During Mid-Carboniferous and Coal Measure times, some of the above "Calciferous" genera persisted, while Elonichthys, Cryphiolepis, and Acrolepis continued even into the Permian, but wholly in freshwater environment. The distribution of the species of Acrolepis moreover from 
first appearance in the Calciferous of Britain, Belgium, and Nova Scotia (A. hortonensis), on through the Coal Measures and into the Permian of Russia, Germany, Britain, and probably also into the Karoo beds of South Africa ( $A$. ?digitata) is proof that extensive intercontinental areas of freshwater existed. The species of Elonichthys also almost equal the last.

At times it seems as if areas had existed for evolution of new genera or species, alongside others of wider distribution. Thus Newberry described at least four species of a new genus Eurylepis, in the richly fossiliferous beds near Linton, Ohio, that were associated with species of Palaeoniscus, Rhizodus, Coelacanthus, etc. (234:347), that all inhabited according to the author "rivers, lagoons, lakes, and bays."

On passing up to the Permian and Triassic beds palaeoniscid life seems to have received a great check early in the former period, accompanied by obliteration of most of the genera, possibly owing to the coming on of widespread xerophytic conditions, but mainly to frequently intermittent volcanic outbursts, succeeded by active and widespread denundation action. As a result Amblypterus and Palaeoniscus_rich in species and individuals-as well as the rarer Pygopterus and Trachelacanthus disappeared in the epoch during which they evolved. But their places were taken in Triassic times by Gyrolepis, Apateolepis, Myriolepis, Urolepis, and Atherstonia, which, as a group of genera, extended from North Central Europe to South Africa and Australia. These organisms, as well as the deposits in which they occur, are acknowledged to be of freshwater origin.

Such genera however, in dying out, were replaced by Oxygnathus, Centrolepis, and Coccolepis, during Lower Liassic days, while the third of these endured even as a lingering remnant into Lower Kimmeridgean strata. From their occurrence alongside other undoubtedly freshwater fishes, and their presence in lower Liassic shales devoid of marine remains, Oxygnathus and Centrolepis continued to be freshwater in habitat like all of their ancestral allies. As to Coccolepis one species C. liassica occurs in the same 
beds as the above two genera, $C$. bucklandi is one of the many freshwater types of the Solenhofen Slates, and C. andrewsii occurs at a still higher level-the Lower Purbeck beds-of the epoch. Brodie says regarding these that "they rest on the Portland series" (235). The fossiliferous rock is a very fine-grained white shaly limestone of laminated structure, and much resembling the Solenhofen slate. The slabs "abound in Fish, Insects, impressions of plants, Cypris, Archaeoniscus and rarely shells, most of which belong to the genus Cyclas, and one species of Paludina."

The species which probably occurs highest in the geologic scale, and which is of special interest geographically is $C$. australis. It was described by Woodward from Talbragar beds of $\mathrm{N}$. S. Wales. Though there may be some doubt attaching to the exact age of these, David, Jack, Pittman, and Woodward agree that they are Jurassic rocks laid down in depressions of Triassic strata (I54). David and Pittman say: "The fishbeds proper form the lowest of the three members into which, on lithological grounds, the deposits to which they belong, may be divided. They consist of laminated hard siliceous shales, cherty in places, rendered ochreous by ferruginous infiltrations. . . . Fish and plants are so abundant that it is difficult to find even a small fragment of the shale devoid of them." They further observe that "the fish-beds are succeeded conformably by white siliceous shales, which do not appear to be fossiliferous. They consist of silica in a very fine state of division," and are about I 5 feet in thickness.

Woodward says: "The fishes are crowded together in shoals as if suddenly destroyed and very' few of them have become disintegrated before fossilization. A glance at the accompanying plates will show how beautifully even the most delicate bones and fin-rays are usually preserved.' The writer would again suggest, as the only known explanation of such conditions, that the fishes were killed by combined shock, poisonous gaseous fumes and volcanic dust. The last was in this case-unlike the Purbeck and Solenhofen slates noted above-a siliceous dust-shower. Then after death and entombment of the fish, plant, and insect 
life, a continued deposit of the dust took place to form the non-fossiliferous bed.

Woodward also draws attention to the fact that while the European species of Coccolepis were small, C. australis was a fairly large fish that measured about 13 inches. It was accompanied by other "ganoids" belonging to the Semionotidae, Pholidophoridae, and Leptolepidae, all of which are treated subsequently in this work.

The Palaeoniscidae then, from Lower Old Red to Mid Jurassic days, were purely freshwater fishes. But while these were evolving into varied genera, two allied divisions, the Platysomidae and Catopteridae were diverging from them, at the same time that they often continued to inhabit the same lakes and rivers. The Platysomidae is made up of the genera Eurynotus, $W$ ardichthy's, Cheirodopsis, Platysomus, Mesolepis, Cheirodus, and Globulodus. The first four all make their earliest appearance in Calciferous rocks, and alongside members of the Palaeoniscidae. Thus reference to the list from Eskdale-Liddesdale (p. 3i 8 ) and to Traquair's list (p. I 45) shows all of them. The most persistent of them throughout geologic time was Platysomus that became-very abundant in lakes of the Coal Measures period. There it occurred with Mesolepis (Fig. 46, p. 282) and Cheirodus, but while they died out at the close of that period Platysomus persisted into Permian time. For in the Upper Permian of North England, Germany and Russia, $P$. gibbosus or an allied species is found in Marl Slate or in the peculiar lacustrine Kupferschiefer rock, where also the nearly allied Globulodus occurs.

As is true of so many other groups of fishes, and even organisms as a whole, steady destruction of all of the Platysomidae as of most of the Palaeoniscidae took place during the Permian, and so the second divergent series from the last-named, or the Catopteridae, first appears in the Triassic. This group, so far as known, is made up of the three genera Catopterus, Dictyopyge and Perleidus. Regarding them A. S. Woodward says ( 160 : Introd. VII) : "These fishes possess a palaeoniscid head and shouldergirdle, while the tail is only hemi-heterocercal, and the single series of supports in the dorsal and anal fins, almost 
equals in number the opposed dermal rays. Such being the case, here is an interesting illustration of the common law, that the links between a lower and a higher group are not to be sought among the specialized types of the former, but among those with the most generalized secondary characters."

In line with the above then, and looking to the long persistence and wide distribution of Palaeoniscus, it seems likely that the Catopteridae evolved as three slightly diverging genera during the late Permian or early Triassic period, and possibly in central Europe. Following the freshwater streams of travel taken by other groups, as already outlined, the species of Dictyopyge radiated out gradually into Britain, Ireland, and Eastern America, also southward by Switzerland and Lombardy-where Perleidus is met with-into South Africa and New South Wales. It may well be that the nearly allied Catopterus evolved as a sideline from Dictyopyge, as the latter migrated westward to America. For the remote position of the dorsal fin in Catopterus is an advance on Dictyopyge and the palaeoniscids generally, though some of Newberry's figures-e.g. of $C$. gracilis-do not well seem to demonstrate the difference.

The strata in which all of them have been found are fresh-water. Thus Newberry in describing $D$. macroura from the Triassic coal field of Richmond, Va., says that there it is very abundant; for one slab of shale, formerly belonging to the Lyceum of Natural History, though scarcely more than a foot square, carried impressions of over twenty individuals. The Karoo and the N. S. Wales beds are also accepted as freshwater; while Newberry to some extent, and Eastman fully, agreed that those of Eastern America are.

The next group - the Belonorhynchidae-includes fishes of Lower Triassic to Upper Liassic age. In structure also the only two genera Belonorhynchus and Saurichthys are highly modified fishes. Woodward says of them: "If these are not degenerate Chondrosteans, they must be abnormally modified Crossopterygians as suggested by O. M. Reis" ( 160 : Introd. VIII). The former is one of the character- 
istic types of the bituminous schists of Raibl and Giffoni, which we have already shown to be freshwater (p. I74). The two species described by Woodward from the Upper Triassic beds of Gosford N. S. W. are also accepted as freshwater by him, since the associated amphibia, plants and other fishes all fortify this view. Equally true is it for species from the Lias. The scattered fragments of Saurichthys tell a like tale.

The discovery of Elipsopholis however in Hawkesbury beds caused Woodward to write: "The new genus is indeed a palaeoniscid fish, but it differs from all known members of its family in exhibiting a row of thick scutes along the course of the lateral line. In the latter feature, and in the nature of its fin rays Elipsopholis agrees with the Belonorhynchidae, and may doubtless be regarded as one of the predicted links between the two families."

"As the fish is almost destitute of scales, its internal skeleton is well displayed, and is proved to resemble, in all essential respects, the palaeoniscid skeleton."

The Lower Liassic genus Chondrosteus (Fig. 52), and the Upper Liassic Gyrosteus, each including one species, are related to modern sturgeons (Fig. 5I) (236:24). But

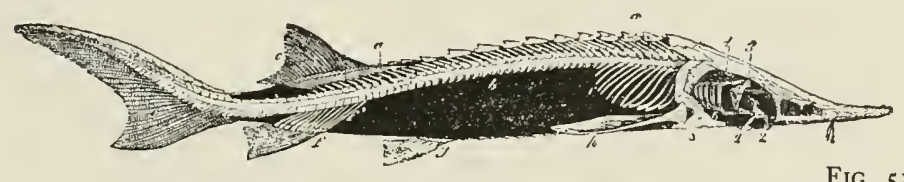

FIG. 5I

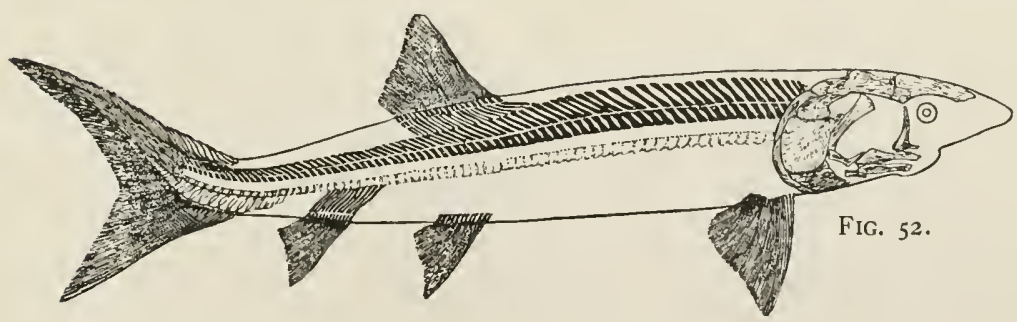

FIG. 51. Skeleton of Existing Sturgeon (Acipenser).

FIG. 52. Restored skeleton of Lower Liassic Sturgeon (Chondrosteus acipenseroides). Both greatly reduced. (After A. S. Woodward). 
the writer has failed to learn exactly as to their environal habitat. Until the exact rock stratum that furnishes these has been studied and associated organisms-if any-are known, it would be idle to speculate regarding them.

The scant remains of Acipenser, suggest that passage seaward was a relatively recent habit, for Leidy's plate from the Miocene, that of E. T. Newton from the freshwater Forest Beds, and the fin-spine from southern France, seem all to indicate freshwater, rather than an anadromous habit.

The additional two genera now alive, Scaphirhynchus and Kessleria (if one separates the three eastern from the single western one generically), are found, the former in the Mississippi valley and Western States, the latter in the rivers of Tartary.

The family Polyodontidae that includes the Spoon-bill sturgeons, are modified derivatives probably of some ancient acipenseroid type, in which the rostrum has become greatly elongated and flattened. The scales of the trunk are small obliquely-placed discs in some fossil forms (Crossopholis), or almost absorbed in the living Polyodon; the larger rhombic scales are restricted to the tail region; the mouth is wide and gaping not tubular as in the sturgeons; small persistent teeth line both jaws as compared with the edentulous state of adult sturgeons.

The oldest known type of the family is Crossopholis that was described by Cope from the freshwater Eocene of Wyoming, but if Pholidurus is to be assigned here it is reported from the Senonian and therefore older Cretaceous beds of Kent.

The Holostei. This great order that for some authors includes two divisions the Protospondyli and Aetheospondyli is, like most of the preceding groups, known largely in the fossil state. But unlike these the order may be said to be Mesozoic in history, if we except a few species of the genus Acentrophorus of Permian age. The origin of the Holostei, however, must therefore be looked for in that age. Woodward's statements ( 169 : Introd. VIII) are at once guarded, and represent the opinion of the highest authority. He says: "The Catopteridae of the Trias incline 
towards a higher type of fish than the Chondrostei, to which they technically belong; but the two known genera cannot be the ancestors of this more advanced race, for at least one of its representatives (Acentrophorus) has already been found in the Upper Permian, while numerous and varied forms are commonly met with in the Trias and Rhaetic. It can only be affirmed that as soon as six important modifications had simultaneously affected the chondrostean skeleton another vigorous race arose, and a new impetus seems to have been given to variation. These changes comprised (I) the almost complete atrophy of the upper caudal lobe, (2) the reduction of the dorsal and anal fin-rays to exactly the same number as their supports, (3) the disappearance of the infraclavicular plates, (4) the loss of the pelvic baseosts, (5) the subdivision of the hinder expansion of the maxilla, and (6) the withdrawal of the preoperculum from its extension over the cheek.

"Numerous types, in some respects parallel to those already noticed among the Chondrostei, are to be recognized in this later race; and the only difficulty is that, owing to the imperfection of the geological record, very few of these types are revealed until approaching full development. It is true that there are links between most of the families, rendering precise definitions almost impossible; and evidences of evolution can be detected in a slight degree, as the different groups are traced upwards in their range. All the families, however, except the modern Lepidosteidae and Amiidae, had already become differentiated before the period of the Lower Oolites."

The eight families included are the Semionotidae, Macrosemiidae, Pycnodontidae, Eugnathidae, Amiidae, (with a living genus $A$ mia, the Bow Fin), Pachycormidae, Aspidorhynchidae, and the Lepidosteidae, (with a living genus Lepidosteus, the Garpike).

The Semionotidae includes some twelve genera: Acentrophorus, Semionotus, Aphnelepis, Serrolepis, Pristisomus, Sargodon, Colobodus, Lepidotus, Dapedius, Cleithrolepis, Aetheolepis, and Tetragonolepis. It may be at once said that all were freshwater fishes in origin and habitat, and for reasons that follow. 
The genus Acentrophorus is primitively represented by a species, $A$. dispersus, that was described by Fritsch from the freshwater "gasköhle" of Bohemia. From the Upper Permian of Durham, England, three other species have been described, while Newberry referred here a lot of imperfect remains, named by him $A$. chicopensis from the freshwater Trias of Chicopee Falls, Conn.

The entire family, however, assumed great importance and wide distribution in the Trias. Twelve species of Semionotus-all from freshwater beds-are known from the lowest Triassic or Muschelkalk beds of Perledo, Italy, and later from Eastern America; from the Keuper of Central France and Germany; from like or possibly somewhat higher beds of the Upper Trias of South Africa; and from Gosford, Australia. These are immediately associated with Aphnelepis, Serrolepis, Cleithrolepis, Aetheolepis, Pristisomus, and Colobodus, in the Australian, South African, and Central German beds; with Lepidotus, Dapedius, and Tetragonolepis in the Kota beds of India (237:3).

The often abundant remains of species of Lepidotus (Fig. 53) from freshwater beds of the English or continental Kimmeridge Clay, the Purbeck, and the Wealden: the equally abundant remains of species of Dapedius (Fig. 27, p. 203) from the "Bucklandi" fish-reptilian strata of the Lower Lias, and similar strata of the Upper Lias; as well as the widely dispersed remains of Tetragonolepis, all proclaim a like environal habitat, while their admixture with other semionotid genera above named, give added testimony.

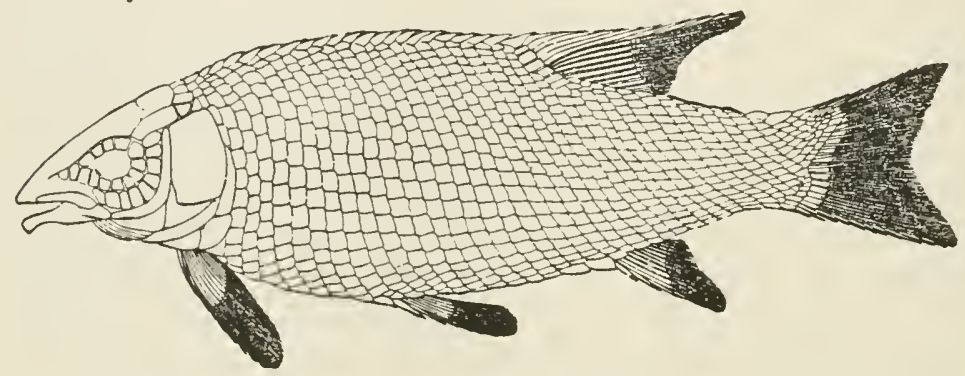

FIG. 53. Lepidotus minor, from Purbeck beds of Upper Jurassic age, Dorset in England. One-fifth natural size. (After A. S. Woodward). 
In the American beds Diplurus, Catopterus, and Dictyopyge-already (p.324) reviewed-lived side by side with Acentrophorus (v.s.), with ten species of Semionotus, and with Ptycholepis noted below (228). From the Raibl beds that we have shown to be freshwater, (Chap. Io, p. 312) not marine, Dapedius and Colobodus are alongside four species of Belonorlynnchus, five of Pholidophorus, (vide infra) and Ptycholepis. Many quotations could be given also which abundantly prove that all of the species of Semionotidae were of freshwater habitat, of great abundance, and of wide distribution.

But when, as in the case of the Perledo beds of N. Italy, Bassani and predecessors describe fishes, reptiles, and even plant remains in the same paper that has descriptions of ammonites and other typically marine "molluschi," one is apt to conclude that all were marine unless some very clear distinction is made. Such distinction, however, is often not emphasized. But in Bassani's paper (pp. 58-59) he notes, on the faith of Barazzetti, that the plants, fishes and reptiles, also a very imperfect and doubtful crustacean, were all found in an upper zone about M. 5.50 thick; while the ammonites and other molluscs were only found in a bed below of about $\mathrm{M} 0.50$ thickness. And he puts this information in graphic form thus:

\begin{tabular}{l|l}
\hline M 5.50 & $\begin{array}{l}\text { Pianti-Pesci } \\
\text { Rettili-Crustacei }\end{array}$ \\
\hline M 0.50 & Molluschi \\
\hline
\end{tabular}

So, as in the Upper Trias of Connecticut, we have here a like association of plants, fishes, and reptiles of freshwater habitat, and all embedded in a clay that was deposited in some rather extensive lake. This lake also may have run nearly parallel to, and at no great distance from, a sea shore. But this lake had resulted after elevation of a sea floor, which while submerged received marine deposits that covered over and preserved molluscs which had lived there. 
The interesting transition in scale structure, from a ganoid to a cycloid type, shown by the Australian genus Aetheolepis, has been pointed out by Woodward, and is set forth in Fig. 54 .

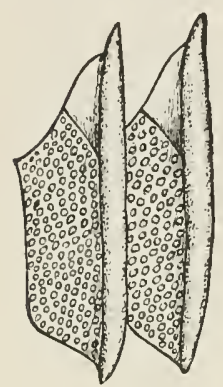

a

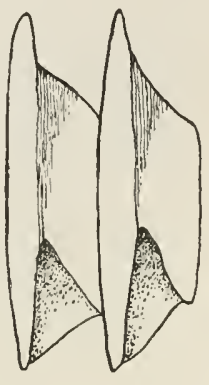

$a^{\prime}$
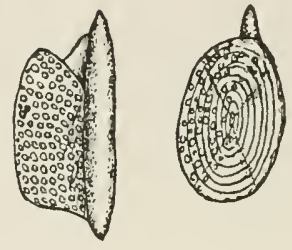

c

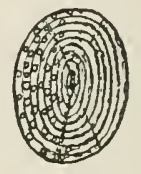

d

FIG. 54. Aetheolepis mirabilis. Scales trom four surfaces of the body, showing transition from ganoid (a) to cycloid (d) type, $\left(a, a^{\prime}\right)$ external and internal views. (After A. S. Woodward).

The Macrosemiidae, and Eugnathidae may for several reasons be treated together, and might well have been also with the Semionotidae. Of the former Woodward writes ( 169 : Introd. XI) : "the earliest term in the series (Ophi$o p s i s)$ is the most generalized, and it has the most extensive range, (Upper Trias-Purbeckian). It is indeed a distinct link between the family of Macrosemiidae and that of the Eugnathidae."

The genera and even species that make up these two families are largely known from the lithographic stone of Bavaria, or of Ain in France, also from the Purbeck and Rhaetic beds of central England, that are rich in insects, freshwater molluscs, amphibians, and other indications of lacustrine or land life. But the genus Petalopteryx of the first family, also Neorhombolepis and Lophiostomus of the second, suggest possible migrations seaward, at least in their later and more evolved species. Thus Woodward, after remarking that "the ganoid fishes of the Chalk, so far as recognizable, are few" then goes on to record Neorhombolepis, Lophiostomus, and even scant remains of Belonostomus and Prionolepis from various southern English "Chalk" localities $(238: 302)$. But where the remains are scant 
the possibility of redeposition from older strata must be borne in mind, and so the possible derived nature of Lophiostomus affinis that he records $(239: 207)$ from the Cambridge Greensand-whose organic remains are notoriously derived, according to the opinion of some geologists-must be kept in view.

But we may next treat together two families which while starting as inhabitants of lakes and rivers in their earlier history - seem gradually to have migrated into marine surroundings, or in some cases to have been more or less anadromous, but which ultimately became thoroughly marine organisms. We refer to the Pycnodontidae and the Pachycormidae. For origin of the former we must look to some ancestral type, probably of Lower Liassic time, that combined inherited characters of the genera Colobodus, Dapedius, Semionotus and Lepidotus, but which as an evolving family, branched off more and more markedly from a common stock during Kimmeridgean, Purbeckian, and Wealden time. Then gradual seaward migration gave rise to species and genera that were typically marine, and some of which survived up to the close of the Eocene, as with Palaeobalistum and Pycnodus. It will be of interest therefore to attempt, as accurately as possible, to trace the geographic and geologic relations of the genera and species, in connection with ecologic changes.

The oldest genus is Mesodon that starts with M. liassicus in the freshwater Lower Lias or "Bucklandi" zone of Central England. In considering it and other "ganoid" fishes, it may here be emphasized again that not a few of the freshwater beds of the Lias, as well as of many other Mesozoic strata have been largely overlooked from the exact descriptive standpoint, owing to the abundant marine organisms found in related strata, and even more owing to the comparative ease with which the often perfect and attractive invertebrate marine fossils can be identified, by aid of the elaborate descriptions and figures of these that have been published in European, American and even Asiatic countries. The most minute details are found in the Memoirs of the British Geological Survey, but here it may be pointed out that over a wide expanse of north-central, 
central and southern English territory, two adjacent sets of beds are known as the lower or "angulatus" and the upper or "Bucklandi" zones, since in their marine constitutents they are characterized by two species of ammonite ( $A$. angulatus and $A$. bucklandi). But the constitutent beds of each of these are by no means uniform. In the "Bucklandi" group especially, some are freshwater-not estuarinesome are marine. The relation of these is succinctly given thus by Phillips-Etheridge $(240: 368)$ "Immediately succeeding the thick "angulatus" limestones, commences the rich series of the Bucklandi or Lima beds, here about roo ft. thick, and composed of 70 alternating beds of shale and limestone, some of the shaly beds measuring from 2 to I 5 feet. These Bucklandi shales have yielded nearly all the fish and saurian remains for which this locality is famous. (Ital. present writer). Twenty beds of grey semi-crystallized and earthy limestone alternating with dark shales, comprise the whole thickness of the Bucklandi zone here" (i.e. at Lyme Regis).

The often large slabs of Liassic reptilian remains that adorn the cases of some museums, belong to this one, and the absence of marine invertebrates from these is noteworthy.

Succeeding to Mesodon liassicus, two or three species occur in the freshwater beds of the Stonesfield Slates, and still higher in the Corallian beds. But the climax of development for the genus evidently occurred in the Kimmeridgian period, for six to nine species are listed from an area that would fairly well include a belt across Central Europe. Of these Mesodon macropterus is most perfectly known, for well preserved specimens have been found in the Solenhofen rocks. Fig. 55 shows a striking restoration of it, for the anterior body scales are alone developed. The genus then decreased markedly in the freshwater Portland and Purbeck beds, being represented in the latter by Mesodon daviesi of the "shell limestone" and "Paludina clay." It then seems to have died out at the close of the latter period.

The genera Microdon, Mesturus, and Athrodon can be treated together as being closely related genera. Most 


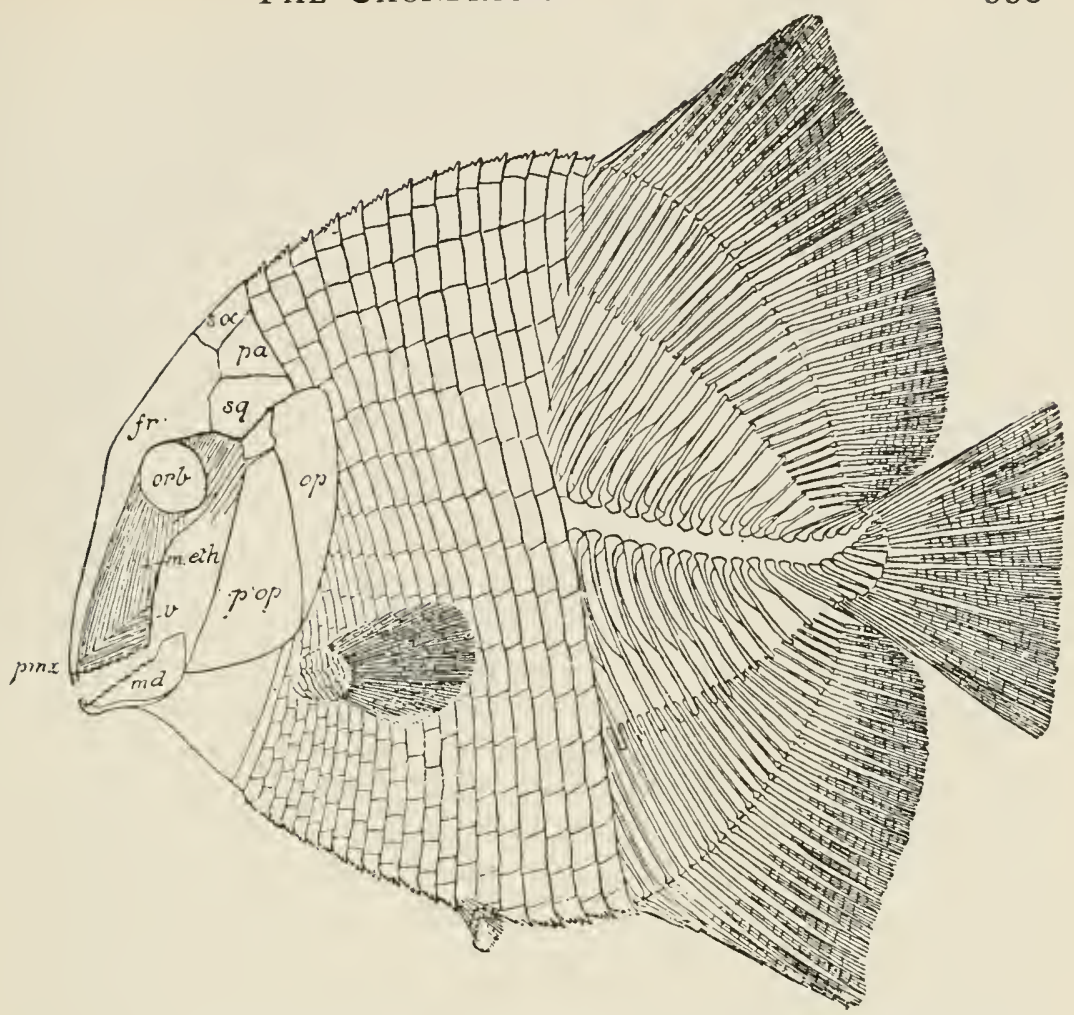

FIG. 55. Mesodon macropterus, a freshwater pycnodont fish from the Solenhofen or Lithographic Stone of Bavaria, restored by A. S. Woodward. The surface and skeletal aspects are shown, and the larger head bones are lettered. Somewhat reduced in size. (After A. S. Woodward).

of the species that compose these have been recorded from the freshwater beds of Ain and Cerin in France, from the lithographic stone of Altmühl in Bavaria, or from the still higher Portlandian and Purbeckian beds.

In passing now, however, to Gyrodus and Coelodus, a new habitat-relation seems gradually to have been established. For while one or other of these occurs from the Kimmeridge Clay through Purbeck to freshwater Wealden beds, about the time of deposit of the Neocomian or Gault on through Cenomanian to Senonian deposits, the remains of both are found in Chalk strata, and alongside selachians which by this time had reinvaded and repopulated many seas. 
So with the passage of time, and with increasing specialization and condensation of the types in shape, in dentition, in scale-structure, in fin-structure and disposition, the pycnodonts appear wholly to have died out in freshwaters by the Mid-Cretaceous at latest, and to have become a marine series up to the period of the Eocene.

But some beds, rich in pycnodont remains, deserve critical study. For while classed as marine in the past, practically all of the evidence we have of them, shows that they were at least in part freshwater. Amongst others we may here cite the lowest Cretaceous or Neocomian strata, which with their enclosed organisms, are described by Pictet from the Virgulian rocks of the Jura-system of Neuchatel (2 $7 I$ :I). From the manner in which the marine invertebrate remains are described with the fishes and the saurians, one might conclude that all are marine. But there are two distinct sets of deposits, the lower evidently marine, the upper freshwater. Writing of the latter he says: "Les beaux fossile sont rares. A la carriere des Brenets, on a recueilli des dents de Pycnodus, de Sphaerodus, de Strophodus, de Lepidotus, et des fragments de carapace de tortue. Mais la piece la plus interessante est le bel echantillon de Lepidotus qui sera decrit plus loin." Then above this bed he describes a calcareous non-fossiliferous dolomite, above which beds "d'eau douce infra-cretace" containing Planorbis, Valva, Physa, etc. along with Chara remains, are found.

Similarly the five species of "Pycnodus" from the Neocomian of Sainte Croix (op. cit. 56) that are now variously distributed among the recently arranged genera of pycnodonts, are a quite distinct, and evidently freshwater set, as compared with chimaeroids and selachians that are described with them from the Gault and other higher Cretaceous rocks.

During much of Cretaceous time frequent elevations and depressions of land, as well as silting up of shore tracts were proceeding, and only too often the marine invertebrate remains are listed, or even alone mentioned, while the freshwater and land organisms are neglected.

But as a consequence of the above change of habitat, the most recent and most highly modified genera, Anomoe- 
odus, Coccodus, Palaeobalistum, and Pycnodus are met with in marine strata, from the Greensand and Cenomanian up to beds of the Miocene, when the last named and lingering genus disappears. Thus in the marine beds of Mt. Lebanon in Syria, in the Senonian of England, France and Bohemia, in the Monte Bolca beds of Upper Eocene age in Italy, as well as elsewhere, more or less perfect remains of species belonging to some of the above genera, have been secured.

On the accompanying chart the above striking stratigraphic and evolutionary procession of the Pycnodonts is set forth as perfectly as our present very fragmentary knowledge of the number of species hitherto recorded permits. But future vigorous investigation of each stratigraphic zone, in connection with the organic remains of it, may somewhat alter-though we believe not fundamentally -our present conceptions.

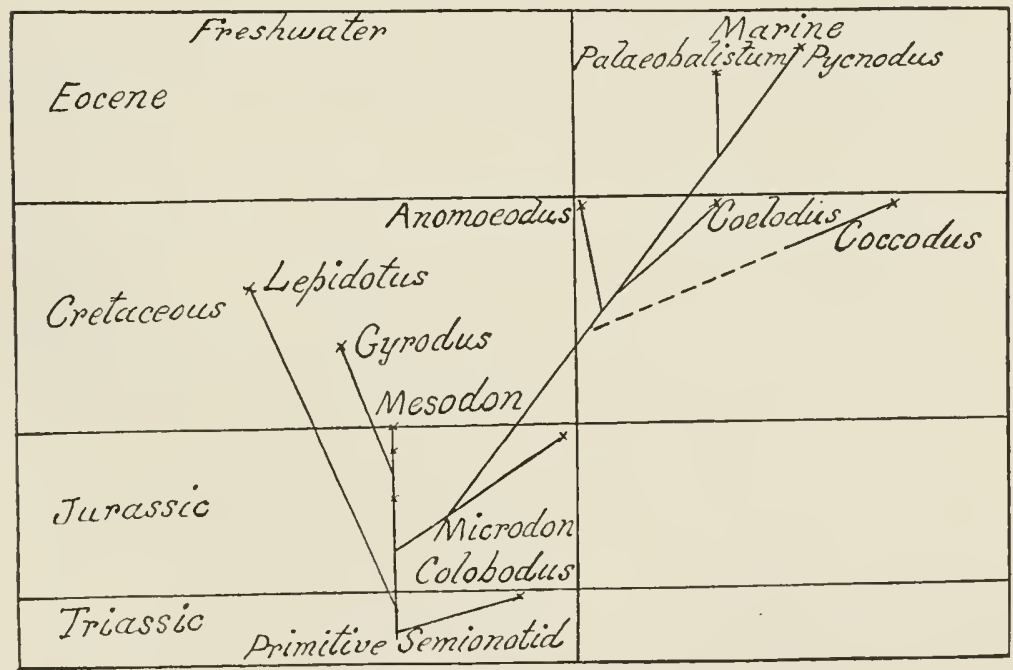

The Pachycormidae as a group seems to possess a special evolutionary significance that is as suggestive as is its range in time and space. For from genera like Eugnathus and Caturus of the family Eugnathidae, that range from Lower Liassic up to Purbeckian times, derivative forms branched off that took on more and more the struc- 
tural characters typical of certain families belonging to the present-day dominant group of fishes-the Teleostei. For while the last studied group of Pycnodontidae developed into an increasingly evolved but physiologically decadent type of organisms, the pachycormid derivatives from a eugnathid stock became increasingly lithe, active, adaptable and numerous. Moreover, from their structural details they seem to have been the Mesozoic progenitors of certain groups of Teleostei which in surviving the tremendous volcanic upheavals and changes of early Eoceneor more likely upper Cretaceous-time, are now represented in descendants that are in part the living bony fishes.

Already in beds of Upper Liassic age the oldest known genera Sauropsis, Prosauropsis, Euthynotus, and Pachycormus have left remains that indicate animals of a foot to three feet in length, and which from the numbers preserved on a single slab, must have been more or less social in habit and abundant in individuals. Side by side with these also, and only found as a rule in an argillaceous or a blue bituminous and typically nodular shale occur Ptycholepis, Lepidotus, Tetragonolepis, Dapedius, Gyrosteus, and other genera already treated of, as well as Leptolepis and others mentioned below (p.344). Associated with all of these again, are remains of insects, fossilized freshwater shells and wood, but most conspicuously great saurian and crocodilian remains, that together proclaim a combination of land and freshwater as contributing centres of organic life. (240:396-400). These freshwater Upper Liassic beds are continued from West England across into Belgium, France, and thence into Germany, thus indicating large lakes or lacustrine swamps, that existed at no great distance from the Upper Liassic seas of the period. Such lacustrine areas probably originated first as arms of the sea, that by land oscillation, or by formation of sand-bars, or both, became inland lakes into which rivers emptied, and from which rivers passed to the sea.

It is somewhat peculiar that our knowledge is still extremely limited regarding the Jurassic and early Cretaceous fish-life of all regions outside Europe. This seems the more peculiar, when we remember how abundant and varied 
were the gymnospermic plant life and the reptilian life. In part we believe that this is explained by the minor attention given by palaeontologists to the regions involved, in part to the greater difficulty attending correct identification of vertebrate and not least fish remains. A very wide field is here open for future study.

Though our knowledge regarding intermediate and connecting stages in the history of the above four genera between Upper Liassic and commencing Cretaceous times, is still sadly imperfect, it seems almost assured that species of Hypsocormus gradually moved seaward, driven in part probably by the abundant reptilian carnivorous forms that preyed on them (p.2 I 7 ). In the process diverging structural details were acquired, that suggest analogous resemblances to some of the sharks and reptiles, that they were contending against in the struggle for existence. During the period therefore that intervened between Kimmeridgian and early Cretaceous rock deposits, a new genus evolved that shows close affinity with Hypsocormus, but differs in the elongated snout, in the large sharp deeplyset teeth, in the powerful pectoral fins, and the expanded almost homocercal tail.

This is the genus Protosphyraena, remains of which are found in the Neocomian beds of Russia, in the overlying Gault and Upper Greensand of east central England, but which became specially abundant and widespread throughout the various "Chalk" strata from the Cenomanian and Turonian to the top of the Senonian formation, and is included in Woodward's "Ganoid Fishes of the Chalk" (238:302). It ultimately took possession of a sea-territory that at least extended from Russia westward across what is now S. England, to S. E. North America, and thence onward to Kansas. In the latter region again, it seems to have given rise to a related marine type, with greatly elongated and flattened snout, that Cope has named Erisichthe.

So while the vast majority of protospondylian ganoids continued-like their ancestors-to evolve in freshwater territories, groups of the Pycnodonts and of the Pachycormids passed almost simultaneously into the sea, during the 
late Wealden or early Neocomian period, along with evolving members of the sharks and dogfishes, and temporarily became important factors in the marine life of the times, and this also over a wide area.

But the Pycnodonts and Pachycormids represented two totally different types of organization and evolution, though starting in late Triassic days from related ancestral freshwater organisms. For the short sub-circular and compressed body, the heavily-plated head, the small mouth, the rounded and pavement teeth, the small paired fins, and the rather slender tail fin of typical Pycnodonts, (Fig. 55) all suggest bottom-feeding, and crushing of small molluscs, crustaceans or other marine invertebrates. In contrast the elongate fusiform body, the tapered head, the expanded mouth with strong carnassial teeth, the welldeveloped paired and caudal fins of Pachycormids like Protosphyraena that closely resembled the more ancient Hypsocormus (Fig. 56), not to say the presence along the intestinal tract of fossilized fish-prey in process of digestion, all proclaim strong carnivorous propensities.

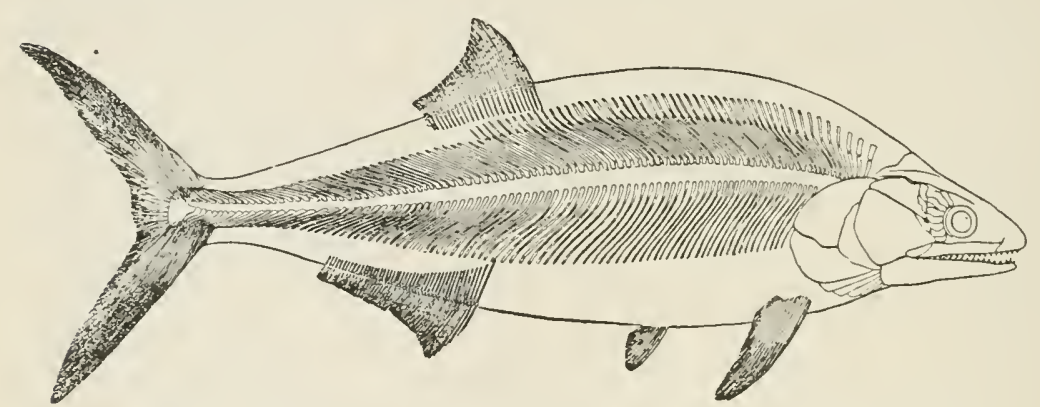

FIG. 56. Hypsocormus insignis, a freshwater Jurassic fish, closely related to the more recent Cretaceous and marine genus Protosphyraena. One-eighth natural size. (After A. S. Woodward).

The preliminary remarks made on the previous page for origin of the Pachycormidae, would apply almost perfectly for the Amiidae, that in many details of structure show ancestral affinity with the Eugnathidae. The family includes, according to the varying views of palaeontologists, four or five genera, namely Liodesmus from the lithographic slates of Bavaria; Megalurus mainly known in four 
species from the same strata, but also by two species from like beds of Ain in France, and still others from the more recent Purbeck beds of Dorset, England; Pappichthys with related types Protamia and Amiopsis from the lower freshwater Eocene of W. America and of France; and Amia that probably evolved first in central N. America during early Eocene times, reached western Europe in late Eocene times to die out there by close of the Miocene period, but which still persists as Amia calva-the bow-fin-over a large area of the lake and river regions of N. America.

All of them evolved in, and remained in, freshwater regions, as is shown by the rocks in which they occur; the immediately associated fossils; the continued persistence of the three last-named genera amongst the ramified EoceneMiocene lake-system of Western America, as outlined by Cope and others; also by the survival of Amia over an even more expanded territory probably at the present day.

The last of the protospondylean groups is the Aspidorhynchidae that includes Aspidorhynchus and Belonostomus. These with the still-surviving Lepidosteus of the family Lepidosteidae, make up a morphologically transition assemblage between the protospondylean and teleostean divisions that has been named the Aetheospondyli, on account of the progressively advancing evolution of the vertebral column.

The above two genera both appear first in the lithographic stone of Bavaria and France, and from the mixedup nature of the organic contents in the former it would be hazardous to suggest the natural environal habitat. But the list of fishes and other organisms, given by Thiolliere and subsequent collaborators, from Bugey (242) helps more perfectly when one compares this with the exact stratigraphic descriptions given jointly by M. M. Falsan and Dumortier. Then one learns that from the "Bajocien" and Bathonian upward to the Corallian the beds and their included fossils are marine. No fish remains occur amongst these. But at the top of the Corallian or base of the Kimmeridgean occurs a bed with Ostrea virgula, and just above this the fauna changes, the palaeontological facies is modified, and there is ushered in the richly bituminous 
group of freshwater beds that enclose the extensive sets of plants, fishes, reptiles and other organisms which have rendered the beds famous. Above the bituminous schists, but continuous with them, are the lithographic slates that closely resemble those of Solenhofen-Eichstadt, and are according to Thiolliere and his successors of the same age and mode of deposit, but which at Bugey are rather poor in organic remains.

The writer would interpret the Bugey deposits as follows. Soon after deposition of the Ostrea virgula beds along a.seabeach or bank, extensive volcanic disturbances occurred that elevated the land and converted a large area into an extensive but shallow lake, which extended at least from W. Bavaria to near the present Rhone. This became surrounded by a typical Jurassic vegetation, and a group of crocodilean and saurophidian reptiles, while the waters became stocked with a typical freshwater fish life of the period. Then came a volcanic outburst, some dozens of miles distant, but which destroyed life over a wide area, and deposited a thick layer of volcanic dust, over the lake and its environs. At Solenhofen fish life had been somewhat scant, and the fishes along with other organisms were gradually killed and mixed up in the dust deposits as these successively were laid down. So the strata are only faintly bituminous.

In the Bugey area as has so often happened under like conditions, great shoals of the fishes had been killed and piled on each other during the earlier period of eruption. From these oozed out later the copious products which by subsequent analysis became the intrinsic rock petroleum. After destruction and entombment of these fishes, of the reptiles, and of the plants, continued deposit of volcanic dust in zones that alternated with thin zones of other detrital debris, represented probably alternating periods - a day or two only it may have been-when changes in wind currents occurred. For a few hours or longer the winds may have carried the volcanic dust, then for a few hours it may have veered and fitful gusts may have deposited fine debris of aeolian character from higher ground around. 
Included then in the group of freshwater fishes thus preserved, are three species of Belonostomus as noted below. But included by Sauvage (243:3 I) from the "Calcaire bitumineux d'Orbagnoux," of like deposit as the above, are two species of Belonostomus and one species of Aspidorhynchus, along with other freshwater types. And in order to bring before the reader the assemblage of which these formed a part, we now append the entire list of fishes from Bugey, as presented in part II of the sumptuous "Thiolliere memorial volume." This list also throws a welcome sidelight on problems already studied, or on others dealt with in succeding pages.

\section{Selachei}

\section{RAIADAE}

Spathobatis bugesiacus

Belemnobatis sismond

\section{Pycnodontidae}

Pycnodus sauvanausi

Pycnodus bernardi

Pycnodus itieri

Pycnodus egertoni

Microdon elegans

Microdon hexagonus

Gyrodus macrophthalmus

Mesodon comosus

Mesodon gibbosus

\section{LEPTOI.EPIDAE}

Oligopleurus esocinus

Megalurus idanicus

Megalurus austeni

Megalurus polyspondylus

Megalurus damoni

Pleuropholis ?

Attakeopsis desori

Thrissops salmoneus

Thrissops formosus

Thrissops cephalus

Thrissops heckeli

Thrissops regleyi
Squalidae

Phorcynis catulina

\section{GanoIdeI}

Disticholepis dumortieri

Callopterus agassizi

Notagogus inimontis

Notagogus margaritae

Lepidotus itieri

Lepidotus notopterus

Pholidophorus micronyx ?

Pholidophorus sp.

Caturus velifer

Caturus segusianus

Caturus furcatus

Caturus elongatus

Caturus latus

Amblysemius bellicianus

Ophiopsis guigardi

Ophiopsis macrodus

Ophiopsis attenuata

Eugnathus praelongus

Leptolepis sprattiformis

Belonostomus sphyraenoides

Belonostomus tenuirostris

Belonostomus münsteri

Coelacanthidae

Undina striolata

Undina cerinensis

The records for Aspidorhynchus and Belonostomus from other and more recent beds are still doubtful. But if remains of the former from the Hughenden beds are "associated with ammonites and other fossils of cretaceous 
age," and if $B$. sioceti from the "Rolling Downs" of Australia undoubtedly is found with marine remains, such would suggest that both genera may have become marine before dying out. But added and exact information is needed.

Lepidosteus, the sole surviving genus of the family Lepidosteidae is and has been purely freshwater in habitat, as the descriptions of Leidy, Cope and others indicate. In the transition Bridger beds that usher in the Eocene formation of Western America, remains of several species have been secured. In the Upper Eocene and in Miocene beds of England, Belgium and West Germany, various rather scant but determinable traces have been found. With complete separation of the land areas of Europe and N. America, the genus persisted in the latter region, where it is now represented by the two large, voracious, and powerful species of Gar-pike, L. platysomus that is abundant in most rivers and lakes of the United States, and $L$. viridis that is native to the Southern States, also Cuba and Mexico.

The remaining groups of the "ganoid" fishes that are now usually united into a large sub-order the Isospondyli can next be examined. The term is applied, and the series is so distinguished, because the vertebral centra from now onward in the ascending scale of evolution, become throughout the entire length of the notochord definite osseous rings of tissue that encircle it, and that show equal anterior and posterior faces to the vertebrae, so that these are amphicoelous.

In the more primitive families of the Sub-order, many typical characters of the Aetheospondyli still persist, apart from the ganoid scales, but as with the Aetheospondyli so with the Isospondyli, the highest representatives pass almost insensibly into the most ancient of the Teleosteans. The three included families are the Pholidophoridae, the Oligopleuridae, and the Leptolepidae.

The first of these is made up of at least seven genera, Thoracopterus, Pholidopleurus, Peltopleurus, Pholidophorus, Archaeomene, Pleuropholis, and Ceramurus. In the Upper Triassic beds of Europe, Asia, Africa and Australia, a remarkable admixture of protospondylic and isospondylic ganoids is met with. So true is this that side by side on 
the same slab, specimens of the two divisions may be got. This condition holds also, throughout the entire geologic record, up to the close of the Jurassic, when the above seven genera disappear as such. It follows therefore that both groups were freshwater in habitat, and this is fully confirmed when detailed study of the known species as well as genera, is made.

From the Ladinian or Lower Mid Trias of Perledo in Lombardy, and even more abundantly from the somewhat higher beds of Raibl in Carinthia, also from Besano in Lombardy, at least five species of Pholidophorus have been secured. These are found side by side with species of the Eugnathidae, Macrosemiidae, Semionotidae, and Belonorhynchidae. The beds-hitherto treated as marine-are as already indicated (p. 329) typically freshwater, and so we accept it that the earliest isospondylian fishes originated amid freshwaters, and probably as offshoots from the Semionotidae.

But Pholidophorus again is associated in the Raibl, the Besano, and the Perledo beds with Pholidopleurus and usually also with Peltopleurus, while Thoracopterus in the Raibl beds is alongside species of Pholidopleurus and Peltopleurus that are also common to the Besano beds. So the conclusion is clearly justified that all four genera were fully established, in lakes of the Keuper period. But while some barrier seems to have prevented their passage westward beyond Britain to N. America, Pholidophorus, Peltopleurus and derivative genera reached Australia, and there persisted through Jurassic times, in strata that are acknowledged to be freshwater. From these strata also Woodward has described the as yet purely Australian Archaeomene.

Persisting also in central Europe through Liassic and Kimmeridgian rocks, the Pholidophoridae seem to have been richest in species and individuals, during deposition of the early Purbeck beds. For in Central-South England Pholidophorus, Pleuropholis and Ceramurus are all found, intermixed with the land or freshwater organisms already described (p. 192).

But meanwhile the more highly organized and more perfectly ossified families Leptolepidae and Oligopleuridae 
were evolving; the former-and structurally less specialized -appearing in late Triassic or in Liassic time; the latter -and more evolved-from the Kimmeridgean upward. The genera Leptolepis, Lycoptera, Aethalion, and Thrissops make up the former; Oligopleurus, Oenoscopus, and Spathiurus the latter.

The first of these easily became the dominant genus through a long period. For remains of Leptolepis-often in great abundance-occur in Upper Liassic strata across the whole of Central Europe. But it is in Purbeck beds that they seem to have swarmed. Thus Brodie, in referring to the closely allied forms Leptolepis nanus, L. brodiei, Ceramurus macrocephalus and a Pholidophorus, associates them with insects, freshwater molluscs, and other freshwater fishes like Lepidotus already discussed. He also describes the shoals of Leptolepis that seem often to have been entombed.

But as an excellent illustration of mixed-up records de Lapparent gives from beds near Mazenay (67: I I 4 I-42) Leptolepis constrictus, and L. affinis (both synonyms of the common central European L. bronni), along with Lioceras serpentinus, Inoceramus cinctus, Belemnites, etc. He somewhat corrects this statement, though NOT the false impression formed, by tabulating the beds in exact succession thus :

(5) Schists with Belemnites tripartitus and Inocerami.

(4) Schists and calcareous rocks with Lioceras serpentinus and Beleminites grandis.

(3) Fish-limestone with Ptychodus, Leptolepis, Cephenoplosus, (Pachycormus) and Lepidotus.

(2) "Feuillet a Posidonia Bronni."

(I) Passage beds with Monotis substriata.

Further comment on the above is unnecessary, though Sauvage repeats (244: I 2 ) the admixture. His observations on the Leptolepidae and allies however are suggestive.

But the most graphic references to Leptolepis are by A. S. Woodward, in describing the fish-fauna of the Aus- 
tralian set of beds. Thus of L. talbragarensis he writes: "This is by far the most abundant fish in the Talbragar deposits," and again after reviewing other and associated fishes he says: "the preceding genera however are rare, compared with the great shoals of Leptolepis" while structurally he draws attention to the fact that in the more primitive species of Leptolepis of the Upper Lias "the vertebral centrum is a simple constricted cylinder," while in the Kimmeridgean and Purbeckian "the centra are robust and are more or less strengthened by a peripheral ossification." It would be superfluous at present to attempt to picture the pathway of connection for the Leptolepidae in passing from Europe to Australia. But when the geology and palaeobiology of Asis Minor, of Persia, of India and of Africa, are better known, more ample results will doubtless be forthcoming.

While Oligopleurus and Oenoscopus of the Oligopleuridae are from Kimmeridgean and Purbeck beds, and so probably are freshwater, the genus Spathiurus from the Chalk of Mt. Lebanon, and the allied Opsigonus from the Lesina beds of Dalmatia strongly suggest that both are marine derivatives from freshwater Oligopleuridae which migrated seaward along with so many other types, during early Cretaceous times. An exactly similar claim might be made for Leptolepis neumayri, also for Thrissops microdon and T. exiguus, from Dalmatian Cretaceous beds.

Nearly related to Thrissops is a still rare and local genus Lycoptera, of which the species $L$. middendorfii was secured by Eichwald in the Trans-Baikal region of Siberia. Apart from the nature of the rock, the presence of Estheria middendorfii and remains of Belonorhynchus (p. 324) would stamp the deposit as a freshwater one. The only other species, found in Shantung, China, is still little known as to environal relations.

In review then it can be said that all of the genera of isospondylous ganoids originated as freshwater derivations from still older forms of like environment, while one or two derivative genera, and some species of these seem to have branched off as marine fishes, though the evidence for such is by no means wholly convincing as yet. 


\section{CHAPTER XII.}

\section{The Evolution of Fishes}

\section{The Soft-Finned Teleostei.}

In beginning our study of the distribution in time and space of the Teleostei, it may be helpful to bear in mind-what all ichthyologists are now agreed on-that the only, and very natural, as well as continuous line of descent of these, is from and through the "ganoids." But as shown in preceding pages the "ganoids" originated in and remained in freshwaters, throughout their entire history, except for a few specialized, and often decadent, offshoots or side lines like the Acipenseridae, Pachycormidae, and Pycnodontidae, the first of which is now a rare group and is either freshwater or anadromous in habit. The two latter groups have become wholly extinct, after assuming a marine life.

It clearly follows therefore that the entire group of Teleostei, started fundamentally, if not directly for each family, as freshwater fishes. This view the writer set forth in 1912 and he published regarding its main details in 1918 , $(I: 402-405)$. But had such a viewpoint been secured decades ago, many problems would have been rendered easy that have given rise to intricate and prolonged discussions. Not only so, instead of minimizing the wide-spread distribution, richness, and importance of freshwater fishes, through attempts to trace and derive them from a marine ancestry, their high value, from the evolutionary and morphological standpoints would have been recognized, a position that has only in part and slowly been recently accepted from the joint studies of A. S. Woodward, Boulenger and Eigenmann.

In viewing existing Teleostei as a whole, it can most correctly and graphically be considered that two divergent lines of descent were early established, and these are indicated by the now somewhat disused or restricted taxonomic terms Malacopterygii and Acanthopterygii, or the soft-rayed and the spiny-rayed Teleosts. But another and equally marked 
morphological feature is the position of the pelvic fins. These, in nearly all of the former, are well back from the pectorals, that is they are abdominal in position, as contrasted with the thoracic or the jugular position of most of them in the latter. A third morphological character that deserves notice here, as being a somewhat helpful guide toward ecological and distributional relations, is the presence in most Malacopterygii and freshwater Acanthopterygii of a more or less well developed swim-bladder, and the partial or complete absorption of it in those forms that become marine, or that come to live in the highly oxygenated waters of tumbling alpine streams and rivers.

Now it is a noteworthy fact that the members of the more primitive groups of the ganoids have soft fin-rays, have abdominal pelvic fins, and have a well-developed airbladder. These features persist most strongly in the Malacopterygii, that are largely freshwater, as we hope to prove below, and they become most altered or departed from in the Acanthopterygii, that are mainly marine. Accordingly the writer proposes now to follow the classification of older authors $(2,5)$, as modified and utilized by Boulenger (246:XIII-XVII), and Goodrich (247).

In commencing this study it may be worth while to draw attention to the curious circumstance, that the S. American and even to a large extent the $\mathrm{N}$. American continents have as yet furnished few "ganoid" representatives to the palaeontological list, while Europe mainly, Asia and Australia to a less degree, and Africa still less have contributed their quota. The writer hopes to show that this has an important bearing on the subject of the distribution of teleosteans in time and space. But it is unquestionably correct to say that $\mathrm{N}$. and S. America as well as Africa will in time furnish lists that will more than equal those of Europe. The needed workers who might demonstrate this are not yet forthcoming, owing to want of support, and to the disgraceful and semi-savage competitive and militaristic systems that characterize "civilized" nations.

The oldest teleost fishes probably date back to the Lower Cretaceous, and are there represented by Spathodactylus from the Neocomian of Voirons near Geneva, and Chirocen- 
trites from the Neocomian of Istria. The writer has already dealt with the Voirons fish-beds; and regarding those of Istria the most suggestive paper is that of $\mathrm{J}$. J. Heckel $(24 \mathcal{S}: 20 \mathrm{I})$ on the black bituminous chalk beds of the Karst mountain near Goriansk. He there points out that Chirocentrites forms a natural connecting link between ganoid and teleost fishes with decided affinities to the freshwater ganoid genus Thrissops. It is unfortunate that he gives no exact stratigraphic or biologic details that would have guided one as to other organisms around, and also as to their habitats. But a somewhat doubtful species of the related Chirocentrus-C. polyodon-has been described from the freshwater tertiary lignites of Sumatra, while the one living species, $C$. dorab, is marine and found in the Indian and China seas.

Now the nearest and most primitive ancestors of the above two genera Spathodactylus and Chirocentrites probably are Leptolepis and Thrissops (Family Leptolepidae), that range from the Upper Lias and Kimmeridgean upward. Ample time therefore elapsed for evolution of the two above teleostean genera.

It is undoubted however that evolving members of the Chirocentridae must early have passed into a marine Cretaceous habitat, for in upper Cretaceous beds of Europe, America and even Australia, bulky species of such genera as Ichthyodectes, Portheus, (Fig 29, p. 227) and Saurodon must have been as abundant as they were formidable.

But a consideration at once comes up that has an important bearing on the present inquiry. It is that the Cretaceous, as a geological epoch, is preeminently a marine one, in the beds that have been carefully explored, or that are most accessible to study. But as observed in an earlier chapter, freshwater beds of considerable importance, including even thick seams of coal, are not at all unfrequent.

These strata however have been largely neglected, while a study of the teleost fishes associated with them is greatly more difficult than is that of the more easily characterized forms of the older strata. We venture confidently to predict that when the vertebrate remains of the Cretaceous formation are studied, a greatly richer freshwater 
Cretaceous fish-fauna will be revealed than that now known.

Meanwhile the somewhat curious anomaly exists, that while several large groups of the most primitive freshwater fishes structurally, do not appear till in latest Cretaceous or early Eocene age, a few freshwater ones but many marine ones appear from the Neocomian and Gault upwards. We would explain the apparent anomaly by considering that numerous representatives of the large freshwater teleost families Characinidae, Cyprinidae, Gymnotidae, Siluridae and Loricaridae amongst others, were rapidly evolving from more primitive "ganoid" ancestors, but failed to leave traces of their remains, or more likely have as yet been overlooked in freshwater Cretaceous and Eocene strata.

Our reasons for the above positions are: (a) that where such strata have been recognized and studied, as with the Laramie, the Wasatch, and the Bridger beds of Western America, an abundant freshwater teleost fauna is encountered as Cope and others since have demonstrated; (b) the latest Cretaceous or earliest Eocene representatives of the great morphological group Ostariophysi, already have the delicate auditory arrangements perfected, that caused Cope and Sagemehl to view them as a closely related series. So a considerable period of time must have elapsed, between commencing evolution of the Ostariophysi from some ganoid ancestor devoid of such auditory arrangements, and the perfected condition of it in the typical group; (c) the world-wide distribution of the Ostariophysi in freshwaters, and the high adaptation of many genera to special freshwater areas, compel us to recognize that the group had been evolving in special areas, through a long period of time.

The families Characinidae and Gymnotidae, the Cyprinidae, the Siluridae, and the Loricaridae will now be treated in succession. In their gradual evolution, three diverging groups evidently started from one or a few primitive ancestral species. The Characinidae-with the Gymnotidae as a highly specialized offshoot from it, or from between it and the Siluridae-spread steadily over Gondwana land, from some ancestor that, tentatively and with complete 
reserve we would suggest, lived in Central America or Northern S. America. The only fossil genus is Tetragonopterus, of which two species have been described from the "Tertiary Lignite" of Sao Paulo, Brazil, while about 50 living representatives of it occur over Northern S. America, and one is found as far north as the Rio Grande of Western Texas. By utilization of the Cretaceous-Eocene bridge-that later is emphasized-the group evidently reached and spread widely across the freshwaters of Africa (p. $42 \mathrm{I}$ ) where the family is now richly represented.

The Cyprinidae started probably from common ancestry with the last, and from, or near, the same centre, but became distributed north-eastward and northward through freshwaters of N. America, of Europe and of Asia, while a few entered N. Africa (Fig. 70, p. 4I7). The oldest fossil types are from the Lower Tertiary beds of America. In more recent Miocene beds of Europe, and in (Upper?) Miocene strata of Sumatra several genera have been recognized.

'The third family Siluridae with the highly modified derivative families Loricaridae and Aspredinidae, starting probably from like ancestry as the two last seem then to have evolved in the central and southern parts of the U.S., where Rhineastes was abundantly represented in early Eocene times, then they seem to have spread mainly along the northern side of Gondwana continent, made northward connections by means of Arius and Bucklandium into the Atlantis continent when it was continuous with Europe, while in late Miocene or early Pliocene days the family reached tropical Asia. The last derivatives we would regard-as do ichthyologists generally-as the most highly modified of the three series (Fig. 69, p. 4I6).

If now we review the above three families somewhat more in detail, it may be said that the Characinidae is a purely freshwater group that includes many genera and about 600 species, that are constantly being added to by Boulenger, Eigenmann, and others, as African and S. American lakes and rivers are explored. Though known only by Tetragonopterus in the fossil state, we confidently predict that other and even Cretaceous genera will yet be 
revealed to science. The majority of the genera and species are S. American, rarely Central American, but many are widely extended over a large part of Africa. Their extension eastward was probably effected at a time when by enormous faulting and volcanic action, the sea was encroaching on, and breaking up the eastern or "Lemuria" part of Gondwana into a western African half, and a south-eastern Asiatic half. So while they reached Africa, they failed to pass further eastward. On the whole the African genera and species are more highly modified from the average type, than are the American.

The remarkable family Gymnotidae, or the group of electric eels, is now generally accepted as a specialized offshoot from the Characinidae. But alike from structure, evolutionary relations, and distribution, it suggests derivation from a form intermediate between Characinidae and Siluridae, and which gradually spread southward from Central America. It is now represented by upward of 30 species that inhabit lakes and rivers of S. America.

The Cyprinidae is "the largest of all the families of fishes, comprising 200 genera and 2000 species found throughout the North Temperate zone, but not extending to the Arctic circle on the North, nor much beyond the tropic of Cancer on the south." Amyzon, of early Eocene age, is known from strata of the Western States by four or five species, while in individuals it must of ten have been extremely abundant. Diastichus, Gobio, and Leuciscus succeeded, as members of the family spread eastward into Europe, while Thynnichthys and Barbus evolved as east Asiatic genera. Such distribution would suggest that during late Cretaceous or early Eocene time, land connection existed from Western N. America across to eastern Asia. But the existence also of about Ioo species in Africa indicates that numerous derivative types from those that entered N. E. Asia, had spread westward alike into East Europe and Africa.

From the abundance of fossil individuals as well as species of such genera as Tinca, Leuciscus, Rhodeus etc., as described by Reuss and Meyer $(I 88: 49)$, also by Winkler (249: I6), the cyprinoids attained to a dominant freshwater position during the Miocene age. 
A noteworthy feature, phylogenetically, is that the small sub-family Homalopteridae has become environally adapted to life in mountain-streams, from India to China and Borneo. Evidently for the same reason as causes the gradual absorption of the air-bladder in species that become marine, namely the more perfect and rapid aeration of the blood and the tissues, owing to life in constantly agitated and oxygenated water, the air-bladder in these becomes small or is entirely absorbed. Later we shall see that a like principle always holds for other groups or genera in alpine streams.

The Siluridae, along with the derivative and highly modified families Loricaridae and Aspredinidae, comprise fully 200 species. By far the greater number of the I 50 or thereby genera, consist purely of river and lake dwellers, as were all of the fossil types at present known. But while Arius of Eocene times was freshwater or possibly anadromous in one species, the existing species of it have become marine, as have Diplomystes, Galeichthys, Felichthys, and a few other genera, that are found mainly along the eastern American coast. On the other hand, the group Plotosidae of east Asia, evidently represents another and more recently evolved series, most of the species of which have become marine shore-dwellers.

The air-bladder in the Siluridae is not only as well developed as in Characinidae and Cyprinidae, it usually attains even greater size and complexity than in these two families, being often composed of three instead of two chambers, and these may give off secondary lobes. In contrast to this, and exactly simulating the sub-family Homalopteridae, noted above, and the family Loricaridae to be noted below, some like the sub-family Pygididae, have been carried up with what are now high mountain streams of the Andes and other S. American ranges as these underwent elevation. So gradual reduction of the air-bladder has taken place till in some (Cetopsis etc.) it is almost or altogether absorbed.

The Loricaridae and Aspredinidae are highly modified derivatives from the Siluridae, that include about 240 species, most of which are found in brawling mountain streams and rivers of Central and South America. So, as in 
like environally modified groups above named, the airbladder shows all stages of reduction to almost complete absorption.

The above brief study of three important teleostean families and their near allies, brings before us nearly 4000 species, that were evidently wholly freshwater in ancestry, and are almost wholly freshwater still. Furthermore it has been noted that when offshoots have migrated either into brawling mountain streams or oceanward, marked morphological modification on the average structure of each of the three groups has occurred. And not least in all three when such happened, steady reduction almost or quite to the absorption of the air-bladder-a striking hereditary structure derived from ganoid and even more remote ancestry-has been effected.

Now were we to find, either in the fossil state, or in the living state at present, even a few primitive marine representatives, that morphologically might serve as the starting point for origin of those now swarming in lakes, swamps and rivers of four continents, a slight basis would exist for possible acceptance of the view that all originated in the sea, and had gradually invaded inland waters. Instead of this the converse is true, where, as amongst a few of the Siluridae, marine genera or species are encountered. These are clearly derivative and evolved marine members, alike morphologically and distributionally, from the inland forms.

Again all facts of distribution-botanical as well as zoological- emphasize the existence, in former geologic periods, of extensive land-connections that are now sundered. The acceptance of such connections, in correlation with the gradual spread over them of species, genera, and families of freshwater fishes as well as of other groups of animals, at once affords the key to what otherwise are inexplicable problems.

So with Sagemehl we accept it that all three families above outlined, were derivative from some "ganoid" ancestor allied to Amia of freshwater habitat. We would further claim that by direct descent from such, and by gradual migration into wider and wider freshwater areas 
from America eastward, a correct and sure basis is secured for future explanațion and fitting together of morphologic, physiologic, taxonomic, and geographic facts that hitherto have been uncorrelated and inexplicable.

With advent of the Mid and Upper Cretaceous periods, a rich teleost fauna unfolded. For from Cenomanian and specially Turonian age, upward to the close of the Cretaceous, more than 50 genera have been described. The origin of these also proceeded from various more primitive ganoid stocks. Thus the Elopidae exhibit close structural resemblances to the freshwater amioid Megalurus of Kimmeridgean and Purbeck rocks. By mid and upper Cretaceous times however nine or ten genera had appeared in abundance from west-central America to central Europe, most or all of which must have migrated seaward during Neocomian to Gault time. But that they still show decided freshwater affinity is strongly indicated by the fact that the young and the adults of Elops and Megalops still enter rivers freely.

Other families of probably primitive amioid ancestry, or that are derived from some intermediate type between the Eugnathidae and Amiidae are the Albulidae, and the Osteoglossidae, the former of which took to a marine life even during the Cretaceous age. So from some early Cretaceous genus of the former family the widely distributed Albula (Butirinus) of tropical seas, and the deepsea genus Pterothrissus, that closely resembles Istieus of Cretaceous age, seem to have originated.

From the latter and still purely freshwater family, Osteoglossidae, derivative genera like Dapedoglossus of the U. S. Green River shales, and Brychaetus of the London Clay lead up to the four existing genera Osteoglossum and Arapaima of S. America, Heterotis of Central Africa, and Scleropages of Malaya and N. Australia. The distribution of these is of exceptional interest, and resembles many other like cases referred to in subsequent pages. For from some S. American ally of the known N. American Dapedoglossus derivative types seem rapidly to have spread over the lakes, swamps and sluggish rivers of the Gondwana continent, and then multiplying in localized centres of it originated other 
descendant Osteoglossidae. The Notopteridae, and more recently the now purely African family Mormyridae, also the curious derivative and highly evolved family the Pantodontidae, that includes only the West African "freshwater flying-fish," likewise the Phractolaemidae of the lower Niger, and the Hyodontidae or Moon-eyes of western N. America, all show interblended affinities with the Osteoglossidae, and doubtless had common ancestral origin.

These families collectively must have overspread the entire mid-Gondwana continent from western S. America to eastern Australia. The accompanying diagram, in its sectinnal outlines, indicates the present-day distribution of these while the central grouping of them from eastern S. America to central Africa, and thence to India sets forth the probable area of Gondwana-land, as it existed toward the close of the Cretaceous epoch. So as explained more fully on a later page (p. 428) all of the above, as well as the Albulidae, might appropriately be united into a cohort, the Dapedoglossales.

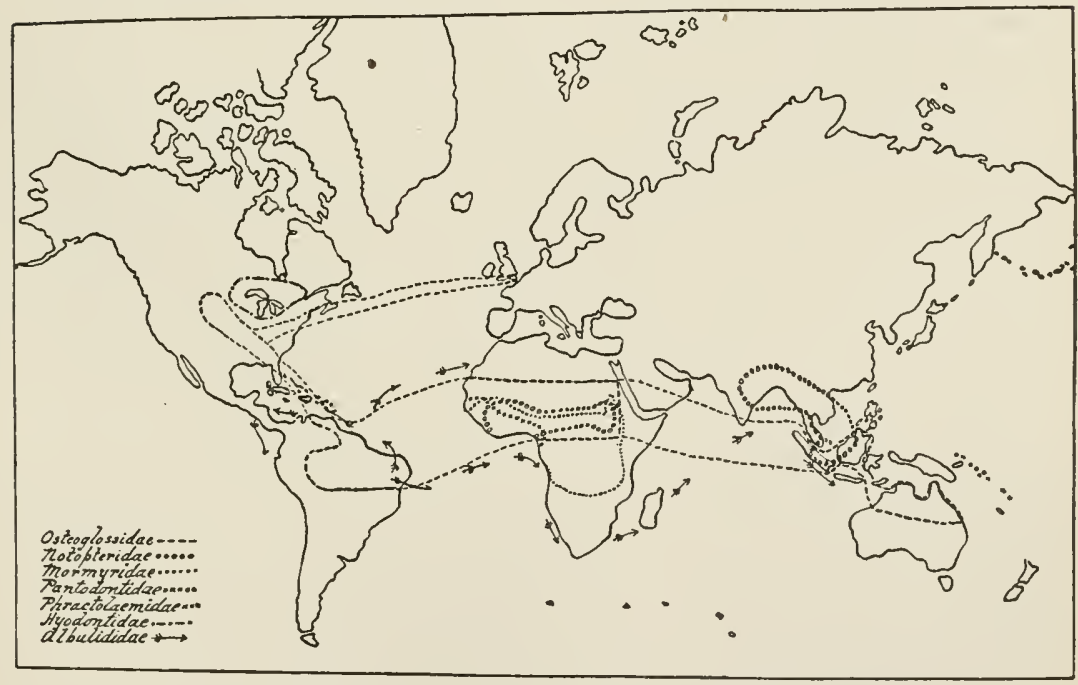

FIG. 57. Distributional outlines of six related freshwater families, also of an allied and probably derived marine family, the Albulidae. The intercontinental connecting lines indicate the former existence of a N. Atlantis bridge, a S. Atlantis bridge, and an Afro-Indian bridge. 
As to the Albulidae, after passing seaward these evidently spread along the warm coastal margin of Gondwana, and later gave rise to the widely extended interoceanic genus Albula, and the deep sea Pterothrissus.

The Chirocentridae-including the Saurodontidae-are probably derived, as stated above, from the freshwater Jurassic Thrissops, and are first recorded from Neocomian freshwater strata (24I), where they are represented by Chirocentrites and Spathodactylus. Chirocentrus of Sumatran freshwater strata, $(250: 438)$ if correctly placed, would then be a direct ecological representative.

Woodward says regarding their phylogenetic affinities: "The primitive nature of the Chirocentridae has long been inferred from the presence of a rudimentary spiral valve in the intestine of the sole surviving species Chirocentrus dorab. This family of fishes is, indeed, now proved to be very old, dating back at least to the beginning of the Cretaceous period, during which it attained its maximum development. Early Cretaceous forms, such as Chirocentrites cannot even be distinguished from the typical species of the Upper Jurassic Thrissops, until the cranium be available for detailed study."

But during Mid-Cretaceous time migration of some types into the sea evidently took place, and by the close of the period genera like Chiromystus, Portheus, Ichthyodectes, and Saurocephalus had taken possession of marine stretches that must have been continuous from Kansas to Central Europe at least, and which doubtless formed part of the marine sea that extended between the northern Atlantis continent and the southern Gondwana. The single living type therefore, Chirocentrus dorab is probably a northern derivative, that has migrated from the seas of China-Japan into the more southerly Indian Ocean. The extensive lists of these Cretaceous marine species given by Cope (25I.272-297) supplemented by those of Stewart (165) and Loomis ( 166 ) might again be mentioned.

The Clupeidae is a family that deserves attention as shedding considerable light on the main thesis of this work. For some of the included species are now freshwater, some are markedly anadromous, while most are purely marine. 
The oldest known genera seem to be Clupea and Crossognathus from freshwater Neocomian strata of the Voirons. Pictet (24I) regards the latter genus as intermediate between the Leptolepidae and Teleostei, while most ichthyologists now place it in or near the Clupeidae. Woodward (ISO: Introd. VII) writes: "The true clupeoid fishes date back to the beginning of the Cretaceous period, and their skeleton is so closely similar to that of the typical Jurassic Leptolepidae, that they may well be direct descendants of the latter." It follows that if the Leptolepidae were all freshwater in origin (p. 344), and largely remained so, the Clupeoids would naturally show freshwater ancestry and affinities.

By the time of the upper Cretaceous, the family, as the writer would interpret, tended to split up into one series typified by Pseudoberyx, the types of which became the forerunners of many Acanthopterii, and these early passed largely into the sea. Another series that remained softfinned split up into groups the species of which retained freshwater existence, like Halecopsis of the London Clay, also some species of Diplomyistus (Fig. 34, p. 238) and Clupea. Others became anadromous, and are now represented by the Thwaite, Allis, and American Shad, which live a considerable part of each year in rivers where they spawn. Still others became permanent sea-dwellers, though "none belong to the deep-sea fauna." The species of Histiotlirissa, Scombroclupea, and of Pseudoberyx from the marine chalk of Mt. Lebanon, also the species of Clupea from Monte Bolca and Miocene beds of Italy, are examples of the marine forms.

In contrast to the Osteoglossidae, the Clupeidae remained almost wholly a northern hemisphere family, though it is instructive to find that some species and even genera extend down along the coasts of S. America and India to New Zealand.

Though not as yet known from Cretaceous strata the family Salmonidae may next be studied. For its close natural affinity to the Clupeidae, its comparatively primitive teleostean structure, and its present geographical distribution, are all of importance. Like preceding teleost 
families a well-developed air-bladder, inherited from ganoid ancestors, is seen in all the freshwater types, and in reduced state usually in marine genera. But in the amphibious Retropinna, and in the deep-sea Salanx it is absorbed.

Subsequent to the cataclysmic volcanic activity that prevailed during late Cretaceous or early Eocene time, and which greatly obliterated ganoid and evolving teleost life, the Salmonidae, evidently derived from freshwater clupeoid ancestry, seem gradually to have spread as genera of colonial fishes, from the Miocene period onward. They are restricted to the northern hemisphere, which they may be said to encircle.

Against a possible marine ancestry for Salmonidae many grave objections can be urged. Thus the more primitive genera are wholly or mainly freshwater, the more evolved ones are marine or even deep sea. Again it is difficult to imagine genera like Salmo, Coregonus, and Thymallus, which show few or no truly marine species, becoming dispersed as they are over land areas of the northern hemisphere, if they originally were marine-even coastal-derivatives. A considerable number further, show the anadromous or "homing" instinct, in that though often migrating seaward to feed, they return to rivers or lakes to spawn. And as is known to all, the efforts some show-like the salmon-in overcoming obstacles in order to reach real inland regions, is one of the most arresting facts in natural history. The swim-bladder, also, is highly developed in primitive and freshwater types, but gradually becomes small and even absorbed in marine species. These with other strong reasons compel the writer to accept a freshwater origin for the family.

Closely related to the last are the Gonorhynchidae and Cromeriidae. The former can be traced back in the genus Charitosomus to upper Cretaceous marine beds of Lebanon, and in Notogoneus to the lower or Green River Eocene of western N. America, as well as the upper Eocene and Oligocene of Europe. The only living species-Gonorhynchus greyi-is met with along the coastal regions of the eastern hemisphere, and the absence of an air-bladder is noteworthy. The latter family consists only of a single 
genus Cromeria, peculiar to the White Nile, and in contrast to the previous genus has "a long slender air-bladder."

Though very doubtfully represented by fossil remains it may here be added that the Stomiatidae and the Alepocephalidae have generally been viewed by ichthyologists $(2: 569 ; 247: 394)$ as closely related to the Salmonidae. They are all marine fishes, and as with a few marine Salmonidae the air-bladder has been absorbed. Such strikingly modified deep-sea fishes as Astronesthes with its phosphorescent organs, Malacosteus with its huge eyes, or Sternoptyx with weird condensed body, are all evidently end-members of a series of Stomiatidae, that in themselves we would regard as evolved salmonid migrants from inland waters.

The pelvic fins of the Alepocephalidae have been absorbed in Platytroctes, while in Aleposomus the scales have ceased to develop. All of these morphological details again suggest that marine fishes are evolved descendants of more primitively freshwater ancestry, and that gradual absorption of the air-bladder goes hand-in-hand with gradual passage into a marine habitat.

In structural, in evolutionary, and largely in geologic relation, the Haplomi or Esociformes succeed the above. If the morphologic character shown in the above groups - that ichthyologists regard as most primitive of the teleosts-be a true index, namely, separation of the supraocipital bone from the frontals by the parietals, then two families of the Haplomi deserve first consideration. These are the Galaxidae and the Haplochitonidae that both show a most suggestive freshwater geographic distribution, though unknown in the fossil state. Galaxias and Neochanna make up the former; Haplochiton and Prototroctes the latter.

"The genus Galaxias has an interesting distribution, the species of which it is made up occurring in the freshwaters of the Southern Hemisphere, viz 8 in New Zealand and neighboring islands, 7 in N. S. Wales, 3 or 4 in S. Australis, I in W. Australia, 2 in Tasmania, 7 in S. America from Chile southwards, and I at the Cape of Good Hope. One species ( $G$. attenuatus) is even believed to be identical in New Zealand, Tasmania, South Australia, the Falkland Islands, and South America. This conclusion is probably 
correct from the fact, which may account for the distribution of the whole genus, that it is not confined to freshwaters, but occurs also in the sea " $(2: 607)$."

Though the above conclusion is strongly urged by so eminent as authority as Boulenger (252:84) the writer would venture to give a different explanation, and one that will apply equally to the Haplochitonidae. It is that these represent southern stranded outliers of ancient teleosts, which inhabited, in continuous relation, areas of an extreme southern continent, before final breaking up of that land mass took place. For one may well ask why it was that the same species or genus of marine fish took to rivers of three continents, as well as the outlying New Zealand islands, without leaving a better remnant than one marine species now. Again they possess an air-bladder as a ganoid heritage. So the sole marine species of the Chatham Islands could appropriately be viewed as a marine derivative from an evidently ancient freshwater stock; while Neochanna retains its old environment in New Zealand.

The same line of reasoning would apply to Haplochiton that is alone found in freshwaters of Patagonia, Chile and the Falkland Islands; and to Prototroctes, that is represented by one species each in New Zealand, Queensland, and S. Australia. But the entire question raises issues of so wide a kind that the writer devotes a subsequent chapter (Ch. I 5 ) to its discussion.

In seeking however for the earliest known types of the Haplomi (Esociformes) one is carried back to Upper Cretaceous times, and largely to what seem truly marine strata. For the families Enchodontidae, Scopelidae, Chirothricidae, and others are well represented in strata of those times. Greatly as already described for Clupeidae, it can be suggested that the primitive types of Haplomi developed first in the early Cretaceous period or possibly in the late Jurassic period. Next, between that period and late Cretaceous days, a splitting ecologically of the group seems to have taken place. This resulted, during the later Cretaceous and early Tertiary period, in development of such families as the Esocidae, Dalliidae, Kneriidae, Cyprinodontidae, Amblyopsidae, and Percopsidae that remained in 
rivers and lakes; also of the Enchodontidae-which disappeared at close of the Cretaceous-likewise of the Scopelidae, Aleposauridae, Chirothricidae, and Stephanoberycidae, that gradually spread into marine environment.

The most ancient now known is the Enchodontidae, which seems to be made up typically of marine animals. Whence derived it is impossible to say till connecting links between "ganoids" and the modern Haplomi are obtained. All of them disappeared during the cataclysmic period that brought to a close eastern Cretaceous deposits. But the view is generally accepted that the Aleposauridae of the Scopelidae are near living examples.

The natural group of families that has in recent years been called the Heteromi or Notacanthiformes is evidently a very ancient one. For three of the five component families, viz Dercetidae, Halosauridae, and Notacanthidae are all encountered in upper Cretaceous marine rocks from central Europe south-ward to Lebanon. But like the Enchodontidae they are also found in the Cretaceous of N. America. Now since apparently reliable remains of Enchodus have been described from the Greensand, also from the Niobrara of N. America and from still higher strata of Mid-Europe, it seems not unlikely that all evolved from some still earlier clupeo-salmonid freshwater ancestor of western North America. In the living forms the airbladder is still retained, but is a closed sac.

The Scopelidae were well represented in the Cretaceous by at least ten genera, and the Chirothricidae by three, all of which disappeared at the close of the period. But evolving collateral descendants must have carried both families on into Eocene and later periods. So the full century of living species are known only as marine inhabitants. Many also of them are highly modified, in structure and in phosphorescent material, as deep-sea fishes.

Like remarks apply to the usually highly modified Stephanoberycidae and Aleposauridae, all of which are, and seem through long past time to have been, marine. It seems impossible however at present to trace their earliest derivation from ganoid ancestors. But it may be added that a gradual absorption of the air-bladder is proceeding 
from the Scopelidae onward. For in some of these it is fairly large, in others absorbed; in some of the Stephanoberycidae it still exists; but in the most highly modified Aleposauridae and Chirocentridae it has been wholly absorbed.

The remaining freshwater families of the Haplomi form a striking series, alike as to structure and distribution. The Esocidae or Pike family, though only known back to the Miocene period suggests in its distribution, a much more remote ancestry. For while made up of but two genera, Esox and Umbra, the former has gradually spread across the entire northern hemisphere. Since several species of Esox have been described from central European strata of Miocene age; since the only two species of Umbra are found one in Austria, and the other in the eastern United States and Canada; and since species of Esox connect these widely apart regions, it is highly probable that the group spread from Europe across Asia and thence across N. America to its eastern seaboard. The peculiarly modified genus Dallia of eastern Siberia and Alaska, suggests ancient derivation-as a side-line of organic evolution-from some type allied to Umbra. It also indicates that Umbra itself once had a much wider range.

But the more evolved family Cyprinodontidae is even more arresting. The group is first known from freshwater Miocene beds of Central and South Europe in the form of the genera Prolebias (Fig. 40, p. 249) and Pachylebias. As the figure shows, the former of these must have lived and been killed in swarming shoals. Little trace is known of them in more recent deposits till we reach present-day types. Of these there are about 200 species, which are almost wholly dwellers in rivers, lakes or swamp-lands of the United States, of central and S. America, of all Africa, and a skirting south-western part of Asia on to Borneo. But in some species, mainly belonging to Fundulus, a tendency toward marine life is noted. Thus while most of the species are truly freshwater, three occur in rivers and lakes of the Eastern States, but frequently pass out to, and are abundant along, the seacoast. Some species of Cyprinodon again 
of N. Africa are at home in brine pools, certain of which even may be of relatively high temperature.

While numerous genera and species however occur over the area above indicated, none are met with in intervening seas and estuaries, aside from the three migrants just noted. But if we consider the group to have already developed in earliest Eocene times, while S. America was joined by S. Atlantis to Africa, and it again connected by a slight bridge with S. Europe on the north and with S. W. Asia in eastward extension, a complete understanding of the problem is got. On the other hand endless difficulties arise in attempting to explain their origin from marine ancestors. For of such we have no trace. But had such once existed, some common impulse, such as we practically never notice in true marine species, must have caused them to press inward and upward along rivers, so as ultimately to reach, as in the case of Orestias and others, the waters of Lake Titicaca at $\mathrm{I} 3,000 \mathrm{ft}$. elevation. We have already satisfactorily explained the origin of the striking fish fauna of this lake, without needing to resort to marine sources.

Further, why do a few venture seaward in rare cases, but none become ocean dwellers? In face of these and many other related difficulties, we are compelled to accept an ancestral freshwater environment, alike for the whole family and its predecessors. That no trace of them occurs in the Australasian area, suggests that their main evolution proceeded after Sino-Malaya had been separated from Australasia in the later Oligo-Miocene period.

The family that has been designated the Scombresocidae next deserves mention. For its structural peculiarities ally it with the Cyprinodonts. But the entire group is now marine environally, and more or less highly modified in structure. It first appears in the Upper Eocene, and so time was given for possible derivation of the group from a more primitive freshwater early Eocene stock.

Resulting as two restricted side-lines and modifications from the Cyprinodontidae, as did the Dalliidae from the Esocidae, are the small freshwater families Amblyopsidae and Percopsidae. 
The former consists of a compact set of genera and species that are met with over the eastern half of the United States. The interest attaching to them lies in the fact that, following the universal law of action and reaction between environment and organism, while in Chologaster the eyes are well or fairly developed, the body is lithe and plump, and the skin is finely colored, the allied genera $A$ mblyopsis and Typhlichthys have migrated from the light into the darkness of the extensive caves over the east-central States. As light stimulated and evolved optic organization, with all its associated neuro-muscular connections, so also has its removal caused, in the progressively degenerating types Chologaster agassizi, Amblyopsis, Typhlichthys, and Troglichillys, progressive absorption of the eyes and their related mechanisms, as well as blanching of the skin-color, till in the last it almost reaches to the point of complete absorption.

The Percopsidae is regarded by the writer as a family of exceptional importance phylogenetically. This view has already been set forth by skilled ichthyologists. Thus Boulenger $(2: 620)$ writes: "This is a most interesting group of fishes, from the resemblance which they bear to Perches, and they have therefore been raised to the rank of a suborder, Salmopercae, by Jordan and Evermann, who regard them as 'archaic fishes, relics of some earlier fauna, and apparently derived directly from the extinct transitional forms through which the Haplomi and Acanthopteri have descended from allies of the Isospondyli (Malacopterygii). On the other hand an analysis of their characters shows them to belong to the Haplomi, of which they may be regarded as highly specialized members, having evolved in the direction of the Acanthopterygii."

Percopsis and Columbia, each with a single species, are found from North-central Canada westward to the Columbia river, and southward to Kansas and Ohio. Such distribution suggests that the great set of lakes of late Upper Cretaceous, Eocene and Miocene age, referred to by Cope and many others since, and which occupied a large part of west-central N. America, were not only extremely rich in 
individuals and species, they almost surely were the centres also for evolution of new connecting genera and families of teleosts.

It may also be emphasized here, and will be returned to later, that in this region was the organic centre for the Aphredoderidae, usually made a small freshwater division of the marine Berycidae, but which during lower Eocene and later times included such freshwater genera as $A m p h i$ plaga, Asineops, Erismatopterus, Trichophanes, and is now represented by the single species Aphredoderus sayanus of the Mississippi valley and eastward.

The true interpretation for the family evidently is that it combines transition characters from the SalmonidaeClupeidae to the Haplomi, and thence on to the Percidae and Berycidae, while the past and present distribution of the genera strongly indicate that the $\mathrm{N}$. American lakes formed a great organic focal centre in which freshwater, and in some cases what later became marine, families evolved, and then radiated out.

The alliance of families that ichthyologists have united as the Hemibranchii, Catosteomi, Thoracostei or Phthinobranchii, is a transition series between the soft-finned and the spiny-finned fishes that are of great interest, alike from the structural, palaeontological and distributional standpoints. Though unknown in the fossil state the Gastrosteidae or Sticklebacks, indicate equally by their generalized structure and practically continuous distribution over freshwater regions of the Northern Hemisphere, that they are a very ancient family. The presence also, in Upper Eocene and in Miocene strata, of freshwater species of the allied but greatly more specialized families Aulorhynchidae, Fistulariidae, Centriscidae, and Syngnathidae that are now wholly marine, is also highly suggestive. The writer would propose the following as explanatory for the gradual evolution and distribution of the entire group.

Derived, like Pseudoberyx, also like the Percopsidae, and the Aphredoderidae, from a more primitive clupeosalmonid stock, the five genera of Stickleback, namely Gastrosteus, Pygosteus, Apeltes Eucalia and Spinachia, are met with in streams, pools and ponds across the entire North 
Temperate zone. In such environment, the true Sticklebacks construct special nests for the eggs and young. But they have invaded, and become thoroughly at home in, brakish water, while several species, such as the common $G$. aculeatus inhabits equally American and European seashores. The more evolved and abundantly spined Pygosteus is essentially marine, while Spinacia vulgaris is the Sea Stickleback.

That we have here to do with a real case of seaward migration of a primitively freshwater group is perfectly indicated by some observations of Jordan who says (253:229): "The sticklebacks inhabit brakish and freshwaters of Northern Europe, Asia and America. The same species is subject to great variations. The degree of development of spines and bony plates is greatest in individuals living in the sea, and in clear streams of the interior. Each of the mailed species has its series of half-mailed or even naked varieties found in the freshwaters. This is true in Europe, New England, California and Japan. The further the individuals are from the sea, the less perfect is their armature. Thus Gastrosteus cataphractus, which in the sea has a full armature of bony plates on the side, about 30 in number, will have in river-mouths from 6 to 20 plates, and in strictly freshwater only 2 or 3 or even none at all."

Here we would claim is a clear case where migration from fresh to salt water has still left us in the individuals, the varieties, the species and the genera of a group, with morphological as well as distributional stages of progression that become highly indicative for other but less plastic genera or families.

The Aulostomidae and Fistulariidae are now two divergent but related families, that have branched off from some member or near ally of the Gastrosteidae, but which show connection with it by the Tertiary freshwater genus Protosyngnathus of Sumatra. Both families however, have now become marine, as are the still more divergent, but derivative families Centriscidae, Syngnathidae, and Pegasidae, some of which have become remarkably modified, as for example the flute-mouths, sea-horses, and pipe-fishes of tropical and semitropical seashores. 
So in the division Catosteomi an excellent example is furnished in the freshwater stickleback, of a primitive and comparatively simple organization, of progressive advance in defensive armature when some members became marine, of added advance when other and allied genera passed seaward permanently, and of final weird modification along lines of protective simulation and defence, in those that have become condensed and highly modified shore or ocean dwellers.

Of the soft-finned teleosts there remains a heterogeneous assemblage, the constitutent families of which will doubtless in time be referred to other and appropriate alliances. This assemblage has variously been called the Percesoces, Percomorphi, or Mugiliformes, and includes the garpikes, sandeels, flying fish, mullets, etc. Technically the families are the Ammodytidae, Atherinidae, Mugilidae, Polynemidae, Chiasmodontidae, Sphyraenidae, Tetragonuridae, Stromateidae, Ophiocephalidae, and Anabantidae. Some of these are treated of below; of the remainder it seems best to the writer to leave most of them till more wide and exact details are secured regarding them. But the presence of one or more dorsal fin-spines in many of them, indicates that transition from soft-finned to spinyfinned types has been a gradual process, and one that several lines of families may have passed through.

The Atherinidae or Silver-fishes consist of some I 5 genera and 70 species, the simplest types of which, and the richest in species, are Atherina and Chirostoma. Atherina and the allied genus Rhamphognathus are first recorded from the Upper Eocene to Miocene marine rocks of S. E. Europe, and mainly from the Monte Bolca deposits. But the existing species of Atherina are either freshwater, or anadromous, or marine. Chirostoma has been shown by Jordan, Snyder, and Meek to include a large assemblage of species native to and very abundant in the lakes of central Mexico. "Another small species, very slender and very graceful, is the brook Silver-side, Labidesthes sicculus, which swarms in clear streams from Lake Ontario to Texas" (253:2I 7 ). But migration seaward, during late Cretaceous or more likely early Eocene times, of species of Ather- 
ina and other genera, passage of these eastward to Europe along the N. Atlantis shore, and evolution of new genera, alike in N. American, European, and later in Asiatic seas, then proceeded. But these marine genera, which include Kirtlandia, Atherinopsis and Basilichthy's of American waters, Iso of Japanese waters, and Atherinosoma of Australia are nearly always more specialized in structure than are the freshwater types.

The small family of the Ophiocephalidae probably is an evolved and modified offshoot from freshwater forms of the last which passed from American lakes-where they are now absent-along the northern borders of the $S$. Atlantis bridge to Africa and later to Asia. While 3 species of Opliocephalus are now found across tropical Africa, 25 species are scattered eastward across Asia, and the only other genus Channa includes 3 species from Ceylon to China. The absorption of the ventral fins and of pyloric appendages in the latter genus, indicates that it has become modified along devolving lines during its passage eastward. It would be of interest to learn what environal factors have operated to produce such results.

The Mugilidae is represented in the lower freshwater Oligocene of Aix-en-Provence and similar central European strata by species of Mugil. But they must have existed even earlier over a wide area. For land connection must still have persisted between Europe and America to permit the presence of freshwater genera in the latter country. Regarding two of these Jordan says: "The genus Agonostomus includes freshwater mullets of the mountain rivers of the East and West Indies and Mexico, locally known as trucha or trout. A. nasutus of Mexico is the best-known species. The Toturo or Bobo, Toturus pichardi, is a very large robust and vigorous mullet, which abounds at the foot of waterfalls in the mountain torrents of Cuba, eastern Mexico, and Central America."

From its structural characters we would regard Agonostomus as more primitive and simple than Mugil or Myxus, for the absorption of teeth, the mode of feeding, and the related pharyngeal modifications, the complicated stomach, as well as the numerous points of skeletal advance in Mugil 
proclaim it a more evolved genus than Agonostomus. The latter, in its species, is not only freshwater, the II-I2 species are found from Mexico and Central America to Mauritius, the East Indies, Australia, Tasmania and New Zealand. Of the nearly 70 species of Mugil, about onethird are dwellers in freshwater or brakish water from $\mathrm{N}$. Africa, the Nile, and the Cape, eastward to rivers of the East Indies; the remaining two-thirds are scattered along coasts from the West Indies and Mexico eastward to India, China and even Australia.

Of the common striped mullet (Mugil cephalus) Jordan says (254:2 I9): "This is found throughout eastern Europe, and from Cape Cod to Brazil, from Monterey, Cal. to Chile, and across the Pacific to Hawaii, Japan and the Red Sea. Among specimens from all of these regions we can detect no differences."

We would regard all as of freshwater and central American origin. As they multiplied some spread abroad to Africa and later to Asia, where they still persist. Others early took to marine coastal life, and became distributed along lines nearly parallel to those pursued by the denizens of freshwaters.

But derivative and often striking genera seem to have branched off from members of the above three families, to constitute the remaining families already named. Nearly all of these are now marine and spread over the seas of the world. Thus of the Chiasmodontidae we need only refer to the highly modified pelagic and deep-sea genera like Chiasmodon and Champsodon; of the Ammodytidae to the vermiform sandeels (Ammodytes); and of the Icosteidae to the ragfish Icosteus and the giant Acrotus. Further, if the steady retention of an air-bladder is a delicate guide or indicator, then its continued presence in most of these might indicate that their invasion of the sea was relatively of recent date.

The Anabantidae, and Osphromenidae occupy a territory that is almost exactly co-extensive with that of the Ophiocephalidae. No marine derivatives of them are known, though the Climbing Perch (Anabas scandens) sometimes passes into the estuaries of tropical east Asiatic rivers. Both 
families show striking affinities with the Ophiocephalidae, and they all agree in having a superbranchial respiratory or accessory gill cavity, that enables some of them to breathe air directly. This is specially true of the climbing perch. There seems also to be a progressive tendency to the formation of an increasing number of fin-spines, from the Ophiocephalidae in which they are absent, to the Anabantidae in which the dorsal, ventral and anal are more or less spine-rayed, then to the Osphromenidae, in which the genus Betta has none, others like Osphromenus may have as few as 2 or as many as I 3 spines in the dorsal fin.

The group of three families that ichthyologists have united as the Anacanthini or Gadiformes form a puzzling series whose affinities and evolution seem as yet difficult to trace. With the exception of the genus Lota all are marine fishes.

In proceeding from the present series of soft-finned teleosts just dealt with, to those with spiny fins that are treated of in the next chapter, several noteworthy and coincident changes gradually occur that deserve emphasis here. First: attention has repeatedly been drawn in preceding pages to the fact that when teleosts pass either into the sea, or upward into the agitated waters of alpine streams, reduction in size of the swim-bladder to the point of complete absorption frequently takes place. Second: In passing from the soft-finned to the spiny-finned groups, steady increase in the number and distribution of the dorsal finspines proceeds, often also in the spines of the pelvic and anal fins. So instead of only I-3 anterior dorsal spines, as in some families and genera like Percopsis and Columbia, or Gastrosteus and Spinachia, most or all of the dorsal rays may become so modified. Third: while, in the ganoids and in nearly all of the teleosts already reviewed, the pectoral and the pelvic fins are distant from each other, the former occupying a thoracic and the latter an abdominal position, a shifting forward of the latter takes place, till they are sub-thoracic, thoracic or even jugular in position. Already we have dealt with some prophetic types, like the Percopsidae (p. 364) and Gastrosteidae (p. 366), in which such transition is taking place; while those treated in next chapter 
show the completed change. Fourth: where all of the above three changes are observed to be proceeding coincidently, the fishes showing such are often passing, or have passed in some genera from a freshwater to a marine habitat.

Special reference need not be made here to anatomical details that have contributed to some of the above changes, as these are dealt with later. But it should be added, that while these changes are broadly and fairly minutely applicable throughout, they are indicative rather than absolute.

A review of the observations set forth in this chapter causes the writer to accept that from preexisting leptolepid or amioid stock of Cretaceous or early Eocene age, most of the existing genera and species of malacopterous teleostean fishes are descended. The most active and extensive area of evolution evidently was the great system of freshwater lakes that once covered a large part of the N. American continent, though this need not preclude the former existence of other and even large lakes which may have been located over that part of North Atlantis that now is submerged beneath the Atlantic. There is ample and everincreasing evidence also, that great stretches of freshwater existed along the eastern part of South America, and that these were populated by an abundant fish fauna. See for this the author's work "Fishes the Source of Petroleum" (p.p. 286-288). An acceptance of the primitively freshwater origin of these malacopterous fishes, and of the later migration of some derivative groups into the sea, furnishes the important Key to their present-day structure, affinities, ecology, taxonomy, and distribution. 


\section{CHAPTER XIII.}

\section{The Evolution of Fishes.}

\section{(5) The Spine-Finned Teleostei.}

The observations already made (p. 348) as to our preponderant knowledge regarding the occurrence and preservation of marine over freshwater organisms during the Cretaceous, applies also to a large extent, when we start to trace the earliest reported occurrences of the spiny-rayed teleosts or Acanthopterygii. But the writer trusts that, by adoption of a process of comparison and elimination, he may be able to set forth the correct main lines of their evolution, and at least approximately when such took place.

As a biological and ecological feature of great interest also, he would recall Jordan's statement (p. 366) as to the production of an increasing number of fin-spines in species of Stickleback, as these pass from a freshwater to a marine environment. For in this connection it may at once be said, no matter how we may explain the fact, that in contrast to the soft-rayed teleosts, which are largely freshwater, the species of Acanthopterygii are largely marine. Further the pelvic fins are subthoracic, thoracic to jugular in position, and the air-bladder becomes usually a closed sac-specially in types that remain freshwater,-or undergoes reduction to final absorption as is largely true of marine types.

Now, if the Teleostei are derived from a "ganoid" or holostean ancestry, some connecting types must have lived, or even may survive now, that are annectant in structure between the ganoids and typical Acanthopterygii, and especially that show in combined relation, progressive forward movement of the ventral or pelvic fins, gradually increasing hardening of the dorsal and it may be the pelvic and anal fin-rays, closure and even absorption of the airbladder, and gradual absorption of the mesocoracoid arch. All of these requirements are satisfied in a set of living fishes that comprise in progressive relation the Salmonidae, the Percopsidae that is made up of the two living genera Percopsis and Columbia, Aphredoderus that has been vari- 
ously referred to the Percidae or the Berycidae or even made into a separate family, but which from the studies of Starks is most probably a percoid, and finally the varied genera of the Percidae. It may be well then to look more closely into their affinities and nearest allies.

The Salmonidae, evidently closely allied to and descended from freshwater Clupeidae like Diplomystus of early Eocene rocks, are only known by fossil remains from the Miocene onward. But the brittle and destructable character of salmonid bones probably explains their absence from earlier strata, such as the Upper or Mid-Cretaceous. The Percopsidae are unknown in the fossil state, but the two genera Percopsis and Columbia, both native to rivers of N. America, are truly annectant between soft and hard spined types. So Jordan says (253:24I) "Two species only are known among living fishes, these emphasize more perfectly than any other known forms, the close relation really existing between spinous and soft-rayed forms. The single family of Percopsidae would seem to find its place in Cretaceous rocks, rather than in the waters of to-day." The existence of mucous cavities in the bones of the head of these, at once suggests possible affinity with such percoids as Acerina.

Aphredoderus, represented only now by one living species, found in streams of the Mississippi valley, was undoubtedly once represented by abundant freshwater ancestral fishes in Eocene lakes of N. America. For Cope has described Amphiplaga, Asineops, Erismatopterus, and Trichophanes, from the Green River Shales or from the Florissant beds of the Western States. In these the dorsal, pelvic, and anal fins all show one to three anterior spines. The transition from the last to the varied genera of the Percidae is an easy one, and doubtless also was in evolutionary continuity.

So the writer would accept it, that from primitive freshwater clupeoid and salmonid ancestry of early Cretaceous to Eocene age, and probable American habitat, three more or less divergent lines arose. One of these now ends in the highly modified Pantodontidae of West Africa, another, that early became a marine derivative, gave origin to the 


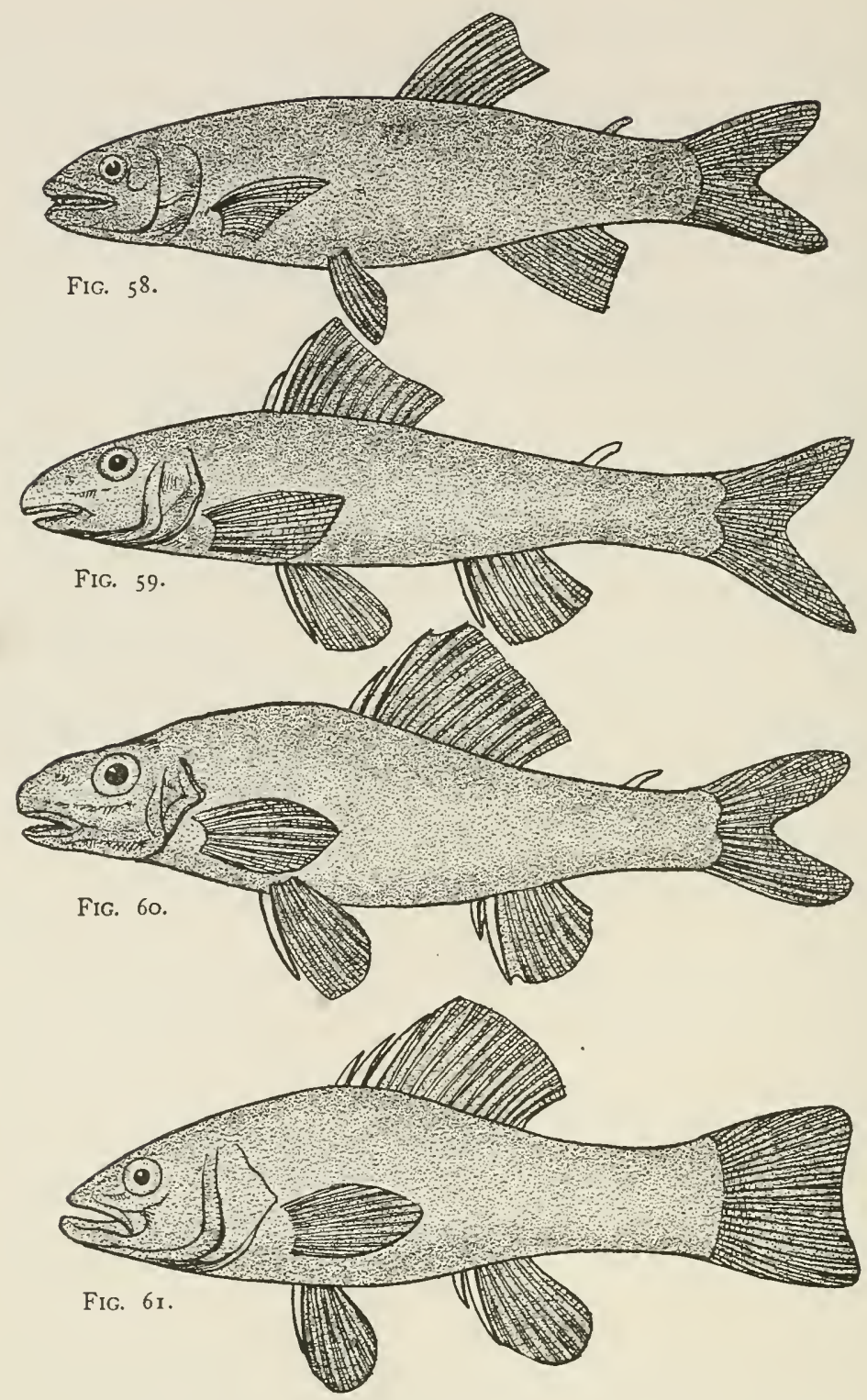

Comparative views of modifications in structure of fins as transition is made from a soft ${ }^{-}$to a spine-rayed state. Fig. 58. Prototroctes oxyrhynchus, (after Guenther); Fig. 59. Percopsis guttatus; FIG. 60. Columbia transmontana; FIG. 6r. Aphredoderus sayanus. (After Jordan). 


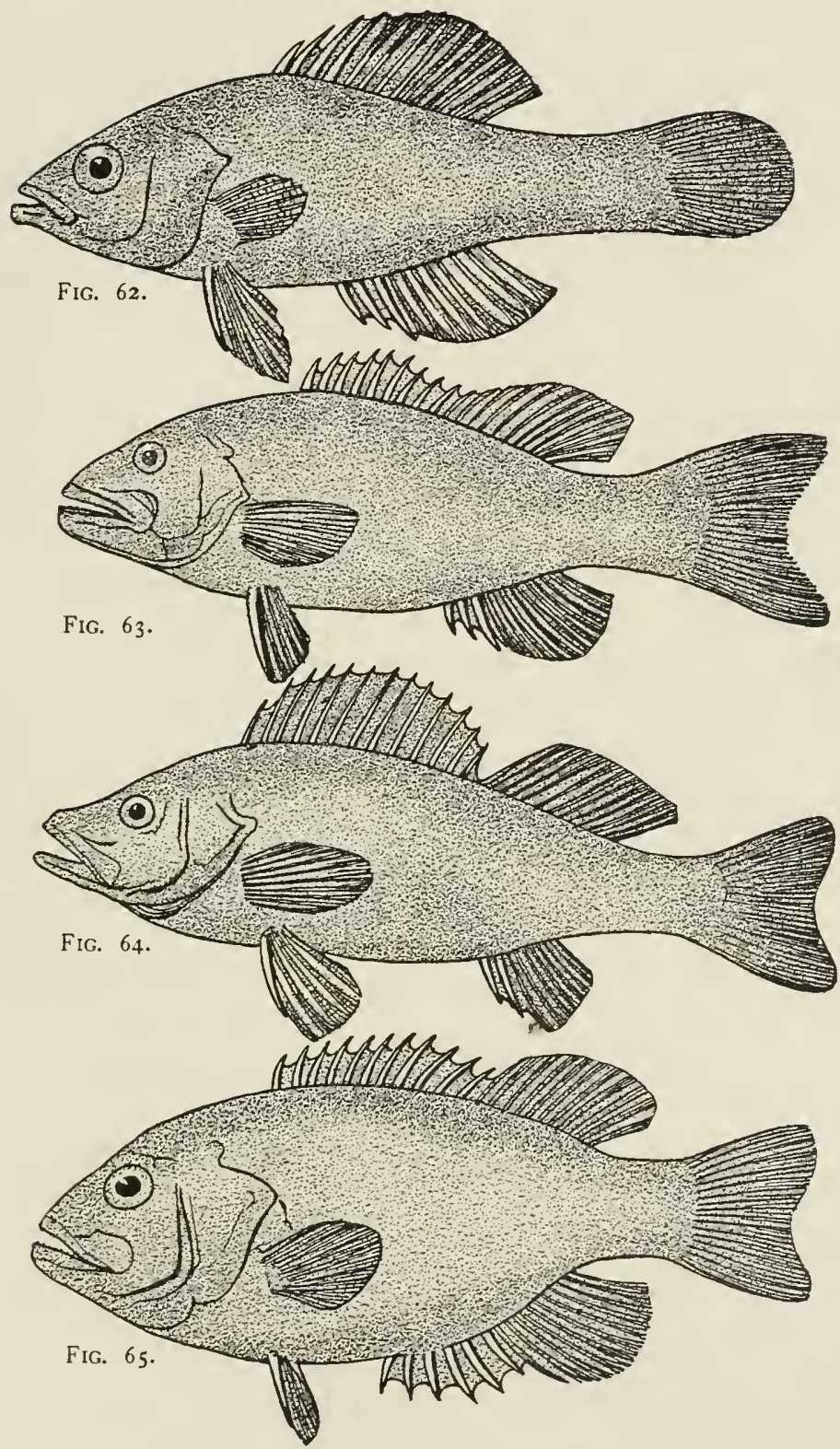

Comparative views of modifications in structure of fins, (cont'd.). Fig. 62. Elassoma evergladei; Fig. 63. Micropterus dolomieu; FIG. 64. Perca flavescens; Fig. 65. Ambloplites rupestris, (all after Jordan). Scales are omitted throughout. 
Ctenothrissidae, another and for our present purpose important, line, leads from Percopsis and Columbia, through the Aphredoderids to the percoid types.

If such a related series as the writer has presented, is appropriate and evolutionarily correct, it should probably be possible to trace a fairly continuous line of descent, along with possible side-lines for the entire series of spiny-finned teleosts, as descended from soft-finned forms, which in turn were derived, as now commonly accepted, from a ganoid ancestry. The series of illustrations on p.p. 374,375 sets forth what the writer would present as a possible outline grouping of such a phylogenetic continuity.

From Cretaceous clupeoid and salmonid ancestors then of Cretaceous age we would consider that the Percopsidae arose, and these again originated the Aphredoderidae. But already during late Cretaceous and early Eocene time the last were evolving into a group of freshwater genera from which sprang, the Centrarchidae and Percidae, and into a group of marine genera that evolved as the Beryciformes, and the nearly allied Scombriformes. The Perciformes in turn gave rise to such important freshwater families as the Cichlidae, the Nandidae, the Serranidae and the Lobotidae, the two latter of which in turn gave off genera that passed seaward and became modified derivative genera.

But, as will be fully described later on, the Chaetodontiformes, the Scorpaenidae, and the Gobiiformes again separated off as seaward derivatives of the Percidae, and then evolved into the varied, often highly modified and somewhat degraded, fishes that will be referred to below.

To compare now somewhat closely the constitution of salmonid-percopsid and derivative fish-fins, the first of these, Prototroctes shows (Fig. 58) an adipose dorsal fin, the soft-fin rays of the main dorsal fin are $I 2$, the anal rays are 8 , and those of the ventrals are 8 . The position of the ventral fins is between the vertical line of the dorsal and the pectorals. In Percopsis (Fig. 59) there are 2 spines and 9 soft rays in the dorsal fin, I or 2 spines and 7 soft rays in the anal, and one spine also 8 soft rays in the ventrals. In Columbia (Fig. 60) there are 2 spines and 9-Io soft rays in the dorsal fin, 2 spines and 7-8 soft rays in the anal, 
and I spine with $S$ soft rays in each one of the ventrals. In all of these also the salmonid adipose dorsal fin still persists.

In the living species of Aphredoderus (Fig. 6I) there are 3 spines and II-I 2 soft rays in the dorsal fin, 2 spines and 6 rays in the anal, I spine and $S$ rays in the ventrals. But here the adipose fin if originally present, has now failed to develop. From the last to such genera of the Centrarchidae and Percidae as are shown in Figures 62, 63,64 and 65 , the transitions are beautiful and gradual, up to such evolved and specialized types as the Yellow Perch, (Perca flavescens) of the Eastern States and Amblopletes as well as many related forms.

We can now pursue study of the evolution and distribution of the Acanthopterygii as a whole. Prolates heberti from the Upper Cretaceous strata of Mont Aimé, in France, seems to be the oldest known type. But simultaneously, so far as can be determined at present, various genera of the nearly related Berycidae had also appeared in marine strata. We can explain the evolutionary continuity of the Berycidae with the earlier types of freshwater Aphredoderidae, but there seems no good means for explaining the appearance of the Berycidae except from such a freshwater source.

As to the possible centre of such origin, all present data point to the extensive lake-regions of Western America. For though the sea extended over considerable parts of eastern and southern North America in Cretaceous-Eocene times, a large lake or lakes persisted more or less in the central-western part, up even into northern Canada. In truth to understand the probable origin of the rich freshwater fish-fauna that Leidy, Cope and more recent workers have described, we must suppose the previous existence near there of abundant progenitors in large lakes.

We accept it then as most consonant with all known facts, that by Mid Cretaceous time the freshwater Centrarchidae and Percidae, also the marine Berycidae, had already diverged ecologically into two distinct environal areas, and were starting evolution of the varied genera that now make up each of the three families. 
Until much more is known about fossil forms, one can only speak in the most general way as to the above centre of origin. But when we note that the living Percopsidae and Aphredoderidae, as well as several fossil Eocene genera of the latter are or were inhabitants of N. W. America; that the Centrarchidae-which are an advance on the second-consist of 9 genera and 24 species that also are N. American, except for Kuhlia that occurs in fresh and brakish waters of rivers from Central Africa to N. Australia; that of living Percidae there are 12 - 14 genera with about 90 species, of which 9 genera and 76 species are N. American, while 3 decidedly evolved genera and Io or I I species extend from N. America to W. Europe thence to N. Asia and Australia, strong grounds are furnished for accepting N. W. America as the primitive centre of evolution for the primitive Acanthopterygii.

Again in the Aphredoderidae, the Centrarchidae, and the Percidae, community of structure and descent is suggested with the Percopsidae, in that muciferous canals are developed in some genera of all four great groups, while other structural features show close affinities throughout. Finally not a few of those which have travelled furthest from the N. American continent show a more evolved structure than do the most specialized of those that still exist there.

In a succeeding chapter various details of structure that bear on the geographical distribution will be presented. But here one may appropriately refer further to some points of special geographic interest. To treat first of the Centrarchidae that seem perfectly to unite the Aphredoderidae with the Percidae, these are all N. American except Kuhlia. Except for one or two, nearly all are centred east of the Rocky Mountains (Fig. 66). This might indicate that they mainly evolved after the later extensive upheaval of these mountains. But the remarkable distribution of the six known species of Kuhlia would indicate that during early Tertiary times a few Centrarchids had passed down to S. America, and then migrated over Koken's South Atlantis. For thus alone does it appear possible and likely to people regions that include $\mathrm{S}$. and $\mathrm{E}$. Africa, the Mascarene 
Islands, Seychelles, Indian Ocean, Malay Archipelago, New Guinea and Caroline Islands. (255:36-40).

The small family of the Nandidae shows close affinity with the Centrarchidae, through such genera as Lepomis and specially Kuhlia. Like the latter genus also the distribution is striking. For Badis, Catopra, and Nandina are found in freshwaters from Bengal to Borneo and thence to the Moluccas, Polycentropsis occurs in West Africa, while the highly modified Polycentrus and Monocirrus occur in freshwaters of Essequibo and Brazil. But these again lead almost insensibly, as Günther and others have suggested, to the group of families that in the older classifications were known as the Pharyngognathi.

The Percidae are even more suggestive. While 7 of the 12 recognized genera are purely N. American, and one rather primitive genus Etheostoma alone includes 45 species, the two relatively recent and highly evolved genera Perca and Lucioperca include between them 8 species, some of which are N. American, and others are common to $\mathrm{W}$. and E. Europe on to West and East Central Asia. These therefore, probably crossed the N. Atlantis and Islandic bridge, and later spread into $\mathrm{E}$. Asia during Miocene time. Such would explain also the presence of three highly evolved genera, namely of Aspro in the Danube, of Amper in the Rhone, of Percarina in the Black and Azov Sea areas, and of Acerina from Britain eastward through central and north Europe to the Danube, Galicia, S. Russia, and thence eastward to Lake Baikal (Fig: 66).

The family that has not inappropriately been called popularly the Sea Perches, namely the Serranidae, now deserves consideration. For the included genera evidently form a natural group that has gradually branched off from a more primitive percoid ancestry, and has broken up into many genera-about 50-a few of the more percoid of which still inhabit freshwaters, a few others are brakish inhabitants, but by far the most abundant and most highly evolved genera are now marine.

Accepting the number and nature of the fin-rays as a helpful guide to the explanation of progressive structural advance, it may be said that the existing genera Morone, 
Centropomus, and Lates approach near to the Percidae. For the fin-formula (Dorsal I spine, 7 - 8 soft rays; ventral I spine, Io-I 2 rays; anal 3 spines, $6-9$ rays) indicates an intermediate condition between average simpler percoids and the higher Serranidae, while Percichthy's and Percilia are rather more advanced. Now these are five of the ten genera that are all typically freshwater. But these five, in geographical distribution, are fairly typical of the ten. For Morone (Roccus, in part) mississippiensis and $M$. multilineata are thoroughly freshwater; $M$. americana inhabits rivers and streams, but is at home also along the Atlantic coast from Nova Scotia to Carolina. M. lineata is anadromous, while $M$. labrax and $M$. punctata are essentially coastal fishes.

Percichthys in its three species, and Percilia in its one species, inhabit the river-systems of Chile and West Argentina; Centropomus, in its seven species, inhabits riversystems from Cuba, Jamaica, and Panama, southward to Rio Janeiro and interior Brazil ; but they also pass out freely into coastal regions of this area. Of the two known species of Lates, one, L. niloticus is common to Senegal, the Niger, and the Nile, while L. calcarifer inhabits "Coasts and mouths of rivers of S. E. Asia, from India and Southern China to North Australia." Oligorus, Percalates, Ctenolates, and Macquaria all inhabit the rivers of Australia, while the two or three species of Siniperca occur in the rivers of China, Mandschuria and Japan.

Now all of the above fairly clearly indicates that the ancestral Serranids were, like their percoid progenitors, $\mathrm{N}$. American freshwater fishes. These, in addition to remaining in the ancestral areas, gave off three freshwater groups, as the writer would interpret. One of these, working down the western coast lands of S. America, spread into Chili-Argentina. Another line of migrants passed into E. Brazil, and thence into West Central and later into East Africa by the S. Atlantis bridge. Still another, passing northwestward into Siberia, gave rise to the species of Simiperca.

But a striking feature of the Serranids is that some species which had reached the coasts in all of the above- 
named lands, branched out completely into a marine life, and by gradual modification and specialization-not least in fin, in scale, and in color development-originated that wealth of species and variety of structural aspect, that we now see in the 300 or thereby species of tropical and subtropical seas.

Transition can next be made to the large and very compact family of the Cichlidae (Chromidae of some authors), that is made up of about 45 genera and 300 species, all of which are strictly freshwater, even though a few pass to the mouths of rivers, or migrate along some coasts from one river to another. The family is also compact in distribution, and clearly indicates the former existence of a wide $\mathrm{S}$. Atlantis and also of a Lemuria or Indo-Mascarene bridge that together connected South America with south-central Asia (Fig. 35, p. 240). The present distribution from Texas and New Mexico southward to the Argentine, and eastward to S. India and Ceylon, is shown by a fine dotted line in the accompanying map (Fig. 66).

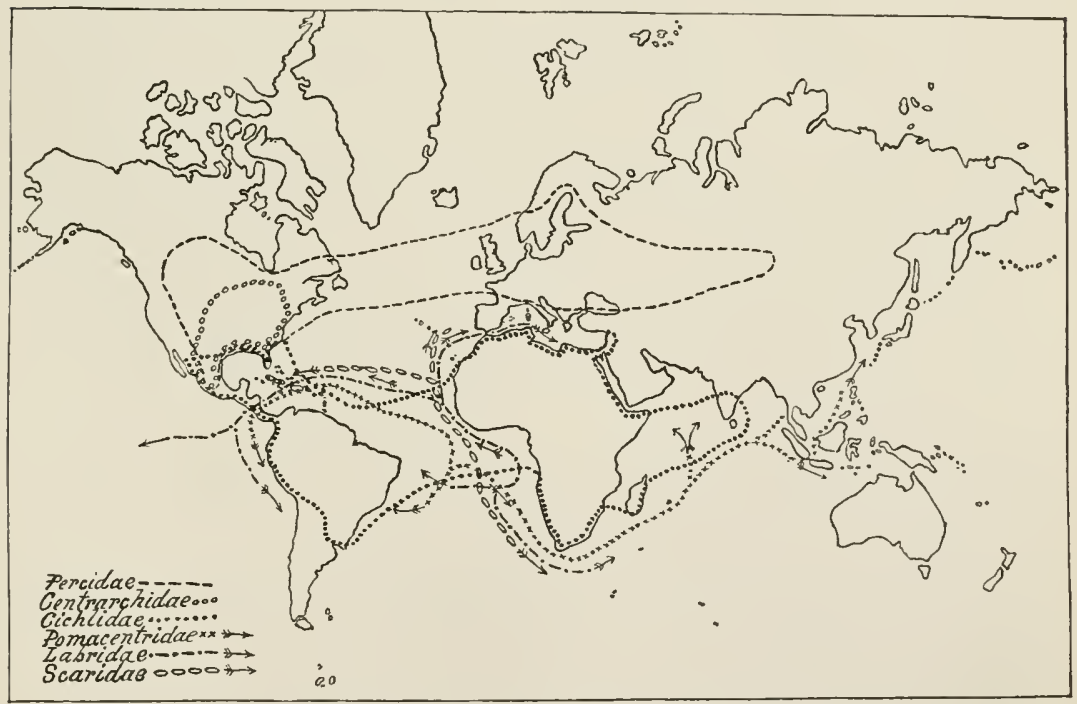

FIG. 66. Distribution of three large freshwater and three derivative marine teleostean families. The wide areas occupied indicate the former existence of wide N. Atlantis, S. Atlantis and IndoMascarene bridges. 
The structurally primitive members of the family make exact and easy connection with the rather primitive Centrarchidae. And it is specially interesting here to note that, while the two families in part differ in that the latter have, and the former are devoid of vomerine teeth, the only fossil cichlid genus Priscacara from Lower Eocene freshwater strata, is described by Cope as having these. The family also resembles the more primitive percoids and the simpler serranids in having a continuous dorsal fin, and this character is seen in Priscacara. Rarely here, as in the genus Cichla, is there a tendency shown toward division of the dorsal fin into an anterior spinous-rayed, and posterior softrayed part. The family then probably evolved from some annectant type between primitive members of the Centrarchidae, Percidae, and freshwater Serranidae.

We would also place the area for origin of the group in the central or southwestern United States, and here Priscacara was native during early Eocene times. But already probably, and almost certainly, during the mid or late Cretaceous period, migrant as well as evolving genera had passed into S. America, and there peopled the lakes and rivers with numerous representatives, whose descendants are now seen in the nearly I 50 species native to the northern part of that continent. Then migrating across the $\mathrm{S}$. Atlantis bridge they reached the W. African coast, and spreading eastward-as did quite a number of other families-they gave rise in time to the 150 species that are now found there, and which have constituted one of the chief features in the great "Tanganyika Problem." Passing to the south-east coast and also down the Nile, they advanced by the former line of migration through Madagascar along the Indo-Mascarene bridge to India and Ceylon, where they are now represented by three species.

The writer would refrain from such direct assertion as is contained in the above paragraphs, did he not fully believe that this exactly fits the facts of the case, and even more fits many similar cases already referred to, or to be cited in later context. But the group of the Cichlidae forms a very natural assemblage over three continents, that has at the same time no marine representatives. For while the marine 
Serranidae show near affinity, they differ in several important minor yet constant features, such as the two nostrils on each side, the toothed vomerine palate, the distinct pharyngeal bones, and the pseudobranchiae. No other marine family however approaches nearer than it. So we would consider that Moore's derivation of the African Cichlidae as of other groups of Central African fishes, from a marine ancestry is unwarranted in fact, while the entire question thus raised is fully discussed in a subsequent chapter ( $\mathrm{p} .463$ ).

Having dealt now with the acanthopterygian families that are wholly freshwater, or whose freshwater antecedants seem evident, we can now examine the families that are very largely or wholly marine. These include numerous genera, and also the large majority of those groups that have become highly modified as coral-strand or pelagic or deep-sea fishes, and which of ten show brilliant coloration as well as striking morphological modifications.

One of the largest and apparently the oldest family is the Berycidae, which seems to have arisen from common ancestors with the Aphredoderidae, the Percidae, and the Centrarchidae during early Cretaceous time. As in all of these the head has large mucous cavities, and the pelvic fins are nearly or exactly subpectoral. As in the Salmonidae the anal fin is made up of more than ten-often many-soft rays. But it is as yet impossible to trace the graded series of connecting types that would link theBerycidae with more primitive soft-rayed fishes, or fishes with only a few finspines. But if we suppose a type to have existed in MidCretaceous or early upper Cretaceous time that still frequented freshwater or had recently passed seaward, such would satisfy required conditions, for the earliest Berycids are in Upper Cretaceous rocks, and even then are evidently marine. The fossil genera and species also so far as known are N. American and Europeo-Mediterranean.

But even in these the dorsal fin was fairly extended, and showed-as in Acrogaster and Sphenocephalus-3 to 5 dorsal spines in addition to IO - I 4 soft rays. The anal fin also possessed 3 spines and 9 - I 4 soft rays, while the pelvic fins had I spine and $6-8$ soft rays, thus being inter- 
mediate between Percopsidae and more recent Berycidae.

The hypothesis may be of very small value, but if one were to accept that such a primitive and intermediate type or types existed in northern S. America, and that these then spread along the northern coastal edge of the south-Atlantis continent in mid or early late-Cretaceous times, such would satisfactorily explain the distribution alike of fossil and of recent genera.

When one compares the Cretaceous and Eocene fossil forms with living genera, it is seen that progressive evolutionary modification in the fins is effected in a manner which closely parallels that seen in the Centrarchidae, Percidae, and Serranidae. Thus in Sphenocephalus and Acrogaster the dorsal fin is continuous and shows only $3-5$ spines with IO-I 2 soft rays. But steady increase in the number of spines, and resulting lobed or ultimately divided condition of the dorsal fin occurs, till in Myripristis and Holocentrum it consists of IO--I 2 spiny also I soft anterior ray, and I I - I 6 soft posterior dorsal rays that make up the twolobed structure. In like manner also the anal fins become increased in their spine-rays but reduced in their soft rays.

The swim-bladder has persisted in at least many of the Berycidae, but usually as a simple sac, that rarely has an open duct as in Beryx. This persistence may be explained in part by the fishes having become largely deepsea types, where oxygenation may be sluggish.

The Pempheridae and Monocentridae appear both to be derivative families from the last. They are composed of a few genera and species of wide distribution over tropical seas.

The highly modified marine group of families that Boulenger has called the Zeorhombi shows closest affinity with the Berycidae, but must early have diverged-probably in the late Cretaceous-from the more condensed and compressed representatives of that group. The three families that compose it are the Amphistiidae, the Zeidae, and the Pleuronectidae or familiar flat-fishes. Practically all of these are marine, but some species of the last-named family inhabit eastern rivers. Thus while most species of Synaptura live along the sea-coasts of the East Indies and China, 
two species inhabit the rivers of Borneo, Sumatra, and Java. Similarly three species of Cynoglossus are freshwater, one or two others inhabit the Gangetic and other deltas, while the remaining 24 are marine. All indications at present are that the fluviatile species are derivative from the marine, and this is one of the decidedly rare instances in which adaptation from a marine to a freshwater environment has been fairly well effected.

The remaining marine families of Acanthopterygii indicate derivation from some one of the freshwater groups above studied. And this has occurred either by direct descent, or proximately from one that had become marine.

The small family Lobotidae would be extremely difficult of explanation were it not for the existence of the genus Kululia (p. 378) of the Centrarchidae, as well as many parallel cases that receive, as we believe, like explanations with it. The family consists of Datnioides that includes two species, occurring in the rivers of the Malay Archipelago, and westward to Siam, Burmah, and the mouth of the Ganges. Lobotes has one or possibly two species that extend along the shores of the United States southward to the Guiana coast, and that reappears from Ceylon eastward to the Chinese sea, the Sunda and the Moluccas Islands. If we regard both genera as derivative from the Centrarchidae-as has already been proposed $(2: 658)$ - then while Lobotes was becoming a marine form and working eastward along the former S. Atlantis and Gondwana shorelines, Datnioides continued as a river type through annectant species that worked eastward along the S. Atlantis continent, and then became distributed over the Eastern Archipelago, as is Kullia also still. But while Kuhlia has left traces of its eastward progress in African rivers, and even reached Australia, Datmioides has been obliterated in Africa, and seems to have failed in reaching Australia.

That the above explanation is alike feasible and probably exactly correct is perfectly demonstrated in such groups as the Characinidae, the Mormyridae, the Osteoglossidae, and the Cichlidae amongst others, except that these have all become more abundant, have remained wholly in freshwater, and have suffered less serious organic denudation. 
Even more exact parallelism is furnished by the Serranidae, which while now largely marine, still retains more ancient freshwater representatives in widely apart regions.

The Cichlidae have already been treated in relation to the Centrarchidae, but from the latter, or possibly from such a serranid genus as Centrogenys, a series of marine groups seem clearly derivative, which with the Cichlidae have by some been united as the group Pharyngognathi. For while in the Centrarchidae and Percidae the two lower pharyngeal bones remain distinct, these are more or less joined along the median sutural line in Cichlidae. But in derivative marine families fusion gradually proceeds till a solid composite pharyngeal bone results. At the same time the teeth gradually change from conical and pointed to rounded, then to flattened, and ultimately to close pavement teeth or knobs. A commencing indication of such union however is seen when one compares the serranid genus Trachypoma with the closely related Centrogenys. For while in the former the lower pharyngeal bones are still separate, in the latter they are united. It would be of interest to know as to the food and feeding habits of both. These changes are explained by the fishes that bear them becoming more and more modified and adapted so as to crush the shells of molluscs, the bodies of which form the food of the fishes. This change is seen in its most primitive

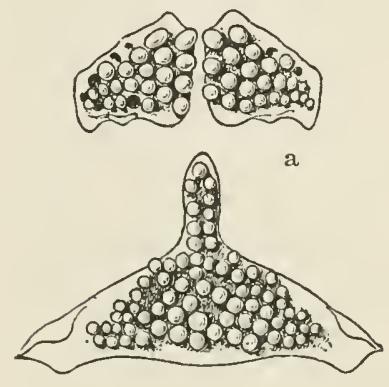

b

FIG. 67.

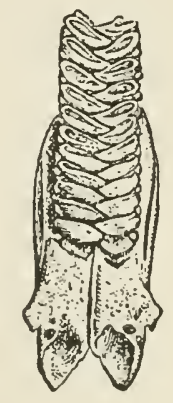

a

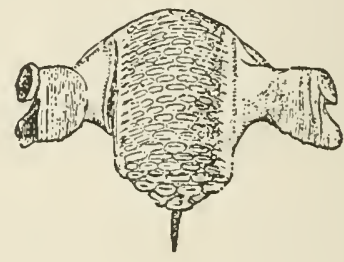

b

FIG. 68.

FIG. 67. Upper (a) and lower (b) pharyngeal bones of Labrus.

Fig. 68. Upper (a) and lower (b) pharyngeal bones of Scarus; complete fusion of the upper bones (a) and close aggregation of the teeth is seen in the latter. 
state in the Pomacentridae, where the teeth are still pointed, conical, and even delicate. It becomes greatly more pronounced in the Labridae, where the upper and lower pharyngeals become studded with rounded teeth like pavementknobs (Fig. 67). The jaws also become correspondingly shortened and parrot-like. Finally the Scaridae have short compressed mouths and jaws lined with dense crushing teeth (Fig. 68) while the lower pharyngeals in them reach the climax of specialization. One need merely note in passing the exact analogy established here with the evolving groups of the Pycnodonts, which curiously enough gradually passed seaward, as did the Labridae and Scaridae, when undergoing the above progressive changes up to the point of extinction.

When the geographical distribution of the genera and species of Pomacentridae, Labridae, and Scaridae is studied, the conditions and relations seem utterly confusing and hopeless for explanation. But if we accept that the primitive ancestors were derived from Centrarchids, or even more likely from some type like Etheostoma of the Percidae, that existed in lakes of western or south-western $\mathrm{N}$. America, during late Cretaceous or early Eocene time, the first necessary explanation is obtained. If next it be conceded that during late Cretaceous or early Eocene time such land bridges existed as have been outlined by Koken and Arldt (256: charts 19,20 ) also that prepared by the writer as Figure 35, p. 240 -and which are abundantly verified in their approximate outlines at least by the distribution of many organic groups-a second and equally helpful aid toward explanation is got.

We can now gather up, in as condensed manner as possible, the geographical distribution of each of the three above large groups. The Pomacentridae is made up of about 160 species included under 8 or 9 genera, of which the three most important are Glyphidodon with about 55 species, Pomacentrus with 45, and Heliastes with 16 , and these we may alone observe further. Glyphidodon has 2 species in tropical Atlantic and Carribean seas, 2 species on the coasts of Cuba and Barbadoes, I on the tropical Atlantic and Pacific coasts of Central America (that would indicate 
former marine continuity there), 3 on the coast from Lower California to Nicaragua, 3 from Mozambique to Mauritius, 2 from Mauritius eastward to the Philippines and southern Chinese sea, 22 amid islands of the E. Indian Archipelago, 3 peculiar to the coast of Java, 2 in the Timor Friendly and Fiji Islands, 2 from the "Red Sea through all the Indian seas to Polynesia" and a few additional round the East Indian Islands.

Pomacentrus has 2 round the Cuban coast, I round Jamaica, I along the Atlantic coast of tropical America, I round Bahia, 2 from Lower California to central America, I round Peru, I round the Sandwich Islands, 3 from Mozambique to the Moluccas, 2 from the Isle de France to the E. Indian Archipelago, Polynesia and the Australian coast, I 4 from the E. Indian Archipelago in general, and the remainder round the E. Indian Islands.

Heliastes includes 2 species round the Cuban coast, I from the Caribbean sea, I common to the coasts of Bahia and Lower California, as well as I peculiar to California, I from the Chilean coasts, I from Madeira and the Mediterranean, I each from Mauritius, New Guinea and the Moluccas seas, 2 from the East Indian Archipelago, and I from the southern Chinese sea.

If now, before dealing similarly with the Labridae and Scaridae, an attempt be made to correlate the above into a possible systematized line of advance, the following might reasonably be set forth as exactly in line with like distributions shown by many plant and animal groups. Granted that during later Cretaceous or earliest Eocene time migration of a few freshwater members of Centrarchidae or Percidae like Etheostoma took place into southern marine waters of $\mathrm{N}$. America. These, favored by the rich coloration inherited from their freshwater ancestors, became, through action of the law of Pentamorphogeny (p. I3), increasingly adapted to algoid, coralloid, and rock surroundings.

They then seem to have spread nearly simultaneously across the shallow coastal seas to California and Hawaii, as well as round the $\mathrm{N}$. Atlantis Bay to the east Brazilian coast. Thereafter across the tropical northern edge of 
the S. Atlantis shores they passed to Africa, thence to the coasts of Ceylon and the E. Indian Archipelago, while outliers passed into the Chinese sea and on to N. Australia. Favored by the extensive algoid and coralloid banks, reefs, and shoals of the Indian and Australian shores, as well as by the abundant molluscan and crustacean life, rapid and diverging variation was doubtless effected in even the few that reached these areas. Further and very importantly it should be emphasized that their defensive spines, protective colorings, and resort to rocky coves or fissures favored their life-continuance and wide distribution. It is worth observing also that-like many plant-groupsthey have evolved as a tropical family with only a few subtropical or warm-temperate outliers.

The Labridae as a family is richer in genera and species than the last, for it comprises close on 40 genera and upwards of 400 species. The structure of these proclaims a progressive but decided advance on, and from, members of the last family. If the fundamental geographical conceptions then, that were set forth above for the Pomacentridae, are further illustrated and emphasized here, this will yield added proof of the probable correctness of these conceptions. But in this instance also, space will only permit us to discuss shortly a few of the leading genera, though these can well be accepted as exemplifying the whole.

Platyglossus is the richest genus with 58 species. Of these the coasts of Cuba harbor 4, Martinique 3, the Caribbean seas 3, the Caribbean-Bahia region 2, the tropical Atlantis coasts 2, the Red Sea, Mauritius, Mozambique, Ceylon, and India carry 6, the E. Indian Archipelago I 8 , Singapore, Java and Celebes include 4, The Red Sea and Ceylon have 2 in common, the East Indies and Chinese sea have 4. One very curiously is common to the Celebes and Sandwich Islands, I to Fiji and Amboyna, while the remainder are peculiar to local E. Indian Islands.

Cossyphus includes about 20 species, one of which extends from Jamaica to Brazil, and thence across to St. Helena; 2 inhabit the coasts of Lower California, I the Madeira, Canary and Cape Verde Islands, 6 surround Mauritius, $\mathrm{I}$ is continuous from Mauritius and Madagascar 
to the New Hebrides, I extends from Mozambique and Mauritius to Sumatra, I is in the Moluccas, and 2 extend to Australia.

Labrus and Crenilabrus are together in marked contrast to the above, and indicate a different distributional line of travel. For the 9 species of Labrus, and the I 2 species of Crenilabrus occur as follows: 2 extend from the N. IV. African coast on to the European coast and into the Mediterranean, Io are peculiar to the last, I to Madeira and the Mediterranean, 2 are continuous from the Mediterranean to the Black Sea, 4 are peculiar to it. Ctenolabrus and Acantholabrus extend from the Atlantic coasts of the U. S. and Canada eastward to Madeira and the N. W. European seas. Centrolabrus extends from the Canary and Madeira Islands on to the European coasts. The single species of Tautoga occurs along the coasts of the N. E. States; the single species of Malopterurus is peculiar to Juan Fernandez, and that of Trochocopus is peculiar to the Galapagos.

Such distributional features reveal conditions resembling those of Pomacentridae, as well as others that fundamentally differ. Thus in both families extension and new evolution of species was continued southward by the Gulf and Carribean sea on the one hand, as well as across a Panama or nearby strait of sea into Lower California, and thence down the western S. American coast. But another and striking line of distribution, that is scarcely even suggested by the Pomacentridae, was effected along the northern coastal edge of the South Atlantis continent to N. W. African shores, and thence gradually into the cold waters of the N.W. European coasts.

The fossilized remains of Labrus, Crenilabrus and Labrodon from W. and S. Europe, that are of Miocene and Pliocene age, indicate that the north-eastward extension had already taken place in the Miocene period. Phyllodus, Egertonia, and Platylaemus represent however a still earlier and primitive Eocene invasion. The eastward extension of the group, along the tropical or subtropical lower edge of the S. Atlantis continent, into the Mozambique and IndoMascarene coasts, resembles that for the Pomacentridae, 
as does the extremely rich and varied evolution of genera and species, effected when the algoid, coralloid, and molluscan banks of the $\mathrm{E}$. Indies were reached.

It seems premature as yet to attempt any minute morphological comparison of the western and eastern species of the family, as local specific or generic modifications seem often to develop, that have only a local signficance. The varied and often brilliant coloration also, that has largely been used in distinguishing the species is of rather variable and uncertain application.

The Scaridae are alone explicable morphologically in terms of the more ancestral Labridae, as the latter are of the Pomacentridae. The family is made up of 7 or 8 genera, and close on Ioo species, all of marine habitat. They represent the end members also of a structural series that has undergone extreme specialization in mouth structure and fin-development, to a degree that becomes a precarious heritage. The three genera that are most abundant in species, and most suggestive in distribution, are Scarus, Calliodon, and Pseudoscarus. Scarus consists of about a dozen species. Three of these surround Cuba, Jamaica, Trinidad and other $W$. Indian Isles, 2 occur in the Caribbean sea, 3 are more or less continuous from Jamaica to Bahia, one extends across the Atlantic to the Mediterranean, while one is met with in the Madeira and Canary Isles, but also extends to the Mediterranean. The species of Calliodon may be said to live as the poles apart. For while 2 extend from San Domingo to Trinidad and Bahia, 6 inhabit the eastern Archipelago, and I of these passes up to southern Japanese seas. But the presence of one in the Red Sea is proof that many connecting species have been swept out of existence since the time of the Miocene.

The largest genus Pseudoscarus is made up of 65 species, 4 of which occur round Cuba and Jamaica, 4 are Caribbean, I is from the Sandwich Islands, I is N. E. Brazilian, 2 extend from Mozambique to Mauritius, one is peculiar to Mauritius, 4 to the Red Sea, 2 extend from the Red Sea and Mauritius to Java and Celebes, 8 are peculiar to the coasts of Java, Io are distributed more or less amongst the E. 
Indian Isles, I is peculiar to the Caroline Islands, and 3 surround Tahiti.

If a short review be now made of the six related families Percidae, Centrarchidae, Cichlidae, Pomacentridae, Labridae and Scaridae, it can be said that the two first are almost wholly N. American and purely freshwater, a few species only of the first having spread out across the Behring sea area into N. Asia and then into Europe. From species inhabiting the S.W. States or Northern Mexico, the Cichlidae branched off into rivers and lakes of S. America, as a tropical freshwater group that steadily migrated eastward across swamps and rivers of the S. Atlantis bridge into Africa, where they abundantly multiplied, and are now represented in nearly all the lakes, rivers and extensive swamps of the central continental area. Outliers from these passed northeastward along the Indo-Mascarene bridge till they reached Madagascar, India and Ceylon.

The Pomacentridae, diverging from centrarchid or percid ancestry, gradually acquired a brakish and later a marine coastal habitat, along the southern or south-eastern States region, and about a time when sea-connection existed between the Gulf and the Pacific. Thus arose the western and the eastern pomacentrid representatives, probably in early Eocene time. Evolving species and genera moved eastward along the southern coastal edges of the $\mathrm{S}$. Atlantis continent, that was effecting, along its inland freshwaters, the simultaneous advance of the Cichlidae. By late Eocene or Oligocene days the Cichlidae in freshwaters, and the Pomacentridae along the coasts, had reached Indian fresh and saltwaters respectively. But while the land-freshwater environal conditions surrounding the Cichlidae retarded further eastward progress, the highly favorable shore and coral-reef environment, with rich and varied associated life, stimulated the origin of those abundant marine species of Pomacentridae that now occur over the Easter Archipelago from N. Australia to S. Japan.

Ancestors of the Labridae, and in turn of the Scaridae, branching off, the former from the Pomacentridae, the latter from the Labridae, followed the main lines of migration already pursued by the Pomacentridae, except that a 
warm-temperate and ultimately temperate marine offshoot passed across the $\mathrm{N}$. Atlantis southern shore to the $\mathrm{N}$. W. African and later the west-central European shores. Meanwhile both families, amid the same environment as proved stimulating to the Pomacentridae, became abundant inhabitants of coral reefs, rocky shores, and algoid beds of the eastern archipelago.

The Embiotocidae, usually included in the Pharyngognathi group of families, seem from many structural peculiarities to have been derived from two or even three distinct types or genera of the Cichlidae. Thus the one freshwater genus Hysterocarpus that in its single species $H$. traskii is native to the lower reaches of the Sacramento river in California, seems to be most nearly derivative from a series now typified by Symphysodon and Pterophyllum of the Cupai river in Brazil. The marine genera apparently approach most nearly to the living Brazilian Hygrogonus, no other genus of the Cichlidae or of any other acanthopterous group seeming otherwise to approach them. The 23 or thereby marine species, are often abundant in shallow water along the California coast, where they mainly feed on crustaceans. One genus however, Zalembius, is now a deep-sea fish (257: I 500, pl. 229), and as so often happens in such environment, has developed large and prominent eyes. Finally while most of the species of Ditrema are coastal fishes from San Francisco northward to Vancouver, two species have passed over, doubtless by the N. IV. American bridge, to Japan.

So, small though the last family is, it strongly favors direct origin from the large freshwater group of Cichlidae, and still includes one freshwater species that makes close generic connection with these. The remaining marine species can only be interpreted at the present day as shoreward migrants from more primitive freshwater ancestors that descended from the Cichlidae.

The Gobiidae, that may next be treated, is of exceptional interest as being a family that fairly divides its species between fresh- and salt-waters, with preponderance toward the latter. The writer would recall Boulenger's view that they "are not very remote from the Perciformes, 
and may have evolved out of a type not very different from the Percidae" (2:68s). Jordan's position therefore seems scarcely justified when he says (253:459) that they have "no near relations among the spiny-rayed fishes." Reasons will gradually be given below, as well as later for the writer's position, in seconding Boulenger's conclusion.

The family is a large one, being made up of about 30 genera and 600 species. If one tries to construct a picture of the average external and internal structure of a primitive genus of the family, it can be said that the composite type conforms closely to such percoids as Boleosoma, Etheostoma, Ammocrypta, and Crystallaria of the group Percidae, all of which inhabit the east-central or southern U. States. Further, we would regard Eleotris as the primitive gobioid for the following reasons. The living Gobiidae, as subdivided by Günther, include four groups: (I) The Gobuna section with two separate dorsal fins, and ventral fins distinct or fused to form a disc; (2) the Amblyopma section with a fused and continuous dorsal fin and ventrals united; (3) the Trypauchenina section with continuous dorsal fins and disconnected or fused ventrals; (4) the Callionymma section with two separate dorsal fins and ventral fins widely apart. Eleotris falls under the first section, for in its fin structure and many other morphological details, it shows closest affinity to the percoids named.

Now, upwards of 50 species of Eleotris are known, mostly from tropical and sub-tropical, more rarely temperate areas. Of these $30-32$ are freshwater, 6 show great adaptability for living in freshwater or brakish or marine coastal regions, while I 3 - I4 are marine. But 9 of the species are still found in freshwaters from Mexico and Lower California eastward to San Domingo and Cuba, also southward to the Equator and Guiana. One is found in Mascarene rivers, while another ( $E$. fusca) resembles it, but also becomes more or less coastal-marine and appears in Mauritius, thence on to Polynesia. Now did we not know the structure, general habitat, near affinities to American percoids, and the distributional trend of the entire genus, we might have readily supposed that $E$. fusca was a primitive type, which was gradually passing into freshwaters, also 
that most of the other species had already completely effected the change. We have no hesitation in saying that the latter supposition is devoid of real support.

Other species spreading eastward, have become distributed in exactly similar manner to the combined Cichlidae, Labridae, and Scaridae, over the rivers, more rarely along the coastal regions, of the East Indies, and even northward in a few cases to rivers or coasts of China-Japan, as well as southward, in one species, to the rivers and coasts of New Zealand. The air-bladder in all of these is large.

The I 3 species of Sicydium are all freshwater, and are decidedly more evolved than is Eleotris. One only is W. Indian, 2 are found in Bourbon and Isle de France, the remainder are E. Indian.

In contrast to Eleotris and Sicydium the large genus Gobius, that includes about I 60 species, has I 25 marine species, $\delta$ that show marked adaptability to marine or freshwater life, and only 25 that are freshwater. Of the last however 6 are American. The distribution of the freshwater and of the anadromous species makes it tolerably certain that, apart from an early migration of some into the sea in Central America, many species may have expanded eastward in freshwaters, during Oligocene time, along the remnant of the $\mathrm{S}$. Atlantis continental bridge, and working eastward may have given off here and there at intervals, shoreward migrants, that became in time the organic foci for evolution of new marine species. But highly detailed specific studies could alone satisfactorily determine such a possibility. Like marine forms in general, and in contrast to Eleotris, the air-bladder is usually absorbed.

The small and remarkably modified group of the sharksuckers or Echeneididae have been very variously viewed by ichthyologists. As will be indicated by comparative statistics later the group exhibits characters that would place it in or near the family Gobiidae, as suggested by Müller and later by Jordan, instead of in the Scombridae as advocated by Guenther and later by Storms, who protests that "none of the characters of Echeneis glaronensis point toward the Gobiidae." On the contrary in shape of the 
fish, in structure of the fins, in number of vertebrae, in presence of villous and often also of stronger or canine teeth, and many other details, such a primitive gobioid genus as Eleotris shows close agreement. Further if the 6 to 8 spines of the anterior dorsal fin-lobe in Eleotris were condensed, moved forward, and split into jointed halves, as Storms has suggested, the I 2 laminae of the peculiar disc in the fossil Opisthomyzon (Echeneis) glaronensis would be explained. Continued subdivision of the rays, and conversion into laminae would explain also the $17-25$ laminae in the disc of some modern species. A steady multiplication in number of the vertebrae also, from 24 or 25 to as many as $27-30$ is seen proceeding from the fossil to the recent species. So from some primitive, probably early Eocene genus allied to Eleotris, through the Oligocene Opisthomyzon, and thence to recent species of Echeneis, the steps seem to be progressive and fairly continuous. But when we compare the less modified fossil type with existing ones Storm's remark $(258: 67)$ is appropriate for the former when he regards it as "a more normally shaped fish" than any of the living representatives.

The family Serranidae, already reviewed, was shown to have early sent off from freshwater genera others that became marine, and that speedily evolved a large series of marine genera and species. This seems to have taken place at least in early Eocene times, probably in mid or late Cretaceous, and possibly in several separate centres of evolution. For in distribution of the Serranidae over the world, the same lines of voyaging were doubtless pursued, that we have already outlined in previous pages, while the regions reached were as diverse and often as remote. In this process then groups arose in definite centres that, by steady and continuous variations, became in time of family value.

So from the Serranidae new families must have branched off that are now wholly marine, and which constitute the Pseudochromidae, with succeeding derivative families the Sillaginidae and the Cepolidae. Again the Sparidae, Mullidae, Gerridae, Sciaenidae, Latrididae, and Haplodactylidae, are related families that show affinities and also 
differences in structure, due to the continuous action of the varied factors that together constitute the fundamental law of Pentamorphogeny. ( $I:$ I 74$)$.

The series of families which by Boulenger has been called the Scleroparei shows, in such of them as the Scorpaenidae and Hexagrammidae, very direct and marked affinity with some of the Serranidae. But such seem decidedly apart from the Cottidae, the Cyclopteridae, the Agonidae, the Trigulidae and the Dactylopteridae, not least in the absence amongst the latter of spines to the many-rayed anal fin. The distribution also is highly perplexing. For while the entire series belongs to the northern temperate hemisphere, the first-named two families are purely marine, while the Cottidae and Comephoridae include freshwater species of wide distribution. Thus 8 out of the 28 species of Cottus are wholly freshwater, and 3 of the ro species of Centridermichthys are. In regard however to probable absorption of the three anal spines that are so typical of Serranidae and of most Scorpaenidae, it should be noted that reduction to 2 or $\mathrm{I}$, or even total absorption of the spines, is seen going on in some Hexagrammidae (e. $g$. Zaniolepis) and in some Comephoridae. It may be that the Cottidae and Comephoridae are derivative from some primitive freshwater Serranid, and passing seaward developed the Agonidae, the Cyclopteridae, and allies. But it seems impossible as yet to correlate the geographic distribution with the structural affinities shown.

The wholly marine alliance of families that by recent ichthyologists has been grouped as the Scombriformes, includes about nine families widely distributed over tropical, subtropical and temperate seas. These are the Carangidae, Rhachicentridae, Histiophoridae, Scombridae, Luvaridae, Coryphaenidae, Xiphiidae, Bramidae, and Trichiuridae. These seem to come off from some ancient marine forms of the Serranidae, distinct from, though related to, types like those that originated the Pseudochromidae and near allies. The Carangidae show marked generic variations, that might indicate descent of its genera from several distinct Serranid genera. Thus Anthias, Odontanthias and Holanthias of the Serranidae have combined characters 
that approach very closely to those shown by the genus Caranx. Other marked relationships between genera of the two families could be cited.

Without pursuing the inquiry further, it might be suggested that the Scombriformes very likely arose as increasingly modified, often degenerate, and specialized offshoots from various marine Serranidae between late Cretaceous and Miocene time. It may be observed also that the most highly modified-like the Coryphaenidae, the Luvaridae and the Bramidae-are those which contain the often remarkable pelagic fishes which live at greatest distances from sea-shores, and which not unfrequently also become highly adapted for life at great sea depths. So the depths of the ocean, and its surface areas, are the regions most removed ecologically-not necessarily geographicallyfrom the lakes, rivers and swamps, in which primitive members of the teleost fishes evolved. There also we encounter the types that have become highly modified in structural details, if we except those shore types that, by continuous feeding amid, and gliding over, muddy or gravelly shores, have become changed into "flat-fishes."

The set of families that Boulenger has retained together under the old morphological name of Jugulares, undoubtedly represents some of the most highly evolved of spiny-rayed fishes. For the shifting forward of the pelvic fins not merely to a thoracic but to jugular position, is a fundamental change of marked significance. Their distribution, over shores and seas of the entire world, specially in warm climes, might indicate that they are derivative from more ancient marine families that had thoracic, or even still earlier pelvic fins. Entirely in keeping with such a secondary derivation is the fact that they are most recent in geologic time, and that very few have been found in the fossil state.

While the tendency has been to regard them as derivatives from berycid ancestors, the writer would regard at least some of them as descendants from the Serranids. For the persistence of one spine, and of 5-becoming by absorption 4-soft rays in the pelvic (now become jugular) fins, or even complete absorption of these fins; the number of 
vertebrae that steadily advance from the 24 to 35 of Serranids, retained as such by the Uranoscopidae and Gobiosocidae, but increasing to $35-45$ in Bleniidae and Trachinidae; the tendency to partial or complete subdivision of the dorsal fin, and to formation of numerous spiny rays in these two subdivisions, that show all stages of increase from 7 - 2 spines of Serranids to the 40 or more of Blenniidae, are characters that are most nearly explicable in terms of a serranid ancestry.

Of the 12 to 15 families recognized by recent ichthyologists, the three which the writer would regard as nearly related, and also as most primitive, are the Blenniidae, the Trachinidae, and the Uranoscopidae. But the diverse and striking modifications in the number and structure of parts seen in the first of these, as one passes from the more typical or normal to the most modified of the group, is proof that rapid evolution, selection, and variation have been acting from Miocene on to recent times.

The distribution of such blennioid genera also as Clinus, Salarias, and Blennius over the warm seas of the whole world suggests that since the time of derivation from some marine serranid ancestor, constant migration, new environal action, proenvironal response with variation, and readaptation, have been proceeding at a rapid rate.

The outcome of such is that the other families of the Jugulares, which show decided affinity to, as well as progressive or regressive variation from, the three families above named, have often acquired those remarkable characteristics that now distinguish them. Thus the Zoarcidae, the Gobiesocidae, the Ophidiidae, and the Batrachidae are amongst the most curious and highly modified of acanthopterous fishes. But some of these again lead to still more altered families or even orders. For the Batrachidae or toad-fishes evidently lead on to the Lophiidae or fishing-frogs, the Ceratiidae or devil-fishes, and the Antennariidae or anglers. The very rare-but still occasionalpresence of an isolated species of some of the above in freshwater, as for example of Blennius vulgaris in Italian lakes, or of the Cuban blindfishes Lucifuga and Stigicola in cave-waters of that island, again prove that return of 
acclimated marine species to a freshwater environment is a matter relatively of rare occurrence.

What is probably the most condensed and highly modified group of the Teleosts the Plectognathi-requires short notice here. For all are coastal or deep-sea types, whose derivation and evolution from the Acanthuridae, as of it again from brightly colored Chaetodontidae, has been repeatedly emphasized during the past half century. The existence of genera of all of these great divisions, back in Eocene strata, shows that marine fishes, allied to those now living, must have been evolving through the greater part of Eocene time, a conclusion that direct fossil evidence verifies.

A brief review then of the detailed studies presented in this chapter indicates that the Acanthopterygii first evolved over the N. American continent during the Cretaceous period, and amid extensive lakes, swamps and rivers, some of the last of which may have flowed into the Cretaceous sea, that existed then from Kansas southeastward, or westward into the Pacific, before the western coastal ranges had fully developed. The living groups Percesoces and Aphredoderidae known from that region, with extinct types of the latter, are regarded as transitions from the soft-finned families to the higher spine-finned ones. But these two transition groups were probably derived from ancestral soft-finned types allied to the clupeo-salmonids, whichas judged by the abundance of Diplomystus-were widespread over the above region. These again seem traceable backward into Jurassic time as migrant derivatives from freshwater Leptolepidae, like Leptolepis or Thrissops of European origin. From derivatives of the Aphredoderidae or from allies as yet unknown, the Centrarchidae and Percidae evolved, largely over the N. American continent, where they now abound in its rivers and lakes. But from like ancestry the Berycidae early migrated into a marine habitat, and soon spread over a wide sea territory.

In further dispersion alike of the primitive freshwater and derived marine ones, several important land-masses that have now disappeared acted as connecting bridges, while their shore-margins favored passage from a freshwater to a marine habitat for not a few of the evolving 
groups. These bridges were the S. and N. Atlantis landmasses, the former of which connected the Central S. American with the West African coast, the latter the N. E. North American with the South European coast; also the Indo-Mascarene bridge that more or less connected Madagascar and S. E. Africa with India. A mid or late Cretaceous connection seems also to have united the East Indies with Australia.

Along these land-bridges with their freshwater passageways, the Centrarchidae and Percidae, along with derivative Cichlid and Serranid families, migrated eastward into and across Africa till the East Indies and even Australia were reached. Derivative marine genera and families passed off from some of these, or from the Berycidae, and established ever wider geographic connections in the bays, seas and oceans.

A less striking migration across the Americo-European or North Atlantis bridge was also effected, contemporaneously with active migration in both directions of salmonid, cyprinid, silurid, esocid and gastrosteid families and genera.

From Oligocene on to late Miocene times the bridges were completely destroyed, and continued evolution of the above took place most actively over marine areas that were widely connected; while evolution of species and genera-rarely larger groups-proceeded in the freshwater centres or passageway's that were left, after destruction of the connecting bridges, and rearrangement of the remaining continental masses, had been effected. 


\section{CHAPTER XIV.}

\section{Past Geographic and Geologic Conditions in Relation to the Distribution of Fishes.}

In the immediately preceding chapters an effort has been made so to trace the relation of fishes in time and space, as to discover some principle of evolutionary continuity running through the whole. Such the writer hopes, and even believes, has been established.

But during the process certain positions have been assumed, that are still open to wide discussion, according to not a few distinguished naturalists. The heading of the present chapter raises two of these disputed positions. For the geographer of today, who studies the distribution of plants and animals over the world, can choose any one of three or four decisive views that his biological brethren may present. And again one school of geologists may still assert that the land and sea masses are largely at present in outline and connection as they were during previous epochs, while another school may proclaim that fundamental alterations in the relation of land and sea have repeatedly occurred, while still a third party may advocate a middle course.

In the five chapters preceding this, the writer has stated the known facts that bear on the first known appearance and distribution of fishes in time and space. But in doing this he did not refrain from stating his views as to how some of these facts might naturally and scientifically be linked together, so as to reach larger facts and conclusions. Now he proposes to analyze groups of these facts from the geographic and the geologic standpoints.

Ample proof we believe has been adduced, for acceptance of the view that the Dipnoi developed in, have lived in, and now inhabit sluggish rivers, swamps, and related freshwater areas. But if such be true it means that we must also accept the view that they inhabited land which was continuous in time for some part of its mass. So when we successively encounter freshwater dipnoan remains in West Russia, in Britain, in N. America, in Africa, in India and in 
Australia, it implies that all of these geographic regions were at some time, and to some extent, in continuity. Against such a conclusion it may be objected that detached and floating fragments of land may have drifted across oceanic expanses, and reaching other land masses, carried new and important plants as well as animals to the latter. The history of freshwater fishes entirely militates against such a possibility. But any one who will make a detailed study of some one large plant family of evolved type, and somewhat recent appearance on the earth, must be gradually convinced that continuous extension, even it may be with gradually changing configuration, in definite areas of the earth, alone give a key to the situation though such may seem at first to be against preconceived views.

Now in past monographs on fishes, each monographer candidly confessed that a natural key to the evolutionary distribution of fishes has not been secured. In I9I 2 and again on succeeding occasions up to I9I7, the writer published his view, that a successful explanation could alone be got if it were accepted that fishes evolved as inhabitants of freshwater areas, and in some groups only gradually spread at varying periods into the sea. Such is the main thesis of this volume. To prove the truth of this one must take account of the relation of land and sea, from time to time at least, when fishes first appeared as fossils in the rocks. Such in turn involves combined geographic and geologic studies, with all accompanying details of each of these studies.

If in a few succeeding pages the writer discusses some geologic positions first, this may later conduce to clearer geographic views. In chapters II, V and VI frequent reference was made to the wholesale destruction of myriads of plant and animal types, at definite stages in geologic periods. But equally noteworthy has been the extrusion, between or upon rock masses already formed, of enormous deposits of igneous rock that often cover many thousands of square miles. A third and equally noteworthy event has been the tremendous faulting as well as folding and even overthrowing of hundreds-in some cases of thousands-of miles of strata, due in part probably to internal 
volcanic action, in larger part probably to earth-shrinkage, or to a combination of both. The faults that can be traced across Scotland in Old Red rocks, the folding of later Carboniferous rocks there, the upheaval and dislocation of rocks during formation of the Andes and the Rocky mountains from Cretaceous to late Tertiary time, the gigantic "rifts" that formed in Africa during Tertiary times, and the displacements in South African and East Australian rocks all testify to violent cataclysmic changes in the earth's surface-crust at least.

Lastly, the gradually increasing elevation of strata into higher and higher folds or ridges that ultimately constituted such ranges as the Andes and Rocky Mountains, the Alps, the Himalayas, etc. form phenomena of striking significance. Now, if such phenomenal and widespread changes have occurred in many of the geologic epochs, it is alike unscientific and contrary to all organic evidences to assert, that present-day seas and oceans did not undergo as extensive and fundamental changes as did the landmasses, specially if multitudes of distributional facts seem only to be explicable when such changes are admitted.

Thus to suppose that the gigantic and repeated "rift" faults which cross central Africa were confined in their origin almost wholly to the continent itself, and did not affect areas east and west that now are deep under the sea, is to demand an impossibility. So in the subsequent context the writer accepts in the main the conclusions of Suess, DeLapparent, Neumayr and Koken, as well as the additional evidence cited by Arldt, and many geographic as well as geologic details that the writer has brought together in favor of these views, in part from the plant, in part from the animal side.

But no more sensitive group probably than the fishes could be selected as a test of these views, for they clearly demonstrate in their historic evolution that wide-spread and fundamental alterations in sea and land have constantly occurred in past times.

The writer proposes to study the fishes now in their geographic and geologic relations, starting from the existing species, genera and families. The groups that, from the 
progressive evolutionary standpoint, are the most recent and the most highly developed are the Jugulares, the Anacanthini, and the Acanthopteri that typically show more than Io spines in the dorsal fin. None of these so far as known date back further than the Tertiary period, and mainly from Upper Eocene onward, except the late Cretaceous genus Prolates of the freshwater group Percidae. It seems to be closely allied to and possibly ancestral to Lates that is known from Upper Eocene on through higher strata to living representatives.

The preponderating number of these is marine. In geographical distribution species may be said to occur in nearly every tropical, subtropical and temperate sea, more rarely in subarctic. The continuity of marine gulfs, seas, and oceans would explain how such resulted. They include fishes which, in color, in shape, in special adaptation to environment, often also in fin modifications, are strikingly evolved. Further they can nearly all be shown to have some fundamental primitive details that ally them more or less clearly with simpler and in nearly all cases freshwater fishes. This has been traced in earlier chapters.

But the more primitive acanthopterous families are largely, or in some instances wholly freshwater, and in their present geographical distribution present many peculiar distributional features that call for explanation. We may first refer in detail to the regions occupied by the Anabantidae, Ophiocephalidae, and Osphromenidae, three nearly related and wholly freshwater groups. The ten African and four S. E. Asian species of the first are now separated by many hundred miles, while between the eastern limit of the African ones and the present coast line there is a wide stretch of country. The three African and twenty-five Asiatic species of Ophiocephalids occupy a reversed area of territory that approximates in ratio to the number of species. But a like East African zone is devoid of them. The Osphromenidae occur in central and west-central Africa where are three species, and in South East Asia where are nineteen. Such distribution therefore suggests that in earlier Tertiary times Africa and S. E. Asia were either directly connected across what is now the Indian Ocean, 
or across S. E. Arabia and Persia where more recent obliteration of them has happened. Scarcely anything favors the latter, nearly every fact favors the former view. But further while marine deposits of Cretaceous and Tertiary age are met with from Mozambique northward along the African and Arabian coasts, continuity from Central East Africa to Madagascar and India seems to have persisted well into Eocene or even Oligocene times. If then the head-water areas of the Zambesi, the Nile, the Congo, and the Ogowe formed a common distributional region during late Eocene and Oligocene time, and were connected eastward through S. Mozambique and Madagascar to India, such would wholly explain the present distribution.

The Cichlidae and related groups might next concern us. In the last chapter evidence was adduced to show that the Cichlidae, Pomacentridae, Labridae, and Scaridae form a progressive and specializing series, that start with primitive Cichlids. A chart of their present distribution is given on page $38 \mathrm{I}$. We learn then that $\mathrm{I} 40$ species of Cichlids extend from the southern United States and Cuba to Central South America; that I 50 species have spread over Africa and Madagascar, while three only occur in S. India. But further, as before noted (p. 3 $S_{2}$ ) Cope has discovered seven species of Priscacara from the Green River and Manti Shales of the IVestern States, that show at least some primitive characters compared with existing species. The possible relation of these then to ancient North American Percidae or Centrarchidae will be returned to later. Here is not only again suggested a direct connection from S. E. Africa to India, but even an extensive S. AmericanAfrican bridge of Eocene to early Oligocene date.

But some brakish-water species of Cichlids that lived increasingly on hard-shelled molluscs and crustaceans evidently passed outward from the rivers of Western $\mathrm{N}$. America, of Central and South America, as well as along the coastal line of the American-African bridge, and there lurking among rocks or coral reefs, had the teeth condensed and the pharyngeal bones fused. Later by proenvironal and selective action, as a hard-shell diet became frequent, these had the body condensed in mechanical re- 
lation to the head, and so developed the 150 species of Pomacentridae that cluster along the Mexican, Peruvian, Chilian, and East Brazilian coast; that are continued across to African shores, thence round S. Africa and Madagascar on to India, the East Indian Archipelago and even to Australia. Since probable types of the Pomacentridae like Odonteus have been found in Upper Eocene to Miocene rocks of Southern Europe the migration along the northern sea edge of the American-African bridge may have been effected in Mid-Eocene time.

Possibly from one centre, but by no means unlikely from several marine centres, members of the Pomacentridae gradually evolved in body shape, in fin and spine relation, but particularly in condensation and modification of the cephalic bones and the teeth, as a food-diet that contained calcified constituents was increasingly adopted. So coastal genera of the Labridae arose as offshoots from the Pomacentridae, whose remains are met with in rocks of the Miocene-Pliocene and onward, while with gradual breaking down of the Americo-African bridge and the Afro-Indian bridge they more freely spread into increasingly wider marine areas.

As to the disappearance of the South Atlantic (?Antarctic) and the Afro-American bridges biologic and geologic facts would suggest that such was effected during late Oligocene or early Miocene times. For, as the studies of Drummond, Scott Elliott, and especially Moore have revealed, enormous "eurycolpic" (Moore) foldings of the Central African region took place before or during Pliocene times, and these resulted in extensive faults that must have shaken a great part of the world during their formation. Subsequently, over the entire altered area late Tertiary strata of freshwater origin were laid down, that are still being added to in the form of swamp, flood-plain or lake deposits. Again along the eastern American coast, from Trinidad to Argentina, depressions-either rather sudden or in part steady-took place, so that the valleys of the Amazon and Orinoco became arms of the sea.

The Indo-Mascarene bridge seems to have been removed about the same time as the above, for the subsequent 
evolution in Madagascar, in North India, and in the Malay region, of purely indigenous species, requires a lapse of time that must have extended from at least late Oligocene days to the present.

As a biological outcome of such changes, the Cichlidae, Anabantidae, Ophiocephalidae and Osphromenidae became split up from previous geographic continuity into a series of localized groups, the South American, the African, and the South East Asiatic. Of these the central African group is preeminently suggestive. For while the Great Lake and swamp areas must have existed there from at least Eocene times, the extensive faulting above noted gave rise to deep lakes, river valleys, and swamps that became more or less isolated from each other. Most notable of these was the deep but elevated fissure now occupied by Lake Tanganyika to which reference has already been made.

As Boulenger specially has shown (227) and as Moore has further emphasized (259) many Cichlid genera evolved in or became-amid destructive geologic changes-restricted to that Lake. Thus of thirteen known species of Lamprologus, eleven are peculiar to Tanganyika. The three species of Ectodus; the two species of Batlybates, Xenotilapia, Trematocara, Telmatochromis, Tropheus and Petrochromis; the single species of Grammatotria, Gephyrochromis, Steatocranus, Asprotilapia, Eretmodus, Spathodus, Perissodus, Xenochromis and Plecodus are all similarly endemic. On the other hand Paratilapia with thirty species, and Tilapia with sixty species, are distributed over a large part of Africa from the south central part including Madagascar, northward to Asiatic Syria. Such facts might suggest that these two genera are the most ancient and primitive migrants from eastern South America, and that from them as derivatives the other genera were comparatively recently evolved.

In contrast Acara, a genus still surviving, has been described by Woodward from the tertiary of San Paulo, Brazil, while Priscacara is an early Eocene North American genus that is known in several species. Origin of the entire group Cichlidae in North America is therefore fairly well indicated, with subsequent spread into South America and 
thence, as well as later, into Africa and India. The Indian genus Etroplus in its lobed crowded teeth, many dorsal fin-spines, and other characters, seems to be one of the most specialized genera, as it is furthest removed from ancestral beginnings of the entire family.

As has been advocated by Branner (and Steinman) the Antilles belonged during later Cretaceous days to a wide continental mass that was again connected with the North East American continent and its extensive lake system. Evolving in the latter region, and widely prevalent in the freshwaters of it, were the two large and closely related families of the Percidae and Centrarchidae. The former of these seems to be the oldest Acanthopterous family of which we have sufficient and exact record. For several species of Mioplosus have been described by Cope from Lower Eocene or Green River shales, while numerous specimens of Prolates from the Mountain or Upper Cretaceous beds of France indicate that already the Percidae occupied a wide area of the northern hemisphere. But even these in constructive structure are anticipated, and led up to, as already explained, by the Percopsidae and Aphredoderidae, the two genera of the former of which we would regard as sole remaining representatives of ancestral Acanthopterygii, which though unknown in the fossil state, probably traced back in origin to the Mid-Cretaceous period.

Here it is worth emphasizing that while the Old World or Eastern Hemisphere region was evidently shaken to its core by seismic and volcanic action, and had most of its teleostean genera obliterated during the late Cretaceous and early Eocene periods, the North American and largely also the northern half of the South American region were less convulsed, and retained more direct continuity in their organic life. So while the Percidae sent freshwater derivative types southward that evolved the primitive or freshwater Serranidae, and the Cichlidae, that both spread over South America and in turn reached Africa, the Centrarchidae evolved wholly in North America as descendants from evolving Percopsidae and Aphredoderidae, or from primitive Percidae of the continent. The Percidae on the other hand-taking advantage of the wide North Atlantis 
bridge-extended over into Europe, but owing to a sea barrier that cut in between eastern Europe, North Atlantis, and the Angara continent, they failed as a group in reaching Siberia. Only since union of these land masses has slight further migration eastward been effected.

In review then it may be said that given the above Cretaceous-Eocene land bridges, and their relation to present continental land masses; given also the inclination in former Cretaceous-Tertiary times, for some of the freshwater species to become brakish and later coastal marine dwellers, as is abundantly and strikingly indicated by Boulenger for west African teleostean fishes, we may exactly and minutely explain the origin, migrations and present distribution of all the Acanthopterygii. For starting in lakes of northern central North America, as types akin to but somewhat simpler than Percopsis or Columbia, evolution and distribution went hand in hand for production there of Aphredoderidae, Centrarchidae and Percidae. From one or other of the two last started the primitive freshwater Serranidae, that later branched off almost wholly into marine life. From most if not all of these "primary" groups, derivative forms had eventually invaded the brakish waters, still later the shores, of all of the geographic areas above indicated. While, as in the case of the Cichlidae, Pomacentridae, Labridae and Scaridae, it is possible readily to trace continuous modification and specializing evolution proceeding during such migrations; in other cases outlined in last chapter, more minute comparisons will require to be instituted before complete assurance is obtained as to derivative origins, in relation to geographic and geologic conditions.

To appreciate the possible origin of the Berycidae in connection with geologic conditions, one has to trace the changes proceeding over the North American continent during Lower or Comanchean and Upper or later Cretaceous times. For while such genera as Acrogaster, Dinopteryx, Homonotus, Hoplopteryx, Pycnosterinx and Sphenocephalus have been described from upper Cretaceous rocks of Europe or W. Asia, we would regard these all as migrants from the active centre of evolution, viz. the North 
American region. And to understand at least approximately the changing conditions of land and sea there, we cannot do better than quote the excellent description by Chamberlin $(8: 106)$.

"The history of the Cretaceous period, as that term has commonly been used, is rather complex. The general sequence of events in North America is somewhat as follows: (I) Early in the period there was a somewhat widespread warping of the continental surface, resulting in sedimentation at many points within the continental borders. Submergence was extensive in Mexico and Texas, and the sea extended thence as far north as the Ouachita Mountains, and temporarily beyond, while on the Pacific coast a narrow border of the present land was beneath the sea. Along the Atlantic and Gulf coasts, and in some parts of the western interior, considerable tracts were brought so low, or into such an attitude, as to become the sites of deposition, though not submerged beneath the sea. A prolonged period of sedimentation followed these geographic changes. (2) This period of sedimentation was followed by an interval when most of the areas which had recently been the sites of deposition, whether marine or non-marine, were exposed to subaerial degradation. (3) After this interval had been sufficiently long to allow of very considerable erosion of the Early Cretaceous beds, the sea encroached upon the Atlantic and Gulf borders, covering, and in general spreading beyond, the non-marine formations of the earlier stage. It again covered Texas, and presently extended northward over the Great Plains to the Arctic Ocean, forming a great Mediterranean sea several hundred miles wide from the mouth of the Mackenzie River on the north, to the mouth of the Rio Grande on the south, dividing the continent into two unequal parts, a larger eastern, and a smaller western. On the Pacific coast also, the sea extended its area somewhat at the expense of the land. There have been few greater incursions of the sea over the land, and therefore few equally great geographic changes, during the long history of the North American continent. A long period of deposition was initiated by the submergence, and this was succeeded in turn by (4) a wide- 
spread withdrawal of the waters. The mediterranean sea disappeared, and the borders of the land were extended seaward on the east, the south, and the west, and the continent became nearly or quite as large as now.'

How enormous were the lacustrine and marsh land deposits of the Lower Cretaceous is shown by their attaining in places a thickness of from 4000 to at least 15,000 feet, while the coal beds, the of ten abundant plant remains of warm temperate or subtropical character, the bituminous zones and the remains of fishes as well as of reptiles, all proclaim an environment suited to an abundant freshwater life. Similarly in the Upper Cretaceous the heavy deposits of Dakotan, of Montana, and of Laramie age, all prove that opportunities for evolution of freshwater species were ample. But the distinct evidences of extensive oscillations and local marine invasions on both land and lake regions, afforded the opportunities for gradual migration of freshwater fishes seaward.

Bearing in mind then that the four genera of Aphredoderidae-Amphiplaga, Asineops, Erismatopterus and Trichophanes-have all been reported from Lower Tertiary beds; that the even more primitive acanthopterygian genera Percopsis and Columbia, which connect with Salmonidae, are both living North American types, it seems highly probable that primitive representatives of the Berycidae branched off into marine life during Lower Cretaceous times, and into some of the marine areas that seem often then to have taken the place of the land. As evidenced by fossil remains, and by distribution at the present day, the group probably spread abroad both eastward by seaways that covered New Jersey and interior parts, to west central America, either temporarily or for a prolonged period. Thence along the edge of the North Atlantis bridge, the evolving genera could readily extend their passage till they reached the European shore expanses and northward connections of Upper Cretaceous date. Thus could be explained the presence of the six genera already named that have been laid bare, from rocks in England on the west to those of Mt. Lebanon on the east. 
But another marine invasion westward, along the northwestern shores, and later by the wide bridge that Koken and others accept as having then existed between America and east Asia, would explain the present location of species from Japan southward even to Australia. In the last chapter we outlined what appear to be the derivative families that in turn branched off from the Berycidae as marine dwellers.

From the geographic and geologic standpoints then, we would anew affirm that all present evidence points to origin of the Acanthopterygii in freshwater expanses of late Commanchean age, and over the north-central part of the North American continent. The Percopsidae, as represented by the two living genera Percopsis and Columbia, also the Aphredoderidae, as alone represented now by Aphredoderus, constitute the annectant types, that point backward to Salmonidae-Clupeidae as predecessors, and forward to the Percidae, Centrarchidae, and Berycidae as evolved descendants.

If it be accepted that the chart-figures 35 (p. 240) and 66 (p.38 I ) set forth approximately the relation of land and sea areas that have above been traced, in connection with acanthopterygian fish-life, a satisfactory basis is got for explanation, in large part, of the distribution of the soft-finned and undoubtedly more primitive teleosteans.

The freshwater family Siluridae, with about rooo species, is highly instructive in its general as well as in its sub-family distribution. Divided by Boulenger into eight sub-families, that which we would regard as probably the most ancient is the Bagrinae, which includes the greatest number of genera, as well as the fossil genera, Amiurus, Arius, Macrones, and Rita, that still have living representatives. Arius moreover has been recorded in MidEocene to Mid-Oligocene strata from East Brazil, England, and Germany, also in more recent (?Pliocene) strata of Madagascar and the Siwaliks of India. It is the genus likewise that now includes by far the largest number of species-upwards of 70 . Their present distribution also is remarkable. For they occur in rivers of the Southern States, in Porto Rico, Panama, Guatemala, West Indian 
Islands, Cayenne, Surinam, Brazil, Senegal, and the W. African coast, in the Niger, from the Red Sea to India, Singapore, Cochin China, Siam, Formosa, China with one or two migrant species into the Chinese Sea, on to the N. W. coast of Australia, and even to the Sandwich Islands.

The genus Pimelodus is the next richest in species; has nearly the same American distribution as the last; has reached W. Africa and also the Sandwich Islands. The above localities are mentioned in detail, in order exactly to bring out the wide areas occupied by each genus. Now, we are here dealing with ancient genera that are purely freshwater except for American members of the division Hexanematichthys, also Arius falcarius, $A$. dussumierii, and $A$. venaticus that in reaching their eastern extension as species of the genus, have become largely or wholly marine.

Arius latiscutatus again is found in the Congo River but passes out along the W. African coast to Fernando Po. Broadly too it may be said that the $75-80$ genera which make up the family have a freshwater distribution that follows closely that of Arius.

How then it may be asked is such to be explained geologically? For here we are dealing with what was anciently a freshwater group, as the associated beds and their organisms testify; one also that has remained almost wholly freshwater, but which shows a few of more advanced structure, that are becoming or have become brakish to marine in habitat. The "floating raft" theory in no way solves the problem, for it would be hard to imagine even a large piece of land becoming separated, and yet retaining a freshwater area on it, in which freshwater fishes would survive.

Almost as difficult would it be to imagine that eggs of freshwater fishes could be carried on such miniature floating islands, and yet survive to hatch out. The problem however becomes a natural and easy one, if we again accept such land connections geologically as have already been outlined, and which may have existed at least from late Cretaceous to early Eocene time.

The distribution of the species in the other seven subfamilies, follows greatly what has been outlined for Arius. But it may be noted that the relation of those known fossil 
genera that still include living species is as follows: Arius is known from freshwater strata of Mid-Eocene to MidOligocene age, and extends from Brazil to England and Germany. Amiurus is recorded from Lower Miocene rocks of Western Canada, and is now abundant from Massachussets south to Texas and even Guatemala. Clarias, Heterobranchus, and Silurus are found as Pliocene fossils in the Siwalik hills of India, but the first of these still exists from Senegal and the Nile eastward through Syria and Siam to Java, Borneo, and the Philippines. The second nearly duplicates Clarias, while Silurus extends from the Rhine eastward through Afghanistan to Formosa, Cochin China and the East Indian Archipelago. Macrodes and Rita, also fossil in the lower Pliocene of the Siwalik Hills, is represented now by one species from Asia Minor, and fully twenty from India and the East Indian Archipelago.

Such facts furnish collective proof that the Siluridae must have had wide distribution, by some fairly continuous landways, from America to the East Indian Archipelago, and this not later than Oligocene time. Finally it should be again emphasized that the Loricaridae and Aspredinidae are clearly highly specialized offshoots from more simple Siluridae, that are now wholly confined to rivers-often to mountain streams-of Central and S. America. It seems by no means unlikely that these have reached the high altitudes where they at present live, not by skilful and vigorous leaps over rapids and cataracts as do salmon now, but that they originally existed at much lower levels, and when steady or sudden elevation of Andean and other mountain ranges took place, up to the point of attaining their highest positions, ancestors of these families participated in the general uplift, and yet survived. For C. Darwin (260: 232), A. Agassiz (26I) and many others since have shown that relatively recent but steady elevation of the Andes has gone on through thousands of feet.

The gradual reduction in size, and ultimate disappearance of scales, among species of such genera as Schizopygopsis, Gymnocypris, Mola, Paraphoximus, and Nemachilus, in the succeeding family Cyprinidae, might well indicate that the now scaleless Siluridae developed from one or 
two ancient genera intermediate between the Salmonidae and Percesoces.

In reviewing the above, and the evidence furnished by the accompanying chart (Fig. 69), the writer concludes that the Siluridae evolved in central America or northern $\mathrm{S}$. America during late Cretaceous time, that extensive migration into $\mathrm{N}$. America took place later, when many subtropical plants and animals also moved into the U. S. and even Canada; that an early and important migration from N. E. Brazil and Guiana along the S. Atlantis continent introduced types into western, central and later east Africa. Eastward penetration along the Indo-Mascarene land-mass ensured invasion ultimately as far as the E. Indian Archipelago. Meanwhile through adaptation to a brakish life, and later to a shore life, the sea catfishes-Arius, Galeichthys, and Aelurichthys-branched off from more ancient types, specially in S. America and the E. Indies. Such distributions yield added and confirmatory proof, that only with acceptance of the existence of past geologic land

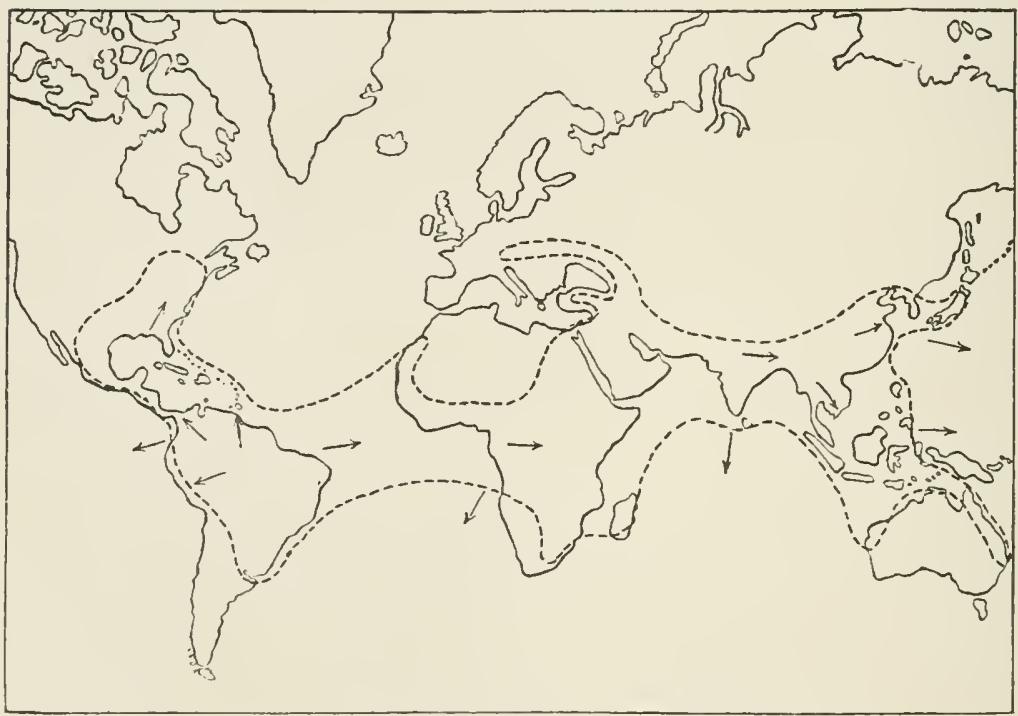

Fig. 69. Chart showing present and probable past distributional area occupied by Siluridae. The arrows indicate pathways followed, these in a few cases leading to an acquired marine life. 
masses, is it possible to reach correct understanding of present of ten puzzling distributions.

The Cyprinidae, with about I300 species, contrasts markedly with the Siluridae in geologic relation and evident lines of geographic evolution. The chart (Fig. 70) sets forth the areas now occupied by species of the four sub-families Catostominae, Cyprininae, Cobitidinae, and Homalopterinae. At a glance the chart would indicate that the entire family evolved as a northern temperateregion group. It further indicates that the Catostominae

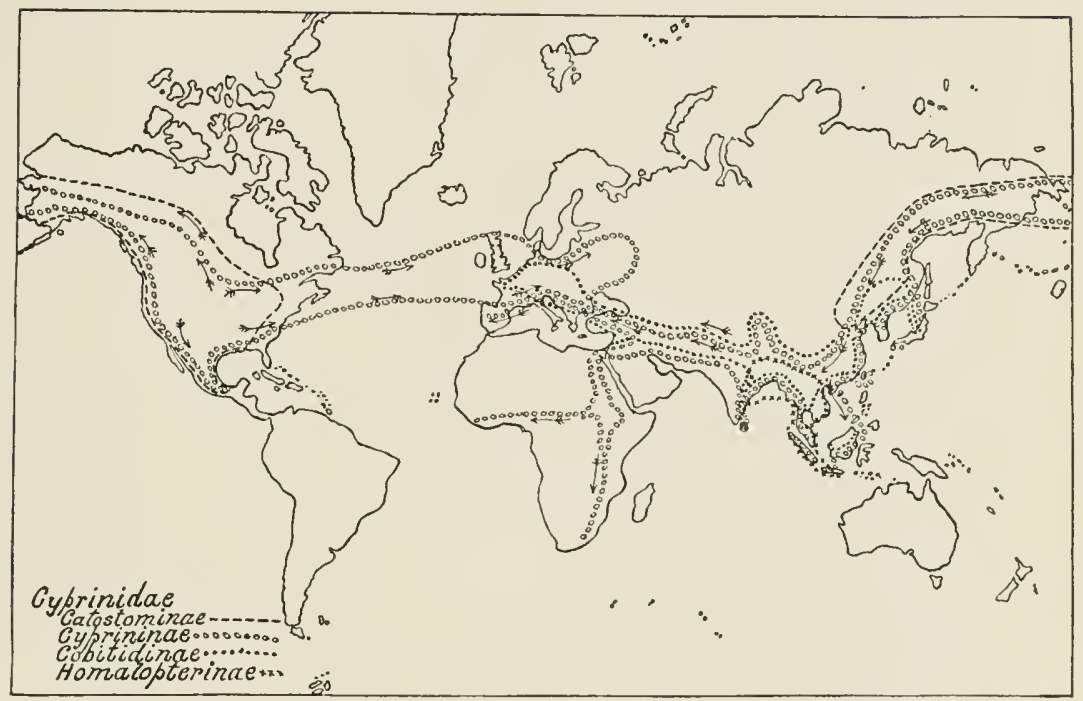

Fig. 70. Chart of distributional areas gradually occupied by sub-families of the Cyprinidae. The arrows indicate the lines of travel from the primitive N. American centre.

and Cyprininae, specially the latter, have been the "dominant" divisions. We may now try to learn how such has resulted.

The sub-family Catostominae must have been abundant in such genera as Amyzon and Catostomus over considerable reaches of $N$. America during early Eocene times. This is partial indication that at least in late Cretaceous beds of that region, more primitive types might be expected. These, and evolving Cyprininae, seem gradually to have 
diverged, the Catostominae along one, the Cyprininae along two northern and-what might now be called-extracontinental lines, that extend in opposite directions. One was the evidently wide landmass that-during late Cretaceous and much, if not all of Eocene time-connected N. W. America with a broad extension toward it of the Old Angara continent.

Few species of Catostominae crossed this mass into Siberia, or if once abundant, they are now indicated onlyso far as accurately known-by one or two species of Catostomus. On the other hand the Cyprininae not only effected an important migration thitherward, they evidently spread westward into Siberia and southward into China, Japan, India, and ultimately the E. Indian Archipelago, as the genera Barbus, Squaliobarbus, and Achilognathus show. Now Barbus, with about 300 species, is the largest genus of the sub-family, and is also known fossil from mid and later Tertiary strata through S. E. Asia to central Germany.

But not a few genera-especially the tropical Asiatic ones-doubtless evolved on that continent. Meanwhile from E. America along the N. Atlantis landmass, an equally important migration set in toward W. Europe, probably led by the genus Leuciscus, that has been reported from Miocene rocks of $\mathrm{N}$. America. In having upwards of 80 existing species, it is next to Barbus the richest in the family. In addition to many that cover the $\mathrm{N}$. American continent down to Mexico, species are found in Britain, Holland, Belgium, Germany, Switzerland, Spain, Austria, Italy to Crimea, Asia Minor, and eastward to the Tigris.

Abramis, with a somewhat more restricted range, and with fewer species, seems to have spread parallel to, but along a line north of, that followed by Leuciscus.

The above double and diverging migration on the one hand into Asia, on the other into Europe, evidently resulted in an occasional and ultimate meeting and interblending of the two streams of fishes. This seems to have taken place along a region that was alternately land and sea, and where the Angara or Asian and the N. Atlantis masses approached, and at times connected with each other. This ran approxi- 
mately from Asia Minor northward through West Siberia. So Carassius, that evidently migrated through N. China and E. Siberia into Thibet, India, and Ceylon, spread even to Syria and Eastern Europe, where it was met by Leuciscus in its eastward progress.

But Barbus, Capoeta, Labeo, and Barilius, all eastern types in their primitive derivation, as we would view the matter, ultimately worked south-westward into the great central African lake region, and there became intermingled with Characinidae, Cichlidae and other families, which came in directly from the South American continent. If it be objected that the above four genera may have entered Africa from the S. American continent, and thence spread eastward by way of Syria, Persia, and Afghanistan to India, China, Tibet, and Japan, we would reply that very few of the family live or have lived in S. America : nor do any of the above-named four genera, which have their headquarters in the East, occur even in N. America. Further, the western and African genera in particular show no species in the extreme west of Africa, that connects with American species. Connection with European species is also unlikely, since a wide Cretaceo-Tertiary sea separated the two continents during a long period.

The Lobotinae (or Cobitidinae) probably evolved from some genus of the Cyprininae by increase in barbels, and specially by formation of an osseous casement to the swimbladder. The genus Botia, that is distributed from Japan to India, Siam, and Borneo, indicates the possible existence and derivation of such a type. The entire group extends from China and Japan, westward to Sweden and Holland, as well as southward to Ceylon, Borneo and Syria. The not unfrequent gradual reduction in size of the scales, and restriction of them over the body in some species, up to their ultimate absorption, has already been drawn attention to and is observed also in other families.

The fourth sub-family or Homalopterinae indicates derivation in S. E. Asia from some genus that combined characters of Culter of the Cyprininae, and those of Cobitidinae. The former shows, among other characters, a tripartite air-bladder with the median posterior lobe minute, 
the other two lateral and paired. In Homalopterinae the small air-bladder consists of paired halves with bony enclosure. The reduced air-bladder that in some is almost absorbed, appears to result, as already stated (p. 352) from the group having become inhabitants of mountainstreams, in which rapid oxygenation of the blood and tissues is effected, so that use of the air-bladder can be dispensed with.

From the geological standpoint then, the united testimony of fossil and recent genera of the Cyprinidae is that the family started in N. America, probably in the late Cretaceous period, and with forms referable to the simplest or catostomid section. Extending widely over the northern continent, they evolved numerous cyprinid descendants by early Eocene days, but they were prevented reaching $\mathrm{S}$. America, owing to discontinuity between the two continents in the late Eocene and in Miocene times. Favored by a wide western connection with Angara-land, the now abundant species of Cyprinids extended into that land, along with a few catostomid forms, and these spread westward as well as southward, in the latter case giving rise to genera that became subtropical and later tropical in environment. These overran the Angara continent to its western limit, reaching even to central and south Europe by late Oligocene days.

An equally strong extension across N. Atlantis ultimately met the above in derivative species of each; while the Lobotinae or Cobitidinae, coming off as a sideline from east Asiatic Cyprinids, overspread Asia and Europe, with an outlier along the Nile valley, in relatively recent periods. From a derivative type, intermediate between the Cyprininae and Lobotinae the Homalopterinae probably arose. And it seems not unlikely that the mountain types, which mainly compose the last group, may, through gradual folding and upheaval of the Himalaya-Malaya ranges, have acquired their present peculiarities, owing to proenvironal adaptations to new and changing environal stimuli that started when the mountains were upheaved to their final limit, during the Pliocene period.

The Characinidae closely suggest geologic and geographic connections similar to those that permitted distri- 
bution of the Cichlidae, the Cyprinodontidae, and the southern section of the Siluridae, but with this difference that none of the Characinidae were able to invade and spread eastward along the Asiatic continents. (Fig 7 I). Were we to think only of the number of existing genera and species, the northern part of the S. American continent would claim to be their centre of evolution. For fully ioo genera are S. American, while about 24 are African. Slight additional proof is the finding of two fossil species of Tetragonopterus in the Tertiary Lignites of San Paulo, Brazil. Again, the last named genus is by far the richest in living species, there being about 35 species that now extend from Mexico and the Guianas in the north to Buenos Aires in the south. The genera also that approach it most nearly in number of species, like Curimatus (40), Myletes and Leporimus (each 32), Prochilodus (26), and Serrasalmo (23) are widely distributed over South America.

The family has been divided by systematists into nine or ten groups; of which five are purely American; two are very largely' so, and one of these-Hydrocyonina-is

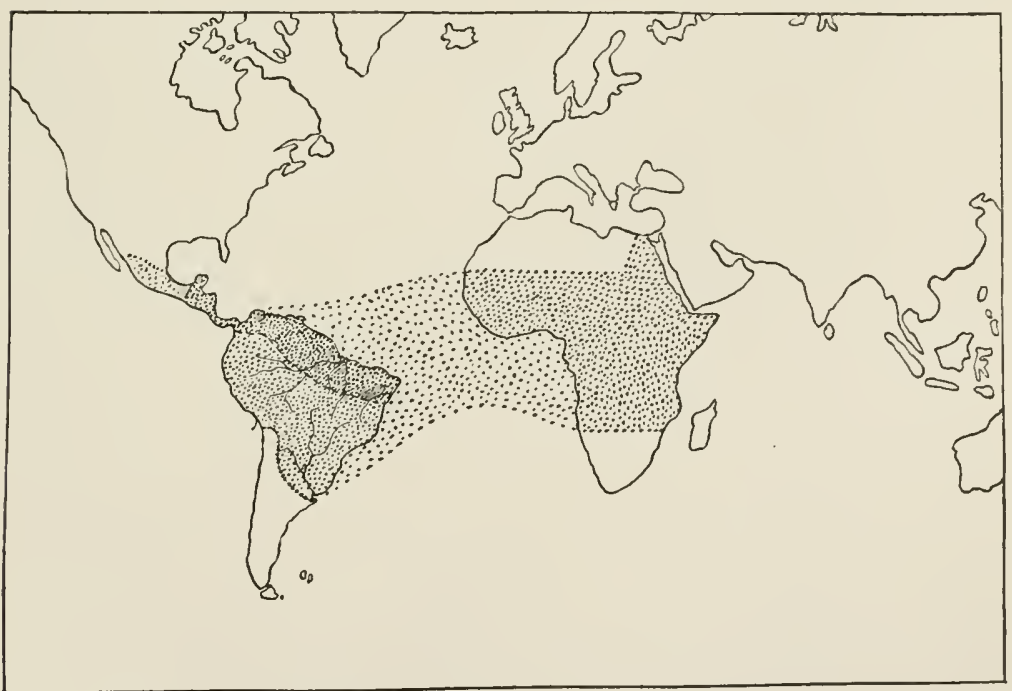

FIG. 7I. Chart showing distribution of the Characinidae from Central America or possibly northern S. America across to Africa. The dark area shows distribution of the related family Gymnotidae. 
richest in genera; while three are African. But the Hydrocyonina or River wolves, and the Citharinina, deserve special attention, for these include genera the greater number of which are found in S. America, but some have reached Africa. So putting all of the above facts together, one strongly inclines to regard S. America as the centre of evolution.

If we accept such, the wide expansion of the species over S. America seems to point to the conclusion that that continent has witnessed no sudden fundamental geologic changes, except those of erosion and related phenomena, over its larger northeastern area in recent geologic time. But the entire absence of Characinidae from the southern and southeastern coastal parts, might be due to an averagely overcold condition, that would prove injurious to an essentially tropical or sub-tropical group of fishes. Or it may be that during steady elevation and even folding of strata in the west during the elevation of the Andes, the land on the south-eastern side was under the sea, a view that has been demonstrated as correct by the Princeton Patagonian Expedition, and that has been fully accepted by subsequent workers.

A highly interesting feature however is the presence of ten or more species, along the coastal and western Andean regions, which belong to genera that extend over the entire eastern half of the continent. Thus Tetragonopterus brevirostris and T. microphthalmus are encountered in the "Western Andes of Ecuador" and from the "Pacific coast of Guatemala." A possible explanation is that members of the family had become distributed over the entire width of the continent, before any marked elevation of the Andes with attendant faulting and probable volcanic action, had taken place. When such happened, outlier-species may have been separated on the western Andean side, that have evolved into the species now found there. But as an alternate possibility, it must also be kept in mind that about the time now under consideration free communication existed between the Pacific and the Gulf of Mexico. So it may be that accustomment to a marine environment was effected further north. 
The close affinity between such S. American genera as Anacyrtus, Salminus, Xiphostoma, and Cynodon, with African genera like Hydrocyon and Sarcodaces; or between Piabucina and Tetragonopterus as compared with Alestes and Micralestes of Africa, almost demands an important land connection between the two continents during late Cretaceous and early Eocene times. But further the existing distribution of many species of the African genera, agrees with what is now known to be true of other freshwater groups of fishes. For not merely genera, even species have a continuous range from Senegal, across Central Africa to the Nile Valley. The older records which demonstrated this, have been abundantly confirmed and supplemented by the recent valuable work of Moore (259), and the investigations of Boulenger (227). Thus Alestes macrolepidotus is continuous from the rivers of Senegal across Central Africa (Lake Tanganyika) to the Nile valley. Distichodus rostratus with its near ally $D$. niloticus cover the same territory, while other of the species extend from Mozambique to the Lower Nile. Citharinus geoffroyi is found alike at Gambia and along the Nile valley. Other species occur only from W. Africa to the Congo basin.

In some cases even, incipient or recently established species, due to geographic isolation, can be traced. Thus while Peters reduces the African Hydrocyon to one species with varieties, Boulenger is compelled to recognize three. Two of these $H$. forskalii and $H$. brevis are from the Nile, $H$. lineatus extends from Senegal across the Congo basin to Tanganyika, the Zambesi, and even to the Limpopo river in the Transvaal. But, as Boulenger has shown, not a few of the African Characinidae are peculiar to the Congo, or to the "Rift-valley" Lakes, and particularly to Tanganyika. Thus of Petersius that author says it is "very near to Tetragonopterus of which the very numerous species inhabit Central and South America. It differs in the complete absence of teeth on the maxillary bone, as in Alestes and Micralestes, from which it is probably derived." The four species that he describes are all peculiar to the Congo basin.

All that is necessary then, for explanation of the African species, is the migration eastward into Africa across 
the S. Atlantis bridge, of a few species of Tetragonopterus in late Eocene time, that would start the subsequent evolution there of Alestes, Petersius, etc.; also of Cynodon and Xiphostoma that would start the evolution of related African forms like Hydrocyon and Sarcodaces.

While these were in process of evolution over the Central African plateau, those extensive "eurycolpic" folds, faults, upheavals, and depressions occurred, probably during Miocene time, that equally obliterated connection of Africa with S. America, and that gave rise to, or certainly accentuated, those rift valleys like Lake Tanganyika, the Nile valley, the Red Sea, and lesser valleys. Since that time continued steady uplift from the "Great Western range," has given rise to the localized areas, in which species and genera peculiar to each region have evolved.

In brief summary then the writer would set forth, that the Characinidae first arose in the north-central part of S. America, and during mid or late Cretaceous times. Gradually spreading and breaking up into evolving species and genera, these by Eocene times, had invaded the continent from eastern coast to western, while as yet the Andean upliftings and foldings had advanced little. But, as these became increasingly pronounced, a pacific or western series became separated from the eastern types, while migration northward of outliers into Central and Mexican America proceeded. Meanwhile a few derivative species were carried across river or swamp areas of South Atlantis into west Africa during Eocene times, and multiplying there were carried across the African continent, from Senegal and Gaboon to the Upper Nile and the Zambesi. These in turn were in considerable part obliterated during the tremendous earth disturbances that gave rise to the higher Andes, to the Great African Range, that destroyed the South Atlantis bridge, and that formed or assuredly accentuated the African rifts or "graben." The high eastern face of the Nile and the Red Sea ravine-wall, prevented further migration eastward after early Pliocene times.

The highly modified family Gymnotidae is now generally accepted by ichthyologists as a derivative group from the last. Its restriction to Central and South America, and its 
extreme specialization over that region, are slightly added proofs that the family was ancestral to the latter area.

Probably no family of the Teleostei appears more puzzling from the geographic and geologic standpoints than the Cyprinodontidae. For though including only about 200 species that are typically freshwater, or that rarely become brakish-water or semi-marine in habitat, the distribution over tropical and warm-temperate land-areas of the world is now extensive. Two genera Prolebias and Pachylebias are known in about ro species from Lower Oligocene up to Upper Miocene strata of freshwater character over central and south Europe. This might seem to favor origin for the group there. Cope's doubtful genera Gephyrura and Proballostomus from Tertiary rocks of South Dakota need not now be considered.

Three genera Fundulus (including Haplochilus) with about 54 species, Cyprinodon with I 2 species, and Gerardimus with IO, stand out conspicuously from the other genera, alike from abundance of species, from wide distribution, and from their close structural relation to fossil forms. The first of these is "the most primitive and the least specialized" (257:63I). About 32 of its species are distributed from Nebraska, Missouri and New York southward to Costa Rica, Texas, Florida and Jamaica in $\mathrm{N}$. America, 7 are native from Guatemala to East Brazil in S. America, while the remaining I4 extend from West Africa to Japan.

But before treating of the extra-american, some attention should be given to the remaining genera of the family, which are nearly all found from Central to S. America, and amount to about I 5. The presence of species in the southern coastal states, in Cuba, San Domingo, Barbadoes, Trinidad, Martinique, Mexico, Honduras, Panama, Guatemala, Venezuela, Brazil, and southward to Monte Video, furnishes almost conclusive proof that northern S. America was the centre for evolution of the family.

The genus Orestias is of exceptional interest, for the Io known species are only found in Lake Titicaca and a neighboring lake, so at an elevation in the Andes of more than 12,000 feet. It represents a degenerate evolutionary 
type from some other genus, probably Fundulus. For Garman (262: 145) says: "Excepting the absence of ventral fins in this genus, young specimens up to medium size, resemble Fundulus." We would explain its present geographic position as a genus, in terms of past geologic conditions as follows: Species of Fundulus are widespread over western Brazil, and must have existed there for a long period. If one of these had nearly reached the west coast, before final and pronounced elevation of the Andes took place, such may have persisted in individuals that inhabited lakes which were uplifted during the elevation process. Isolated then in a new environment from allied forms, it has in course of time split up into the ten species recorded by Garman.

With all respect to so painstaking an ichthyologist as Eigenmann, we are entirely at a loss to understand why he should have regarded the Io species of the genus, or the associated catfish Pygidium rivulatum, as in any way associated with a "marine character." Nor does Titicaca in any way suggest that it "was an arm of the sea, in which its nearest relatives flourish." All of the Cyprinodonts are freshwater typically, and there is no ground for considering that they had even remote ancestral connection with the sea.

The continuity of genera, both across the Isthmus into Mexico and California, also across such West Indian islands as have been already named, into Florida, Alabama, and the S. E. States is added proof that geologically a continuous passage-way once existed in the west between the two continents, at least since Eocene to Oligocene time, and that in the east what are now scattered islands were once more or less connected, either as a continuous freshwater passageway, or as large islands that every now and again became so connected as to exchange faunal-as they undoubtedly have exchanged floral-types.

As regards the Afro-Asiatic genera these are so closely similar to American forms, that they have been regarded by many systematists as generically alike, in the case of Cyprinodon and Fundulus. So striking is the relationship, and so requisite is a land connection, that Eigenmann (263:523) 
has expressed it thus: "A land connection, whether a land bridge, intermediate continent or land-wave, between the two continents is imperative. This land continent must have existed before the origin of existing genera, and before many of the existing families."

The distribution of the species of the above two genera aid us fairly well in suggesting the lines of distribution from N. E. Brazil eastward. For 5 species occur in extreme W. Africa that would form the nearest contact point, I is common to N. Africa, Sardinia, and S. Europe, I is peculiar to Spain, I is found from Sierra Leone to the Upper Nile, and 3 are recorded by Boulenger across Africa from Lower Congo to Tanganyika. This would indicate that the entrant African forms had split into a series that passed northward along a coastal land elevation from Senegal, and entered S. W. Europe by the Gibraltar bridge during late Eocene time. Another series passed, like so many other organisms, eastward across the central African continent, before formation of the great Eastern African Range and the deeper rift valleys.

A splitting in the migrational journey again took place, so that some attenuate lines passed by the MozambiqueMadagascar and Indian bridge into Ceylon, and ultimately Japan; while another passed,--previous to Pliocene earth shrinkage and rift valley formation-across Abysinia, North Egypt, and Syria into Persia. Differentiation thereafter into isolated species such as now characterize Tanganyika, Madagascar, Malabar, Spain, and other areas, was slowly effected probably from Pliocene to recent times.

We now come to several families of bony fishes that indicate origin from some of the most primitive teleosts; that suggest fundamentally similar geographic distribution with each other; and which in geologic relation both confirm and extend the views already accepted. These are the Hyodontidae, the Osteoglossidae, the Notopteridae, the Mormyridae, the Phractolaemidae, the Pantodontidae, the Symbranchidae, and the collective families of the Apodes.

Though known only by three living species of Hyodon, that range from the Gulf States to Canada, the first of these families is probably primitive to all of the others. 
The second of these, though now reduced to four living genera, must once have been an important and widely extended group. For in addition to the area now inhabited by the living types, fossil remains of Dapedoglossus from the Green River Shales of Lower Eocene age have been described by Cope, and of Brychaetus from the London Clay of about the same age in S. England by Agassiz and others. So if we combine our knowledge of all of these, it can be said that from Wyoming southward to N. Central Brazil, and thence eastward to Central Africa, again from Borneo-Sumatra southeastward to Northern Australia the group extended.

But how are the wide separating gaps between Wyoming and central Brazil, between the latter and the West African continent, between Central Africa-across which Heterotis extends-and Sumatra or Australia to be accounted for? In reply it can be said that of all known types -living or fossil-one that would combine somewhat the characters of Dapedoglossus and Osteoglossum with tendency toward Seleropages of Australia would most nearly fulfill requirements. If then in mid or late Cretaceous time such a common primitive type lived in northern $\mathrm{S}$. America, this spreading northward by the Isthmus bridge might by shortening and condensation of body and of vertebrae, give rise to Dapedoglossus of Wyoming strata. But again extending its territory southeastward it probably developed primitive members of Osteoglossum and Arapaima in the Guianas, in Brazil, and extending by the $\mathrm{S}$. Atlantis bridge reached the central and south-central African areas. During passage across these areas proenvironal adaptations in some individuals resulted in evolution of Heterotis which spread gradually during Eocene to Miocene time from West Africa to the White Nile. It seems then to have been blocked in its eastward extension by the eastern walls of the Nile and the Red Sea rift-valleys. A series that more nearly retained primitive characters of Osteoglossum, seems to have passed southeastward by Madagascar and the Afro-Indian bridge, till it reached the East Indian region. Here, though denudation, earthshrinkage, volcanic action, and land displacements have 
obliterated Oligocene, Miocene or recent remains over the western part, the existence of two species of Scleropages, as little modified but far-travelled descendants of an osteoglossid type, from Sumatra and Borneo to N. E. Australia, links up the whole in geologic continuity.

A second Arapaima offshoot may either have worked northward as Brychaetus by the Afro-Hispanic bridge or may have crossed directly by the N. Atlantis bridge.

The Notopteridae are remnants of a group that must have had a wide distribution in geologic time, and which during their evolution must have followed pretty closely, the later line of travel pursued by the Osteoglossidae, to which and to the Hyodontidae, rather than to the Clupeidae, we would most nearly assign them. So the rather primitive and normal genus Notopterus, and the more modified Xenomystus, that are found from West Africa to the White Nile, are represented by three species of the former in India, Burmah, and Malaya, having doubtless spread thither by the Afro-Indian land mass, that the Osteoglossids and numerous others took advantage of. Many structural characters again ally Notopterus with Osteoglossum and Arapaima. All of these facts then require for their explanation, such past geologic connections as those already indicated, for their proper interpretation.

The remarkable family Mormyridae, that includes 93 species peculiar to central Africa, from the west coast to the Nile, shows marked affinities with the Notopteridae, the Osteoglossidae, the Hyodontidae, and the Albulidae. They are probably descended from a type that more or less combined characters of all of these. The very circumscribed area in Africa that some species or genera occupy; the extreme modification in oral structure that many of them show-which however is paralleled in central S. America by Sternarchus and related genera of Gymnodontidae;-their entire absence from the American continents; as well as the affinities above suggested; would all incline one to believe that from some primitively American ancestry, related to the families just treated of, descendants that alone survived in the Central African area, evolved actively into many as well as varied new species and genera, 
during later geologic periods. These all apparently evolved from a few individuals which multiplied so recently in the geologic history of the continent, that they were all retained west of the rift-valley walls and of the Great Central Mountain Chain.

It is extremely likely that the ancient family Albulidae started in the early Cretaceous period, as a marine derivative from like ancestry with all of the above. For though it must be confessed that, apart from structural details that ally it with the above families, we have absolutely no good proof that they were ever freshwater. The close affinities shown with Notopteridae, Osteoglossidae and Mormyridae are in themselves a strong argument in favor of their being descended from a common ancestor with these. The existence of several species of Anogmius in the marine Cretaceous Niobrara beds of N. America, of Prochanos, Istieus and related genera in the Cretaceous of central S. Europe, and of others in more recent south and central European beds, might be explained by our viewing all of these as early derivatives from some freshwater ancestors of Lower Cretaceous age that were common and ancestral for all of the above families. 


\section{CHAPTER XV.}

Fishes in Relation to A South Atlantic Continent.

The writer has reserved for separate discussion, a small series of teleostean families that are puzzling in their geographic distribution, that often undergo marked structural modification, that indicate frequent points of contactrelation with the families studied in last chapter, and which also suggest past geologic conditions and land-connections that some may regard as too extreme for acceptance as yet, or until more abundant confirmatory evidence is secured.

We refer to the Galaxidae, the Aplochitonidae, the Symbranchidae, the Amphipnoidae, and the Anguillidae. The first four of these are freshwater, the last is freshwater, brakish, or mainly marine. The geographic distribution of the first four is arresting, of the fifth confusing, unless some exact line of action can be shown to be in operation. So if the main contentions of this volume are correct, some light should be shed on their origin.

Regarding the Galaxidae Boulenger says (252:84) that "eight are known from N. Zealand and the neighboring islands, seven from N. S. Wales, three or four from South Australia, one from West Australia, two from Tasmania, seven from S. America from Chile southwards, and one from the Cape of Good Hope." At the same time he records the finding of "a marine Galaxias" that "was taken out of the mouth of a specimen of Merganser australis during the collecting excursion to the southern islands of New Zealand." In this connection also he sounds a note of warning against regarding the Galaxidae as freshwater in origin, specially seeing that one native to the Falkland Islands and to N. Zealand "periodically descends to the sea, where it spawns, from January to March, and returns from March to May" to the freshwaters. The question then here is: Should we regard the 28 freshwater species (now increased to 30 ), found in seven widely apart localities, as freshwater derivatives from a marine genus, of which at most two species are catadromous, or are seashore dwellers. 
Before attempting any decision we may first try to secure collateral evidence. The next-though a small-family to the Galaxidae is the Aplochitonidae, and both of these exhibit decided affinity with the Esocidae, the Cyprinodontidae, Amblyopsidae, and Percopsidae that are freshwater, also the Enchodontidae - an extinct marine cretaceous family,-the Scopelidae, and two other smaller highly modified marine families. The geographical distribution of the Aplochitonidae is as arresting as is that of the Galaxidae. For of the two included genera Aplochiton (Haplochiton of some systematists) is made up of two species found in $\mathrm{S}$. Chile, Tierra del Fuego and the Falkland Islands, while Prototroctes has one species in $\mathrm{N}$. Zealand, one in $\mathrm{S}$. Australia, and one in Queensland.

So the much discussed question of a possible geologic connection between Patagonia, N. Zealand, Tasmania and Australia, possibly also the Cape of Good Hope, is presented. We need not here review all of the alternative suggestions made. But before treating of the above two families, and of facts both from the botanical and the zoological sides that may greatly aid in reaching a correct decision, we may give attention to the Symbranchidae and Amphipnoidae.

One genus Chilobranchus includes a species native to Tasmania, and another to N. W. Australia. Symbranchus includes a species that extends from Mexico to the rivers of S. Brazil. Now at first sight such might favor the former existence of a wide southern bridge from eastern S. America to Tasmania. But the distribution of the remainder causes the Symbranchidae to resemble, and the allied Amphipnoidae to fall in with, other large groups whose past geologic expansion we have already considered. For two species of Symbranchus extend from the Hoogly to the East Indian Archipelago, the single species of Amphipnous inhabits the rivers and brakish waters of India and Burmah; while Monopterus extends from Malaya to S. China and Japan.

A quite natural and continuous interpretation here would be that both families evolved either in eastern Brazil or in Africa, and in the former case migrated eastward 
along the S. Atlantis and Afro-Indian bridge to India. Or in the latter case the evolving species spread from Africa both westward into Brazil and eastward into India. By subsequent organic denudation, both groups have disappeared from Africa, but in India they not only persisted, they extended northward to China-Japan, and southward they reached Australia and Tasmania during that relatively recent and short period when Malaya, Australia and Tasmania were more or less continuous. During this short period also the more evolved Australian marsupials - that had migrated from America along another passageway described below-passed northward from that island (p. I 4I) into Malaya, and this at a much later time than when they first entered Australia by its south and S. E. coasts.

But such an explanation in no way applies to the species of Galaxidae and Aplochitonidae, whose distribution is almost identical, except that none of the latter group occurs with the former in S. Africa. Before dealing in detail with them, it may be well to observe that fishes from the Southern Hemisphere have at times been reported as freshwater that do not deserve such a designation. For they are all southern outliers of more northern marine genera, that occasionally pass into the mouths of rivers. A case in point is the list of "Freshwater species" that succeeds the much longer list of "Marine Species" collected by Mr. Gulliver at Rodriguez (264:47I).

The question involved in distribution of the Galaxidae and Aplochitonidae is a very large one from every biologic and geologic standpoint. So the writer proposes to deal somewhat fully with it in the remainder of this chapter. Attempts have been repeatedly made to get over the diffculties of the case, by supposing that the above two families were derived from a marine ancestry, as has in part been indicated above. But the effort invariably leads one into strained and even quite unscientific views. The question then is: How are we to explain the existence in freshwaters of lower S. America, of the Falkland Islands, of extreme S. W. Africa, of New Zealand, Tasmania, and of widely 
apart areas of Australia, of nearly 40 species of fish belonging to four genera of two related families?

Even though it may seem a recapitulation in part of oft-rehearsed views, the writer proposes to bring together threads of evidence, alike from the botanical and the zoological fields. And his aim will be to answer as perfectly as possible the question; Did an extensive and in time fairly continuous continent extend across the lower or southern part of the Atlantic and Indian oceans from Patagonia to S. Africa, thence to Tasmania, N. Zealand and the S. E. Australian coast, with a temporary extension even to New Caledonia, the New Hebrides and the Fiji Islands. Existing terrestrial configurations and bathmetric oceanic conditions seem entirely to negative such a possibility. But the accumulating observations of the past half century have caused a striking and fundamental change in the minds of geologists and biologists alike. Such change was gradually induced and prepared for by the studies of Lyell, J. D. Hooker, Suess, and Koken during the mid and latter part of last century, and has since been carried forward by numerous successors.

The most careful and suggestive array and recapitulation of arguments in favor of such an extensive connection, is contained in the paper of $\mathrm{H}$. O. Forbes on "The Chatham Islands," (265:607) to which the writer has been in considerable part indebted for his results. But in the chart which accompanies the paper Forbes has plotted some land configurations that seem superfluous, according to present knowledge. But such configurations make appropriate the name "Antarctica," that he has conferred on this southern circumpolar landmass. It should be candidly said also that the striking discoveries of the various antarctic expeditions of the past twenty years seem all to fortify his main conclusions, and those of his predecessors.

The earliest investigator who placed the issue in an important light was J. D. Hooker. Writing of Kerguelen Island plants (266: 14 ) in 1879 he said. "Various phenomena, of very different relative value and nature, but common to the three archipelagos, Kerguelen, the Crozets, and Marion, favor the supposition of these all having been 
peopled with land plants from South America, by means of intermediate tracts of land that have now disappeared; in other words that these islands constitute the wrecks of either an ancient continent, or an archipelago which formerly extended further westwards, and that their present vegetation consists of the waifs and strays of a mainly Fuegian flora, together with a few survivals of an endemic one."

Then speaking of Amsterdam and St. Pauls Islands to the N. E. of Kerguelen and almost in line between the tip of Africa and the S. Australian coast he wrote: "their scanty vegetation is on the whole more temperate than antarctic, and approximates to that of S. Africa, in containing such genera as Phylica, Spartina, and Danthonia." And of Tristan da Cunha group, between S. Africa and Fuegia he remarked "Their flora is essentially Fuegian, with an admixture of Cape genera, but with none of those characteristics of Kerguelen Island."

The gradual and successive publication of Hooker's "Flora Tasmanica" (267), of his "Flora Zeylanica" (268) and of Bentham's "Flora Australiensis" further revealed in striking manner, that not only was there a specific or generic identity between many plants of these three areas, but also that between S. Patagonia, Fuegia, the Falkland Islands, Tristan da Cunha, Kerguelen Island, New Zealand, Tasmania, and S. or S. E. Australia, there was much in common. And for reasons that will appear later the writer would emphasize that S. or S. E. Australia seems to have been the important connecting region with Tasmania, and earlier-though for a short time geologically-with $\mathrm{N}$. Zealand.

Hooker's study "On the Flora of Australia" in his Flora of Tasmania, and the recent exhaustive study by Cockayne of the New Zealand flora in relation to those of southern lands, that forms the fourteenth volume of "Die Vegetation der Erde," both emphasize our present contention. So many specific resemblances also between N. Zealand and the Chatham, Auckland, Campbell-Macquarie isles can be traced, that we are forced to accept the continuity of all of these with each other and the main masses, at some not very remote past period. For the view that ocean currents, 
or birds of passage, or floating rafts have more than a very trivial share in spreading typically inland-not littoral or halogen-plants has, alike from the experimental and the observational standpoints, been proved of small value.

The publications of the Challenger Expedition, of the German South Seas Expedition, of the Princeton Expedition to Patagonia, and the Transit of Venus Expedition, as well as the more recent and various Antarctic expeditions, have now made us accurately acquainted with the surviving flora of the islands referred to by Hooker, or of the southern part of S. America. We are thus able now to compare both the flora and the fauna of the entire southern region, and in the following pages an outlined sketch is attempted, beginning with the plants.

The arborescent coniferous genera Arancaria, Libocedrus, Podocarpus and Dacrydium have representative species from Fuegia to N. Zealand or even Norfolk Islands. Further, species of the first and third are found in Chile, Brazil, and even for Podocarpus in Central America. The grass Deschampsia rariflora extends from Fuegia, the Falkland and St. Georges Islands to Kerguelen, a distance of nearly 7000 miles. The peculiar sedge genus Oreobolus includes three closely allied species, that extend from Chile, Fuegia, and the Falkland Islands across to Auckland Islands and Australia. Four species of Astelia have a similar distribution.

The genus Drimy's, one S. American species of which yields Winter's Bark of pharmacal value, is represented by about twelve species that extend from the mountains of Venezuela and Brazil south to Patagonia, thence by Howes Island to N. Zealand, Australia, New Caledonia and even Borneo. The rhamnaceous genus Discaria includes, like Drimy's, about twelve species that occur: one in W. Brazil, one in Andean Peru, one in Chile, three in southern Argentina, one in Chile-Patagonia, one each in N. Zealand and Australia.

The single species of Pringlea, once supposed to be eminently peculiar to Kerguelen, has later been found in Heard Islands, the Crozets, and Marion Islands. Now this monotypic genus belongs to a subfamily of the Bras- 
sicaceae (Cruciferae) called the Thelypodieae. It is made up of the genus Nothothlaspi with three N. Zealand species, of Decaptera with one, Hexaptera with six, Menonvillea with four, and Cremolobus with eight species, all of which are mainly S. to N. Chilean, though some occur eastward into Argentina, and others northward into Peru and W Grenada. It consists also of the genus Thelypodium native from Mexico to Oregon; of Streptanthus found from Mexico to Arkansas; of Caulanthus from California to Utah; of Stanleya from California to Missouri; and of Warea in Florida. A decided distributional continuity and community of descent is therefore indicated here, that extends from central N. America to West Patagonia, thence across the southern hemisphere to the Crozets, Kerguelen and N. Zealand.

The caryophyllous plant Colobanthus quitensis extends from the Mexican Andes south to Cape Horn and Fuegia, thence across the southern ocean to Amsterdam Islands, to Kerguelen and Heard's Islands as C. kerguelensis, and again to the mountains of N. Zealand and Tasmania, where it has split up into two closely related types $C$. quitensis and C. billardieri. The continuous line of distribution then, followed by this one species, is about 14000 miles, while throughout it remains a subalpine plant. The question then may pertinently be asked here, though the answer will be deferred till later: Did the species arise in Patagonia, and then spread northward along the Andes, as well as eastward to N. Zealand, or did it originate in the former or the latter area?

The tiliaceous genus Aristotelia includes only five species that closely resemble each other. One is found in Chile, two occur in N. Zealand, and two in TasmaniaAustralia. The small spreading rosaceous genus of the Southern Hemisphere Acaena has three nearly related species that extend from Chile through Fuegia and the Falkland Islands eastward to Tristan da Cunha, the Marion, Crozet, and Kerguelen Islands, thence to the Macquarie, Auckland, and Campbell Islands, ultimately reaching Australia, N. Zealand, and Kermadec Islands. This indicates a distributional line of at least 13,000 miles. 
The peculiar genus Gunnera that has no near living affinities, consists of about twenty species, the ancestors of which probably evolved in the Peruvian-Andean region and spread southward to N. Zealand-where now are four species-thence to Tasmania, Australia, and ultimately Java, where a striking and decidedly evolved species is found. A somewhat similar distribution is seen in the well known garden genus Fuchsia. Originating, we would conclude, in some centre not far removed from that for Gunnera fourteen species occur in Ecuador and Columbia, a like number in Mexico and from Peru southward, three are Brazilian, five extend from Chile to Fuegia, while three are found in N. Zealand. One might also insert here Muehlenbeckia adpressa and Euphrasia antarctica as similarly distributed with the above.

Even more remarkable is the highly modified umbelliferous Crantzia with only one existing species $C$. lineata. This "is a native of the United States and Mexico, the Andes of N. Grenada and Peru, Chile and the Falkland Islands, Tasmania and Victoria," as well as N. Zealand. Many other similar facts might be cited.

But the existing flora of Tristan da Cunha and Gough Island, of Marion and Crozet Islands, even of distant Amsterdam Island, that is about 5000 miles from Tristan, and about 3500 from S. Africa, while indicating in some of their plants such wide extension as is outlined above, include also species that must have passed over from $\mathrm{S}$. Africa directly. Thus the arborescent Pliylica arborea is most suggestive. Hooker $(269: 474)$ says: "The genus Phylica consists of some 65 species the headquarters of which are S. Africa, a few are Madagascarian, one is peculiar to St. Helena, and the only other is the subject of this notice." He then points out its presence in Tristan da Cunha, and as it had years before been found in great abundance on Amsterdam Island he regarded such as "a most singular fact, considering that about 5000 miles of ocean intervene between these oceanic specks of land."

One might enlarge on the genera Cotula, Wahlenbergia, Sebaea, and Mesembryanthemum that are typically S. African genera. But the myrtaceous genus Metrosideros, 
also Pittosporum and Vitex deserve to be emphasized, not only in themselves, but in their frequent relation as hostplants for members of the mistleto family or Loranthaceae. All three genera, in the species they contain, and in the present geographical distribution of these, probably were of East Asiatic origin, and though Metrosideros is absent from Australia, its near ally Callistemon is abundant there. Either by the Afro-Indian or the Australian-Tasmanian passage-way these must have reached the Southern Continent and there spread profusely. But further, during the migrational period, they' acted as hosts for species of Loranthus, that are quite incapable of growing on the ground. So whether we regard the coeval passage of Loranthus along with its host plant as having been effected by the one bridge or other indicated above, the necessity for a continuous land passageway is strongly indicated.

But if a wide southern continent once stretched from W. Patagonia eastward to N. Zealand and the Kermadec Islands, one would expect, on the basis of all present evolutionary evidence, that specific variations would often occur, and that these variations would in turn start new or incipient species and even genera, that would become in not a few cases geographically isolated, owing to constant changes in the configuration of land and water. Both results are strikingly true.

Thus J. D. Hooker, in his N. Zealand and Tasmanian floras, also subsequent writers on the flora of Patagonia, of Tristan, of Kerguelen, of N. Zealand, and of Tasmania, often refer to the marked variability of species described, or confess the difficulty they have experienced in referring a certain plant to one species or to another previously named. And again each of the geographic regions mentioned, possesses species and even genera peculiar to itself, or to a restricted geographic area. Thus Pringlea antiscorbutica, Acaena affinis and Colobanthus kerguelensis are confined to the Marion, Crozet, Heard and Kerguelen groups, or to one or more of them; Aciphylla, Nothothlaspi, Hectorella, Hoheria, Entelia, Alectryon, Corynocarpus, and Carmichaelia are genera of the Australasian area; Pen- 
nantia, Chloraea, Saxegothea, Philesia, Nanodea and Hamadryas are restricted to Chile-Patagonia.

All of the features shown by the usually slowly migrating and slowly adaptable plants, are exhibited in equally or even more marked manner by animals. Forbes, as already stated, (p. 607 op. cit.) advocated the existence of an "Antarctica" continent. Lydekker, in rejecting such a view (270: I I 8 ) says: "It seems advisable to refer to some recent views as to the existence of a great southern circumpolar continent in Tertiary times, extending into comparatively low latitudes, and connected, at all events temporarily, with America, Africa, and Australia. For this continent the name Antarctica has been suggested by Dr. H. O. Forbes, who urges that many of the types of animal life now confined to the southern hemisphere have originated there. It is chiefly to show the fallacy of these latter views that the subject is referred to here, palaeontological evidence clearly proving that several of the groups of animals assumed to be essentially southern, really had a northern origin. It may be premised that according to the view of Dr. Forbes "Antarctica" followed nearly the 2000 fathom line, extending northwards from a circumpolar area by broad expansions, one to join an old New Zealand continental island (including the Antipodes, Macquaries, New Zealand, and Chatham, Lord Howe, Norfolk, and the Kermadec and Fiji Islands); a second to east Australia and Tasmania; a third to the Mascarene and adjacent islands; perhaps one to South Africa; and finally one to South America."

Lydekker then takes up the marsupials, parrots, trogons, and struthious birds, as well as the giant land tortoises, "to show the fallacy". of Forbes' views. But we believe it is possible "to show the fallacy" of Lydekker's views, and the fundamental correctness of those of Forbes. For he assumes throughout that most of those groups which Forbes considers to have originated in, or at least were distributed across, the southern continent originated there. But such is by no means Forbes' fundamental contention. Lydekker first cites the marsupials. But even granting that the Jurassic and Cretaceous jaws and teeth, that have 
been found in Europe and N. America, are truly marsupial, - a conclusion that is still open to question-the ancestors of the bearers of these might well have spread from Europe into America, or in reverse relation, by early Cretaceous times. But the writer would postulate that, as with many plants and invertebrate animals, a great migration southward from N. America into S. America took place in late Jurassic or early Cretaceous times, also then and later a great extension of Jurassic-Cretaceous types of plant and animal was effected over N. America. And so far as present evidence goes, the marsupial family Didelphidae may have evolved during mid or late Cretaceous times in Central or South America, along with Prothylacinus and other polyprotodont marsupials. The Didelphidae, spreading into North America and thence across North Atlantis into Europe, could well have existed there in Eocene time, and have left those Oligocene opossum remains that have been found there.

But during late Cretaceous and early Eocene times, a more and more extensive connection was made from temperate South America to Southern Atlantis or even to-what we now know to have definitely existed-the climatically favorable Antarctica. Along this southern land polyprotodont and evolving diprotodont marsupials evidently travelled, side by side with plants, earthworms like Acanthodrilus, and other groups to be recorded. Early contact was evidently made, probably in the Eocene period, with Tasmania and south-east Australia. Along the eastern side of Australia marsupials must have multiplied and varied rapidly, till they reached and passed along a short-lived and probably early Miocene land-bridge that connected Cape York and Eastern New Guinea with some of the East Indian Islands. This accordingly became the most northern area for marsupial invasion of Asia.

If we turn however to other vertebrate groups; an amphibian series that strikingly confirms Forbes' contention is that of the Cystignathous Frogs. These consist of about I 8 genera, distributed mainly from Central America to western S. America, with a few eastern outliers; also of 8 genera that extend over eastern and central Australia. 
The distribution also of the tree frogs ( $H y l a$ ) parallels, in suggestive manner, that of the polyprotodont marsupials. No connection is known to exist for any of these with East Indian lands.

Amongst reptiles equally confirmatory results are got. Thus in the division Chelonia, the family Chelididae includes Chelys of S. America, and the allied genus Chelodina of S. and E. Australia; while one species of Chelodina survives that had reached up into New Guinea. But during the short-lived connection that permitted this, the Malayan Crocodile (Crocodilus porosus) was able to pass across into, and now inhabits N. Australia. But this species only, and none of the northern or Arctogaea tortoises, reached Australia.

The lizards, and not least the snake-like Pygopodidae are most instructive, but their history is too extended for study here. Amongst snakes the poisonous group Elapinae, so far as known at present, suggests any one of three distributional possibilities. (I) Either the group may have evolved as a northern or Arctogaean series that spread into Australia, and later across the Antarctic continent to S. America, where species of Elaps are now widely scattered; or (2) the reverse journey may have been made; or (3) a double invasion of Australia may have been effected, one from S. America by way of Tasmania, and another from the north by the Cape York peninsula. The first of these seems most likely. But the question can probably be correctly decided only after exhaustive comparisons have been made of all species of the existing genera.

The migrational powers, and adaptive capacity of flying birds are so great that very limited deduction can be drawn from the group. As to freshwater or land invertebrates, the many striking facts already gathered almost wholly favor Forbes' contentions. Enough therefore has been advanced to "show the fallacy" of Lydekker's views.

But we may now present further some definite evidence in favor of Forbes' views, and which parallels the record from the side of plant life. Amongst primitive cyclostome fishes Geotria chilensis occurs in Valdivia, is expected by Eigenmann in Patagonia, and appears also in N. Zealand 
and Australia. Mordacia or Caragola mordax occurs in Chile and Tasmania. The writer has already claimed ( $I: 402$ ) a freshwater origin for the group, even though some are now anadromous or wholly marine. The group is evidently a very ancient one, in fact the writer would claim for it the oldest pedigree of the entire series that we ordinarily call "Fishes."

The observations by some of the zoologists who studied the material secured by the Transit of Venus expedition in Kerguelen are very valuable. Of the molluscs Smith writes: "The malacological fauna resembles generally that of the Falkland Islands and South Patagonia. More than half of the genera, and seven or eight of the species found at Kerguelen Island are known to occur at those localities," and he adds (p. I68) a comparative table in illustration.

In his study of the Crustacea Miers writes "Amongst I 5 indigenous species several are characteristic of the Antarctic region, which in its widest sense embraces Tierra del Fuego, the Falklands, and the lands and islands of the Antarctic Ocean. Halicarcinus planatus and Sphaeroma gigas are known to inhabit the seas of Patagonia and New Zealand, and are especially abundant in the former area." He then gives Tierra del Fuego, "the Falklands, abundant," Kerguelen, the Auckland Islands, and New Zealand as the range of the former; while for the latter (p. 203) he gives the Falklands (var. lanceolata), Kerguelen, Auckland Islands, New Zealand and Australia.

Geoffry Smith writes (27I:2 I6): "The copepod genus Diaptomus, characteristic of lake plankton, ranges all over the northern hemisphere and into the tropics, but it is almost entirely replaced in the southern hemisphere by the related but distinct genus Boeckella, which occurs in temperate South America, New Zealand and south Australia, and was found by the author to be the chief inhabitant in the highland lakes and tarns of Tasmania, Diaptomus being entirely absent. Then in commenting on the chorology of Niphargus and Gammarus he says (p. 2 I 7 ) "it seems probable that they' have reached South Australia by way of South America," and later he adds "the other common freshwater Amphipod in temperate Australia and New 
Zealand is Chiltonia, whose nearest ally is Hyalella from Lake Titicaca on the Andes, and temperate South America."

A striking feature of the Kerguelen insects, as of the celebrated "wingless birds" of the Southern Hemisphere, is the large number of nearly or completely apterous types.

As to the earthworms Lankester observes, regarding the only genus found in Kerguelen, that of four known species two are from New Caledonia, one is from Madagascar, and one from Kerguelen. E. A. Smith notes that of ten or eleven species of echinoderms known from Patagonia four are also indigenous to Kerguelen.

R. B. Sharpe's treatment of the Kerguelen birds is alike careful and suggestive. The great majority show a distribution that eminently favors a former continuous land connection, and though most are shore or marine birds, their feeding habits would scarcely explain passage of them across wide ocean stretches, while in the case of the penguins their entire structure prohibits extensive or rapid migrations.

The distribution of a few only of the birds, amongst others equally striking, can be given. Thus Larus dominicanus (p. I07) is recorded from Valparaiso, Straits of Magellan, East Patagonia, Cape of Good Hope, Kerguelen, and New Zealand. Stercorarius antarcticus occurs in the Antarctic seas, S. Africa, Kerguelen, Campbell Island, New Zealand, and Norfolk Islands. Daption capensis is known from Valparaiso, the Cape of Good Hope, Kerguelen, N. Zealand, and W. Australia. Prion vittatus and $P$. desolatus extend from the Cape Seas eastward to Australia. The penguins are all instructive, but "the rockhopper" (Eudyptes saltator) deserves mention, for it extends from the Falklands, Bounty, Tristan da Cunha, to the Cape of Good Hope and Kerguelen.

Though much importance need not be attached to the distribution of so thoroughly a marine group as the seals, yet their origin as a relatively recent mammalian offshoot should be remembered. When then the Sea Leopard (Ogmorhinus leptonyx) is "met with in South Georgia, the Falklands, Kerguelen, South Australia, Tasmania, N. 
Zealand, Campbell Islands, etc" it favors the possibility of the persistence of at least considerable stretches of a southern continent, till comparatively recent geologic time.

But in the past twenty years it can well be said that the need for a wide southern continent, has been increasing. ly insisted on and accepted, as plant and animal chorographers have compared their fast accumulating data. Thus von Ihering, Ortmann, Gaudry, Geoffry Smith, Chilton, Ancey, Hedley, Dusen, Skottsberg, and others have all accepted such, though in some cases with caution or in modified form from that of Forbes, as is true specially for Hedley. As before stated, (p. 434) Forbes has advocated a central Antarctic landmass, and in doing so writes: "If the Antarctic sea-floor were elevated to a height not exceeding 2000 fathoms, the exposed land would form approximately the continent which I think the evidence adduced in this paper seems to demand; practically none of that area is now below what Dr. Mill in his valuable "Realm of Nature" terms the line of mean sphere level."

Hedley considered $(272: 278)$ that a strip passing across the Antarctic circle and joining S. America with the N. Zealand area would suffice. Ortmann accepted the joint view of Ruetimayer and Hutton that a southern continent stretched across the S. Atlantis and Indian Oceans, but modified according to Hedley's plan. So he writes: (273:324 ) "we accept the first theory of Ruetimayer and Hutton, with the restrictions put upon it by Hedley."

Such a position as that of Hedley and Ortmann is now rendered more likely, seeing that Antarctic discovery of the past fifteen years by several of the national expeditions has clearly shown that mild conditions existed during Tertiary times over the whole or certainly a large part of "Antarctica." The fossil flora alone definitely established this.

In connection however with our present study of fishdistribution, as determined by past geographic and geologic changes, the possible origin and distribution of the Marsupialia deserves attention. It is now generally conceded that the most primitive of the three sub-groups of that family is the Polyprotodonta. This includes the Opossums 


\section{(Didelphys) and Water Opossums (Chironectes) of} America, that are spread over both North and South Continents down to Patagonia. These evidently originated somewhere over this wide region, as palaeontological exploration increasingly shows. But other genera of this sub-group occur alike in America and Australasia, so that a common mammalian bond is thus established. The second or Pauciprotodonta exists also in Western America, but can be traced back, as Scott has shown (274), in fossil types through the Miocene of the Santa Cruz and Patagonian beds. The third or Diprotodonta is the highest and most specialized of the great group, and is wholly Australasian. Now the existing distribution of these and of the Australian polyprotodonts indicates-if relative number of species over a given area, and relative simplicity or complexity of structure are used as a criterion-that the entire group passed through Tasmania into south-east Australia, and thence spread westward and northward till highly specialized outliers reached N. E. Australia, N. Guinea, and a few of the E. Indian islands. Their absence from N. Zealand and from Africa would suggest that important and earlier connections once existing between these and a wide southern land, which in turn connected with Australia, had already been broken when the marsupials were working eastward.

Here then, as in so many instances already cited in this work, we have to drop all thought of "Permanency of the great land masses," and have to think rather of a-sometimes steadily sometimes suddenly-changing relation of land areas. And this brings us to the question as to when and to what extent a southern land-bridge existed. As clearly appears from the studies of Staunton and Ortmann (273), a large part of lower S. America, including E. Patagonia, was covered by sea during lower and upper Cretaceous times. But a considerable area of IV. Patagonia existed as a great migrational bridge southward for incomers from the north, alike then and on into Midtertiary times. Along this many northern plant genera travelled southward, favored evidently by the mild climate 
that then prevailed, and of which we now have direct evidence.

Thus such genera as Podocarpus*, Ephedra, Libertia, Chloraea, Acaena*, Discaria, Fuchsia*, Oreomyrrhis, A zorella*, Empetrum*, Pernettya*, Buddleia, Collomia, Nama, Pectocarya, Plagiobotrys, Lycium, Jaborosa, Nierembergia, Veronica*, Ourisia*, Calceolaria, Cruckshanksia, Pratia*, Boopis, Vittadinia*, Baccharis, Tessaria, Chevreulia, Verbesina, Lagenophora, Tagetes, and Dysodia,-to mention only a few amongst some sixty-five other genera-are more or less continuous in distribution from Peru, from Mexico, or even from western and central N. America down to Patagonia, and may be in some cases continued across to N. Zealand or Tasmania, as is true of those with asterisks above. The highly evolved and typically Mexican-S. American group of the Compositae-liguliflorae, in such genera as Chaptalia, Leuceria, Mutisia, Nassauvia, Perezia, Lasiorrhiza, and Proustia, all extend from N. Chile or even from Mexico and the southern United States to South Patagonia.

But a study of the flora of the Juan Fernandez and of the Galapagos Islands, reveals that all of these show quite a number of plants which in genera or even species are identical with or closely allied to those of the American mainland. Thus in the valuable studies of Johow (275) he has listed 236 species from Juan, 62 of which are endemic to the islands, 64 are common to them and to Chile-Peru, 24 were intentionally, and the remainder were unintentionally introduced by man. The distribution of some of these is noteworthy. Lobelia anceps is found in Juan, Chile, S. Africa, New Zealand and Australia. Haloragis alata is a small shrub common to Juan, New Zealand and South Australia, and which often grows in Juan beside Pernettya rigida. The latter genus includes about 40 species, 15 of which are found from Mexico and Costa Rica to Chile, 2 from Chile to Magellan, I is peculiar to Juan, and I to Tasmania. But Pernettya and the nearly allied ericaceous shrub Gaultheria seem both to have evolved and diverged from a common ancestry in Central America or in northern S. America. Gaultheria spread 
widely eastward, but also southward to Chile, Magellan, New Zealand and Australia, where 7 species are found, also northward to the Philippines. Other like suggestive distributions could be cited.

The observations on the Annelida, Crustacea, Arachnida, and Fishes that are given in "Fauna Chilensis" (276) also emphasize like common bonds as do the plants and their inhabited territory.

The varied literature that the Galapagos Isles have called forth, from the time of Darwin's visit onward, shows that two diverse views have been held which might explain their origin, also origin of their flora and fauna. Some still hold that they are oceanic in formation, and have received their organisms by fortuitous arrivals. But most now accept that they are old continental, a view that has been strongly advocated and fortified by G. Baur (277:66 I, 777, 864).

A study however of the affinities shown by the plants of these islands may greatly aid us in reaching true conclusions. It should be remembered that the islands are opposite to, belong to, and are about 580 miles west of, Ecuador. They are therefore equatorial in position, though southern sea breezes temper the otherwise tropical climate. The main oceanic currents also are of cool Antarctic origin. This fact deserves to be kept in view in any attempted explanation of plant origins and introductions.

A careful and critical study of the Flora has been made by nearly a dozen botanists, whose results have been extended and summarized by Robinson (278:77). Neglecting the lower or spore-bearing plants that are often disseminated by wind currents, it may be said that the seedplants number about 445. Of these, close on 200 are regarded as endemic, and they are discussed below. Of the remaining 245, their relation to the flora of the Tropics and of the mainland is striking. Thus $\delta_{3}$ of the species are world-wide in the tropics, or have evidently been introduced as weeds or as cultivated plants by man. Subtracting these from the above number, there remain $6_{2}$ to be accounted for. Of these, I 57 are found on the South American continent, and 126 of them occur also in Mexico. But that 
there is a distinct community of descent with plants of the West Indies-Robinson's statement notwithstanding-is proved by 60 of them being likewise found there. The number also common to the Indies and to Columbia, Venezuela, Guiana, Ecuador, and Peru, strongly suggest a southward migration of types, when structural details are considered. The marked affinity with Mexico is specially noteworthy, and speaks strongly for migrational interchange.

Of the 204 endemic species, the larger number belong to genera that have allied and continental species on the islands, and so which are included in the I 57 above mentioned as being continental. But further a few genera like Cyperus, Peperomia, Telanthera, Acalypha, Euphorbia, Ipomoea, Cordia, Borreria, and Scalesia include about 90 species that seem truly to have evolved within the islands, as divergent types from a few other and more primitive ones.

The genus Phoradendron, with its four endemic species, forms a strong argument in favor of a continental origin for the islands and their organisms. For it is typically tropical American in 46 of the nearly 70 species, that all form parasitic attachment on trees from N. America southward to Chile. Even if the berries survived a sea-voyage, as castaways on a seashore, they would there need to be transported to some appropriate tree, on which as parasites they could grow, and on which alone they would germinate.

Nearly all of the above facts then favor Baur's view that the Galapagos formed the western part of a more exterided South American continent, while the degree of variation in many of the endemic species from allied continental ones, affords some measure of the rate and amount of such variation-tendency that may be shown after isolation had been effected.

The flora of Cocos Island, that is about midway between Costa Rica and the Galapagos, indicates nearer affinity with Columbia, N. Brazil, and Guiana, as might be expected from its geographic position. The Cocos, Galapagos, and Juan Islands then eminently favor a former wide extension of the western S. American coast, from South 
Mexico to Cape Horn. For the flora and fauna of each island group indicate direct derivation from the nearest continental land, as well as a derivation of that flora and fauna from a Central or even North American source.

It seems highly probable therefore that before elevation of the Andes, and during later Cretaceous time, a wide and easy pathway existed for passage of northern seed-plants, of the later reptiles, and of primitive mammals of early polyprotodont type, down into western S. America. In this latter region the San Martin and Lower Lignite beds, at least in the southern part of the continent, indicate great freshwater deposits that may be 5000 to 6000 feet thick. The pathway probably continued throughout Eocene and Oligocene times, in more or less changing state, as progressive elevation of the Andes proceeded. During this time also migration from South America across the Southern or Antarctic continent proceeded most actively, so that even freshwater fishes of northern ancestry not only reached Magellan; they were carried eastward with plants and with many land or freshwater animals, to New Zealand, Tasmania, and Australia.

Possibly during Miocene time the climax of Andean mountain building was reached, and coeval with this or later, extensive faults and downthrows of wide areas took place, so as to submerge a large part of the former land-bridge. For the long "deep" or "trench" that runs parallel to the Chilean-Peruvian coasts as "the Atacama trench," is from I 2,000 to fully 20,000 feet deep, and has been viewed by some geologists as a gigantic fault that depressed the land almost as greatly, as were the Cretaceous and other strata folded and uplifted to constitute the Andean ranges.

Taking all of the above facts into account, the writer would put forth what may to many seem an unlikely and far-fetched suggestion, but which undoubtedly has many distributional facts in its favor, and which is illustrated in Figure 35, p. 240 . It is that a wide western area of land extended during Cretaceous times from Southern Mexico southward by, as well as including the Galapagos and Juan Fernandez Islands to Magellan, that then was of wider westward expanse than now. This region constituted the 
primitive or oldest or incipient axis of the Andean cordillera; and in part owing to earth-crumpling in part to activity of a row of volcanoes was considerably elevated along its central line. This central line represented the incipient ridge of the Andes, and was largely separated at times along its length by water from the very persistent Guiana-Brazilian landmass that by various authors has been called Archenchelis. But in the Bolivian region-possibly at other points also-eastward connections were probably formed with the Archenchelis mass, if we may judge from all we have learned of the plant and animal records. Along this elevated and wide expanse, plants and animals of northern origin and affinity undoubtedly migrated southward from Central America, Mexico and even the States; while rivers and lakes, that were quite distinct from, and differently disposed from those now occupying the region, aided in the migrational movements.

Now the nearest allies to the Galaxidae and Aplochitonidae are the Salmonidae on the one hand, and the Esocidae on the other, both however inhabitants of the freshwaters of the Northern Hemisphere. Derivative forms from these two evolving groups, may well have migrated down along with the numerous genera of plants and animals that we can trace to have pursued this passageway. By late Cretaceous times then, these along with primitive polyprotodont marsupials from the north, reached the higher ground of Western Patagonia, of Magellan, and the Falklands. Thence they evidently spread eastward along the southern continent, while as yet central and eastern Patagonia, as well as a large part of Argentina, were submerged under a Cretaceous sea.

Then in Tertiary times and onward at intervals till late Miocene days tremendous earth-shrinkage, crumpling, and folding, accompanied by equally pronounced faultings evidently took place mainly in longitudinal direction. The main faulting must have been along or not far from the $S$. American Pacific coast, and resulted seemingly in a great downthrow of land for hundreds or thousands of fathoms below the Pacific. This left the abrupt and broken strata as the Chilean-Patagonian coast line. The main upfolding 
of these strata gave rise to the Western Andean range, while the numerous volcanic peaks along that range attest the mighty character of the disturbances.

Many of the plants then, from Miocene time onward, along the elevated area of this land mass, as well as eastward along the Falkland and Crozet line, took on, if they had not already assumed, the subalpine to alpine character that they now possess, though along its lower reaches, and especially along the northern edge of the South Continent, mild to warm-temperate conditions probably prevailed.

During the late Cretaceous or very early Eocene period, the South Continent probably had its most extensive eastward continuation to $\mathrm{N}$. Zealand, and then permitted the species Galaxias attemuatus to extend its area from $\mathrm{S}$. America to S. E. Australia, N. Zealand and Tasmania. In transit, and while exposed to changing environal states, Galaxias (Fig. 7 Ia, p.462 doubtless evolved new species, some of which entered or originated in N. Zealand and Tasmania. It also permitted Prototroctes to reach the former area, while Aplochiton seems to have lagged behind in $\mathrm{S}$. America, or has been blotted out over the Southern Continent. But at this time the marsupials had not reached either centre, though moving across the continent.

A break between the N. Zealand-Norfolk Island area on the one hand, and the Tasmano-Australian area on the other seems now to have been effected, and during late Eocene to Oligocene time, the polyprotodont marsupials entered by Tasmania and S. E. Australia. It is not unlikely however that during the journey across the South Continent, specializing side members from the polyprotodonts may have attained to the diprotodont stage of specialization.

As proving the climatic and nutritive possibilities for the production of such results as the above, and also from results secured by the Swedish South Polar Expedition (279) and others, we now know definitely that during the Cretaceous and again during Tertiary time, comparatively mild conditions prevailed even in Graham's Land, in Seymour Island, and probably on to or near the South Pole. Also that such was accompanied by an abundant and varied temperate or warm temperate flora. Thus Halle in his 
description of "The Mesozoic Flora" (279: III:4) describes a pteridophytic, gymnospermic, and angiospermic series of plant remains, that correspond closely with forms from "Gondwana" Cretaceous rocks.

Dusen in his paper "Ueber die Tertiare Flora der Seymour Insel "(Schwed. S. Polar Exped. V. 3 p. 3 ) gives a considerable list of what were probably late Eocene or early Miocene plants, several of which he either identifies with living South American species, or regards them as closely allied species. Thus Fagus dicksoni, Nothofagus magellanica, Caldecluvia mirabilis, and about a dozen additional, all conform to one or other relation. The environal conditions therefore must have existed, for migration both of freshwater fishes and of marsupials, during Tertiary times, over a considerable part of the southern hemisphere. So whether one accepts the Forbes or the Hedley theory of an antarctic landmass, or the view that the writer inclines to accept, of a southern continent that stretched with varying continuity from S. America and the Falklands across to Norfolk Island, and whose middle line was about $50^{\circ} \mathrm{S}$. lat. the final distributional result would be the same.

The writer, therefore, definitely accepts it that the Galaxidae and Aplochitonidae exhibit exactly the same geographical and biological connections as do many other animal groups, and not a few genera of plants. Also that their total absence from intermediate islands, is wholly due to fundamental and wide-spread physical or biological conditions of an adverse kind, that have caused their obliteration.

But facts that we now possess strongly indicate, that similar terrestrial forces which operated to alter and break up land areas over the southern continent, were also operative over the South Australian continent, and at least in part caused elevation of land-masses along with their fauna. Thus Galaxias alpinus and G. coxei are found, the former in alpine lakes of Hardy peninsula, Tierra-del-Fuego; the latter in a rivulet near the summit of Mount Wilson, and at an elevation of about $3500 \mathrm{ft}$. Macleay $(280: 45)$ in describing the latter states that it delights in cold shady 
waters; and, in listing twenty species, he remarks regarding the genus that: "it is rare in rivers of N. S. Wales, more abundant in Victoria, still more so in Tasmania and $\mathrm{N}$. Zealand." But it is at least likely-almost assured-that both species originally occurred, as do the others of the genus, at relatively low levels, and that the regions now inhabited by them were subjected to an upthrow or to a gradual elevation of at least 2000 feet to 3000 feet, during the late Miocene or early Pliocene when extensive terrene disturbances took place. The passage of one or two into a brakish and later marine environment, is in keeping with the origin of marine teleosts in general.

In this connection loose and contradictory statements have at times been made regarding the group of fishes now under discussion, that might tend to obscure exact issues. Thus in "Fishes of New Zealand" (28I:6I) Hutton, in listing the only other species and genus-Neochanna apoda -of the Galaxidae, calls it appropriately "Mud Fish," but gives as its locality "West Coast of North and South Island." Hector, in describing "Edible Fishes" in the same publication, shows that it is not only a mud or swamp fish, but that alike over the north and south island "wherever this curious fish has been found it is always buried in the mud, and it is singular that it should have such a wide distribution, if it does not also exist in the neighboring rivers." He quotes Günther's opinion also that it is "a degraded form of the more highly developed type of Galaxias," being devoid of ventral fins, and showing a rudimentary condition of the eyes. Both structural features are evidently the result of the slow proenvironal response of the species to its environal habitat. But like the other species of Galaxias it is truly a freshwater type.

But probably about the period that species of Galaxias were being raised into high elevations, alike in east Australia and in Tierra del Fuego, the same process was proceding along the Andes, and so caused separation and elevation of a species of Trichomycterus that is now found in Lake Titicaca, from other species of the genus that were left at varying elevations along the Andes, from Caracas to S. Chile. Other fishes of Lake Titicaca have been al- 
ready noticed (p. 352). Similarly species of Stygogenes and of Arges are found at elevations of I0,000 or more feet in the mountains of Ecuador, while related members of the curious family Loricariidae occur at varying lower elevations.

If then an extensive and more or less continuous southern landmass existed from Eocene to the close of Miocene time, it might be expected that-in addition to freshwater forms-various types that had already permanently adopted a marine life, might have spread along the shores, and particularly the northern shores of this southern continent. Excluding from consideration a considerable number given in Hutton's later list $(282: 275)$ which we would trace as immigrants from Asiatic seas, others are still left that seem perfectly to agree with such an origin. Thus Scorpis occurs along the coasts of Chile, S. Africa, Australia and N. Zealand; Thyrsites atun is common to the S. African, Tasmanian and Australian coasts; Notothenia is met with in Chile, the Falklands, Kerguelen, Auckland Island, Cape Howe and N. Zealand, as well as southward to the antarctic islands; while the Southern Sandeel (Gonorhynchus grevi) occurs round Cape of Good Hope, St. Pauls Island, N. Zealand, Australia, and on to Japan. These doubtless are only a small remnant of others, that may abundantly have inhabited, and passed along the coastal seas, between the American and the Australian continents.

The remarkable development of the Nototheniidae, and to a less degree of the Leptoscopidae, as marine antarctic groups, is strikingly set forth in Dollo's studies of the fishes secured by the "Belgica Expedition" ( $2 \delta_{3}:$ "Fishes"); in Boulenger's studies for the "National Antarctic Expedition" (284: II) ; in those of Vaillant for the French Antarctic Expedition (285: "Fishes") and in those of Regan for the "Terra Nova Expedition" of I 9 io (286: I ). Such may indicate that on breaking up of the South Continent, the genera and species of the above two families became increasingly adapted to cold conditions, and multiplied in these regions. Further, as the great continental mass must have broken up, and became submerged as now to a depth of I 000-3000 fathoms below sea level, these originally coastal 
fishes, that were derived from more primitively freshwater forms like Chimarrhichthy's if we may judge from structural resemblances, became slowly adapted by environal action and proenvironal response to a deeper marine habitat. Gradual increase in size of the eyes, increase in size of the head as compared with body-size, lengthening of some of the fin-rays, formation of accessory dermal outgrowths, softening of the tissues, and frequent softening or thinness of the bones, are a few of the structural changes usually effected in the process.

It will be observed that the writer has described a gradual migration of plants and animals from the American continent eastward to beyond Australia and New Zealand. This is absolutely necessary when we trace phylogenetically the affinities and ancestral habitats of most of the plants and animals that peopled the entire Southern continent. For the great majority clearly indicate such a west-to-east migrational trend. This would lead one to believe also that in upbuilding of the southern continent, a wave of elevation took place in like direction. And further it is not only unnecessary to consider that all points of the southern continent were in geographic continuity at one time, the known facts indicate that New Zealand, Norfolk Island, and the Fijis, were connected with Australia as well as America at one time and then separated; also that the connection with S. and S. E. Africa was relatively a short one.

But that a certain amount of migration in the reverse or opposite direction occurred, is proved we believe by not a few facts of organic distribution, notably by that of plants. A few only can here be referred to. Thus the large and ancient angiospermic family Proteaceae is pre-eminently Australian, and the most primitive genera like Bellendina, Symphyonema, and Persoonia still inhabit the same region. But a westward migration must early have started, at a time when the southern continent was about its maximal size, and this probably in Early or Mid--Eocene time. So ancestors of the fairly evolved genera Mimetes, Nivenia and Serruria reached S. Africa, and there they, with succeeding migrants or evolved genera from these three have 
multiplied abundantly, till now they form a conspicuous element in S. African forest and shrub vegetation.

Now in a recent paper on "Some general principles of Plant Distribution as illustrated by the South African Flora" (287:33) Bews says: "Of those who have dealt with plant distribution, Darwin and Wallace objected to invoking geographical change as a solution of every difficulty, while Hooker was more inclined to postulate continental extensions to explain the connections between the floras of the southern hemisphere. Schönland, after carefully considering the facts, finds a land connection between South Africa and Australia, and between West Africa and America to afford the simplest explanation."

So, a quarter century ago it might have seemed a rash speculation to have suggested that the common Fuegian plant Embothrium coccineum was an Australian migrant that had reached Fuegian shores. The discovery however by members of the Swedish South Polar Expedition, of fossil Proteaceae in the Tertiary strata of Seymour Island, that lies S. E. from Fuegia, converts such a suggestion into a natural explanation. For they found there remains of four species of Lomatia, and two of Knightia. Now, if we confine attention to these three related genera Embothrium, Lomatia, and Knightia, the first is now represented by E. lanceolatum that is indigenous in S. Chile, also by $\mathrm{E}$. grandiflorum that extends northward into Peru and Ecuador. But on the mountains of tropical E. Australia is found E. wickhami. Lomatia includes nine living species, four of which occur in E. Australia, two in Tasmania, and three in Chile. Knightia has two species in N. Caledonia and N. Zealand.

If then we collate the evidence of the fossil and of the living plants, a strong confirmatory argument is got for westward migration of genera of the originally Australian family; as well as for a connection-more or less extended -with S. Africa. Drapetes, Allodape (Lebetanthus), Phyllachne, Veronica elliptica, and Drosera uniflora are additional genera and species of S. America that tell a like tale. But the comparative paucity of these, again indicates that extension of Fuegia eastward was gradually made, 
and that complete continuity of Africa and S. America through Tasmania with S. E. Australia was not of long duration; while with N. Zealand, Norfolk Island and New Caledonia connection was earlier and even shorter.

Illustrations from the animal kingdom will at present be restricted to the group of fishes. Pseudaphritis is a monotypic genus of S. E. Australia, that includes the one species $P$. urvillii. It is found in streams of that region, and according to Regan (286:29) it "most nearly represents the prototype of the whole group." Now the family is that of the Nototheniidae, that is referred to above ( $p$. 455 ). It is closely related again to the Leptoscopidae, that includes the freshwater alpine genus Chimarrhichthys of New Zealand that is "remarkably adapted for living in alpine torrents." Now Pseudaphritis is regarded by Regan as the most primitive genus of the sub-family Bovichthyidae that includes also Cottoperca and Bovichthys. Species of both of these extend from the shores of S. E. Australia and N. Zealand to St. Paul, Tristan, the Falklands, and Magellan on to Chile, though none pass into antarctic seas. But the derivative and more evolved sub-families Nototheniidae, Bathydraconidae, and Chaenichthyidae have gradually split up into genera that not only are represented along the shores or in the deep waters surrounding all of the above localities, but also are around Marion, Kerguelen, and Heard Islands, while what can only be regarded as derivative species from these, and belonging mainly to the genera Notothenia, Trematomus, Artedidraco etc., have gradually migrated southward as truly antarctic species. The striking enlargement of the eyes, as figured by all of the authors referred to above, in many of these fishes that have become deep-sea inhabitants should be recalled, as examples of specialized evolution through environal action and pro-environal response.

But it might be objected to the above reasoning, that the entire series originated in Chile or Fuegia as marine fishes, which by degrees spread eastward to Australia, and there gave off, as imigrants into freshwaters, the ancestors of the morphologically more primitive Pseudaphritis. To this practically impossible happening one can only reply 
that at present no equally or more primitive fish than Pseudaphritis is known that is marine.

An exactly parallel case is furnished by Chimarrichthys that is a freshwater genus of N. Zealand. As described by Haast it was secured, along with Galaxias brevipinnis and Retropinna richardsonii, in the Otira stream, "where that alpine torrent leaves its picturesque gorge." So like Pseudaphritis for the Nototheniidae, this genus for the Leptoscopidae is evidently a primitive one, from which have radiated off one line of marine derivatives like Leptoscopus and Kathetostoma, from shores of New Zealand and South Australia that have migrated northward toward the tropics, and another line like Pleuragramma and some allies that have become antarctic types. Thus Pleuragramma antarcticum is stated by Boulenger to occur amid deep waters in $78^{\circ} 35^{\prime}$ south, the most southern habitat for any known fish.

We would conclude then that while the Galaxidae and the Aplochitonidae were primitively freshwater American - probably in earliest origin N. American-fishes that gradually spread southward and then eastward to the Australo-N. Zealand area, but remained wholly freshwater in habitat, the Nototheniidae and Leptoscopidae were both of Australo-N. Zealand origin. These seem to have migrated westward, and in the act gave off shore and then deep-sea derivatives, some of which reached even to the Falklands and Chile, while others, before or after breaking up of the Southern continent, migrated into the most southern habitat now known for fishes.

In brief summary the writer would now condense the main conclusions of the present chapter, so far as these pertain to fishes, as follows:

I. The Galaxidae, Aplochitonidae, and some Cyclostomata, as freshwater groups, show a geographical distribution that is strikingly different from that of any other family. This distribution suggests a possible continuous land-connection from Chile, Fuegia, and the Falklands to Tristan, the Cape, Kerguelen, and thence to Tasmania, Australia, New Zealand and New Caledonia. 
2. A study of the past and present known distribution of the Marsupials, as well as of other animal groups cited, likewise favors the former existence of such a land-connection.

3. The surviving genera and species of plants, common to all of the land areas between Fuegia and Australo-N. Zealand, favor such a connection to a marked degree, since many identical genera, and in some cases even species, extend to both limits just named.

4. The west Patagonian flora, and at least some groups of the fauna like the fishes now under discussion, as well as the marsupials, proclaim original descent from northern or central American ancestors. These travelled down along an Andean continental line till they reached Fuegia and the Falkland area, probably during late Cretaceous. They then spread eastward along an important land connection in late cretaceous or earliest eocene time, when they made slight connection with the S. E. extremity of Africa, and ultimately reached New Zealand, Tasmania, and Australia.

5. While recent discoveries lend decided and direct support to the former existence of an Antarctic Continent, that may have been the main landmass for effecting such connections and organic distributions, the writer would favor more the former existence of a South Continent, that extended in fairly direct line from Fuegia to N. Zealand and Tasmania-Australia, but may also have connected with Antarctic land.

6. The bulk of evidence indicates that the above migrational bridge formed in direct continuity with W. Fuegia and W. Patagonia during late Cretaceous time, and when East Patagonia and Argentina were largely covered by a Cretaceous sea.

7. The line of the Andes is the middle and now greatly elevated part of an extensive landmass that was at times connected with, at times largely separate from a great Guiano-Brazilian landmass or Archenchelis. This Archenchelis landmass was at times directly continuous with mid and north America, from the last of which many of its organic types migrated. It probably also was, at least for 
some time, continuous with Juan Fernandez, the Galapagos, and the Cocos Islands.

8. Through extensive earth-shrinkage, faulting, and volcanic activity from late Cretaceous and early Eocene time onward, a large western section of this Archandean continent was thrown deeply down, while the eastern part was correspondingly elevated. Continued elevation in successive sections gave rise to the eastern or palaeozoic range, and the western or mesozoic range of the Andean chain, according as the main masses of rock are exposed.

9. The Geotridae of the Cyclostomata, also the Galaxidae, and the Aplochitonidae are all probable descendants from North American freshwater fishes. The two latter families are intermediate between the Salmonidae and the Esocidae, both of which are still mainly freshwater fishes of the Northern Hemisphere. All three of these, by migration along the swamps, rivers and lakes of the Archandean continent, seem to have reached Fuegian-Falkland Island Territory by late Cretaceous times.

Io. Eastward connection with Australia, Tasmania, New Zealand and Norfolk Island was early established, and by this the above fishes or derivative forms were introduced. Such took place while as yet the American polyprotodonts had not reached the east. When separation of the $\mathrm{N}$. Zealand area had been effected the migrating polyprotodonts entered Tasmania and S. E. Australia, where they still are most abundant and varied. They as well as diprotodont descendants, spread westward and specially northward in Australia, till they reached E. Indian Territory where the most highly evolved diprotodonts now are.

I I. By aid of rivers, lakes, and swamps the Geotridae, Galaxidae, and Aplochitonidae gradually spread over the entire South Continent from Fuegia to S. Africa, N. Zealand, and Australia, where various of their descendants now are. So far as at present known they have been obliterated over intermediate regions.

I2. While few of the freshwater fishes now known, passed westward from the $\mathrm{N}$. Zealand and Australian region, derivatives of primitive Nototheniidae and Leptoscopidae of freshwater habitat took to a marine life and 
passed westward by St. Paul, Tristan, The Falklands and -Magellan to Chile. Derivatives of these passed northward to Africa; or became modified, often in remarkable manner, for deep sea life; or, as breaking up of the Southern continent went on, they reached the most southern marine habitats now known for fishes.

I.3. The final breaking up of the Southern Continent probably took place in late Miocene or early Pliocene time, when the most pronounced elevation of the Andes, and of the great Eastern Chain of Africa took place.

I4. Through extensive faulting and depression of the entire South Continent its place is now covered by a deep sea, except for the few isolated-often volcanic-islandpeaks that still mark the line of the sunken mass.

I 5. The species of Galaxidae and Aplochitonidae, that now inhabit elevated lakes or streams, have been carried to these elevated regions, not by ascent of ancestral individuals, but by earth-movements that have simultaneously raised large areas of land, along with the fishes that inhabited the lakes or streams of such land, before elevation took place.

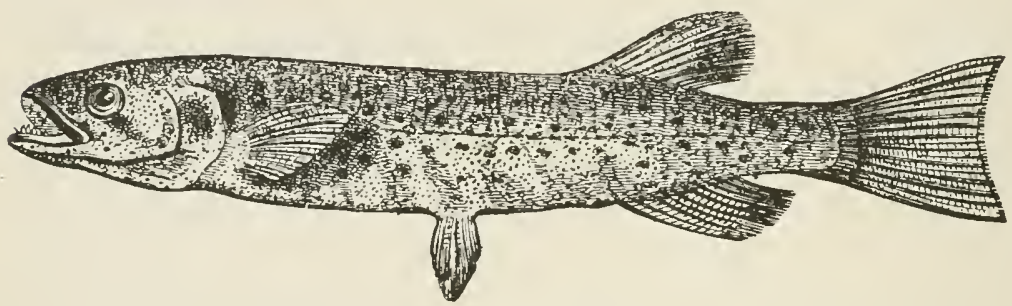

FIG. 7ra. Galaxias truttaceus. Enlarged after Günther. 


\section{CHAPTER XVI}

\section{A Review of the Tanganyika Problem. In its Geologic, Geographic, And Biologic Relations.}

In several of the foregoing chapters reference has been made to the fishes of Tanganyika, and to questions suggested by the fauna of that and of other Central African lakes. The entire subject is so closely akin to corresponding problems already discussed, and the peculiar as well as abundant fish-fauna has been so variously viewed as to its origin, that the writer proposes now to deal with the entire question from the widest standpoint of natural history.

The remarkable aggregation of freshwater faunal forms first revealed by the Belgian explorers of the Congo, later by the important discoveries of Moore, and still later supplemented by those of Cunnington, stamps the region as one of exceptional biological interest. Moore, when confronted by the aggregate of Peridinium-like organisms, of sponges, of medusae, of polyzoa, of some macrurous and brachyurous crustacea, particularly of the regional molluscs, also of peculiar groups of teleostean fishes, endeavored in his special volume "The Tanganyika Problem" (259) to trace all of the above to a marine ancestry.

He was doubtless induced to accept such a view, owing to the generally accepted-but according to the writer mistaken-view, that faunal life originated in, and later migrated riverward from the ocean. IVe propose therefore now to review the organisms recorded from that lake, to compare them with related types from the Congo and from the other central African lakes, to learn then what light these may throw on present and past geologic, geographic and biologic problems as explanatory of fish distribution, and finally to ascertain how far such results may aid us in reaching correct conclusions as to the evolution and history of fishes.

Of Sponges Lake Tanganyika has yielded eight of the nineteen known African freshwater species (289:218). 
All of these are referable to the large typically freshwater group Spongillinae, that is now practically world-wide in its included species.

The native hydromedusan Limnocnida tanganyicae, that appears according to Moore and Cunnington in countless numbers at certain seasons, is closely related to Limnocodium sowerbyi, whose native home probably is the inner river-system of the Amazon. But it is now known that the former is not confined to Lake Tanganyika. For Scott Elliot has found a variety of it $(290: 643)$ in Victoria Nyanza; while Browne has described it (29I:304) from the Niger, Again in the Egyptian lake of Birket el Kerun (Qurun) C. L. Boulenger and Cunnington met with another that the former named Moerisia lyonsi. Still more recently the finding in abundance of Limnocnida rhodesiae in a tributary of the Middle Zambesi, and also in the Limpopo river system (292:7I) furnish proof that these fragile and delicate organisms have a wide distribution over the central African area. But the discovery by Gravely and Agharkar and the description by Annandale of an E. Indian species - Limnocnida indica-that occurs "in streams in the Western Ghats, that finally enter tributaries of the Krishna river, Satara district, Bombay Presidency" causes us to consider that, from the Amazon river-basin across to and through central Africa, on to the Bombay plateau, identical or closely related freshwater medusae are often to be found in profusion.

The most recent discovery, in enormous abundance, of Limnocodium (Craspedacusta) in freshwaters of Kentucky and Indiana, in the east-central States (293:v. 26:638; v. $44: 858 ;$ v. 50:4I 3 ) is proof, along with the above-cited cases, that freshwater polyps and medusae of decidedly simple structure, have had a wide distribution over the earth. As the writer has already contended $(I: 385)$ they seem even to be the ancestral and still persistent freshwater forms from which the more evolved marine ones have originated. The last-cited cases however are somewhat open to doubt, and may be tropical importations.

Now a feature of special interest is that most of the above medusae have been found not at or near the sea- 
level, but at elevations of from 2000 feet, to fully 4000 feet. Thus the examples from Tanganyika occur at about 2700 feet, those from Victoria, from the Zambesi, and from the Norquane of the Limpopo system are from 4000 to 4500 feet elevation; that from the Krishna in West India is at 2100 to 2200 feet. This becomes an important consideration in any attempted explanation of faunal origins, and will be discussed later. Another feature that merits passing attention is that equally in the African and Indian medusae these are infested by an infusor-Trichodina pediculus - that is "able to lead an endoparasitic existence within the gastrovascular system of the medusae." The genus Trichodina has only been "found on the surface of Hydra, Sponges, Planarians, and other freshwater animals, and also occasionally in the bladder of Frogs, Newts, and Fishes." These medusae then must be added to the list of hosts.

Of Polyzoa six freshwater species are now known from Lake Tanganyika, three of which belong to the sub-class Phylactolaemata, and three to the Gymnolaemata. All of them, in their semicolonial mode of growth, and strongly individualized polypides, suggest primitive forms of the Class $(I: 39$ I). Most of the Tanganyika genera also are of wide geographic distribution, and all are wholly of freshwater habitat. Thus Plumatella is found in nearly every region of the world, while Fredericella, Pectinatella and Victorella are becoming known from more and more widely removed localities. The existence then of these and of some other species in the central African lakes, would be added proof that solitary or semicolonial freshwater polyzoa are and have been much more important and widespread types of faunal life than has usually been accepted, while it helps to confirm the above-cited conclusions already published by the author.

Of higher Crustacea three were described from Moore's expeditions. One of these, Palaemon moorei, belongs to a family-Palaemonidae-that is now largely marine, but some freshwater and brakish species have a wide distribution. The latter, we hope to show in another work, are persistent survivals of primitive members of the family 
that started in freshwater. The prawns of Tanganyika are now known to include twelve species. Of these Caridina nilotica was first reported from freshwaters of the Nile, but later was discovered in Algiers and in Oran. It is now known to be represented in Tanganyika by a variety $C$. $n$. gracilipes. The remaining eleven species all belong, like the last, to the purely freshwater family Atyidae.

In his revision of this family Ortmann (294:397) proceeds throughout on the assumption that it is an ancient freshwater derivative from an older marine tribe, and as to the genera of it, that "their several characters are connected with a change of habits, and with immigration to freshwaters." The writer hopes in time to show that the reverse is true. But Ortmann fully accepts it that the family Atyidae as such "contains only freshwater forms." Calman writes (295: 187) "every one of the twelve species found in Tanganyika is, so far as we yet know, peculiar to that lake." Such might suggest that the lake has been an isolated centre for evolution of new species, through a considerable period of time; and such is the view accepted by not a few.

Two species of crab, belonging to the freshwater family Thelphusidae have been secured at depths of I oo-60o feet. One genus of the family, Thelphusa, includes about a hundred species scattered over the tropics and subtropics. We need not now discuss the views expressed by Moore (op. cit. pp. 284-86) as to the possible phylogeny of these.

In the report of $G$. O. Sars on the Copepoda and Ostracoda he describes 29 species from the Tanganyika area; I I from Nyasa, and 7 from Lake Victoria (296:3 I), belonging to the genera Cyclops, Diaptomus, Ergasiloides, Schizopera, and Ilyophilus. While accepting the first three as typically freshwater, he says regarding the two last: "both of these genera must evidently be regarded as of marine origin, and the question thus arises, how we shall explain the occurrence of species of these genera in the purely freshwater lakes of Central Africa." His conclusion is, not that they were inland "relict" forms of primitively marine origin, but that they were carried inland by birds from the seashore. This means that they were suddenly 
transported from a marine to a freshwater environment, a change that at least seems serious to the writer. He believes that a natural explanation can be got, which is in line with the exhaustive studies of C. B. Wilson on the Argulidae and related organisms, (297:25 (I 903); 28 (I 905); 3 I ( I 907$) ; 33$ ( I 908); 39 (I 9I I).

This author shows that, starting with such free-swimming freshwater types as the Cyclopidae, a progressive series of organisms can be traced which tend to become increasingly parasitic, and so correspondingly condensed and degraded. Thus the Argulidae, Caligidae, Trebinae, Euryphorinae, Pandarinae, Ergasilidae, and Lernaeopodidae show transition from a free facultative parasitism on the skin or gills of fishes to a complete parasitism on the latter groups, with corresponding simplification of structure. Now according to calculations by the writer the majority of the Argulidae are, like the Cyclopidae, freshwater organisms, and are either free-swimming or parasitic at will. Further as emphasized by Wilson, some attach themselves to anadromous fishes, and so may become themselves anadromous. This again would gradually lead to a continuous marine life, as is now true of some Argulidae, most Caligidae, and the majority of the more degraded groups. But the continued existence of degraded freshwater species on freshwater fishes, indicates to the writer the primitive origin and persistent habit of the entire series. This exactly corresponds also with the history of the fishes on which they have become holoparasitic.

Now Cunnington in his "Report on the Branchiura" (298:262) records $S$ species of Argulus from Tanganyika, one of which $A$. africanus he also gives from Victoria Nyanza, Albert Nyanza and Nyasa. Dolops ranarum seems to have an equally wide range, and is the organism that is known at times to infest frog tadpoles. But a point of some interest is that not a few of the species of Argulus and of Dolops, described by earlier authors, are parasitic on freshwater fishes of Brazil and the Guianas, not least on species of the Cichlidae. But the writer presents evidence for the view $\left(\mathrm{p} .3 \delta_{2}\right)$, that these and other groups of freshwater 
fishes spread from eastern S. America to West Africa, and thence across the Continent.

So it seems not unlikely that a tendency to incipient parasitism, on the part of some Cyclopidae, started in the extensive swamp and river system of eastern S. America, and thence spread eastward with the fishes that acted as hosts. For these and other reasons then, the writer would consider that the apparent derivative marine forms of Sars are species that have persisted amid freshwater, while most of their near allies have become by slow degree, and by increasing selection of a marine host, in the manner experimentally demonstrated by Wilson, dwellers in the sea.

What has been said above would apply equally to the Ostracoda, described by Sars (Proc. Zool. Soc. (I9IO) 732). The group however is well-known to be an ancient one, and may well have passed through varying vicissitudes of geographic and geologic kinds, before taking on the relations shown by those of the Central African region.

It is not intended to treat here of the Molluscs. The writer would venture the prediction however, that not only the typical freshwater species given by Moore (op. cit. p. 2 I 7 ), but such as he also discusses on pp. 2 I $\$-265$, will all prove, when critically studied, to have a freshwater ancestry.

The group of fishes has received careful attention by many investigators of the Tanganyika fauna. As a result upwards of $\mathrm{I} 20$ species are now known as composing it, and this mainly through the skilled taxonomic efforts of $\mathrm{G}$. A. Boulenger. Two of his latest papers (300: I 7,399) give recent additions. But to appreciate past geographic and geologic changes, a correlation must be effected between the freshwater fish fauna of S. America as synopsized mainly by Eigenmann ( $30 I$ ) that of the West Niger and Congo areas as given by Boulenger (227), and that of the Nile basin in the widest sense, as treated by the same author (302).

When survey is made of the above wide area, many striking features are revealed, some of which have already been slightly referred to. Thus the large freshwater family Siluridae shows fully 300 species in S. America, about 
140 of which occur in the Amazon; I5O species occur in Africa, 58 of which are found in the Congo area, Io in Tanganyika, and $4 \mathrm{I}$ in the Nile basin. The Characinidae includes 659 species in S. America, of which 317 are found in the Amazon; 98 species are African and of these 52 are from the Congo, i 8 from the Nile basin, and 5 from Tanganyika. The Cyprinodontidae (Poecilidae) has I60 S. American including I 4 Amazon species; 42 are from Africa and 8 of these are from the Nile, $\mathrm{r}$ from Tanganyika. The Cichlidae includes 187 species from S. America, 55 of which are in the Amazon basin; 215 species are African, and 85 of these are from the Congo, about 40 from the Nile basin, and 75 from Tanganyika.

Another important feature, which has been strongly emphasized by Boulenger $(303: 4 \mathrm{I})$ and others is, that not merely numerous genera but even species have a distribution that extends across the African continent from Senegal to the Nile. Thus Protopterus, in its three variable varieties or species, extends from Senegal to the White Nile, and occurs at 2700 feet elevation in Tanganyika, at 3100 feet in Albert Edward and at 4000 feet in Lake Victoria. Mormyrus longirostris has been secured at Stanley Pool on the Congo at 800 feet elevation; at Lake Moero at 3000 feet; at Tanganyika at $2700 \mathrm{feet}$, as well as in the Zambesi. The nearly related $M$. caschive occurs in the Nile.

Marcusenius discorhynchus extends from the Lower Zambesi and Lake Nyasa (elev. I65o ft.) to Khartum on the Nile (elev. I $252 \mathrm{ft}$.) ; it has been found at Lofoi on the Upper Congo (elev. $3000 \mathrm{ft}$.), and is closely related to $M$. tanganicus of Lake Tanganyika (elev. $2700 \mathrm{ft}$.). Tilapia nilotica is found in Senegambia, on the Niger, also in the Nile river at rather low elevations; it is in Lake Rudolf (elev. I $250 \mathrm{ft}$.), in Tanganyika (elev. $2700 \mathrm{ft}$.), in Albert Edward (elev. 3 I06 ft.), in Victoria (elev. 4000 $\mathrm{ft}$. ), and in Lake Kivu (elev. 484 I ft.). Similar details might be cited for Hydrocyon lineatus, for Alestes macrolepidotus, for Paratilapia bloyeti, and other species.

Now the above is proof that such species once inhabited -more or less densely - an area included within the most distant points where they now exist, and such would cover 
a region from Senegal to the Upper Nile at least, and south to southern Congo, Nyasa, and the Zambesi. But even more arresting are the varied elevations at which one and the same species may be found. This has caused all writers on African biochorology to accept-what the rocks abundantly demonstrate-that great changes have occurred in surface configuration during Tertiary time. These changes might be due to denudation alone, or to this along with elevation, or conversely depression of land, or to all of these combined. For the finding of what are, and long have been, freshwater fishes of the same species, from near sea level up to almost 5000 feet as in Lake Kivu, requires appropriate explanation. To this we can return later.

Another important feature is that the fishes which inhabit the above area, are practically without exception freshwater, alike in their past history as already traced, in their present affinities, and in their relation to fishes of other regions of the world. Thus the dipnoan, the mormyrid, the cyprinid, the characinid, the silurid, the cyprinodont, the cichlid, and the mastacembelid families, are all continental in origin and distribution.

Still another point of importance, often emphasized by past writers, is that while a relatively small number of common or nearly related species, inhabits the entire area, each special lake or drainage region is characterized by a group of endemic species. With entire show of reason, these endemic species have been regarded as types that have slowly evolved, after the localized regions had become separated from wider areas with which they were formerly connected. Of such localized regions Lake Tanganyika is undoubtedly the most striking example. For of the Cichlidae alone this lake has 75 species, or almost onethird of the 2 I 5 found in Africa. Lakes Victoria, Rudolf. and Nyasa show like conditions.

One must be cautious however in concluding that absence of any species from a definite locality, so far as present knowledge goes, is proof that such never existed there. Lake Tanganyika is a case in point. For while it was once supposed that only one species was common to it and lakes beyond it, we now know that at least 7 species are common. 
The rather abrupt manner in which the great groups of fishes above-named disappear when the northern part of the Soudan is passed, suggests that from Cretaceous times onward either a Cretaceous, and later in the northern and N. E. Sahara an Eocene sea covered most of that region; or when such seas were withdrawn physical conditions due to hot suns, intense desiccation, sand storms etc., prevented northward migration except at a late period, and indirectly down the Nile Valley, then thence along the south Mediterranean coast. Similar obstacles long acted to prevent extension into S. Africa until comparatively recently, and then only to a small degree.

Though some writers have tried to minimize the resemblances-one might truly say the abruptly close affinities-traceable between many genera of the Siluridae, Characinidae, Cyprinodontidae, and Cichlidae of Africa and eastern S. America, such must be accepted as existing, and the writer adduced reasons (p. 40o) for considering that all primarily evolved in America, and became established as increasingly dominant groups during late Cretaceous time. How then, it may be asked, did they pass to Africa? Before giving answer, it should be pointed out that the greatest number of African species in these four families occur in western and central Africa, while the number markedly decreases toward the Nile, and becomes still smaller when one traces them eastward into Asia.

Any attempted explanation therefore must involve the former existence of a wide tract of land that was of such elevation, and was so connected in its marshes, lakes or river systems, as to permit the gradual migration from the Guiana-Brazilian or Archenchelis continent to what is now the great Nile system, of at least some representative genera in each of the four families above-named.

The chart on next page (Fig. 72) gives in outline what the writer would regard as the condition of affairs, toward the close of the cretaceous period. At that time the great Archenchelis massif seems to have been of considerable elevation, but was being drained and denuded by rivers such as are now represented by the Amazon, the Araguay, the Parnahyba, and the San Francisco. Extending from the 
eastern Brazilian coast that now is, must have been an extensive area of land, that at least for some considerable time stretched more or less continuously to the W. African coast of to-day. This may even have included the Cape Verde Islands as an area of volcanic activity on the north.

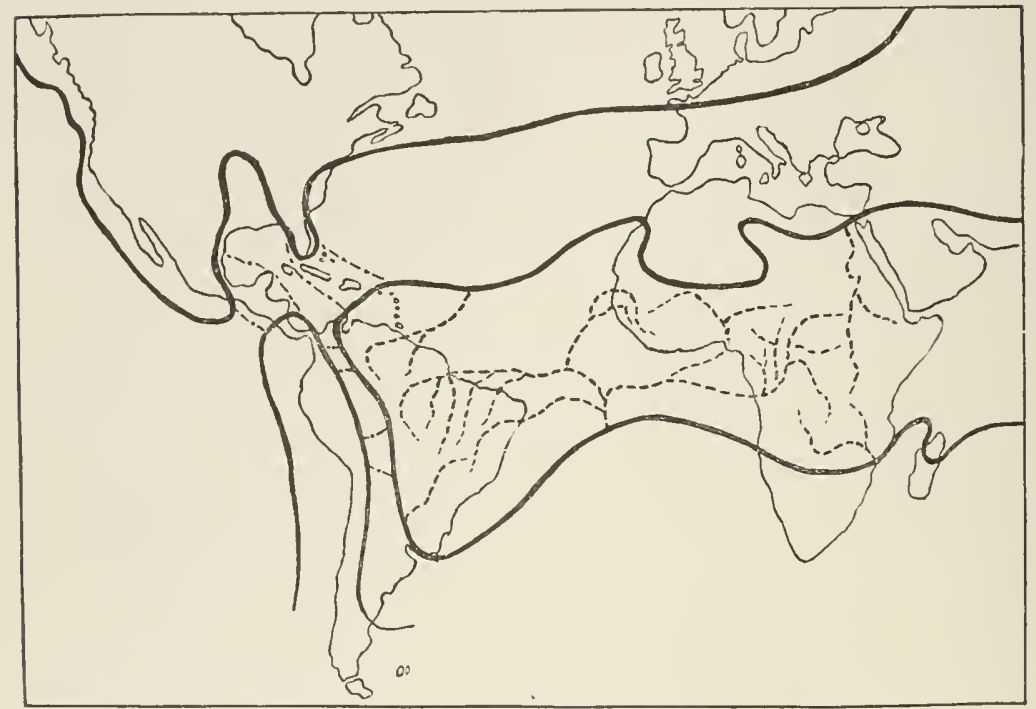

FIG. 72. Chart showing probable distribution of land during early Eocene time, outlined in black. The dotted lines indicate possible river-systems whose course and extent might explain distribution of several large families of fishes.

The above-named American rivers, passing into this S. Atlantis continent, may have traversed areas which, like the Congo, Niger, Amazon and other basins now, were periodically swollen into extensive swamps and swamplakes during each rainy season. Across the central part of this Atlantis, most of which may have been only Iooo to I 500 feet above sea-level, connection could be made with the waters of the Senegal on the east and the extended Orinoco on the west. These with other rivers from east and west probably discharged into a North Atlantic or a South Atlantic ocean. Thus could be explained the gradual passage or transition of the serranid, pseudochromid, latrid and sparid groups from a freshwater to a marine life (pp. 387-392) in northward or southward direction. 
A large part of the Niger, South Soudan, and central African region seems to have been of no great elevation, though what is now the Congo drainage area may have been considerably higher on till Miocene time. The united eastern American and Niger rivers may gradually have joined over this S. Atlantis basin, and discharged southwardly into a South Atlantic sea. Such would again explain how various primitively freshwater teleosts sent outlying members into brakish and ultimately marine surroundings of southern waters, from which they could spread widely during succeeding periods of time.

Across the connecting land a few representatives of silurid, characinid, cyprinodont and cichlid families, with others of lesser subsequent importance, must have passed, their migration being doubtless greatly helped during periods of marsh-land flooding. That the migration was not wholly eastward from America to Africa however, but that a westward invasion also took place, is suggested by the probable relation of the African Protopterus to the American Lepidosiren. For owing to the more primitive structure of Protopterus, as compared with the closely allied Lepidosiren, Kerr, Boulenger and other authors have considered it probable that modified derivatives of Protopterus crossed the connecting land-area-possibly in early Eocene times-and gave rise to the American genus. At the time of the early Eocene then, Africa and S. America were simultaneously being stocked with evolving members of the above four families, though on the whole conditions seem to have been more helpful in America for their multiplication from that time to the present. For while S. America now has about 300 species of silurids, Africa has I 50 ; while the characinids number 659 species in the former area, there are about Ioo in the latter; while the cyprinodonts number about $\mathrm{I} 60$ species in S. America, there are 42 in Africa. The cichlids alone seem to have found a more congenial home, or special environal factors that hastened specific variation in Africa over America. For while the latter contains about 190 species, there are close on 220 in the former. 
A partial explanation of the above difference is doubtless to be found in the earlier occupation of S. America by evolving members of the above families. But much more we believe, depends on the great changes that took place in the Central African region after these fishes had reached parts of it. And to these we can now give attention.

If then, over the mid-African area there existed in early Eocene times fairly extensive systems of swamps, lakes, and connecting rivers with their streams, such as largely characterize wide sections of it and other continents still, these would receive and shelter a varied freshwater fauna of greater or less specific richness. If we may judge from parallel cases of Brazil, of the east central United States and of some Indian localities, this fauna would consist of genera and species of Infusoria that showed varied structure and habits, and from one of which has evolved Trichodina pediculus already mentioned (p. 465) that established parasitic relation, and spread over African, Indian and possibly over Brazilian territory. Freshwater sponges, of ancient origin, would occur over shells, rocks, or sunken lumber. These, with advancing investigation, are now known to represent not a few world-wide species, but numerous specific variation-forms, that are for some species of wide distribution, for others of localized endemic nature. But all are everywhere referable to the great freshwater class Spongillinae. Of these the central African region had its share.

The freshwater medusae of Brazil, of Central Africa, of India, and of the United States all belong to the Hydrida or Corynida, that have wholly or in part fixed freshwater hydroid stages, as well as the reproductive crystalline bells. None have been found as marine organisms, and there is absolutely no evidence, that they are marine derivatives. We would readily accept however that from these simple freshwater organisms the increasingly complex Corynids, Sertularians, and Campanularians branched off into marine life, and this at a period that was immensely antecedent to the Eocene or the Cretaceous. The freshwater ancestors, and the more complex marine derivatives are alike left alive still in their appropriate habitats. 
The simple or semi-colonial Polyzoons, described by Moore from Tanganyika, show marked affinity to primitive freshwater types that are being recognized and identified more and more widely over the earth's surface. They are evidently lingering and ancient survivors from ancestors of Ordovician or even of Archaean age, that probably peopled the lakes and swamps of that period. The writer has discussed their evolutionary value elsewhere.

In Cretaceous and early Eocene pools, lakes, and swamps of Brazilian, African, and Indian regions, Cyclops and related Copepods or Ostracods must undoubtedly have flourished. These show clearest evidence of a long-drawn ancestral history that was wholly apart from marine surroundings, as the writer hopes to demonstrate at another time. But gradually some of these must have acquired a loosely ectoparasitic habit-possibly in Permian or Triassic if not earlier days-and such like all parasitic tendencies became a more confirmed and degrading habit, till in the early Eocene period species of Argulus, Dolops and allies had firmly attached themselves to Characinids, Cichlids, and other fishes. Such is now witnessed in African lakes.

In view then of ecological, structural, and embryological evidence that the writer has already brought together, he does not hesitate to affirm that the macrurous crustaceans of the African lakes were not migrants from marine ancestral environs, but were direct descendants of fairly ancient lake or river dwellers, from which derivative branches passed into the sea. He would express exactly the same view for origin of the African and specially the Tanganyika molluscs, though the full evidence is still in suspension.

Nothing need be added to what has already been stated for the fish-fauna. The distribution of all of the above at the present day however, is what might now engage attention. For such may furnish added evidence as to past geologic connections and conditions. If toward the close of the Oligocene period groups of freshwater organisms, similar to those above reviewed, existed in the swamps, lakes, and rivers of Central Africa at an elevation of 500 2000 feet, then, owing to food, light, temperature, struggle 
with other animals and with environal lake surroundings, there would be a natural tendency for these animals to segregate in waters that were of varying but specially considerable depth; that were at the same time in contact with inflowing streams, or with swamp areas, which were in turn connected wtih wide stretches of country during flood period; and that in time became permanently cut off from each other owing to denudation, or to more sudden changes, with upheavals or depressions of the earth's crust. Such environal alterations would start and more or less accentuate localized variation-changes in the organisms there, from steady action of the great law of proenvironment ( $p .15$ ). Such seem to have existed as incipient conditions, toward close of the Oligocene, or in the early Miocene, and in the six or eight principal lakes of the central African region.

If then there started an extensive but steady change in the earth's crust over the above area, as is demonstrated to have taken place through the observations of ScottElliott, Gregory, Moore, and others since, shrinkage, faulting, downthrow and upthrow of strata must have occurred. The heat generated by such extensive stratigraphic changes would start volcanic action, and originate mountains such as are now seen in the Fort Hill, Mfumbiro, and Ruwenzori mountains. Great stretches of country would thus be elevated or depressed. And while at times and in some places cataclysmic destruction of life would follow, incipient variations in species that were saved alive would often tend to be preserved, and even in time further accentuated. The very inequalities in elevation and depression shown by Lakes Nyasa, Rikwa, Tanganyika, Kivu, Victoria and Rudolf, would involve differences in many environal factors, as travellers have noted. Such in turn would by proenvironal reaction, affect and alter the organisms involved.

But insufficient knowledge of biological relations, or of the changes proceeding, may cause one to assume mistaken positions. Thus Moore (op. cit. p. I 28 ) in comparing Lakes Tanganyika and Kivu, concluded that "their faunas are entirely distinct," and then recorded five species of fish from Kivu. But further on he remarks (p. I 36 ) : "Tilapia burtoni is found outside the confines of Tanganyika, this 
single species having made its way up the Russisi river into Lake Kivu." Of the remaining four species he records $T$. nilotica from both lakes, and it has a much wider range as before noted. The remaining three are now also known from Tanganyika.

So as some succeeding authors have indicated the history evidently is that Kivu and Tanganyika once formed parts of a continuous lake-and this at no very remote past date, geologically speaking. By subsequent upheaval however of the north end, and possibly when the Mfumbiro mountains were ejected as volcanic masses, many of the I 20 species of fish found in Tanganyika were destroyed. But two at least survived the upheaval strains, and remain identical with those of the larger and lower lake. So instead of "having made its way up the Russisi river into Lake Kivu" against the wild cataract torrents that Moore graphically describes, we would accept it that two species of the group survived elevation with the lake and the surrounding land, till fully 2000 feet of altitudinal difference was established between. The invertebrate organisms confirm the above conclusions.

To account then for the rich and varied freshwater fauna of Tanganyika, it can be said that so far as the invertebrates are a criterion the lake may have existed as such from Jurassic time onward. For all of the invertebrates-even the crustaceans-had by then evolved to the dignity and structural complexity of the present lake inhabitants. If then Tanganyika had, by crustal earthmovements, become of considerable depth as a "rift" lake by late Cretaceous time, it would the more securely shelter the organisms that drifted or floated into it.

But the fish fauna raises very important considerations. And its exceptional richness, beyond that of the invertebrate groups, gives added importance to the question. The two species of Tanganyika, Polypterus congicus and Protopterus aethiopicus - may well represent the oldest and earliest surviving fishes in these lakes. Boulenger's view also $(227: 23)$ that the former is intermediate in structure between the Senegambian P. lapradii and $P$. endlicheri of the Upper Nile is suggestive; while its presence along the 
Congo proves that connection between lake and all three rivers was once possible.

The recording by Moore of Protopterus not only from Tanganyika, but also from Albert Edward and Victoria Nyanza, similarly proves the fundamental identity of certain species over a wide area.

Passing to the bony fishes, it can be definitely asserted that, unless all past palaeontological data are defective, the early teleosts branched off from freshwater ganoids during late Jurassic and early Cretaceous time. But only in the late Cretaceous and early Eocene periods did they become abundant and spread abroad into many and varied regions. We have already claimed and accepted it that the four leading families reached Western and later Central Africa from eastern S. America at one or the other time. Tanganyika, as well as other of the central lakes, must then have become stocked with one or a few parent forms of each of the four families, since we would consider that these lakes were then of rather low elevation, and were more or less connected with each other during flood times. These parent forms multiplied, and becoming geographically restricted to definite centres or lines of migration, owing to geologic changes proceeding, started varietal and later specific peculiarities. Then toward close of the Oligocene or in early Miocene time, marked earth shrinkage, faulting, and volcanic activity combined to deepen Tanganyika-that included then Kivu-and to shut it off wholly from other lakes as a long rift valley.

For reasons that we seem to be wholly ignorant of as yet, environal surroundings favored multiplication of the Cichlidae beyond all others. But that about 75 species of this family should have evolved in a single lake, and also that most of them are specifically peculiar to it are equally arresting facts.

Elevation of the entire deep narrow rift lake to about 2700 feet, caused isolation of it, and made it different from the lower Nyasa, and the more elevated Nyanzas. This also seems in part to account for a progressive evolutionary separateness, from late Oligocene to recent time. 
The Cyprinidae of Tanganyika seem to be the most far-travelled of its teleostean families. For though consisting only of eight species, referable to the three genera Barbus, Barilius, and Capoeta, these all show greatest affinity with, and derivation from, others that entered Africa from the east. The probable line of travel has been already traced (p. 4I 7 ). They may have entered Africa during the early Oligocene, and spread westward to Tanganyika. Later, as elevation of Tanganyika, of Lake Victoria, and of Lake Albert, brought these to a level with the head waters of the Congo, an added westward migration became possible.

Some additional features of interest shown by Tanganyika and the other African lakes, as compared with $\mathrm{S}$. America, may now be treated of. The Aspredinidae with 22 species, the closely related Loricaridae with fully 200 species, the Gymnotidae with 3 I species, and the Atherinidae with 33 species, are all absent from Africa. These are all highly evolved families, and at least the first three seem to have appeared originally over the Archandean continent. So when union of it and Archenchelis took place, and migration of the above families went on into Eastern Brazil, land connection with West Africa was probably sundered, and so eastward migration into Africa was impossible.

But the two important and thoroughly freshwater families, Mormyridae and Mastacembelidae, that are unrepresented in America, are decidedly puzzling in their African distribution. The former is a purely African family, and includes upwards of 60 species, some of which are native from Senegal and Gaboon across the continent to the Nile. For some time it was supposed to be absent from Tanganyika, but Mormyrus longirostris, and Marcusenius tanganicus now found there, furnish proof that the family is of fairly ancient ancestry and rather wide distribution. The former also is one of the simplest genera, the latter one of the most evolved genera (227:53). Boulenger further has suggested a close affinity between the Mormyridae and Albulidae. But in spite of some marked differences, the writer would suggest a closer affinity even with the Osteo- 
glossidae, that is represented by Heterotis from the Senegal-Gambia to the Nile. This in turn connects with Osteoglossum and Arapaima in S. America, and with the more primitive Dapedoglossum of N. America. The eastward extension as Scleropages into the E. Indies and Australia, has already been noted (p. 354).

The puzzling family Mastacembelidae must have entered, or evolved in, Africa, not later than early Eocene time. It now includes some 38 or 40 species, at least 7 of which are peculiar to Tanganyika, and 24 are tropical African. The remainder extend from the Nile through Syria and Mesopotamia to the East Indies. The entire family is as typically freshwater as any of those studied in this chapter, but its derivation is puzzling. It seems to combine characters of the Notopteridae and the Mormyridae, specially of Gymnarchus in the latter family. But other characters are markedly divergent, and seem to ally it with the acanthopterous family Blenniidae, near which it is usually placed.

In condensed review then of this chapter, it is suggested that toward mid or late Cretaceous time the Brazilian and Guiana areas of $\mathrm{S}$. America, that collectively have been called Archenchelis, formed a rather elevated table-land, over which there already existed, or there were evolving, not merely a varied invertebrate fauna, but more importantly a fish fauna in which four families-the Siluridae, the Characinidae, the Cyprinodontidae and the Cichlidaewere becoming dominant, alongside others. Through earthshrinkage and volcanic upheaval a large part of the central Atlantis region became considerably elevated as a south Atlantis bridge, that at least for a time connected BrazilGuiana with West Africa. Into and across this were probably continued the large Brazilian rivers, and at least the Niger, possibly also other West African rivers like the Komoe and Volta. The entire area, traversed by the lower reaches of these, seems to have consisted of lakes, marshlands and streams, that were subject then-as a large part of central Africa is still-to alternating periods of flood expansion and of drying. 
Such however permitted the gradual eastward migration of species of the above families of fishes; as well as of various invertebrate groups, that gradually mingled with the older African types. It permitted also the westward passage of Protopterus, and its gradual condensing modication into Lepidosiren, that passed into the Amazon and into tributary as well as more southern rivers.

The lower Atlantic-African drainage area probably did not exceed 500 feet to 1500 feet, and was continued eastward to the Upper waters of the IVhite Nile, as well as in bow-like fashion, southeastward to the Nyanzas, Tanganyika, Rudolf, and Nyasa. Of these lakes Tanganyika was probably the oldest, and even in early Eocene time was probably already a deep "rift" lake-ravine, that for long periods before had accumulated numerous freshwater invertebrate types from earlier epochs. At this time the Congo basin seems to have been a more elevated plateau, into which the eastwardly migrant fishes only later penetrated, when by combined denudation action and depression by faulting its level was considerably reduced.

By late Oligocene or by Miocene times the Atlantis bridge was largely broken up, by extensive faulting and depression, and a segregated evolution of species and of genera belonging to the above four families of fishes, proceeded, though in some cases - as with Fundulus-generic continuity can still be traced over the two sundered continents. But further segregation resulted when-from late Oligocene to early Pliocene times, and even on till now-steady but local changes took place, through combined faulting, elevation, depression and volcanic outbursts, that made themselves more or less felt over the entire mid-African area, and which probably were coeval with those depressions, faultings or foldings that almost obliterated the Southern Continent, treated of in last chapter.

Then started specific and generic variations in the five or six main lake centres, as well as in Chad to the far north. During this process one or two of the four groups of fishes named, became dominant in each lake-centre. Thus the Cichlidae far outreach the other families in Tanganyika, and form a good second in Victoria. The species and even 
genera again in Victoria, are largely different from those of the White Nile below. The Siluridae have specially multiplied and varied in the White Nile. The Characinidae have passed down into the main Nile river, and on to near its mouth. The Congo shows a more recently derived and immigrant group of species, whose ancestral types entered it from several sources.

From the eastern or Asiatic side, and probably along the Mesopotamia-Syria line, migrant species of the Cyprinidae entered, after working across Asia from their primitive N. American home. But that the western and the eastern streams of migrants only slightly if at all intermixed, is graphically illustrated by the fish-fauna of Lake Tsana in Abyssinia. High though it now is-about 6000 feet-it received such a stream of incoming cyprinids from the east, that I 7 species are now known from it, while the affluent Blue Nile has I 2. In marked contrast not a single western Characinid has reached its waters. And though 29 species of Silurids occur in the White Nile, only two now reach eastward to Tsana.

Lake Tanganyika therefore, and probably also Nyasa, are evidently old freshwater lakes, that in their earliest origin may date back beyond the Cretaceous to the Jurassic or even a more remote epoch, though a late Cretaceous date seems ample. But the fishes that so distinguish the former now, seem clearly to be-except for such puzzling groups as Mormyridae and Mastacembelidae-S. American freshwater derivatives, that usually show common generic ancestral types with others in the lakes, swamps, and rivers of that continent. But owing to isolation-probably from the Pliocene onward-and to action of varied and complexly interacting environal factors not as yet sufficiently estimated, proenvironal variations have proceeded apace, and have resulted in the evolution of numerous species, that are largely peculiar to the two lakes. Lake Kivu we have regarded as originally the upper end of Tanganyika, and so it had a fish-fauna that was largely the same. But during upheaval of it and the surrounding country, most of the species were obliterated, though at least two species are now known to be common to the two lakes. 


\section{CHAPTER XVII.}

\section{The Geographic and Geologic Relations of the More Primitive Fishes.}

As passage backward is made to the older rock-strata, and as types of fish are encountered that depart more and more in species, genera, and families from the abundant ones of recent times, it becomes correspondingly difficult to trace the extent and trend of the land-masses over which freshwater areas existed, that enabled migration of freshwater fishes to proceed. So there is equal difficulty in tracing the exact distributional lines followed by these fishes. Further, we still lack definite information as to whether certain strata and their fish-remains were of freshwater or of marine origin. For as has often been pointed out in previous chapters, vast deposits that were assigned to the latter, should by clearest evidence be grouped under the former or freshwater mode of deposit.

Having already dealt with the relation of the Teleosts to past land-masses, we can now study those transition families of fishes that connect the Teleosts with the cartilaginous fishes, viz. the Leptolepidae, Oligopleuridae, Archaeomenidae, and Pholidophoridae. Along with these the more primitive Holostei or Protospondylii, and the Chondrostei can be linked up in their land connections.

From statements already made (pp. 343-345) it would appear that during early Cretaceous and much of Jurassic time, an extensive and more or less continuous freshwater passageway existed between central and south Europe, Central Siberia, China and Australia. For Lycoptera, Leptolepis, Oligopleurus, Oenoscopus, Archaeomene, Pleuropholis and other related types extend over this entire region either side by side, or so dovetailing into each other from one section of the above-named land-masses to another, that geographic and geologic continuity become a necessity, Thus Leptolepis, as already shortly referred to (p.p.206-207) includes species from Western England, Central and S. Europe, and from the Talbragar beds of 
Australia. Similarly the few known specimens of Lycoptera suggest a gradual distribution during Jurassic and on thence to Cretaceous time, from areas in S. Siberia on to China, and then often associated with the equally widely distributed freshwater crustacean, Estheria middendorfii. Such an extensive region is that outlined by Neumayr, de Lapparent, Kelloway, and Arldt (pl. I 8 ) as the Eurasian-Australian continent. This continuity may not have been coeval in all of its constituent land-parts, but even a make-and-break action must have left ways and means for steady migration of the genera above-named. If we were acquainted more fully however, with the fossil fishes of South Siberia, China, Siam, New Guinea, and Australia, which lived during that time, the evidence would be more satisfactory.

But one or two allied genera to the above seem not only to favor such a land-connection, they suggest either a continuous or interrupted connection back to Triassic times. Thus Pholidophorus, in its known species, extends from Purbeck and Kimmeridgean beds down to those of the Lower Lias; while if such species as $P$. furcatus, $P$. (Baleiichthys) sibiricus, $P$. gregarius, and $P$. dubius are truly referable to this genus, they indicate distribution for the genus from Britain through Central and S. Europe on by Siberia to Australia. But the connection between central and S. E. Asia with Australia seems to have broken up toward late Jurassic or early Cretaceous time, so that these two areas were probably quite apart till mid-tertiary time, when reestablishment of a rather short-lived connection permitted the passage northward into $\mathrm{E}$. Asia of the most evolved types of marsupials (p.446) and the intermingling of genera belonging to various plant families.

Meanwhile in connection with, and so far confirmatory of, results already set forth for higher teleosts, we may next gather information from the aethiospondylic Holosteans, a group that is made up of the genera Lepidosteus that still survives-and of the two fossil genera Belonostomus and Aspidorhynchus. The first of these includes five living species that occur over the $\mathrm{N}$. American continent southward to Central America. But the genus can also be traced back in the West to the Bridger beds of lower Eocene 
age in Wyoming. Probably therefore it existed over at least the central N. American area back into Cretaceous. So in early Eocene time it could spread across the $\mathrm{N}$. Atlantis bridge along with many teleosts already referred to. Remains of several species, however, have been recorded from lower and mid Eocene beds up possibly to Lower Miocene strata of east central Europe. But there the group has since been wholly obliterated.

Lepidosteus, however, in general morphology, and not least in the highly complex bony constituents of the head and jaws, seems truly to be the end member of a series that included the more ancient Aspidorhynchus and Belonostomus. Now, species belonging to one or other of these two can be traced from Upper Cretaceous through Purbeck to Kimmeridgean age, and this over a wide extent of territory. Thus Belonostomus, while existing apparently for a long period in central S. Europe, has been reported from the Upper Cretaceous of Mexico, from Ceara in Brazil, from Queensland, and in a doubtful specimen from India.

This lends support to the view that the genus may have branched off from common ancient ancestors with Aspidorhynchus, that were native in Western Europe back to the time of deposit of the Stonesfield slates at least. For from these slates $A$. crassus has been described. So early passage westward across the $\mathrm{N}$. Atlantis bridge, as well as extension eastward into Australia, between Kimmeridgean and Purbeck time could satisfactorily account for distribution of the Aetheospondylii as a whole. Species representing all three genera then, may have existed side-by-side from central Europe across N. Atlantis to central N. America, as well as eastward through S. Siberia and China to Australia. Progressive modification and southward extension of descendants that reached the Southern States may have proceeded, till they invaded the east Brazilian region during the late Cretaceous. A similar journey, however, was being carried out by teleosts of the same or somewhat later period, as has been already indicated. The above three genera then anew emphasize the view that during Jurassic and possibly early Cretaceous age, some extensive systems of freshwater 
communication existed over a great northern continental mass. This evidently extended from central North America eastward to east Asia, and even for a time, in the late Jurassic period, into Australia.

Alongside the above in some of their habitats, were the even more primitive protospondylic fishes, that make up the Amiidae, Eugnathidae, Macrosemiidae and Semionotidae. The first of these is still represented by the one living species Amia calva of $\mathrm{N}$. America, while the genus passes back in the same area to at least early Eocene. This anew demonstrates the correctness of the view, advocated by Cope, Leidy and successors, viz. that a large part of central and west-central N. America has undergone little profound change since the Eocene, though slow denudation action, that permitted the fishes to exist and readapt themselves amid such changes, were steadily going on.

But the fact that species of $A$ mia occur in upper Eocene, and in Oligocene-Miocene beds of France, Prussia, and Bohemia, is proof that some mode of freshwater communication existed during the Eocene between America and Europe. It would be a mistake however to suppose-at least with present knowledge-that the entire group Amiidae originated in the western Continent. For the related but much older genera Megalurus and Liodesmus are only known from Jurassic beds of S. W. Europe, if we accept $M$. maresoni that Woodward has described (304:87) from the freshwater cretaceous of Bahia in Brazil. The parallelism between this distribution, and a similar one referred to above, as well as of others that follow, strongly indicates that the same land-masses existed, and similar lines of travel were taken, by different groups of fishes.

Known facts then favor the view that the Amiidae evolved during early or mid-Jurassic time in lakes and river areas of west-central Europe, and persisted there till at least Lower Miocene days, when they disappeared from that region during the mid or upper Miocene. Representatives travelling westward however, during the Cretaceous period, to N. America spread widely there, and of these Amia calia still persists, while Megalurus, pursuing a line 
of travel taken by many fishes reached E. Brazil, only to be later obliterated there as well as in Europe.

With five such genera now before us as Belonostomus, Aspidorhynchus, Lepidosteus, Megalurus, and Amia, the question might well be asked whether their distribution was wholly effected by freshwater pathways or whether they were aided and even hastened in distribution by the adoption of an anadromous habit, as with the salmon, or whether they were originally marine, and after spreading along coast lines passed gradually into inland waters, in several distinct centres. The last possibility involves so many unlikely and strained relations that we are compelled to reject it. The second would be very helpful, if it can be proved to have existed, and in the case of the salmon and sea-trout amongst teleosts, such a capacity has undoubtedly greatly aided in dispersion from primitively freshwater habitats, as already observed (p. 358). But Lepidosteus and $A m i a$ are, and evidently both have been, freshwater fishes, alike as to their phylogeny, their habitat, their associated organisms of rock strata, and their present-day tendencies.

Belonostomus and Aspidorhynchus were-as already explained (p. 339)-primitively freshwater genera, but became in the Cretaceous period anadromous, or in such species as $B$. lesinaensis, $B$. cinctus and $A$. euodus, apparently marine. It seems not unlikely then that an anadromous habit may have been developed by some, at least temporarily. But no such evidence has as yet been adduced for Lepidosteus and Amia, which extended geographically as freshwater genera, during Eocene to Miocene time, from IVyoming to Central Germany at least. If this be demonstrably true for these genera, it may equally be for their allies.

Such organic continuity not only suggests more or less continuous land connections, it equally suggests a river, lake, and flood plain continuity for $4000-6000$ miles. But were the head-waters or the lower reaches of two such rivers as the Lena, the Yenisei, the Nile, the Amazon, or the Mississippi to be connected even for a time by floodplain waters, as almost certainly were the Nile and Congo; 
furthermore were the two to flow in somewhat divergent east and west directions, the conditions would be satisfied geographically and geologically which would explain the above distribution of Amia, Lepidosteus, and allies.

Our present knowledge of the family Pachycormidae would indicate that the more ancient genera like Euthynotus and Pachycormus from the Lias, originated in some rather restricted land area of Central South Europe, and the finding of the small freshwater Leptolepis as fossilized food-remains, inside a specimen of the latter genus from Normandy, is partial proof. But adoption of an anadromus and later of a wholly marine habit, enabled them to extend their range, until, from early Cretaceous time onward they ranged from the seas of Russia westward to the Niobrara seas of Kansas. So if we compare the Amiidae, the Lepidosteidae, and the Pachycormidae, it seems as if all three had a common and coeval central or eastern European freshwater origin in Upper Liassic or early Kimmeridgean times. Then the two former spread westward into N. America by the N. Atlantis bridge, while synchronously the pachycormids-becoming probably first anadromous but later purely marine, travelled in parallel advance with the amioids and allies toward N. America, but along the southern shores of the N. Atlantis bridge. The evolved descendants like Protosphyraena and Erisich.the, that are found in Cretaceous beds from Kansas in the IVest to Russian Kursk and to Lebanon in the east, would indicate that a more or less continuous expanse of sea existed alongside the $\mathrm{N}$. Atlantis land at least to the lastnamed locality.

The above conclusions as to parallel continental and oceanic migrational movements receive added confirmation when comparison is made of the Engnathidae, Macrosemiidae, and Semionotidae-all of which were persistently freshwater families-with the related Pycnodontidae. For the latter resembled the Pachycormidae in beginning, and in long remaining, as a freshwater family. But in later evolution and distribution (p. 334) they became purely marine. 
The oldest Eugnathidae like Heterolepidotus, Allolepidotus, and Ptycholepis had already spread, as freshwater genera in Upper Triassic time, from east and S. E. Europe westward to Britain, and in the last genus to at least Connecticut. The two first persist into the Lias. Caturus, that is as yet only known from Central-South European strata of Triassic age, is there continued through the Liassic and Kimmeridgean into Purbeck beds. It can safely be assumed then that the family lived and gradually evolved, over a land area that at one time or another connected from S. E. Europe to Connecticut. Whether the more recent Neorhombolepis and Lophiostomus that pass into upper Cretaceous rocks, are wholly freshwater, or anadromous, or even marine, seems at present doubtful.

The Semionotidae evidently originated and continued as a freshwater group. It also is suggestive as to the disposition of land masses from the period of the Upper Permian when Acentrophorus is first known from Durham, England east to Bohemia. Through the succeeding Bunter, Keuper and Rhaetic rocks of the Triassic, the family became extremely abundant and widespread in such genera as Semionotus, Serrolepis, Pristisomus, and Colobodus. These, along with smaller genera, indicate that land areas for their dispersion must have existed from parts, if not most, of the Eastern American States across to central-south Europe, thence across South Germany to Italy and into the Karoo region even of S. Africa. A possible offshoot from one or other of the two last seems to have spread across the Triassic Gondwana continent into Australia, and there became modified into the species of Semionotus, Aphnelepis, and Pristisomus, that are found in the Lower and Upper Hawkesbury-Wianamatta beds of N. S. Wales.

With the evolution of more recent genera like Cleithrolepis, Aetheolepis, Dapedius, Tetragonolepis, and Lepidotus, that extend from Upper Triassic to Wealden or Upper Jurassic time, the above geographic area was not only persisted in, extensions were made into India and S. Siberia over the Eurasian continent of that time. The required land and freshwater facilities for the above distributional passages would be amply met, were we to accept 
such land outlines as are set forth in the diagram that forms Figure 23 (p. I79), and which represents the views of Koken and Arldt for land areas of the Triassic period. The old idea of persistence of continental land masses would in no way furnish an explanation. Though we could wish for more numerous examples of species and genera than those above described, the recording of Lepidotus mawsoni from Eastern Brazil and from Cretaceous beds there, as well as of fragments of doubtful species from India of approximately the same age, indicate that these lingering remnants of the once abundant Jurassic Semionotidae, took advantage of the same migrational pathways as did more evolved groups already reviewed.

The soft cartilaginous body of the Chondrosteans, seems to have militated against their frequent preservation. But the known remains emphasize an exactly similar continental relation as do the Semionotidae and some others already dealt with in this chapter. Thus the two genera Catopterus and Dictyopyge, first known in the latter genus from the Bunter or Lower Triassic beds of Switzerland, probably spread eastward and then southward till they reached N. S. Wales and S. Africa, also westward over a wide area of the Eastern States. The related genera Belonorhynchus and Saurichthys extend in one or other genus from England and Germany to N. Italy and Austria, also in the species $B$. gracilis and $B$. gigas to the upper Trias of N. S. Wales.

In view then of the facts set forth in the last few pages, we must conclude that one or more extensive land-masses stretched in Triassic and Jurassic times, from the Eastern U. S. to India and S. Siberia. Also that such northern land or lands were so related at some point or points with the African continent, that frequent migration of different groups of freshwater fishes took place till S. Africa was reached. The bridge or passage-way must have been a fairly easy and continuous one, but from all present evidence most of this has been destroyed, or has failed as yet of recognition. Finally either from S. Africa across Gondwanaland, or from S. Europe by Persia and India long-continued connection must have been kept up with Australia in its N. S. 
Wales territory, if not more extensively. So from Massachusetts to Virginia on the West, and thence through central Europe to India and N. S. Wales on the east, as well as down to S. Africa, a wonderful similarity of fish-genera can be traced from the upper Triassic till the Liassic or even later. The genera and, it may be, families of these fishes, as we have seen, are constantly changing, as successive geologic strata are passed through, but in any single system of rocks, the very wide extension of the freshwater fish fauna, in genera and at times even in species, is an arresting fact of fundamental importance.

The cartilaginous Actinopterygii carry us back into still older geologic strata, and into still older continental land masses. Of the two families Palaeoniscidae and Platysomidae that compose the group, the former seems to be the older and more primitive, alike as to shape of body, expanse of mouth, sectorial teeth, simpler scales and other structural details. But both groups indicate that they gradually came to occupy the same continental habitats from the Lower Carboniferous-or Calciferous-period onward, while all remained freshwater fishes, or only rarely seem to have been anadromous to a slight extent.

The most extensive and continuous distribution of the two families, according to our present knowledge of fossil remains, occurred from Upper Carboniferous to Triassic time, and the remarkable similarity in this distribution to what has been outlined above for the Semionotidae, will be at once apparent. Thus Palaeoniscus appears first in the Upper Coal Measures of France; is doubtfully known from the Lower Permian of Hohenelbe, and has been reported in different species from the Upper Permian of Durham and Northumberland, of Hannover, of Thuringia and Saxony, of Kargala in Russia, and from the Karoo beds of Triassic age in S. Africa.

The related genera Acrolepis, Apateolepis, Gyrolepis, Atherstonia and Myriolepis, start with the first of these in Scottish Calciferous rocks, while expansion to England, Belgium and Nova Scotia then followed. In the Permian Acrolepis is reported from East England, Germany, and Russia, while one species is reported from the Karoo beds, 
where Atherstonia is also known. But Gyrolepis, Urolepis, and Myriolepis, not only carry the family through the Triassic, they prove that a more or less continuous freshwater connection had existed from Britain-probably also from N. E. America-through France, S. Germany, Italy and S. Africa as well as N. S. IVales. The persistence of this migrational line into later times is indicated by the finding of species of Coccolepis in Upper Triassic beds of Talbragar in Australia; in Lower Liassic beds of Lyme Regis; in Lower Kimmeridgian of Bavaria; in the Lower Purbeck of S. England; and in all these cases in freshwater deposits.

The map already referred to (Fig. 23, p. I79), supplemented by observations for late Carboniferous and Permian times, would satisfactorily explain the probable landconnections that aided such distributions. As compared with the maps of Frech, of de Lapparent, and of Arldt the writer would incline to emphasize a more intimate and direct communication between the North-Atlantis and Eurasian continents on the one hand, and the Gondwana continent on the other. But of the river, lake, or flood-plain conditions that existed over these we are as yet ignorant. This by no means implies, however, that such knowledge may not yet be got. For if careful note be made-as has already been done in a few cases - of the attitude assumed and the direction to the strata of the fossilized fishes; of the position, consistence and size of the accompanying plant remains; of the trend in deposition of the strata; and the relative perfection of the organisms; in other words, the general ecological bearing of all recognisable factors, much may yet be learned that undoubtedly will greatly extend our knowledge.

Unless vestiges of them are discovered later over a wider areas than now known, it would seem that the Platysomidae remained more restricted in distribution than did the Palaeoniscidae. According to present knowledge they gradually spread during early Carboniferous time from a primitive centre of evolution that included Ireland, Scotland, and Belgium. Thence they migrated from late 
Carboniferous to late Permian time, till Illinois on the west and Saxony on the east were invaded.

To return however to the primitive palaeoniscids, these had become extremely abundant series, over a wide continental area, that was evidently fairly continuous from East Canada, Illinois and Ohio, through Britain, France, Belgium and Germany to W. Russia. For the known occurrence of species of Rhadinichthys, of Amblypterus, and of Gonatodus amongst others from these centres, and that ranged from Calciferous to Upper Carboniferous time, is a fragmentary indication of what once must have been both the abundance and variety of the fish-life, as it is of wide continental territory that these were scattered over.

The most ancient known genus, Cheirolepis, is, as already noted (p.3 I 7 ) frequent in Lower Old Red beds of North Scotland as $C$. traillii, while $C$. canadensis from Upper Devonian beds of East Canada, proclaims probable descent from a species of W. European origin.

The Crossopterygii is the only remaining order of the Teleostomi from which evidence for former geographic and geologic connections can be secured. It is also the order that is at once the most primitive and the most persistent through geologic time. For from the first abundant appearance of several genera in the Old Red Sandstone of Scotland, derivative representatives have persisted up till now. The two existing genera Polypterus and Calamichthys are Central African and freshwater in habitat. For though the one species of Calamichthys is now known to occur along the Cameroon coastal region, this habitat is clearly derivative and untypical. It is deserving of passing note here also that the continental distribution of the living dipnoan genus Protopterus is almost identical with that of the living Polypterus, while the ancestral Dipnoi and Crossopterygii can equally be traced back to Old Red Rocks.

But we have already seen that exactly the same distributional area of Africa is occupied by several groups of teleostean fishes that are either peculiar to it, or that show close affinity with nearly related South American groups. As yet no living or fossil types of Crossopterygii however are known from the latter continent. In relation to their 
distribution two peculiarities of the living group Polypteridae, and of the now extinct related group Coelacanthidae deserve mention. These all are, and seem to have been small-mouthed fishes, that lived in muddy pools, and that had rather imperfect oxydation. So migration was probably rather slow and limited in extent. Second, and doubtless in correlation with the above habit, the air-bladder is a large and usually ossified lobed structure that occurs often fossilized in the coelacanths.

As yet there is a wide gap in our knowledge of the Crossopterygians. For none are known between the two living genera and Macropoma of the Senonian and Turonian Cretaceous rocks. The latter connects with Heptanema, Coccoderma, Libys, Undina and Graphiurus of Jurassic or late Triassic age. Reference has already been made to the probable freshwater habitat of all of these except possibly Macropoma, that may have become marine. The above five genera, so far as now known, collectively occupied a geographic area from S. E. England to Bavaria and N. Italy, a region this that we have already indicated as the likely evolutionary centre for many Jurassic and Upper Triassic fishes. But Diplurus from the Trias of Connecticut and N. Jersey, that is in many structural points intermediate between Undina of Kimmeridgean Liassic age, and Graphiurus of Upper Keuper beds, again yields proof that at that time central and south Europe were continuous with Eastern America.

The oldest genus Coelacanthus includes a species from the Upper Permian of Durham in England and Hesse in Germany, several from the Coal Measures of England, Scotland, S. Ireland and Ohio, U. S. also one (C. huxleyi) that is the oldest, smallest and most primitive from the Calciferous rocks of S. Scotland. These occurrences would seem to indicate connection, during Carboniferous times, probably also in the Permian, from eastern N. America to central Germany.

The five still older divisions of the Crossopterygii accepted by Woodward, viz. the Onychodontidae, the Osteolepidae, the Rhizodontidae, the Holoptychiidae and the Tarrasiidae indicate collectively some extensive freshwater 
systems, that other groups of equally ancient fishes, which are reviewed below, seem fully to confirm. If we neglect the little known Onychodus, it can be said that most of the Osteolepidae are only recorded from Britain, but species of Glyptopomus have been found from Belgium and Scotland, west to the Catskill group on the Susquehanna of $\mathrm{N}$. America. The Rhizodontidae, that have a vertical persistence very nearly like that of the last, viz. from the Lower Old Red to the Upper Coal Measures, are known from an even wider area. Thus Strepsodus, Rhizodus, and Rhizodopsis collectively extend from Galicia through Britain, to Ohio, Nova Scotia, and doubtfully to Spitzbergen. Cricodus, Eusthenopteron, and Holoptychiusmainly from Upper Devonian beds-extend from W. Russia through Belgium and Scotland to E. Canada, N. York and Pennsylvania.

The Dipneusti, like the Crossopterygii, can be traced backward from such living genera as Protopterus, Lepidosiren, and Neoceratodus, through successively older and wholly freshwater strata, to rocks of Lower Old Red age. Regarding the two first of these as indicating an AfroAmerican Cretaceous-Eocene continent, nothing need be added to what has already been set forth. The existing Neoceratodus of Queensland connects fairly well, though by a wide geologic gap, with the species of Ceratodus that once peopled the rivers and pools of lower Triassic to mid Jurassic age. And like not a few groups already treated of, they seem to have been most abundant at that time in central Europe, but extended eastward to Upper Triassic beds of India and of Australia, as well as southward to the Karoo beds of Africa. If $C$. guentheri also is correctly recorded and interpreted $(305: 76)$ this species reached Colorado in Upper Jurassic time. Here then is added proof that N. America, central and S. Europe, India, S. Africa, and-by the genus Gosfordia-East Australia were more or less in organic relation during Triassic-Jurassic time.

A gap in the history of the group again exists from the Triassic to the Lower Permian, but from the latter period Sagenodus, Ctenodus, Phaneropleuron, and Dipterus, carry 
back the continuity of Dipneusti to Lower Old Red beds. Curiously enough also, as with the most ancient Crossopterygii, the area for evolution of, and early distribution of, these four genera stretched from Canada and eastern U. S. through Britain and France into W. Russia, though a region that centred round east and north-east Scotland may have been the most active and ancient home for the evolving genera and sub-families.

Accepting the views of Newberry, Woodward, and Eastman as to the close affinities of primitive Dipneusteans with the Arthrodira, the latter lived through a much shorter period, and inhabited a greatly more restricted territory than did the former. This is almost certainly due to their increasingly heavy' armament, also to their having adopted an even more pronounced method of ground-feeding than did the Dipneusti. From the time of their undoubted first appearance in Lower Old Red beds, till their extinction in upper beds of the same formation, the freshwater area occupied extended from at least Ohio and Illinois eastward through Britain to the Orkneys, and thence northward to Spitzbergen-where Lophostracon spitzbergense has been gathered-to N. W. Russia, also eastward through Belgium to the Eifel region of Germany.

Such distribution would suggest a rather more expanded N. Atlantis continent than that outlined by Frech (105). If Barrande's fragmentary specimens of a supposed Coccosteus from the Silurian of Bohemia are correctly identified (306:638-40) the group may have originated in some shallow lakes of Central Europe, from which new and larger types may have radiated, till all culminated in the huge and cumbrous Homosteus, Dinichthys, and Titanichthys of Russian, Scotch and eastern N. American territory. So while the Dipnoi evolved along structural lines that were adaptive and capable of receiving impressions from without which could be fairly rapidly linked up into a proenvironal response, the Arthrodira, showing such capacity in less marked degree, survived only through the Old Red period, and became extinct in the early Carboniferous.

The three ancient divisions of the Antiarchi, the Osteostraci and Ostracodermi, date back from Upper Devonian 
to Upper Silurian times, and representatives have been reported from much the same localities as above cited for the Arthrodira.

In structure, habits, and capacity of response to environal agents, all of the genera that make up the above three groups closely resemble the Arthrodira, and so after invading nearly the same territory, and living at times side by side with the latter, they disappeared, before the dawn of the Carboniferous period. In their earliest evolution they antedated the Arthrodira, but resembled them in that the oldest and most primitive genera Auchenaspis, Eukeraspis, Cephalaspis, Cyathaspis and Scaphaspis probably originated in the freshwaters of a Silurian tract of land, that may have fairly corresponded with the North Atlantis.

The isolation of this northern continent from a continuous and massive S. Atlantis-Gondwana continent, up to nearly the close of the Devonian; and the gradual formation later of a fairly wide connection between N. Atlantis and S. Atlantis-Gondwana, as compared with Frech's outlines, would serve to explain satisfactorily the migrations of several fish-groups from a northern and ancestral home, to African, Indian, and Australian areas of ultimate invasion.

The small group of the Coelolepidae consists of the genera Coelolepis, Thelodus, Lanarkia, and Ateleaspis that are distributed from Scotland to W. Russia; and like some groups studied above, very likely evolved in some part of this territory, also amid freshwater surroundings. It may here be added that, apart from any question as to the taxonomic affinities of Palaeospondylus, that remarkable fish came from the same territory as the preceding.

All five of these genera we would regard as the most primitive of known fishes. So this would cause us to accept at least as a temporary conclusion that fish-life originated in freshwaters over a limited area of land that extended from W. Russia to Scotland. It should be borne in mind however that this land and its enclosed fishes may have extended further west and even north, but geologic changes of far-reaching nature have destroyed the evidence, if such actually existed. 
Though we would not as yet attach much importance to the fact, it should however be kept in view that the area over which conodonts (p.IO7) are distributed agrees exactly with that above given as the centre for evolution of fishes as a great group.

It is not the writer's purpose to attempt a completeeven superficial- review of the geographic and geologic indications yielded by the great and persistent group of the Elasmobranchii, except in the two ancient divisions, Pleuracanthidae and Acanthodii. For we cannot as yet deal fully and intelligently with most of them.

The seven genera of the Acanthodii are known from localities that are identical with or closely related to those for Arthrodira and early Dipneusteans, except that the area of occupation is even more limited, as regards the earlier species of the group. For most have been met with in the Lower Old Red only over the British, and specially over the north-east Scottish region, where their richness in individuals is at times remarkable. In the Upper Devonian, and onward to the Permian where they die out, a steady geographic extension of genera like Acanthodes and Acanthodopsis took place along the lines of migration already demonstrated. We therefore find species of Acanthodes in the Upper Devonian of Scaumenac in Canada, in the Calciferous formation of S. Scotland, in the Coal Measures of England and Scotland, also in the Permian of France, Central Germany and Bohemia. Not unfrequently therefore they are companion-forms with dipnoans, arthrodires, and in the Permo-Carboniferous with crossopterygians. But so far as at present known they never transgressed the limits of the N. Atlantis continent.

The Pleuracanthidae and Cladodontidae, that make up the Order Ichthyotomi, conform in distribution to the last, except that they are somewhat later in geologic appearance. The single genus Pleuracanthus (including Diplodus) is first met with in the Lower Carboniferous of the east Scottish area and of central England, but extends its range into the Upper Coal not only of that region; it occurs in practically all the coal fields of Britain; at Commentry in France; also abundantly westward to the Ohio, Indiana, 
Illinois, and even Nebraska coal fields. Still later in the Permian beds of France, Rhenish Prussia, Silesia, and Bohemia on the east, also in those of Illinois and Texas, remains of the genus are frequent. Now over this entire area the associated organisms are freshwater, and all traces of marine organisms are absent. So the facts seem fully to warrant the conclusion that the Pleuracanthidae started in some lake or river habitat of Central Europe, during the deposition of the earlier beds of the Calciferous system, but radiated outward till Bohemia on the east and IllinoisNebraska-Texas on the West, had been peopled with at times teeming individuals belonging to some one species of the genus. For these then as for the Acanthodii, we would only repeat the closing part of last paragraph: "they never transgressed the limits of the N. Atlantis Continent."

In closing this chapter it may not be inappropriate to sum up some of the positions reached in the above inquiry.

First: Unless future discoveries in southern continental areas entirely change our present knowledge, it can be said that all existing evidence points to the conclusion that fish life originated in freshwaters of a wide northern continental mass, which by Frech and others has been called North Atlantis.

Second: This continent extended, during late Silurian and Devonian times, from W. Russia and E. Germany, to Canada and the N. E. United States. Though furnishing no evidence of high elevations (above 2000-3000 feet), nor of surrounding great ocean depths, it had a widely developed intrinsic system of rivers, lakes, and flood-plain areas that permitted gradual extension from a focal centre somewhere between N. E. Scotland and W. Russia, of evolving genera and often even of species that represented primitive freshwater fishes. So by "Old Red" and Carboniferous times or even earlier, genera like Thelodus, Cephalaspis, Bothriolepis, Acanthodes, Pleuracanthus, Dipterus, and Sagenodus had become continuous in habitat over the above continent.

Third: Most of these primitive fishes were clumsy and sluggish in response reaction, were often cumbered by a heavy bony coat of mail, and seem to have been bottom- 
feeders over muddy beds. Their remains therefore occur in continental freshwater deposits, alongside plant remains, freshwater molluscs, or freshwater eurypterids and crustaceans.

Fourth: Though from evidence yielded by plant and by invertebrate remains, a S. Atlantis and also a Gondwana continent existed in the Siluro-Devonian time, fishes do not seem to have reached either of these continents from $\mathrm{N}$. Atlantis till close of the "Old Red" or during earlier Carboniferous time. Then through some fundamental changes in the configuration and relations of these continents, connection was established with north and south Africa, also at least with part of India and the eastern part of Australia, thence onward to antarctic lands (p.136). From all of these regions freshwater fishes have been secured.

Fifth: During late Devonian or early Carboniferous times derivative species from primitive freshwater elasmobranchs-rarely from other groups of fishes-became either anadromous in habit or ultimately marine, and spread abundantly - so far as present knowledge helps usalong the shores, bays and shallower seas that surrounded the N. Atlantis continent, from W. Russia to Canadian, Wisconsin and Iowan shores. But in the early Permian period some widespread and highly destructive agency or agencies so operated as to obliterate these largely or wholly; and not till Jurassic times did a reinvasion of the sea by more specialized elasmobranchs, and such ganoids as the specializing pycnodonts, take place.

Sixth: When such connection, as is indicated under the fourth caption, had been made all of the primitive mailed fishes had already been obliterated, and only taper, fairly lithe, and scale-covered types persisted. But during mid or late Triassic times these migrated along far-reaching inter-continental freshwater channels of travel, so that they entered S. Africa, India and even Australia. Therefore alike over N. Atlantis and S. Atlantis-Gondwana, Actinopterygians like Acrolepis, Coccolepis, Atherstonia and Myriolepis, were represented by related species of each of these genera, or by genera of near affinity with each other. 
Seventh: While the evidence is as yet largely negative, it seems that fishes may not have reached the S. Atlantis continent till Triassic or possibly Jurassic times, or if they did we are still ignorant of their nature and time of distribution. If this suggestion is a correct one it might indicate that a considerable seabarrier intervened between North and South Atlantis from the Silurian or Devonian till the Triassic period; or if any connection existed it was of a temporary kind and not helpful for passage of a freshwater fish fauna.

Eighth: Great and fundamental continental changes were effected during the late Jurassic and specially during the Cretaceous epoch. Not the least important of these were the formation of a wide bridge from N. to S. America, and the widening even of the Afro-S. Atlantis bridge. During this time many species and genera evolved over N. Atlantis. These sent migrant types of evolved "ganoids," and derivative evolving teleosts southward into GuayanoBrazilian freshwaters on the east, and into Archandea on the west. Later, and during upper Cretaceous to lower Eocene time, the Brazilian groups sent migrant and largely teleostean types across the Afro-S. Atlantis bridge into West and Central Africa; while Lepidosiren and possibly other fishes,- - the former probably derived from a common African ancestor with the African Protopterus-travelled westward into Brazil and Paraguay.

Ninth: During late Jurassic and early Cretaceous times numerous derivative elasmobranch genera, as well as teleostean genera, gradually evolved from elasmobranch and "ganoid"ancestors that had all been of freshwater habitat. Some of these migrated into the sea, spread rapidly, and gave rise to the abundant marine teleostean fish-fauna that populated the shores of $\mathrm{N}$. Atlantis up to close of the Cretaceous at least. Owing to some widely destructive agency or agencies thereafter, the elasmobranch genera were in part obliterated, the teleostean very largely.

Tenth: During the mid and late Cretaceous, and from then onward through Eocene to early Miocene time, an extensive South Continent arose, that connected on the West with Andean S. America, and extended eastward till 
it united with N. Zealand, Australia and New Caledonia. Thus many western migrants spread eastward along freshwater routes, coincidentally with or earlier than, Marsupials as well as many other animals and land plants, remnants of which now occur on widely apart islands of southern seas. This connection seems gradually to have broken up during Miocene-Pliocene time.

Eleventh: Extensive intercontinental changes took place between Oligocene and late Miocene times, by which the $\mathrm{N}$. and S. American eastern bridge became sundered, and the western one at times attenuated, at times broken. The Afro-Brazilian and the Europeo-N. American bridges were widely broken up and destroyed; the Archandean continent was split lengthwise by a great fault and on the Pacific side thrown down; but owing to Andean mountain elevation proceeding, it became closely joined with the Archenchelis or Guiano-Brazilian mass.

In stating such conclusions the writer desires it to be understood that he expresses them not dogmatically, but tentatively and suggestively. He states them the more confidently from knowledge that they are more or less in line with views already reached by de Lapparent, Neumayr, Frech, Arldt and others. They also undoubtedly furnish a helpful key to many problems in the past distribution of plants and animals that have engaged the writer's attention during the past forty years, and regarding which he hopes yet to publish details. As in all scientific proenvironments, whatever of the above can stand the test of continued investigation will remain, whatever fails in this respect should rightly be forgot. 


\section{CHAPTER XVIII.}

\section{Evolution and Distribution of Fishes.}

Synoptic Review of Previous Chapters.

On this and succeeding pages the author presents, in synoptic manner, the main conclusions reached by him in the preceding chapters. These are not necessarily in the exact sequence given in the general text, but are so arranged as to give a fairly condensed, concrete, and continuous idea of the evolution of fishes.

\section{Chapter I.}

Energy, not matter, is the fundamental factor in organic as in inorganic evolution.

In the upbuilding and evolution of organic molecules, colloid constituents are essential.

In the evolution of animals up to the stage of fishes, three progressive condensations of higher or organic energy are necessary, (a) the biotic; (b) the cognitic; (c) the cogitic.

Such energies when in action start: (I) irritability, (2) nutrition, (3) respiration, (4) growth, (5) reproduction, as intrinsic properties or activities of the organism.

Organic evolution proceeds through joint action and reaction of an organism to environal stimuli. Such evolution is due to the cooperative activity of Pentamorphogeny, or the five factors of (I) heredity; (2) environment; (3) proenvironment; (4) selection; (5) reproduction.

The ecological factors that act as stimuli are: thermic, lumic, chemic, electric, geotropic, (or geotactic), hydrotactic, and organismal stimuli.

A detailed study of the factors of Pentamorphogeny is then given.

CHAPTER 2. Geologic conditions in relation to the evolution of fishes.

During primitive evolution of metanemertean, protochordate, and chordate organisms, the earth's crust long 
remained soft, plastic, and adaptable to local weightings. Thus neither high mountains nor great ocean depths existed, but oscillations between land and water were frequent. So wide areas now submerged were then continuous. Extensive rivers, flood plains, lakes, and marshes were thus formed, while diastrophic and seismic changes were frequent and extensive. "Delta" conditions have been greatly overestimated geologically and palaeontologically.

Organisms probably evolved first during the mid Archean or Protobiotic stage of the earths history; while Archean to Lower Silurian deposits in total thickness about equal the combined thickness of succeeding formations.

The earliest organisms, as well as the ancestors of the leading groups of plants and animals, all evolved in fresh or inland waters, while migration seaward was a later event for many. The anadromous habit therefore of sea lampreys, sturgeons, salmon and many others is a true index to the ancient environment of fishes.

For accurate conclusions as to the evolution and environment of fishes exact record of every finest and changing rock film should be made. When such is done it appears often that definite, even though thin, rock strata may extend over hundreds or even thousands of square miles of territory.

Some of these beds, known as "bone-beds," "oil-shales," etc. are now well known from the Silurian system upward to Pleistocene age. It is in the Silurian, and specially Upper Silurian, system also that fish remains are first definitely recognized.

Wherever such beds, with rich remains, occur, there or in close proximity to them abundant supplies of petroleum are often discovered.

Volcanic dust showers, seismic changes, faulting and folding of the earth's crust, hot-spring discharges, and other agencies, caused death and entombment, often of myriads of fishes, which on decay yielded the fish oil from which petroleum has come.

A comparison by Baird and Goode of the destruction wrought in a season amongst Menhaden fish (3,000,000$000,000,000,000)$, would account for more oil than is rep- 
resented in the total yield of petroleum $(234,9$ I $7,043,3$ I 2 gallons) throughout the world up to I9I4. Fishes are the only organisms and the only sources from which such an oil and petroleum supply could be obtained.

With the probable exception of fishes which had migrated seaward in the Carboniferous Limestone period, all the earlier oil supplies up to late Jurassic or even early Cretaceous time, were derived from freshwater forms, The researches of Warren-Storer, later of Engler and of Day, clearly prove that all the important petroleum products can be obtained, from fish-oil alone, or from it when heated in presence of lime or wood, or other substances.

Chapter 3. The evolution of fishes from invertebrates.

In detailed study of the Metanemertinea and their descendant groups the Hemichordata, Urochordata, Cephalocordata, and Chordata, comparison is made of the relative size and shape, of the color, of dermal structures including glands, thread cells, dermal scales or plates, and stylet teeth. A review of the sense organs of the head is then made. In study of the mouth and alimentary canal, emphasis is laid on the homology between the attachment line of the proboscis with its sheath in metanemerteans, and the velum or velar membrane of vertebrates. Like emphasis is laid on the homological continuity of at least a part of the highly glandular mid-oesophagus of metanemerteans, and the endostyle, hypopharyngeal groove, or thyroid gland of chordate animals. Homological continuity of the median forward diverticulum from the gut in metanemerteans, with the similar simple organ that is the liver of Petromyzon and Lepidosteus, and with the bilobed or trilobed liver of higher fishes is indicated. The apparent formation during embryonic life, of the mesoblastic mesenteries is traced.

The relations between the parts of the proboscis and proboscis-sheath of Metanemerteans, and the notochord, pituitary body, horny teeth, and associated parts of chordate animals, are followed out.

A correlation of two pairs of brain-lobes in metanemerteans, with the corresponding primitive lobes in Dipnoi, 
as traced by Kerr, leads up to the more complex brain of elasmobranch and ganoid fishes. The dorsal, the lateral, and the ventral pairs of nerves in metanemerteans are regarded as originating Reissner's fibre, the two lobed mass of the spinal cord, and the sympathetic system of fishes and other chordates. So in this as in various other details of structure, the Urochordata and Cephalochordata are evidently degraded and derivative groups. In study of such sense-centres as the nasal sac, the paired and unpaired eyes, the auditory organs and related structures, these are reviewed in light of the Author's published statements in "Causes and Course of Organic Evolution."

The blood-vascular system not only shows numerous points of homological resemblances, Dendy's microscopic study of the walls of the vessels of metanemerteans reveals like structural details with those of chordate animals.

In considering the excretory system the writer seconds the earlier views of Dendy and Spencer that it and the vascular system probably had a common origin, and that gradually the functions of oxygen and food conveyanceor the anagenetic function-was assumed by the main vessels, while that involving removal of the effete products -or the katagenetic function-was assumed by the finer and terminal tubes. So the derivation, in succession to the archinephros, of a pronephros, a mesonephros, and a metanephros is sketched.

Graded transitions are traced for the reproductive organs from metanemerteans through cyclostomes and amphibians as one line of evolution, and through ganoids to teleosteans as another line. Holoblastic segmentation of the egg in metanemerteans, Amphioxus, Petromyzon and some higher fishes, and evolved meroblastic in Myxine and in other groups of higher fishes are compared.

In embryonic development five mesoblastic cell-plates arise during "direct" development in metanemerteans and Amphioxus, or two rather irregular plates-regarded by the writer as due to fusion amongst the five-arise in Petromyzon and other fishes. These originate the mesoblastic tissue of the adult. 
ChApter 4. The physical and biological environment of fishes during the Silurian and Devonian periods.

After review of earlier writings on the Upper Silurian of Central England the author concludes that the abundant primitive fish remains, crustaceans, eurypterids, and the alga Pachytheca are a freshwater association, and that marine organisms are wholly absent, the broken shells of Lingula etc. being wash-outs from older deposits. The Downtonian beds of Scotland, of W. Russia, of S. Norway, of $\mathrm{E}$. Canada and of Pennsylvania are similarly regarded. Their fish remains, including many "conodont" organisms, were primitive types derived from evolved metanemertean ancestors.

In study of the Devonian rocks fish-life is shown to have inhabited only the wide river, flood-plain, lake and swampy areas whose deposits were known as the Old Red formation. Descendants of primitive Upper Silurian fishes swarmed in these retreats, and have left their remains as teeth, scales, plates, or spines. Sudden and wide-spread destruction also of these-specially in the Upper Old Red period-gave rise to the bone-beds, fish-beds, and petroliferous shales of the Old World and the New.

In these Old Red freshwater deposits ancestral types of the Cyclostomata, the Elasmobranchs, the Dipnoans and the Ganoids were abundant. None are met with alongside marine organisms in marine beds of the period. Comparison also of Old Red remains from W. Russia, Bohemia, Britain, Hudson's Bay, Ellesmere Land, and westward to Iowa, and at least from Australia southward to Antarctica, shows that like genera and identical or nearly allied species extended over freshwater areas that must have reached almost from Pole to Pole.

ChApter 5. The physical and biological environment of fishes during the Carbo-Permian periods.

The Calciferous or Lowest Carboniferous beds of Scotland are shown to be almost wholly of freshwater origin, and in their strata-oil shales, freshwater limestones, shaly sandstones etc. - to contain remains of abundant plants, 
eurypterids, crustaceans, freshwater molluscs, and abundant fishes. While the mailed fishes of earlier periods had largely died out, a prolific dipnoan, elasmobranch, and ganoid series stocked the freshwater areas. Sudden destruction of great masses of the fishes by diastrophic, volcanic, and other physical agencies, gave rise to free fish-oils that were deposited with argillaceous, calcareous, or siliceous particles to form the extensive beds in which, by transformation of the oil, petroleum is now obtained, alike in the Old and New Worlds.

The beds of corresponding age, namely the HortonAlbert and the Lower Mississippian in Canada and the Eastern or Central States, show similar geologic and palaeontologic details to the last. But gradual migration seaward of elasmobranch genera was now proceeding, and so originated the marine elasmobranch life of the next higher or Carboniferous Limestone or Upper Mississippian period. This is further discussed in Chapter 9.

The Coal Measures or Pennsylvania beds of the Old and New Worlds are very largely of freshwater origin, and so enclose evidences of an often teeming flora and fauna. The remains of the former where appropriately deposited originated coal. The latter include great aggregations of crustaceans, arachnids, insects, freshwater molluscs, dipnoan elasmobranch and ganoid fishes, as well as numerous species of amphibians.

Where fishes abounded in the lakes and swamps that were forming coal, and were killed in masses, the product became a cannel coal. But where as in Kansas, Oklahoma, and Texas fish destruction was effected on a great scale, there petroliferous shales were formed.

The migrant elasmobranchs which had invaded the sea seem largely if not wholly to have been obliterated by close of the period. In transition to the Permian profound physico-geologic changes were proceeding that largely altered the rocks, the flora, and the fauna. So a mixture of palaeozoic and mesozoic types occurs. Volcanic activity was frequent and widespread also, throughout the Old and New Worlds. This may in part account for the obliteration of marine fishes, and for their great diminution even in 
freshwaters. The striking Permian deposits of France, of Bohemia, and of Texas with their floral and faunal features are specially referred to.

ChAPTER 6. The physical and biological environment of fishes during Triassic-Jurassic time.

The Triassic formation reveals frequent and at times alternating deposits of freshwater and marine character, some of which are treated of. In the marine deposits fishes, amphibians, land plants and other ecologically related organisms are absent. In the freshwater deposits a varied and abundant fish-life is revealed. But the ganoid fishes are now predominant, while the elasmobranch and to some degree the dipnoan types are rarer.

Comparison is made of the British. Austrian, Italian and Eastern States fauna. While the last has been regarded by Newberry and successors as freshwater in origin, they and European palaeontologists have viewed the others as marine. The writer shows that all were closely similar in origin and were freshwater organisms. The rich fishbeds and the associated petroliferous products are correlated with extensive and active volcanic and diastrophic changes. The wide development of the system from Texas down to extreme southern parts of South America indicates far reaching continental deposits.

The nature of the beds, and the organisms-especially the fishes-that make up the Karoo series of S. Africa, the Triassic of India, and the Gosford-Hawkesbury beds of Australia are considered, and comparison is made of the types of fish-mainly freshwater ganoids-that occur in these.

The Jurassic system is of interest as showing in its upper beds proof of a commencing remigration of Elasmobranchs, and also a primary migration of gano-teleostean fishes into a marine environment. This result was a summated biologic reaction to frequent sea encroachments, to reduction in some regions of lake and flood-plain areas, to aggressive action of increasingly larger land and freshwater reptiles, to increasing perfection in defensive and even more 
in offensive action of some species of fish, also to the rich stores of invertebrate food obtained in the sea.

The Jurassic deposits that are mainly or wholly freshwater, and those that are marine, are distinguished, their faunal types are compared, and fishes that show anadromous tendencies, or that become marine are noted. The prevailing types of fish belonged to the dipnoan and ganoid divisions. These wholly inhabited freshwater, or some highly specialized ganoids were migrating seaward during the later Jurassic. The marine elasmobranchs however were again becoming dominant fish forms.

The remarkable Solenhofen-Eichstadt "lithographic" beds, and their strangely heterogeneous freshwater-marine organisms are studied, while all of the species of fishes are listed after Walther's extensive observations and records.

In summing up the entire evidence for the period the writer concludes "that all of the great groups of fishes continued as inhabitants of the lakes, rivers and swamps throughout the Jurassic and into the Cretaceous, except for genera of the rays, the dog fishes, probably some of the Pycnodonts like Coelodus, also more doubtfully a few 'ganoid' genera like Hypsocormus and Aspidorhynchus. But even the earlier species of Hybodus and Acrodus that occur in the Lias and Stonesfield Slate, were still largely lake dwellers."

But from Souabe he cites one amongst such cases, where a mixing of freshwater and marine rocks along with the organisms peculiar to these, has caused loose and erroneous statements to be made.

The extension of Jurassic (Upper Liassic) beds into Central Siberia, India, and Australia, also the presence in these of freshwater fish genera and other organisms, that are identical in some cases with those found in Western Europe, are proofs that considerable connection now existed between the great northern and southern continents of that time.

CHAPTER 7. The physical and biological environment of fishes during Cretaceous time.

This is viewed as an important stage in the earth's history. "For all accumulated evidence combines to show 
that a great and varied extension of elasmobranchs into the sea now took place. It also emphasizes the view that the Dipnoans, most of the Holosteans, the Chondrosteans, and most of the 'ganoids,' as well as many of the derivative Teleosteans remained as freshwater dwellers. Here also it may be observed that the only genera of the fishes which occur in Jurassic strata and have come down through the Cretaceous to our own day in living representatives are Rhina, Rhinobatus, Notidanus, Cestracion, Pristiurus, and Ceratodus," all of which had apparently become thoroughly marine by the beginning of the Cretaceous, except Ceratodus which persisted throughout in freshwater. Frequent continuity stratigraphically with Purbeck beds is accepted, and a parallelism is drawn between Cretaceous beds of the Old and New Worlds. The tremendous volcanic activity then proceeding is evidenced by the Deccan traps of India, and the Laramide beds of the Western States. Such activity must have affected the whole earth. As a partial result, commencing upheaval into conspicuous mountain chains, and depression into ocean depths now started. Such favored rapid evolutionary changes. The commencing Jurassic migration of various selachian, cestraciont, pycnodont and pachycormid fishes into marine surroundings was now added to, owing to like migration of teleost derivatives from more primitive ganoids.

The nature of the rocks, and the enclosed organisms found in Wealden and in successively higher strata of the system indicate that derivative marine fishes-mainly elasmobranch or teleost-were gradually becoming more numerous than freshwater types, and so occur now abundantly alongside typical marine invertebrates. Further, while amphibians are wholly unrepresented in the latter beds, giant saurians that had passed seaward during Jurassic time are common, and had largely aided probably in driving groups of fishes seaward also. While dipnoan and ganoid fishes still abound in freshwaters, a small and steadily specializing ganoid derivative line passed seaward as the marine pycnodont fishes, and these so persisted till their extinction in Upper Eocene time. With them were derivative teleost forms "from the Eugnathidae, Pachycormidae, 
Aspidorhynchidae, Semionotidae, and Leptolepidae." But in freshwaters "abundant representatives of the Semionotidae Pholidophoridae, and Leptolepidae," became progenitors of our existing freshwater teleost groups. The transition types shown between some of these are discussed in their structural details.

It thus results that great marine deposits like the Benton-Niobrara enclose a rich and characteristic fauna, chief amongst which are elasmobranch and teleostean fish remains Great freshwater deposits also like the Laramie proclaim equally clearly their formation over continental areas, while the fish remains in these are well known. On the land also a striking mammalian fauna existed. From the oil shales therefore of Central Europe, and from the Lower Benton or Mowry shales of N. America come great supplies of petroleum derived from marine Cretaceous fishes. And from the great masses of Laramie shale come the Cretaceous freshwater supplies of the Central western States. The fish-bearing strata of Westphalia, the Sussex beds of England, and the Sahel-Hakel beds of Lebanon are also reviewed.

CHAPTER 8. The physical and biological environment of fishes from Eocene to recent time.

The pronounced volcanic and sedimentation changes that proceeded during the last period were largely continued at intervals now, and seem to have reached a climax during late Miocene time. Solidification, thickening, and faulting of the earth's crust also, aided by volcanic action, gave rise to the great ridges that, after denudation and earth sculpture, now form our main mountain chains. By damming up of water courses, by elevation of coastal mud areas, and related changes meanwhile, those large lakes and wide flood-plains arose, the deposits of which can readily be traced.

During the oldest or Eocene epoch thick freshwater as well as marine beds can be traced over wide areas of existing continents. Alike in Europe and America flowering plants and not least dictoyledons have left their remains often alongside lake mussels, insects, ganoid and teleostean 
fishes. Lepidosteans were then abundant from Wyoming to Germany. The Green River shales of the States, the Bituminous schists of East Brazil, and corresponding beds of Europe had a fauna that showed much in common.

But a striking fact is that the genera of Cretaceous teleosts were practically obliterated, and a new set of Eocene types-evolving largely apparently amid the great $\mathrm{N}$. American lakes, spread abroad to replace those destroyed. A like obliteration of marine genera also occurred. But as already noted quite a number of Cretaceous elasmobranch genera-about I 5 in all-persisted to our time.

The great "nummulitic sea" stretched at this period across Europe and Central Asia on to Japan at least, and received heavy nummulitic limestone deposits. Of recorded Eocene teleost fishes 52 genera are wholly or largely freshwater, and 47 genera are purely marine. There is clear evidence then of two successive teleostean migrations from a freshwater to a marine life. First "from freshwater ganoid ancestors, belonging to Pachycormidae, Aspidorhynchidae, Pholidophoridae and Leptolepidae, originated the late Jurassic or Cretaceous families Saurodontidae, Holosauridae, Enchodontidae and others. After these were largely blotted out at close of the Cretaceous, a new seaward migration of Clupeidae, Aphredoderidae, Percidae, etc. then took place. During Oligo-Miocene time varying elevations and depressions of land occurred. S. America and Africa, also Europe and N. America, which had hitherto been connected by a southern and a northern bridge, became sundered. Of deposits rich in organic remains, the great east-west Oligo-Miocene group of strata, that stretched from France through Austria, Bulgaria, the Caucasus, and S. Asia to Japan, was a marine group that included several important fishbeds-the Amphisyle, the Meletta (or menilite), and at least two others higher in position. Great supplies of petroleum are now got from these. Suess suspected that the vast accumulations of fossil fishes, and the oil of the fish shales or of nearby porous rock, might be explained by origin of the latter from the former. The fishes and petroleum were here again marine. But numerous areas in Central and S. France, in N. and S. Italy, in 
Switzerland, in Bohemia, in N. America, in Sumatra and elsewhere, show oil shales with piled together fish remains, that are renowned as petroleum producers. These beds also often include or adjoin strata with land plants, insects, frogs, tortoises, etc. Heer's graphic description of the Oeningen locality is specially noted, and from his accounts it seems likely that the deposit is a volcanic dust.

Comparative tables of the freshwater and marine fishes of these beds are then presented.

\section{Chapter 9. The Primitive Fishes in time and space.}

Review is next made of the occurrence and relation of the primitive fishes. The author divides these, as well as the higher fishes, into three groups, the Malacodermata, the Placodermata, and the Lepidodermata. The first includes the Cyclostomata and Palaeospondylida. To the former of these the writer would asign many "genera" of the conodonts found in rocks from Silurian to Carboniferous age. They occur usually side by side with other and higher fish remains from Russia to N. America, and from their often teeming abundance indicate a prolific conodont fauna.. Reasons are given for regarding many of these as true cyclostome teeth. From its structure Palaeospondylus is placed near the Cyclostomata.

Account is next taken of the types that make up the seven subdivisions of the Placodermata, and their destruction in time and space is traced. Evidences are advanced for viewing all of the ancestral forms of these as lake, river, or marsh dwellers. The seventh subgroup of Microplacoda or Elasmobranchii is viewed as probably derivative from genera like Birkenia or Lasanius. Types like or related to these seem to have evolved the Acanthodii, the Cladoselachei, and the Pleuracanthii, of all of which however the remains often consist only of teeth, spines, or scales. The included genera were all freshwater, and persisted more or less from Lower Old Red to Permian days. Their remains occur also alongside the giant arthrodires and other cuirassed fishes in Old Red Strata. Evidence is again advanced in support of the view that in early Carboniferous time a considerable seaward migration of 
elasmobranchs took place. The studies of Young, Davis, and Hind in Europe, also Newberry, Worthen and others in America are considered. It is concluded therefore that though some species remained wholly in freshwaters, others became anadromous, while a considerable number became marine. So though petroleum products had hitherto been derived wholly from Silurian and Old Red beds, supplies from S. Illinois at least seem to come from the Carboniferous Limestone series and from marine elasmobranchs.

So the writer sums up conclusions regarding Carboniferous fish life thus: "on a conservative basis it appears that there were at least 55 genera and 360 species. Of these about 20 genera and close on Ioo species remained as freshwater or anadromous species, the remainder became largely or wholly marine." The freshwater ones show westward extension also to Iowa, Missouri, and probably also to Nebraska and Kansas.

But after deposition of the Coal Measures beds, some widespread set of events blotted out the elasmobranchs wholesale, for only 5 freshwater genera-Acanthodes, Pleuracanthus, Diplodus, Janassa, and Wodnika-survived, though in greatly reduced number of species. The inland freshwater types then alone persisted till Jurassic time, when a reinvasion of the sea took place.

From papers by Roche, Fritsch, Cope, Hussakof and others, the history of the surviving freshwater Permian forms is traced, and the extension of some of them even to Australia is quoted from Woodward. The cestracionts Acrodus and Hybodus of Upper Permian beds, seem to have been the most abundant and persistent types of freshwater elasmobranch that lived on till Cretaceous time. When reinvasion of the sea was made during the Jurassic period, the Notidantidae, Scyllidae, Rhinidae, and Rhinobatidae, all primitive groups of Rays, also Palaeospinax and Cestracion, became the marine types, and have existed there till present time.

Chapter io. The Dipneusti and Crossopterygii in time and space.

Next to the Cyclostomata the former is regarded as probably the most primitive, continuous, and least variable 
group in the entire range of fish life. Such is in line with Kerr's emphasis on "the numerous primitive characters observed in living genera." All evidently evolved in, and have remained till now in freshwater areas. As in the case of other groups already reviewed, the earlier or Palaeozoic forms spread by degrees from their probable ancestral evolutionary centre in the east part of the Eria or Atlantis continent, and from the Old Red period onward till they had reached Iowa in the west, also by some Atlanto-Gondwana bridge to Africa, India, and Australia. If moreover East's view be accepted that the scaleless arthrodires are Dipneusteans-as seems likely-then also if the oldest known fragments of Coccostens are correctly diagnosed, it follows that these existed during the late Silurian period. Similarly if the view be accepted that the scaled types or Dipnoi evolved from more primitive organisms that combined characters of the Silurian Birkenia with those of primitive Pleuracanthidae, these also would date back to the Silurian.

The earlier and smaller arthrodires like Coccosteus, of Lower Old Red strata, seem when traced from Europe to America and when studied there in ascending strata up to the topmost Old Red beds, to increase in size and to assume the characters of the giant Dinichthy's of Ohio and other central states. The abundance of these and contemporary fish-groups in Upper Old Red rocks seem to have originated the petroleum supplies of the Cleveland Shale and related beds. Eastman's valuable lists of fishes for New York, Iowa, and elsewhere are referred to. The scaled Dipneusti or Dipnoi (lung fishes of modern times) are abundant Lower Old Red fossils. Dipterus as a primitive genus spread probably from Central Atlantis or Eria, till the area from Russia to Central N. America was invaded in its rivers and lakes. More recent genera like Ctenodus and Sagenodus of Carboniferous age, connected with Gosfordia of Permo-Triassic lake life; while the world range was extended by degrees till Australia at least was reached.

Ceratodus again continued the group biologically from Triassic upward to Cretaceous days, while the very close resemblance of it to the living Neoceratodus of E. Aus- 
tralia, compels us to accept that after spreading over African, Indian, and Australian lakes and river swamps, the group gradually became restricted to Australia and Africa, while from one of the African species of Protopterus that had migrated westward across the Afro-American bridge Lepidosiren may have evolved. Ceratodus however seems to have lingered on in N. America, till at least the close of the Cretaceous, if the fragmentary specimens described by Cope are accepted in evidence.

The crossopterygian ganoids are viewed as a decidedly higher and more evolved group than any of those just treated of, specially in their endoskeletal and cephalic complexity, in their advancing ossification of the notochordal tube, in the perfectioning and attachment of the paired and unpaired fins, and in a higher type of respiratory interchange.

They are viewed as an intermediate offshoot between primitive dipnoan and pleuracanth forms that probably started in late Silurian times. Their close association with Palaeospondylus, with Dipneustean, and with Elasmobranch species, as shown by the records of Agassiz, Flett and others, in lakes of Old Red age, and their total absence from marine beds, proves that all had evolved in continental centres. Distinct evolutionary advance is observed in the genera through Mid Old Red rocks till Holoptychius, Bothriolepis, and allies are met with in the Upper series. But the distribution in space by that time is arresting. For evidently originating in eastern Atlantis or Eria during the late Silurian period, they had spread by degrees westward to central N. America as well as southward to Australia and Antarctica. But the exact line of advance southward-though probably by Australia-has yet to be accurately determined.

Just as change from Lowest to Uppermost Old Red beds presents totally new assemblages of species and even genera of Crossopterygians, so in transition to the Carboniferous, new and more specialized genera like Rhi odus, Strepsodus and Megalichthys appear. But all of these inhabited quite distinct as well as freshwater areas, compared with those from which Davis, Worthen, Traquair and 
others have listed marine elasmobranchs. Occasional mixing of records however, or mistaken identification, by some authors, are recorded, and such have given rise to incorrect conclusions. Generic continuity of life conditions from Carboniferous to Permian is proved by the presence of Megalichthy's and Coelacanthus in lower, or even in upper Permian rocks of Germany, England and Texas.

But new and more evolved genera-at times however devolving ones-continue the group to Triassic and on even to Jurassic age, alike in the Old and New Worlds. All of these, like Diplurus, Heptanema, and Undina were freshwater dwellers. But while the New World fishes have been so accepted, the mistake has been made of regarding those from the Austrian and Italian bituminous strata as marine. All resembled each other in their environal habitat.

One genus however, Macropoma, according to all present evidence either became wholly marine by the time of the Lower Chalk, or if anadromous it seems to have been more abundant in marine than in estuarine or fresh waters. The only surviving genera Polypterus and Calamichthys of Central Africa are lingering remnants of a once large, but now disappearing group.

Chapter I I. The Chondrostei and Holostei in time and space.

The above two groups of ganoid fishes "rank next in time of appearance and structure to those already" reviewed. For the occurrence of only one genus in Old Red rocks, the more perfectly ossified skeleton, the usually heterocercal or homocercal tail fin, are in part confirmatory. After short reference to the distribution of the four or five living genera of Chondrostei and to the pioneer Old Red genus Cheirolepis, the numerous genera of Calciferous or lower Mississippian age like Elonichthys, Acrolepis, and others are invariably freshwater, as already emphasized. So they are absent from marine lists. The fact that these and the older Cheirolepis are known from North Britain to Russia, and that their modified descendants appear chiefly in higher and later coal beds of Canada and the States, also in the $\mathrm{Karoo}$ beds of $\mathrm{S}$. A frica, indicates that the same lines of 
distribution were followed, as by the more primitive fishes already examined. But in the early Permian palaeoniscid life received a severe check, and most genera were apparently obliterated, owing to combined xerophytic and volcanic action. Thus Amblypterus and Pygopterus appeared and again disappeared during deposit of this system. Other and doubtless descendant genera like Centrolepis and Coccolepis first occur in Lower Lias beds, and the latter persists into beds of the Kimmeridge Clay. Special interest attaches to Coccolepis australis found in the Talbragar beds of $\mathrm{N}$. S. Wales, that are regarded as of Jurassic age. Woodward says of the fishes: "these are crowded together in shoals as if suddenly destroyed, and very few of these have become disintegrated before fossilization." Here as in many other like cases the author considers that they were killed and covered over by volcanic dust.

From the more ancient Palaeoniscidae, the divisions Platysomidae and Catopteridae seem to have diverged, as evolving types during the Carboniferous and on to Liassic days. These also have representative species distributed from Connecticut and Virginia on the west, to Austria and thence even to S. Africa and N. S. Wales. Elipsopholis of Woodward seems to be a highly modified and far-travelled type, which like the others lived in freshwaters. The liassic genera Chondrosteus and Gyrosteus show affinities with modern sturgeons, and along with scant remains of Acipenser in Coenozoic (Neobiotic) strata, connect the ancient chondrosteans with existing sturgeons. Species of the last are still largely freshwater, others are anadromous, but none are strictly marine. All however ascend rivers in order to spawn, an ancestral habit that is powerfully retained.

The recent and wholly freshwater genera Scaphirhynchus and Kessleria, that are known as the shovel-nosed sturgeons are now found in rivers of $\mathrm{N}$. America and of Central Asia. This indicates a former land connection between the two continents, a position that abundant distribuional facts verify. They are probably a divergent and specialized offshoot from primitive sturgeons. But there also segregated off from small primitive sturgeons, the 
spoonbill sturgeons, of which Crossopholis and Pholidurus are ancient types, Polyodon and Psephurus are recent. Their distribution resembles that of the previous group. The Holostei start with a few representatives like Acentrophorus in Permian time, and as a probable offshoot from more ancient chondrosteans. They attain their climax however in Mesozoic lakes, rivers, and swamps. All of the holostean families had already become differentiated before the period of the Lower Oolite, except the modern Lepidosteidae and Amiidae. During the Triassic numerous genera and species evolved and spread abroad from Connecticut to France, Germany, Austria, N. Italy, S. Africa, India, and East Australia. Such suggests some fairly easy and connected line of travel, that linked up these geographic centres. But there is considerable evidence to indicate that Neorhombolepis, Belonostomus and some others became marine livers, if the "Chalk" strata in which they occur are truly sea deposits. Two holostean subgroups however gradually became pronounced sea fishes. One of these, the Pachycormidae, started with such large lithe freshwater forms as some species of Pachycormus, includes such a transition genus as Hypsocormus and developed into types like the marine Protosphyraena, that might well be called the "ganoid shark" of the Chalk formation.

The other of these, the Pycnodontidae started in the Jurassic with freshwater genera like Gyrodus, but ultimately they condensed, as they migrated seaward, into short rounded marine fishes like Coelodus and Palaeobalistum of Upper Cretaceous and Eocene strata.

The holostean group Amiidae seems to have descended from the more ancient Eugnathidae during later Jurassic time, and amid lakes or swamps of Central Europe. But in late Cretaceous or early Eocene time and onward they reached and rapidly multiplied in the extensive lake-river system of N. America. Here the one species Amia calva is found. Reference is next made to the Aspidorhynchidae of the calcareo-bituminous rocks of Cerin and Solenhofen -both probably of volcanic origin. The abundance of fishes in the strata of Cerin evidently explains the mode of origin of the "bituminous schists" of that region. A list 
of these fishes is given from the elaborate "Thiolliere" memorial volume. The holostean group Lepidosteidae probably evolved amid the great Cretaceo-Eocene lakes of $\mathrm{N}$. America, migrated eastward into Central Europe in late Eocene time, died out in the latter area in the late Miocene, but now persists in three or four species that are scattered from the North-Eastern States to Mexico.

The gano-teleostean genera that form the division Isospondyli are undoubtedly the highest of the series, as they are also the latest to appear. They, along with the already advanced members of the previous division-the Protospondylii-must have stocked abundantly the rivers and lakes of Upper Triassic age in Europe, Asia, Africa, and even Australia. A striking feature however is that the earlier and more primitive Isospondyli are wholly absent from the American continent, so far at least as we at present know, though the individuals of such genera as Pholidophorus and specially Leptolepis must have swarmed in countless numbers over inland waters of the above continents.

Chapter I2. The soft-finned Teleostei in time and space.

It is postulated that since primitive ganoid ancestors of the Teleostei were, and remained as, inhabitants of freshwaters, the descendant soft-finned teleosts must have originated amid like environment. The entire history of the group demonstrates this. Further the ancestral ganoteleosteans early split up into two evolving and diverging lines. The older of these that wholly or largely retained soft fin-rays have had the convenient term retained of Malacopterygii, the newer and more evolved is called the Acanthopterygii. The former includes the largest number of existing freshwater teleosts. These all retain the soft fin-rays, the positions of pectoral and pelvic fins, the frequent cycloid scaling, the degree of ossification, and other inherited ganoid characters. The Acanthopterygii, that have become largely marine, show change and advance on these characters. It is again emphasized that the South American, and to large extent the North American conti- 
nents yielded few ancestral isospondylous ganoid types, which are evidently Old World in origin.

The probable ganoid forerunners of the earliest teleosts are Leptolepis and Thrissops, both abundant freshwater fishes from Upper Lias on to Cretaceous days. These also are close allies of Chirocentrites and Spathodactylus of European Lower Cretaceous beds. But Chirocentrids must early have reached a marine environment, and then spread abroad widely, for such bulky Upper Cretaceous marine genera as Portheus, Ichthyodectes and Saurodon are known from Europe, America, and even Australia.

The relation between freshwater and marine teleosts is then discussed, and the presence by migration of masses of the former in Cretaceo-Eocene Lake-beds of North America is explained. So in early Eocene time we can look to the North American continent as a great centre for evolution of new species and even groups.

The family Characinidae with its offshoot Gymnotidae, also the Cyprinidae, the Siluridae, and Loricaridae are then studied as to their evolution and distribution in time and space. Tetragonopterus is viewed as the earliest known fossil representative of the first, Amy zon and Leuciscus of the second or Cyprinidae. This family now comprises upward of 200 genera and 2000 species of the North Temperate zone, and so, "is the largest of all the families of fishes." From earliest origin in the western lake area of North America, during late Cretaceous time, they seem to have spread into Europe during the Eocene period, also northeastward into Asia about the same time. Connection of $\mathrm{S}$. Europe with N. Africa during this or Oligocene time, permitted passage also into N. Africa. Such distribution for Cyprinidae is amply verified by like parallel distribution for other freshwater teleosts. The family seems to have attained its climax of development and abundance in the Miocene age, and in such genera as Tinca, Leuciscus, Rhodeus, etc.

The sub-group Homalopteridae, like numerous other cited cases, is now found in mountain streams of India to Borneo, owing doubtless to diastrophic elevation of land as well as of lakes in which the fishes were, during Oligo- 
Miocene time. As in the case of marine migrants, and owing to like constant agitation of water with resulting high oxgenation of blood, the air-bladder inherited from ganoid fish ancestors has become small or is even wholly absorbed.

The Siluridae, with derivative families Loricaridae and Aspredinidae, that include fully I 50 genera and 1200 species are lake and river dwellers chiefly of subtropical and tropical regions. But while the genus Arius in its early Eocene and Oligocene history was also, some species gradually migrated seaward, so that the modern species as well as the genera Galeichthy's and Felichthys are marine. The same history attaches to the group Plotosidae of East Asia. Genera of the aberrant families Loricaridae and Aspredinidae inhabit like localities and show all stages of reduction up to absorption of the air-bladder. The writer therefore concludes from the evidence furnished by the above families and derivatives from them, that all teleosts have evolved from, and are descendants of, freshwater ganoid ancestors, and so that the most primitive teleostean families-which are also the families richest in species-are the existing soft-finned ones. Amia is regarded as one of the nearest existing genera to the required ancestral form of some.

From a different but related ancestor like Megalurus of Kimmeridgean age, Elops and Megalops seem to have started and migrated seaward. But the young and even adults still enter rivers freely.

From forms intermediate between Eugnathidae and Amiadae the Albulidae and Osteoglossidae arose, the latter still keeping to swamps and lakes, the former marine. The relations of Istieus, Albula, and Pterothrissus amongst Albulidae; also of Dapedoglossus, Osteoglossum, and others amongst Osteoglossidae, are traced geographically.

The Notopteridae, Pantodontidae, Phractolaemidae, and Hyodontidae, show interblended affinities with Osteoglossidae, and doubtless had common ancestral origin. Distribution of these over Gondwana land is traced.

Thrissops, Chirocentrites, and Chirocentrus polyodon of Sumatran freshwater strata, are all early forerunners of the types that migrated seaward, and there originated 
numerous marine Cretaceous to Miocene genera like Portheus, Ichthyodectes, and more recent derivatives.

The origin of the Clupeidae from ancestral Jurassic Leptolepidae, and the gradual splitting up of the genera into a freshwater series that is typified by Diplomystus, also into a derivative marine group that is typified by Clupea, proceeded from early Cretaceous time onward. In contrast to Osteoglossidae, but resembling Cyprinidae, the Clupeidae remained largely a North American family, but migrant marine outliers passed gradually down the coast to $\mathrm{S}$ America, and later across even to India and $\mathrm{New}$ Zealand with other groups.

The closely allied family Salmonidae is in fullest sense a freshwater and Northern Hemisphere group, that probably evolved from an early Eocene stage onward, and from a freshwater clupeoid ancestry like or allied to Diplomystus.

The most primitive genera structurally are freshwater or anadromous, the few marine ones are the more evolved. Like all primitive freshwater teleosts the air-bladder is well developed. But in a few marine offshoots and in the derivative marine families Gonorhynchidae, Cromeriidae, Stomatidae, and Alepocephalidae, the air-bladder is rudimentary or absorbed.

In study of the Haplomi or Esociformes the families Galaxidae and Aplochitonidae are viewed as connecting and freshwater alliances that unite the families already examined with the more evolved teleosts. A detailed study of both families, specially from the standpoint of their striking distribution, is reserved to a future chapter.

But regarding other Haplomi these are first traced in early Cretaceous marine strata, and in the families Enchodontidae. Scopelidae, and Chirothricidae, whose derivation from more primitive and probably Jurassic freshwater ganoids has still to be unravelled. But after suffering extensive destruction, toward the close of that period, surviving descendants multiplied in freshwater centres as the Esocidae, Dalliidae, Cyprinodontidae, and Percopsidae, also in the sea as the Scopelidae, Aleposauridae, and allies. In succession the Heteromi, the Catosteomi, and Anacanthini are studied along lines that parallel those pursued above. 
And throughout it is shown that freshwater teleosts are nearly always the primitive and environally ancestral groups, while the marine ones are derivative and more evolved.

Chapter r 3. The spine-finned Teleostei in time and space.

Study of these recalls Jordan's observation that in Sticklebacks an increasing number of fin-spines develops as these pass from a freshwater to a marine environment. In transition from certain of the soft-rayed to the hard or spiny-rayed teleosteans the writer accepts such a series as the Clupeidae, Salmonidae, Percopsidae and Berycidae as furnishing needed types. Thus Diplomystus, Salmo, Percopsis, Acerina and Aphredoderus among living forms; also Asineops, Erismatopterus and Trichophanes amongst fossil ones, are strikingly graded in series. But in process of evolution three divergent lines of modification seem to have arisen. One ended in the highly specialized Pantodon of IV. Africa; a second became marine as the Ctenothrissidae; a third and highly important one led from Percopsis and Columbia through the Aphredoderidae to the Percidae or perches. These are illustrated in their transition details.

The Percidae and nearly allied Centrarchidae seem, in early Eocene time, to have sent off into the sea the two marine alliances the Beryciformes and Scombriformes. But meanwhile the large families Cichlidae, Nandidae, Serranidae, and Lobotidae developed in lakes and rivers, except that the two last families gave off genera which passed seaward. But, as traced in detail, the Chaetodontiformes, Scorpaenidae, and Gobiiformes also passed seaward from freshwater Percidae, and then often underwent striking structural modifications. The changes undergone in the positions of the paired and unpaired fins are then traced in the above families, and these are shown to have a definite relation to their evolution and distribution. The great centre of origin and even of evolutionary change is regarded as the western lake area of $\mathrm{N}$. America, and this during Cretaceous to Eocene time. The distribution of the main groups, and also of the important genera of each group, from the above region as a centre is traced. 
Detailed attention is given to the family Serranidae, as being one that in part continued in freshwater, in considerable part became marine; also to the Cichlidae that attained to a special wealth of species and of structural detail in Brazil. Then migrating across the S. Atlantis land bridge into Africa, the latter evolved into the numerous species that now inhabit the central African lake region. Having reviewed the graded connections and evolutionary sequence of the Percopsidae, Aphredoderidae, Percidae, Centrarchidae, Serranidae, Cichlidae, Nandidae and derivative acanthopterous families, that largely remained in freshwater, or that sent small derivative outliers into the sea, attention is next given to important families that became wholly marine. Perhaps the most striking series is that which, starting with Centrogenys of the Centrarchidae, or possibly Etheostoma of the Percidae, underwent graded condensation in body and mouth parts, also modification and condensation with ultimate flattening in the teeth. So through such families as the Pomacentridae, Labridae, and Scaridae a transition is effected in marine types that exactly simulates the change effected in the ganoid Pycnodonts already studied. The stages in their marine geographic distribution are next traced, and thus a connected sequence is established that parallels the morphological changes.

The families Embiotocidae, Cobiidae, Echeneididae, also the larger groups Scleroparei and Jugulares are then treated of in their affinities, structure, and distribution, while the aberrant Plectognathi are shortly studied.

\section{Chapter i 4. Past Geographic and Geologic Conditions in relation to the Distribution of fishes.}

Consideration is first given to possible changes that might fundamentally affect groups of plants and animals. Fishes are regarded as the most sensitive, responsive, and indicative organisms for registration of such changes. So beginning with existing conditions a graded backward review is attempted.

The relatively recent and evolved Acanthopterygii, suggest in their marine, and still more fundamentally in their freshwater distribution, the existence of a wide land bridge 
that connected Africa and S. E. Asia in earlier Tertiary time, probably up to the close of Oligocene time. Further migrational continuity from central Africa to Madagascar and India seems equally assured. Such also have often been demanded in the past by biogeographers.

From evidence already gathered regarding Centrarchidae, Percidae, Cichlidae, and Pomacentridae on to the Scaridae, it is accepted that a wide Gondwana land bridge stretched from north-east Brazil to western Africa, during Cretaceo-Eocene time. So migration and progressive evolution of freshwater families like Cichlidae, also divergent migration from these or allied groups into marine surroundings along the north and south shores of this intercontinental land, gave rise to Pomacentridae and other families.

Breaking up and disappearance of this land-bridge probably occurred during Oligo-Miocene time, and correlative changes in Africa gave rise to the great "eurycolpic" crustal folds and to the extensive lakes that have existed there since Pliocene days. About the same time the IndoMascarene bridge was breaking up, and thereafter centres or foci for separate evolution alike of freshwater and of marine forms originated. Detailed consideration is then given to the resulting evolution of the Cichlidae in $\mathrm{S}$. America and in Central Africa.

Branner's contention is accepted as correct for fish distribution, namely that the existing Antilles were, during the Cretaceous period, parts of a wide connecting land that united N. and S. America. So evolving representatives of the families Percidae, Centrarchidae, Percopsidae, and Aphredoderidae, were enabled to spread southward into the Brazilian "massif" or Archenchelis of that period, and there to undergo further evolution.

But while steady evolution, even amid considerable seismic, volcanic, and diastrophic change, was proceeding over the above areas of North and South America, the Old World in large part was "evidently shaken to its core by seismic and volcanic action, and had most of its teleostean genera obliterated during the late Cretaceous and early Eocene periods." 
The origin, at a still more remote period, of the Berycidae, is traced to the time when extensive lake and river deposits were being laid down during mid and late Cretaceous time in the Judith River and Laramie epochs. So "all present evidence points to origin of the Acanthopterygii in freshwater areas of Comanchean age, and over the central part of the N. American continent."

A history of geologic conditions as revealed in distribution of the Siluridae fortifies the contention above accepted that the central part of the N. American continent was a great and fairly safe evolutionary centre for fishes during Cretaceo-Eocene time. Partial evidence is furnished by the Cyprinidae that are next studied, and are shown to agree with the above, from the geographic and geologic standpoints. Like agreement is shown by the Characinidae, except that the earliest ancestors seem to have started in the extreme south, or even in northern Archenchelis, and at such a time that only late and slight contact was made with Africa, but none still later with Asia. The known facts all indicate that the family branched off from an allied malacopterous ancestry during Cretaceo-Eocene time. So only in late Eocene or in Oligocene time did species reach and spread in Africa, before sundering of the AmericoAfrican or South Atlantis bridge.

The Cyprinodontidae, Hyodontidae, and Osteoglossidae along with a few related families, all serve to confirm, by their distributional affinities, the above fundamental geologic and geographic relationships from Cretaceous time onward.

Chapter I 5. Fishes in relation to a South Atlantic or Antarctica Continent.

The writer here restricts attention mainly to the teleostean families Galaxidae, Aplochitonidae, Symbranchidae, and Amphipnoidae, that all suggest a peculiar distribution over southern continental and island centres. Regarding the two latter families their evolution in Africa, and subsequent westward migration into Brazil, also eastward to India and even into Australia and Tasmania is accepted. 
But the two former present a greatly more complicated problem. Their possible marine ancestry, and subsequent migration into widely apart freshwaters as advocated by some, is rejected as being entirely unsupported by nearly all known facts. The possible former existence of a wide southern continent, or even an extensive Antartica, as advocated specially by $\mathrm{H}$. O. Forbes is presented. The views of J. D. Hooker, and later the publications of the Challenger, the German South Seas, the Princeton, and the Transit of Venus expeditions are examined. Detailed consideration is then given to the nature and possible affinities of the flora that is traced from Chile-Patagonia across southern island lands to New Zealand, Tasmania and Australia.

The statements of Forbes and of Lydekker regarding southern faunal types are then compared, and the conclusions of the former are wholly favored. The author then deals in detail with the invertebrate and vertebrate organisms found in widely isolated southern islands, and compares these with types now living in S. American and in Tasmano-Australian lands. The present distribution of the Marsupialia, and the direct evidence now secured of a former mild Tertiary flora and fauna in antarctic regions, are advanced in favor of the former existence of a southern continental land or Antarctica. But returning to the flora, the writer shows that it, like the fauna, seems to be largely traceable to older types or species that must once have inhabited an extensive western S. American land, which included not only Ecuador, Peru, and Chile, but also the Galapagos and Juan Fernandez islands. These lived before, and also while the ranges of the Andes were in process of formation. But such organisms again show close affinity often with western N. American species or genera cited by the author. These were probably evolving along a land mass that lay west of the great Benton-Niobrara sea, and that later developed the ranges of the Sierras and Rocky Mountains.

So the author shows that from primitive salmonid and esocid ancestry, the Galaxidae and Aplochitonidae probably started in lakes of the above land that were of Upper Cretaceous time. Spreading southward to Patagonia and the 
Falklands, they then migrated eastward along rivers and lakes of the southern continent, somewhat ahead also of the great marsupial migration of late Eocene and Oligocene time. But all reached, first Tasmania and S. E. Australia, later S. Africa and Malaya temporarily, and over this entire region species of these two families of freshwater fishes now survive along with the land marsupials that are only absent from S. Africa.

The distribution and mode of life of the species that make up the genera of Galaxidae and Aplochitonidae are then deal with, and all are viewed as constituting a fairly compact biologic and geographic series that once overspread Chile-Patagonia-Antarctica, and Tasmano-Australia. Evidence however is adduced to show that at least in the case of plants and to a slight degree of animals, a contemporaneous east to west migration was proceding. Thus a westward migration of certain freshwater fishes can be traced. But so far as we know these gradually took to the sea during the migration process. Thus from Pseudaphritis and Chimarrichthys to Cottoperca and Bovichthys one can pass gradually to the south sea families Nototheniidae, Bathydraconidae, and Chaenichthyidae that are now wholly marine. The remarkable and highly specialized forms of Notothenia and allied genera, that now live in the abysses of antarctic seas, represent the end members of a highly evolved series. The writer then summarizes his conclusions as to an antarctic continent and its associated fish fauna.

Chapter i6. A Review of the Tanganyika Problem.

The rich and peculiar fish-fauna of Tanganyika has attracted the attention of many investigators. Chief amongst these are Moore and Boulenger. The former in his suggestive volume entitled "The Tanganyika Problem" brought forward many facts and new observations that the writer now examines. The lists of peridinial, sponge, medusoid, polyzoan, crustacean, molluscan, and not least of fish types, caused Moore and others to view the whole as of marine origin.

The writer accordingly takes up all of the organisms in detail, except the molluscs, and shows that they are 
wholly of freshwater ancestry and descent. Particular interest attaches to the crustaceans of the region, as indicating that the present author's views regarding their origin in freshwater receive here striking confirmatory proof.

The affinities of the approximately $\mathrm{I} 20$ species of Tanganyika fish, in relation to those of other African as well as Eastern American lakes and rivers, are considered. The conclusion is reached that ancestral forms of most of these originated primarily as migrants from the eastern lakes and rivers of $\mathrm{S}$. America, having migrated from the Archenchelis land by the Cretaceo-Eocene land bridge. But that the migration was not wholly in one direction is at least suggested in the probable history of Protopterus and Lepidosiren. For several zoologists have considered that modified derivatives of the former from Africa crossed by the flood plains or rivers of the connecting land, and gradually gave rise to Lepidosiren of the Amazon and Argentina regions. Thereafter, owing to profound diastrophic changes that occurred over the entire area, the bridge sank, the African strata were greatly altered from Miocene to recent time, while many and indigenous species and genera of Cichlidae, Osteoglossidae, Characinidae, and other families evolved. Thus Tanganyika and Kivu, which seem to have been parts once of a continuous lake became elevated, and then separated owing to further elevation and sundering of the latter. But two species of fish still survive that are common to both.

The view is held then that the present fish fauna of the lake represents descendant species from ancestors that only reached the region during the Cretaceo-Eocene period, if we except the species of Polypterus and Protopterus that may date further back in their ancestral origins, according to all present knowledge.

The species of Cyprinidae now found in Tanganyika are held to be derivative species from older types that reached the lake, and not by migration across the AmericoAfrican bridge, but as pioneer invaders from the east, whose north-western American ancestors earlier had reached East Asia, then India, and finally East Africa. An attempt is made to explain the origin of the indigenous family Mormyridae, and the Afro-Asiatic family Masta- 
cembelidae. But regarding both we are still largely in the dark. In summary it is claimed that toward mid or late Cretaceous time, and over an Archenchelis region, the families Siluridae, Characinidae, Cyprinodontidae and Cichlidae were becoming dominant. The above region connected with West Africa by a south Atlantis bridge, across which continuations of American and African rivers flowed, to empty into a southern and a northern Atlantis sea. Wide marsh, lake, and river systems traversed the whole, and gave opportunity for fish migrations. Of only moderate elevation probably during Cretaceo-Eocene time, the region became greatly altered in Oligo-Miocene days, and the bridge then largely or wholly sank beneath the Atlantic. Specific and generic variation in the now isolated American and African fauna then started, and so a wealth of species typical of both areas gradually appeared. This is specially true of Tanganyika and some other of the lakes which have undergone marked diastrophic changes.

\section{Chapter i 7. The Geographic and Geologic Relations of the more primitive Fishes.}

As passage backward is made toward older rocks increasing difficulty is felt in tracing the extent and trend of dry land and freshwaters, as compared with the sea; also in determining the degree to which faunal organisms have spread over these. But having essayed to trace teleostean distribution as affected by geologic and geographic conditions, the same methods may be applied to the more ancient and primitive fishes. The study already made of ganoid fishes reveals that in early Cretaceous and in Jurassic time, more or less perfect continuity of land permitted migration of ganoids across a great northern continent that extended from at least Britain to Siberia, China, and Australia. This has been named in part the Angara or as a whole the Eurasian continent.

But connection between S. E. Asia and Australia was evidently broken in mid or late Cretaceous, and these areas remained apart till a short-lived reunion was made in OligoMiocene time, when brief passage of a few fishes, of marsupials and a few other animals along with certain groups 
of plants was effected northward. A reverse and very limited southward migration into Australia then took place also.

But many genera and even families of ganoids clearly demonstrate that a great North Atlantis land stretched from Europe to $\mathrm{N}$. America. In the lakes and rivers of this great region steady evolution of some of the ganoids there present into higher teleosteans proceeded. But the heavy deposits of Upper Cretaceous marine strata spread over Kansas and adjoining states, with their marine pachycormid types of fish, prove that land oscillation and seaward migration of gano-teleosteans had actively begun.

During Jurassic and Triassic times a great part of the North Atlantis and Eurasian continents must have remained intact. Further, finding of species of related genera in Brazil, S. Africa, India, and Australia during Triassic time proves that some connection probably existed between Archenchelis and the East.

The land masses of Triassic backward to Carboniferous time must have differed greatly in outline from those of today, but a North Atlantis now separate from Angara or a N. E. Asian continent though contemporaneous with a great southern or Gondwana continent, are all proclaimed by the record of fossil fish life as well as other organisms.

But the most remarkable geographic and geologic revelations that bear on fish life are those in recent years by Arctic explorers. For study of the Carboniferous and Old Red strata clearly prove that from North Pole to South several identical genera lived in rivers or lakes, not the least extensive of which seem to have been in the midst of an Antarctica continent.

But a much more intimate knowledge of the older Mesozoic and of Palaeozic strata is needed, before we can speak with assurance on the continental and the marine outlines of the early geologic periods. 


\section{REFERENCES TO LITERATURE}

I. Macfarlane, J. M...... Causes and Course of Org. Evol. (1918).

2. Boulenger, G. A........ Camb. Nat. Hist. 7 (rgro).

3. Le Bon, G............ Evol, of Forces (in Inter. Scient. Ser. (rgog).

4. Leduc, S............Mechanism of Life (I9II).

5. Kerr, J. G............ Proc. Roy. Phys. Soc. I8 (r910).

6. Bürger, O................

7. Geikie, A............. Textbook of Geol. ed. + (1903).

8. Chamberlin, T. C.-

Salisbury, R. D........Geology (1906).

9. Macfarlane, J. M ..... Journ. Acad. Nat. Sc. Phila. S. 2, I5 (I912).

ro. Patten, W..........Evol. of Verteb. and Kin (1912).

11. Joly, T............ Trans. Roy. Dublin Soc. S. 2, 7 (1899).

12. Jones, T. Rupert.......Mem. Palaeo. Soc. (1874).

13. Chamberlin, T. C........Journ. of Geol. 8 (1900).

14. Campbell, R.......... Trans. Roy. Soc. Edin. 48 (1913).

1 5. Spencer, W. B......... Proc. Roy. Soc. Victoria. n. s. 4 (1892).

16. Rohon, J. V...........Mem. Acad. St. Petersb. S. 7, 38 (1892).

17. Russell, I. C.......... Volcanoes of N. America (1897).

18. Bonney, T. G..........Volcanoes (in Inter. Scient. Ser.) (1899).

19. Judd, J. W............ Volcanoes (1881).

20. Verbeek, R. D. M........Krakatau (1885).

21. Royal Society Comm..... Eruption of Krakatoa (1888).

22. Flett, J. S........... Trans. Roy. Soc. Edin. 39 (1900)

23. Geikie, A........... Trans. Roy Soc. Edin. 28 (1879).

24. Engler, A.-Höfer, H.... Das Erdöl (r 909 ).

25. Redwood, B..........Petroleum, ed. 3 (r9r3).

26. Murchison, R. I.......... Siluria, ed. 5 (1872).

27. Murchison, R. I........Trans. Geol. Soc. S. 2, I I (1827).

28. Murchison, R. I .........Proc. Geol. Soc. I (1829).

29. Goode, G. Brown.......A History of Menhaden (r880).

30. Lesley, J. P..........Geol. Surv. Penn., Summ. Rep 2 (1892); 3 (1895).

3I. Warren, C. M.-

Storer, F. H.........Memoirs Amer. Acad. Science 2, 9 (1867).

32. Parker, W. N......... Trans. Roy. Irish Acad. 30 (1892).

33. Keferstein, W ........Zeit. f. Wissen. Zool. I2 (1863).

34. Graff, L. v............Morph. Jahr. 5 ( 1879$)$.

35. Dendy, A........... Proc. Roy. Soc. Vict. n. s. 4 (1892).

36. Bridge, T. W......... Camb. Nat. Hist. 7 (19ro).

37. Graff, L. v...........Monograph. d. Turbellar. (Bronn's Tierreichs).

38. Montgomery, T. H.....Zool. Jahrb. ro (1897-98).

39. Balfour, F. M.......... Collected Works, 3 (I885).

40. Herdman, W. A........ Camb. Nat. Hist. 7 (1910). 
41. Hubrecht, A. A. W...... Q. J. Micro. Sci. n. s. 23 (1883).

42. Dean, B............. Fishes, living and fossil (1895).

43. Kerr, J. G............ Textbook of Embryo.; Vert. (1919).

44. Kerr, J. G............. Proc. Roy. Phys. Soc. I6 (1906).

45. Sargent, P. E.......... Bull. Mus. Comp. Zool. 45 (1904).

46. Nicholls, G. E......... Q. J. Micro. Sci. 58 (1912).

47. Studnicka, F. K........ Oppels Lehrb. 5 (1905).

48. Dendy, A............ J. Micro. Sci. n. s. 51 (1907).

49. Hubrecht, A. A. W......Zool. Anz. 8 (1885).

50. Oudemans, A. C......... O. J. Micro. Sci. c. 2, 25 (1885) Suppl.

51. Goodrich, E. S.........Lankest. Treat. on Zool. 9 (1909).

52. Symonds, W. S.........Q. J. Geol. Soc. 16 (1860).

53. Symonds, W. S.-

Lambert, A........Q. J. Geol. Soc. I7 (186I).

54. Roberts, G.-Randall, J..Q. J. Geol. Soc. I9 (1863).

55. Randall, J............Geol. Mag. 1o (1873).

56. Woodward, A. S.........Proc. Geol. Assoc. 18 (1904).

57. Symonds, W. S........Records of the Rocks (1872).

58. Elles, G. L.-Slater, I. L. .Q. J. Geol. Soc. 62 (1906).

59. King, W. W.-

Lewis, W. J........Geol. Mag. S. 5, 9 (1912).

6o. Goodchild, J. G........ Geol. Mag. S. 5, 9 (1912).

6ı. Kiaer, J................ Skrif. Videnskap. i. Krist., Math. Nat.

Kl. I (1912).

62. Claypole, E. W........Amer. Nat. 18 (1884); Q. J. Geol. Soc.

63. Matthew, G. F........Trans. Roy. Soc. Canada, 6 (1888).

64. Claypole, E. W.........Amer. Geol. I7 (1896).

65. Clarke, J. M.-

Ruedemann ........... York State Mus., Memoir I4 (Ig12).

66. Prestwich, J............ Geology (1886-88).

67. Lapparent, A. de....... Traite de Geol. (1906).

68. Roemer, F. V.-Frech, F. .Leth. geogn. I (1897); 2 (1902).

69. Geikie, A............ J. Geol. Soc. 18 (1860).

70. Geikie, A............Ancient Volcanoes of G. Britain (1898).

71. Goodchild, J. G......... Geol. Mag. d. 5, I (1904).

72. Powrie, J............ Q. J. Geol. Soc. 20 (1864).

73. Hull, E............. J. Geol. Soc. 36 (1880).

74. Macnair, P.-Reid, J.... Geol. Mag., S. 4, 3 (1896).

75. Mitchell, H............ J. Geol. Soc. 17 (1861).

76. Horne, J.............Geol. Mag. S. 4, 8 (1901).

77. Traquair, R. H........ Trans. Roy. Soc. Edin. 40 (1905).

78. Jones, T. Rupert.........Mem. Palaeo. Soc. (1862).

79. Barrell, J.............Bull. Geol. Soc. Amer. 27 (1916).

8o. Traquair, R. H........Palaeonto. Soc. (1868-19r4).

81. Rogers, I...........Geol. Mag. S. 6, 6 (1919).

82. Evans, J. W..........Geol. Mag. S. 6, 6 (19r9). p. 547.

83. Newberry, J. S.........Geol. Surv. Ohio, Palaeon. I (1873). 
84. Orton, E.-

Newberry, J. S........Geol. Surv. Ohio, Geol. 3 (1878).

85. Dawson, J. W........Acadian Geology, ed. 4 ( $189 \mathrm{r}$ ).

86. Newberry, J. S.........U. S. Geol. Surv., Monogr. 16 (1889).

87. Claypole, E. W...........Amer. Geol. 32 (1903).

88. Prosser, C. S..........Journ. of Geol. 1o (Ig02).

89. Eastman, C. R........... York State Mus, 6oth Ann. Rep., 5 (1906).

90. Newton, R. B...........Geol. Mag. S. 4, 6 (1899).

9ra. Kiaer, J...........Report 2nd. Norw., Arct. Exped. 4 (rgrg)

No. 33 .

9rb. Woodward, A. S....... Terra Nova Exped., Geol. I (1921).

92. Macfarlane, J. M....... Trans. Bot. Soc. Edin. 14 (1883).

93. Heer, O............ J. Geol. Soc. 28 (1872).

94. Traquair, R. H........Geol. Mag. 8 (1881); 9 (1882).

95. Moodie, R. ............ Publ. Carnegie Inst. 238 (1916).

96. Dawson, J. W..........Canad. Naturalist, n. s, 8 (1878).

97. Lambe, L. M...........Geol. Surv. Canada, Palaeo. 3 (1910).

98. Newberry, J. S.-

Worthen, A. H.....Geol. Surv. Illinois, 2 (1886).

99. Condit, D. D .........Geol. Surv. Ohio, n. s, Bull. 17 (1912).

10o. Kirkby, J. W........... Geol. Mag., S. 3, 5 (1888).

ror. Ward, J ............ Trans. N. Staff. Inst. Min. Engin. 1o (1890).

102. Stobbs, J. T.......... Q. J. Geol. Soc. 6I (I905).

103. Bolton, H........... Geol. Mag. d. 4, 3 (1896).

104. Woodward, A. S........Geol. Mag. d. 4, 10 (rg03).

105. Frech, F.............. Lethaea geogn.

106. Hind, Wheelton.........Palaeo. Soc. Monogr (r896).

107. Woodward, H.........Palaeo. Soc. Monogr. (r866-78).

108. Laurie, M............ Trans. Roy. Soc. Edin. 37 (1895).

109. Case, E. C.-

Moodie, R. L........Publ. Carnegie Inst. 146 (1911)；207|1915); $238(1916) ; 283$ (1919).

110. Davis, J. W........... J. Geol. Soc. 36 (1880).

11. Young, J...........Cata. West. Scottish Fossils (1876).

112. Carne, J. E...........Mem. Geol. Surv. N. S. Wales, Geol. 3

(1903).

113. Suessmilch, C. A........Geol. of N. S. Wales, ed. 2 (1914).

114. Woodward, A. S...... Mem. Nat. Mus. Melbourne, I (1906).

I15. King, W............Palaeo. Soc. Monogr. (1850).

116. Geinitz, H. B......... Die Dyas (186r).

117. Weiss, C. E...........Fossil Flora d. Steinkohl. (1869-72).

118. Goeppert, H. R.........Fossil Flora Perm. Format. (r864-65).

119. Fritsch, A............. Fauna der Gaskohle (1879-1901).

120. Oldham, R. D.........Geol. of India, ed. 2 (1893).

121. Fontaine, W. M.-

White, D.........Geol. Surv. Penna., Rep. (1880).

122. Prosser, C. S..........Geol. Surv. Kansas, 3 (1897). 
123. Hussakof, L. H.-

Case, E. C.........Publ. Carnegie Inst., I46 (1911); 207 (1915).

124. Gaudry, A............ Archiv. Mus. Nat. Paris, ro (1887).

125. Cummins, W. F.......Geol. Surv. Texas, rst Ann. Rep. (1889).

126. Gordon, C. H........U. S. Geol. Surv., Irrig. papers 317 (1913).

127. Miklucho-Maclay, N.

von ............... Jenais. Zeit. 3 (1867).

128. Frech, F.............. Lethaea geogn. 2 (r903-rgo8).

129. Newton, E. T.-

Brodie, P. B........ Q. J. Geol. Soc. 43 (1887).

х30. Wilson, E........... Q. J. Geol. Soc. 43 (1887).

131. Wills, L. J...........Geol. Mag. d. 5, 4 (1907).

132. Richardson, L........Q. J. Geol. Soc. 6r (r9o5).

133. Richardson, L......... Geol. Mag., d. 5, 9 (I9r2).

134. Newberry, J. S........ U. S. Geol. Surv. Monogr. 14 (1888).

135. Lull, R. S............Amer. Journ. Sc. s. 4, 33 (1912).

136. Eastman, C. R........ Conn. Geol. and Nat. Hist. Surv. Bull. 18

(1911).

137. Corstorphine, G. S..... Brit. Assoc. Report (I9ro).

138. Hatch, F. H.-

Corstorphine, G. S....Geol. of S. Africa (r905).

139. Woodward, A. S....... Ann. Mag. Nat. Hist. s. x, 4 (r889)

12 ( 1893 ).

r40. Broom, R........... Geol. Mag. d. 5, 3 (r9o6).

141. Woodward, A. S.......Mem. Geol. Surv. N. S. Wales, Pal. s I-4 (1888-90); 10 (1908).

142. Feistmantel, O.........Mem. Geol. Surv. N. S. Wales, Pal. 3 (r890).

143. Sauvage, H. E......... Biblio. d. l'Ecol. d. Haut. Etud., 13 (1875)

144. Wright, T......... Q. J. Geol. Soc. I4 (1857-58).

No. 5 .

145. Roberts, T.......... Q. J. Gecl. Soc. 43 ( 1887).

146. Judd, J. W........... Q. J. Geol. Soc. 29 (1873).

147. Oppel, A........... Jie Jura Formation (1858).

148. Quenstedt, F. A........ Der Jura $\left(185_{8} 8\right)$.

149. Walther, I. .......... Jena. Denkschr. f. Med. u. Natur. I I (I904).

I 50. Sykes, H........... Q. J. Geol. Soc. 7 (185I).

I51. Bell, T. L.......... Q. J. Geol. Soc. 8 (1852); 9 (1853).

I52. Bell, T. L.-

Egerton, P. M......Q. J. Geol. Soc. Io ( 1854 ).

I53. Mansell-Pleydell, J. C...Geol. Mag. S. I, ro (1873).

154. Woodward, A. S. et al...Mem. Geol. Surv. N. S. Wales, Palaeo. 9

( 1895$)$.

155. Meyer, C. J. A.......Q. J. Geol. Soc. 28 (1872).

156. Woodward, A. S.......Geol. Mag. S. 4, 3 (1896).

157. Woodward, A. S.......Palaeo. Soc. Monogr. (1902-12).

r 58. Marck, W. v. d........Palaeontographica, II (1863); I5 (1868); $22(1876) ; 31(1885)$.

159. Reuss, A. E......... Verstein. böhm. Kreide, 2 (1846). 
r6o. Geinitz, H. B......... Char. d. Sch. u. Petref. sach-böhm. Kreidege.

16r. Fritsch, A............ Böhm. Kreide (1878).

(1839-42).

162. Bassani, F........... Atti. d. Soc. Ital. d. Sc. Nat. 29 (1886).

163. Davis, J: W...........Tr. Roy. Dublin Soc. S. 2, 3 (1887).

164. Pictet, F. J.............Poissons foss. Mont Liban (1850).

165. Stewart, A.......... Univ. Geol. Surv. Kansas, 2 (1897).

166. Loomis, F. B..........Palaeontographica, 46 (1900).

167. Woodward, A. S........Geol. Mag. S. 3, 5 (1888).

168. Miall, et al...........Brit. Assoc. Report, 44 (1874).

169. Woodward, A. S....... Cata. Foss. Fishes, Brit. Mus. 3 (1895).

170. Fenneman, N. M.......U. S. Geol. Surv. Bull. 213 (1903).

171. Adams, G. I..........U. S. Geol. Surv. Bull. 184 (rgor).

172. Prosser-Logan-Williston.. Univ. Geol. Surv. Kansas, 2 (1897).

173. Macfarlane, J. M........Fishes the Source of Petroleum (1923).

174. Leidy, J.............. U. S. Geol. Surv. Territ. I (1873).

175. Cope, E. D...........Geol. of Wyoming, 6th report (1873).

176. Woodward, A. S.-

Ihering, H. v........ Revista do Museo Paulista, 3 (1898).

177. Lesquereux, L.......... U. S. Geol. and Geo. Surv. Terr., 8 (1883).

178. Cope, E. D........... U. S. Geol. and Geo. Surv. Terr. 5 (1880).

179. Cope, E. D............Amer. Naturalist, II (1877).

180. Woodward, A. S........ Cata. Foss. Fishes. Brit. Mus. 4 (1901).

181. Hauer, F. von..........Jahr. k. k. Geol. Reichs, 9 (1858).

182. Suess, E............. Sitz. d. k. k. Akad. d. Wiss. m. n. kl., 54

(1886).

183. Heer, O............ Primeval World of Switzerland, Eng. tr.

184. Dunker, W..........Palaeontographica, I (1851).

$(1876)$.

185. Meyer, H. von.........Palaeontographica, 2 (1852).

186. Eser, F. S............ Jahr. d. Vereins f. Vat. Natur. in Wurt., $4(1849)$.

187. Sauvage, E........... Bull. Soc. Hist. nat. Toulouse, 8 (1874).

188. Reuss, A. E.-

Mayer, C. J. A.......Palaeontographica, 2 (1852).

189. Wettstein, A..........Abhand. d. Schweiz. Pal. Gesell. 13 (1886).

19o. Scudder, S............Bull. U. S. Geol. Surv. 93 (1892).

rgoa. Pander, C. ............Foss. Fische d. Sil. Syst. d. Russ. (1856).

19r. Newberry, J. S.........Palaeo. of Ohio, 2 (1875).

192. Hinde, G. J........... Q. J. Geol. Soc. 35 (1879).

193. Lönnberg, E............ Thier-Reich; 6, Abt. I (1905).

194. Beard, J..............Zool. Jahrb. 3 (1889).

195. Woodward, A. S....... Cata. Brit. Mus. Foss. Fishes, I (1889).

196. Newberry, J. S.........Geol. of Ohio, 3 (1878).

197. Newberry, J. S........ Geol. of Ohio, Palaeo. I, pt. I (1873).

198. Eastman, C............ Iowa Geol. Surv. 18 (1908).

199. Woodward, A. S....... Cata. Brit. Mus. Foss Fishes, 2 (189r). 
200. Woodward, A. S........Vert. Palaeontology (1898).

201. Brongniart, C.-

Sauvage, E..........tud. s. l. Terr. houill. d. Comm. 3 (1888).

202. Young, J.............Trans. Geol. Soc. Glasgow, 6 (1880).

203. Vaughan, A.......... Q. J. Geol. Soc. 61 (1905).

204. Davis, J. W............Q. J. Geol. Soc. 32 (1876); 35 (1879).

205. Davis, J. W............. J. Geol. Soc. 40 (1884).

206. Atthey, T............Ann. Mag. Nat. Hist. s. 4, I (1868).

207. Davis, J. W.......... Trans. Roy. Dublin Soc., s. 2, I (1883).

208. Eastman, C..........Bull. Mus. Zool. Harvard, 39 (I902).

209. Newberry-Worthen-

St. John..........Geol. Surv. Illinois, 4 (1870); 7 (1883).

210. Roche, M. E..........Bull. Soc. Geol. Fr. s. 3, 9 (1880-81).

211. Fritsch, A........... Fauna der Gaskohle, 3 (1890).

212. Cope, E. D............Proc. Amer. Phil. Soc. (1877) ; (1884).

213. Hussakof, L............Publ. Carnegie Inst. 146 (19xi).

214. Woodward, A. S........Mem. Geol. Surv. N. S. Wales; Palaeo. ro

(1908).

215. Richardson, L........Q. J. Geol. Soc. 61 (1905).

216. Richardson, L.........Geol. Mag. s. 5, 9 (1912).

217. Brodie, P. B.......... Q. J. Geol. Soc. 43 (1887).

218. Wills, L. J.-Smith, W. C.Geol. Mag. s. 5, ro (1913).

219. Brown, C.............

220. Etheridge, R...........Proc. Cardiff Nat. Soc. 3 (1872).

22 I. Huxley, T. H.........Mem. Geol. Surv. Gt. Britain. Foss. d. ro

(1861); I 2 (1866).

222. Eastman, C...........Amer. Journ. Sc. s. 4, 2 I (1906).

223. Eastman, C............Bull. Mus. Comp. Zool. 50 (1906).

224. Newberry, J. C........Palaeo. of Ohio, 2 (1875).

225. Eastman, C..........Journ. of Geol. 8 (1900).

226. Oldham, T................ Geol. Surv. India, I (1859).

227. Boulenger, G .A........Poissons du Bassin du Congo (1901).

228. Eastman, C...........Bull. Connect. Geol. Surv. I8 (I9ri).

229. Alessandri, G. d.........Mem. Soc. Ital. Sc. di Milano, 7 (rgor).

230. Bronn, H. G........... Neues Jahrb. f. Mineral. etc. (1858).

231. Boué, A..............Mem. d. 1. Soc. geol. 2 (1835).

232. Morlot, A. v..........Jahrb. d. Geol. Reichs. I (1850).

233. Brown, J.............Mem. Geol. Surv. Un. King. 2 (1903).

234. Newberry, J. G.........Geol. of Ohio. I, pt. 2 (1873).

235. Brodie, P. B............ History of Fossil Insects, (1845).

236. Woodward, A. S.........Proc. Geol. Assoc. II (I889).

237. Egerton, P..........Palaeo. Indica, s. 4, I (1878).

238. Woodward, A. S........Proc. Geol. Assoc. ro (1888).

239. Woodward, A. S....... Geol. Mag. d. 4, 2 (1895).

240. Phillips-Etheridge .....Manual of Geology, 2 (1 885 ).

241. Pictet, F. J.............Palaeo. Suisse, 3 (1860).

242. Thiolliere V. et al......Poissons foss. de Bugey ( $1854-73$ ).

243. Sauvage, E...........Bull. Soc. Hist. nat. Autun, 6 (1893). 
244. Sauvage, E...........Ann. d. Sc. Geol. 6 (1875).

245. Guenther, A......... The Study of Fishes (1880).

246. Boulenger, G. A....... Camb. Nat. Hist. 7 (1910).

247. Goodrich, E. S........ Treatise on Zool. 9 (1909).

248. Heckel, J. J............ Denk. d. Kais. Akad. d. Wiss. I (1850).

249. Winkler, T. C.......... Nat. Verhand. Holl. Maat. I4 (I861).

250. Guenther, A..........Geol. Mag. d. 2, 3 (1876).

251. Cope, E. D..........Report U. S. Geol. Suvr. Terr. 2 (1875).

252. Boulenger, G. A....... Nature, 67 (1902).

253. Jordan, D. S......... The Study of Fishes, 2 (1898).

254. Jordan, D. S.......... Fishes of N. Amer. 2 (1898).

255. Boulenger, G. A........ Cata. Brit. Mus. ed. 2, Percif. fish. (1895).

256. Arldt, T............ Entwicklung der Kontinente, (1907).

257. Jordan, D. S.-

Evermann, B. W......American Food and Game Fishes (r9o2).

258. Storms, R........... Ann. Mag. Nat. Hist., s. 6, 2 (1888).

259. Moore, J. E. S........ The Tanganyika Problem (1903).

260. Darwin, C...........Geol. Observations, ed. 2 (1876).

26r. Agassiz, A............Bull. Mus. Comp. Zool. Harv. 3 (1876).

262. Garman, S............Bull. Mus. Comp. Zool. Harv. 19 (1895).

263. Eigenmann, C. H.......Popular Science Monthly, 68 (igo6).

264. Gulliver, G........... Phil. Trans. I68 (1879).

265. Forbes, H. O.........Roy. Geograph. Soc. Suppl. papers, 3 (1893).

266. Hooker, J. D.......... Phil. Trans. 168 (1879).

267. Hooker, J. D..........Flora Tasmanica, (1860).

268. Hooker, J. D...........Flora Nov. Zeylan. (1867).

269. Hooker, J. D............ Proc. Linn. Soc. It (1875).

270. Lydekker, R..........Geograph. Hist. of Mammals (1896).

271. Smith, G............ Cambr. Nat. Hist. 4 (1909).

272. Hedley, C.............Proc. Roy. Soc. N. S. Wales, 29 (1895).

273. Ortmann, A............Princeton Patag. Exped. 4 (1906).

274. Scott, W. B........... History of Land Mammals, etc. (1913).

275. Johow, F............ Flora d. I. Islas d. Juan Fern. (1896).

276. Plate, L. et al..........Fauna Chil. in Zool. Jahr. Suppl. 4 (1898).

277. Baur, G.............Amer. Nat. 31 (1897).

278. Robinson, B. L......... Proc. Amer. Acad. Arts, Sc. 38 (1903).

279. Halle, T. G........... Schwed. S. Polar. Exped. III, pt. It (I913).

280. Macleay, W............Proc. Linn. Soc. N. S. Wales, 5 ( $188 \mathrm{I}$ ).

281. Hutton, F. W........... Colon. Mus. and Geol. Surv. (1872).

282. Hutton, F. W.........Tr. Proc. N. Zeal. Inst. 22 (1889).

283. Dollo, M. L..........Voyag. d. S. T. Belgica, (r904), Fishes.

284. Boulenger, G. A........ Nat. Antarct. Exped. Zool. 2 (1907).

285. Vaillant, L........... Expedit. Antarct. Franc. (1903-05).

286. Regan, C. T.......... Terra Nova Exped. Zool. I (1914).

287. Bews, J. W..........Ann. of Botany, 35 (1921).

288. Woodward, A. S........ Ann. Mag. Nat. Hist., s. 7, 9 (1902).

289. Kirkpatrick, R.........Proc. Zool. Soc. (1906).

290. Guenther, A..........Proc. Zool. Soc. (r907). 
291. Browne, E. T......... Ann. Mag. Nat. Hist., S. 7, 17 (1906).

292. Arnold?Boulenger ......Proc. Zool. Soc. (1915), p. 7 r.

293. Hargitt, C. W W.-

Garman, H......... Science, 26 (1907); 44 (1916); 50 (1919).

294. Ortmann, A............ Proc. Acad. Nat. Sc. Phila. (1894).

295. Calman, W. T......... Proc. Zool. Soc. (1906).

296. Sars, G. O........... Proc. Zool. Soc. (1909).

297. Wilson, C. B.......... Proc. Nat. Mus. Wash. 25 (1903); 28 (1905); 31 (1907); 33 (1908); 39 (I911).

298. Cunnington, W. A......Proc. Zool. Soc. (1913).

299. Sars, G. O...........Proc. Zool. Soc. (1910).

300. Boulenger, G. A.........Proc. Zool. Soc. (1919).

30r. Eigenmann, C. H........Report Princeton Exped. 3 (Ig05-II).

302. Boulenger, G. A........Fishes of the Nile, (1907).

303. Boulenger, G. A........ Report Brit. Assoc. (1905).

304. Marsh, O. C...........Amer. Jour. Sc., S. 3, I5 (1878).

305. Woodward, A. S........ Ann. Mag. Nat. Hist., S. 7, 9 (1902).

306. Barrande, J.......... Syst. Silur. Bohem. I Suppl. (1872). 


\section{INDEX}

Academy of Natural Sciences.....4 Acadia, bituminous shales of ....106 Acanthias .............239 Acanthodes ........134, 169 170, $265,266,498$

Acanthodes, distribution of....265 Acanthodes mitchelli ..........119 Acanthodes semistriatus ......270 Acanthodes sulcatus........... 43 Acanthodes Wardii ....... 44,276 Acanthodian beds ...........118 Acanthodidae ......285, 287, 498 Acanthodopsis .......134, 246, 265 Acanthodopsis Wardii .........144 Acanthoderma ............252 Acanthopleurus ............252 Acanthopterygii $\cdots \cdots 346,347,357$, $364,372,383,385,400,405,410,521$ Acentrophorus 326, 327, 328, 329, 520 Acentrophorus dispersus .....328 Aceraspis robustus $\ldots \ldots \ldots \ldots$ ro6 Acipenser ................. 317 Acipenseridae $\ldots \ldots \ldots \ldots . . .346$ Acondylacanthus jenkinsoni.143, I44 Acrodus minimus .....173, 178, 289 Acrolepis ..............320, 49I Acrolepis digitata ............ Acrolepis hortonensis .........321 Acrolepis semigranulosa ...... 145 Adams, G. I. on bituminous shale 224 Aestocephalus ........... 147 Aetheolepis mirabilis ..206, 328, 489 Aetholepis mirabilis figure.....330 Aetheospondyli ........339, 342 African lakes....467, 469, 470, 476 Aganacanthus striatulus ...... 144

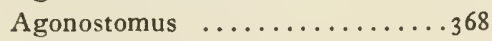
Agassiz, L..............215 Airbladder, absorption in alpine fishes ............... 352, 353 Aistopod batrachians ....... 147 Aix, gypses of............237 Alaska, Volcanic dust .........
Albert shales, N. B. $147,148,149,319$ Albula ..................... 354 Albulidae ....220, 235, 238, 354 Albulidae, distribution of $\ldots \ldots 430$ Albumen products .............50 Alepocephalidae .........359, 36r Aleposauridae ........36r, 362 Alessandri G. de............. 312 Alum Bay beds ............234 Amazon river ......464, 471, 472 Amazon, rise and fall .........32 Amblyopsidae ..........360, 363 Amblyopsis ........................ 364 Amblypterus ........321, 493, 519 Amblypterus latus .........170 Amia ..........353,486, 487, 488 Amia calva ........18, 233, 327, $339,486,520$

Amiidae................. 327, 354, 488

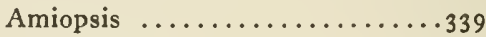
Ammodytidae ................369 Amphibia .................. Amphicoelous vertebrae ...... 342 Amphioxus ...14, 61, 68, 80, 94, 506 Amphioxus, embryo of ........6r Amphioxus, endostyle of.......69 Amphioxus, olfactory organ....64 Amphipnoidae ..........431, 432 Amphipnous ..............4432 Amphiporus ............24, 83 Amphiporus, blood vessels.....88 Amphisyle beds ...........243 Amphisyle heinrichi .........243 Amphisyle scutata .......243, 244 Ampullae of ear .............8 3 Amsterdam Island ..........435 Amsterdam Island, flora of ....438 Amylene .................57

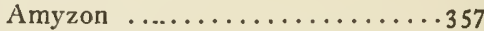
Anabantidae ....369, 370, 405, 408 Anabas scandens..............369 Anadromous fishes $\ldots \ldots 33,273,279$, 284,443 
Anapterus $\quad \ldots \ldots \ldots \ldots \ldots \ldots 239$

Anaspidae ...............257

Andean Cordillera ..........45

Angara Continent..410, 419, 420, 532

Annularia ..............284

Anodontacanthus americanus.... 68

Anodonta jukesii ......122, 131, 306

Anodonta, of Old Red...........II7

Anogmius ................430

Anomoeodus in Cretaceous beds.214

Anoplophora ............. 73

Antarctic fish genera .........458

Antarctic plants, distribution of 436 440

Antarctica Continent......434, $4+5$ Antarctica, plants of.....436, 437 Anthracosaurus russelli ......276 Anthrapalaemon grossartii....276 Antiarchi $\ldots \ldots \ldots 257,262,496$ Anticlinal strata .............50 Apateolepis australis ..... $187,49 \mathrm{r}$ Apeltes ...................365 Aphnelepis .............206 Aphredoderidae ....235, 242, 376, $378,383,400,409,410,412,413,525$ A phredoderus sayanus. $365,372,373$,

377,413

Aplochiton (or Haplochiton) 359,360 Aplochitonidae (Haplochitonidae)

$43 \mathrm{I}, 432,45 \mathrm{I}, 452,453,459,46 \mathrm{I}$, 462,530

Apodes

Appalachia

Aptian-Cenomanian beds .....209 Aquitanian beds of Europe. 237, $2+5$ Arachnida ............... I Io Arapaima ............354, 429 Archaean period ........24, 26, 27 Archaean rocks ........25, 504 Archaeomaene robustus ......206 Archaeomaene tenuis ........206 Archaeopteris ............ I 8 Archandean Continent ...46r, 479 Archanodon jukesii ............ I3 I Archenchelis Continent....451, 460, $471,479,480,532$

Archiannelida ............ 77

Archibald on Krakatoa .......45
Archidesmus ............. I 8

A rchinephros ...............90

Arctogaea ...............2 ro

Argulidae, of Tanganyika ....467

Arius ............... 350,414

Arldt, T.....24, I79, 404, 484, 492

Arthaber on Raibl fish beds..... I74

Artemia $\ldots \ldots \ldots \ldots \ldots \ldots \ldots 43$

Arthrodira .........266, 293, 496

Arthropods ...............80

Ascidia ..................68

Ascidia mentula, branchial sac of .69 Ascoli, volcanic dust.........40 Asineops .........234, 365, 525 Asphalt, occurrence of........49 Aspidichthys ..............129 Aspidorhynchidae ....219, 242, 339 Aspidorhynchus .....201, 339, 341, $484,485,487,510,520$

Aspius ................246 Aspredinidae $\ldots \ldots \ldots \ldots \ldots \ldots 352$

Assam, oil fields ............56

Asteracanthus ............20

Asterolepis ...............123

Asterolepis clarkei ..........127

Asterosteus ............ 128, 129

Astronesthes ...............359

Atacama trench .............450

Ateleaspis ........... 104, 497

Atherinidae ..........235, 367

Atherina ....................... 367

Atherstonia ........ $887,321,491$

Athrodon ............214, 219

Atlantis, South..............23 I

Atlantis, North............231

Atthey, T., on Newsham beds... .278 Auchenaspis ......36, 97, 112, 497

Augite $\ldots \ldots \ldots \ldots \ldots \ldots \ldots+\ldots \ldots$

Aulostomidae ..............366

Australia, Geonemertes in......24

Australian Jurassic fishes ....205

Australian marsupials ........443

Australian oil shales ..........160

Autun, bituminous schists of ...286

Avicula contorta ...........173

Avicula contorta zone.........173

Aviculoidea .............. 178

Aymestry beds .......97, 98, 101 
Bacterial diseases............ 3

Baird, J., on marsipobranch teeth.258

Belemnobatis ..............201

Balfour, F. M...........6o, 75

Balruddery Den, fish bed in....116

Barazzetti on Perledo beds.....329

Barbus

.419

Barramunda ............ 175

Barrell, J............... r23

Barrande, J.............294

Bassani, F............312, 329

Baur, G. on Galapagos...448, 449

Bavaria, Jurassic beds of.......195

Bdellodus ..............289

Bdellostoma, respiratory pouches.70

Bear Island ................ 140

Bedford shale.............284

Belemnites gracilis .........202

Belemnites grandis............344

Belemnites tripartitus .....202, 344

Bell, T. L., on Kota beds......204

Bellendina .............4.456

Belonorhynchidae ............343

Belonorhynchus ....324, 345, 490

Belonorhynchus gigas ........ 187

Belonorhynchus gracilis ........187

Belonorhynchus striolatus....... 774

Belonostomus .......339, 34r, 342, $484,485,487$

Benton-Niobrara beds....216, 226, 229, 512

Benzole, from fish oil........ 57

Berycidae ..238, 239, 242, 377, 383

Berycidae, genera of ........ 4 II

Beryx .............239, 314

Besano, bituminous beds of......r 74

Bews, J. W., on S. African flora.457

Biotic energy...........9, 503

Birkenia elegans, figure of.....262

Birkenia ............264, 294

Bituminous beds of Orbagnoux..34I

Bitumen ..................... 50

Bituminous Schists........50, 58

Bituminous shale of Connecticut.18 I

Bissacanthoides debenhami..... r 32

Blenniidae ................ 399

Blood vessels of Nemerteans.....86

Bohmig, structure of vessels....89
Bone beds. $35,58,504$

Bon le, G..................

Bonney T. G. on volcanoes.....39

Bothriolepis ..........53, 124

Bothriolepis antarctica ....... 132

Bothriolepis canadensis........124

Boulenger, G. A.4, 346, 350, 393, 394

$397,398,408,414,423,427$

Boulenger, G, A., on Tanganyika

fishes ................468

Bovichthyidae ............458

Bowfin fish.............. 8

Brachydirus .............294

Brachyops laticeps..........204

Bracklesham beds..........234

Branchiostoma ..............80

bridge, $T$. W., on tooth formation $64,66,85$

Bridger beds..........233, 234

Brodie, P. B., on fossil insects..190

Bronn, H. G.............. 312

Broom, R., on Karoo fauna.....184

Brown, C...............291

Brychaetus ............354,427

Buccal cavity of Nemerteans.....66

Bucklandium ................. 350

Bucklandi marine beds........ 332

Bucklandi shales.............332

Bugey, fish beds..........340, 34I

Bugey, list of fishes............

Bunodes lunula................36

Bunodes rugosus............... 36

Bunter beds..............172

Burdie House, Limestones of ...2, 141

Bürger, $0 \ldots 60,6$ I, 75, 80, 8I, 84, 88

Bürger, $O$. , on horny teeth.......63

Burlington beds.........147, 150

Burnett river, flood plains of ....32

Caithness, bituminous strata of ..57

Caithness, flagstones of $\ldots \ldots \ldots$ so

Calamichthys .........3 15,493

Calamites .....2, 118, 122, 128, 164

Calcareous deposits, Nemertean...17

Chitinous deposits, Nemertean....17

Calciferous sandstone $\ldots .3,137,139$,

$140,141,143,146,148,507$

California, oil strata of......236 
Callopristodus pectinatus....... I44

Calman, WV. T., Tanganyika Crustacea .................466

Cambrian times......19, 23, 26, 27 Campbell-Macquarie Isles . . . 435 Campbell, R. .........31, 109, 118 Campbellton, N. B., Devonian fishes, 270

Campodus ............192, 288

Camps, Limestones of..........

Canada, Old Red of............40

Candona globosa............. 192

Cannel coal............ 158 , 159

Cannel Coal of Yorkshire.......155

Cannel Coal, Cope on.........308

Cannelton beds.............. 59

Canobius...........317, 318, 319

Caproylene from fish oil.......57

Caragola mordax...........443

Carangidae ......235, 238, 397

Carassius ................ 4 r9

Carbonicola ................ 53

Carboniferous, diagram of Edinburgh ............. $\mathbf{r}_{42}$

Carboniferous Limestone ......2, 3

Carboniferous limestone fishes...278

Carboniferous period. .25, 27, 54, 137

Carbo-permian beds....... 166,182

Cardium .................250

Carinella rubicunda........8 $8_{3}, 8_{5}$

Carne, J. E., on oil shales...... 60

Carnegie Institution.........146

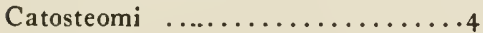

Catostomus $\ldots \ldots \ldots \ldots \ldots \ldots \ldots \ldots \ldots \ldots$

Carterland Den, fish bed in.....1 6

Case, E. C., on amphibians...... Is4

Case. E. C., on permian beds.... 167

Catskill strata.............270

Catopterus .........182, 323, 324

Caturus ................. 98

Cell-nucleus ................

Cenomanian deposits $\ldots . .333,335$,

337,354

Centrarchidae ......377, 378, 379,

$382,383,384,385,386,392,410$,

$413,525,527$

Centriscidae .366

Centrophorus
Centrogenys ..............386

Cephalaspis .......97, 98, ro, I12, I17, 127, 497

Cephalaspis beds ...........1 8

Cephalaspis lyelli ........r8, I 9

Cephalochordata ....... 19, 61, 256

Cephaloplacoda ............262

Cephalopod molluscs .........

Cephalothix, blood system......86

Cepolidae ................396

Ceramurus .............343, 344

Ceratiocaris ........... ro4, r 10

Ceratiocaris nöttingi .........36

Ceratodus .........170, 175, 208, 299, 300, 30I, 495, 516

Ceratodus avus .............188

Ceratodus capensis ......... 184

Ceratodus favosus............. 68

Ceratodus kannemeyeri ......184

Ceratodus latissimus (altus) ....173

Ceratodus parvus ...........173

Ceratodus silesiacus $\ldots \ldots \ldots \ldots$ r 73

Cerebral organs $\ldots \ldots \ldots \ldots \ldots 82$

Cerebratulus ..........24, 76

Cerebratulus, sense organs of....64

Cerebratulus, thread or stinging cells ................62

Cerin strata ............... 95

Cestracion .........193, 239, 291

Challenger Expedition ........446

Chamberlin, T. C......26, 30, 159, $182,212,270,273,411$

Chamberlin-Salisbury $25,96,126,163$

Channa ......................68

Chara .................203

Characinidae, Chart of.......421

Characinidae, distribution...421, 424

Characinidae, groups of ...421, 424

Characinidae ..235, 349, 351, 385, 532

Charitosomus ............... 358

Chatham Islands, Forbes on.... 434

Chelonia, Southern distribution of, $44^{2}$

Chelyophorus .............294

Cheirodus crassus ........... 445

Cheirodus granulosus ........ 445

Cheiracanthus murchisonii..120, 303

Cheiracanthus grandispinus ....303 
Cheiracanthus latus.......120, 303 Cheirolepis .....3 $316,318,493,518$ Cheirolepis trailli .120,303, 317, 493

Cheirolepis canadensis........493

Chemic energy ............ 12

Chemical atoms .............

Chemung strata ...........270

Chiasmodon ..................... 369

Chiasmodontidae ...............69

Chicago, dolomite of ..........52

Chilean-Patagonian Coast line...45 I

Chilobranchus .............432

Chirocentridae ...235, 238, 362, 523

Chirocentrites ..........348, 356

Chiropteris digitata ........ 177

Chimarrhichthys $\ldots 456,458,459,530$

Chimeroid sharks........... 7

Cinder beds, of Purbeck ........19I

Chirothrix libanicus.....228, 229

Chirothricidae .........360, 36 I

Chironectes ...............446

Chitinous deposits, nemertean.... 7

Chologaster ...............364

Chondrosteii $\ldots \ldots \ldots \ldots 4,5,91,316$,

$317,483,511$

Chondrenchelys problematica...27

Chonetes Flags............. ror

Chonetes lata ...........97, 100

Chonetes striatella ...........102

Chordata ................61

Christiania, Downton beds ...... I05

Chromatin substance ........10, 15

Chromidae ..............235

Cichlidae $\ldots \ldots \cdots \cdots 376,381,382$,

$3^{8} 8,385,386,395,406,408,527$

Cichlidae, genera of......408, 409

Cichlidae of Tanganyika...469, 472

Cladodontidae ...........285

Cladodus mirabilis ....143, 144, 277

Cladodus striatus ......... I43, I 44

Cladoselache ......64, 134, 264

Cladoselache fyleri ........27 I

Clarke, J. M..............30, I I I

Clarke-Ruedemann, on Eurypterids 154

Claypole, E. W...... 106, I30, I3 I

Clear Fork formation.......... 67

Cleithrolepis .............283
Cleithrolepis extoni .........184

Cleithrolepis granulatus ......187

Cleithrolepis latus ..........187

Cleveland shale, conodonts in ...258

Cleveland bituminous shale....296

Climatius ............. I 2,265

Climatius latispinosus ........127

Climatius ornatus $\ldots \ldots \ldots \ldots \ldots 18$

Climbing perch ............369

Clinton beds ................ 106

Clupea ............250, 356

Clupeidae ..220, 235,238, 242, 356

Coal measures ........ 3, 357,158

Coal measures, fishes of.....277

Cobites ...............246

Coccoderma .............3 II, 494

Coccodus ...........283, 335

Coccolepis ...............492

Coccolepis australis.....206, 323

Coccolepis bucklandi .....206, 322

Coccolepis liassica ...........32I

Coccosteus ..........119, 128, 133,

I $51,294,295,496,516$

Coccosteus decipiens ......II9, 120

Coccosteus minor ..... I20, 294, 303

Cochliodontidae ..........280

Cochlear nerve of ear .........83

Cochliodus contortus....... I $43, \mathrm{I}+4$

Cocos Islands, flora of ........449

Coelacanthus ...........494, 518

Coelacanthus elegans...... I $+5,308$

Coelacanthus granulatus .......308

Coelacanthus abdenensis ....... +4

Coelacanthus hybodoides ...... I 56

Coelacanthus lepturus ....... 56, 308

Coelacanthus .....272, 306, 307, $308,309,494,518$

Coelolepis ............. 497

Coelodus .............283, 333

Coelodus in cretaceous beds...214

Cogitic energy ........... r, 503

Cognitic energy .......... 10, 503

Coelacanthidae ..........31, 494

Coenozoic period $\ldots \ldots \ldots \ldots 42,47$

Colloid molecules .............8

Colloid states ................ 8

Colobanthus quitensis . . . . . 4 437 
Colobodus chorzowensis........172

Colobodus gogolinensis ......... $17^{2}$

Columbia ...........364, 370, 372, $376,410,413,525$

Comanchean beds.......209, 4II

Comen, fish beds of ............ 313

Compsacanthus ...........272

Compsacanthus triangularis.... 156

Compsacanthus major ........ 156

Conchidium knightii .......... ror

Condit, D. D................ I5

Conemaugh Formation, Condit on 151

Congo basin ................... 8

Connecticut beds ...181, 309, 310, 3 II

Conodontes ..............257

Conodonts ....107, 108, 257, 258, 259

Conodont genera ...........23

Conodonts, Silurian ..........94

Consequina, Volcano of.........39

Continental masses, in Pliocene..23I

Cope, E. D...........222, 356

Cope, E. D., on Green River shales, $373,409,427$

Cope, E. D., on Priscacara . . . 407

Copepoda of Tanganyika.....466

Copodus planus ......... I43, I44

Corbins Mill section ..........126

Cordaites ............128, 167

Coregonus $\ldots \ldots \ldots \ldots \ldots \ldots . \cdots \cdots 5^{8}$

Corniferous beds .........30, 48

Corniferous limestone, bone beds, 129 , 267

Corniferous beds, Newberry on.267

Corpus albicans.............75

Corstorphine, G. S., on Karoo beds, 184

Cossyphus

Cotopaxi, ert

(of

Cottidae ...................397

Craigleith sandstone............ I4I

Cretaceous formation, divisions of 2 II, 4II

Cretaceous volcanic rocks ..210, 230

Cretaceous period ........ 5, 6, 22

Cretaceous Period, history of....4II

Cretaceous Period, fishes in.208, 383

Cretaceous Period, flora of.....220

Cretaceous reptiles.........236
Cretaceo-Eocene, chart of......240

Cretaceous-Eocene land-bridge, 350, 410

Cretaceous coal beds ........208

Cretaceous Teleosts, genera of..226

Cretaceous strata ........... r9o

Crocodile, Malayan ..........442

Cromeria of White Nile ......358

Cromeriidae ................ 358

Crossognathidae ..........2.238

Crossognathus ...............356

Crossopterygii .........5, 9I, I4I, $168,293,302,303,307,316,493$, $495,515,517$

Crozet Islands ..........436, 452

Crozet Island plants...434, 437, 438, 439

Crustacea in Tanganyika ....4465

Cryphiolepis striatus ......... I45

Crustacea, Myers on Antarctic..443

Ctenacanthus major ..........276

Ctenodus breviceps ........ 88, 299

Ctenodus cristatus .....145, 276

Ctenodus elegans ........... 156

Ctenodus interruptus .......... 445

Ctenodus tuberculatus ......276

Ctenoptychius apicalis ........144

Ctenoptychius lobatus ......143, 144

Ctenoptychius serratus... $443,144,276$

Ctenothrissa vexillifer .......228

Ctenothrissa radicans ......... 14

Ctenothrissidae ............2 38

Culm of Austria ......31, 137, 140

Cummins, W. F., on permian beds 166

Cunnington, W. A., on Tanganyika 463,467

Cunnington, W. A., on Tanganyika Branchiura ..............467

Cuyahoga shales ............. 447

Cyathaspis....IIO, I12, 26I, 262, 497

Cyathaspis Banksii ..........100

Cyathaspis Campbelli ......... ro4

Cyathaspis ludensis .......... 106

Cyclobatis ...........215, 239

Cyclopteridae ..............397

Cycloptychius .............. 317

Cyclurus ...........246, 25 I 
Cyclostomata

$67,70,257,260,459,46 \mathrm{I}$

Cyclostomata, mucus glands

Cyclostomes ... $44,107,447,259,260$

Cyclostomes, auditory organs of...65

Cyclostomes, eyes of .........65

Cyclostomes, olfactory organs...65

Cynopodius crenulatus........ 143

Cypricardites catskillensis .....131

Cyprides

Cypris

$.25 \mathrm{I}$

Cyprinidae ..235, 349, 350, 351, 352

Cyprinidae, chart of ......... 417

Cyprinidae, sub-families of . . . 417

Cyprinidae, Distribution of..417, 421

Cyprinidae of Tanganyika....449

Cyprinodon ..........362, 426

Cyprinodontidae.....360, 362, 363, 424,532

Cyprinodontidae, distribution of.424, 427

Cyprinoidei $\ldots \ldots \ldots \ldots \ldots \ldots 246$

Cyrena in Jurassic beds........ 191

Cystignathous frogs $\ldots \ldots \ldots \ldots 44$ I

Cythere .................. 48

Dadocrinus zone............ 772

Dadoxylon newberryi ....126, 129

Dakota beds ...............209

Dakota formation, Chamberlin-Salisbury on ............... 1

Dakota sandstones .........225

Dalliidae .........360, 363, 524

Danian Period ............231

Dapedoglossales ............355

Dapedoglossus....354, 427, 428, 523

Dapedius..........283, 331, 336

Dapedius politus...........203

Dapedius egertoni...........204

Diplaspis acadica........... 106

Darwin, C.............. 78

Darwin, C., on Galapagos Isles.448

Datnioides ................ 385

David, T. W. E., on Gosford rocks, 185

Davis, J. W., fishes of Coal measures,
Davis, J. W., fishes of Carboniferous time ............278, 317

Dawson, J. W........128, 147, 319

Dayia navicula............. ror

Dean, B., on Bdellostoma......77

Deccan volcanic deposits......209

Deister Coal beds ...........208

Deister Sandstone, plants of....214

Dendrodus ............... 125

Dendy, A., on Geonemertes...68, 69

Dendy, A., on Geotria........82

Dendy, A., on nephridial system..89

Dercetidae ................ 361

Dercetis ..............216

Destruction of fishes ..........12

Devoletzky ................. $8_{5}$

Devolution, organic ..........13

Devonian Age......18, 22, 25, 27 30, 31, 35

Devonian fishes ...........1 3

Discina .................. 30

Dicentrodus bicuspidatus....... 144

Dicranodon texensis.......... 168

Dicranodon platypternus ...... 68

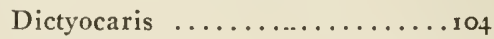

Dictyopyge ........183, 323, 324

Dictyopyge draperi ........... 184

Dictyopyge illustrans ........187

Dictyopyge robusta ........ 187

Dictyopyge symmetrica ........ 887

Didelphidae ...............

Didelphidae, American, distribution, 44I

Didelphys $\ldots \ldots \ldots \ldots \ldots \ldots 446$

Dinichthidae .............129

Dinichthids ............. 8

Dinichthys ........131, 268, 269, $270,295,296,297,301,496,516$

Dinichthys hertzeri ....... I28, 295

Dinichthys intermedius .......269

Dinichthys pustulosus .......295

Dinichthys terrelli ......269, 295

Dinichthys tuberculatus ...295, 296

Diplacanthus striatus .......120

Diplodus ...............287

Diplodus gibbosus ........144, 156

Diplodus parvulus........... 144

Diplodus tenuistriatus ........ r20 
Diplomystes .............. 352

Diplomystidae ...........220

Diplomystus ..234, 238, 357,400, 524

Diplomystus dentatus .......238

Diplopterus ...............302

Diplopterus agassizii ......120, 303

Diplurus ....183, 309, 310, 311, 494

Dipneusti............ 5, $3 \mathbf{I}$,

293, 298, 306, 495, 515

Dipnoi ...........

91, 299, 402, 496

Dipnoites .299

Dipnoans ................

Diprotodont marsupials ...44I, 446, 461

Dipteronotus cyphus $\ldots \ldots 176$, 177

Dipterus macropterus ......... 120

Dipterus valenciennesii 119, 120, 298

Dohrn, A................67

Dollo, M L., on "Belgica" fishes..455

Dorset, geology of ........205

Downton, bone beds .......... Ior

Downton series $\ldots .23,35,36,48,98$

Drepanaspis, Traquair on ......121

Drepanaspis ........257, 26I

Drepanophorus, Cerebral Canal of 83

Drepanophorus, size and shape...6I

Drydenius insignis..........145

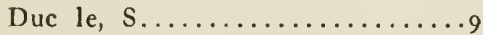

Ductus cochlearis of ear.......84

Ductus endolymphaticus .......84

Dunker, W..............249

Dunnet Head, Geikie on........48

Duplo-electric Energy .......8, 9

Dura Den .................

Dusen, on Tertiary flora......453

Eastman, C., on fish beds...130, 182, 309, 310, 3 I I

Echeneididae .............395

Echeneis glaronensis ....395, 396

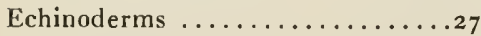

Ecology .............12, 503

Ectosteorhachis of Texas.......308

Edestus ............. 153,283

Edinburgh, Calciferous rocks...... I

Egerton, P. M., on Kota beds....204
Eifelian deposits, Bohemia......130

Eichstadt beds............. 98

Eichstadt deposits ............ 36

Eigenmann, C.....346, 350, 426, 468

Elasmobranchii.......91, 257, 498

Elasmobranch fishes, eocene....239

Elasmobranch fishes, origin of ...285

Elasmosaurus .............. 17

Flasmosaurus, Cope on.......218

Eldridge, R., on Trinity beds...225

Eldridge, R., on California beds.254

Electric energy .......... 8 , 12

Elles ................... 100

Elipsopholis dunstanii .......187

Elopidae ........220, 238, 354

Elonichthys .......... 317, 518

Elonichthys armatus.......... 187

Elonichthys browni........149, I 50

Elonichthys bucklandi......... I 9

Flonichthys multistriatus... 145, 320

Flonichthys pectinatus ........145

Elonichthys robisoni......139, 143, 145,320

Elonichthys striatus ......... I45

Elonichthys semilineatus ...... I87

Embothrium coccineum ........457

Embiotocidae ...............393

Embryology of Nemerteans .....72

Enchodontidae ...238, 242, 360, 36I

Enchodus ................ 15

Encrinus $\ldots \ldots \ldots \ldots \ldots \ldots \ldots$

Engler-Höfer, on petroleum..49, 54, 58,505

End-buds, of fishes .........66

Energy, states of......... 503

English chalk, fishes of.......215

Enstatite ................ 6

Entomostracans ...............

Environal stimuli .......10, 15, 503

Environment .......11, 13, 14, 503

Eocene ............ 232, 234

Eocene beds, flora of........234

Eocene elasmobranchs ........239

Epibiotic organisms ............

Epidermal hairs .............66

Epidermal hairs of fishes.......66

Equilibrium, organic .........13

Equisetites columnaris ....... 197 
Equisetites arenaceus ........ 177

Erisichthe of Kansas beds..337, 488

Erismatopterus .........234, 365

Eser, F. S., on Ulm beds......250

Esocidae .........360, 363, 451

Esociformes (or Haplomi) .....360

Esox ...................... 362

Estheriae in Waterstone beds...176

Estherian flagstones .......... 122

Estheria brodieana .........192

Estheria Coglani ............ 185

Estheria mangaliensis .......204

Estheria middendorfii $\ldots \ldots 345,484$

Estheria minuta $\ldots 176,177,178,288$

Estheria membranacea ....118, 122, $123,124,304$

Estheria tenella .............. 54

Etheostoma ....379, 387, 388, 526

Euchordata .............. 9

Euctenius elegans............ 144

Eugnathidae .....219, 335, 338, $343,354,489$

Eugnathus ................ 192

Eunemertes, crystal cells .......63

Eunemertes, cerebral organ of...83

Euomphalus ...............

Euphanerops ..............135

Euphyacanthus semistriatus ...144

Eupolia ...............77, 78

European triassic fish beds..312, 313, 314

Eurycolpic folds of Moore..408, 423

Eurylepis ............ 308, 321

Eurylepis scotticus .........145

Eurynotus crenatus, 139, 143, 145, 320

Eurynotus macrolepidotus.......145

Eurypteridae ............ 101, 110

Eurypterids ......... 30, 99, го1, 102, 103, 105

Eurypterus ..........118, 131

Eurypterus fischeri $\ldots \ldots \ldots \ldots 36$

Eurypterus minutus .......... 105

Eurypterus norvegicus .........105

Eurypterus scouleri ..........139

Eusthenopteron foordi ....304, 305

Evans, J. W................ 125

Evermann, B. W............364

Evolution, organic .......13, 503
Falkland Islands, flora of..435, 436, 437,438

Fauna Chilensis ...........448

Felichthys ................ 352

Felspar ............46, 47

Fenneman on Cretaceous oil field, 223

Fifeshire, Calciferous rocks.......

Firth of Forth ...............

Fish oil and bacterial action....58

Fishes, evolution of .........66

Fishes, mucus glands of .......62

Fishes of European miocene....251

Fishes of European oligocene....252

Fishes of Minat ..........250

Fishes of Mowry Shales.......223

Fishes of New Zealand.........454

Fistulariidae ............... 366

Flagstones of Caithness .......50

Flammenmergel of Germany...209

Flett, J. S......48, I 8 , I19, 303

Flora Australiensis of Bentham. .435

Flora Tasmanica of Hooker...435

Flora Zeylanica of Hooker.....+435

Florissant, fishes in shales. 237,253

Flysch rocks ..............243

Forbes, H. O.......434, 440, 44I,

$442,453,529$

Fox Hill group...........230

Fram expedition ..........132

Frech ..........24, 28, 33, 172

Fritsch, A ............ 64,287

Fuegia ..........435,436, 437

Fundulus $\ldots \ldots \ldots \ldots 362,425,426$

Fungoid diseases ............13

Galapagos Islands, flora of . ...447

Galaxidae ........359, 431, 432,

$433,453,454,459,461,462,530$

Galaxias ....359, 43I, 452, 453, 454

Galaxias attenuatus, wide distribu-

tion of $\ldots \ldots \ldots \ldots \ldots \ldots \ldots \ldots+359$

Galeichthys $\ldots \ldots \ldots \ldots \ldots \ldots . \cdots 352$

Gampsonyx .............287

Ganglionic masses............ II

Ganodus .................. 192

Ganoid fishes .............. 4

Ganoid fishes of chalk .........337 
Ganorhynchus süssmilchi ... 88,299

Ganorhynchus beecheri .....299

Gaspé fish beds ............127

Gastrosteidae …...365, 366, 370

Gastrosteus ................ $365 \quad 370$

Gastrosteus aculeatus .......366

Gastrosteus cataphractus.......366

Gaudry, A.............................

Geikie, A.....25, 26, 29, 39, 48, $96,114,209,212,303$

Geikie, A., Ancient Volcanoes....II5

Geikie, A., on Old Red Sandstone. 15

Geinitz, H. B., on permian rocks.164

Geonemertes ...........24, 82

Geonemertes australis.........6r

Geonemertes, eyes of...........65

Geonemertes, lime cells of.....6 63

Geonemertes, liver of .........7 I

Geonemertes, view of head region, 67

Geotria ..........82, 108, 442

Geotropism ............12

Giffoni, bituminous beds of.....174

Gigantopteris ............ 67

Gilmerton ironstone .......... I 43

Ginglymostoma ............239

Glands of Nemerteans.......62

Glengariff beds ........... 116

Glossopteris flora .......... 184

Glyptoptychius angustus .....120

Glyptopomus ...............305

Glyptolepis paucidens .....120, 303

Glyptolepis leptopterus .......306

Gnathostomata $\ldots \ldots .5,19,22,71$

Gnathorhiza pusilla ............ 168

Gobiidae ...............393, 395

Gobiidae, genera of .....394, 395

Gobio ..................246

Gold, colloid ............. 8

Gompholepis ...........299

Gonatodus ................. 317

Gonatodus macrolepis ........320

Gondwana continent ....293, 301,

Gonorhynchidae ............. $35^{8}$

Gonorhynchus greyi, air bladder absorbed ...............455

Goodchild, J. G........116, 118, 119

Goode, Brown......51, 54, 233, 504

Goodrich, E. S............. 347
Gordon, C. H., on permian beds. 166

Gosfordia truncata.......188, 299

Grabau .................26

Graben or rift valleys........424

Graff, von, on nemerteans.68, 73, 89

Graham's Land ............452

Granite rocks, composition of ....38

Graphiurus .....309, 311, 313, 494

Gravic energy .............. 2

Green River beds .......233, 235

Green Sand-Gault .........209

Gnayaquil, volcanic ashes at...40

Guelph strata .............105

Guenther, A. ..........395, 454

Guiana-Brazilian land mass....45 , 460,471

Gulliver, G., on fishes of Rodriguez, 433

Gymnotidae

$.349,351,424$

Gypsum .................2

Gyracanthides murrayi .....160, I6I

Gyracanthus formosus..144, 276, 278

Gyracanthus nobilis .......... I44

Gyracanthus rectus ......... I44

Gyracanthus tuberculatus....276

Gyracanthus Youngi .......... I44

Gyrodus ........................ 333

Gyrolepis $\ldots \ldots \ldots \ldots \ldots \ldots .280$

Gyrolepis Alberti ..........178

Gyroptychius microlepidotus ...120

Haemoglobin, in nemerteans....89

Hag fishes..............

Hairs of nemerteans.........66

Hairs of rhabdocoels ........66

Hakel, fish beds of...........228

Hakel-Sahel beds...........226

Halle, T. G., on Mesozoic flora..452

Halosauridae ............. 36 I

Hamilton shales ............ 30

Haplomi ................

Haplochiton or Aplochiton..359, 360

Haplochitonidae ..............359

Haplomi (or Esociformes)..360, 36r, 362,364

Harpacanthus fimbriatus...143, 144, 146

Harpacanthus major......... 444 
Harting .60

Hatch, F. H.,-Corstorphine.184, 185 Hauer, F. v................243

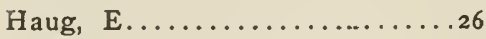

Haug, on Prolebias..........249

Hawkesbury fishes .........287

Hawkesbury formation..........186

Hawkesbury-Wianamatta Series.206

Hayes, on volcanic dust.......4I

Head-glands in Metanemerteans..65

Head-grooves of Nemerteans....65

Hecla, eruption at..........39

Hedley, C., on Antarctic Continent, 445,453

Heer, O. ......243, 245, 246, 248

Helderbergian beds ........ 127

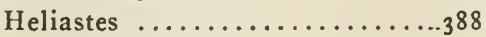

Helodus simplex .........144, 156

Helvetian beds ..........245

Hemibranchii .......................

Hemichordata ............ 61

Hepaticae, oil in ...........49

Heredity .............11, 13

Hesperornis ............. 218

Heterotis ............354, 428

Heterolepidotus $\ldots \ldots \ldots \ldots \ldots+89$

Heteronemerteans .............85

Heteroplacoda .......257, 26r

Heteromi ............2, 36r

Heterodontus ...........291

Heterostraci ...............257

Hexagrammidae ..............................

Heywood ................245

Hils-thon, in Westphalia .....213

Hind, Wheelton .....156, 273, 275

Hinde, G. J............. 107, 258

Histiothrissa $\ldots \ldots \ldots \ldots \ldots \cdots 357$

Histiurus of Costa.........238

Holoblastic segmentation ......93

Holocentrum ..............239

Holonema rugosum .......... I3 I

Holoptychius .......124, 125, 132,

134, 270, 304, 306, 495

Holoptychius scheii ...........132

Holoptychius antarcticus .....132

Holoptychius americanus ......134

Holoptychius decoratus .......305

Holoptychius flemingi ........134
Holoptychius giganteus ....134, 305

Holoptychius hallii ........... 134

Holoptychius nobilissimus... 134, 305

Holosauridae ............242

Holostei ........4, 91, 316, 326

Homacanthus ............ 127

Homalopteridae ....... 352, 522

Homalopterinae, air-bladder of .420

Homo ................. . 242

Homosteus ..............295

Hooker, J. D., on Pachytheca . . .99

Hooker, J. D......444, 435, 436, $438,439,457,529$

Horny stylets of Nemerteans....6.63

Horton beds of Canada......... 447

Hubrecht $\ldots \ldots 60,72,74,76,77,90$

Hudson's Bay, fossil fishes.......5t

Hull, E., on Devonian strata....116

Hunsrücken slates...........121

Huron bituminous shale ...268, 296

Huron shales ............ 130

Huronian system ............96

Hussakof, L...........283, 287

Hussakof, L. H., on permian fishes, $169,283,287$

Hutton, F. W., on New Zealand fishes $\ldots \ldots \ldots \ldots \ldots \ldots \ldots .454$

Hybodontidae .............280

Hybodus ...........288, 5 ro

Hybodus cloacinus ........178, 289

Hybodus dubius ............. 192

Hybodus fraasi, figure of . . . . 193

Hybodus hauffianus .......... 993

Hybodus laeviusculus......... 173

Hybodus minor .......173, 178, 289

Hybridization, artificial .......18

Hyperodapedon .....177, 178, 204

Hyperplacoda .........257, 263

Hyodontidae .......... 355, 427

Hyomandibular Cleft ..........70

Hypopharyngeal groove.....68, 505

Hypophysis cerebri .........74

Hypophysis of cyclostomes . . . .667

Hypsiprimnus beds of Tasmania.233

Hypsocormus.....201, 337, 338, 5 10

Iceland, geysers of .......26

Ichthyodectes ...215,348,356, 522 
Ichthyosauria $\ldots \ldots \ldots \ldots \ldots \ldots 217$

Ichthyotomi $\ldots \ldots \ldots$ 155, 168, 27 I

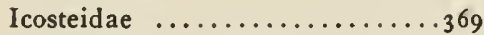

Ihering, H. v., on petroleum beds, 235,236

Illinois oil beds ........... 550

Infundibulum .......6.67, 74, 75

Inoceramus $\ldots \ldots \ldots \ldots \ldots 224,344$

Inoceramus labiatus $\ldots \ldots \ldots \ldots 229$

Irritability $\ldots \ldots \ldots \ldots \ldots \ldots \ldots$.

Ischnacanthus $\ldots \ldots \ldots \ldots \ldots$. 34

Ischypterus $\ldots \ldots \ldots \ldots \ldots \ldots \ldots$ I 83

Ischyodus $\ldots \ldots \ldots \ldots \ldots \ldots \ldots 2$

Isospondylic ganoids.........342

Istieus $\ldots \ldots \ldots \ldots \ldots \ldots \ldots \ldots \ldots+430$

Janassa bituminosa, in Permian..28 1 287

Janassa linguaeformis ........ I 44

Janassa strigilina .......... 68

Janassa gurleyana .......... 68

Japan, thermal springs .......26

John Day beds ............253

Jones, R., on Estherieae ........29

Jones, R., on phyllopoda ......43

Jordan, D. S........366, 367, 368, $372,394,395,525$

Jordan, D. S., on Salmopercae...364 Joly, T.................28

Juan Fernandez, flora of. .....447

Judd, J. W., on Jurassic rocks..191 Judd, J. W., on pumice .....40, 42 Jugulares .........398, 399, 405 Jurassic period.........22, 25, 188 Jurassic reptiles...........236

Kampecaris ............118

Kampecaris forfarensis ....... I 8

Karoo beds ........... 184, 509

Kelheim beds ............. 198

Kerr, Graham...19, 32, 78, 293, 516

Kerr, Graham, on Dipnoi......69

Kerguelen insects............444

Kerguelen earth worms, Lankester on $\ldots \ldots \ldots \ldots \ldots \ldots \ldots \ldots . \ldots 444$

Kerguelen birds, Sharpe on.....444

Kerguelen Island plants ...434, 435, $436,437,439$
Kermadec Islands.....437, 439, 440 Kessleria ................... 519

Kettlestone beds ..........247

Keuper beds ........172, 177, 180

Kiaer, on Downton fauna ......105

Kidston, R. .........139, 146, I 5 I

Kielkond ................. 36

Kiltorcan rocks .........122, 305

Kimmeridge beds .......195, 219, 345

Kimmeridge clay, bituminous deposits ............205, 333

Kincardine ............23, 3 I

King, on Silurian ........... 103

Kirkby, J. W............ 152

Kivu Lake .......4469, 470, 476, $477,478,482$

Kner ......................2

Kneriidae ................. 360

Knorria ..................122

Knoxville beds ...........223

Koken ................404, 434

Kootenay beds ............223

Körnchen of ear ............85

Kota-Maleri beds ...........300

Krakatoa, eruption of........43, 45 Kuhlia ..........378, 379, 385

Kupferschiefer ........165, 171

Labridae .........387, 388, 389, $391,392,395,406,411$

Labridae, genera of .........390

Labrus .................386, 390

Lake Caledonia ...........115

Lake Cheviot .............. Ir5

Lake Lorne ............... II5

Lake Orcadie, ..........15, 304

Lake Orcadie, Geikie on.......29

Lambe, L. M., on Albert shales, 148, $149,318,319$

Lambert ................97

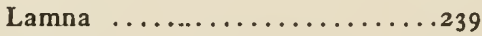

Lamprey .................. 33

Lanarkia, placoid granules . 63, 104 Lanarkia ........110, I12, 261, 497 Langia ............... 78,86

Lankester, E. R......66, 119; 444

Lapparent de....24, 26, 33, I14, 404

Lapparent de, on Mazenay beds. 344 
Laramie, strata .........209, 2 II

Lasanius problematicus, figure of, 262, 264

Lates calcarifer ............380

Lates niloticus .............. 380

Laurentian system ...........996

Leaia leidyi ........... 147, 154

Lebanon, chalk rocks of.......228

Ledbury tunnel ...........97

Leidy, J.................48 48

Leidy, J., on Green River shales.235

Leidy, J., on Acipenser ........326

Lemuria ...........231, 35 I

Leperditia ............... 103

Leperditia scoto-burdiegalensis.. 2, 139

Leperditia suberecta $\ldots \ldots \ldots \ldots 147$

Lepidodendra $\ldots \ldots \ldots \ldots \ldots \ldots$

Lepidodendron .......57, 122, 140, 164,270

Lepidodermata ..........260

Lepidophloios .......57, 138, 139

Lepidopus ...............244

Lepidosiren, food and fat of.....55

Lepidosiren ........ 134, 136, 300, $301,473,48 \mathrm{r}$

Lepidosteidae ..........327, 521

Lepidosteus ........234, 327, 339, $342,484,485$

Lepidosteus, liver of.......71, 505

Lepidosteus platysomus . ......342

Lepidosteus viridis $\ldots \ldots \ldots \ldots . . .342$

Lepidotus ........282, 327, 328, $331,334,336,34 \mathrm{I}, 490$

Lepidotus breviceps .........204

Lepidotus deccanensis .......204

Lepidotus longiceps .........204

Lepidotus minor ........ 192, 328

Lepracanthus colei .......... 44

Lesquereux, Leo, on Florissant beds, 237

Lethaea geognostica ......28, 172

Leptolepidae .....207, 219, 235, $344,345,348,400,483,52 \mathrm{I}$

Leptolepis ........197, 198, 336, $344,345,348,400,483,52$ I

Leptolepis affinis ............ 344

Leptolepis browni ............344
Leptolepis brodiei ..........344

Leptolepis constrictus ......344

Leptolepis gregarius .......206

Leptolepis lowii ..........206

Leptolepis nanus .......... 344

Leptolepis neumayri ......... 345

Leptolepis talbragarensis, Woodward on beds with............. 345

Leptolepis talbragarensis .....206

Leptolepis sprattiformis .....206

Leptoscopidae ........455, 459, 46x

Leptosomus macrurus ........228

I.esley, J. P........... 54, I 50

Leuciscus …....246, 247, 248, $351,418,419,522$

Lewis on Silurian .......... 103

Lhangian beds ............245

Liassic period ..........55, 189

I.iburnian beds ..........233

Libys ............309, 311, 313

Lima $\ldots \ldots \ldots \ldots \ldots \ldots \ldots \ldots \ldots \ldots$

Limnocnida, in Tanganyika ...4464

Lingula ...997, 99, 100, 101, 103, 1 30

Linksfield slates ............ 192

Linley brook, beds...........998

Linton fish beds of Ohio....158, 283

Lioceras serpentinum......202, 344

Listracanthus Wardi .........275

Livingston group.........230

Llandovery beds .........97, ro9

I.oanhead beds ...............36

Lobotidae ............376, 385

Logan on Cretaceous elasmobranchs, 224

London Clay .............233

Lönnberg, E.............250

Loomis, F. B., on cretaceous fishes, 224

Lophiostomus........330, 331, 489

Lophostracon spitzbergense ....496

Lowdon ship .............44

Loxomma .................320

Ludlow series ........... 35, 97

Ludlow bone bed .......97, 98, 100, 101, 102, 103, 104

Lull, R. S., on life of Trias.... $18 \mathrm{I}$

Lumezzane, bituminous beds of. I74

Lumic energy ........... 12 
Lutianus ................ 19

Lycopodites ............... 178

Lycoptera ................484

Lycoptera middendorfii........345

Lydekker, R........440, 442, 529

Lyell, C..................4434

Lysorophus $\ldots \ldots \ldots \ldots \ldots \ldots 147$

Machaeracanthus. .127, 129, 269, 270 Macleay, W., on Galaxias.....453

Macquaria .................. 380

Macromerium scoticum ........320

Macropetalichthys......128, 129, 133 I51, 295

Macropoma .309, 314

Macrosemiidae .........327, 330

Macrura, thread or stinging cells. 62 Magnetite of lavas .........40, 46 Malacopterygii..4, 257,346,347,364

Malacobdella ..............23

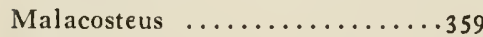

Malacodermata ............257

Mallet, F. R............... 56

Malvern tunnel .............97

Mammalia ................

Mammalia, infundibulum of ....75

Mansell-Pleydell ...........205

Mantell, G.................... 14

Marcellus shales ...........267

Marck ...............229

Marion Islands, flora of $\ldots \ldots+38$

Marsipobranch fishes .........258

Mastacembelidae ..........480

Mastodonsaurus ...178, 185, 288, 289

Mauch Chunk shales .........147

Mayencian beds ...........245

Mazon Creek beds ............ 159

Mazenay beds ............202

Megalichthys .........306, 517

Megalichthys ciceronis........ 68

Megalichthys coccolepis .....276

Megalichthys hibberti..145, 156, 276

Megalichthys laevis ......... 145

Megalichthys laticeps ......... 145

Megalichthys nitidus.......... 68

Megalichthys pygmaeus .......145

Megalichthys rugosus $\ldots \ldots \ldots 276$

Megalops .............. 354,523
Megalurus $\ldots 33^{8}, 354,486,487,523$

Meletta crenata ...........244

Meletta sardinites ..........244

Menat, fish beds of $\ldots \ldots \ldots \ldots 250$

Menhaden .............51, 504

Menhaden, destruction of.......5 I

Menhaden oil ...............57

Menilite shales ...........244

Meroblastic segmentation .......93

Mesacanthus peachi ......120, 303

Mesacanthus pusillus .....120, 303

Mesodon.....201, 214, 219, 283, 331

Mesodon liassicus ........331, 332

Mesodon daviesi .............332

Mesodon macropterus.....332, 333

Mesolepis scalaris, figure of ...282

Mesonephros ................ I

Mesopoma macrocephalum ...... 445

Mesturus ............201, 332

Metanemerteans .......19, 503, 505

Metanemertean proboscis, view of, 73

Metanemertinea ........... 9

Meyer, C. J. A., on Wealden ...212

Meyer, H. v. ...........249

Mfumbiro mountains ....476, 477

Micraspis gracilis ..........105

Microbrachius .............262

Microbrachius dicki.......120, 303

Microdon .....201, 214, 283, 332

Microlestes ............... 178

Microplacoda ........257, 263, 264

Mid Calder, limestones ..........

Mid Lothian, oil shales of......57

Miers, Antarctic crustacea .....443

Marine migration of fishes.....280

Miguasha, N. B............. 53

Miklucho-Maclay, N. v....... I 7 I

Mill, H. R., on Realm of Nature.445

Miller, A. W..............

Millstone Grit.......... I, 140, I5I

Mimetes ................456

Miocene oil strata .........236

Miocene period .......232, 239

Mioplosus, Cope on .........409

Mississippi formation ...30, 31, 137, I $38,147,270,273,284,285,508$

Mitchell ............... 118

Modiola hilliana............ 192 
Modiola sp.............. 192

Molasse .................245

Molasse, Red ............245

Molgophis ............... 47

Mollusca ...................

Moluccas Islands ........... 385

Monocentridae ............... 384

Mono Lake, waters of ........43

Monte Bolca beds ...........238

Monterey beds ............254

Montgomery, $T$., on horny teeth...63

Moodie, on Amphibians ....... 54

Moore, J. E. S., on Cichlid genera, 408

Moore, J. E. S., on African lakes, $463,476,477$

Mordacia mordax ..........443

Mormyridae .....91, 355, 385, 421

Mormyridae, distribution of . . .429

Mormyridae of Tanganyika...469, 479,480

Morone .379

Morone americana ...........380

Morone labrax ...............................

Morone lineata...............380

Morone mississippiensis ......380

Morone multilineata .........380

Morone punctata .............380

Mosasaurus ............224

Mossbunker ...............

Mountain limestone, conodonts in, 258

Mowry shales .......223, 225, 5I2

Mud Fish or Neochanna .......454

Mugil ............. 368, 369

Mugil cephalus .............369

Mugilidae ................ 368

Murchison, R. I......35, 50, 51, 97

Muschelkalk beds ...........172

Myophoria ................ 73

Myriapod beds ............ I 8

Myriolepis clarkei ......... 87

Myriolepis pectinata ......... 187

Myripristis ........239, 384

Myxine .......6.61, 81, 259, 506

Myxinoides ............257

Naiadites .............. 154
Nandidae ...........376, 379

Nandina ........................

Nebraska, volcanic dust in ....39

Nematoptychius greenocki.....143, 145, 320

Nemerteans .........I1, I4, 16, 23

Nemerteans, brain substance ...78

Nemerteans, egg development ...92

Nemerteans, reproductive sacs ...91

Nemertinea, blood system ......88

Nemertinea .......... 19, 60, 6r

Neoceratodus .........32, 133, 136,

I 71, 299, 300, 301, 495

Neochanna ...........359, 454

Neocomian beds .....209, 333, 334

Neorhombolepis .....213,330, 489

Nephridial system...........89

Nerve cells, neuratin of.....II, I 5

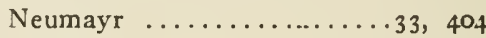

Neuratin .............. I

Neuropteris $\ldots \ldots \ldots \ldots \ldots \ldots \mathbf{1}_{67}$

Neuropteridium australe ......205

Newark, Triassic beds of .....182

Newberry, J. S.......30, 107, 128, $129,157,258,266,267,283,296$

Newberry on Connecticut beds... I 8 I

Newberry on Triassic fauna.....181

Newberry-Worthen-St. John ...284

Newburg, fish scales at ......268

Newton, E. T............... 326

New Zealand, hot springs.......26

New Zealand lamprey .........82

Niagara strata .......... 105, ro9

Nicholls on Reissner's fibre.....779

Niger, rise and fall...........32

Nivenia ..................456

Noeggerathia vogesiaca ......313

Notacanthidae ............238

Notidanus .........201, 208, 239

Notochord ............67, 78

Notogaea ...............210

Notogoneus . . . . . . . . . . $35^{8}$

Notopteridae .......355, 427, 429

Notopteridae, distribution of ....429

Nototheniidae ...4455,458, 459, 46r

Nucleus, cell .................

Nummulites .............239

Nutrition .................9 
Odontaspis

239

Odontopteris

167

Oeningen fauna, flora...245, 250, 253

Oenoscopus .................. 345

Oesel beds ..........23, 31, 36

Gesophagus of nemerteans .....668

Ohio, devonian of .......129, 266

Ohio shale, section of........269

Oil field of Boulder, Colo.......223

Oil field of Kansas...........223

Oil shales of Lothians.........141

Oligacene fishes ...........252

Oligocene formation...237, 239, 242

Oligocene oil strata .........236

Old Red formation .....29, 31, 48,

54, $110,114,302,303,304$

Olfactory organ .........664,65

Oligopleuridae .....207, 342, 343,

345,483

Oligopleurus ......220, 344, 345

Onchus ..........97, 112, 134

Oniscolepis $\ldots \ldots \ldots \ldots \ldots \ldots \ldots . \ldots \ldots$

Onychodus .....129, 304, 305, 306

Oolites ................... 190

Ophiocephalidae..368,370, 405, 408

Ophiocephalus ..............368

Opisthomyzon (or Echeneis) ...396

Opossum .............44r, 445

Opossum, water .............446

Oppel on Jurassic strata ......195

Opsigonus ....................

Orbiculoidea rugata ..........102

Orcadie, Lake ..........115, 304

Orcadian series ..........116, I19

Ordovician times ......19, 23, 25

Orestias ...............363,425

Oriskanian beds ............127

Orthacanthus .......201, 272, 277

Orodus .................28

Orthopleurodus ...........283

Ortmann, A., on Antarctica ...446

Ortmann, A., on Tanganyika...466

Orton, E.................. 127

Osphromenidae .....369, 405, 408

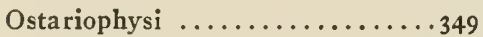

Osteostraci ............257, 496

Osteoglossidae .......354, 355, 357, 385,427
Osteoglossum....234, 354, 428, 523

Osteolepis microlepidotus....... II 9 , 120, 303

Osteolepis macrolepidotus..120, 303

Ostracanthus dilatatus.........156

Ostracoda of Tanganyika......468

Ostracoderm fishes ....... 105, 497

Ostrea virgula ..........339, 340

Oudemans, on excretory tubes....90

Oxyrhina ................239

Pachycormidae ......219, 242, 336, $337,338,346,488,520$

Pachylebias ........... 362, 425

Pachylepis ................ 36

Pachytheca sphaerica ...98, 99, ro3, I 8,507

Palaeaspis ...........106, 26r

Palaedaphus ............... 124

Palaeoniscidae .........31, 492

Palaeoniscus ..............284

Palaeoniscus antipodeus ......187

Palaeoniscus bainii .......... 184

Palaeoniscus crassus ..........187

Palaeoniscus macropomus .......I7

Palaeoniscus sculptus ....... 184

Palaeoniscus superstes ........ 76

Palaeopteris .......... I22, I31

Palaeophonus ............ ro4, I Io

Palaeosaurus ............. r78

Palaeospondylides ......257, 260

Palaeospondylus gunni .....121, 303 , 497,514

Palaeospinax ............29r

Palaeozoic period ............29

Palau Isles, Geonemertes in.....24

Paludina ............173, 192

Pander .............123, 257

Pappichthys .......234, 238, 339

Parabatrachus .............308

Parascopelus .............239

Parexus recurvus .......... Ir8

Parietal eye ...............65

Parka decipiens ......... I 10 , 118

Parker on Protopterus .....62, 69

Passamaquoddy bay .......... I06

Patten, W..........27, 53, 124

Pauciprotodonta ..........446 
Peach, B. N......119, 139, 146, 151

Peach, C. W. ...........122, 140

Pelagonemertes..............23

Peltopleurus ........... 342, 343

Peltopleurus dubius ......... 187

Pelly river, deposits..........4 r

Yempheridae ................. 384

Pennington beds ............. 447

Pennsylvanian beds ...... 152, 508

Pentamorphogeny...... I1, 12 13, 17 , $388,397,503$

Pentland hills, Silurian rocks...... I

Fentamerus Knightii ........997

Perca .................246

Perca flavescens ............ 377

Percarina ...................379

Percichthys ...............

Percesoces .................367

Percidae ...235, 238, 242, 376, 378, $378,383,392,400,409,410$

Percilia ................... 380

Percomorphi ..............367

Percopsidae ......360, 363, 364, 409, 4I 3

Percopsis.......364, 370, 372, 376 $410,413,525$

Perledo, bituminous beds of. . .174

Perleidus ............323, 324

Permian elasmobranch fauna...286

Permian bituminous schists....286

Permian fishes.....5, I41, 162, 164, I 69, 508

Permian formation......22, 24, 137

Permian formation. $141,162,164,508$

Persoonia .................456

Petalodontidae ...... 155, 280, 285

Petalodus acuminatus ..... I43, 144

Petalopteryx ..............330

Petalorhynchus psittacinus..143, 144

Petrified Fish Cut ...........235

Petroleum in relation to fishes...49

Petroleum production ....49, 59, 135

Petroleum, yield to $1885 \ldots \ldots \ldots 52$

Petroleum, yield to $1914 \ldots \ldots \ldots 52$

Petromyzon.....19, 6I, 74, 81, 108

Petromyzon, section of larva.....68

Petromyzontes ...........257

Pflanzen-qüader of Bohemia..208, 2 I 6
Phanerosteon $\ldots \ldots \ldots \ldots \ldots, 317$

Phaneropleuron ..124, 298, 299, 495

Phaneropleuron andersoni .....125

Pharyngeal teeth ..........64

Pharyngognathi ......... 386,393

Pharyngolepis oblongus .......105

Pharynx of nemerteans.......66

Philadelphia, Academy of Sciences.4 Phlyctaenaspis ......117, 121, 151

Phlyctaenaspis acadica.....127, 294

Pholiderpeton .........44, 276

Fholidogaster ...............320

Pholidophoridae ....207, 219, 235,

242, 342, 343

Pholidophorus ......192, 219, 342,

343,344

Pholidophorus australis.......187

Pholidophorus gregarius ....... 187

Pholidopleurus .......... 342, 343

Pholidopleurus typus.......... 74

Phoradendron in Galapagos....449

Phractolaemidae ....... 355, 427

Phylembryo .............27

Phyllocarids ..............

Phyllopoda, R. Jones on. . . . . 43

Phyllolepis concentrica .........305

Phyllopoda .........117, 135

Physocaris ................ 103

Pimelodus ..........234, 414

Pineal eye ............65, 82

Pittmann, E. F., on fish beds....205

Pituitary body.....11, 67, 74, 75, 505

Placodermata ........257, 260

Pläner series ............229

Platinum, colloid ............

Platychisma bed ........... 101

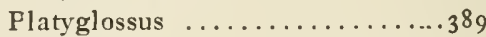

Platysomus ................ 323

Platysomus palmaris ......... 68

Platysomus gibbosus figure....281

Plectognathi ..............400

Plectrodus ...............997

Pleistocene, continents during...23I

Plesiosauria ...............217

Plesiosaurus ............ 192

Pleuracanthidae..264, 285,498, 499

Pleuracanthus ......271, 272, 287

Pleuracanthus alatus ......... 56 
Pleuracanthus alternidentatus... I 56

Pleuracanthus elegans ........144

Pleuracanthus erectus .......156

Pleuracanthus fastigiatus .......144

Pleuracanthus gaudryi.......272

Pleuracanthus gracilis ...... 68

Pleuracanthus gracillimus ..... I44

Pleuracanthus horridulus ...... I44

Pleuracanthus laevissimus... I44, 156

Pleuracanthus parvidens ...187, 287

Pleuracanthus pulchellus .....156

Pleuracanthus quadriseriatus ...168

Pleuracanthus robustus ....... I56

Pleuroplax falcatus ......... I44

Pleuroplax affinis .........278

Pleuroplax rankinei ....... 444,278

Pleuropterygii ..........27 I

Pliocene, continents during ....23 I

Podocys ................253

Podozamites lanceolatus ......205

Poecilia ..............246

Poecilodus jonesii ......... I43, I44

Pogie ................... I

Polycentrus . . . . . . . . . . . . . 379

Polygnathus $\ldots \ldots \ldots \ldots \ldots \ldots$ 108

Polyodontidae $\ldots \ldots \ldots \ldots \ldots \ldots \ldots+326$

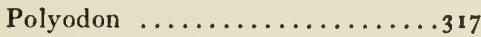

Polyplacoda .............257

Polyplocodus leptognathus ...305

Polyprotodont marsupials ..441, 442, $445,446,451,452,461$

Polypterus .........315, 477, 493

Folypteridae ........4, 302, 493

Polyrhizodus magnus ...... I43, 144

Polyzoa of Lake Tanganyika....465

Pomacentridae ......387, 392, 393, $406,407,411,527$

Pomacentrus $\ldots \ldots \ldots \ldots \ldots \ldots 388$

Pompton fish beds ........... 309

Pons varolii $\ldots \ldots \ldots \ldots \ldots \ldots 78$

Portheus molossus ...215, 227, 348, 356,522

Portland beds

Portland oolite ............. 190

Posidonia bronni ...........202

Potassium phosphate .......... 3

Potomac strata ...........223

Powrie ............ 116, 118
Praelimulus ...............164

Prestwich ..........26, II4

Prestwich, Cambrian system ....96

Prestwichia in Permian ....... 176

Princeton Expedition ..........4436

Friscacara .........382, 407, 409

Pristisomus crassus .......... 187

Pristisomus gracilis .........187

Pristisomus latus ............ 187

Pristiurus ...........208, 239

Pristodus falcatus .....x43, 144,146

Proboscis of metanemerteans.63, 72, 73

Proboscis-pituitary body . ...78, 505 Proboscis sheath...66, 67, 72, 76, 505

Productus ................

Proenvironment .....11, 13, 15, 503

Prolates ............405,409

Prolebias cephalotes ........249

Prolebias ...........362, 425

Pronephrops ...............90

Prosser, C. S., on Sunbury shale. 130

Prostoma .................24

Protacanthodes ...........287

Protamia .......................... 339

Proteaceae of Antarctica .......457

Proterozoic ................26

Protitanichthys ............. 128

Protoplacoda ......257, 261, 263

Protoplasm ..............9, 10

Protopterus.......55, 62, 133, 136,

299, 300, 469,473,477,478,48I,

493, $517,53 \mathrm{I}$

Protopterus dolloi ...........30r

Protosphyraena $\ldots \cdots 337,488,520$

Protospondylic ganoids ....342, 483

Protospondylei .............316

Prototroctes ..........360, 376, 452

Psammodus rugosus ...143, 144, 276

Psammodontidae ..... I55, 280, 282

Psammosteus .......132, 261, 305

Psephodus magnus .........143, 144

Pseudobornia ..............268

Psilophyton $\ldots \ldots \ldots \ldots \ldots \ldots \ldots 118$

Pseudaphritis .............4.458

Pteraspis....35, 97, 98, 1 1 7, 129, 261

Pterichthyids .............. 8

Pterichthys $\ldots \ldots \ldots \ldots \ldots \ldots 262$ 
Pterichthys milleri ......... r20

Pterichthys oblongus .........120

Pterichthys productus .......... 120

Pterinopecten papyraceus....... 55

Pterolepis nitidus .......... ro5

Pterophyllum minus..........3 3

Pterosaurus $\ldots \ldots \ldots \ldots \ldots \ldots 217$

Pterothrissus $\ldots \ldots \ldots \ldots \ldots . \cdots 356$

Pterygotus ...97, 100, 110, 118, 131

Pterygotus beds ............ 118

Pterygotus osiliensis ..........36

Pterygotus problematicus .....36

Ptycholepis raiblensis ........ 174

Ptycholepis ............... $8_{3}$

Ptyonius .................147

Pullastra arenicola .........202

Pumice as powder ..........40 I

Purbeck beds..190, 191, 195, 202, 219

Puzzolana .................42

Pycnodontidae $\cdots \cdots 327,331,336$, 346,520

Pycnodus, in Cretaceous beds...214, 334

Pygididae $\ldots \ldots \ldots \ldots \ldots \ldots+\cdots \cdot 352$

Pygidium rivulatum in Titicaca, 426

Pygopterus ........... 170, 321

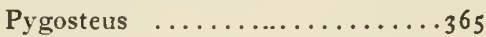

Pyroxene ...............47

Pythonomorpha ..........217

Raibl, bituminous beds of ...... 174

Raja ..............215, 239

Randall, on Downton beds ......998

Redwood, B., on Dakota sandstones, 225

Redwood, B., on petroleum.49, 54, 55

References to literature ........8

Regan, C. T...............458

Reissner's fibre .........77, 79

Reproduction ........9, 13, 18

Respiration ................

Retropinna, absorption of air bladder $\ldots \ldots \ldots \ldots \ldots \ldots . \ldots . \ldots . \ldots 5^{8}$

Retropinna richardsoni ......4459

Reuss-Mayer on Cyprinoids....351

Rhadinichthys alberti .....149, 319

Rhadinichthys brevis ......... 445

Rhadinichthys carinatus ....... 145
Rhadinichthys ferox .......... 145

Rhadinichthys ornatissimus..139, 145

Rhadinichthys ...317, 318, 319, 493

Rhaetic beds .......... 172, 177

Rhaetic bone beds .......... 173

Rhamphignathus $\ldots \ldots \ldots \ldots \ldots 367$

Rhineastes ........................

Rhinobatus .........193, 208, 239

Rhizodontidae .............495

Rhizodopsis.....162, 306, 307, 495

Khizodus hibberti..139, 143, I45, 320

Rhizodus ornatus ........ 145, 320

Richardson, L............289

Richardson, L., on Rhaetic rocks. 177

Rhabdocoel turbellarians....60 79, 80,89

Rhodeus .....................351

Rhynchocoel in nemerteans...74, 75

Rhynchodoeum of Bürger ...75, 77

Rhyncholepis parvulus ........ I05

Rhynchodus ..........129, 297

Rift valleys, African ..404, 423, 424, $427,428,429$

River wolves ...........42 I

Roberts, T., on Jurassic fauna...I9I

Roberts-Randall ..........98, 99

Robinson, B. L., on Galapagos flora, $44^{8}$

Roche, M. E.............286

Rodriguez, Geonemertes in.....24

Roemer-Frech ..............114

Rogers, I.................125

Rohon, J. V., on Jurassic strata..195

Rossie Den, fish bed........116

Rothliegende beds .......164, 165

Royal Society committee ......43

Ruedemann .................. II

Rupert-Jones ........122, 123, I41

Russell, I. C.......38, 4I, 42, 52

Russia, Carboniferous rocks of .. 137

Sacculus of ear.............88

Sagemehl ........................ 353

Sagenodus dialophus . . . . . . r 68

Sagenodus fossatus .......... 68

Sagenodus quinquecostatus .. 145, 320 Salanx, air bladder absorbed...358

Salina beds .............. rog 
Salmo $35^{8}$

Salmo, Day on ... 8

Salmonidae. $.91,358,373,383$ 451,524

Salter, J. W., on Pachytheca ....98 Salmopercae of Jordan .......364 Samari Isles...............24 Saporta on gypses of Aix.....237 Sardinius .............216 Sargodon tomicus ........175, 289 Sars, G. O., on Copepoda-Ostracoda, 466

Saurichthys acuminatus ......289

Saurichthys alberti .........178

Saurichthys latifrons ......... $77^{2}$

Saurichthys lepidosteus .........172

Sauripterus .........125, 305

Saurodon ......................... 348

Saurodontidae .....226, 238, 242

Sauvage, H. E., on liassic beds... 89 , 341

Scapanorhynchus

Scaphaspis .239

Scaphirhynchus $\ldots \ldots \ldots \ldots 326,5$ I 9

Scaridae.......391, 392, 406, 4II

Scaridae, genera of ...........39 I

Scaumenac bay, fish bed........ $3 \mathbf{I}$, 265,305

Schei, Dr., at Ellesmere Land....132

Schlüter .............12

Schuchert .............33, 126

Schwager, A., on dust.........44

Scleropages ............354, 428

Scombresocidae ................ $3^{6} 3$

Scombridae ...........235, 238

Scombriformes .........397, 398

Scopelidae, cretaceous.....36o, 36r

Scopelidae ................238

Scopeloides ..............239

Scott-Elliot, G. F..........408

Scrope, M................44

Scyllium .................239

Sedgwick, A................ II4

Seefeld, bituminous beds of..... 74

Seefeld, Tyrol ..........51, 57

Selachii $\ldots \ldots \ldots \ldots \ldots 4,5$, I12, I 68

Selection, natural ....11, 13, 17, 18

Semicircular canals ..........85
Semionotidae....219, 235, 327, 489

Semionotus ............327, 489

Semionotus agassizii ........174

Semionotus australis .........187

Semionotus brodiei ..........176

Semionotus capensis .........r84

Semionotus formosus ......... 187

Semionotus punctatus ........ 192

Semionotus tenuis $\ldots \ldots \ldots \ldots \ldots 187$

Senonian period.....231, 333, 337,

$208,218,260,332,340,510$

Sestian beds .............245

Serranidae.....235, 376, 396, 397

Serruria in S. Africa...........456

Siwalik beds of India........255

Sexual dimorphism .......... 8

Sexual selection ............. 8

Seymour Island ............452

Seymour Island, Tertiary Flora of, 453

Sharpe, R. B., on Kerguelen birds, 444

Sidlaws, fish bed ...........116

Sierra Nevada mountains ......209

Sigillaria ...........118, I64

Siniperca ................380

Siluria of Murchison.........997

Silurian bone beds........... III

Silurian fishes, affinities......... II I

Silurian rocks...... I, 3 I, 49, 50, 504

Siluridae...235, 349, 350, 352, 414

Siluridae, distribution of...415, 523, 532

Siluridae, chart of..........4r 6

Siluridae of Tanganyika......468

Silver, colloid ...............8

Silurian times...6, 22, 23, 25, 27, 35

Silicon, colloid.............8

Slater on Silurian rocks........100

Smerdis .................250

Smith, G., on antarctic copepods.443

Snappers ................ 19

Somatopleura in nemerteans.....94

Solenhofen beds ............56

Solenhofen slates ......190, 193, 195, $208,218,332,260,340,510$

Solenhofen slates, fishes of..... 98 , 189,200 
South Atlantic Continent......431

Southern plant genera........447

Spaniodon ...............216

Sparidae ................238

Spathiurus $\ldots \ldots \ldots \ldots \ldots \ldots \ldots \ldots \ldots \ldots+345$

Spathodactylus $\ldots \ldots \ldots \cdot 347, \quad 356$

Spawning, fish ..................

Spencer, B..........32, 89, 1 10

Spermatodus pustulosus........ 68

Sphaerodus ............. 78

Sphaerolepis arctata ........ 68

Sphenacanthus hybodoides....... I44

Sphenacanthus serrulatus...143, 144

Sphenocephalus .........383, $3^{8} 4$

Sphenonchus martini ......... 192

Sphenophyllum ........... 67

Sphenopteris affinis .........139

Sphenopteris bifida ........... 139

Sphenopteris hoeninghausii ....139

Spinachia ................. 365

Spinachia vulgaris $\ldots \ldots \ldots \ldots 366$

Spine-finned Teleostei .......372

Spiracular cleft ..............70

Spiral valve in fishes .........7

Spirifer ..................

Spirifera elevata ......... Iог, 102

Spirorbis carbonarius ......... 156

Splanchnopleura in nemerteans...94

Sponges in Lake Tanganyika....463

Spoonbill sturgeon ............4

Squatina ........................

Squatina speciosa ........194, 215

Stampian beds ............2 +5

Stephanoberycidae ......... 36 I

Stewart, R. D............ 449

Stewart, A. S...216, 224, 225, 230

Stichostemma eilhardi ........70

Stickleback......18, 365, 366, 372

Stigmaria .............. I3 I, 155

Stobbs, J. T..........152, 275

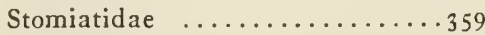

Stonesfield slates.... 190, 195, 200, 201, 219, 300, 332

Storer on fish oil......... $57,5^{8}$

Stormberg beds ........... 185

Storms on Echeneididae ...395, 396

St. Paul's Islands, vegetation of . 435

Strepsodus sauroides .....145, 276
Strepsodus striatulus ......... 445

Strepsodus sulcatus .......... 145

Stromateidae ............238

Stromboli, eruption of ........44

Strophodus ..............20I

Studnicka on lamprey.........82

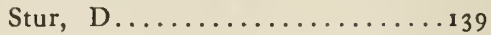

Stygogenes, in alpine lakes of Ecuador .................. 455

Stylonurus in Old Red rocks.... I17 Suess, E...........243, 404, 434 Suessmilch on fossil fish........ 60 Suessonian period ......233, 237 Sulphur, colloid ............

Sulphate of soda............. 3

Sumbawa, volcano ..........45

Swedish S. Polar Expedition.....452

Sweetland Creek beds.........297

Symbranchii .............

Symbranchidae .........431, 432

Sykes, H., on Kota beds........204

Symonds on Silurian .........997

Symplacoda ..........257, 26 I

Symbranchus $\ldots \ldots \ldots \ldots \ldots \ldots+32$

Synechodus ................292

Synclinal strata ............50

Syngnathidae $\ldots \ldots \ldots \ldots \ldots \ldots+\cdots 66$

Taeniopteris daintreei ......205

Taeniopteris marantacea ..... 313

Talbragar beds of Australia...205

Tanganyika.......243,408, 423, 424,463

Tanganyika problem...463, 530, 53 I

Tar from Menhaden oil.........57

Tar sands...............225

Tarrasius .............306, 307

Taubate, bituminous beds of...235

Taylor marls .............224

Teleosteans ............. 5

Teleostei $\ldots \ldots \ldots \ldots \ldots \ldots \ldots \ldots 4$

Teleostei, soft-finned......... 446

Teleosts, nasal sacs of........65

Temeside bone-bed.......102, 103

Temeside shales .......... IOr, 102

Terebratula .............. 73

Terra Nova expedition ........132

Tertiary bituminous schists ...235 
Tertiary lignites of Brazil. 350,421 Tetrastemma ........24, 83, 91 Tetrastemma, lime cells of.....63 Tetragonolepis $\ldots \ldots \ldots \ldots \ldots 336$

Tetragonopterus...350, +21, 422, 522 Texas, oil beds of..........236 Thalamencephalon ..........75 Thelodus ...........36,63,64, $98,110,112,127,261,497$

Thermic energy ...........8, 12 Thinnfeldia odontopteroides....205 Thiolliere on Bugey-Ain beds..339, 340

Thoracopterus .............. 343

Thrissolepis ............ 70

Thrissops.......348, 400, 522, 523

Thrissops exiguus $\ldots \ldots \ldots \ldots . \cdots 345$

Thrissops microdon .......... 345

Thursius macrolepidotus ...120, 303

Thursius pholidotus ...... 120, 303

Thyestes ....................... 36

Thymallus $\ldots \ldots \ldots \ldots \ldots \ldots .358$

Thyroid gland of fishes.........68

Tinca ............... $55 \mathrm{r}, 522$

Titanichthids ............. 8

Titanichthys... 131, 151, 295, 301, 496

Titicaca, Lake, fishes of...363 425, 426,454

Toluol from fish oil..........57

Tomboro, eruption of...........45

Tomodus convexus .........277

Tongrian beds ........237, 243

Toturus pichardi $\ldots \ldots \ldots \ldots \ldots 368$

Trachinus, poison glands ......62

Transit of Venus Expedition.....436

Traquair, R. H........2, 36, 121, $125,139,141,142,143,146,151$, $271,317,320$

Traquairia .287

Tremataspis ............36, 110

Triassic beds, Wilson on....... 177

Triassic beds of Connecticut.182, 310

Triassic fish beds of Europe.312-315

Triassic period..........25, 56

Triassic system......165, 172, 509

Trichodina, a Tanganyika Infusor, 465,474

Trichomycterus of Titicaca....454
Trichophanes .................. 365

Trinity beds..............223

Tristan da Cunha....435,437,438

Tristichopterus .............. 303

Tristychius arcuatus...143, I44, 278

Tristychius minor ............ 44

Troglichthys ............... 364

Truckee canyon, Nev............ $3^{8}$

Tubulanus ..............24

Turbellaria, and Nemertinea....66

Turonian fish bed...........228

Turonian-Senonian beds......209

Typhlichthys ..............364

Uinta mountains $\ldots \ldots \ldots \ldots 222$

Uinta beds ...............234

Ulodendron ...........57, 131

Umbra ..................362

Undina gulo, figure........... 31 I

Undina penicillata ............ 311

Undina ............309, 311, 494

Urochordata.... 19, 61, 256, 505, 506

Urolepis .............. 321,492

Uronemus ........... 175, 299

Uronemus lobatus ............145

Uronemus splendens .......... I45

Urosthenes australis ......... 60

Utriculus of ear ...........83

Vaughan, A., on Carboniferous Lime .................275

Velum.........66, 67, 70, 505

Velar $\operatorname{rim} \ldots \ldots \ldots \ldots \ldots \ldots . \ldots 76$

Veliger stage $\ldots \ldots \ldots \ldots \ldots \ldots 27$

Verbeek on Krakatoa....43, 44, 45

Vertebrates, embryonic ear.......65

Vesuvius, eruption of.........44

Virginia, West, oil area.........54

Virgulian rocks .............334

Volcanic dust..........37, 38,40

Volcanoes, Ancient........... 115

Voltzia.......176, 177, 289, 313

Walchia .............. 64,167

Wallace, A. R............. 17

Walther, I., on Solenhofen beds, 195, 196, 510

Ward, J................ 52 
Ward, L. F., on Laramie beds...222

Wardie shales ............. $\mathbf{I}^{\mathrm{I}}$

Wardichthys cyclostoma.... 45,323

Warren-Storer on fish oil.57, 58, 505

Wasatch Lake, Cope on...233, 253

Wasatch mountains .....209, 222

Waterlime rocks.........23, 3r

Waterstone beds, Estheriae in... 176

Waterstone beds, batrachians of. 176

Waterstone beds, fishes of...... I77

Waverley shales of Ohio....... I47

Wealden coal..............208

Wealden strata....191, 192, 212,338

Weaver fishes, poison glands...62

Wenlock beds.........36, 97, 109

Whiteaves on fish beds........130

White River beds.....237, 243, 253

Whymper, on volcanic dust.....4I

Wichita beds............. 66

Williston, on Cretaceous elasmobranchs ...............224

Wills, L. J., on Triassic beds....177 289

Winkler, T. C., on cyprinoids ...35 I

Winkler on volcanic dust......44

Wilson, C. B., on Argulidae ...467

Wita-steinbruch ..............36

Wodnika .......286, 291, 515
Wolff, Dr., on ashes.........40

Woodward, A. S......160, 161, 185, I86, 194, 203, 215, 216, 220, 228, $229,235,238,253,285,287,288$, $316,322,323,325,326,330,337$ 346,357

IVright, T., on Jurassic fauna....I9I Wurtemburg bone beds....... I73 Wysogorski on Muschelkalk.... I72

Xenacanthidae $\ldots \ldots \ldots \ldots \ldots$............... 66

Xenacanthus $\ldots \ldots \ldots \ldots \ldots 265,272$

Xiphactinus $\ldots \ldots \ldots \ldots \ldots \ldots 226$

Xylol from fish oil..........557

Xystrodus striatus ....... I43, 144

Young, J., on freshwater beds...274 Young, J., on Scottish fossils...275 Young, J., on fossil fishes......278

Young, J, list of fishes.......279 Yukon river $\ldots \ldots \ldots \ldots \ldots \ldots$ I

Zalembius $\ldots \ldots \ldots \ldots \ldots \ldots \ldots 393$

Zambezi ........32, 464, 470

Zamites vogesiacus..........177

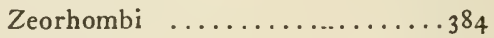

Zittel, K. v..............258

Zoarcidae .................399 





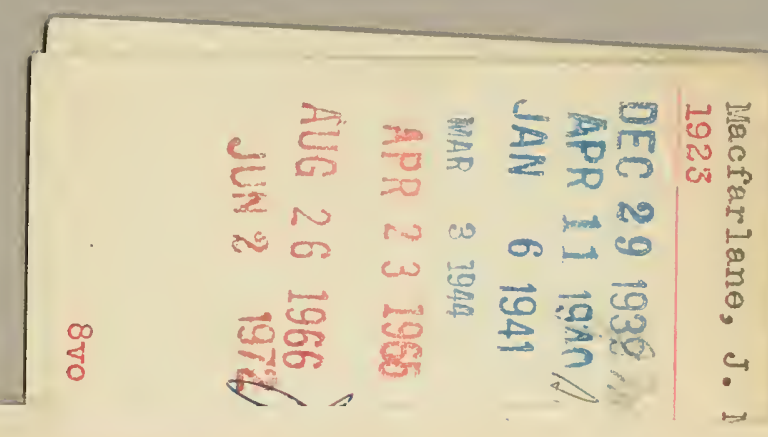


